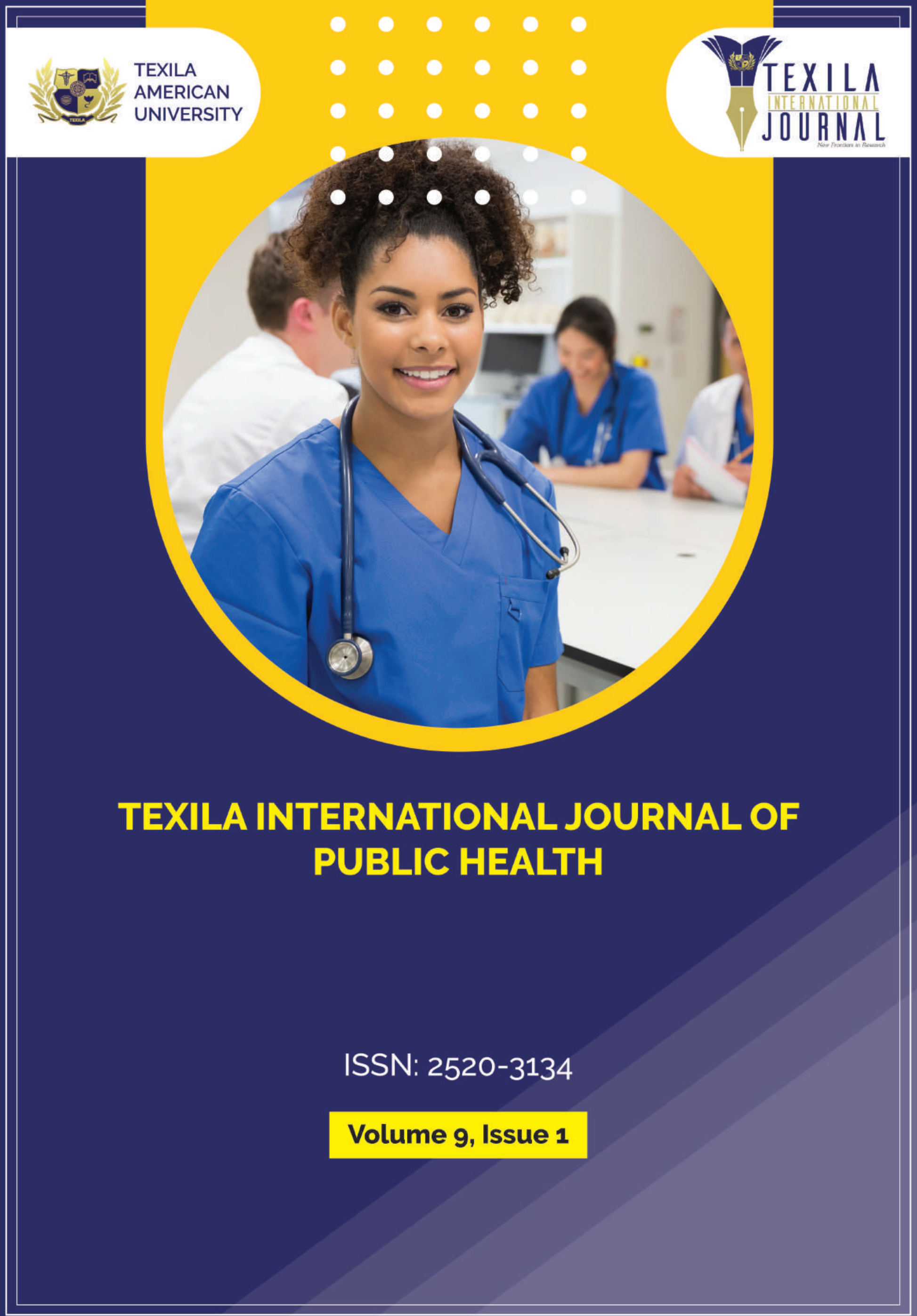




\section{EDITORIAL POLICY}

Papers must be submitted with the understanding that they have not been published elsewhere (except in the form of an abstract or as part of a published lecture, review, or thesis) and are not currently under consideration by another journal published or any other publisher. The submitting (Corresponding) author is responsible for ensuring that the article's publication has been approved by all the other coauthors. It is also the authors' responsibility to ensure that the articles coming from a particular institution are submitted with the approval of the necessary institution. Only an acknowledgment from the editorial office officially establishes the date of receipt. It is a condition for submission of a paper that the authors permit editing of the paper for readability. All enquiries concerning the publication of accepted papers should be addressed to ejournal.assist@tau.edu.gy

\section{CHIEF EDITOR}

Dr. T. Selvankumar, Professor and Head, Mahendra Arts \& Science College.

\section{PEER REVIEWERS}

Dr. Neerja Sood, Assistant Professor in School of Health Sciences, Indira Gandhi National Open University, New Delhi.

Dr Nirmallya Chatterjee, Lecturer, Ma Sarada College of Nursing.

Dr. Sunil Kumar D, Associate professor in the Department of Community Medicine, JSS.

Dr. Jitendra Kumar Chaudhary, College of Veterinary Sciences, Mizoram.

Dr. Rahul Diliprao Suryawanshi, Department of Veterinary Public Health and Epidemiology, College of Veterinary and Animal Sciences, Udgir, Dist. Latur.

Dr. Atulomah, Nnodimele Onuigbo, Babcock University, School of Public and Allied Health, Department of Public Health, Nigeria. 


\section{ABOUT PLAGIARISM}

Plagiarism is the use or close imitation of the language and ideas of another author and representation of them as one's own original work. Duplicate publication, sometimes called self-plagiarism, occurs when an author reuses substantial parts of his or her own published work without providing the appropriate references. This can range from getting an identical paper published in multiple journals, where authors add small amounts of new data to a previous paper.

Plagiarism can be said to have clearly occurred when large chunks of text have been cut and pasted. Such manuscripts would not be considered for publication in TIJPH Journal. But minor plagiarism without dishonest intent is relatively frequent, for example when an author reuses parts of an introduction from an earlier paper. The editors will judge any case of which they become aware (either by their own knowledge of and reading about the literature, or when alerted by referees) on its own merits.

The paper containing the plagiarism will be obviously returned back to the author's for review, but we earnestly request the authors to avoid submitting plagiarized. 


\section{DISCLAIMER}

Texila International Journal of Public Health (TIJPH) make every effort to ensure the accuracy of all the information (the "Content") contained in its publications. However, the TIJPH and its agents make no representations or warranties whatsoever as to the accuracy, completeness or suitability for any purpose of the Content and disclaim all such representations and warranties whether express or implied to the maximum extent permitted by law. Any views expressed in this publication are the views of the authors and are not necessarily the views of the Editor's or Texila International Journal of Public Health. 


\section{TABLE OF CONTENT}

1 Effects of Divorce on Women and Children

Adaora Isabella Odis

2 The Impact and Aftermath of Coronavirus on Southern African 15 Development Community Consumers

Josephine Shailemo

3 Accessibility and Utilization of Tuberculosis Directly Observed Therapy in 29 Primary Health Care Facilities in Katsina State, North West Nigeria

Yahaya Shamsuddeen Suleiman

4 A Synopsis on COVID-19 and Associated Risk Factors: Optimizing Preventive and Clinical Outcomes through Lifestyle Intervention

Abiodun Bamidele Adelowo

5 Epidemiologial Survey on the Utilization of Insecticide Treated Mosquito Nets in Malaria Control among Gyadi-Gyadi Communities in Kano, Nigeria

Ahmad Salisu Aliyu

6 Cost-Benefit Analysis during Lockdown and Health Belief Model (HBM) 56 of COVID-19 Pandemic in Ogun State, South-Western Nigeria

Oni, Olawale Bashir-Ud-Deen

7 Mitigating Strategies and its Challenges of COVID-19 Pandemic in Ogun State, Nigeria

Oni, Olawale Bashir-Ud-Deen

8 Responding to Cholera Outbreaks in Zimbabwe: Building Resilience over 82 Time - A Critical Review of Article

N.P. Sithole-Sibanda

9 Point of Care (POC) for Early Infant Diagnosis (EID) in Nigeria? Healthcare Workers Opinion 
10 Accuracy and Feasibility of Point of Care (POC) Early Infant Diagnosis

(EID) in Nigeria: A Field Evaluation

Busari Olusegun

11 Breast Self-Examination: Knowledge and Practice Among Female Secondary School Students in Delta State, Nigeria

Morenike O. Akpo

12 Determinants of EC Utilization among the Youth in the Tamale Municipality - A Cross-Sectional Study

Abdul-Malik, Abdulai

13 Health Budgeting at Woreda level and Effect on Access and Quality of Health Services in Somali Region of Ethiopia

Oladeji Olusola

14 Health Risk Associated with Near-Road Ambient Air Concentration of Particulate Matter in Mukono Municipal Council, Uganda

Edward Kibikyo Mukooza

15 Emergency Contraceptives for the Prevention of Unwanted Pregnancy among the Youth in Tamale - Perspective of the Clergy

Abdul-malik, abdulai

16 Effectiveness of Mobile Positive Health Dignity and Prevention Messages on the Attitude of HIV Positive Young Adults receiving Antiretroviral Treatment in Yola, Nigeria

S O Adeyemi

17 Assessing Factors Contributing to Erratic Water Supply in Peri Urban Areas. A Case Study of Chazanga Compound in Lusaka

Reuben Lazarus Zulu

18 Appraisal of Nature of Capacity Building Programs of HIV/AIDS Supply Chain Workforce in Nigeria

Sunday O Aguora

19 Determinants of Immunization Coverage and Associated Factors among Children aged under Two-Year-Old in the National Immunization Program of Mewat district, Haryana (2019-2020)

\section{Vishesh Kumar}

20 Effectiveness of Mobile Phone Reminders in Improving Adherence and Treatment Outcomes of Patients on Art in Adamawa State, Nigeria: A Ramdomized Controlled Trail 


\title{
Effects of Divorce on Women and Children
}

\author{
Adaora Isabella Odis \\ Department of Public Health, Texila American University, Nigeria
}

\begin{abstract}
Divorce is a legal separation of husband and wife, leaving each other free to remarry. It is also to break off a marriage legally. Marriage is a state of being legally joined as husband and wife. A family's social support is one of the major ways that family positively impacts health. Marriage is associated with physical health, psychological well-being, and low mortality. Marriage in particular has been studied in the way it affects health. Marriage is thought to protect well-being by providing companionship, emotional support, and economic security. It was also revealed that divorce has psychological and emotional effects on women. This article review discovered that divorced women and children experience more social isolation, which makes them end up producing greater feelings of loneliness, unhappiness, and lower self-esteem. Some psychological and emotional effects of divorce on women which include factors like; low appetite, reduced physical energy and strength, chest pain, severe pressure in chest difficulty in hearing, eye pain, digestive problem, lower abdomen pain, back pain headache, sleeping disturbance, worthless, suicidal attempt, decreased level of confidence, shocked, feeling of shame, feeling of sorrow in her heart, worried, anxious, irritated towards her life, suppressed problem, feeling bad, upset, feeling of miserable life, among other things as the major emotional and psychological effects of divorce on women.
\end{abstract}

Keywords: Children, Divorce, Marriage, Mental health, Women.

\section{Introduction}

Divorce is a legal separation of husband and wife, leaving each other free to remarry. It is also to break off a marriage legally. Marriage is a state of being legally joined as husband and wife.

Family is a group of people who are closely related, especially father, mother and their children.

Infidelity means disloyalty or a state of being unfaithful to the husband or wife's sexuality out matrimonial home. Couple simply means two married people, especially a husband and wife. Youngster is a young person or young boys and girls yet to marry. Early marriage is a situation where either of the spouses is not ripe enough for marriage before getting married. Universal escape means of regaining freedom from tensions of marriage. Family goals are the aims which a family strive to achieve for better living.

Cultural expectations define appropriate potential marriage partners. Cultural rules emphasizing the need to marry within a cultural group are known as endogamy. People are sometimes expected to marry within religious communities, to marry someone who is ethnically or racially similar or who comes from a similar economic or educational background. These are endogamous marriages: marriages within a group. Cultural expectations for marriage outside a particular group are called exogamy. Many cultures require that individuals should marry only outside their own kinship groups. For instance, In the United States laws prevent marriage between close relatives such as first cousins. There was a time in the not-so-distant past, however, when it was culturally preferred for Europeans and EuroAmericans to marry first cousins. Royalty and aristocrats betrothed their children to relatives, often cousins. Charles Darwin, who was British, married his first cousin Emma. This was often done to keep property and wealth in the family [1].

Arranged marriages were typical in many cultures around the world in the past, including in the United States. Marriages are arranged by families for many reasons: because the families have something in common, for financial reasons, to match people with others from the 
"correct" social, economic or religious group, and for many other reasons [1].

Divorce in the ancient times was also rare, because of penalties of proven infidelity and fear of offending with of both families.

In Nigeria, there are four clearly defined types of marriages, we have the church marriage conducted in the church, court marriage is performed at the court, then Moslem marriage conducted at the mosque and marriages contracted according to the native law and customs of any given ethnic group known as the traditional marriage.

Two essential elements of family marriage and parenthood - reveal God's character like nothing else in Creation. The love between a husband and wife provides a glimpse of Christ's passionate devotion to us as His bride. In the same way, the ups and downs of parenthood offer a compelling picture of God's tenderness and patience toward us as His children [2].

And family does more than reflect God's character. It provides a safe place where children can experience God's love (through their parents) and learn how to love other people [2].

The family this time needs a home to live in and feel secured, thus home is a place where a family live and also a place where one secures love. It is a place which provides all individual need, in order to fit into the society successfully. A home provides for good physical, mental, psychological and spiritual development of its members. A home built on love, mutual understanding and good planning can meet its goals, and a home where love and understanding are lacking is bound to crack in all directions. Thus, broken homes are homes or families where either the father or the mother has ceased to be a member of such home or family through divorce, desertion to mention but a few [3].

Divorce can be defined as a personal misfortune for either of the spouse in any society. But it is a universal escape for the inevitable tension of marriage. Divorce as a matter-of-fact break through bonds which once united two individual and their family. Marriage is a step-in life, in which a person plans as in a career or even business where one can either fail or succeed. This bond dissolution can occur as a result of extra-marital practices by either the partners, early marriages [3].

The objective of the family is the proper upbringing of children, which is very important to them than the happiness of the parents. This is because the early years of child's life are for the information of personality and these are the years that are spent mainly in association with parents, sibling and the family. The home as the child's immediate environment forms the basis for personality development, which accompanies the individual throughout life [3].

As a result of divorce or broken home, children fail to develop ties to one or few important persons in the family and when these ties are disrupted, children are taught to be impaired in developing close relationship in adulthood. These children feel bitter and carry over the tension from home to school. As a result, they cannot think clearly or critically as a happy person and at the same time they cannot concentrate on anything taught at school, when a mother is out of a home, leaving the children under the charity and mercy of step mother, these children are made to face many problems, like emotional disturbance (fear insecurity), malnutrition, sickness and disease, negligence, and they are not likely to perform up to expectation at school. Public health is defined as the science and art of preventing disease, prolonging life and promoting human health through organized efforts and informed choices of society, organizations, public and private, communities and individuals. Having a closeknit and supportive family provides emotional support, economic well-being, and increases overall health. However, the opposite is also true. When family life is characterized by stress and conflict, the health of family members tends to be negatively affected [4].

\section{Positive Aspects of Family Dynamics and Health}

A family's social support is one of the major ways that family positively impacts health. Social relationships which found in close families have been demonstrated to decrease the likelihood of the onset of chronic disease, disability, mental illness, and death [5]. Marriage in particular has been studied in the way it affects health. Marriage is thought to protect well-being by providing companionship, emotional support, and 
economic security. Marriage is associated with physical health, psychological well-being, and low mortality [6]. One study found that "Controlling on Considering every other risk factor for death that we know, including physical health status, rates of all-cause mortality are twice as high among the unmarried as the married" [7]. Another study found that "On the whole, marriage produces a net improvement in avoiding the onset of disease, which is called primary prevention" [8]. Married people are more likely to avoid risky behavior, such as heavy drinking and high-fat diets, and married people are also more likely to see the doctor for checkups and screenings [9].

One does not have to be married to obtain the health benefits from family. Studies have also confirmed that social support from parents, friends and relatives has positive effects, especially on mental health. "Prospective cohort studies have confirmed the direct beneficial effects of various forms of social support on global mental health, incidence of depressive symptoms, recovery from a unipolar depressive episode, psychologic distress, psychologic strain, physical symptoms and allcauses of mortality" [10]. Social integration and social support like marriage have protective effects on reducing mortality risks. For example, "those reporting higher levels of support from close friends and family exhibit lower heart rate and systolic blood pressure, lower serum cholesterol, and higher immune function" [11]. Thus, available data provide evidence to support the idea that one's social environment or family situation "does get under the skin to affect important physiologic parameters including neuroendocrine, immune and cardiovascular functioning" [12].

\section{Negative Aspects of Family Dynamics and Health}

Though good familial relations and social support serve as protective factors against mortality risks and improve overall health. Studies have shown that not all familial relations positively impact health. Problematic and non-supportive familial interactions have a negative impact on health. "There is increasing evidence that poor-quality relationships can actually harm physical and mental health. Indeed, persons in unhappy marriages exhibit worse physical and mental health than unmarried persons" [13]. Further, marriages characterized by an unequal division of decision making and power are associated with high levels of depression on the part of both spouses [14]. Growing up in an unsupported, neglectful or violent home is also associated with poor physical health and development [15].

\section{Women Prevented from Accessing Health Care}

Family power dynamics and gender roles may have a negative impact on a woman's health and her ability to seek health care. In many cultures, for a woman to access health care, she must receive permission from her husband, father or mother in-law and must be accompanied by a male to her appointments. "Researchers have noted that gender inequities play a role across many cultures in women's ability to obtain needed medical care for sexual and reproductive health concerns, have recognized that family dynamics, in addition to institutional sources, are a key part in the practice of unequal treatment" [16]. For example, in Malawi, gender roles shape the ability of men and women to access health care. "Women in Malawi, as in several other developing countries, have less power to decide about using resources and often have to seek their husband's approval before incurring expenses for health care" [17]. In Afghanistan, men continue to prevent women from receiving health care at hospitals with male staff, even if they have life-threatening conditions [18]. A survey conducted in Afghanistan found that $12 \%$ of women stated that their major reason for not giving birth in a health care structure was because their husbands did not allow them to access a health facility [19]. In Turkey, a pregnant woman must also seek permission from her mother-in-law or husband to seek care. However, most people in rural Turkey only seek care for serious, life-threatening conditions. Thus, some family members delay access to care for minor conditions until they worsen or signs are visible, which can have a significant negative impact on health. The National Maternal Mortality Study conducted in Turkey documents that delays in recognizing the problem and delayed health seeking by the 
family contributed to $30 \%$ of all pregnancyrelated deaths in Turkey [20].

\section{Family Dynamics and Children}

Families characterized by conflict, anger and aggression have particularly negative effects on children. Physical abuse and neglect represent immediate threats to the health of children. In addition, "the fact that children's developing physiological and neuroendocrine systems must repeatedly adapt to the threatening and stressful circumstances created by these environments increases the likelihood of biological dysregulation that may contribute to a buildup of allostatic load, that is, the premature physiological aging of the organism that enhances vulnerability to chronic disease and to early mortality in adulthood" [21]. Children who grow up in risky families are also especially likely to exhibit risky behaviors such as smoking, alcohol abuse, and drug abuse. "Anger and aggression are highly noxious agents in a family environment. Conditions ranging from living with irritable and quarreling parents to being exposed to violence and abuse at home show associations with mental and physical health problems in childhood with lasting effects in the adult years" [22].

\section{Reasons for Divorce}

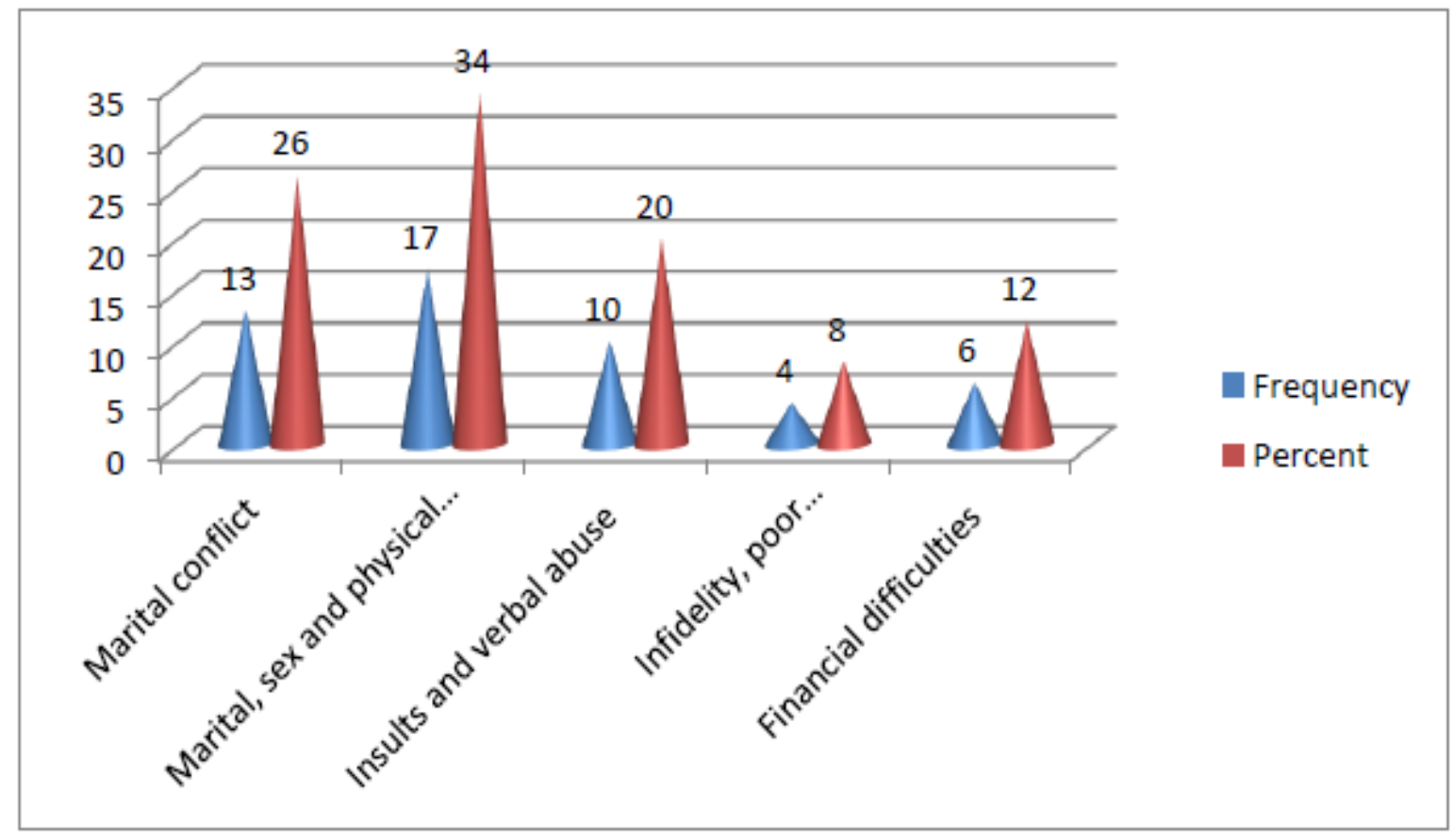

Figure 1. Reasons for Divorce

Source: John Nachinaab Onzaberigu Research Field Work, 2014

The data in figure 1 shows that $26 \%$ (13) of the divorce broke out of marriage because of marital conflict, $34 \%$ (17) of the respondents indicated that they got divorced because of marital, sex and physical abuse, 20\% (10) of the respondents cited insults and verbal abuse as the causes of divorce, $8 \%$ (4) of the respondents argued that infidelity, poor communication and lack of trust made them to divorce, whilst $12 \%$ (6) of the respondents feel that financial difficulties was the cause of their divorce [23].

The study found that marital conflict, marital, sex, physical abuse, insults, verbal abuse, infidelity, poor communication, lack of trust and financial difficulties were the reasons why the respondent's divorce. This means that marriages that suffer from these factors are more likely to end up in divorce, as respondents cited these factors as the cause of divorce [23].

This finding is in line with the views of [24], that sexual and physical abuse, insults, verbal abuse, infidelity, poor communication, lack of trust and financial difficulties are the common causes of divorce in many marital unions [23]. 


\section{Identification of concepts}

\section{Financial Distress}

A woman may suffer financially after divorce, particularly if she is the primary caregiver to the children. Without her husband's salary, she will have less money to cover bills and household expenses. The average divorced woman has less money than the average married woman and women don't completely recover from the financial consequences of divorce until they remarry, note Pamela $\mathrm{J}$. Smock, Wendy D. Manning and Sanjiv Gupta, in "The Effect of Marriage and Divorce on Women's Economic Well-Being," a 1999 article published in the "American Sociological Review" [25].

\section{Emotional Distress}

Divorce may leave a woman feeling hurt, lonely and unhappy. Even if it was her choice to end the marriage, she may bear the scars of the broken relationship for a long time. According to the Short-Term and Decade-Long Effects of Divorce on Women's Midlife Health, an article published in the Journal of Health and Social Behavior in 2006, divorced women reported significantly higher psychological distress levels than married women in the years following the divorce. The stresses of being in an unhappy marriage may simply be replaced by different worries, such as not being able to trust a man again, struggling to find her perfect partner or a fear of being rejected [25].

\section{Freedom}

Despite the potential negative effects of divorce on a woman, there are many cases in which divorce leads to a happier, healthier life. If a woman is getting out of a marriage fraught with conflict or violence, she will be happier in the long term, say Alan Hawkins, Tamara Fackrell and Brian Higginbotham, developers of the Utah Divorce Orientation program. A woman may still require professional help to get over the unhealthy relationship and subsequent breakdown of the marriage, particularly if she was the victim of domestic violence [25].

\section{Taking Control}

For a divorce to have more positive effects on a woman than negative, she must make the most of the chance to change her life for the better. Some women say that the first few years after divorce are a time of significant personal growth with greater independence and more personal choices. It is crucial to work to create a better life, say Hawkins, Fackrell and Higginbotham. Every single decision a woman makes after divorce, from where to live to how to increase her income, is an important part of this process [25].

\section{Insecurity in children}

Step mother or step father show little love and affection to their step children, which makes them suffer from mental retardation and miserable. They show behavioral responses like lying, stealing, playing, truant in school etc [3].

\section{Children's poor academic performance}

Many problems are associated with divorce or a broken home, which reflects on the performance of children in schools. It has been observed that children from broken homes suffer. Some of these problems are nonprovision of some basic necessities like clothing, food, learning materials, etc. There is an increase in domestic work and redistribution of household chores, which leaves the children with little or no time for their studies [3].

\section{Critical analysis of these concepts}

Women Forced into Prostitution due to financial distress, emotional distress, freedom and taking control. Young girl children are also pushed into prostitution due to insecurity and poor academic performance.

As Nicholas Kristof and his wife, Sheryl WuDunn explain in their book "Half the Sky as Turning Oppression into Opportunity for Women Worldwide", "it's not hyperbole to say that millions of women and girls are actually enslaved today. The term that is usually used for this phenomenon, 'sex trafficking,' is a misnomer. The problem isn't sex, nor is it prostitution. In many countries China, Brazil, and most of sub-Saharan Africa prostitution is widespread but mostly voluntary (in the sense that it is driven by economic pressure rather than physical compulsion). In those places, brothels do not lock up women, and many women work on their own without pimps or brothers. Nor is the problem exactly 'trafficking' since forced prostitution doesn't 
always depend on a girl being transported over a great distance by a middleman. The horror of sex trafficking can more properly be labeled slavery" [26].

The number of women who are forced into prostitution is hard to estimate. However, the Lancet calculates that 1 million children are forced into prostitution every year and the total number of children forced into prostitution could be as high as 10 million. The problem is particularly great in South East Asia, where up to a quarter million women and girls are forced into prostitution each year. These girls are often raped, locked up, denied food, water, medical care and are drugged if they refuse to comply with the brothel owners wishes. Most girls are lured away by promises of jobs as domestic workers, restaurant workers, or educational opportunities only to end up in brothels. In India, it is estimated that there are two million prostitutes and at any one time 20,000 girls are transported from one part of the country to another. Research also shows that around 5,000 to 7,000 Nepalese girls are trafficked yearly into India [28]. In addition to the horrendous human rights violations that these adolescent girls suffer, they are also highly susceptible to contracting HIV and other STDs. For example, in Indonesia, HIV prevalence was nearly $20 \%$ among trafficked women who had been sexually exploited for a year or more. In Cambodia, $73 \%$ of women and girls tested positive for sexually transmitted infections.

Sex trafficking and forced prostitution is a large economic industry. The industry has grown in recent years because it is extremely profitable and the risk of prosecution is low since most countries have weak laws on trafficking. An analysis of the Thai economy shows that earnings from trafficking, Thai women are close to $\$ 3$ billion annually. In addition, the U.S data suggest that traffickers earn about $\$ 60$ million a year from trafficking women and children [29]. Thus, "the economic approach to forced prostitution indicates that, because of the profit margins at stake and the large number of beneficiaries involved, it will not wither away. Rather, its existence must be actively assailed by addressing the supply as well as the demand side" [30].

\section{Psychological and Emotional Effect of Divorce on Women}

A large number of studies published during the 1990s found that divorced individuals compared with married individuals, experience lower levels of psychological wellbeing including less happiness, more symptoms of psychological distress and poorer self-concepts [31].

Women undergoing divorce often exhibit marked emotional liability characterized by euphoria and optimism alternating with anger, irritability, anxiety, loneliness, sadness, depression, suicidal, associated changes in selfconcept and self-esteem. Divorce is generally viewed as a prominent cause of depression in adults [32]. A review of sex differences in a depressive reaction to major life stressors found males and females were equally likely to experience depression following marital breakdown [33]. Single mothers (including those who are separated and divorced) have consistently been found to evidence higher rates of depression and psychiatric illnesses, relative to their married counterparts. Reasons cited include differences in stress and social support.

Women are particularly likely to experience negative effects of divorce. A pervasive problem is suffering of loneliness caused by the feeling that they have lost their children and feelings of inadequacy about their role as a parent.

Women undergoing separation and divorce also tend to avoid problems rather than to face them. They tend not to express their concerns and are reluctant to seek help (if they do; it is from friends or relatives rather than from professionals). Women appeared to be generally unaware of and unprepared for separation, often 'shut down' their feelings about the relationship. As a consequence, women often carry unresolved feelings of bitterness, grief and hurt for many years after the initial separation, which may impact on their physical and mental health. Other studies have found that females tend to experience higher rates of distress than males. In addition, 'leavers' initially often fare better in terms of emotional wellbeing than those who have been 'left' and who often feel rejected [34]. 
Parents who divorce also experience adverse effects on their physical, emotional, and financial well-being which may also in turn affect their children.

Married (male/female) people are more likely to have better physical health.

1. Married people smoke and drink less [35].

2. Married men are less likely to commit suicide than men who are divorced or separated [36].

3. Married individuals have the lowest incidence of diabetes, hypertension, and heart disease [37].

4. Married men are more likely to live longer after a diagnosis of cancer, especially prostate cancer [38].

5. Married men live longer than men who never married.

a. In the Framingham Offspring Study, married men had a 46 percent lower rate of dying from cardiovascular disease than unmarried men.

Married (male/female) people are more likely to have higher incomes [39].

1. Individuals who are married have greater wealth.

2. The longer they stay married, the greater the wealth accumulation [40].

3. Women who experience divorce face a 27 percent decrease in their standard of living [41].

Married women are more likely to be physically safer than divorced or separated women in terms of abuse at workplace, society and rape.

Divorce may have adverse long-term emotional effects for parents.

1. In Wallerstein's long-term study, half of the women were still very angry with their former spouses [42].

2. One-third of the women felt that life was unfair and disappointing [43].

Each child and each family are obviously unique with different strengths and weaknesses, unique personalities and temperaments and varying degrees of social, emotional and economic resources as well as differing family situations prior to divorce. Despite these differences, divorce has been shown to diminish a child's future competence in all areas of life, including family relationships, education, emotional well-being, and future earning power. One review of the literature conducted in the United Kingdom found that "although children are at increased risk of adverse outcomes following family breakdown and that negative outcomes can persist into adulthood, the difference between children from intact and non-intact families is small and the majority of children will not be adversely affected in the long-term" [44]. There is much research, however, that offers evidence to the contrary.

Two large meta-analyses, one reported in 1991 and the other reported ten years later in 2001, showed that "children with divorced parents continued to score significantly lower on measures of academic achievement, conduct, psychological adjustment, self-concept, and social relations" $[45,46]$.

A research states that, when a child experiences parental divorce, there are significant losses that must be acknowledged [47].

The child may lose time with each parent

1. Parents must adjust to their own losses as well as to their new role as a divorced parent. Thus, parents may not have as much emotional strength and time to invest in parenting. i.e., the parents experience a "moratorium on parenting."

2. Although laws are gradually changing, most children spend more time with one custodial parent and obviously have less time with each parent overall.

3. For most children, this means much less time spent with their fathers.

4. The child may also spend less time with their mother, as she may need to work longer hours to support the family [47].

The child may lose economic security

1. Custodial mothers experience the loss of 25-50 percent of their pre-divorce income.

2. Children living with single mothers are much more likely to live in poverty than children living with both married parents [48].

a. In 2009, children living with a divorced parent were more likely to live in a household below the poverty level (28\%) compared with other children (19\%) [49]. 
3. Unmarried women are more likely to remain in poverty compared with married individuals and unmarried men.

a. Approximately $32.2 \%$ of people in single-mother families in poverty during the first two months of 2009 continued to be in poverty for 36 months. In contrast, only 18.7 percent of people in married-couple families in poverty during this same time remained in poverty for 36 months [49].

4. Children living with single parents are less likely to experience upward financial mobility.

a. The fraction of children living in singleparent households is the strongest negative correlate of upward income mobility, according to one study [50].

b. The percentage of married families in a community also contributes to future upward economic mobility of all children in the community [50].

The child may lose emotional security [51]

1. The child may have a weakened relationship with his/her mother.

a. Divorced mothers are less able to provide emotional support [52].

2. The child may have a weakened relationship with his/her father.

a. Divorced fathers spend less time with their children.

b. A study in 1996 found that fewer than half of children living with a divorced mother had seen their fathers at all in more than one year, and only one in six saw their fathers once a week $[53,54]$.

c. Divorced fathers are rated as less caring by their adolescents. [55].

d. The child may find it more difficult to trust his/her father [56].

3. The child may have a weakened relationship with grandparents or relatives-especially the parents of the noncustodial parent [57].

4. The child may lose family traditions, celebrations and daily routines. Even adult children whose adult parents divorced later in life experienced the loss of family traditions and disruption of celebrations [58].
5. The change in residence may lead to loss of friends, school environment, and other support systems [47].

The child may have decreased social and psychological maturation

1. College students whose parents were divorced were more likely to experience verbal aggression and violence from their partner during conflict resolution [59].

2. Children of divorced parents may have lower scores on self-concept and social relations [60].

3. Anxiety and depression seem to worsen after the divorce event.

The child may change his or her outlook on sexual behavior [61]

1. There is increased approval (by children of divorced parents) of premarital sex, cohabitation and divorce [62].

2. There is earlier sexual debut [63].

3. Girls whose fathers left the home before they were five years old were eight times more likely to become pregnant as adolescents than girls from intact families [64].

4. Boys similarly have earlier sexual debut and higher rates of sexually transmitted disease when they have experienced divorce in their family.

5. As adults, the female children of divorced parents experience less trust and satisfaction in romantic relationships [65].

6 . The children of divorced parents are less likely to view marriage as permanent and less likely to view it as a lifelong commitment [66].

7. The children of divorced parents are two to three times more likely to cohabit and to do so at younger ages [45].

The child may lose his/her religious faith and practice [67]

1. Following a divorce, children are more likely to abandon their faith [68].

2. As adults, those raised in step-families are less likely to be religious than those raised by both biologic parents [67].

3. Since religious practice has benefits in areas such as sexual restraint, the child of divorce may lose this protection [69]. 
The child may lose cognitive and academic stimulation

1. Children in divorced homes have less language stimulation.

2. Children of divorced parents are more likely to have lower grade point averages (GPAs) and be asked to repeat a year of school [70].

3. A study of eleven industrialized countries showed that children living in two-parent families had higher math and science scores [70].

4. Children in single-mother families were twice as likely to have been absent from school for eleven or more days in the past year due to illness or injury (6\%) compared with children in two-parent families (3\%) [71].

5. Children of married parents attained higher income levels as adults.

The child may be less physically healthy

1. Fewer children in nuclear families were considered being in poor health than children in non-nuclear families $(12 \%$ of children in nuclear family versus $22 \%$ of children of single parent) [72].

2. Children living with married parents are less likely to be abused or neglected. In one study, the relative risk that children from a single-parent family would be physically abused or neglected more than doubled [47].

3. Children living with divorced Mum may not be able to vaccinate their children against diseases because of cost. Likewise, Single fathers may not remember to follow his child's vaccine schedule religiously.

4. Children who are on medication may miss their dosage because of cost of drugs and emotional imbalance of his Mother or Father.

5. Children living with divorced parent may be overweight or underweight because the parent may not have time to prepare proper meals for children and cost of food.

The child may have a higher risk of emotional distress

1. A study of almost one million children in Sweden demonstrated that children growing up with single parents were more than twice as likely to experience a serious psychiatric disorder, commit or attempt suicide, or develop an alcohol addiction [73].

2. Children of single parents are twice as likely to have emotional and behavioral problems -8 percent versus 4 percent for children from two-parent households [74].

3. The CDC reported on adverse family experiences among children in nonparental care. The study found, "Children living with one biological parent were between 3 and 8 times as likely as children living with two biological parents to have experienced neighborhood violence, caregiver violence, or caregiver incarceration or to have lived with a caregiver with mental illness or an alcohol or drug problem" [75]. 


\section{The Application of the Concept to the Real World}

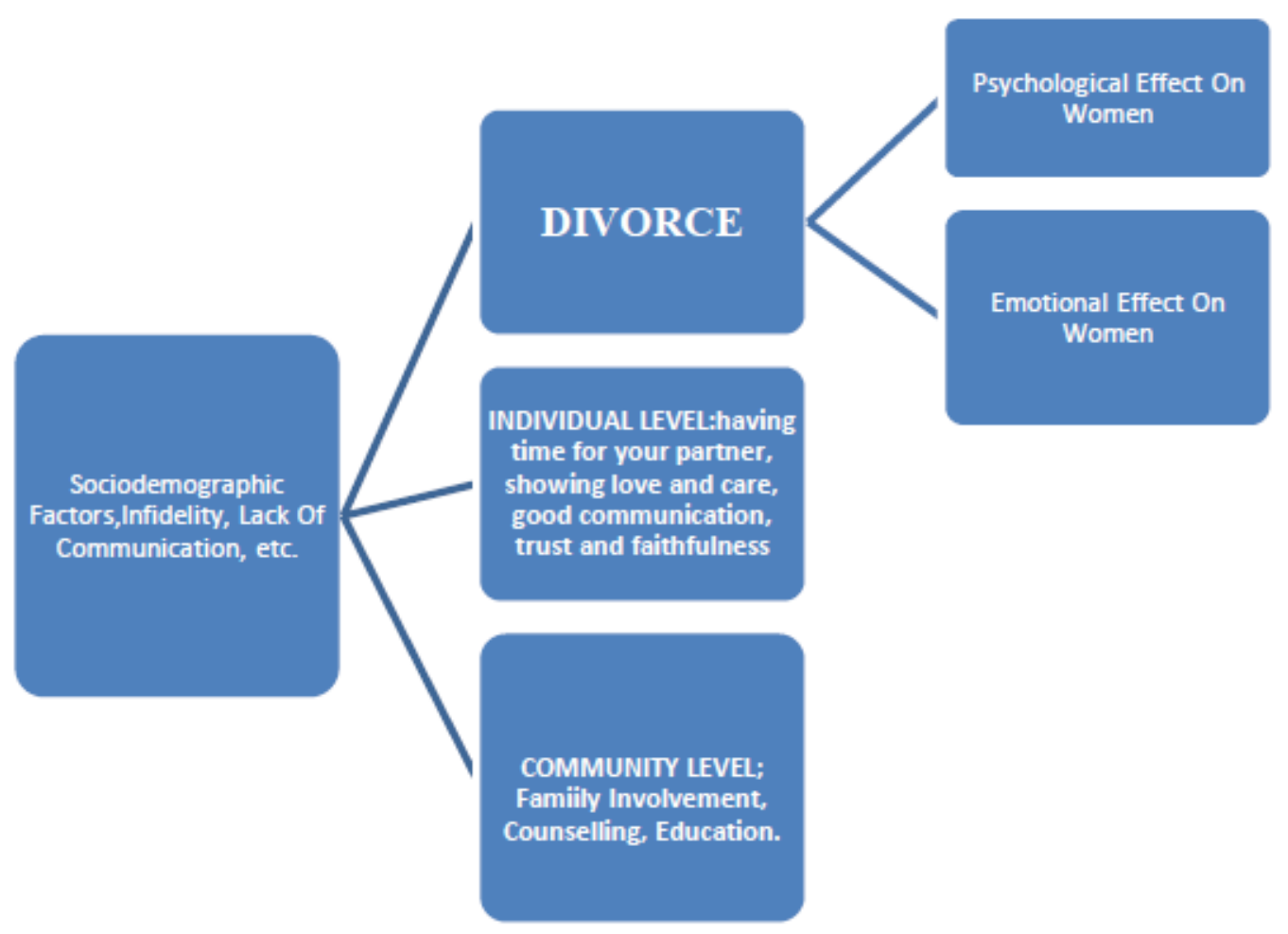

Figure 2. Divorce Conceptual Framework

Source: John Nachinaab Onzaberigu Research Field Work 2014

From the construct above, it is clear that divorce is as a result of factors such as sociodemographic characteristics of the individual, infidelity of the part of one partner in a relationship, poor or lack of good communication amongst couple, etc.

Most marriages end up in divorce because of the socio-demographic characteristic such as couples' level of education, income status, age/years of marriage, the socio-cultural background of couple, etc. Equally, extramarital affair is one major cause of the increase in divorce in recent times. Also, many relationships failed because of poor communication. Many couples find it hard to express how they feel for each other. They do not know how to verbalize their needs, and they do not know how to listen carefully. Poor communication can be a major cause of divorce.

Divorce has both psychological and emotional effect on women. Women are mostly affected by divorce psychological and emotional. They feel guilt, anxious, distress, depress, grieve, etc. The reasons might be that most women less expect divorce, suffer in child caring, or are mostly dependent on their husband, such that separation or divorce leads to greater psychological and emotional bearing on the women.

Divorce can be minimized by addressing it from the individual and community or societal level. Within the individual level, couple should learn how to trust their partners, develop good communication, avoid extra-marital affairs, show love and care for their partners, etc. The society or the community can as well help in reducing divorce by organizing educational programs on divorce effects so as to lighten couples on the negative side of divorce. Counseling program should be made available to couples facing marital problems to help them cope with their problems. Family members should also help by conducting a proper investigation on to family their children will be marriage to help in the selection of proper spouses for their children to avoid reduce divorce. 


\section{Conclusion}

It was also revealed that divorce has psychological and emotional effects on women. This contextual project discovered that divorced women and children experience more social isolation, which makes them end up producing greater feelings of loneliness, unhappiness and lower self-esteem. Some psychological and emotional effects of divorce on women which include factors like low appetite, reduced physical energy, strength, chest pain, severe

\section{References}

[1] Gilliland M. K., (2018). Family and marriage, https://courses.lumenlearning.com/suny-esc-

culturalanthropology/chapter/family_and_marriage/. [2] Bruner Kurt, 2017, The purpose of the family, https://www.focusonthefamily.com/parenting/thepurpose-of-the-family/.

[3] Effect of divorce on the academic performance of students in some selected secondary schools in Oredo local government area of Edo state https://www.grossarchive.com/upload/1416644906. htm.

[4] http://www.uniteforsight.org/genderpower/module1.

[5] George, L. K., \& Durham, N. C. (2016). The health-promoting effects of social bonds.

[6] Ross, C., Mirowsky, J., and Goldsteen, K. "The Impact of the Family on Health: The Decade in Review." Journal of Marriage and the Family. 52. (1990):1059-1078.

[7] George, L. K., \& Durham, N. C. (2016). The health-promoting effects of social bonds.

[8] Ross, C., Mirowsky, J., and Goldsteen, K. "The Impact of the Family on Health: The Decade in Review." Journal of Marriage and the Family. 52. (1990):1059-1078.

[9] Huliyappa, Deepadarshan and Hiremath, Shweta, "Lifestyle factors and lifestyle diseases among rural population of Bengaluru rural district", International Journal of Community Medicine and Public Health (2017) Volume 4 (5):1558. 10.18203/23946040.ijcmph20171763.

[10] Broadhead, W., Kaplan, B., James, S., et. al. "The Epidemiologic Evidence for a Relationship Between Social Support and Health." American Journal of Epidemiology. 117.5 (1983).

[11] Seeman, T. (1996) "Social ties and health: The benefits of social integration." Annals of Epidemiology. 6.5. pressure in chest, difficulty in hearing, eye pain, digestive problem, lower abdomen pain, back pain headache, sleeping disturbance, worthless, suicidal attempt, decreased level of confidence, shocked, feeling of shame, feeling of sorrow in her heart, worried, anxious, irritated towards her life, suppressed problem, feeling bad, upset, feeling of miserable life, among other things as the major emotional and psychological effects of divorce on women.

[12] Yang, Y. C., Boen, C., Gerken, K., Li, T., Schorpp, K., \& Harris, K. M. (2016). Social relationships and physiological determinants of longevity across the human life span. Proceedings of the National Academy of Sciences of the United States of America, 113(3), 578-583. https://doi.org/10.1073/pnas.1511085112.

[13] George, L. K., \& Durham, N. C. (2016). The health-promoting effects of social bonds.

[14]Ross, C., Mirowsky, J., and Goldsteen, K. "The Impact of the Family on Health: The Decade in Review." Journal of Marriage and the Family. 52. (1990):1059-1078.

[15] George, L. K., \& Durham, N. C. (2016). The health-promoting effects of social bonds.

[16] Regmi, K., Smart, R., \& Kottler, J. "Understanding Gender and Power Dynamics Within the Family: A Qualitative Study of Nepali Women's Experience." The Australian and New Zealand Journal of Family Therapy. 31.2 (2010).

[17]Department for International Development. (1 Jan. 2005) "REACH: Challenging Barriers to Health Care." https://www.gov.uk/dfid-researchoutputs/reach-challenging-barriers-to-health-care-inmalawi.

[18] Synovitz, R. (3 Mar. 2004) Afghanistan: Gender Taboos Keep Women from Seeking Medical Care." Radio Free Europe. https://www.rferl.org/a/1051746.html.

[19] IbnSina and ICRH. (Oct. 2002) "KAP Survey regarding reproductive health." http://icrhm.org/sites/default/files/KAPsurveyKabulI CRHIbnSina.pdf.

[20] Ay, P., Hayran, O., Topuzoglu, A., et. al. "The influence of gender roles on health seeking behaviour during pregnancy in Turkey." The European Journal of Contraception and Reproductive Health Care. 14.4 (2009).

[21] George, L. K., \& Durham, N. C. (2016). The health-promoting effects of social bonds. 
[22] Repetti, R., Taylor, S., and Seeman, T. "Risky Families: Family Social Environments and the Mental and Physical Health of Offspring." Psychological Bulletin. 128.2 (2002): 330-366.

[23] Nachinaab J. (2014). "Psychological and emotional effects of divorce on women". (DOC) PSYCHOLOGICAL AND EMOTIONAL EFFECTS OF DIVORCE ON WOMEN | john onzaberigu nachinaab - Academia.edu.

[24] Wolcott and Hughes, (1999), "Towards understanding the reasons for divorce" (Working Paper No. 20). Melbourne: Australian Institute of Family Studies.

https://aifs.gov.au/publications/towards-

understanding-reasons-divorce.

[25] Giles C. (2018). "The Effects of Divorce on Women; Our everyday life: Relationships and family" https://oureverydaylife.com/the-effects-ofdivorce-on-women-5050311.html.

[26] Kristof, N. \& WuDunn, S. "Half the Sky: Turning Oppression into Opportunity for Women Worldwide." (New York: Random House, 2009).

[27]Lyn, T. (12 Aug. 2009) "Trafficked women face high HIV infection risk." Reuters. https://www.reuters.com/article/idINIndia-

41716620090812.

[28] Chattoraj, B. "Sex related offences and their prevention and control measures: an Indian perspective."

https://www.unafei.or.jp/publications/pdf/RS_No72/ No72_13VE_Chattoraj.pdf.

[29] United Nations, 2008, “An Introduction to Human Trafficking: Vulnerability, Impact and Action" https://www.unodc.org/documents/humantrafficking/An_Introduction_to_Human_Trafficking _-_Background_Paper.pdf.

[30] Kempadoo, K. "Trafficking and Prostitution Reconsidered: New Perspectives on Migration, Sex Work, and Human Rights." Canadian Journal of Sociology Online. (2007).

[31] Demo, D.H. \& Acock, A.C. (1988). The Impact of Divorce on Children. Journal of Marriage and the Family, 50, 619-648.

[32] Tennant C., 2002. Life events, stress and depression: A review of recent finding. Australian and New Zealand Journal of Psychiatry, 36, 173 182.

[33] Maciejewski PK, Prigerson HG, Mazure CM. Sex differences in event-related risk for major depression. Psychol Med 31: 593-604.

[34] Brickman, P., Rabinowitz, V. C., Karuza, J., Jr., Coates, D., Cohn, E., \& Kidder, L. (1982). Models of helping and coping. American Psychologist, 37, 368-384.

[35] ChildStats.gov. 2013. America's Children: Key National Indicators of Well-Being, 2013: Emotional and Behavioral Difficulties (2013) http://www.childstats.gov/americaschildren/health3. asp.

[36] Schoenborn C.A.2004. Marital status and health: United States, 1999-2002. In Advance data from Vital and Health Statistics, Centers for Disease Control and Prevention, No. 351. [PubMed] [Google Scholar].

[37] Kposowa A.J.2000. Marital status and suicide in the National Longitudinal Mortality Study. Journal of Epidemiology and Community Health 54: 254 61. [PMC free article] [PubMed] [Google Scholar].

[38] Pienta A.M.2000. Health consequences of marriage for the retirement years. Journal of Family Issues 21: 559-86. [Google Scholar].

[39] Goodwin J.S., Hunt W.C., Key C.R., and Sarmet J.M. 1987. The effect of marital status on stage, treatment, and survival of cancer patients. Journal of the American Medical Association 258: 3125-30. [PubMed] [Google Scholar].

[40] Marriage and Men's Health. 2010. Harvard Men's Health Watch (2010) Harvard Health Publications.http://www.health.harvard.edu/newslett ers/Harvard_Mens_Health_Watch/2010/July/marria ge-and-mens-health.

[41] Stratton L.S.2002. Examining the wage differential for married and cohabiting men. Economic Inquiry 40: 199-212. [Google Scholar].

[42] Keyes C.L.M.2002. Social civility in the United States. Sociological Inquiry 72: 393-408 As cited in The Family in America New Research, November 2002. [Google Scholar].

[43] Wallerstein J.S., and Blakeslee S. 2004. Second chances: Men, women, and children a decade after divorce. Boston, MA: Houghton Mifflin. [Google Scholar].

[44] Mooney A., Oliver C., and Smith M. 2009. Impact of family breakdown on children's wellbeing evidence review DCSF-RR113. London: University of London, Institute of Education, Thomas Coram Research Unit. [Google Scholar].

[45] Amato P.R., and Booth A. 1997. A generation at risk: Growing up in an era of family upheaval. Cambridge, MA: Harvard University Press. [Google Scholar].

[46] Amato P.R., and Keith B. 1991. Parental divorce and the well-being of children: A metaanalysis. Psychological Bulletin 110: 26-46. [PubMed] [Google Scholar]. 
[47] Anderson J. (2014). The impact of family structure on the health of children: Effects of divorce. The Linacre quarterly, 81(4), 378-387. https://doi.org/10.1179/0024363914Z.00000000087. [48]Edwards A.N. 2014 Dynamics of Economic Well-being: Poverty, 2009-2001: Household Economic Studies (2014) United States Census Bureau Web Site. http://www.census.gov/prod/2014pubs/p70-137.pdf. [49]US Census Bureau. 2011. Divorce Rates Highest in the South, Lowest in the Northeast, Census Bureau Reports United States Census Bureau Web Site. http://www.census.gov/newsroom/releases/archives/ marital_status_living_arrangements/cb11-144.html.

[50] Chetty R., Hendren N., Kline P., and Saez E. 2014 The Geography of Intergenerational Mobility in the United States (2014) Harvard University. http://obs.rc.fas.harvard.edu/chetty/mobility_geo.pdf

[51] Amato P.R., and Afifi T.D. 2006. Feeling caught between parents: Adult children's relations with parents and subjective well-being. Journal of Marriage and Family 68(1): 231. [Google Scholar]. [52] Miller J.E., and Davis D. 1997. Poverty history, marital history and quality of children's home environments. Journal of Marriage and Family 59: 996-1007. [Google Scholar]

[53] Popenoe D.1996. Life without father. New York, NY: The Free Press; As quoted by Fagan, P.F., and A. Churchill. The effects of divorce on children. Marri Research January 11, 2012: 6. [Google Scholar].

[54]Fagan P.F., and Churchill A. The effects of divorce on children. Marri Research. January 11, 2012. [Google Scholar].

[55]Dunlop R., Burns A., and Bermingham S. 2001. Parent-child relations and adolescent self-image following divorce: A ten-year study. Journal of Youth and Adolescence 30: 117-34. [Google Scholar].

[56] King V.2002. Parental divorce and interpersonal trust in adult offspring. Journal of Marriage Family 64(3): 642-56. [Google Scholar].

[57]Kruk E., and Hall B.L. 1995. The disengagement of paternal grandparents subsequent to divorce. Journal of Divorce and Remarriage 23: 131-47. [Google Scholar].

[58] Pett M.A., Lang N., and Gander A. 1992. Latelife divorce: Its impact on family rituals. Journal of Family Issues 13: 526-52. [Google Scholar].

[59]Billingham R.E., and Notebaert N.L. 1993. Divorce and dating violence revisited: Multivariate analyses using Straus's conflict tactics subscores. Psychological Reports 73: 679-84. [PubMed] [Google Scholar].

[60] Amato P.R.2001. Children of divorce in the 1990s. An update of the Amato and Keith (1991) meta-analysis. Journal of Family Psychology 15: 355-75. [PubMed] [Google Scholar].

[61] Strohschein L.2005. Parental divorce and child mental health trajectories. Journal of Marriage and Family 67: 1286. [Google Scholar].

[62] Jeynes W.H.2001. The effects of recent parental divorce on their children's sexual attitudes and behavior. Journal of Divorce and Remarriage 35: 125. [Google Scholar].

[63] Strohschein L.2005. Parental divorce and child mental health trajectories. Journal of Marriage and Family 67: 1286. [Google Scholar].

[64]Ellis B.J., Bates J.E., Dodge K.A., Fergusson D.M., Horwood L.J., Pettit G.S., and Woodward L. 2003. Does father absence place daughters at special risk for early sexual activity and teenage pregnancy? Child Dev 74: 810-1. [PMC free article] [PubMed] [Google Scholar].

[65]Jacquet S.E., and Surra C.A. 2001. Parental divorce and premarital couples: Commitment and other relationship characteristics. Journal of Marriage and Family 63: 627. [Google Scholar].

[66] Weigel D.J.2007. Parental divorce and the types of commitment-related messages people gain from their families of origin. Journal of Divorce and Remarriage 47: 23. [Google Scholar].

[67] Myers S.M.1996. An interactive model of religiosity inheritance: The importance of family context. American Sociological Review 61: 864-5. [Google Scholar].

[68]Feigelman W., Gorman B.S., and Varacalli J.A. 1992. Americans who give up religion. Sociology and Social Research 76: 138-43 [Google Scholar]. [69]Rostosky S.S., Regnerus M.D., and Wright M.L.C. 2003. Coital debut: The role of religiosity and sex attitudes in the add health survey. Journal of Sex Research 40: 358-67. [PubMed] [Google Scholar].

[70] Jeynes W.H.2000. The effects of several of the most common family structures on the academic achievement of eighth graders. Marriage and Family Review 30: 88. [Google Scholar].

[71]Pong S.L., Dronkers J., and HampdenThompson G. 2003. Family policies and children's school achievement in single-versus two-parent families. Journal of Marriage and Family 65: 68199. [Google Scholar]. 
[72] CDC/NCHS National Health Interview Survey. 2012. Centers for Disease Control and Prevention Web Site

(2013).

http://www.cdc.gov/nchs/data/series/sr_10/sr10_258 .pdf.

[73] Brown J., Cohen P., Johnson J.G., and Salzinger S. 1998. A longitudinal analysis of risk factors for child maltreatment: Findings of a 17-year prospective study of officially recorded and selfreported child abuse and neglect. Child Abuse Negl 22: 1065-78. [PubMed] [Google Scholar].
[74] Kelleher K.J., McInerny T.K., Gardner W.P., Childs G.E., and Wasserman R.C. 2000. Increasing identification of psychosocial problems: 1979-1996. Pediatrics 105: 1313-21. [PubMed] [Google Scholar].

[75] Bramlett M.D., and Radel L.F. 2014 Adverse Family Experiences Among Children in Nonparental Care, 2011-2012. National Center for Health Statistics, $\mathrm{n}$. 74 , http://www.cdc.gov/nchs/data/nhsr/nhsr074.pdf. 


\title{
The Impact and Aftermath of Coronavirus on Southern African Development Community Consumers
}

\author{
Josephine Shailemo \\ Department of Management, Texila American University, Namibia
}

\begin{abstract}
This paper is all about the impact and aftermath of corona virus (COVID-19) on Southern African Development Community (SADC) consumers. Major impacts as well as aftermath of COVID-19 were criticized and analyzed thoroughly to give more clarity. The study employed both qualitative and quantitative research designs, and the study was a descriptive research of a survey kind of. The targeted population was SADC consumers. The sample size of 200 consumers was taken from Namibia and South Africa only among other SADC countries. Questionnaires were drafted distributed and handed to respondents. Primary data was collected by the means of interviews as well as structured questionnaires, while Secondary data was collected from journals and by the use of internet. Data were analyzed and finally presented in a form of tables and pie charts. The two hypotheses (Null and Alternative) testing were identified, which led to the explanation of the phenomena. The study concluded that coronavirus is still affecting SADC consumers but anyway it is a worldwide pandemic and therefore no one knows when it will end. It was difficult for one to determine the exact outcomes of the aftermath of corona virus as it was still skyrocketing.
\end{abstract}

Keywords: Aftermath, Coronavirus, Consumers, Impact.

\section{Introduction}

No other virus has made headline globally compared to coronavirus [1] where Southern African Development Community (SADC) is no exception. Early December 2019, the world was hit by a deadly virus called corona virus. This deadly virus is dangerous and epidemic. It started in Wuhan-Hubei province in China.

It is believed that this novel virus is coming from eating or consuming bats and snakes. Other people are saying the virus is caused by technology $(5 \mathrm{G})$, as it was first rolled out in Wuhan city. Factories are coming to a standstill as many employees are affected, and those who are not affected are fearing for their lives.

The corona virus [1] has resulted in mass production shutdowns and supply chain disruptions due to port closures in China, causing global ripple effects across all economic sectors in rare "twin supply demand shock". Most of SADC countries also reported cases of COVID-19 and plans to control the further spreading of the deadly virus. With the help of World Health Organization [3] proper precautions are followed by countries worldwide. Global gross domestic product (GDP) growth is dropping negatively. Although Chinese growth will fall the in short term, it is expected to rebound quickly, some suggested this could even happen in the second quarter of 2020 when the virus will hopefully be contained. In the meantime, central banks are implementing measures to mitigate the effects of the virus on the economy, cutting interest rates and injecting liquidity into the banking system in some countries [2].

For the Southern African Development Community with the main objectives to achieve economic development, peace, security, growth and alleviate poverty, enhance the standard and quality of life of the people of Southern Africa, and support the socially disadvantaged through regional integration. Consumers are finding it hard to survive as they mainly depend on Chinese products, which is currently on lockdown no shipment of products are coming in. Markets are dropping drastically; some are even closing down as they have no products or stocks to sell to end-users.

\section{Statement of Research Problem}

Attention has thus far been directed to SADC consumers who mostly depend on the 
Chinese markets to start producing the same products as those that the Chinese market can offer. The time is now, corona virus is teaching marketers a lesson to be self- sustainable and independent for example now, marketers are inneedy of face masks but no SADC country manufacture masks, this simplifies that Chinese markets should tap in to assist.

This research purpose is to create awareness so that consumers are proactive and understand the danger of COVID-19 and with all its hindrances and obstacles it causes. On the other hand, the study is not only creating awareness but wants to establish whether there is a complete cure for corona virus. Furthermore, the study wants to know how consumers will survive the deadly virus, what to consume and what not. Finally, the study also wants to understand if SADC consumers can stand on their own and produce most of their local products without depending on the Chinese markets.

\section{Research Objectives}

The following objectives guided the study:

- To know how SADC Consumers will survive during the time of coronavirus.

- To determine challenges facing SADC companies and their marketers.

- To link the co-operation of SADC marketers and consumers with one another.

\section{Research Questions}

1. Is there a link of co-operation between SADC marketers and consumers?

2. How will SADC consumers survive during the time of coronavirus?
3. What are the challenges facing SADC companies and their marketers?

4. Is there a link of co-operation between SADC marketers and consumers?

\section{Research Hypotheses}

The following assumptions concerning the impact and aftermath of COVID-19 on SADC consumers were looked on:

\section{H1}

H1 a: SADC consumers know how to survive during the time of coronavirus.

$\mathrm{H} 1 \mathrm{~b}$ : There are challenges facing SADC companies and their marketers.

$\mathrm{H} 1 \mathrm{c}$ : There is a link of co-operation between SADC marketers and consumers.

\section{H0}

H0 a: SADC consumers do not know how to survive during the time of coronavirus.

$\mathrm{HO}$ b: There are no challenges facing SADC companies and their marketers.

$\mathrm{H} 0 \mathrm{c}$ : There is no link of co-operation between SADC marketers and consumers.

\section{Review of Literature}

\section{Introduction}

This is a chapter that yields the reader's insight with too much information and knowledge, and such a process can be very challenging as one has to combine viewpoints of various authors in order to arrive at a new viewpoint. Literature review includes a review of books, journals, internet as well as other publications to derive to a theoretical background of the study. 


\section{Conceptual Framework}

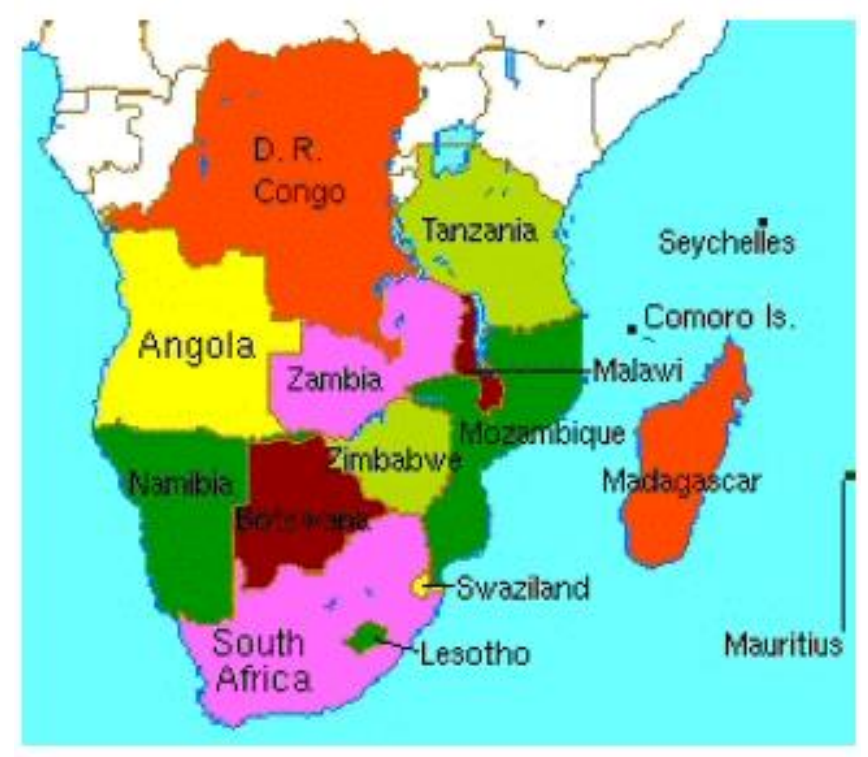

Figure 1. SADC Countries

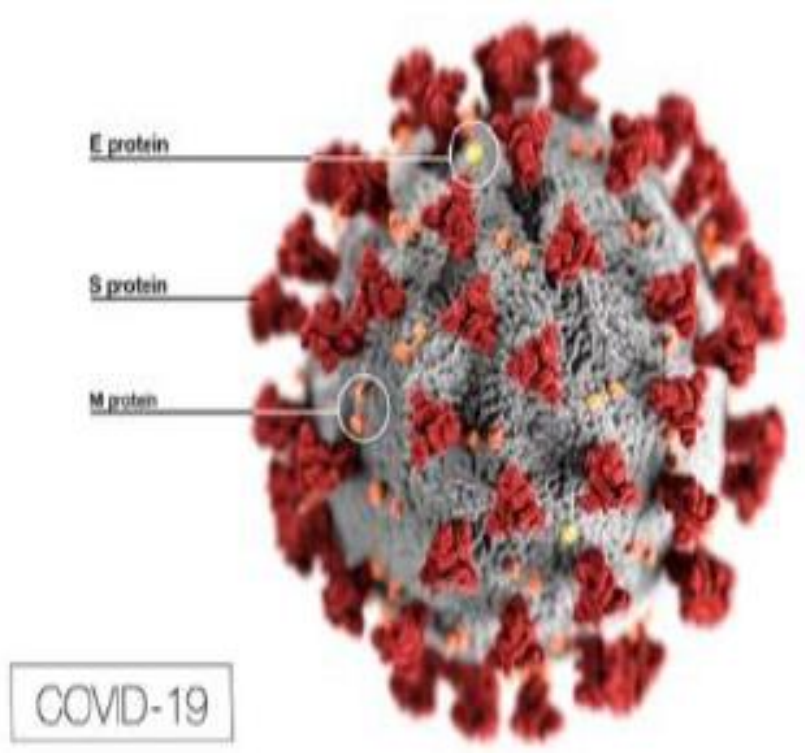

Figure 1a. COVID-19

\section{Theoretical Framework}

\section{Lockdown on SADC Countries}

Most of SADC countries are on lockdown due to corona virus [1] and this place a danger on the economy of countries. Business is on recess with no income, some are forced by the situation to close down or retrench valuable employees. A good example is that of a luxurious five-star Hilton hotel in the vicinity of Windhoek-Namibia, which forced its employees on unpaid leave for two consecutive months [4]. Another example is that of airline industry West Air, which retrenches some of its employees. West Air customers can be assured that the company has gone above and beyond the recommendations from the Word Health Organization [3] and all other local government and civil aviation agencies. The Covid-19 epidemic has resulted in travel bans across the globe as well as locally, with a negative impact on all aspects of the global economy, but an instant and devastating effect on travel and tourism [4].

There is a problem of cross border trade only essential services is allowed to operate, trucks that are transporting other various goods are stopped and only those that offer essential 
goods such as food, fuel and perhaps medicine. This places a burden on marketers who want to market their products to consumers, and in return consumers are suffering silently. There is a shortage of basic necessities to protect people from COVID-19 such as masks, gloves, sanitizers and other products relating to the prevention of COVID-19.

SADC countries are experiencing the problem of panic buying and overstocking of products whereby shops are left empty and are in the process of restocking, which is quite difficult for countries on lockdown could not ship or export goods or products to other countries. The lockdown on SADC countries places a control on countries to combat and contain the further spreading of COVID-19 to other places as people are restricted to stay where they are and strictly not to move around.

\section{The Impact of Corona Virus (COVID- 19) ON SADC Countries}

The 2019/2020 corona virus pandemic was confirmed to have spread to Africa on 14 February 2020. Experts have worried about COVID-19 spreading to Africa because many of the healthcare systems on the continent are inadequate, having problems such as lack of equipment, lack of funding, insufficient training of healthcare workers and insufficient data transmission. It was feared that the pandemic could be difficult to keep under control in Africa, specifically in SADC countries, and could cause huge economic problems if it spread widely. Matshidiso Moeti of the World Health Organization said that hand washing and physical distancing could be challenging in some places in Africa. Lockdown may not be possible, and challenges may be exacerbated by the prevalence of diseases such as malaria, HIV, tuberculosis and cholera. He further said that "a problem shared is a problem halved, SADC countries need to share the capacities available to them as much as possible nationally and regionally. The World Health Organization helped many SADC countries to set up laboratories for COVID-19 testing. Many preventative measures have been implemented in SADC countries, including travel restrictions, flight cancellations, event cancellations, school closures, and border closures [5].
Dar es Salaam/ Brazzaville, 10 March 2020ministers of health from the Southern African Development Community (SADC) agreed to harmonize and coordinate their efforts to respond to COVID-19 in the region. Since COVID-19 declared to be a public health emergency of international concern in February (2020); country preparedness levels in the WHO African region have been self- assessed to increase the rigor and reliability of the selfassessment processes, SADC Health Minister agreed to submit their survey results to peer review. These survey results shape members' state response planning and the assistance they receive from the World Health Organization [3].

Levels of preparedness vary considerably between SADC countries, and WHO is working with member states to address gaps in prevention, impact mitigation, and other intervention with emergency and contingency funds. Ten of the sixteen SADC member states also agreed to share information on the COVID-19 outbreak. These countries have reestablished and expanded the terms of reference for the technical committee responsible for coordinating and monitoring the implementation of the SADC Protocol on Health, comprising directors of public health and directors of medical services, said Ummy Mwalimu, Health Minister of Tanzania, and a lot of SADC ministers agreed to suspend regional face-to-face meetings in favor of internet-based conferences. While high-level coordination is vital to effectively respond to COVID-19, simply day-to-day measures are essential too. These include regular hand washing with soap and water, coughing or sneezing into a tissue or a bent elbow, being sure to safely dispose of the tissue afterward, maintaining a social distance of at least one meter, particularly if that person if coughing; avoiding touching the eyes, nose and mouth, and seeking medical attention early if a person develops a fever or cough.

The effects of COVID-19 spreading will have wider implications, not just on how economies function but also how consumers behave across the world [6]. COVID-19 induced changes in behavior could well prove a new tide-change in the direction of SADC's influence. The need for millions to retreat into self-quarantine, caused by the outbreak, has 
forced changes in the way many people have behaved for over a month now. Being cooped up at home for such an extended period will leave an indelible (if subtle) shift in how consumers in SADC countries behave in the future.

\section{The Aftermath of COVID-19 on SADC Consumers}

SADC countries are on lockdown, and the pace of life slows on the SADC consumers working from home is now a new thing. Consumers are now shopping online but this takes time for goods to be delivered or products mighty are the wrong one and some are lost in transit. SADC marketers are left in the dark there is nothing to market, no income, businesses are closing down, bartering and international trade are becoming impossible and deemed as things of the past.

Many SADC Consumers are not aware that life after lockdown on COVID-19 will be very different and must start preparing for a change of life-style right now. Those who are shorted think everything will be normal after lockdown but the opposite is true.

As we speak our future is uncertain for the next 12 months or so, people in urban areas will lose jobs and will struggle to pay rents, school fees, buy food and other necessities.

No one is certain that the end of lockdown would be the end of COVID-19, it might be the starting of armed struggle against the virus of which for now there is no end in sight. Every affected business will in turn affect those who also depend on it, including its workers and their dependents and other business too said Inga Matsuii, Zimbambwe [7]. S/he further added that the following will be affected severely:

\section{Cross Border Business}

Most of our cross borders were travelling to South Africa, Botswana, Tanzania, Dubai, China etc. and chances of these countries reopening their borders to the travelling public anytime soon are very slim. This business will close down at least for now until corona virus it termed.

Many countries will remain on lockdown for longer periods than currently anticipated. United Kingdom (UK) has already hinted that they will remain on lockdown for a year. China has also announced that it will guard its borders jealously to avoid reinfection from foreigners as they consolidate their victory over COVID-19. Here closer home, South Africa and Botswana are likely to do the same to avoid importing new cases. Besides the hospitality of these countries to cross borders, especially from Zimbabwe has all along been found wanting. This time they have a valid and genuine reason of banning cross borders, even for years.

In Zimbabwe, the Gulf, Mupedzanhamo and many other flea markets and boutiques country wide will be hard hit and all those surviving on that business will be rendered useless. While Francistown and Mussina risk becoming ghost towns without Zimbabwean cross borders, these two towns are economically stable and can manage.

\section{Tourism Business}

Hotels and lodges will open, but there will be no meaningful business. No international tourists are expected in the foreseeable future, meaning the sector will remain closed indefinitely. Automatically many workers in this sector will lose their jobs, especially in resort towns like Victoria Falls. The future of Victoria Falls remains oblique, the resort town faces the possibility of degenerating into a ghost town for a while.

\section{Other Companies}

While other companies will open for business after lockdown, not everyone will be recalled. Critical manpower will be called first, while other will be recalled at a later stage. Companies may need more time to recover, and some employees risk not being recalled at all.

\section{Gatherings}

Gatherings, of any kind and purpose, have been banned worldwide and no country will allow gatherings anytime soon as these have been singled out as responsible for promoting the spread of corona virus.

\section{Educational Gatherings}

The real challenge will be in education, especially in Africa. Schools are closed worldwide and while developed nations can resort to E-learning to avoid student gatherings, at least for a semester or two or even a year, Africa Zimbabwe has no such capacity. 


\section{Street Vending}

This will affect thousands of people mainly in big towns like Harare, Byo and Gweru. Many people who survive on street vending must quickly relocate to farms and rural areas, as they will not be able to pay rentals and buy food.

\section{Empirical Literature}

Studies from scientists at Princeton University undergoing peer review show that COVID-19 can survive in the air for up to three hours and can be transmitted in the air and can survive on inanimate surfaces for up to three days. "Tests Indicate Coronavirus Can survive in the Air" The Hill, March 11, 2020 accessible at [8].

People of all ages can be infected by the new coronavirus (2019-nCoV). Older people with pre-existing medical conditions (such as asthma, diabetes, heart disease) appear to be more vulnerable to becoming severely ill with the virus.

WHO advice people of all ages to take steps to protect themselves from the virus for example by following good hand hygiene and good respiratory hygiene. The most effective way to protect yourself against the new coronavirus is by frequently cleaning your hands with alcohol-based hand rub or washing them with soap and water.

Up to now there is no complete cure for coronavirus, Didier Raoult has just tested the coronavirus vaccine made in France and America in animals, but these animals are dead. Didier Raoult declares: it is a with great desolation that I have just done the test of vaccine again the coronavirus in animals but the latter are dead because this vaccine contains poison. Therefore, I have just understood that this vaccine is succinct and was created with the idea of exterminating human population (https://www.instagram.com/p/BW7ld5BflQ/?gshid=t9lk68cltpm7).

\section{Research Methodology}

\section{Research Design}

Research methodology as a systematic way of studying how research is to be carried out to solve a problem by describing, explaining and predicting phenomena, and there are many types of methodologies that can be used [9].
Although many researchers conducted studies on the impact of COVID-19 world - wide, the researcher conducted the same study but on SADC countries. This is a pure unsaturated study but similar study was conducted in China and Asia-Pacific which yielded the same results. The use of qualitative and quantitative approaches was employed for this study.

\section{Qualitative Research}

Qualitative research is a review approach in which the reviewer explores a central phenomenon and asks broad and general questions from participants on their views. These data are expressed in the form of words rather than numbers, but generally the researcher must search and explore with a variety of methods until a deep understanding is reached [10]. A qualitative study design is defined by Creswell [10] as "an inquiry process of understanding a social or human problem based on building or complex, or holistic picture, formed with words, reporting detailed views of respondents or informants, and conducted in a natural setting". Qualitative (flexible) research explores attitudes, behavior, and experiences through such methods as interviews or focus groups. It attempts to get an in-depth opinion from participants. As it is attitudes, behavior and experiences which are important, fewer people take part in the research, but the contact with these people tends to last a lot longer.

\section{Quantitative Research}

This research design emphasizes objectively in measuring and describing phenomena [11]. A research design which maximizes objectively by using numbers, statistics, structure and control.

\section{Descriptive Research}

Descriptive research is research in which a specific situation is studied either to see if it gives rise to any general theories, or to see if the existing general theories are borne out by the specific situation [12].

\section{Target Population}

A population is defined by [13] as the sum total of all the cases that meet our definition of the unit of analysis [14], refers to a population as the entirety of all the members, subjects or 
objects that conform to a set of criteria. The population is the whole group of individuals the researcher is concerned about to gain knowledge. The target population was SADC (which comprising 16 member states) consumers, but only two (2) member states [15] were selected for the study to be interviewed. Population of Namibia $=2.5$ million and South
Africa $=58.8$ million, all together equaling to 61.3 million.

\section{Sample Size}

A sample of 200 consumers [15] was interviewed for the study. The sample size will be $n=200$. The number of randomly selected participants are significant enough as to be related to a population of $\mathrm{N}=61.3$ million.

Table 1. Sample Size

\begin{tabular}{|l|l|}
\hline Countries & Consumers (selected for the study) \\
\hline Namibia & 100 \\
\hline South Africa & 100 \\
\hline Total & 200 \\
\hline
\end{tabular}

Source: Developed for this study

The number of randomly selected participants is significant enough as to be very relevant to a population of $\mathrm{N}=61.3$ million consumers. The researcher approached few consumers from the relevant population and selected elements to access easily until the sample reached the desired size of 200.

\section{Sampling Techniques (Procedures)}

The researcher uses a probability sampling procedure in which all elements of the selected population have an equal chance of participating using simple random sampling as a sampling method. A simple random sample involves drawing a sample frame of all units of population of interest and randomly selecting participants [16]. The participants referred to as respondents together represent a subset of the population that will be studied, their responses being analyzed, and the results inferred to the population.

\section{Research Instruments}

Research instruments are types of tools used in collecting data [17]. Research instruments are measurement tools (for example, questionnaires or scales) designed to obtain data on a topic of interest from research subjects. The research instruments that were employed to collect data in this study were questionnaire. The questionnaire was designed to collect both quantitative and qualitative data. Questionnaires with structures, semi-structured and open-ended, were employed. The researcher felt that questionnaires are more efficient, as they require less time and are less expensive and generate the collection of data from a larger sample.

(https://lib.dmu.edu/db/cinahl/insreuments).

\section{Data Collection Procedure}

Questionnaire is the most widely used technique for obtaining information from subjects [11]. Structured and unstructured questionnaires were sent to respondents, as they contain an explanation of the intended study and were used to analyses the impact and aftermath of COVID-19 on SADC consumers. The researcher approached the SADC Secretariat and some SADC Consumers and then distributed the questionnaires.

\section{Data Analysis}

All collected data were analyzed and quantified. Data analysis is the breaking down of respondents' results in a way as to answer the questions raised by the study [18], while Data analysis follows general procedures for quantitative research including preparing and organizing data, reducing data into themes through a process of coding, and representing data into figures, tables and discussions [19]. The study employed both quantitative and qualitative methods to analyses the data taken from the questionnaire, while extracted data from the questionnaire to group and categorize responses. Open-ended questionnaire was coded for results and closed-ended were combined for similarity, negativity or positivity. Questionnaire was distributed electronically via e-mails and few were posted and hand delivered. Both qualitative and 
quantitative findings were analyzed in a form of written and presented in tables, graphs and pie charts respectively. It was a dilemma to the researcher to come up with proper methods that would produce exact data to measure things like behaviors, attitudes and feelings of respondents.

\section{Validity of the Study}

Validity refers to "the degree to which the instrument measures what it is supposed to be measuring" [20]. Information that is valid is those that the researcher perceives as matching the concepts to be reviewed. The researcher focused on content validity, which refers to the accuracy in which an instrument measures the factors under study. The degree of validity also depends on the relationship between the variables, impact and aftermath of COVID-19 on the SADC consumers. Validity can be borrowed to internal validity. The internal validity of a study is a judgment that is made concerning the confidence with plausible rival hypotheses can be ruled out as explanations of the results [11]. Research instruments were tested for content validity by handing the questionnaires to SADC consumers. The questionnaires included on questions that seek clarity on the impact and aftermath of COVID19 on SADC consumers. The validity of all outcomes concerning the impact of COVID-19 on SADC consumers is valid as it is true that, COVID-19 hit-harder and destroy the wellbeing of many SADC consumers. The researcher can confirm that all the information obtained was accurately collected and analyzed.

\section{Reliability of the Study}

Reliability is the degree to which investigating, testing, observation or any other measuring procedure that produces the same result on frequent trials. It is the steadiness or regularity of scores over time or across rates [21]. Reliability relates to the precision and accuracy of the instrument. If used on a group of respondents in a similar result [22]. Respondents were informed of the purpose of the questionnaires as well as the interview and why they have to tell the truth.

Reliability is mostly used in quantitative research as to test the reliability of the consistency of the results when a study is being conducted for a period of time and when an instrument is used in a similar study yield similar results. Another definition of reliability suggests that measures or data collection methods should uninfluenced by change in the context [23]. In qualitative research, a study is deemed reliable when the quality of information to be reviewed is likely to generate understanding. Likewise, irrelevant data that does not apply to the study is unreliable.

\section{Limitations of the Study}

The researcher faced a shortage of participants who provided honest information as requested. Not all consumers were able to understand the research purpose, and the language used. Time was one of the limitations, as it was not adequate for the researcher to carry out the study. Hence, the results might yield valid but unreliable conclusions.

The researcher aims to carry out research in all SADC countries but the current state (situation is not possible due to lockdown), time, transport and resources were very minimal, Hence, the study was only conducted in two SADC countries [15]. The behavior and reactions from respondents were another limitation in data collection process. The limitations of the study are those characteristics of design or methodology that impacted or influenced the interpretation of the findings from your research [24].

\section{Delimitations of the Study}

Delimitations are those characteristics that limit the scope and define the boundaries of the study [25]. The delimitations are in the researchers' control. Delimitation factors include the choice of objectives, the research questions, variables of interest, theoretical perspectives that are adopted (as opposed to what could have been adopted) and the population investigated. The delimitation section of the study explicates the criteria of participants to enroll in the study, the geographic region covered in the study, and the profession or organisation involved. The study targeted consumers in Southern African Development Community (SADC), but it focused only on consumers from Namibia and South Africa.

\section{Ethical Considerations (issues)}

Rahman [26] defines research ethics as a way to deciding how to act and analyses broad 
issues or problems during a study, while Pera \& van Tonder [27] defines ethics as a code of behavior considered correct. All respondents were treated with confidentiality and were not asked to reveal their credentials. Questionnaire designed are not biased, and all information furnished by respondents was kept confidential.

Welman, Kruger \& Mitchell [28] identified four main ethical considerations to which a researcher should adhere to:

- Informed consent-the researcher obtained the necessary permission from the respondents after thoroughly briefing and informing them of the purpose of the research.

- Right of privacy-respondents were informed about their right to privacy and their identity were not revealed.

- Protection from harm - the safety of respondents was guaranteed from physical and emotional harm.

It is very important that all researchers are aware of research ethics. Ethics relate to two groups of people; those conducting research, whom should be aware of their obligations and responsibilities, and the "researched upon" who have basic rights that should be protected [26]. Respondents were informed of the intention or the purpose of the research before completing the questionnaire and those who agreed were used in this study.

\section{Result and Discussion}

This chapter presents the demographic characteristics of the respondents and the research findings from the study. Data are analyzed systematically based on the objective of the study. Also, the chapter provided the gathered data and researcher's analysis and interpretation, in which all primary and secondary research conducted by the researcher and the results are presented into tables, bar charts and graphs as well as pie charts. Below each figure or table, the results are well depicted, described or discussed, interpreted, and some are linked to literature review where applicable. All of 200 questionnaires distributed were returned answered.

Questionnaire was divided into three sections, namely:

Section A: Demographic data.

Section B: Impact of COVID-19 on SADC consumers.

Section C: Aftermath of COVID-19 on SADC consumers.

Section A: Demographic data.

This section is about a collection of SADC consumers' demographic data; like gender/sex, age as well as their employment rate.

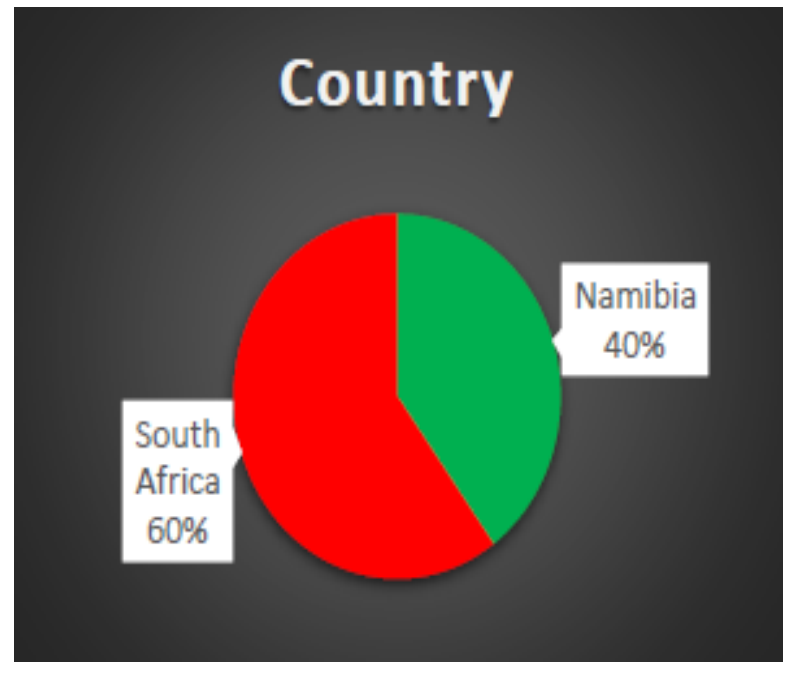

Figure 2. Shows Gender (Male) 


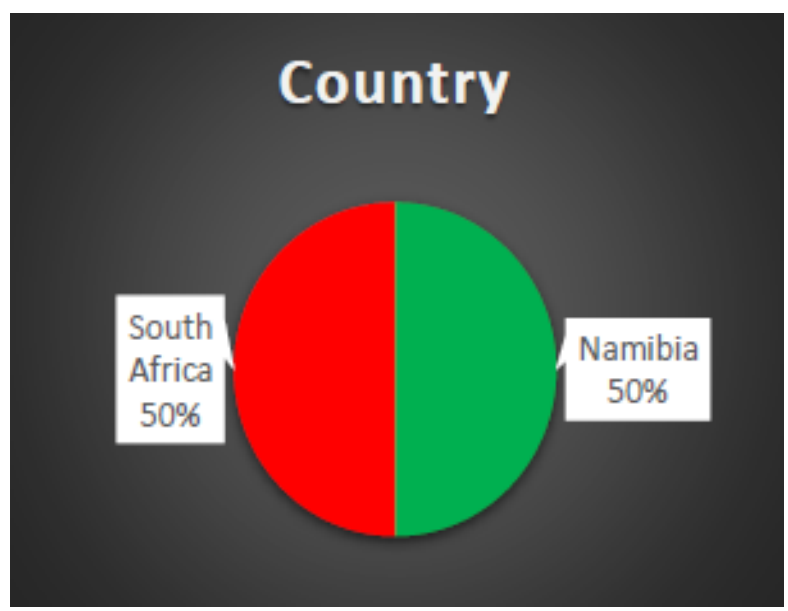

Figure 3. Shows Gender (Female)

The results in Figure 2 show that $60 \%$ of respondents are South African males, while the $40 \%$ of the respondents are Namibian males.
Figure 3 shows that both two countries (Namibia \& South Africa) have equal score/rate of $50 \%$ of female who responded.

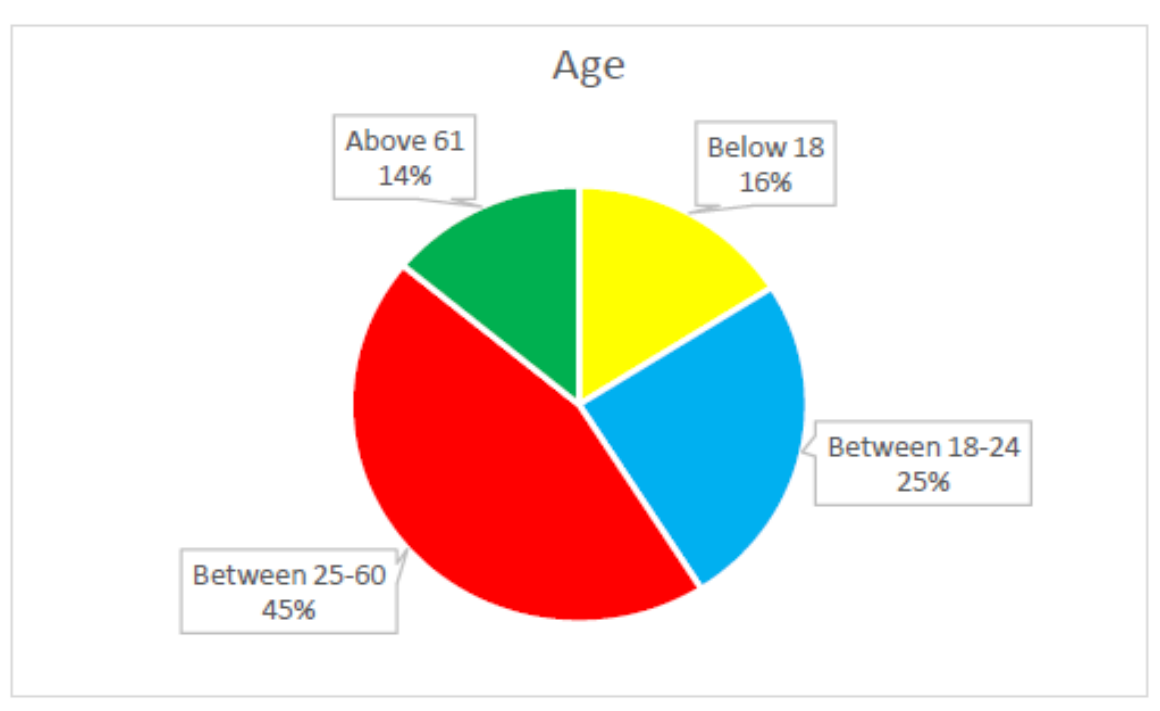

Figure 4. Age Range

Source: Research results (2020)

The study shows that respondents (consumers) between the ages of 25-60 are more than others. Their consumption rate is very high compared to others; this is the age range of working class they have to pay bills, so their responsibilities are far too much compared to other age range. The second age range is the one between the age of $18-24$, with $25 \%$, this age range consists of varsity students who are at tertiary institutions as well as those who did not make it in grade 12 (matric) who are struggling to make ends meet. Finally, $16 \%$ and $14 \%$ is made up of age range below 18 and those of 61 and older; these two-age ranges are often labelled and called the dependent age group because they can hardly strive for themselves but depend more on others.

Table 2. Respondents who are Employed

\begin{tabular}{|l|l|l|}
\hline & No. of Respondents & Accumulative Percentage \\
\hline Yes & 120 & $60 \%$ \\
\hline No & 80 & $40 \%$ \\
\hline Total & 200 & $100 \%$ \\
\hline
\end{tabular}

Source: developed for the study 
The table depicts the percentages of respondents (consumers) who are employed and those who are not employed. It shows that $60 \%$ are employed while $40 \%$ are not employed (out of 200 respondents/consumers 120 are employed and 80 are not employed).

Section B: Respondent's knowledge on the impact of COVID-19 on SADC consumers.

Table 3. Respondents (Consumers) Awareness on COVID-19

\begin{tabular}{|l|l|}
\hline Yes & 200 \\
\hline No & 0 \\
\hline
\end{tabular}

Source: developed for the study

The table (table 3 ) depicts the numbers of respondents who are aware of the impact of COVID-19 on SADC consumers. All respondents are very much aware of the coronavirus and how it spread.

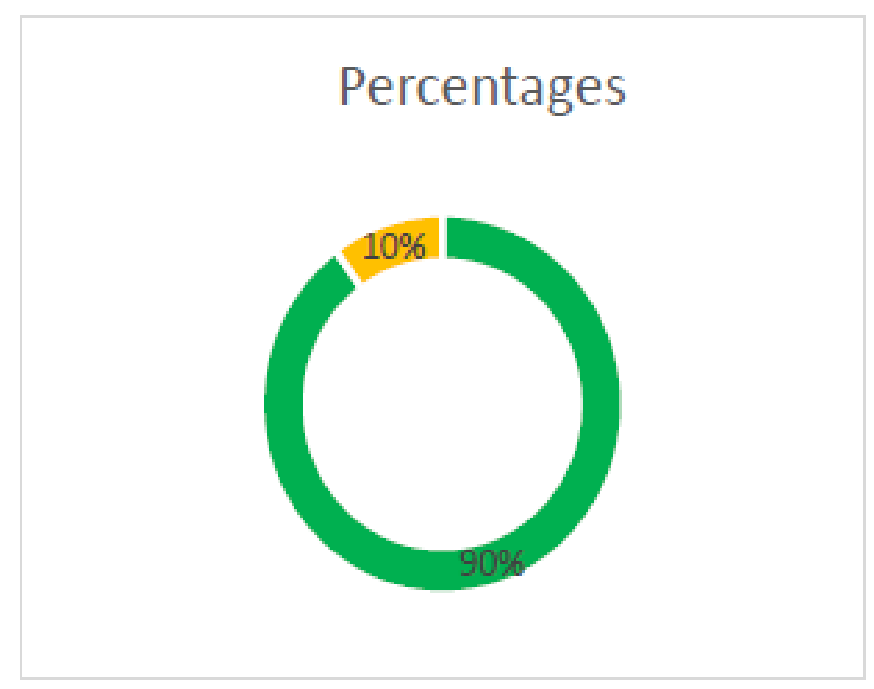

Figure 5. Government Alternative Measures

As indicated in the figure (Fig.5) $90 \%$ of respondents agreed that the government has come up with alternative measures to assist citizen to combat and contain COVID-19 only $10 \%$ of respondents who disagree that the government has not done anything to assist citizen.

Respondents who said that the government has come up with alternative measures to assist citizen, the followings are some measures that they have identified:

- Hygiene products to be used such as hand sanitizers, wearing of masks and gloves especially in public places.

- Creating awareness on COVID-19 through social media, television, radios and other means of communications.

- Closing of borders to all except for essential services.
- Instructing of central banks to lower repo rates so that commercial banks will follow suit.

- Introduction of emergency grant to nonworking citizens and those who lose their jobs.

All of these are kinds of measures that government come up with to assist citizens.

The following are some of the impacts of COVID-19 on SADC consumers

- Death rate has increased drastically, more demands of medicines and other medical supplies such as ventilators

- Shortage of consumable products.

- Closure of businesses.

- Production rate decreased.

- Consumption rate increased. 


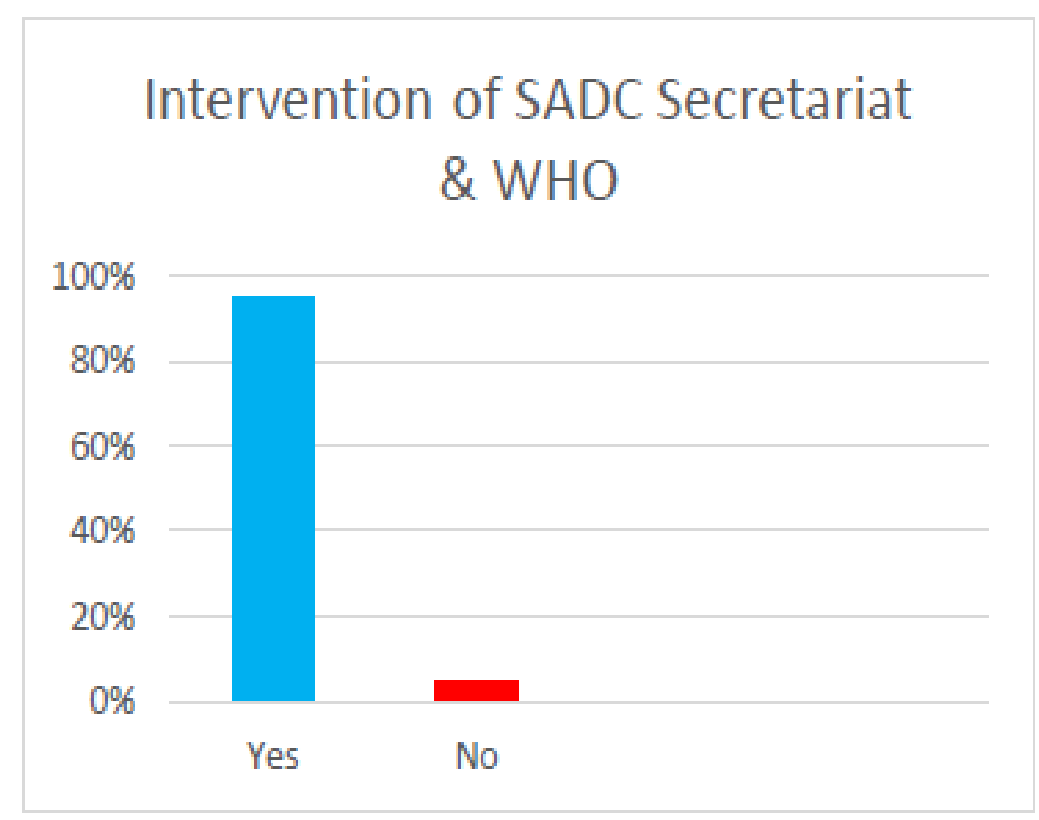

Figure 6. Intervention of SADC Secretariat \& WHO

Source: developed for the study

Figure 6 shows the majority of respondents agreed with $95 \%$ while fewer respondents did not agree with a score of $5 \%$. One can draw a line between the two (yes and no) that many have agreed.

Those who agreed to have this to say. SADC Secretariat really intervened; countries are sharing information and updating each other on what is happening. SADC countries are communicating on ways to assist each other, like recently Namibia opened the Oshikango border to allow Angolan who are seeking medical help to be assisted, while other borders are strictly only open for essential services.

Section C: Aftermath of COVID-19 on SADC consumers.

Respondents were asked to give their thought and opinion on what will happen after COVID-19. These are their thoughts.

- The livelihood of SADC consumers will change drastically, as things will be more expensive than before.

- More orphans as parents will perish due to COVID-19

- Billion children's education will be derailed by shutdowns.

- Changes in education system, the introduction of e-learning and lifelong learning.
- The pandemic will trigger massive losses for big companies and small businesses and will force millions of people out of work.

- The reduction of manpower overtaken by the work of machines (automation).

- The introduction of Artificial Intelligence (AI) which will be rolled out globally.

- Many of the SADC countries will incur more debts as they are forced by COVID19 to borrow and lend money and products from other countries, and this will take longer to pay back such loans.

\section{Summary}

The study is all about the impact and aftermath of COVID-19 on SADC consumers. The study analyses the impact and it further predict what will happen to SADC consumers in the future [1].

The research objectives which answer research questions identified were:

- To know how SADC consumers will survive during the time of coronavirus.

- To determine challenges facing SADC companies (marketers).

- To link the co-operation of SADC marketers and consumers.

\section{Research questions were}

1. How SADC consumers survive during the time of coronavirus? 
2. What are the challenges facing SADC companies/marketers?

3. Is there a link of co-operation between SADC marketers and consumers?

4. All the hypotheses (H1 \& H0) tested indicated that:

\section{H1- Alternative hypothesis}

H1a: SADC consumers know how to survive during the time of coronavirus.

H1b: There are challenges facing SADC companies/marketers.

H1c: There is a link of co-operation between SADC marketers and consumers.

\section{HO - Null hypothesis}

H0a: SADC consumers do not know how to survive during the time of coronavirus.

HOb: There are no challenges facing SADC companies/marketers.

H0c: There is no link of co-operation between SADC marketers and consumers.

The testing of the two hypotheses (null hypothesis \& alternative hypothesis) led to the explanation of the associated phenomena. The study found out that both two hypotheses are correct meaning there is a correlation between the two. The study identified some of the impacts of COVID-19 as well as (the aftermath) what will happen in the future after COVID-19 ends.

\section{Conclusion}

The study presented the existing literature covering impact and aftermath of COVID-19. Although what is being research is an ongoing process, nobody knows when the virus will stop or ends. Measures and precautions are being taken care of, it is a world- wide pandemic even if the study was conducted in SADC countries only lots of lives are lost, the damage is done let's hope for a better tomorrow.

\section{Suggestion for Future Research}

While many people are just passively reading papers and books, one should try to work it all out in some details, analyze and, if possible, research more about it so that you will understand to the core. This study is an ongoing process because it was conducted during the beginning of the pandemic of coronavirus. It is advisable to motivate the young researchers to take up challenging problems.

\section{Future research is recommended}

- When coronavirus ends to determine the severe damage, it has caused and how many people have perished.

- Researches in the entire world might be compared and conducted to give true reflections of what has really transpired, whereby different methods and populations are considered.

- The study suggested that more researches be carried out to determine the true cause of coronavirus.

- The impact of the coronavirus is not a one man's show a group of researchers is advisable to come together as one and conduct research.

- From the results and finding of the study, SADC consumers and marketers are urged to rely on their homegrown products and not depending much on overseas imported products.

- Similar studies may be conducted in areas not covered by this research.

Hopefully, this study might raise concerns and yield good points to SADC consumers and marketers at large in terms of issues concerning the society and also to other researchers that might need to build on this study and use it as a secondary data. 


\section{References}

[1] COVID-19 South African coronavirus news and information portal. SA Corona virus Portal. Retrieved 29 March 2020.

[2] https://www.bakermckenzie.com/en/insight/publi cations/2020/03/the-impact-of-covid19-on-keyafrican-sectors/

[3] https://www.afro.who.int/news/south-africandevelopment-community-unites-tackle-covid-19 Retrieved on 27 March 2020.

[4] New Era newspaper 25, March 2020.

[5] En.m.wikipedia.org/wiki

[6] https://www.mintel.com/blog/consumer-marketnews/research-your-way-out-of-a-crisis-covid-19seffect-on-consumer-behaviour.

[7] Matsuii, I. (2020). A Critical Analysis.

Education Vol 35 No. 2: 66-67; Structure: How to Structure the Research Limitations Section of your Dissertation. Dissertations and Theses: An online Textbook. Laerd.com.

[8] https://www.thehill.com/policy/healthcare/48711 0 -tests-indicate-coronavirus-can-survive-in-the-air.

[9] Rajasekar, S., Philominathan, P. \& Chinnathambi, V. (2013). Research Methodology. arXiv: Submit/0821442 [physics. ed-ph] 14 Oct 2013

[10]Creswell, J.W. \& Clark, V.L. P. (2014). Principles of qualitative research: Designing a qualitative study. Journal of Management, 7-9.

[11]McMillan, J. \& Schumacher, S. (2014). Research in Education: Evidence-Based Inquiry. England. Pearson Education Limited.

[12] Goddard, W. \& Melville, S. (2001). Research Methodology: An Introduction. (2 ${ }^{\text {nd }}$ Edition). Juta \& Co. Ltd.

[13]Mouton, J. (2006). Understanding Social research. Pretoria. South Africa.

[14] Welman, R., Kruger, K. J. and Mitchell. (2009). Research Methodology, Cape Town, South Africa: Oxford University's.

[15] Katjiheve, Charmaine (28 March 2020). Update: Namibia confirms 11 COVID-19 infections: The Namibian.

[16] Nambira, G. (2016). Research Methodology. Lecture.

[17]Cohen, L. (2010). Research Methods in Education.
[18] Weiwei, T. (2010). Impact of corporate image and corporate reputation on customer loyalty. Management Science and Engineering, 1 (2), 57-62. [19] Becker, W. S. \& Burke M. J. (2012). The staff Ride: An Approach to Qualitative Data Generation and Analysis.

[20] Polit, D. F. \& Hunger, B. P. (1995). Nursing Research, Principles and Methods, Philadelphia PA, JB Lippincott.

[21] Howell, J., Miller, P., Park, H., Sattler, D., Schack, T., Spery, E., Widhalm, S., \& Palmquist, M. (2012). Reliability and Validity.

[22] Cohen, L., Marion, L. \& Morrison, K. (2000). Research Methods in Education. London: Routledge/Falmer.

[23]Edwards, A. \& Talbot, R. (1994). A Research handbook for the caring professions. Longman Group Limited. New York.

[24]Price, J. H. \& Murnan, J. (2004). Research Limitations and the necessity of Reporting Them". American Journal of Health.

[25] Simon, M. K. (2011). Dissertation and Scholarly research: Recipes for Success. Seattle, WA, Dissertation Success, LLC.

[26]Rahman, M. S. (2010). Service quality, corporate image and customer satisfaction towards customer perception: An exploratory study on Telecom customers in Bangladesh. Business Intelligence Journal, 56-62.

[27]Pera, S. A \& Van Tonder, S. (1996). Ethics in Nursing Practice. Juta \& CO Ltd, Landsowne.

[28] Welman, K., \& Mitchell, A. (2005). Research Methodology. Cape Town: Oxford University Press. [29] Colorado State University. Retrieved from https://writing.colostate.edu/guides/guide.cfm?guide $\mathrm{id}=66$.

[30]Education Vol 35 No. 2: 66-67; Structure: How to Structure the Research Limitations Section of your Dissertation. Dissertations and Theses: An online Textbook. Laerd.com.

[31] Sekaran, U. (2003). Research Methods for Business, A Skill-Building Approach. $4^{\text {th }}$ ed. John Wiley \& Sons, New York. 


\title{
Accessibility and Utilization of Tuberculosis Directly Observed Therapy in Primary Health Care Facilities in Katsina State, North West Nigeria
}

\author{
Yahaya Shamsuddeen Suleiman ${ }^{1 *}$, Olorukooba Abdulhakeem Abayomi ${ }^{2}$, Abdurrahman \\ Halima $^{3}$, Sambo Nasir $\mathbf{M}^{2}$ \\ ${ }^{1}$ State Primary Health Care Agency, Katsina, Nigeria \\ ${ }^{2}$ Department of Community Medicine, Ahmadu Bello University, Zaria, Nigeria, \\ ${ }^{3}$ Eye Centre, Katsina State, Nigeria
}

\begin{abstract}
Tuberculosis is a public health problem in Katsina state. Previous effort to decrease the burden of $T B$ was substantially targeted at the secondary and tertiary level of care. The new strategy calls for the decentralization of DOTS at the PHC level. This study assessed the resources for diagnosis and treatment of TB, utilization of services in PHC facilities in Katsina state. The study design was a crosssectional descriptive study and it enrolled 225 TB patients in 32 health facilities through a multi-stage sampling technique. A structured interviewer-administered questionnaire was used to obtain data from respondents. Qualitative data were also collected using KII. The data was analyzed using SPSS version 20-software package. For the qualitative aspect, content analysis was done for KII. Of the Health facilities studied 7 (28\%) were diagnostic centres while 25 (72\%) were treatment (intake) centres. The mean age of TB patients was 39+13 years also the mean duration since the commencement of treatment was 3 months. The mean duration time before reaching the hospital was $39+27$ minutes. The majority (98.5\%) of TB patients had easy access to a health facility. About one third (34.4\%) of the health facilities had and were using a microscope. In conclusion, the study revealed that resources for TB diagnosis were not adequate in most of the health facilities. However, resources for TB treatment were sufficient. The state government should provide more support in making TB resources adequate in all facilities.
\end{abstract}

Keywords: Accessibility, DOTS, Katsina, Primary Health Care, Tuberculosis, Utilization.

\section{Introduction}

Tuberculosis (TB) is an infectious disease caused by the bacterium Mycobacterium tuberculosis. It typically affects the lungs (pulmonary TB) but can also affect other sites as well (extra-pulmonary TB) [1].

To deal with the growing global TB problem, the World Health Organization (WHO) declared TB as a global emergency and introduced the Directly Observed Treatment Short-Course (DOTS) strategy in 1994 [2]. The aim of introducing DOTS was to achieve the set targets (to detect $70 \%$ new TB cases and cure $85 \%$ of those detected successfully) and to halve global TB prevalence and deaths by 2015 , relative to the 1990s levels [2].

Nigeria adopted the WHO Directly Observed Treatment Short Course (DOTS) strategy to control the disease in 1993.
The treatment of TB has constituted a major problem in Nigeria for several reasons. First Many people with TB are still not detected and they are not able to access the treatment. Second, the number of new cases of TB is increasing in the country because of the epidemic of HIV/AIDS. Awareness among the communities, especially the leadership of the communities and the citizens about TB, its manifestation, its causes, and modalities for treatment is poor [3].

Although Nigeria receives huge support from donor agencies like WHO and UNDP, there is a wide gap between the resources needed and what is provided. Long distance to the hospitals which limits the chances of patients' financing their treatment, lack of facility for a home visit in most cases and poor supervision in under-aged children are some of the contributing factors for high treatment default rate which often results in the development of multidrug-resistant TB [4]. 
The major challenges to DOTS implementation especially at the PHC level is the low political commitment, especially at the LGA level. The health system that should provide the platform for the delivery of DOTS services is extremely weak at the PHC level and non-availability of skilled health workers and dearth of laboratory services [5].

In Katsina state, TB is still a public health problem with an existing but weakly functioning state TBL control programs with inadequate planning and low-level implementation [6]. There has been limited advocacy on implementation, DOTS service coverage, low tracing capacity and inadequate collaboration with other service providers. Previous effort to decrease the burden of TB was substantially targeted at the secondary and tertiary level of care. The new strategy calls for decentralization of DOTS in PHC Level. Information about the access and utilization of TB services at PHC level will help to provide a basis for improved policies and planning, which could help to foster better TB control in the state. We carried out this study to determine the accessibility and utilization of TB DOTS in PHC settings in Katsina State.

\section{Materials and Methods}

\section{Study Area}

Katsina state is located between latitude $11.7^{0}$ and $13.32^{\circ} \mathrm{N}$ and between longitude $6.52^{\circ}$ and $9.02^{0} \mathrm{E}$. The state shares border with Zamfara and Sokoto state in the west, Kano and Jigawa state in the east, Kaduna state in the south and Niger republic in the north. It has an area of 23,938 square kilometers and a projected population of 5,801,419 based on 2006 census with a projected growth rate of $3.0 \%$ per annum [7].

There are 184 TB DOTS centres, 23 microscopy centres and a functional TB HIV working group which was established in January 2008 in the state. All of the 34 LGAs provide TB DOTS services, of which 20 have state advocacy committees [8]. There are 160 PHC facilities providing TB DOTS Services, including private facilities which are spread across the 34 LGAs and nearly half of the political wards. The drugs and Laboratory investigations are provided free of charge. There are an estimated 8081patients with all forms of TB with case notification rate of 34 per 100,000 . The incidence rate of all forms of TB was 32 and total cases of 2332 with Crude Death Rate of 29\% [8].

The TB control team is structured according to the national guideline for $\mathrm{TB}$ and leprosy control programmed (NTBLCP) in Nigeria. At the state level is the state TB and Leprosy control officer (STBLCO) supported by State TB and Leprosy Supervisors (STBLS). They are responsible for planning, supervision, monitoring and evaluation of the TB activities at the operational levels. They are also responsible for training of personnel in TB control services and offering of technical and logistic supports, including advocacy. The LGA is the operational unit; the team at this level includes the LGA TB and Leprosy Supervisor (LGTBLS), the General Health Care Workers (GHCW), the Medical Officer (MO) and the laboratory staff [9].

\section{Study Design}

The research design was a cross-sectional descriptive study.

\section{Study Population}

The study populations were:

i. Pulmonary TB patients who were receiving treatment at $\mathrm{PHC}$ facilities

ii. Local government TB and Leprosy Supervisors.

\section{Inclusion Criteria}

i. All pulmonary TB patients who have spent at least 2 months on treatment.

ii. Local government $\mathrm{TB}$ and Leprosy Supervisors (LGTBLS).

\section{Exclusion Criteria}

i. Health facilities providing PHC service that are privately owned.

ii. Pulmonary TB patients with other co morbidities.

\section{Sample Size Determination}

\section{Sample Size for Pulmonary TB Patient}

The sample size (n) was calculated using the formula $[10,11]$

$$
\mathrm{n}=\frac{\mathrm{Z}^{2} \mathrm{pq}}{\mathrm{d}^{2}}
$$

Where;

$\mathrm{n}=$ minimum sample size 
$\mathrm{z}=$ standard normal deviate at $95 \%$ confidence interval (1.96)

$\mathrm{p}=$ proportion of $\mathrm{TB}$ patients with highest level of satisfaction in a previous study which is $82.5 \%(0.825)$ [12].

$\mathrm{q}=$ complementary probability of $\mathrm{p}(1-0.825)$ $=0.175$

$\mathrm{d}=$ degree of precision $(0.05)$

$\mathrm{n}=\frac{1.96^{2} \times 0.825 \times 0.175}{0.05^{2}}$ $=222+(10 \%$ of 222

for non-response) $=250$

Since the population of TB patients in Katsina state is less than 10,000. The formula for sample size when a proportion with a population < 10000 was used.

$\mathrm{nf}=\mathrm{n} / 1+(\mathrm{n}) /(\mathrm{N})^{12}$

Where;

$\mathrm{nf}=$ desired sample size when population is less than 10000

$\mathrm{n}=$ desired sample size when population is greater than 10000

$\mathrm{N}=$ estimate of the population $=2329$ [13]

$\mathrm{nf}=250 / 1+250 / 2329=225$

\section{Sampling Technique}

There are 160 PHC facilities providing TB DOTS Services.

Only $20 \%$ were sampled because of limited time and resource.

$160 \times 20 / 100=32$.

\section{Selection of Health Facility}

A multi-stage sampling was be used to get the required sample size.

\section{Stage One: Selection of LGA}

From the list of all the 11 LGAs in each of the senatorial zones, 3 LGAs per zone were randomly selected using balloting technique given 9 LGAs. Consequently, the following LGAs were selected; Katsina, Rimi, Mashi, Dutsi, Safana, Funtua, Dandume, Bakori and Danja LGA.

\section{Stage Two: Selection of Health Facilities Providing DOTS in each of the LGA}

The number of public health facilities providing TB DOTS varies from LGA to LGA; least is 3 and highest is 6 . Proportionate allocation was used to select 32 health facilities across the 9 selected LGAs.

\section{Stage Three: This Involved the Selection of TB Patients and Health Care Workers}

\section{Selection of TB Patients}

The National TB control programme provides central register for each LGA. The register contains names of all patients diagnosed and registered for treatment. The register was used to assign unique identification numbers to all patients. The TB central register was also used to determine the sampling frame for the study. All patients that met the inclusion criteria in the selected LGAs were identified in the central register. They were assigned serial numbers; sampling interval was determined by dividing the total number of eligible participants (760) by the sample size (225) to give an interval 3. The first number (patient) was selected randomly using a random number between 1 and 3 and subsequently every $3^{\text {rd }}$ patient was selected until required sample size was achieved.

\section{Study Instruments}

In the study, both qualitative and quantitative instruments were used.

\section{Quantitative Component}

\section{A. Checklist}

The health facility checklist was adopted from WHO and another study [14]. It contained 3 sections (A-C) covering the Staffing, materials and laboratory equipment.

\section{B. TB Patients' Questionnaire}

The questionnaire on TB patient's perception on DOTS services was a structured; pre-tested, interviewer administered questionnaire and was adapted from a patient satisfaction questionnaire guide and from previous studies [15]. The questionnaire had six sections (A to F) covering respectively (A) Socio-demographic characteristics of respondents, (B) Organizational issues, (C) Facility equipment and supply (D) Availability of service(E) Interpersonal qualities of service provider and (F) Professional competence of skill workers.

\section{Questionnaire for TBLS and Head of Health Facility of DOTS Centre}

The questionnaire for TB and leprosy supervisor and head of TB DOTS facility was semi- structured, pre-tested and selfadministered. It covered staff involved in TB 
DOTS, staff training, supervision, resources for TB diagnosis and treatment and availability of recording and reporting format.

\section{Pre-testing of Questionnaires}

In order to ascertain the validity and reliability of the tools (the questionnaires and the skills checklist), they were first pretested in another PHC Bakiyawa Batagarawa LGA, which had similar characteristics to clinics in the study of local government area but located in a different LGA. It was carried out by the researcher and research assistants. Relevant adjustments were made to the questionnaire based on the observations during the pre-test.

\section{Qualitative Components}

Data for the qualitative component was obtained via key informant interviews (KII) with the TB Control Officer.

The KII guide was developed based on the objectives of the study and was pre-tested by conducting a session with the PHC director in Batagarawa local government areas. Changes were made to the guides after the pre-test.

\section{Data Collection}

Quantitative data collection was conducted by a team of six trained research assistants who were community health workers under close supervision. The service of two supervisors was sought who were medical doctors in the department of Community Medicine ABUTH Zaria, and they checked each completed questionnaire for completeness and consistency. Training of research assistants on quantitative data collection was conducted by the researcher for 2 days.
Qualitative data collection was done by the lead researcher as the moderator and one of the research assistants (as the note taker) who was trained to collect qualitative data.

\section{Measurement of Variables}

Scoring criteria for health facility assessment in PHC facilities implementing TB DOTS Strategy.

Where a parameter was observed a score of one was given but a score of zero was awarded for a parameter that was not observed.

\section{Statistical Analyses}

The questionnaires were checked for accuracy and completeness. The data was analysed using IBM SPSS statistics 20. Descriptive summary statistics such as mean and standard deviation were computed for continuous variables (age of patients, age of health workers, duration of stay in health facility, time spent before reaching health facility and duration of time since commencement of treatment) and proportions for categorical variables (sex, occupation, educational status, designation and overall satisfaction) of the respondents. Data presentation formats in graphical and tabular forms were drawn as appropriate. Cross tabulations were constructed between sociodemographic variables of patients and satisfaction and knowledge of TB and demographic characteristics of health workers. Chi-square test was used to assess statistical associations between proportions of respondents and scores for different variables.

For the qualitative aspect, content analysis was done for key informant interview.

Table 1. Socio Demographic Variable of Respondents

\begin{tabular}{|l|l|l|}
\hline Socio demographic characteristics & Frequency & Percent (\%) \\
\hline Age range & 7 & 3.1 \\
\hline $15-19$ & 16 & 7.1 \\
\hline $20-24$ & 35 & 15.6 \\
\hline $25-29$ & 33 & 14.7 \\
\hline $30-34$ & 31 & 13.8 \\
\hline $35-39$ & 26 & 11.6 \\
\hline $40-44$ & 18 & 8.0 \\
\hline $45-49$ & 19 & 8.4 \\
\hline $50-54$ & 40 & 17.8 \\
\hline $55+$ & \multicolumn{2}{|l|}{} \\
\hline Sex & 158 & 70.2 \\
\hline Male & \multicolumn{2}{|l|}{} \\
\hline
\end{tabular}




\begin{tabular}{|c|c|c|}
\hline Female & 67 & 29.8 \\
\hline \multicolumn{3}{|l|}{ Marital Status } \\
\hline Married & 150 & 66.7 \\
\hline Single & 51 & 22.7 \\
\hline Divorced & 8 & 3.6 \\
\hline Widowed & 16 & 7.1 \\
\hline \multicolumn{3}{|l|}{ Educational Status } \\
\hline No formal education & 111 & 49.3 \\
\hline Primary & 37 & 16.4 \\
\hline Secondary & 65 & 28.9 \\
\hline Tertiary & 12 & 5.3 \\
\hline \multicolumn{3}{|l|}{ Occupation } \\
\hline Farming & 67 & 29.8 \\
\hline Schooling & 20 & 8.9 \\
\hline unemployed & 28 & 12.4 \\
\hline Civil servant & 15 & 6.7 \\
\hline Trading & 66 & 29.3 \\
\hline Artisan & 11 & 4.9 \\
\hline Others & 18 & 8.0 \\
\hline
\end{tabular}

Table 2. Indices of Utilization of TB DOTS in PHC Facilities in Katsina State

\begin{tabular}{|l|l|l|}
\hline Variable & Frequency & Percent (\%) \\
\hline Duration of treatment & 128 & 56.9 \\
\hline Less than 3 months & 97 & 43.1 \\
\hline More than 3 months & \multicolumn{2}{|l|}{} \\
\hline Have easy access to Health facility & 220 & 98.5 \\
\hline Yes & 5 & 1.5 \\
\hline No & 141 & 46.2 \\
\hline Time taken to reach health facility \\
\hline Less than 30 min & 50 & 16.4 \\
\hline 30 minutes to 60 min & 34 & 37.4 \\
\hline More than 1 hour & 185 \\
\hline Cost incurred during treatment & 82.2 \\
\hline Yes & 40 & 17.8 \\
\hline No & 169 & 91.4 \\
\hline Reason for incurring cost & 11 & 5.9 \\
\hline Transport & - & - \\
\hline Food & 5 & 2.7 \\
\hline Provider's fee & \multicolumn{2}{|l|}{} \\
\hline Laboratory services &
\end{tabular}




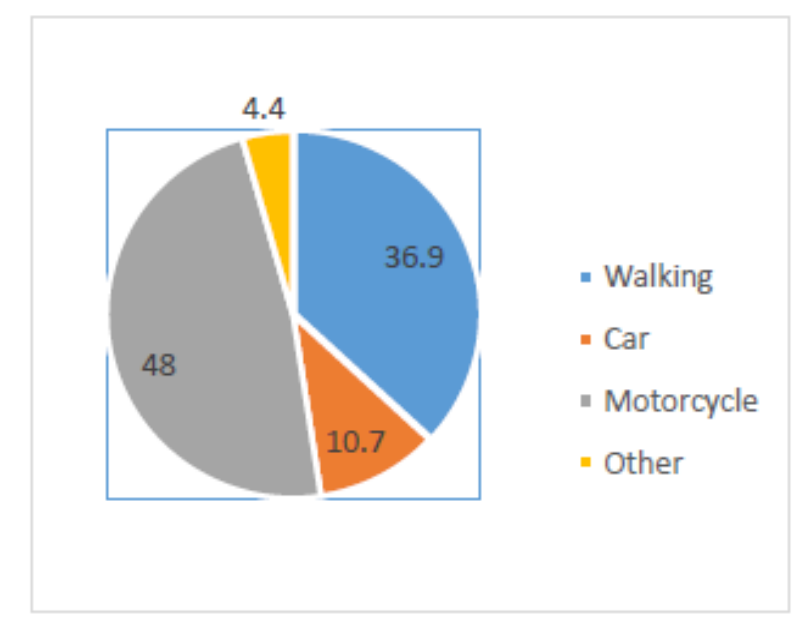

Figure 3. Mode of Transportation by Patients to Access TB Treatment in PHC Facilities in Katsina State

Table 3. Materials for Diagnosis and Treatment of TB in PHC Facilities in Katsina State

\begin{tabular}{|l|l|l|}
\hline Availability of Materials (N=32) & Frequency & Percent (\%) \\
\hline Latest version of NTLCP manual & \multicolumn{1}{l|}{} \\
\hline Available \& in use & 6 & 18 \\
\hline Not available & 26 & 82.2 \\
\hline Latest version of NTLCP Laboratory manual & 1 & 3.2 \\
\hline Available \& in use & 1 & 3.2 \\
\hline Available \& not in use & 30 & 93.6 \\
\hline Not available & \multicolumn{2}{|l|}{} \\
\hline Functional Weighing scale & 31 & 96.9 \\
\hline Available \& in use & - & - \\
\hline Available \& not in use & 1 & 3.1 \\
\hline Not available & 11 & 34.4 \\
\hline Microscope & 2 & 6.3 \\
\hline Available \& in use & 19 & 59.3 \\
\hline Available \& not in use & \multicolumn{2}{|l|}{} \\
\hline Not available & 11 & 34.4 \\
\hline Laboratory reagents & 2 & 6.3 \\
\hline Available \& in use & 19 & 59.3 \\
\hline Available \& not in use & 19 \\
\hline Not available & - & 59.4 \\
\hline Sputum collection container & 13 & - \\
\hline Available \& in use & 31 & 40.6 \\
\hline Available \& not in use & 96.8 \\
\hline Not available & \multicolumn{2}{|l|}{} \\
\hline Fixed Drug combination & \multicolumn{2}{|l|}{} \\
\hline
\end{tabular}

\section{Ethical Considerations}

Ethical approval was sought and obtained from the Ethical and Scientific Committee of the Katsina state ministry of health Ethics and Research Committee (MOH/ADM/1152/1/32). Informed written consent from the participants was obtained before participating in the study. Permission was obtained from Katsina state TB
Control Program. Confidentiality of the participants was ensured. No material reward was attached to the information provided by the participants.

\section{Results}

Most of the respondents were males (70.2\%), married (66.7\%) Muslim (92.4\%) with no formal 
education $(49.3 \%)$ and farming constitute the major occupation of the respondents is farming.

About half of the respondents had been on treatment for less than 3 months (56.9\%) and almost all the patients had easy access to treatment $(98.5 \%)$ with motorcycle as the commonest means of transport (48.0\%). Most of the patients had incurred cost $(82.2 \%)$ due to transport $(91.4 \%)$. Only $8 \%$ of the Health facilities had the latest program Manual, 96\% had functional weighting scale, $34.4 \%$ had microscope, $96.8 \%$ had anti-TB drugs.

\section{Discussion}

Knowledge of utilization of TB DOTS services by patients will provide an important input towards strengthening the services, especially in rural areas [16]. The study revealed that majority of the patients that utilized the services were males (70.2\%) and Muslims $(92.4 \%)$. This is similar to a study which found that larger number of males with pulmonary symptoms and new sputum smear-positive cases utilized RNTCP services than females in the ratio of 1.6:1 and 2.5:1 respectively. This was reported to be due to higher prevalence of persons with pulmonary symptoms and sputum positivity rate among males [16].

Most of the respondents (73.3\%) were able to reach the clinic easily. This is important because difficulty in reaching the health facility can lead to default in treatment. Most of the respondents reach the clinic by motorcycle $(45 \%)$ while $36.9 \%$ was by walking. The study further showed that $(82.2 \%)$ patients incurred cost during treatment and the main reason for incurring cost was transportation. There are several studies that showed that many patients were non-adherent to anti-TB drugs because of lack of money or perceived high cost of treatment, especially in resource-poor settings [17].

TB patients and households in sub-Saharan Africa often incurred high cost when utilizing TB treatment and care, both within and outside DOTS program. For many households, TB treatment and care related costs were considered being catastrophic because the cost incurred commonly amount to $10 \%$ or more per capita. A study in Bauchi, north east Nigeria, that costs of anti-tuberculosis treatment were expensive and potentially catastrophic for many patients and their families [18].
The findings in this study revealed that majority of the health facilities (75\%) had a designated staff assigned in the TB clinic. This is very important because it will help in reducing the waiting time before patients were seen by health care workers. A dedicated staff is also more likely to spend more time with the patients and this will greatly improve satisfaction and compliance with treatment.[19]. These findings contrast with studies from Nepal where human resources were scarce and drugs were in adequate [20]. The implication is that quality of services will be compromised and can lead to Multi drug resistance and consequent increase in morbidity and mortality.

Majority of the Health facilities (HF) had posters $(71.9 \%)$ in local languages, which is an important tool in Information education and communication. Weighting scales were also available in almost all the HF (96.9\%). However, findings from this study differ from a previous study where respondents reported a shortage of weighting scale [21]. This finding is similar to another study in South Africa where posters, sputum bottles \& gloves were available [21].

Lack of weighting scale can lead to under or overdose of anti-TB drugs; since TB drugs, dosage is based on body weight.

All the health facilities visited had drugs (anti-TB). This is very commendable because interruption of anti -TB drugs can lead to drug resistance. Every patient had his own drug kit, which his drugs were kept that the patient uses for the entire period of treatment. Studies in South Africa revealed that majority of HFs had drugs, only (3\%) of HFs experienced a shortage of drug in the last 2 months.

\section{Conclusion}

Our study revealed that resources for TB diagnosis were not adequate in most of the health facilities in Katsina state. However, resources for TB treatment were sufficient. The state government through the state ministry of health should provide more support in making TB resources adequate in all facilities so as to improve diagnosis.

\section{Acknowledgements}

We wish to acknowledge Katsina State Tuberculosis and Leprosy control Program. 


\section{References}

[1] WHO Global Tuberculosis control. Geneva, Switzerland: WHO; 2011. p.3.

[2] Corbett EL, Watt CJ, Walker N, Maher D, Williams BG, Raviglione $\mathrm{M}$, et al. The growing burden of tuberculosis: global trends and interactions with the HIV epidemic. Archives of Internal Medicine. 2003; 163(9):1009-21.

[3] Erah P, Ojieabu W. Success of the Control of Tuberculosis in Nigeria: A Review International Journal of Health Research. March 2009; 2(1):3-14.

[4] Salami T, Samuel S, Eze K, Oziogbe O. Tuberculosis in a Nigerian Teaching Hospital: Incidence and Pattern of distribution. Trop J Health Sci. 2007; 14(2):26-30.

[5] Nigerian Health Review 2007. Primary health Care in Nigeria:30 years after Alma Ata. Abuja, Nigeria: Health Reform Foundation of Nigeria; 2007. p. 12-8.

[6] Namadi A, Idriss H. Mid-term Evaluation of Katsina state TBL control program. Katsina: State ministry of health; 2009. p. 1-10.

[7] Federal Republic of Nigeria. 2006 Population and Housing Census. Priority Table Population Distribution by Age and Sex. Abuja, Nigeria: National Population Commission; April 2010. p. 190203.

[8] National TB and Leprosy Control Program. 2012 Annual statistics Nigeria. Federal ministry of health; 2012. p. 1.

[9] National TB and leprosy control programme workers manual. Revised 5th ed: Federal Ministry of Health Abuja Nigeria; September 2008. p. 110.

[10] Taofeeq I. Research Methodology and Dissertation Writing for Health and Allied Matters. Abuja, Nigeria: Cress Global link Limited Abuja; 2009. p. 113.

[11] Araoye MO. Research Methodology with statistics for Health and Social Sciences. Ilorin: Nathadex Publishers 2004. p. 118.

[12] Kamel MI, Rashed S, Foda NA, Mohie A, Loutfy M. Gender differences in health care utilization and outcome of respiratory tuberculosis in Alexandria. Eastern Mediterranean Health Journal. 2003; 9(4):741-56.
[13]National TB and Leprosy Control Program. Annual TB Statistics Nigeria. 2012. Girma A. Quality Assessment of Directly Observed Treatment ShortCourse of Tuberculosis in Afar National Regional State [Degree of Masters in Public Health]. Addis Ababa: Addis Ababa University; July, 2007. p.44-45. [14] Weis S. The effect of directly observed therapy resistance and relapse in tuberculosis. New England journal of medicine. 1994; 330 (17):1179-84.

[15] Ahmed J, Chadha V, Sing S, Venkatachalappa B, Kumar P. Utilization of RNTCP services in rural areas of Bellary District, Karnataka, by gender, age and distance from health centre. Indian journal of tuberculosis. 2009; 56(2):62-8.

[16] Umar N, Abubakar I, Fordham R, Bachmann M. Direct costs of pulmonary tuberculosis among patients receiving treatment in Bauchi State, Nigeria. Int J Tuberc Lung Dis 2012; 16(6):835-40.

[17] Barter DM AS, Murray MB, Bärnighausen T. Tuberculosis and poverty: the contribution of patient costs in sub-Saharan Africa--a systematic review. BMC Public Health. 2012; 12:980.

[18]Nezenga Z, Yohannes H, Tadese E. Patient satisfaction on tuberculosis treatment service and adherence to treatment in public health facilities of Sidama zone, South Ethiopia, BMC Health Services Research 2013; 13:110.

[19] Marahatta SB, Yadav RK, Giri D, Lama S, Rijal KR, Mishra SR, et al. (2020) Barriers in the access, diagnosis and treatment completion for tuberculosis patients in central and western Nepal: A qualitative study among patients, community members and health care workers. PLoS ONE 15 (1): e0227293. https://doi.org/10.1371/journal. pone.0227293.

[20] Tshitangano TG, Supa P, Karl P. Factors that Contribute to Tuberculosis Control in Primary Health Care Services at Mutale Primary Health Care SubDistrict of the Limpopo Province, South Africa. J Hum Ecol. 2010; 29(2):75-8.

[21] Okeibunor JC, Onyeneho NG, Chukwu JN, Post E. Barriers to Care Seeking in Directly Observed Therapy Short-Course (DOTS) Clinics and Tuberculosis Control in Southern Nigeria: A Qualitative Analysis. International Quarterly of Community Health Education 2007; 27(1):23-37. 


\title{
A Synopsis on COVID-19 and Associated Risk Factors: Optimizing Preventive and Clinical Outcomes through Lifestyle Intervention
}

\author{
Abiodun Bamidele Adelowo \\ Department of Public health, Texila American University, Guyana
}

\begin{abstract}
Since its outbreak in late 2019, Coronavirus Disease 2019 (COVID-19) has been ravaging the health system of most countries of the world. Although many preventive and treatment strategies have been proposed and implemented to combat the disease, these efforts seem to be insufficient, and in some cases ineffective. This is evident by the daily rising global incidence and case fatality of the COVID-19 pandemic. A situation if not mitigated early will likely crumble the global economy and tilt the world to an unprecedented global recession. This challenge demands that researchers and clinicians ask more in-depth questions about the novel coronavirus disease. Aside from age that has been confirmed to be linearly associated, what are the other possible socio-demographic and lifestyle-related risk factors that may be associated with COVID-19? What are the possible factors or comorbid conditions that may worsen clinical progression and determine the clinical outcome in confirmed COVID-19 cases? Does the pre-, peri-, or post-morbid lifestyle choices of people have an impact on COVID-19 preventive and treatment efforts? And how can we use the knowledge of the associated risk factors, comorbid conditions, and lifestyle choices of people to improve preventive efforts and clinical management of COVID-19? Answer to these questions may likely serve as an important guide for policymakers and clinicians in their design and implementation of COVID-19 targeted preventive and treatment policies and programs, especially in Low- and Middle-Income Countries (LMICs). The purpose of this article is to critically review available literature and provide evidence-based recommendations.
\end{abstract}

Keywords: COVID-19 pandemic, lifestyle-related COVID-19 risk factors, chronic non-communicable diseases, COVID-19 prevention, COVID-19 clinical outcomes, lifestyle intervention.

\section{Introduction}

Coronavirus Disease 2019 (COVID-19) was first reported in Wuhan City, Hubei Province, China in December 2019, and within a few months, it has spread rapidly to most countries of the world. This prompted the World Health Organization (WHO) to declare it a Public Health Emergency of International Concern (PHEIC), and by 12 March 2020, it was declared a global pandemic [1, 2, 3, 4]. By this declaration, COVID-19 became one of the few diseases to attain a global pandemic status in recent human history. As of 28 January 2021, COVID-19 has been confirmed in 100,455,529 people, with associated 2,166,440 deaths worldwide [5]. The striking characteristics that drew so much attention to COVID-19 are its high infectivity and fatality rates among the general public and the severely ill patients, respectively.
Globally, the care fatality rate (CFR) of COVID-19 has been noticed to rise rapidly with increasing age; the CFR is $<1 \%$ for patients $<50$ years of age, rising to $1.3 \%$ for 50 -year-old patients, to $3.6 \%$ for 60 -year-old patients, to $8 \%$ for septuagenarians, and $14.8 \%$ for octogenarians [6]. Unfortunately, according to a recent interim report by the WHO Solidarity trial consortium, the commonly used COVID-19 treatment is regimens-Remdesivir, Hydroxychloroquine, Lopinavir, and Interferonappeared to have little or no significant effect on the hospitalization and CFR [7]. For these reasons, this article intends to deepen the conversation on the relationship between the clinical progression of COVID-19 and some related risk factors, and how such knowledge can be harnessed to improve preventive and treatment efforts. 


\section{Methods}

An extensive search (with no language restrictions) was done in Google search engine, Academia, ResearchGate, and MEDLINE database. The websites of reputable public health organizations, like the WHO, United Nations, United Nations Children's Fund (UNICEF), Public Health Ontario, Centre for Disease Control (CDC), and Nigeria Centre for Disease Control (NCDC) were also visited for relevant and current information. Some of the keywords that were searched include COVID19, COVID-19 risk factors, clinical outcome in COVID-19, underlying comorbid diseases in COVID-19, etc. All the obtained data were collected, visualized, profiled, cleansed, prepared, analyzed, and summarized accordingly.

\section{Socio-Demographic Factors and COVID- 19}

Although the entire disease evolution of COVID-19 is not yet fully understood, for now, it appears the disease has a preference for certain socio-demography in the society. Multiple systematic reviews of COVID-19 cases have suggested that the infectivity, hospitalization, and fatality rates are more in the people who are 60 years and above, male gender, and ethnic minority groups. In particular, people of the black race seem to have three times the infectivity rate, and almost six times the rate of deaths, compared to the Caucasians [8]. A retrospective observational study that was done among 1, 591 COVID-19 patients in Italy collaborated these observations. The study discovered that out of all the confirmed COVID19 cases, the infected male population was $82 \%$, the females were $18 \%$, while the median age was 63 years [9]. Particularly among the age groups of 51-60, 61-70, and 71-80 years, the majority of patients were males $(83 \%, 81 \%$, and $82 \%$, respectively) compared to the females (17\%, $19 \%$, and $18 \%$, respectively) [9]. Other studies from China revealed that almost $50 \%$ of patients that were diagnosed with "refractory" COVID19 were of the male gender, older age, and with underlying comorbidities $[9,10]$.

Another study on 41 COVID-19 patients on admission in China, revealed that majority of the infected patients were men (73\%), with a median age of 49.0 years [9]. Yet, another study in China, that involved 69 COVID-19 patients, revealed that $68 \%$ were male, with a mean age of 55.5 years [9]. A retrospective study also in China, with 138 hospitalized patients with confirmed COVID-19, shows that $54.3 \%$ were men, while their median age of 56 years [9]. Also, another study that was done among 1,099 patients with COVID-19 from 552 hospitals in 30 provinces in China, revealed a median age of 47 years, and that $58 \%$ of the patients were of the male gender [9]. However, one study in China comprising 140 confirmed COVID-19 patients, reported a different result. It found an equal distribution by sex, at approximately $1: 1$ ratio of male $(50.7 \%)$ and female $(49.3 \%)$, while majority $(70 \%)$ of them were over 50 years old [9]. A study that investigated 5,700 hospitalized COVID-19 patients in 12 New York City area hospitals, also noticed that the median age of the patient was 63 years, out of which $60.3 \%$ and $51.5 \%$ were males and African-American (and other minority ethnic groups), respectively [11].

\section{Pre-Morbid Lifestyle-Related Risk Factors and COVID-19}

Everybody regardless of their health status can be infected with SARS-CoV-2 [12, 13]. However, evidence abounds that suggest that certain lifestyle-related factors or practices tend to predispose some group of people to COVID19 compare to others. Some of the identified predisposing factors include smoking, overweight/obesity, and hypovitaminosis D. Hypovitaminosis D may result from either poor nutrition/unhealthy diet or reduced exposure to sunlight due to a sedentary lifestyle $[14,15]$.

Studies on tobacco smoking in particular have generated different contrasting results. A study that investigated the relationship between COVID-19 and smoking observed that the percentage of current smoker among COVID-19 patients was low and could not explain the association between smoking and susceptibility to SARS-CoV-2 [9]. One early study even suggested that smoking may be protective against SARS-CoV-2 [16]. However, multiple studies and positional statements by the WHO and other international public health organisations have subsequently clearly associated smoking with a higher probability of contracting SARS-CoV-2 and developing a severe form of COVID-19 [17, 18]. Tobacco smoking tends to evoke adverse pathophysiological changes in the respiratory 
and other systems of the smokers, which tend to worsen the clinical progression of COVID-19. A situation that may progress to ICU admission, ventilator support, or death from related complications [19]. A study on Chinese with confirmed COVID-19 with a history of smoking noticed that the patients had a $14 \%$ higher risk of developing COVID-19 induced pneumonia, and 14 times higher Odd Ratio (OR) of progressing to stage III (severe stage) or dying from COVID19 complications [20]. Some studies have even observed significantly higher ACE2 (the host receptor for SARS-CoV-2) gene expression in former and current smoker's lungs compared to non-smoker's lungs $[9,17]$.

Hypovitaminosis D is another risk factor that has been associated with increase susceptibility and severity of COVID-19 [9, 21]. In a study that was conducted in Spain on 216 hospitalized COVID-19 patients, it was discovered that $82.2 \%$ of the patients were vitamin D deficient, compared to $47.2 \%$ of healthy people of same gender and age [22]. Another study that was conducted in Italy on hospitalized COVID-19 patients, noticed that about $50 \%$ of patients with severe vitamin $\mathrm{D}$ deficiency progressed to a severe form of COVID-19 and died, compared to only 5\% of COVID-19 related death in patients with normal serum level of Vitamin D [22]. Other studies have demonstrated that higher serum level of vitamin D correlate with milder clinical presentation of COVID-19, while countries with high serum levels of vitamin D tend to have lower COVID-19 related case fatality rates [22].

It is also worth noting that since studies have shown a positive correlation between decreasing serum vitamin D levels and increasing age, male gender, and obesity $[9,23]$, this may be some of the reason why COVID-19 is more fatal in these group of people. Low serum Vitamin D may also be related to the regular consumption of certain unhealthy diets that are low in vegetables and fruits $[14,15]$. A sedentary lifestyle may also indirectly lead to reduce serum level of Vitamin D. Here, the affected individuals could not get adequate exposure to sunlight due to inadequate outdoor physical activity [24]. Consequently, vitamin $\mathrm{D}$ rich diets and supplements, with adequate exposure to sunlight, would likely be valid lifestyle intervention measures for preventing and treating COVID-19 among atrisk and confirmed cases, respectively $[9,25]$.

\section{Lifestyle-Related Co-Morbid Conditions and COVID-19}

Multiple studies have indicated that people with certain lifestyle-related underlying disease conditions are more susceptible to contracting SARS-CoV-2, compared to people that are free of these diseases. Aside from age, sex, ethnicity, and lifestyle-related risk factors, other factors that may increase the susceptibility of people to contracting SARS-CoV-2 and developing a severe form of COVID-19, includes underlying lifestyle-related chronic medical conditions, such as chronic obstructive pulmonary diseases (COPD), cardiovascular diseases (like heart disease and stroke), high blood pressure/hypertension, diabetes mellitus, kidney disease, liver disease, some cancers (like leukemia, lymphoma or myeloma) $[12,13,26$, 27].

COVID-19 patients with comorbid diabetes mellitus in particular usually have a significantly increased risk of hospitalization and death compared to other underlying disease conditions $[28,29]$. It is not yet fully understood why diabetes mellitus predisposes to higher susceptibility and severity of COVID-19, but it is well known that diabetic patients usually develop a dysregulated immune system and are generally more susceptible to infections, compared to non-diabetic cases $[9,28]$. Also, most infective processes (viral or otherwise) generally tend to progress faster and worse in diabetes (especially if poorly controlled) compared to non-diabetic cases [30]. Moreover, the late clinical stages of type 2 diabetes have been associated with a distorted functionality of ACE2 receptors, the host receptors for SARSCoV-2 [9].

Available studies also collaborated with the above position on the association of COVID-19 with some comorbid conditions. A meta-analysis involving seven studies and 1, 576 COVID-19 patients, revealed that a significant number of the patients had an underlying chronic disease condition. The most prevalent comorbidities were hypertension $(21.1 \%)$ and diabetes mellitus $(9.7 \%)$, followed by cardiovascular disease $(8.4 \%)$ and respiratory system disease $(1.5 \%)$ [31]. Another study was conducted on 7,736 confirmed COVID-19 patients in Wuhan China, out of which $23.7 \%$ had at least one coexisting chronic disease [32]. In a study conducted in Italy to investigate the association of COVID-19 
with lifestyle-related chronic diseases, hypertension was the most common comorbidity (49\%), followed by cardiovascular disease (21\%), hypercholesterolemia (18\%), and diabetes mellitus (17\%) [9]. A meta-analysis that was conducted in China revealed that the following characteristics are common among deceased COVID-19 cases-advanced age ( $>60$ years), cancers, other underlying chronic diseases, and/or major secondary infections [9]. Another China-based retrospective study on 799 COVID-19 in-patients recorded a $14.1 \%$ mortality rate. The study noticed that certain underlying chronic diseases, like hypertension (48\%) and other CVDs (14\%) were more frequent among deceased patients (24\%) compared to the recovered patients (4\%) [9].

The report of a study of hospitalized COVID19 cases still in China, showed that out of the $26.1 \%$ of patients that were transferred to ICU, most $(72.2 \%)$ had concurrent comorbidities, as opposed to only $37.3 \%$ of patients who did not require ICU care [33]. Among the 1, 099 confirmed COVID-19 cases that were reported in a study, 173 had severe disease presentations. Compared with the non-severe cases, the patients with the severe disease had a higher prevalence of hypertension $(23.75 \%$ versus $13.4 \%)$, diabetes mellitus ( $16.2 \%$ versus $5.7 \%)$, coronary heart disease $(5.8 \%$ versus $1.8 \%)$, COPD $(3.5 \%$ versus $0.6 \%)$ and cerebrovascular disease (2.3\% versus $1.2 \%)$ [33]. A recently conducted meta-analysis also concluded that patients with hypertension, respiratory disease, and CVD had an odd ratio of 2.36, 2.46, and 3.42 , respectively, for developing severe COVID-19 compared with the non-severe cases [33]. Other lifestyle-related underlying chronic diseases that studies have associated with a severe form of COVID-19 are chronic liver disease (CLD) and chronic kidney disease (CKD) $[34,35]$. In most cases, deaths of COVID-19 patients did not primarily result from the disease condition itself [27]. Rather, it resulted from complications arising from the underlying chronic conditions, which in most cases became worse as a result of the acute inflammatory assault of COVID-19 on the multiple organs of the body [27].

\section{Optimizing Preventive and Treatment Efforts in COVID Management through Lifestyle Intervention}

The review strongly suggests that although COVID-19 is primarily a respiratory disease, it is associated with some risk factors that either predispose people to the disease or worsen its clinical outcome. The three main sociodemographic risk factors that are implicated in COVID-19-older age group ( $\geq 60$ years), male gender, and black race-are all well documented non-modifiable risk factors for chronic noncommunicable diseases (NCDs) like hypertension, cardiovascular disease, type 2 diabetes mellitus, and some cancers [36, 37]. The directly implicated lifestyle-related risk factors for contracting SARS-CoV-2 or developing a severe form of COVID-19 are the history of smoking/current smoking, overweight/obesity, high blood pressure, hypercholesterolemia, and hypovitaminosis D. Indirectly, risk factors like poor nutrition/unhealthy diet and outdoor physical inactivity (with poor exposure to sunlight), are also implicated since such habits may likely lead to hypovitaminosis D. These direct and indirect risk factors are also well-documented modifiable risk factors for most chronic NCDs [38]. Chronic NCDs-like chronic obstructive pulmonary diseases (COPD), hypertension, cardiovascular diseases (heart disease, stroke), diabetes mellitus, chronic kidney disease, chronic liver disease, and some cancers (like leukemia, lymphoma or myeloma) were also identified as underlying co-morbid conditions that are associated with and modifies clinical progression and outcomes in COVID-19. The presence of these underlying chronic diseases in many cases tend to increase COVID-19 susceptibility, progression, and worsen the clinical outcome.

Many pieces of evidence have also strongly associated these chronic co-morbid diseases with unhealthy lifestyle choices like unhealthy diets, tobacco use, and physical inactivity [38]. Overweight/obesity, high blood pressure, and hypercholesterolemia, are also lifestyle-related intermediate risk factors for these chronic 
co-morbidities [36]. According to the WHO and some other scientists, some healthy lifestyle choices, if practiced consistently and correctly, have been clinically proven to be effective in controlling these COVID-19 associated modifiable risk factors, and ultimately prevent, control, or even reverse some of the underlying chronic diseases [39, 40]. Some of the well documented healthy lifestyle choices that are capable of performing these tasks include healthy diet, adequate physical activity (especially outdoor), adequate restorative sleep, good stress management, avoidance of alcohol abuse, good mental and psychological health, and social connectivity [39, 40, 41]. During the pre-COVID-19 state, the practice of healthy lifestyle as a preventive effort in addition to other preventive measures will likely reduce the infectivity rate of SARS-CoV-2 [25] and flatten the COVID-19 pandemic curve faster (see Figure 1) [42].

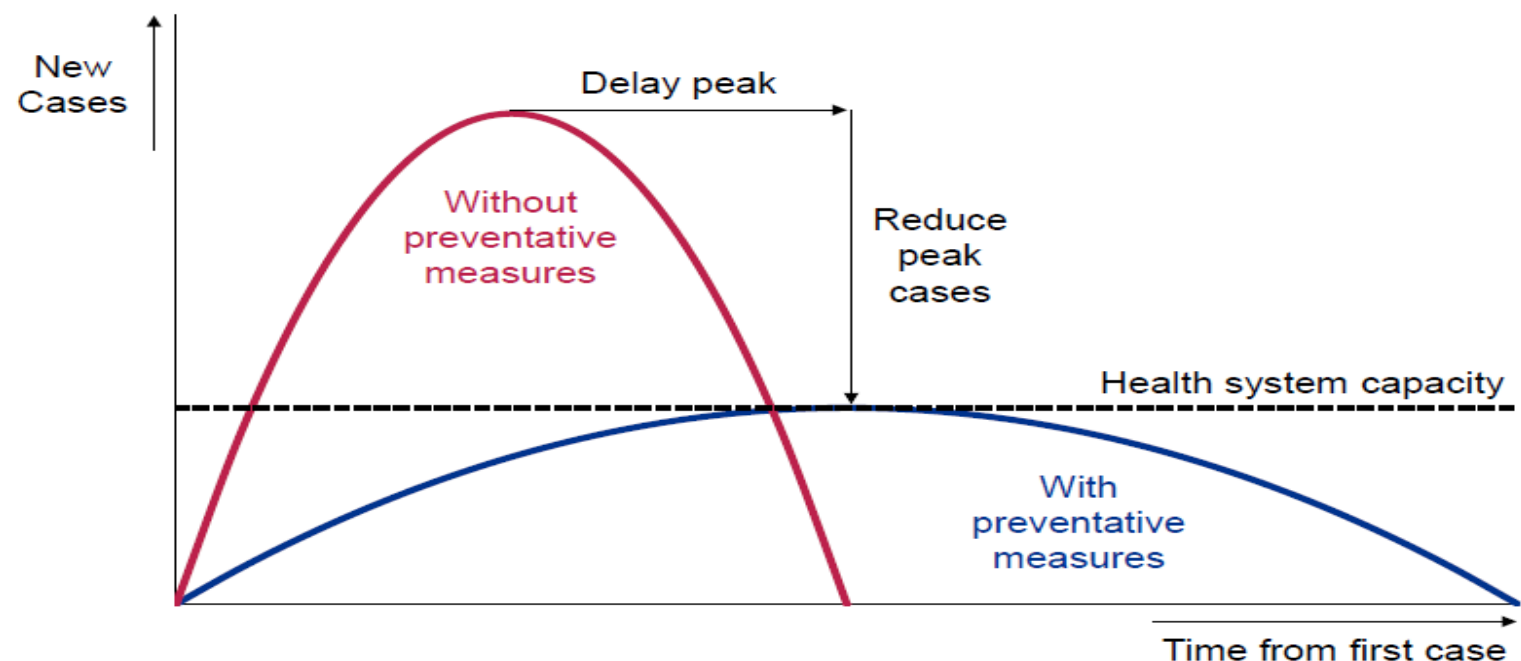

Figure 1. Potential Effect of Preventive Measures on the COVID-19 Pandemic Curve

As depicted by the graph, preventive measures (that include measures like hand washing, physical distancing, healthy lifestyle, etc.), are vital in the global efforts to quickly flatten the COVID-19 pandemic.

For the peri-COVID-19 (confirmed positive COVID-19) state, lifestyle modification will likely slow down the disease progression, stabilize underlying chronic diseases, and significantly improve clinical outcomes, with a consequential reduction in case fatality rate [43]. This lifestyle interventions might be particularly important in cases with poor response to pharmacological intervention. During postCOVID-19 (confirmed negative COVID-19) state, consistent healthy lifestyle practice will likely ensure early recovery of the assaulted multiple organs, stabilizes the underlying disease conditions, and ensure the patients quickly regain their pre-morbid functionality with faster reintegration to the larger society. Some of the general lifestyle intervention principles that should be considered in the management of pre-, peri-, and/or post-COVID19 cases can be found in Table 1 [40, 44, 45, 46].

Table 1. General Lifestyle Intervention Recommendations in COVID-19 Management

\begin{tabular}{|l|l|}
\hline Categories & Recommendations \\
\hline \multirow{3}{*}{ Nutrition } & $\begin{array}{l}\text { Make healthy food choices. The food should be low in saturated fats, trans-fat and } \\
\text { calories, but high in fiber and other nutrients. Such should contain a significant } \\
\text { number of fruits, vegetables, whole grains, legumes, nuts, and seeds. }\end{array}$ \\
\cline { 2 - 3 } Physical Activity & $\begin{array}{l}\text { De physically active. Engage in moderate-intensity aerobic physical activity } \\
\text { (preferably outdoor) of } 30 \text { minutes to } 1 \text { hour every day. This should be done } \\
\text { without compromising the physical distancing rules. }\end{array}$ \\
\hline $\begin{array}{l}\text { Weight } \\
\text { Management }\end{array}$ & $\begin{array}{l}\text { Maintain body mass index (BMI) between } 18.5 \text { to } 24.9 \mathrm{kgm}^{-2} \text { and waist-hip ratio } \\
\text { to less than } 0.8 \text { in women and } 0.9 \text { in men. }\end{array}$ \\
\hline
\end{tabular}




\begin{tabular}{|l|l|}
\hline \multirow{2}{*}{$\begin{array}{l}\text { Harmful } \\
\text { Substances }\end{array}$} & Quit tobacco use, reduce the amount smoked, or do not start the habit. \\
\cline { 2 - 3 } Sleep & If you must drink alcohol, do so in moderation and it should not be every day. \\
\hline Stress & $\begin{array}{l}\text { Adopt a variety of measures to keep stress levels low all the time. Such measures } \\
\text { may include adequate planning of daily activity, adequate coping skills, deep } \\
\text { breathing, meditation, mindfulness, and Yoga. }\end{array}$ \\
\hline $\begin{array}{l}\text { Psychological } \\
\text { Wellbeing }\end{array}$ & $\begin{array}{l}\text { Ensure positive psychological and mental wellbeing all the time with a positive } \\
\text { outlook of situations. Ensure social connection with loved ones, without } \\
\text { compromising the physical distancing rules. }\end{array}$ \\
\hline
\end{tabular}

\section{Conclusion}

Policymakers should carefully consider the association between COVID-19 and some sociodemographic risk factors, lifestyle-related risk factors, and underlying chronic disease. A comprehensive COVID-19 prevention guideline, that emphasizes healthy lifestyle, should be designed to target the general population, but most importantly at-risk population (people whose socio-demography, lifestyle, or occupational status places them at higher risk of contracting SARS-CoV-2).

\section{References}

[1] Beeching N.J., Fletcher T.E., and Fowler R., 2020, BMJ Best Practice: Coronavirus disease 2019 (COVID-19 leaflet), BMJ Publishing Group Ltd 2020, Date of access: 4/7/2020. http://patchsa.org/wpcontent/uploads/2020/03/BMJ-Best-PracticeCOVID-19.pdf.

[2] Bonyan F.A., Shareef L.G., Al-waily A., Abdulrazaq A.A., and Al-Rubayee W.A., 2020, COVID-19 clinical characteristics and outcomes in 60 hospitalized Iraqi patients - Case series. Medical Science, 24(104), 2251-2258.

[3] Chowdhury A.T.M.M, Karim M. R., Mehedi H.M.H, Shahbaz M., Chowdhury M.W., Dan G., et al., 2020, Analysis of the primary presenting symptoms and hematological findings of COVID19 patients in Bangladesh, ResearchGate 2020. DOI: 10.13140/RG.2.2.22406.80969.

[4] Nigeria Centre for Disease Control, 2020, National interim guidelines for clinical management of COVID-19, NCDC 2020, Date of access: $14 / 10 / 2020$.

https://reliefweb.int/sites/reliefweb.int/files/resource s/national_covid19_case_management_guide_ncdc. pdf.
Clinical management guidelines for the confirmed COVID-19 cases should also integrate comprehensive lifestyle modification in the management of cases regardless of the disease stage. Healthy lifestyle should also be incorporated in the rehabilitative phase of confirmed COVID-19 negative patients. Such measures will likely reduce significantly the incidence and case fatality rates of COVID-19 and also facilitate the early restoration of functionality of patients that were severely affected by COVID- 19 .

[5] World Health Organisation, 2020, WHO Coronavirus Disease (COVID-19) Dashboard, Date of access: 14/10/2020. https://covid19.who.int/.

[6] Clerkin K.J., Fried J.A., Raikhelkar J., Sayer G., Griffin J.M., Masoumi A., et al., 2020, COVID-19 and Cardiovascular Disease, Circulation, 141: 1648 1655 ,

DOI: 10.1161/CIRCULATIONAHA.120.046941.

[7] Pan H., Peto R., Karim Q.A., Alejandria M., Henao-Restrepo A.M., García C.H., et al., 2020, Repurposed antiviral drugs for COVID-19-interim WHO SOLIDARITY trial results: WHO Solidarity trial consortium, WHO 2020, Date of access: 18/10/2020.

https://doi.org/10.1101/2020.10.15.20209817.

[8] Khunti K., Singh A.K., Pareek M., and Hanif W., 2020, Is ethnicity linked to incidence or outcomes of covid-19? Preliminary signals must be explored urgently, BMJ, 369: 1 - 2. DOI: 10.1136/bmj.m1548. [9] Ambrosino I., Barbagelata E., Ortona E., Ruggieri A., Massiah G., Giannico O.V., et al., 2020, Gender differences in patients with COVID-19: a narrative review, Monaldi Archives for Chest Disease, 90 (1389): $318-324$.

[10] Mo P., Xing Y., Xiao Y., Deng L., Zhao Q., Wang H., et al., 2020. Characteristics of refractory 
COVID-19 pneumonia in Wuhan, China. Infectious Diseases Society of America, 2020, Oxford University Press, Date of access: 9/10/2020. https://watermark.silverchair.com/ciaa270.pdf?toke $\mathrm{n}=$.

[11] Richardson S., Hirsch J.S., Narasimhan M., Crawford J.M., McGinn T., and Davidson K.W., 2020, Presenting Characteristics, Comorbidities, and Outcomes Among 5, 700 Patients Hospitalized With COVID-19 in the New York City Area, JAMA, 323(20): $2052 \quad-\quad 2059$. DOI:10.1001/jama.2020.6775.

[12] Public Health Ontario, 2020, Coronavirus Disease 2019 (COVID-19): How to Protect Yourself from COVID-19 - Older Adults and People with Chronic Medical Conditions or Weakened Immune Systems. Queen's Printer for Ontario 2020, Date of access:

14/10/2020.

https://www.publichealthontario.ca/-

/media/documents/ncov/factsheet/2020/05/factsheet -covid-19-immunocompromised.pdf?la=en.

[13] National Association of Chronic Disease Directors, 2020, Chronic Disease and COVID-19: What You Need to Know Tips and information to protect yourself and your family, National Association of Chronic Disease Directors 2020.

Date of access: 15/10/2020. https://cdn.ymaws.com/www.chronicdisease.org/re source/resmgr/website-

2020/covid/factsheet_covid19cd.pdf.

[14] Bener A., Alsaied A., Al-Ali M., Hassan A.S., Basha B., Al-Kubaisi A., et al., 2009, Impact of Lifestyle and Dietary Habits on Hypovitaminosis D in Type 1 Diabetes Mellitus and Healthy Children from Qatar, a Sun-Rich Country, Annals of Nutrition \& Metabolism, 53 (3/4): 215 - 222. https://www.jstor.org/stable/48507937.

[15]Zgaga L., Theodoratou E., Farrington S.M., Agakov F., Tenesa A., Walker M., et al., 2011, Diet, Environmental Factors, and Lifestyle Underlie the High Prevalence of Vitamin D Deficiency in Healthy Adults in Scotland, and Supplementation Reduces the Proportion That Are Severely Deficient, The Journal of Nutrition, 6: 1535 - 42. doi:10.3945/jn.111.140012.

[16] Bonevski B., 2020. Does nicotine protect us against coronavirus? The Conversation Africa, Inc. 2020. Date of access: 10/09/2020. https://theconversation.com/does-nicotineprotectus-against-coronavirus-137488.

[17] van Zyl-Smit R., Richards G., and Leone F.T., 2020, Tobacco smoking and COVID-19 infection, thelancet.com/respiratory, 8: $664-5$.
[18] World Health Organization, 2020, WHO statement: Tobacco use and COVID-19. World Health Organization 2020. Date of access: 14/10/2020.

https://www.who.int/newsroom/detail/11-05-2020who-statement-tobacco-use-and-covid- 19.

[19] Banerjee B, and Banerjee R., 2020, Role of tobacco in SARS-CoV-2 infection and COVID-19: A scoping review. Int J Non-Commun Dis, 5:70 - 5. [20] Yu G., 2020, How smoking, vaping and drug use might increase risks from Covid-19. CNN 2020. Date of access: 18/10/2020. https://edition.cnn.com/2020/03/20/health/coronavi rus-vaping-drugs/index.html.

[21] Landsverk G., 2020, There's new evidence vitamin D may help treat COVID-19 by reducing the severity of infection. Insider Inc 2020. Date of access: 28/10/2020. https://www.insider.com/newevidence-suggests-vitamin-d-could-reducecoronavirus-severity-2020-10.

[22] Miller A.M., 2020, Over $80 \%$ of coronavirus patients had vitamin $D$ deficiency in one Spanish hospital. Insider Inc 2020. Date of access: 28/10/2020. https://www.insider.com/80-percentof-hospitalized-coronavirus-patients-had-vitamind-deficiency-2020-10.

[23] Nasri H., and Ardalan M.R., 2012, Association of serum vitamin D level with age in individuals with normal renal function, J Nephropharmacol, 1(1): 7-9.

[24] Roomi M.A., Farooq A., Ullah E., and Lone K.P., 2015, Hypovitaminosis D and its association with lifestyle factors, Pak J Med Sci, 31(5): 1236 1240. http://dx.doi.org/10.12669/pjms.315.7196.

[25] World Health Organization, 2020, Nutrition advice for adults during the COVID-19 outbreak. World Health Organization 2020. Date of access: 27/08/2020.

http://www.emro.who.int/images/stories/nutrition/d ocuments/en_flyer_nutrition_adults_covid_19.pdf? ua $=1$.

[26] World Health Organization, 2020, Clinical management of COVID-19: Interim guidance. WHO 2020, Date of access: 15/10/2020? https://www.who.int/publications/i/item/clinicalmanagement-of-covid-19.

[27] Wang L., 2020, C-reactive protein levels in the early stage of COVID-19, Médecine et maladies infectieuses, 50: 332-334.

[28] Apicella M., Campopiano M.C., Mantuano M., Mazoni L., Coppelli A., and Del Prato S., 2020, COVID-19 in people with diabetes: understanding 
the reasons for worse outcomes. thelancet.com/diabetes-endocrinology, 8: $782-92$. [29] Pugliese G., Vitale M., Resi V., and Orsi E., 2020, Is diabetes mellitus a risk factor for Coronavirus Disease 19 (COVID-19)? Acta Diabetol., 31: 1 - 11. doi: 10.1007/s00592-02001586-6.

[30] Casqueiro J., Casqueiro J., and Alves C., 2012, Infections in patients with diabetes mellitus: A review of pathogenesis, Indian Journal of Endocrinology and Metabolism, 16 (1): 27 - 36. DOI: $10.4103 / 2230-8210.94253$.

[31] Yang J., Zheng Y., Gou X., Pu K., Chen Z., Guo Q., et al., 2020, Prevalence of comorbidities and its effects in patients infected with SARS-CoV-2: a systematic review and meta-analysis. International Journal of Infectious Diseases, 94: 91-95. https://doi.org/10.1016/j.ijid.2020.03.017.

[32] Guan W., Ni Z., Hu Y., Liang W., Ou C., He J. et al., 2020, Clinical Characteristics of Coronavirus Disease 2019 in China, $n$ engl $j$ med, 382: 1708 1720, DOI: 10.1056/NEJMoa2002032.

[33] Pal R., and Bhadada S.K., 2020, COVID-19 and non-communicable diseases, Postgrad Med J, 96: $429-430$

[34] Verma N., Duseja A., and Singh V., 2020, Impact of Pre-existing Chronic Liver Disease on the Outcome of Patients with COVID-19 Disease, Gastroenterology 2020, doi: https://doi.org/10.1053/j.gastro.2020.05.090. Date of access: 15/10/2020. https://www.gastrojournal.org/article/S00165085(20)34782-X/pdf.

[35] Oyelade T., Alqahtani j., and Canciani G., 2020, Prognosis of COVID-19 in Patients with Liver and Kidney Diseases: An Early Systematic Review and Meta-Analysis, Trop. Med. Infect. Dis., 5 (80): 1 14. doi:10.3390/tropicalmed5020080.

[36] Bonita R., Beaglehole R., and Kjellström T., 2006, Basic epidemiology $2^{\text {nd }}$ edition. World Health Organization 2006. Date of access: 16/10/2020. https://apps.who.int/iris/bitstream/handle/10665/43 541/9241547073_eng.pdf?sequence=1\&isAllowed $=\mathrm{y}$.

[37] Mancia G., Fagard R., Narkiewicz K., Redon J., Zanchetti A., Böhm M., et al., 2013, 2013 ESH/ESC guidelines for the management of arterial hypertension: The Task Force for the Management of Arterial Hypertension of the European Society of Hypertension (ESH) and of the European Society of Cardiology (ESC). Eur Heart J., 34(28): 2159-219. DOI: 10.1093/eurheartj/eht151.

[38] Cosentino F., Grant P.J., Aboyans V., Bailey
C.J., Ceriello1 A., Delgado V., et al., 2019, 2019 European Society of Cardiology (ESC) Guidelines on diabetes, pre-diabetes, and cardiovascular diseases developed in collaboration with the European Association of the Study of Diabetes (EASD). European Heart Journal, 00: 1 - 69. DOI:10.1093/eurheartj/ehz486.

[39] World Health Organization, 2009, A Training Manual for Health Workers on Healthy Lifestyle: An Approach for the Prevention and Control of NonCommunicable Diseases. Date of access: 1/10/2020. http://www.wpro.who.int/philippines/publications/t rainersguide.pdf.

[40] Kelly J, \& Shull J., 2019, Foundations of Lifestyle Medicine: The Lifestyle Medicine Board Review Manual. $2^{\text {nd }}$ ed. (Chesterfield, MO: United States of America).

[41] United Nations, 2011, Political declaration of the High-level Meeting of the General Assembly on the Prevention and Control of Non-communicable Diseases. United Nations 2011, Date of access: 15/10/2020.

https://www.who.int/nmh/events/un_ncd_summit2 011/political_declaration_en.pdf?ua=1.

[42]Hunter C.L., Rubin H., and Kim K., 2020, COVID-19 Economic Impacts: Beware the Ides of March - A Day Romans Settled Debts, KPMG Economics 2020, Date of access: 15/10/2020. https://assets.kpmg/content/dam/kpmg/cl/pdf/202003-kpmg-chile-advisory-coronavirus-mapping.pdf. [43] Alschuler L, Weil A, Horwitz R, Stamets P., Chiassona A., Crockera R., and Maizesa V., 2020, Integrative considerations during the COVID-19 pandemic, Explore, (00): 1 - 3 .

[44] World Health Organization, 2007, Prevention of Cardiovascular Disease: Guidelines for Assessment and Management of Cardiovascular Risk. Date of access: 8/10/2020. http://www.who.int/cardiovascular_diseases/guideli nes/Full\%20text.pdf.

[45] Brunzell, J. D., Davidson, M., Furberg, C. D., Goldberg, R. B., Howard, B. V., Stein J. H., et al., 2008, Lipoprotein Management in Patients with Cardiometabolic Risk: Consensus Conference Report from the American Diabetes Association and the American College of Cardiology Foundation, $J$. Am. Coll. Cardiol., 51, 1512 - 1524. DOI: 10.1016/j.jacc.2008.02.034.

[46] University of Leicester, 2012, Updated. The Handbook for Vascular Risk Assessment, Risk Reduction and Risk Management. Date of access: 31/12/2016. https://legacyscreening.phe.org.uk/policydb_download.p hp?doc $=259$. 


\title{
Epidemiologial Survey on the Utilization of Insecticide Treated Mosquito Nets in Malaria Control among Gyadi-Gyadi Communities in Kano, Nigeria
}

\author{
Ahmad Salisu Aliyu ${ }^{1 *}$, Maimuna Yahaya Yakasai ${ }^{2}$, Nazir Lawan Habib ${ }^{1}$, Habu Chadi ${ }^{3}$ \\ ${ }^{I}$ Department Infectious Diseases Hospital (IDH), Medical Laboratory, Kano, Nigeria \\ ${ }^{2}$ Department of Chemistry, Sa'adatu Rimi College of Education, Kano State \\ ${ }^{3}$ Department of Chemistry, Bauchi State University, Gadau
}

\begin{abstract}
Background: Malaria causes an overwhelmingly large number of cases and deaths round the globe every year. Insecticide treated mosquito nets (ITNs) have raised a renewed interest to serve as tools for malaria control in Africa. This survey was, therefore, designed to provide information about the knowledge, attitude and experience of the community about malaria as a disease and its preventive methods, particularly acceptability, affordability and compliance to the use of insecticide treated mosquito nets, and factors influencing its possession and utilization of ITNs among GyadiGyadi communities in Kano, Nigeria. Methods: A community based cross-sectional study was conducted in Gyadi-Gyadi from March 2019 to April 2019. Data was collected using a pretested structured questionnaire. Descriptive analysis was performed to obtain the frequency distribution of the variables. Results: The result shows that 341 participants responded to the questionnaire. $64.5 \%$ of the respondents had heard about the mosquito net. $45 \%$ of the respondents in the survey reported the presence of at least one mosquito net in their households. $69.2 \%$ of the participants perceived fever, headache and chilling of the body as the main symptoms of malaria. Conclusion: The utilization of mosquito nets at the time of the study was very low. However, acceptability and willingness to use ITNs for malaria prevention was very high. It is recommended that communities should be strongly sensitized on the importance of ITNs for malaria control, and the availability and affordability should be insured.
\end{abstract}

Keywords: Gyadi-Gyadi, Insecticide treated mosquito nets (ITNs), Malaria, Utilization.

\section{Introduction}

Malaria is a disease caused by the protozoan parasites of the genus Plasmodium. The five species that commonly infect humans are: Plasmodium falciparum, Plasmodium vivax, Plasmodium ovale, Plasmodium malariae and Plasmodium knowlesi [1]. P. falciparum is found in the tropics and sub- tropics and it is the most important species as it is responsible for $50 \%$ of all morbidity and mortality from severe malaria. $P$. vivax is seen in tropics and sub- tropical areas and is less dangerous but more widespread. It is transmitted to humans by the bite of infected female Anopheles mosquito of more than 30 species [1]. In sub-Saharan Africa, Anopheles gambiae, Anopheles arabiensis and Anopheles funestus are the primary vectors of malaria parasites and show highly anthropophagic tendencies [1].
Malaria is a complex disease that varies widely in epidemiology and clinical manifestation in different parts of the world. This variability is caused by factors such as the species of malaria parasites that occur in a given area, their susceptibility to commonly used or available antimalarial drugs, the distribution and vectorial capacity of mosquito vectors, climate and other environmental conditions and the behaviour and level of acquired immunity of the exposed human populations. In particular, young children, pregnant women, and non-immune visitors to malaria endemic areas are at greatest risk of severe or fatal illness [2].

Early detection and prompt treatment of malaria cases, selective vector control (indoor residual spray, use of insecticide treated mosquito nets and source reduction) and 
epidemic prevention and control are the major strategies adopted in the country. So far, the application of in-house insecticide spraying has been at the center of vector control operations [3].

Malaria remains a major public health problem particularly in many tropical countries, resulting in decreased productive capacity and increased poverty despite the intensive attempts being exerted to control it especially in subSaharan Africa $[4,5,6]$.

In Nigeria, Malaria is a major public health problem where it accounts for more cases and deaths than any other country in the world. Malaria is a risk for $97 \%$ of Nigeria's population. The remaining $3 \%$ of the population live in the malaria free highlands. There are an estimated 100 million malaria cases with over 300,000 deaths per year in Nigeria. This compares with 215,000 deaths per year in Nigeria from HIV/AIDS. Malaria contributes to an estimated $11 \%$ of maternal mortality [7].

In Nigeria, malaria in pregnant women is a major public health concern because it is the major cause of maternal mortality. The major complications in pregnant women resulting from malaria are low birth weight in new-born babies, high placental plasmodia burden, foetal complications, and sometime new born death $[8,9]$.

Currently, insecticide treated mosquito nets (ITNs) have received serious attention and have raised renewed interest to serve as tools in malaria control. In Africa, the use of this control strategy has been proved to be costeffective means for the control of malaria, especially among children under 5 years of age and pregnant women $[5,6]$.

Studies conducted in different African countries have shown the effectiveness of ITNs $[10,11,12]$. Moreover, other controlled trials have also confirmed an over-all reduction in child mortality [13, 14, 15].

Thus, based on these epidemiological evidences, it could be argued that ITNs have become one of the major components of vectortargeted interventions in Africa [5, 6].

Nigeria has adopted the use of ITNs as one of its vector control strategies primarily in selected malarious areas with the view to a gradual scaling-up of the intervention. The use of mosquito nets is, however, limited and there are a number of possible explanations for this low coverage. These may be due to lack of cultural exposure to the use of mosquito nets, lack of awareness, absence of a sustainable mechanism for the distribution of ITNS, low acceptance by the community, and concerns regarding its high cost. Since this strategy, as one of the vector control options in the country, is a new initiative, understanding the perceptions and willingness of the community towards using ITNs as well as the factors influencing its usage is a prerequisite for designing strategies aimed at scaling-up mosquito net implementation programmed in Nigeria.

The rationale for selecting these areas was to initiate the introduction and implementation of ITNs in semi-urban and development project areas and gradually expand it to other malarious areas. The assumption was that the people residing in these areas might have awareness about mosquito nets and their importance in preventing malaria morbidity and mortality. These areas are mostly exempted from regular indoor residual spray activities.

Insecticide-treated nets (ITNs) have become important tools that provide a simple and effective means of preventing malaria in highly endemic areas [16]. At present large scale ITN programs are being implemented in sub-Saharan Africa, Asia and Latin America using a number of operational approaches [17].

Large-scale trials of ITNs have demonstrated that they reduce malaria mortality and morbidity under a variety of Several epidemiological conditions $[18,19$, $20,21,22,23,24,25,26]$. Results from such studies provide enough evidence to galvanize consensus in the global community that provision of ITNs should receive priority [20]. At the African summit on Roll Back Malaria in Abuja, Nigeria in April 2000, heads of states and senior representatives from 44 malaria afflicted countries in Africa agreed to a goal of providing ITNs to at least $60 \%$ of those at risk of malaria, particularly pregnant women and children less than five years of age, by 2005 [20, 27, 28, 29, 30, 31]. This target has also been set by the Ministry of Health and Roll Back Malaria partners in Kano [18]. But coverage in Africa is still unacceptably low $[31,32]$ only $3 \%$ of 
African children are sleeping under ITN, and only about $20 \%$ are sleeping under any kind of net [32].

Apart from coverage, issues regarding the utilization of ITNs are very crucial. This is because the ITNs that are available at a household level may be left unused or even if they are used, vulnerable members of the household may not be given priority and/ or the usage may be intermittent. The maximum malaria reduction impact of ITNs will only be achieved if people acquire nets, treat/ retreat them, make sure that the most vulnerable household members sleep under them, and use nets all year round [33] Discrepancies between possession and utilization have been elicited by studies carried out in different African countries [34, 35].

Yet, there is no properly documented evidence regarding the coverage and utilization of ITNs in the study locality. This survey was, therefore, designed to provide information about the knowledge, attitude and experience of the community about malaria as a disease and its preventive methods, particularly acceptability, affordability and compliance to the use of insecticide treated mosquito nets, and factors influencing its possession and utilization of ITNs among Gyadi-Gyadi communities in Kano, Nigeria.

\section{Methodology}

\section{Study Area and Study Design}

The study was conducted in Gyadi-Gyadi, which is one of the towns found in Tarauni local government Kano state. According to 2006, national housing and population census, the projected estimated population of the Gyadi-Gyadi was 65,000 . A community-based cross- sectional study was conducted using interviewer-administered questionnaire from March 2019 to April 2019.

\section{Sample Size Determination}

In this study, manual calculation of the sample size using Morgan and Krejcie [36] formula was used for sample size determination, as stated below:

$$
\mathrm{S}=\mathrm{X}^{2} \mathrm{NP}(1-\mathrm{P}) \div \mathrm{d}^{2}(\mathrm{~N}-1)+\mathrm{X}^{2} \mathrm{P}(1-\mathrm{P})
$$

Where:

$\mathrm{S}=$ Required sample size

$\mathrm{X}^{2}=$ The table value of the chi-square at desired confidence (3.841)

$\mathrm{N}=$ Study Population size (3000)

$\mathrm{P}=$ Population proportion assumed to be 0.50 since this would provide maximum sample size

$\mathrm{d}^{2}=$ Degree of accuracy of the result expressed as proportion 0.050

$3.841 \times 3000 \times 0.5 \times 0.5$

$0.0025 \times 2999+3.841 \times 0.5 \times 0.5$

$2880.75=341$

8.45775

Hence 341 participants

\section{Inclusion and Exclusion Criteria}

Resident individuals aged 18 years and above and willing to participate were included in the study. Individuals who stayed as guests in the selected households, those who were $<18$ years of age and who had chronic illnesses, were excluded from the study.

\section{Data Collection}

Data was collected from eligible and willing participants using a pre-tested, structured questionnaire, adapted from the sample questionnaire in the guide to developing knowledge, attitude and practice surveys developed by the World Health Organization and Stop malaria Partnership. Socio-demographic information including age, gender, occupation, education, and socio-economic status were collected. The knowledge of the participants on symptoms suggestive of malaria, cause of malaria, treatment and preventive measures, attitude and practices regarding malaria disease were also collected.

\section{Data Analysis}

Data were analyzed using Statistical Package for Social Science (SPSS) software version 16.0 at that time with the help of the Statistician. The descriptive statistical method was used to analyze frequencies and percentages.

\section{Ethical Considerations}

This study was conducted only after obtaining approval from Gyadi-Gyadi District Head. 


\section{Results}

A total of 341 respondents were interviewed, giving 100\% response rate. The majority, 201 (58.9\%) of the respondents were males. Among all, $91(26.7 \%)$ of respondents were $31-35$ years of age. Of the study subjects, $223(65.4 \%)$, were married. The socio-economic characteristics of the study showed that, among all respondents, $221(64.8 \%)$ of respondents attended formal education, among this 145 $(42.5 \%)$ of respondents were primary school completed, $76(22.3 \%)$ of respondents were secondary school and above completed, while $120(35.2 \%)$ of respondents reported that they were took informal education (were illiterate and only read and write). Similarly, results of occupational status of respondents indicated, $150(44 \%)$ of respondents were farmers, 46 (13.5\%) were Government employed, 70 (20.5\%) were Merchants and $75(22 \%)$ were House wives (Table 1).

Table 1. Socio Demographic Characteristics of the Participants $(n=341)$

\begin{tabular}{|l|l|l|}
\hline Characteristics & Frequencies (n=341) & $\begin{array}{l}\text { Percentages } \\
\%\end{array}$ \\
\hline Gender & 201 & 58.9 \\
\hline Males & 140 & 41.1 \\
\hline Females & \multicolumn{2}{|l|}{} \\
\hline Ages & 60 & 17.6 \\
\hline $20-25$ & 70 & 20.5 \\
\hline $26-30$ & 91 & 26.7 \\
\hline $31-35$ & 72 & 21.1 \\
\hline $36-40$ & 48 & 14.1 \\
\hline $41+$ & \multicolumn{2}{|l|}{} \\
\hline Marital Status & 223 & 65.4 \\
\hline Married & 96 & 28.2 \\
\hline Single & 9 & 2.6 \\
\hline Divorce & 13 & 3.8 \\
\hline Widowed & 75 & 22 \\
\hline Education & 45 & 13.2 \\
\hline Illiterate & 145 & 42.5 \\
\hline Can read and write & 76 & 22.3 \\
\hline Primary & 22 \\
\hline Secondary and above & 75 & 44 \\
\hline Occupation & 150 & 13.5 \\
\hline House wife & 46 & 20.5 \\
\hline Farmers & 70 & \\
\hline Government employee & \\
\hline Merchants & \multicolumn{2}{|l|}{} \\
\hline
\end{tabular}

Majority of the households Ever heard about the mosquito net 220 (64.5\%), majority of the households did not own any mosquito net, the main reasons cited being inability to afford the price 95 (27.9\%), Shortage of nets during free provision 49 (14.4\%) Not knowing its use 47 (13.8\%) Surprisingly, 228 (45\%) of the respondents Possess at least one mosquito net.
However, $200 \quad(30 \%)$ of the respondents Possess at least one ITNs. With regard to the sources of ITNs, majority of the respondents $164(48.1 \%)$ said they obtained the ITNs from health institution, freely. Similarly, 224 $(65.7 \%)$ of the respondents said that the Duration of the possession of the nets are 1-5 years (Table 2). 
Table 2. Mosquito Net Possession among the Studied Households $(n=341)$

\begin{tabular}{|c|c|c|}
\hline Characteristics & Frequencies $(\mathrm{n}=341)$ & Percentages $(\%)$ \\
\hline \multicolumn{3}{|l|}{ Ever heard about the mosquito net } \\
\hline Yes & 220 & 64.5 \\
\hline No & 121 & 35.5 \\
\hline \multicolumn{3}{|l|}{ Possession of at least one mosquito net } \\
\hline Yes & 228 & 45 \\
\hline No & 113 & 55 \\
\hline \multicolumn{3}{|l|}{ Possession of at least one ITN } \\
\hline Yes & 200 & 30 \\
\hline No & 141 & 50 \\
\hline Possession of at least 2 mosquito nets & & 20 \\
\hline 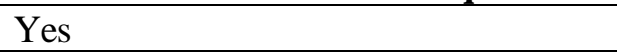 & 140 & \\
\hline No & 201 & 8 \\
\hline Possession of at least 2 ITNs & & 65.3 \\
\hline Yes & 131 & 21.7 \\
\hline No & 210 & 5 \\
\hline \multicolumn{3}{|c|}{ Number of any mosquito net possessed } \\
\hline One & 158 & 7 \\
\hline Two or more & 183 & 93 \\
\hline \multicolumn{3}{|l|}{ Number of ITNs possessed } \\
\hline One & 174 & 51.0 \\
\hline Two or more & 167 & 49.0 \\
\hline \multicolumn{3}{|c|}{ Cumulative number of nets identified during the study } \\
\hline Any mosquito net & 245 & 71.8 \\
\hline ITNs & 96 & 28.2 \\
\hline \multicolumn{3}{|c|}{ Nets observed and presence confirmed } \\
\hline Yes & 318 & 93.3 \\
\hline No & 23 & 6.7 \\
\hline \multicolumn{3}{|l|}{ Source of nets } \\
\hline From health institution, freely & 164 & 48.1 \\
\hline From health institution, with payment & 25 & 7.3 \\
\hline Bought from market/ shop & 112 & 32.8 \\
\hline From other source, freely & 21 & 6.2 \\
\hline From other source, with payment & 19 & 5.6 \\
\hline \multicolumn{3}{|l|}{ Duration of possession of the nets } \\
\hline$<1$ year & 106 & 31.1 \\
\hline $1-5$ years & 224 & 65.7 \\
\hline$\geq 6$ years & 9 & 2.6 \\
\hline Don't remember & 2 & 0.6 \\
\hline \multicolumn{3}{|l|}{ Brand of nets } \\
\hline PermaNet & 221 & 64.8 \\
\hline UNICEF & 102 & 29.9 \\
\hline SafeNite & 12 & 3.5 \\
\hline PowerNet & 3 & 0.9 \\
\hline Olyset & 1 & 0.3 \\
\hline Net Mark & 1 & 0.3 \\
\hline Unknown & 1 & 0.3 \\
\hline \multicolumn{3}{|c|}{ Reason for not owning any mosquito nets } \\
\hline inability to afford the price & 95 & 27.9 \\
\hline
\end{tabular}




\begin{tabular}{|l|l|l|}
\hline Shortage of nets during free provision & 49 & 14.4 \\
\hline Not knowing its use & 47 & 13.8 \\
\hline Absence of mosquitoes & 38 & 11.1 \\
\hline Using other preventive methods & 39 & 11.4 \\
\hline Not knowing where to find it & 36 & 10.6 \\
\hline Other reason & 37 & 10.8 \\
\hline Desire to possess mosquito nets in the future \\
\hline Yes & 199 & 58.3 \\
\hline No & 81 & 23.8 \\
\hline Can't tell & 61 & 17.9 \\
\hline Preferred way of obtaining nets & 187 & 54.8 \\
\hline If distributed freely & 154 & 45.2 \\
\hline If sold with discount
\end{tabular}

Majority of the respondents $282(82.7 \%)$ used available nets, and the frequency of using the nets was consistent throughout the year 218 (63.9\%). Similarly, $265(77.7 \%)$ of the respondents sleep under the ITNs. However, majority of the households did not use any

mosquito net, the main reasons cited being Absence of mosquitoes 61 (17.9\%), old and worn-out net $57(16.7 \%)$, It is hot sleeping under a net $46(13.5 \%)$, Children may get trapped in it 45 (13.2\%), Difficult to get up at night 44 (12.9) (Table 3).

Table 3. Mosquito Net Utilization Pattern $(n=341)$

\begin{tabular}{|c|c|c|}
\hline Characteristics & Frequencies $(n=341)$ & Percentages $(\%)$ \\
\hline \multicolumn{3}{|l|}{ Using the available nets } \\
\hline Yes & 282 & 82.7 \\
\hline No & 59 & 17.3 \\
\hline \multicolumn{3}{|l|}{ Frequency of using the nets } \\
\hline Consistently throughout the year & 218 & 63.9 \\
\hline Intermittently & 123 & 36.1 \\
\hline \multicolumn{3}{|l|}{ Times when intermittent users use their nets } \\
\hline During rainy season & 96 & 28.2 \\
\hline After rainy season & 75 & 22 \\
\hline During dry season & 57 & 16.7 \\
\hline As they like & 57 & 16.7 \\
\hline When hearing mosquitoes buzzing & 56 & 16.4 \\
\hline \multicolumn{3}{|l|}{ Use of any net the preceding night } \\
\hline Yes & 242 & 71.0 \\
\hline No & 99 & 29.0 \\
\hline \multicolumn{3}{|l|}{ Did anyone sleep under an ITN last night } \\
\hline Yes & 265 & 77.7 \\
\hline No & 76 & 22.3 \\
\hline \multicolumn{3}{|l|}{ Reason why nets are not being used } \\
\hline Absence of mosquitoes & 61 & 17.9 \\
\hline old and worn-out net & 57 & 16.7 \\
\hline It is hot sleeping under a net & 46 & 13.5 \\
\hline Children may get trapped in it & 45 & 13.2 \\
\hline Lack of appropriate place for hanging the net & 44 & 12.9 \\
\hline It takes time to tuck in the net each night & 44 & 12.9 \\
\hline Difficult to get up at night & 44 & 12.9 \\
\hline $\begin{array}{l}\text { The fact that malaria can be transmitted from } \\
\text { patient to another person through mosquito } \\
\text { es was known to } 55.7 \% \text { of the respondents. } \\
\text { her modes of transmission mentioned by the }\end{array}$ & \multicolumn{2}{|c|}{$\begin{array}{l}\text { participants were Contact with a malaria patien } \\
19(5.6 \%) \text {. Stagnant water } 189(55.4 \%) \text { was the } \\
\text { most commonly mentioned breeding site of } \\
\text { mosquito and the other site reported were Dirty }\end{array}$} \\
\hline
\end{tabular}


areas $120(35.2 \%)$. Nearly Mosquito net and one or more of the above measures $68(19.9 \%)$ of the participants knew that malaria transmission is preventable and 50 (14.7\%) mentioned that cleaning the surroundings could prevent malaria transmission (Table 4).

Table 4. Knowledge on Malaria Transmission, Mosquito Breeding Sites and Prevention Methods $(n=341)$

\begin{tabular}{|l|l|l|}
\hline Characteristics & Frequencies (n=341) & Percentages (\%) \\
\hline Mode of malaria transmission & 190 & 55.7 \\
\hline Mosquito bite & 19 & 5.6 \\
\hline Breathing bad air & 19 & 5.6 \\
\hline Contact with a malaria patient & 18 & 5.3 \\
\hline Exposure to rain & 18 & 5.3 \\
\hline Bad smell & 13 & 3.8 \\
\hline Eating maize stalk & 16 & 4.7 \\
\hline Wind/cold air & 4 & 1.2 \\
\hline Bedbug/flea & 44 & 12.9 \\
\hline Others & \multicolumn{2}{|l|}{} \\
\hline Mosquito breeding sites & 189 & 55.4 \\
\hline Stagnant water & 120 & 35.2 \\
\hline Dirty areas & 11 & 3.2 \\
\hline Didn't know & 21 & 6.2 \\
\hline Others & \multicolumn{2}{|l|}{} \\
\hline Prevention methods & 50 & 14.7 \\
\hline Cleaning the surroundings & 20 & 16.1 \\
\hline Draining and filling ditches & 55 & 19.1 \\
\hline Insecticides spraying & 65 & 7.0 \\
\hline Chemotherapy & 24 & 7.0 \\
\hline Fumigation and fire smoking & 24 & 10.3 \\
\hline Mosquito net & 35 & 19.9 \\
\hline $\begin{array}{l}\text { Insecticides and one or more of } \\
\text { the above measures }\end{array}$ & $\begin{array}{l}\text { Mosquito net and one or more of } \\
\text { the above measures }\end{array}$ & 68 \\
\hline
\end{tabular}

On the other hand, $69.2 \%$ of the study participants perceived fever, headache and chills as the main signs and symptoms of malaria. More than $48.9 \%$ of the interviewees, also correctly identified the names of the currently used anti-malarial drugs, name Chloroquine and Artemether. With regard to malaria, morbidity and preference of health facilities, $58.4 \%$ of the respondents had their first visit to health care facilities including public and private health services as well as malaria control laboratories, drug venders/pharmacy and Community Health Workers (CHWs) seeking treatment for malaria. A few of the respondents also reported the use of herbalists and other health care providers. About $46.6 \%$ of the households had two to five family members who were sick due to malaria and $38.7 \%$ had only one family member who was sick of the disease (Table 5).

Table 5. Knowledge about the Symptoms of Malaria, Antimalarial Drugs and Preference of Health Service Visit for Malaria Illness $(n=341)$

\begin{tabular}{|c|c|c|}
\hline Characteristics & Frequencies $(n=341)$ & Percentages $(\%)$ \\
\hline \multicolumn{3}{|c|}{ Signs and symptoms of malaria } \\
\hline Fever, headache, chills & 236 & 69.2 \\
\hline Joint and muscle pain, & 34 & 10.0 \\
\hline Nausea and vomit & 71 & 20.8 \\
\hline \multicolumn{3}{|l|}{ Antimalarial drugs } \\
\hline Chloroquine & 167 & 48.9 \\
\hline
\end{tabular}




\begin{tabular}{|l|l|l|}
\hline Artemether & 63 & 18.5 \\
\hline Chloroquine and Artemether & 91 & 26.7 \\
\hline Other & 20 & 5.9 \\
\hline First visit when sick of malaria & \multicolumn{2}{|l|}{} \\
\hline Government health care facility & 199 & 58.4 \\
\hline Malaria control laboratory & 49 & 14.4 \\
\hline Private clinics & 18 & 5.3 \\
\hline Drug vendor/pharmacy & 40 & 11.7 \\
\hline Community health workers & 22 & 6.4 \\
\hline Herbalist & 13 & 3.8 \\
\hline Number of family members sick of malaria in 2 weeks \\
\hline None & 50 & 14.7 \\
\hline 1 & 132 & 38.7 \\
\hline $2-5$ & 159 & 46.6 \\
\hline
\end{tabular}

\section{Discussion}

The aim of this study was to assess the knowledge, perceptions, and practices of the community about malaria, as well as its transmission and prevention methods. Furthermore, it aimed to determine the coverage of ITNs mainly in urban and semiurban areas, and factors influencing its possession and usage.

The awareness about the association between mosquito and malaria in the present study is much higher than the findings reported in previous studies $[37,38]$. The study participants included in this study were mainly from the urban areas unlike those of the previous studies who resided mainly in rural areas. In addition, different interventions, particularly those made to raise the awareness of the community about malaria and its control in the urban areas could be a possible explanation for the high awareness of malaria. In this study, the respondents indicated that stagnant water is the main mosquito breeding site. Previous studies have also confirmed similar findings [37, 39, 40]. The awareness of the relationship between mosquitoes and malaria transmission in the study community is highly important for the possession and utilization of mosquito nets. It is speculated that knowledge of this association predicts high mosquito net use.

Almost all the participants in this study had knowledge about the main signs and symptoms suggestive of malaria, as in all studies. Knowledge is usually high in areas with low-tomoderate transmission rates and where people are aware of the clinical manifestations of the disease [37, 38, 39, 40]. However, it might be low in areas of holo-endemic transmission where the population has protective immunity against malaria [39].

The medications taken for the treatment of malaria episode were mainly antimalarial drugs. Unlike in the rural areas, malaria cases in our study area were usually first identified and treated in public health care facilities and malaria control laboratories. The utilization of private health facilities, traditional herbal remedies, and community health workers was very low in the study areas. This is mainly due to the fact that the coverage and accessibility of public health facilities in the study area is relatively high compared to that in rural malarious areas. However, it has been demonstrated that the coverage of malaria control can be increased substantially by involving communities particularly by training community health workers and mother coordinators, especially on correct antimalarial drug use for children [41, 42].

This study highlights several important issues for the implementation of ITNs as a malaria control strategy. The proportion of people who had not heard about ITNs was significant $(35.5 \%)$. Similarly, the proportion of households who owned ITNs among those who had heard about it was only $28.2 \%$. Among these, those who reported inappropriate use of ITNs were nearly $17.3 \%$. A gap exists between those who have heard about ITNs and those who owned it, and between those who possessed and used mosquito nets appropriately. This discrepancy could be because of either the awareness of the community about ITNs is poor or may reflect the relative unavailability of mosquito nets, suggesting that, at the time of the survey; mosquito net use for malaria control was not 
being adequately promoted in many parts of the country.

This study also suggests ways of increasing demand in relation to the implementation of ITN programme. For example, a significant proportion $(35.5 \%)$ of households who are willing to buy would prefer making payments in installments. This may ensure greater coverage and make ITN affordable to those who may not be able to purchase it immediately and in cash.

The other important issue that should not be overlooked with regard to the affordability of ITNs is the time when the households would need ITN and the time when they would have most money available to buy them. Because of seasonality of crops and income generated, people residing in most parts of the country may prefer to purchase ITN after the harvest. If the perceived risk of malaria is low during these times, spending money on ITNs may not be perceived as a high priority [43]. But when the need is perceived as highest, people may not have adequate money for buying mosquito nets. The time for the occurrence of peak malaria transmission associated with epidemics in Nigeria is during the months of July to October.

The affordability and possession of mosquito nets are not the only factors that affect ITN use and acceptance. The seasonality of malaria and mosquito abundance is also equally important. In surveys conducted in Ghana, net use was considerably higher in the rainy season than the dry season, mainly due to the abundance of mosquitoes as nuisances and the perceived risk of malaria during the rainy season [43]. This is particularly true for Nigeria, where the transmission of malaria and abundance of mosquito population vary across the seasons of the year. When the perceived malaria risk and mosquito density is high, mosquito nets are highly used. But when the mosquito density coupled with malaria risk is low, people may not see the need for continued mosquito net use.

Therefore, the seasonality of malaria and unavailability of mosquito nets for the needy people with an appropriate price can be the barriers against the high coverage of mosquito net particularly in poor rural communities.
These community factors have to be taken into considerations during the implementation of ITN programmes.

\section{Limitation}

This study was not conducted without a limitation. The study was carried out mainly in urban and peri-urban areas during March and April 2019 the time when malaria problem in the country is low. This could lead the respondents to underestimate the risk for malaria and willingness to purchase mosquito nets. It could have been better to undertake such kind of studies during the peak transmission of malaria both in urban and rural areas to elucidate the heartfelt needs of the community. Nevertheless, this study provides useful information about malaria and ITNs that may be of practical importance.

\section{Conclusion}

In conclusion, the utilization of mosquito nets at the time of this survey was very low. However, acceptability and willingness of the community to use ITNs for malaria prevention was very high. It is expected that the expansion of ITN implementation and increasing its coverage both in the urban and rural malarious areas of the country may lead to the success of malaria control. To this end, it is recommended that communities should be strongly sensitized on the importance of treated mosquito nets for malaria prevention and the availability and affordability should be insured. As regular assessment and monitoring of net possession and use provide the best available means to track progress in coverage with this principal malaria intervention, district level rapid assessments of household possession and usage of nets should be encouraged and supported for program evaluation.

\section{Conflicts of Interest}

The authors declare that they have no conflicts of interest.

\section{Acknowledgments}

I am grateful to thank the study participants and acknowledge the team of research assistants. 


\section{References}

[1] World Health Organization. World malaria report. Geneva, Switzerland. (2011); 32-42.

[2] Bloland Peter B. Drug resistance in malaria. WHO/CDS/CSR/DRS. (2001); 4:1-32.

[3] Ministry of Health. National Five-Year Strategic Plan for Malaria Control in Ethiopia: (2001- 2005). Malaria and Other Vector Borne Diseases Prevention and Control Team, Disease Prevention and Control Department, Ministry of Health, Addis Ababa, (2001).

[4] World Health Organization. A global strategy for malaria control. Geneva, Switzerland, (1993).

[5] World Health Organization. WHO expert committee on malaria: twentieth report. Technical Report Series (No. 892), (2000).

[6] World Health Organization. The Abuja declaration and plan of action: an extract from the African summit on the Roll Back Malaria. WHO/CDS/RBM/2000.17.Geneva. Switzerland, (2000).

[7] Federal Ministry of Health. A road map for malaria control in Nigeria, a bridged version, Abuja. Strategic Plan. (2009-2013); Yahian Press Ltd. 2010; 155

[8] Erhabor O., Adias T.C and M.L. Hart (2010). Effect of falciparum malaria on the indices of anaemia among pregnant women in the Niger Delta of Nigeria. Journal of Clinical Medicine and Research, 2(3):035-041.

[9] Jenavine O. Mbah, Njoku O. O, Agwu U. Nnachi, Ijem A. Nnachi, Amacchi J. Nwinyimagu (2015) Incidence of antenatal malaria parasi-taemia and the effects on the haemoglobin pro-file of the pregnant women in Enugu East Local Government Area, Enugu, Nigeria. American Journal of Epidemiology and Infectious Dis-ease, 3(5): 88-94. [10] Choi, H.W., Breman, J.G., Teutsch, S.M., Liu S, Hightower, A.W. and Sexton, J.D. The effectiveness of insecticide-impregnated bed nets in reducing cases of malaria infection: a meta-analysis of published results. Am J Trop Med Hyg (1995); 52(5): 377-382

[11]Binka F.N., Kubaje, A., Adjuik, M., Williams, M.K, Lengeler, C., Maude, G.H. et al. Impact of permethrin impregnated bed nets on child mortality in Kassena- Nankana district, Ghana: a randomized controlled trial. Trop Med Int Health (1996); 1:147154.

[12] Nevill, C.G, Some, E.S., Mung'ala V.O., Muteme, W., New, L., Marsh K. et al. Insecticidetreated bednets reduce mortality and severe morbidity among children on the Kenyan coast.
Trop Med Int Health (1996), 1:139-146.

[13] Alonso, P.L., Lindsay, S.W., Armstrong, S.J., Konteh, M., Hill, A.G., David, P.H. et al. The effect of insecticide-treated bed nets on mortality of Gambian children. Lancet (1991); 337: 1499-1502.

[14] Alonso, P.L., Lindsay, S.W., Armstrong, S.J., Konteh, M., Keita K., Marshal, C. et al. A malaria control trial using insecticide-treated bed nets and targeted Chemoprophylaxis in a rural area of The Gambia, West Africa 5: design and implementation of the trial. Trans R Soc Trop Med Hyg (1993); $87: 31-36$.

[15]D'Alenssadro, U., Olaleye, B.O., McGuire, W., Langerock, P., Bennet, S., Aikins, M.K. et al. Mortality and morbidity for malaria in Gambian children after introduction of an impregnated bed net program. Lancet (1995); 345: 479-483.

[16] Greenwood BM, Bojang K, Whitty CJ, Targett GA. Malaria. Lancet (2005);365(9469):1487-98.

[17]Lengeler C. Insecticide-treated nets for malaria control: real gains. Bulletin of the World Health Organization. (2004); 82:84.

[18]Ministry of Health/UNICEF in Ethiopia. GUIDE for program managers on the use of insecticide-treated nets in Ethiopia. July (2002).

[19] Okrah J, Traore C, Pale A, Sommerfeld J and Müller O. Community factors associated with malaria prevention by mosquito nets: an exploratory study in rural Burkina Faso. Tropical Medicine and International Health (2002); 7 (Issue 3): 240.

[20]Nahlen BL, Clark JP, and Alnwick D. Insecticide- treated Bed Nets. Am J Trop Med Hyg (2003);68(suppl 4):1-2.

[21]Abdulla S, Gemperli A, Mukasa O, et al. Spatial effects of the social marketing of insecticide-treated nets on malaria morbidity. Trop. Med Int. Health (2005); 10(1):11-8.

[22]Adongo PB, Kirkwood B, Kendall C. How local community knowledge about malaria affects insecticide-treated net use in northern Ghana. Trop. Med. Int. Health (2005); 10(4):366-78.

[23]Rowland M, Webster J, Saleh P, et al. Prevention of malaria in Afghanistan through social marketing of insecticide-treated nets: Evaluation of coverage and effectiveness by cross-sectional surveys and passive surveillance. Tropical Medicine and International Health (2002); 7(issue 10):813.

[24] Phillips-Howard PA, Nahlen BL, Alaii JA, et al. The efficacy of permethrin treated bed nets on child mortality and morbidity in western Kenya I. 
Development of infrastructure and description of study site. Am. J. Trop. Med. Hyg. (2003);68(4 suppl):3-9.

[25]Ter Kuile FO, Terloun DJ, Kariuki SK, et al. Impact of Permethrin Treated Bed Nets on Malaria, Anemia and Growth in Infants in an Area of Intense Perennial Malaria Transmission in Western Kenya. Am. J. Trop. Med. Hyg. (2003): 68(4 suppl): 68-77.

[26]Gamble C, Ekwaru JP, Ter Kuile FO. Insecticide- treated nets for preventing malaria inpregnancy. Cochrane Database of Syst Rev. (2006) Apr 19; (2): CD003755.

[27]Negash K, Jima D, Nafo-Traore F, et al. Ethiopian Roll Back Malaria Consultative Mission: Essential Actions to Support the Attainment of the Abuja Targets. $16^{\text {th }}$ to $20^{\text {th }}$ February (2004).

[28] Anyanwu EC, Ehiri JE, Kanu I, Morad M, Ventegodt S, Merrick J. Assessing the effects of long-term exposure to insecticide treated mosquito nets in the control of malaria in endemic regions. Scientific world Journal (2004); 4:97888.

[29]Roll Back Malaria. (2001-2010) United Nations Decade to Roll Back Malaria: Insecticidetreated Mosquito Nets. RBM info sheet. Accessed through: http://www.rbm.who.int. (Accessed on: 15/ 08/ 2006).

[30]Abuja Declaration and the Plan of Action: An Extract from the African Summit on Roll Back Malaria, Abuja, 25 April (2000) (WHO/CDS/RBM/ 2000.17). Available at: http://www.rbm.who.int/docs/abuja_declaration_f inal.htm. (Accessed on: 15/ 08/ 2006).

[31] Worrall E, Hill J, Webster J, and Mortimer J. Experience of targeting subsidies on insecticidetreated nets: What do we know and what are the knowledge gaps? Trop. Med. Int. Health (2005); 10(1): 19-31.

[32]Hill J, Lines J, Rowland M. Insecticidetreated nets. Adv Parasitol. (2006); 61:77-128.

[33]Net Mark research (1999-2006). Available at: http://www.netmarkafrica.org/research. (Accessed on: 15/ 08/2006).
[34]Macintyre K, Keating J, Okbaldt YB, et al. Rolling out insecticide treated nets in Eritrea: examining the determinants of possession and use in malarious zones during rainy seasons. Trop Med Int Health. (2006) Jun; 11(6): 824-33.

[35] Tsuyuoko R, Midizi SM, Dziva P, Makunike B. The acceptability of insecticide treated mosquito nets among community members in Zimbabwe. Cent Afr J Med. (2002) Jul-Aug; 48 (7-8):87-91.

[36]Morgan DW and Krejcie, RV. (1970). Determining Sample size for research activities of Minnesota: USA.

[37]Deressa, W., Ali, A., Enquosellassie F. Knowledge, attitude and practice about malaria, the mosquito and antimalarial drugs in a rural community. Ethiop J Health Dev (2003); 17(2): 99104.

[38] Yeneneh, H., Gyorkos, T.W., Joseph, L., Pickering, J. and Tedla, S. Antimalarial drug utilization by women in Ethiopia: a knowledgeattitudes-practice study. Bull World Health Org (1993); 71: 763-772.

[39] Ongore, D., Kamunvi, F., Knight, R., and Minawa, A. A study of knowledge, attitudes and practices (KAP) of a rural community on malaria and the mosquito vector. East Afr Med J (1989); 66(2): 79-89.

[40] Klein, R.E., Weller, S.C., Zeissig, R., Richards, F.O. and Ruebush, T.K. Knowledge, beliefs, and practices in relation to malaria transmission and vector control in Guatemala. Am J Trop Med Hyg (1995); 52(5): 383-388.

[41] Gebreyesus, T.A., Witten, K.H., Getachew, A. et al. The community-based malaria control in Tigray, northern Ethiopia. A review of programme set-up, activities, outcomes and impact. Parasitologia (2000); 42: 255-240.

[42] Kidane, G. and Morrow, R.H. Teaching mothers to provide home treatment of malaria in Tigray, Ethiopia: a randomized trial. Lancet (2000); 356(9229): 550-555.

[43]Binka, F.N. and Adonso. P. Acceptability and use of insecticide impregnated bed nets in northern Ghana. Trop Med Int Health (1997); 2(5): 499-507. 


\title{
Cost-Benefit Analysis during Lockdown and Health Belief Model (HBM) of COVID-19 Pandemic in Ogun State, South-Western Nigeria
}

\author{
Oni, Olawale Bashir-Ud-Deen \\ Department of Public Health, Texila American University, Guyana, USA
}

\begin{abstract}
Due to unprecedented threat to the economy and the quality of life caused by the COVID-19 pandemic, this study focused on cost-benefit analysis during the lockdown of COVID-19 and the health belief model of COVID-19 pandemic in Ogun State, Nigeria. A total of 2400 copies of the questionnaire were administered to solicit information from the respondents using systematic random sampling technique on the targeted population while 2363 copies were retrieved and analyzed using descriptive statistics. The findings of the study revealed that the lockdown had negative impacts on health, economic, and social impacts. Results showed that $50.7 \%$ of the respondents spent no time going to the market and/or work during COVID-19, and this made $81.9 \%$ of them unable to gain extra gain during the lockdown as they were completely restricted for activities. The lockdown had impacts on socioeconomic activities as the prices of consumable goods increased due to the low supply. $71.8 \%$ of the respondents indicated that the government did not provide palliative measures for the households. The results further showed that everyone could be infected with COVID-19 as $86.0 \%$ of respondents indicated. $48 \%$ revealed that COVID-19 drugs were unavailable and prayers from religious leaders could not cure COVID-19. Besides, $65.5 \%$ were able to follow the basic measures put in place to reduce the spread of COVID-19 in the study area. This study concluded that necessary things should be put in place to ease the affairs of the populace before any other lockdown measure is made.
\end{abstract}

Keywords: Cost-Benefit, COVID-19, Health Beliefs, Nigeria.

\section{Introduction}

COVID-19, an acronym derived from "coronavirus disease 2019" by World Health Organisation (WHO) on February 11, 2020, has been declared and recognized as a global health emergency [1, 2], and a global pandemic [3]. These viruses are closely associated with infections such as pneumonia, the common cold, and conditions like severe acute respiratory syndrome (SARS) and Middle East Respiratory Syndrome (MERS). The most common ways the virus spreads from an infected person to healthy people is when they cough or sneeze and release viral particles into the air and through touching, shaking hands, and other forms of close personal contact [4].

To mitigate the spread of the COVID-19 pandemic, basic precautions were made, including the lockdown approach at many places in Nigeria and other parts of the world. The lockdown measure is highly restrictive on social freedoms and damaging to the economy.
Lockdown is described as the restriction of travels, closing of schools and nonessential businesses, banning social gatherings, and asking citizens to shelter in place [5]. Governments have had difficult choices to make on the best approach for their countries to contain the spread of COVID-19. No matter how wealthy a nation or country is, in the containment and mitigation of the global COVID-19 pandemic, it would eventually have a profound impact on the economy of the world, especially in low- and middle-income nations of the world. These measures may also affect the quality of life of many people in the world.

Furthermore, spiritualism has a significant impact on the health of individuals. Some religions, for example, dictate dietary laws and hygiene practices. It is unimaginable when an individual with a second degree level of education still creates ignorance of COVID-19 because he or she believes prayers work better than anything (e.g. Drugs) in control of the 
diseases. Such belief is completely odd and eventually results in complications such as sudden death, and total family disarray, and eventual greater economic loss. However, religious beliefs should not be a deterrence to medical care. Beliefs are described by [6] as a crucial link between socialization and behaviour; an enduring individual characteristic that shapes behaviour and can be acquired through primary socialization; and a modification that can differentiate between individuals from the same background.

The Health Belief Model (HBM) is recognized as the most widely applied, explanatory model in preventive health behaviour research [7, 8, 9]. Studies have shown that socioeconomic status, gender, ethnicity, and age which constitute demographic characteristics were known to be associated with preventive health-related behaviour patterns as well as differential use of health services [6]. Few studies have recently been conducted on the COVID-19 pandemic, but little or no studies have been conducted on cost-benefit analysis and the Health Belief Model of COVID-19 pandemic in Nigeria and any other part of the world. Therefore, this study focused on cost-benefit analysis during the lockdown and Health Belief Model (HBM) of COVID-19 pandemic in Ogun State, SouthWestern Nigeria. This is especially appropriate at this time in Nigeria because of its economic impact on the beliefs of people in the country.

\section{Health Belief Model}

The main characteristic of the Health Belief Model (HBM) is its emphasis on perception and motivation, thus reflecting the strong influence of Kurt Lewin's field theory [10, 11]. The model serves as a tool that scientists used to try and predict health behaviours. It was originally developed in the 1950s by psychologists Godfrey Hochbaum, Irwin Rosenstock and Stephen Regels working in the US Public Health Service [12, 13], and was updated in the 1980s [14].

The model is based on the theory that a person's willingness to change their health behaviours. The HBM suggests that a person's belief in a personal threat of an illness or disease together with a person's belief in the effectiveness of the recommended health behaviour or action will predict the likelihood the person will adopt the behaviour. According to the model, six primary variables influence a person's choice (Figure. 1). Four variables such as perceived susceptibility to ill-health (risk perception), perceived severity of ill-health (seriousness), perceived benefits of behaviour change (benefits), and barriers were included when the model was initially developed by [12, 15, 13]. It is indicated in Figure 1 that there were no clear guidelines on how to operationalize the links between perceived susceptibility, severity, and overall threat perception.

In general, the health belief model is a theoretical structure developed to explain why and under what conditions people will take preventive actions. In this study, the Health Belief Model (HBM) was used as the theoretical framework to identify and measure the level of concern for COVID-19 risk from religious faith and the reasons for not regularly engaging in preventive health behaviours. 


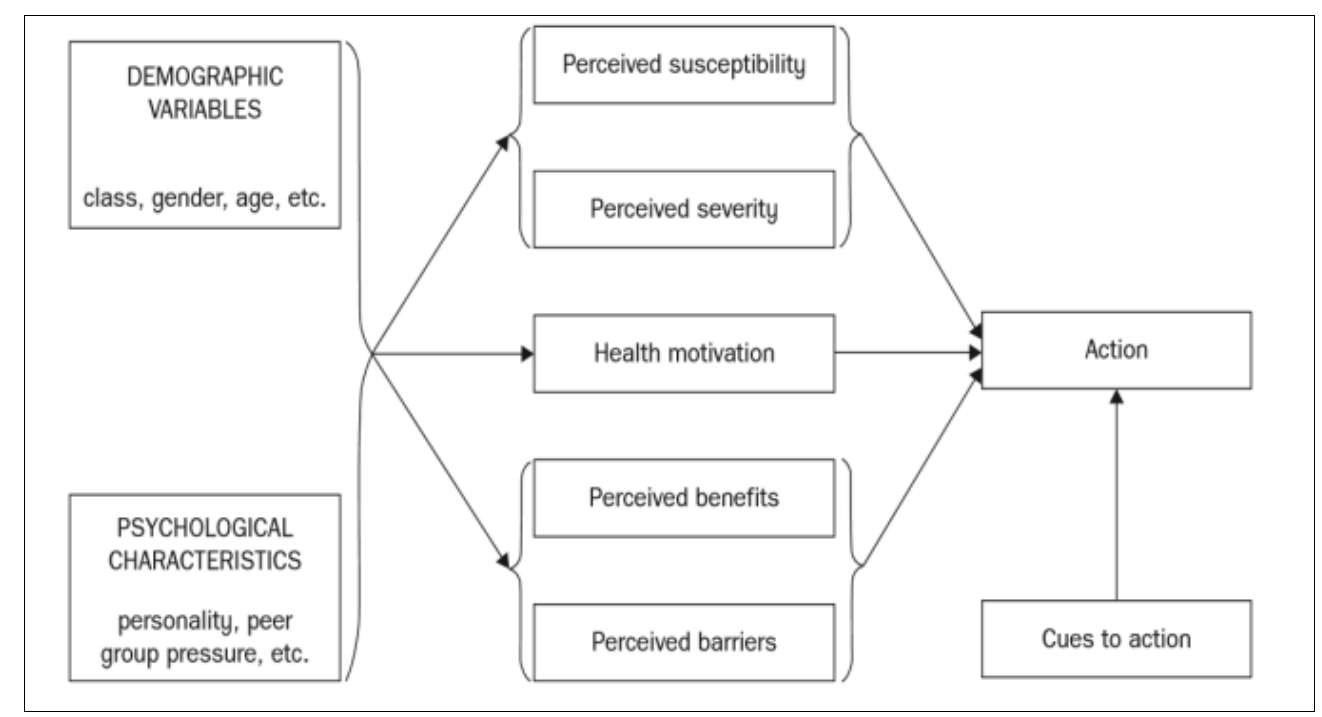

Figure 1. Health Belief Model

\section{Materials and Methods}

The study area was confined to Ogun State, Nigeria. Ogun State is one of the fastest developing states in the country. It lies in the southwestern part of the country between latitudes $6.2^{\circ} \mathrm{N}$ and $7.8^{\circ} \mathrm{N}$ of the equator, and longitudes $3.0^{\circ} \mathrm{E}$ and $5.0^{\circ}$ East of the Greenwich Meridian south (Figure. 2). Ogun State occupies an area of $16,980.55 \mathrm{~km}^{2}$, and a population of $3,751,140$, with a density of $220 / \mathrm{km}^{2}$ [16]. The State is bounded on the west by the Republic of Benin and the east by Ondo State. To the north is Oyo State, while Lagos State and the Atlantic Ocean are to the south. The geographical location of the State makes it accessible to the economically developed regions in Nigeria. Ogun State is made up of 20 Local Government Areas (Figure. 2).

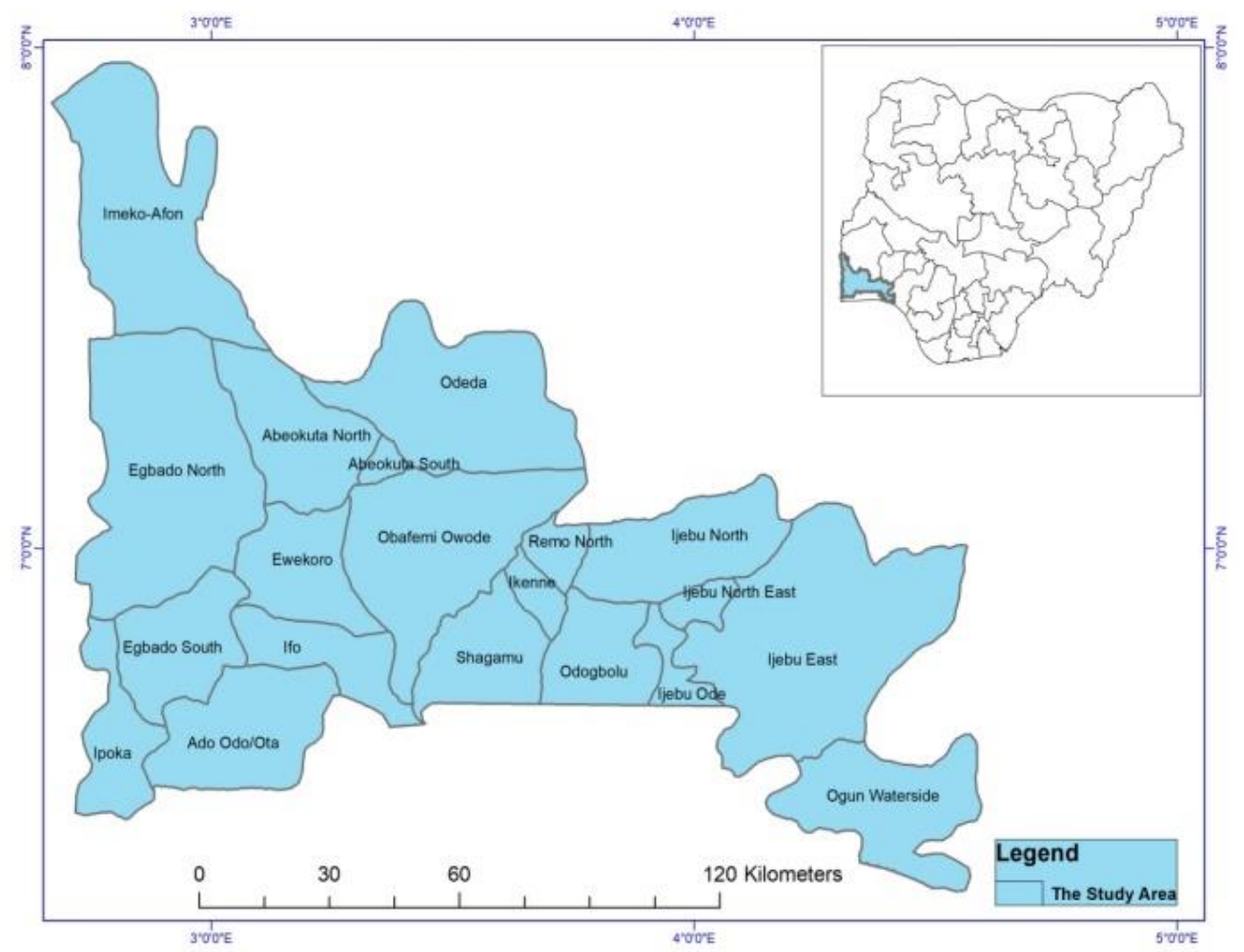

Figure 2. Ogun State, the Study Area 
Data used in this study were collected from primary sources. The primary source of data was collected through the use of a questionnaire. The target sample population was religious goers who were between the ages of 15 and above, and also the residents of the study area. The 2006 total population of the study area was 3, 751, 140 [16]. If the population growth rate would be the same as in the period 2006-2011 (3.36\%/year), the projected total population of the study area in the year 2020 will be 5, 954, 097 [17]. The ever increasing demand for research has created a need for an efficient method of determining the sample size needed to be representative of a given population. The determination of the sample size involves disregarding sampling error. For a sample to be accurate and errorfree, it must be optimum in size and representative enough. The sample size of 2400 was used based on the online sample size calculator by Raosoft, Inc. [18]. The sample size was calculated using the projected population $(5,954,097)$ for the year 2020 , with $2 \%$ margin of error, $95 \%$ confidence level, and $50 \%$ response distribution. A detailed and wellstructured questionnaire was designed and a total of 2400 copies of the questionnaire were administered using systematic random sampling techniques on the targeted population from all the 20 Local Government Areas of the State, who voluntarily walked in for services on Friday or Sunday. 2363 copies of the questionnaire were returned and analyzed using descriptive statistics. Statistical Package for Social Sciences (SPSS) version 23 was used for the analyses while the results were presented in frequencies tables, graphs, pie and bar charts, where applicable.

\section{Results}

\section{Socio-demographic Characteristics of the Respondents}

Table 1 and Figures $3-6$ present the demographic characteristics of the respondents in the study area. In table 1, 2299 (97.3\%) of respondents were Nigerians by nationality. Of all the total respondents considered in this study, $53.8 \%$ of respondents were male, while $46.2 \%$ were female. The majority of the respondents $72(30 \%)$ were between the ages 25 and 34 , while the least age group was $1.3 \%$ representing only 30 respondents between the ages of 75 and above in the study area. Of all the total respondents, $1090 \quad(46.1 \%)$ were married and a total of 1084 respondents representing $(45.9 \%)$ were single.

Only $2.5 \%$ of the total respondents did not have formal education, while the number of respondents with secondary and university education constituted larger percentages with $30.9 \%$ and $20.8 \%$ respectively. A very small number of the respondents which represents $0.3 \%$ belonged to none of the three major religions. A total of 1603 which represents $67.8 \%$ worshiped God since they were born, while only 24 respondents representing 1\% started worshipping God less than 5 years ago.

Figure. 3 shows that majority of the respondents which represent $80 \%$ of the sampled population were residents of Ogun State, the study area while others were $20 \%$ of the respondents were non-residents. Teachers and other professions constituted larger percentages of the respondents in the study area (Figure. 4). The percentages of respondents from different Local Government Areas in the study area were presented in Figure. 5. Figure. 6 shows that $2193(92.8 \%)$ were Yoruba, 103 (4.4\%) were Igbo, while Hausa constitutes 50 (2.1\%) of ethnic groups.

Table 1. Social-Demographic Characteristics

\begin{tabular}{|l|l|l|l|}
\hline Demographic Characteristics & Frequency & Percent (\%) \\
\hline \multirow{2}{*}{ Nationality } & Nigerian & 2299 & 97.3 \\
\cline { 2 - 4 } & Others & 64 & 2.7 \\
\hline \multirow{2}{*}{ Sex } & Male & 1271 & 53.8 \\
\cline { 2 - 4 } & Female & 1092 & 46.2 \\
\hline \multirow{2}{*}{ Age Bracket } & $15-24$ & 648 & 27.4 \\
\cline { 2 - 4 } & $25-34$ & 729 & 30.9 \\
\hline
\end{tabular}




\begin{tabular}{|c|c|c|c|}
\hline & $35-44$ & 471 & 19.9 \\
\hline & $45-54$ & 287 & 12.1 \\
\hline & $55-64$ & 156 & 6.6 \\
\hline & $65-74$ & 42 & 1.8 \\
\hline & $\begin{array}{l}75 \text { and } \\
\text { above }\end{array}$ & 30 & 1.3 \\
\hline \multirow[t]{6}{*}{ Marital Status } & Single & 1084 & 45.9 \\
\hline & Married & 1090 & 46.1 \\
\hline & Divorced & 62 & 2.6 \\
\hline & Separated & 47 & 2.0 \\
\hline & Widow & 38 & 1.6 \\
\hline & Widower & 42 & 1.8 \\
\hline \multirow[t]{7}{*}{$\begin{array}{l}\text { Level of } \\
\text { Education }\end{array}$} & $\begin{array}{l}\text { No Formal } \\
\text { Education }\end{array}$ & 60 & 2.5 \\
\hline & Primary & 108 & 4.6 \\
\hline & Secondary & 731 & 30.9 \\
\hline & $\begin{array}{l}\text { Col. of } \\
\text { Education }\end{array}$ & 262 & 11.1 \\
\hline & Polytechnic & 317 & 13.4 \\
\hline & University & 492 & 20.8 \\
\hline & $\begin{array}{l}\text { Post } \\
\text { Graduate }\end{array}$ & 393 & 16.6 \\
\hline \multirow[t]{4}{*}{ Religion } & Islam & 1388 & 58.7 \\
\hline & Christianity & 899 & 38.0 \\
\hline & Traditional & 69 & 2.9 \\
\hline & Others & 7 & .3 \\
\hline \multirow{5}{*}{$\begin{array}{l}\text { Years of } \\
\text { worshiping God }\end{array}$} & $<5$ years & 24 & 1.0 \\
\hline & $5-10$ years & 154 & 6.5 \\
\hline & $\begin{array}{l}11-20 \\
\text { years }\end{array}$ & 154 & 6.5 \\
\hline & $>20$ years & 428 & 18.1 \\
\hline & since birth & 1603 & 67.8 \\
\hline
\end{tabular}

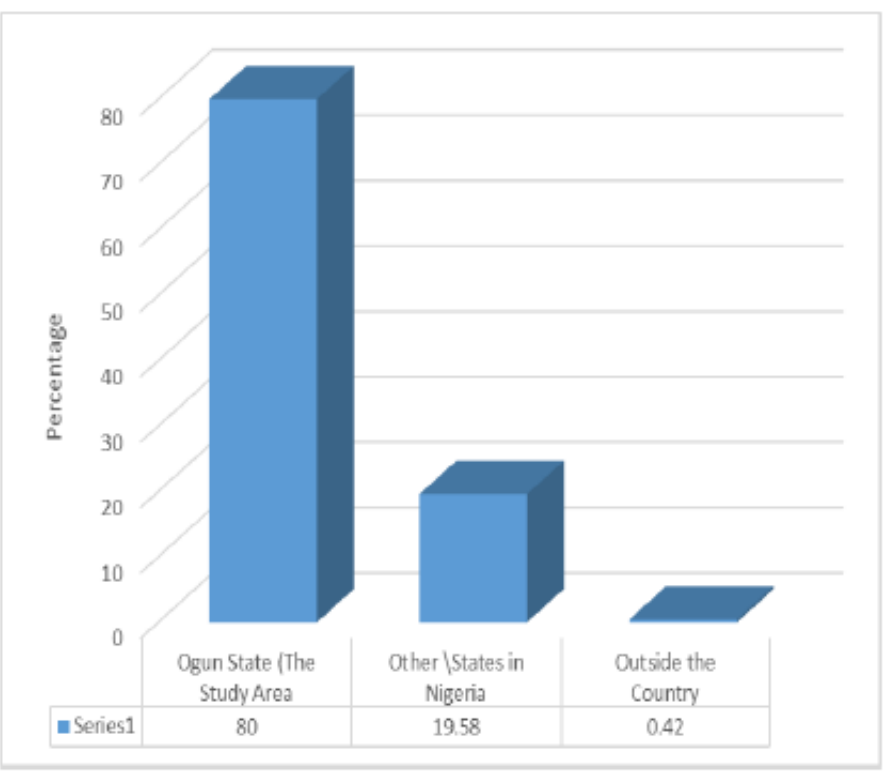

Figure 3. State of Residence 


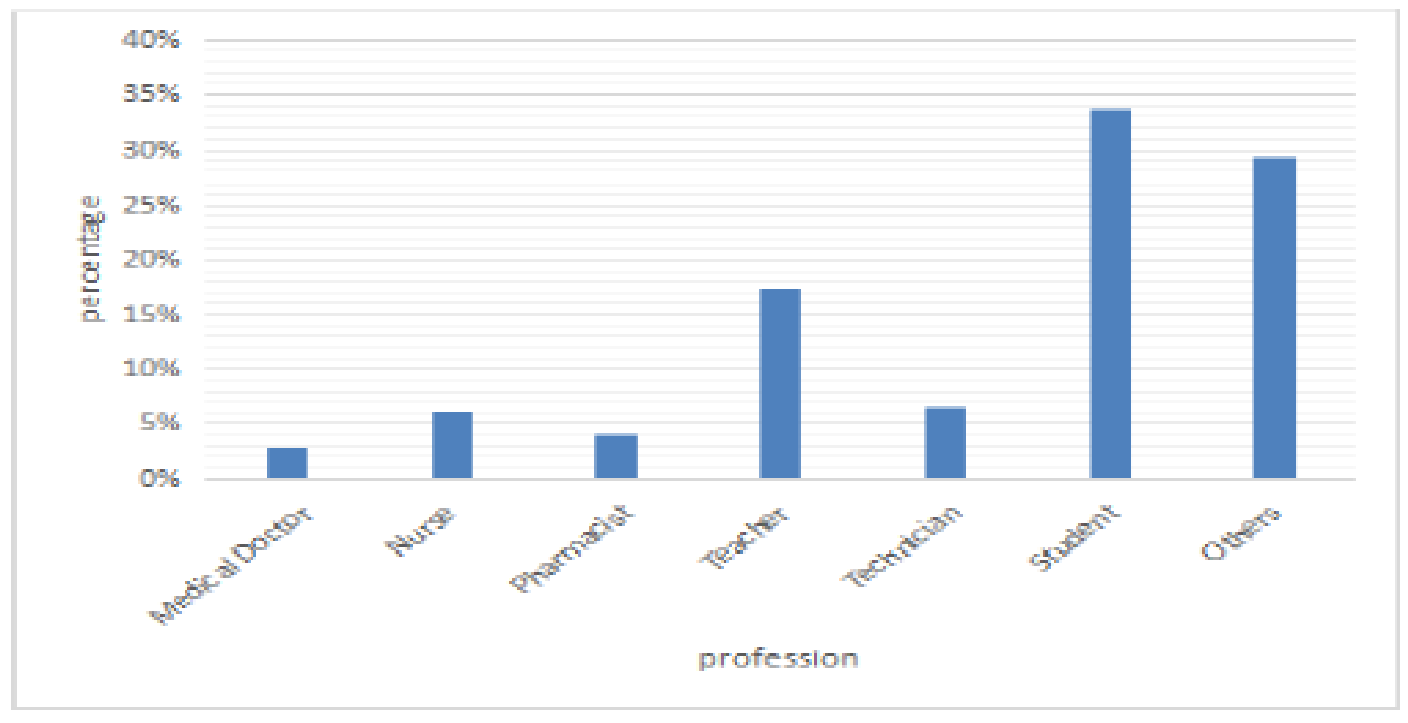

Figure 4. The Profession of Respondents in the Study

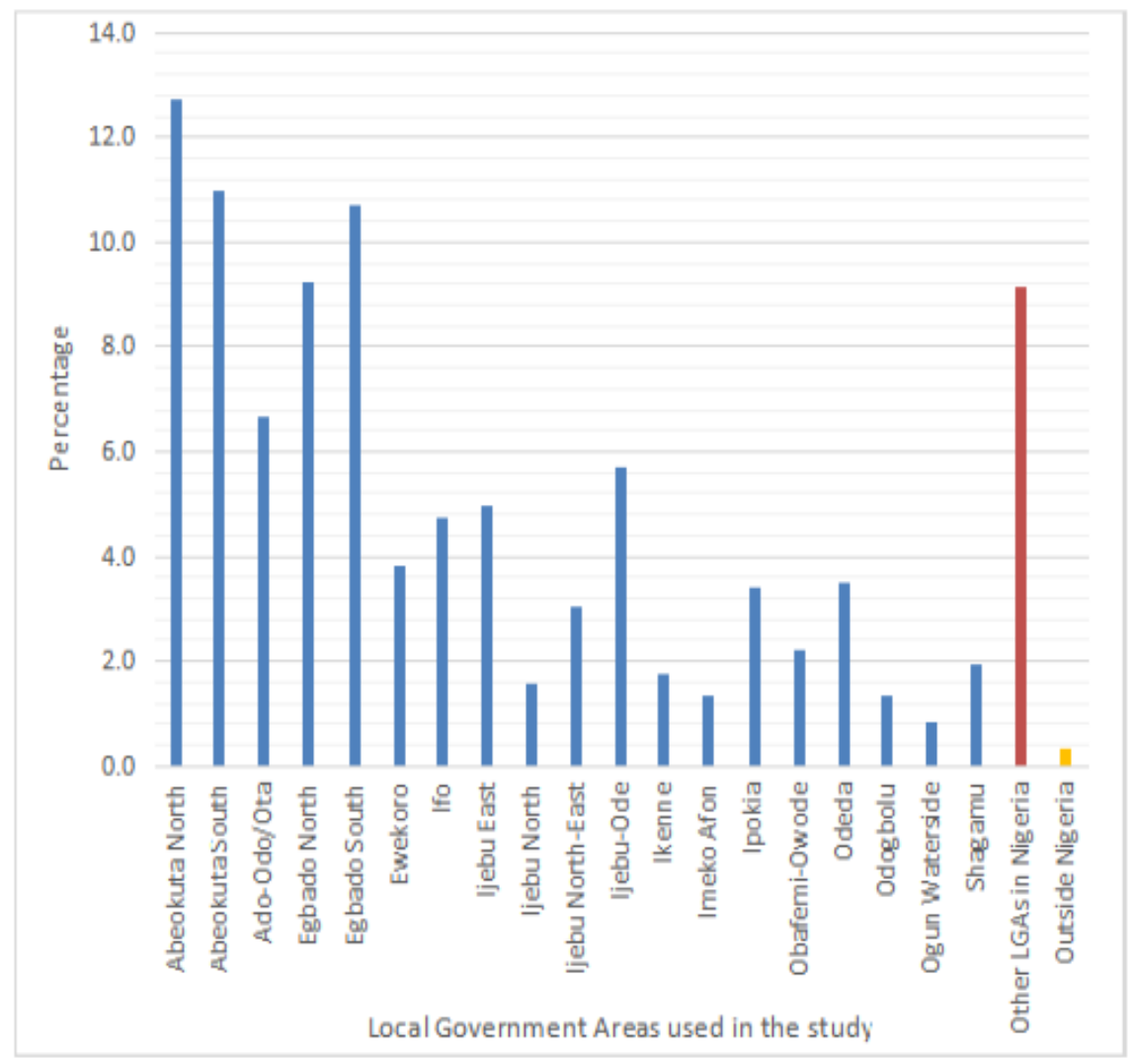

Figure 5. Local Government Areas used in the Study 


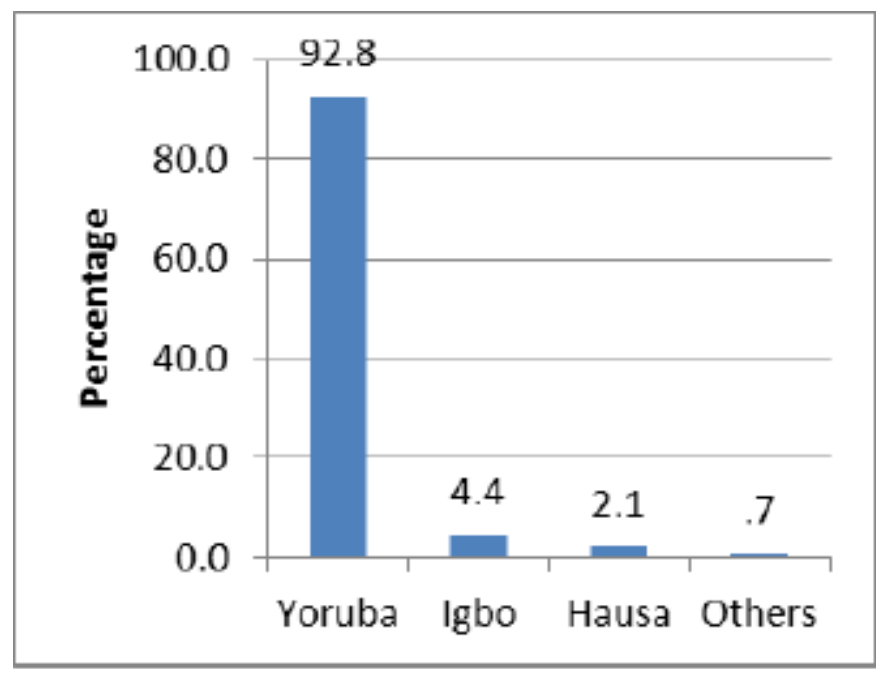

Figure 6. Ethnic Groups' Distribution of the Respondents

\section{Time and other Costs during the Lockdown}

During the lockdown, 1198 (50.7\%) of the respondents spent no time to and fro of the market or the place of work, while $17.9 \%$ and $19.3 \%$ of the respondents spent $1-2$ hours and 3-5 hours respectively (Figure. 7). In Figure 8, the least percentage $(7.2 \%)$ of the respondents showed that there was a percentage increment in the prices of consumable goods ranged between 101 and $300 \%$. The majority, 812 $(34.3 \%)$ of the respondents indicated that the prices of consumables increased between 21 and $40 \%$ (Figure. 8). Figure. 9 shows that $81.1 \%$ which represents 1913 respondents revealed that the cost of living during the lockdown was not suitable. Figure. 10 shows that a larger percentage (71.8\%) which represents 1697 of the total respondents indicated that the government did not provide palliative measures for the households. Table 2 presents the results of the extra profit and loss got by the respondents during the lockdown.

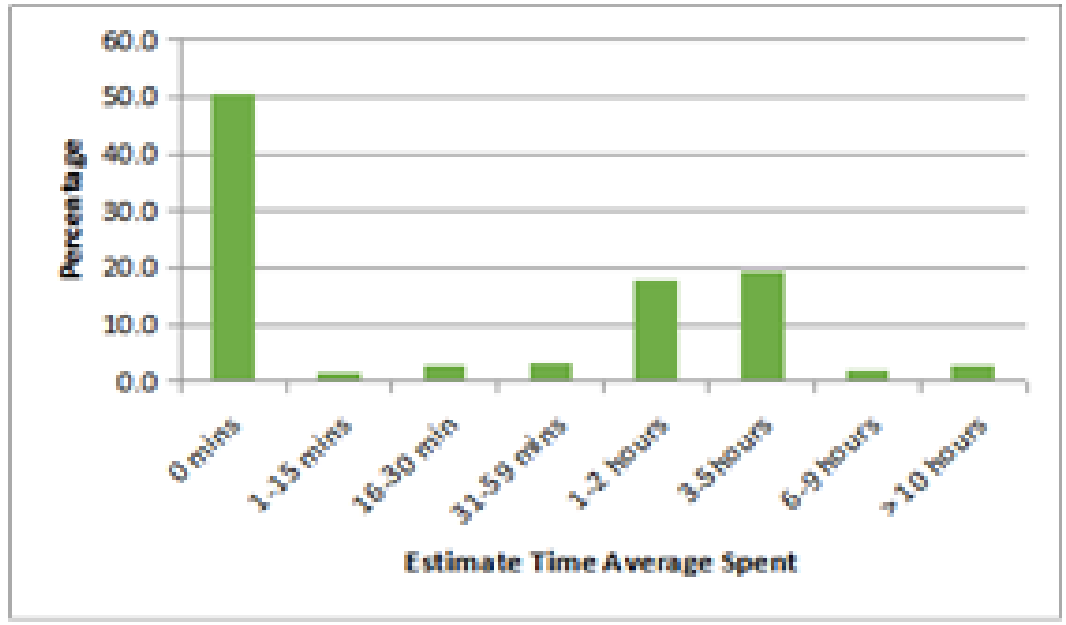

Figure 7. Estimated Time Average Spent to and Fro during the Lockdown 


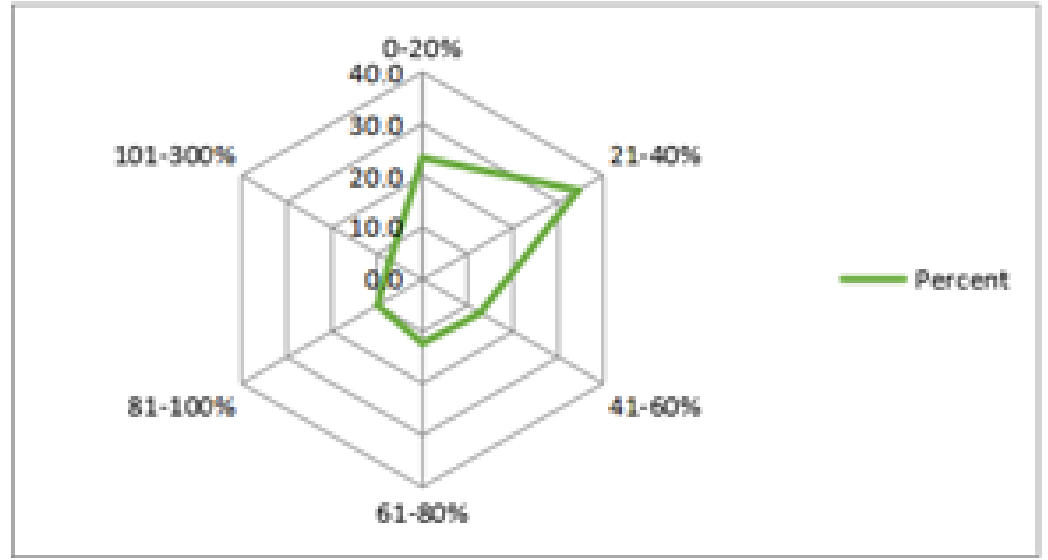

Figure 8. Percentage of Increments in Price of Consumables during the Lockdown

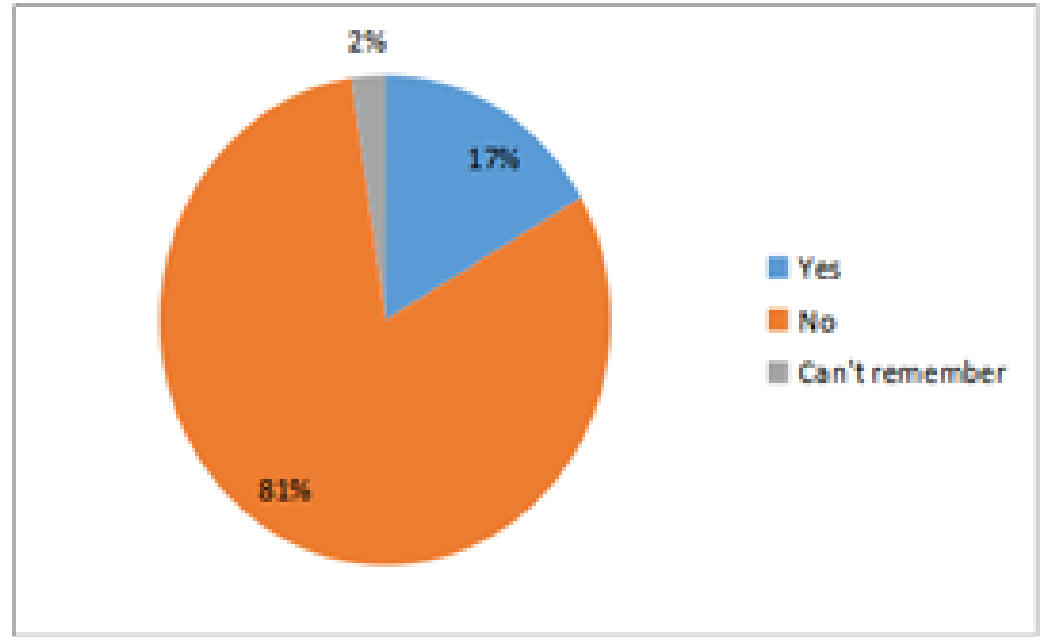

Figure 9. Suitability of Cost of Living During Lockdown

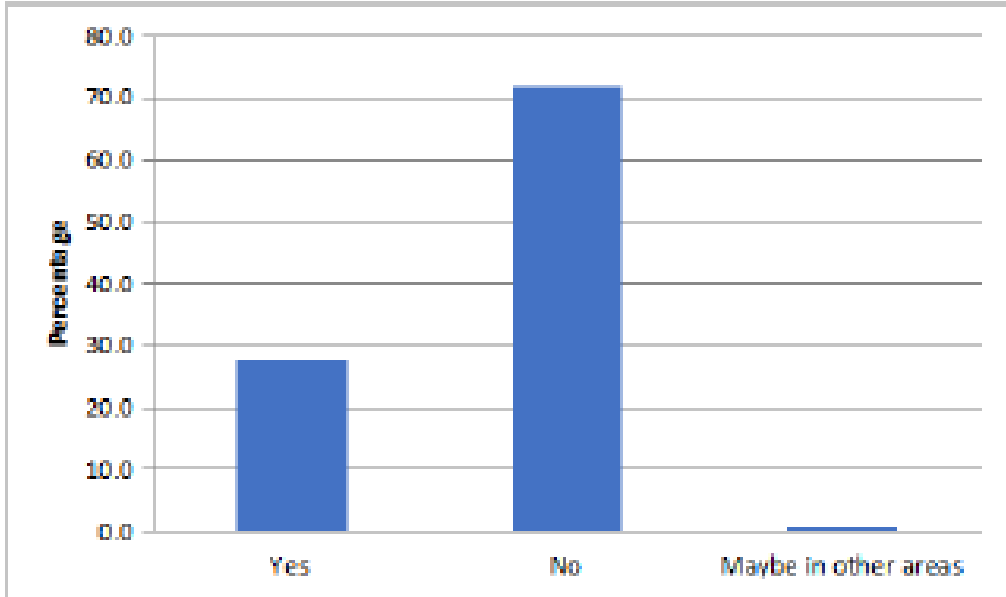

Figure 10. Palliative Measure by the Government

Table 2. Extra Income/Loss got during the Lockdown

\begin{tabular}{|l|l|l|l|}
\hline \multicolumn{2}{|c|}{} & Frequency & Percent \\
\hline \multirow{3}{*}{ Profit/Loss } & Yes & 428 & 18.1 \\
\cline { 2 - 4 } & No & 1935 & 81.9 \\
\cline { 2 - 4 } & Total & 2363 & 100.0 \\
\hline
\end{tabular}




\section{Health Belief Model (HBM) of COVID- 19 Pandemic}

\section{Perceived Susceptibility}

In table 3 , respondents clearly showed that $2031(86.0 \%)$ can be infected with COVID-19 including pastors, imams, and traditionalists while $1628(68.9 \%)$ of respondents were not at risk of COVID-19. $31.1 \%$ of the respondents stated that they were at risk of COVID-19. The majority of 1145 (48.5\%) of respondents showed that people can have COVID-19 without feeling its signs and symptoms. 1689 $(71.5 \%)$ of respondents revealed that COVID19 is not a curse from God and the majority $1689(71.5 \%)$ of respondents showed that COVID-19 is not handwork of evils-doers.

Table 3. Perceived Susceptibility

\begin{tabular}{|l|l|l|l|}
\hline Demographic Characteristics & Yes & No & \multirow{2}{*}{ Don't know } \\
\hline $\begin{array}{l}\text { Everybody can get COVID-19 } \\
\text { including pastors, imams and } \\
\text { traditionalists }\end{array}$ & 2031 & 332 & \multirow{2}{*}{-} \\
\cline { 2 - 4 } & $(86.0 \%)$ & $(14 \%)$ & \\
\hline Risk of COVID-19 & 735 & 1628 & - \\
\cline { 2 - 4 } & $(31.1 \%)$ & $(68.9 \%)$ & \\
\hline $\begin{array}{l}\text { People can have COVID-19 without } \\
\text { feeling its signs and symptoms }\end{array}$ & 1145 & 799 & 419 \\
\cline { 2 - 3 } & $(48.5 \%)$ & $(33.8 \%)$ & \multirow{2}{*}{$17.7 \%)$} \\
\hline COVID-19 is a curse from God & 674 & 1689 & \multirow{2}{*}{-} \\
\cline { 2 - 4 } & $(28.5 \%)$ & $(71.5 \%)$ & \\
\hline \multirow{2}{*}{$\begin{array}{l}\text { COVID-19 is a handwork of evils- } \\
\text { doers }\end{array}$} & 999 & 1364 & - \\
\cline { 2 - 3 } & $(42.3 \%)$ & $(57.7 \%)$ & \\
\hline
\end{tabular}

\section{Perceived Severity}

Figure. 11 shows that $52 \%$ of the respondents stated that COVID-19 drugs were available, while $48 \%$ revealed that COVID-19 drugs were unavailable. The responses of respondents that indicated that COVID-19 drugs are available might be medicinal herbs used to cure coldrelated illness. It was shown that COVID-19 is can lead to death as a larger percentage (84.1\%) of respondents indicated that COVID-19 could lead to death (Figure.12). A large number of the respondents constituting $1149(48.6 \%)$ revealed that prayers from religious leaders can not only cure COVID-19, while $21.8 \%$ of the respondents showed that the prayers from religious leaders may cure COVID-19 (Figure. 13).

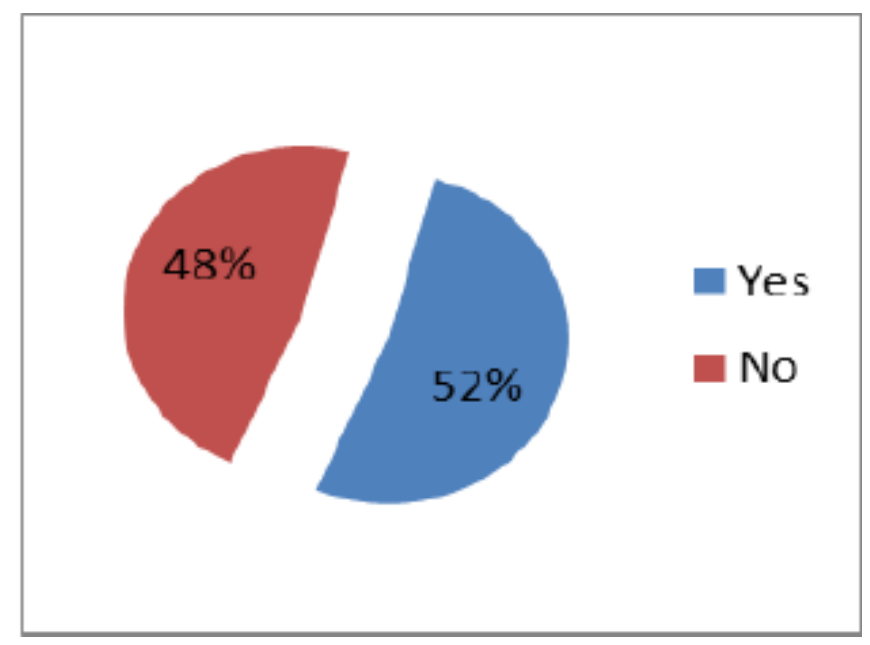

Figure 11. Availability of COVID-19 Drug 


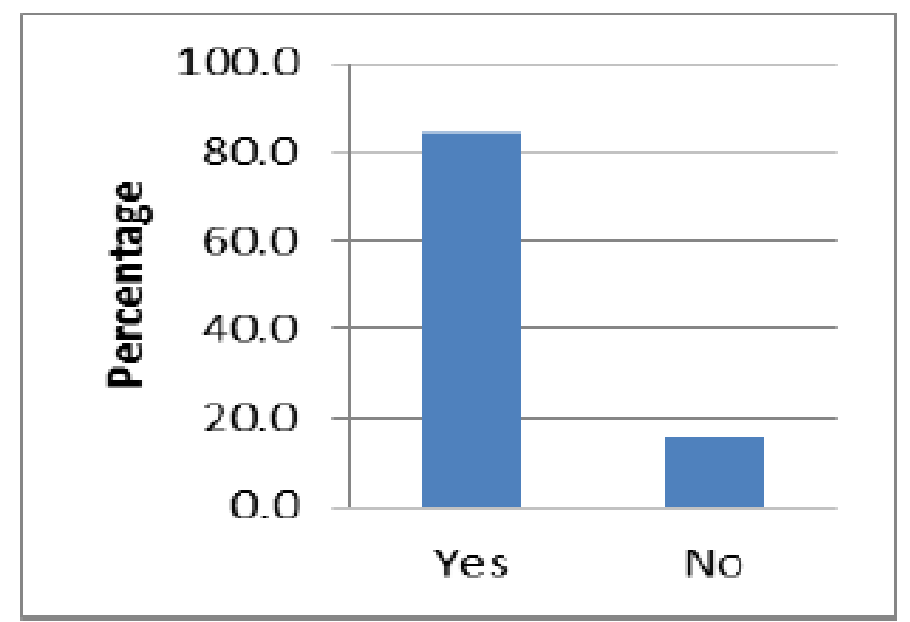

Figure 12. Death as an End Result of COVID-19

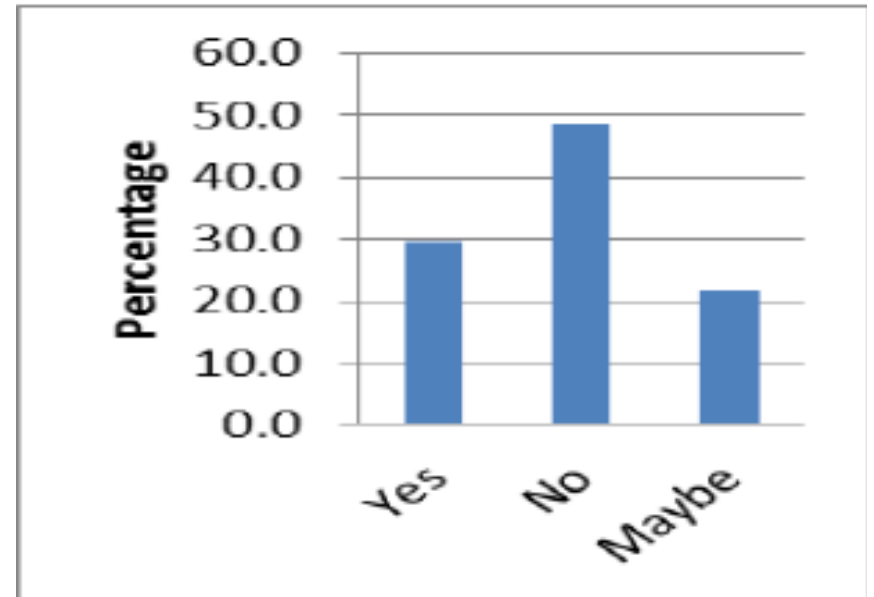

Figure 13. Prayers from Religious Leaders as Cure of COVID-19

\section{Perceived benefits}

In table 4 , it is shown that the three basic measures to prevent the spread of COVID-19 were largely shown by respondents in the study area. $1823(77.1 \%)$ of respondents showed that avoidance of social gathering can prevent the spread of COVID-19, 1993 (84.3\%) of respondents believed in regular hand washing as a measure to prevent the spread of COVID19 , while only 486 (20.6\%) of respondents believed that use of face mask cannot prevent a person from having COVID-19.

Table 4. Perceived Benefits

\begin{tabular}{|l|l|l|l|}
\hline Demographic Characteristics & Yes & No & Don't know \\
\hline $\begin{array}{l}\text { Avoidance of social gathering can } \\
\text { prevent the spread of COVID-19 }\end{array}$ & 1823 & 292 & 248 \\
\cline { 2 - 3 } & $(77.1 \%)$ & $(12.4 \%)$ & $(10.5 \%)$ \\
\hline $\begin{array}{l}\text { Believe in regular hand washing as a } \\
\text { preventive measure to the spread of } \\
\text { COVID-19 }\end{array}$ & 1993 & 370 & - \\
\cline { 2 - 3 } & $(84.3 \%)$ & $(15.7 \%)$ & \\
\hline $\begin{array}{l}\text { The use of a face mask can prevent a } \\
\text { person from having COVID-19 }\end{array}$ & 1877 & 486 & - \\
\cline { 2 - 3 } & $(79.4 \%)$ & $(20.6 \%)$ & \\
\hline
\end{tabular}




\section{Perceived barriers and self-efficacy}

In Figure. 14, 64\% of the respondents preferred going to Churches and/or Mosques to use face masks, while $42 \%$ which represents 993 of the respondents did not have time to use face masks during COVID-19 (Figure. 15). Only $58 \%$ had time to use a face mask or shield. Figure 16 presents how convenient was the face mask or shield to the daily activities of the respondents during COVID-19. The larger percentage of the respondents $(72.4 \%)$ which represents a total of 1710 of the targeted population was not convenient with the use of face masks while a small proportion (3.6\%) of the respondents found it very convenient during COVID-19 (Figure. 16). For not allowing social gatherings during COVID-19, a total of 1165 (49.3\%) of the respondents felt bad for not attending or gathering for social gatherings during COVID-19 (Table 5). In Figure. 17, $79.3 \%$ of the respondents were not satisfied to go to clubbing whenever they felt stressed out or bored during COVID-19.

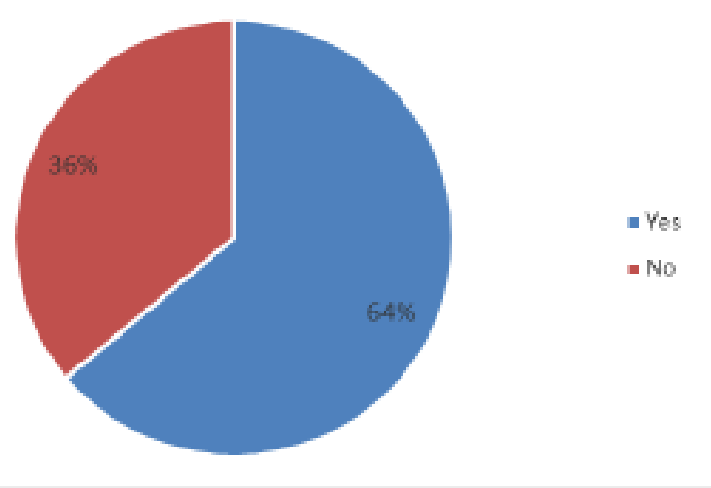

Figure 14. Preference to go to Churches and Mosque instead of using Face Masks

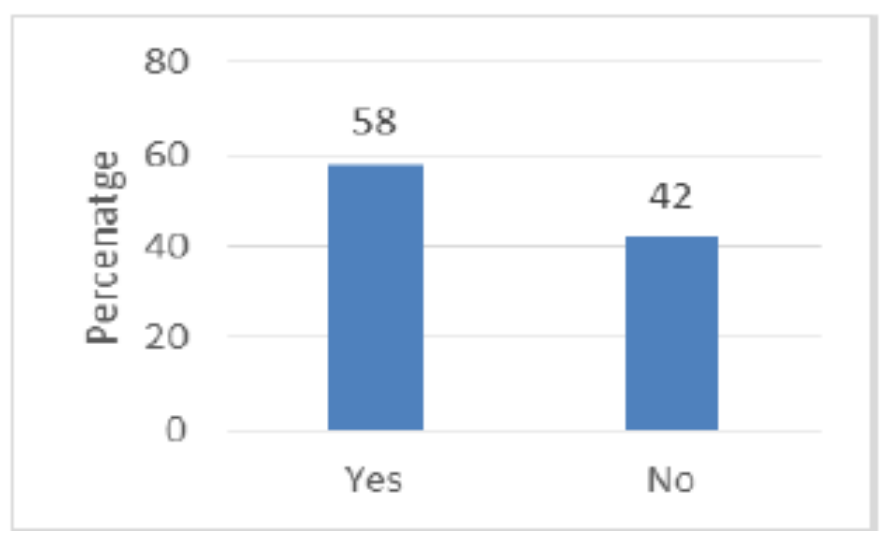

Figure 15. Time to use Face Mask

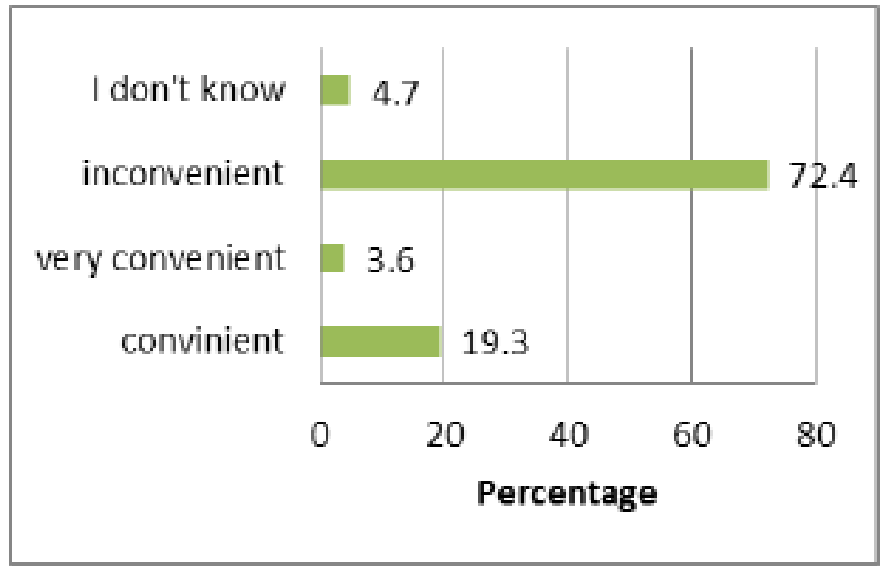

Figure 16. Inconvenience of the use of Face Masks or Shield to Daily Activities 
Table 5. How the Respondents Feel about not Going to a Social Gathering

\begin{tabular}{|l|l|l|}
\hline $\begin{array}{l}\text { Demographic } \\
\text { Characteristics }\end{array}$ & Yes & No \\
\hline Good & 399 & $16.9 \%$ \\
\hline Bad & 1165 & $49.3 \%$ \\
\hline Sick & 141 & $6 \%$ \\
\hline Nothing & 2363 & 27.8 \\
\hline
\end{tabular}

\section{Discussion}

Findings obtained from this study revealed the larger percentage of Nigerians in the study since the study area was conducted in Nigeria, while only a few respondents were nonNigerian. As the percentages of males and females varied in the study area, the ratio of male to female was 0.54 to 0.46 . A decrease in the percentage of aged people sampled in the study area could result in the age group of people who were easily affected by COVID-19. This made aged people not to be involved in this study.

Considering the gender of the respondents in the study area, the little variation in the percentages of the marital status of the respondents might be the large number of students involved in this study. The results of the education levels of the respondents showed an indication that the majority of the people in the study are educated with a very small number of people without formal education. In terms of the occupational activities of people in the study area, the majority of them were still in school, while teachers and other professions constitute larger percentages of the respondents. A very small number of the respondents $(0.3 \%)$ belonged to none of the three major religions, and this justifies that the respondents worshiped nothing. The results of this study showed that Islam and Christianity are the most common religions in the study area.

The larger percentage $(50.7 \%)$ of the respondents that spent no time to and fro to the market or place of work showed that the majority of the respondents did not go anywhere during the lockdown as they were restricted during this period. Considering the responses of respondents on the percentage increment in the prices of consumables, it is shown that the prices of consumables were inflated, which might be associated with low supply or production of consumables during the lockdown. This made the cost of living unsuitable and many people suffered during the lockdown. An indication of the large percentage $(81.1 \%)$ of the respondents of the high cost of living during the lockdown was affected as they adapted to the pandemic's situation.

This study found that COVID-19 poses a significant threat to the local economy, resulting in low income and resultant hunger. This is likely due to the increased cost of purchasing goods or a result of the lockdown, which has denied many individuals the opportunity to earn their income. Denial of opportunities to engage in money-making ventures was experienced and impacts such as hunger were greatly felt among many persons [19]. This explains the need for the provision of palliatives to fight hunger and reduce susceptibility to other infections during the COVID-19 outbreak. Non-provision of palliative measures for the citizens by the government might be attributed to inadequate resources to do so. While many state governments in the country hoard the palliatives which were meant for the citizens, only a few state governments were able to provide the palliative measures for their people in the country. As it affects, the economic activities of the people in the study area, as many respondents could not make an extra profit during the lockdown, this could be attributed to the restriction of people and other commercial activities to take place during the lockdown.

Similarly, decreased productivity and job losses and an unprecedented economic disaster have been reported [20]. Contrary to the finding in this study, other studies have reported stress and anxiety as psychological reactions due to the Coronavirus pandemic [20]. Other psychological reactions such as boredom, anger, and loneliness have been notably identified as resultant threats during the COVID-19 pandemic [21]. This calls for the provision of psychosocial support for individuals during the COVID-19 lockdown. 
Considering the kind of people that can be infected with COVID-19, the result of the larger percentage of respondents indicated that pastors, imams, and traditionalists could be infected with COVID-19. These results signify that everyone was at risk of COVID-19. The small percentage of respondents that showed that they were at risk of COVID-19, might be because COVID-19 is easily spread; old age; traveling from one place to another; nature of their work (health workers); and unknown infected persons to mention but a few. This result corresponds to the study of [22] which reported that a small percentage $(26 \%)$ of the respondents was at risk of COVID-19 in Ibadan, Nigeria.

Education is a very important thing in this study as the level of education of the respondents in the study area enabled individuals to believe that COVID-19 is not a curse from God and also is not the handwork of the devil, as the majority believed. Though, education has nothing to do with health beliefs because $21.8 \%$ of the respondents in the study area indicated that the prayers from religious leaders might cure COVID-19. It is unimaginable when an individual with a good education vehemently opposes seeking health interventionism when an outbreak of (e.g. COVID-19) occurs. This is due to his/her belief that prayers work better than any control of the disease. There are billions of people throughout the world who believe prayers and spirituality are just as vital for healing as modern medicine is, as religious practices and beliefs have consistently been a source of medical treatment for ages [23]. Beliefs such as these may serve to provide a sense of well-being in the face of health difficulties, growing out of the comfort of feeling that one's fate is under the control of a benevolent being. Religious denominations may prescribe lifestyles that promote health.

From the present study, a high rating of the perceived likelihood of contracting COVID-19 was observed among the respondents, while it was maximally perceived as an attack by the Western World. This means that COVID-19 was not a curse from God and not the handwork of the devil. As the majority of the respondents believed that paying attention and/or utilization of the basic measures put in place to curb the spread of COVID-19, only 486 (20.6\%) of respondents believed that use of a face mask cannot prevent a person from having COVID19. This could be a challenge in using face masks to curb the spread of COVID-19. This result corresponds to the study conducted by [22] as the use of face masks and social distancing were the most frequently reported practices for the prevention of COVID-19.

The results of this study showed that $64 \%$ of the respondents preferred going to Churches and/or Mosques to use face masks. This showed that respondents were not comfortable and convenient in using face masks in the study area. A greater proportion $(65.5 \%)$ of the respondents were able to follow the basic measures put in place to reduce the spread of CVOID-19 in the study area The results obtained herein are higher than the knowledge concerning the practice of face masks in Saudi Arabia [24]. Due to its deadly nature, COVID19 has introduced fear which has compelled protective actions from individuals, especially during an epidemic, but such behaviour may not be sustainable $[25,26]$. The adoption of these healthy behaviours in this study is in tandem with the recommendations of the World Health Organisation (WHO) on safety measures for COVID-19 (WHO, 2020).

Another basic measure put in place to curb the spread of COVID-19 which is handwashing is an important measure the respondents also adopted to curb the spread of COVID-19 in the study area. Lassa fever studies conducted in Edo State reported inadequate handwashing as one of the basic practices, while a similar study in Kaduna State, Nigeria, reported good handwashing practices among respondents [27]. The similarities of most of these findings with ours imply the wide acceptance of the practice of basic practices in the management of infectious diseases.

\section{Conclusion}

This study has examined the cost-benefit analysis during the lockdown of COVID-19 and the health belief model of COVID-19 pandemic in Ogun State, Nigeria, as it brought an unprecedented threat to the economy and the quality of life. Results showed that the majority $(50.7 \%)$ of the respondents spent no time to go to the market and/or work during COVID-19 and $81.9 \%$ of them unable to gain extra gain during the lockdown in the study area. The 
findings of this study also revealed that the lockdown had impacts on the socio-economic activities of the people. Respondents also indicated that the government in the study area did not make palliative measures for the households. At this present time, no COVID-19 drugs are available and prayers alone from religious leaders could not only cure it. This study has revealed that the COVID-19 pandemic caused an unprecedented threat to the economy and the quality of life. This study recommends that health education campaigns concerning COVID-19 should be conducted by public health officials in simple, unambiguous

\section{References}

[1] Gallegos, A., 2020, WHO declares public health emergency for novel coronavirus. Medscape Medical News. Accessed: 30/01/2020. https://www.medscape.com/viewarticle/924 596.

[2] Ramzy, A., and McNeil, D.G., 2020, W.H.O. declare global emergency as Wuhan coronavirus spreads. The New York Times. Accessed: 30/01/2020. https://nyti.ms/2RER70M.

[3] The New York Times, 2020, Nigeria Responds to First Coronavirus Case in Sub-Saharan Africa. 28 March 2020.

[4] Centers for Disease Control and Prevention, 2020, How COVID-19 Spreads. Accessed: 04/03/2020

https://www.cdc.gov/coronavirus/2019ncov/prepare/ transmission.html?CDC_AA_refVal=https $\% 3 \mathrm{~A} \% 2 \mathrm{~F}$ \%2Fwww.cdc.gov\%2Fcoronavirus\%2F2019ncov\%2 Fabout\%2Ftransmission.html

[5] Scherbina, B., 2020, Determining the optimal duration of the COVID-19 suppression policy: A cost-benefit analysis. AEI Economics Working Paper 2020-03. American Enterprise Institute, 1-28.

[6] Abraham, C., and Sheeran, P., 2015, The health belief model. In: Predicting and changing health behaviour: Research and Practice with Social Cognition Models, edited by Mark, C., and Paul, N., Third edition (New York, USA: Mark Conner and Paul Norman), pp. 30-69.

[7] Kirscht, J.P., 1983, Preventive health behaviour: A review of research and issues. Health Psychology, 2, 277-301.

[8] Murphy, S.A., 2006, Consumer health information for pet owners. Journal of the Medical Library Association, 94(2), 152-158. languages which will facilitate the understanding of community members. Also, the availability of medical supplies and palliatives would enhance the adherence to safety measures for COVID-19, such as the use of face masks among community members.

\section{Acknowledgment}

The author is grateful to acknowledge those that have helped in one way or the other to the successful completion of this study. I appreciate Salami Afeez Alabi for his immense contribution to the drafting and adjustment of this paper.

[9] Glanz, K., Rimer, B., and Viswanath, K., 2008, Health behavior and health education: Theory, research, and practice. 4th edition (San Francisco: Jossey-Bass).

[10]Lewin, K., 1936, Principles of topological psychology (New York: McGraw-Hill).

[11]Lewin, K.A., 1935, Dynamic theory of personality (New York: McGraw-Hill).

[12] Hochbaum, G.M., 1958, Public participation in medical screening programs: A socio-psychological study. Public health service publication, 572. Washington, DC: US Government Printing Office.

[13] Rosenstock, I.M., 1966, Why people use health services. Milbank Memorial Fund Quarterly, 44, 94-124.

[14]Boskey, E., 2019, Health Belief Model: Use of a condom may hinge on your perceived risk of STDs. Accessed: 20/04/2020.

[15] Kegeles, S.S., 1963, Why people seek dental care. Journal of Health and Human Behavior, 7, 242-254.

[16] National Population Commission, 2006, Federal Republic of Nigeria 2006 Population and Housing Census, Priority Tables, Vol. VII Abuja, Nigeria.

[17] Ogun State Population (2020). Population of Ogun State. Accessed: 16/04/2020. http://population.city/nigeria/adm/ogun/.

[18] Sample Size (2020). Online Sample Size Calculator. Accessed 15/05/2020. http://www.raosoft.com/samplesize.html.

[19] Chukwuorji J.C., Iorfa, S.K., 2020, Commentary on the coronavirus pandemic: Nigeria. Psychological Trauma: Theory, Research, Practice, and Policy, 12(S1), S188-S190 DOI $10.1037 /$ tra0000786.

[20] Atalan, A., 2020, Is the lockdown important to prevent the COVID-9 pandemic? Effects on 
psychology, environment, and economy-perspective. Annals of Medicine and Surgery, 56:38-42. DOI 10.1016/j.amsu.2020.06.010.

[21] Aluh, D.O., Onu, J.U., 2020, The need for psychosocial support amid COVID-19 crises in Nigeria. Epub ahead of print 22 June 2020. Psychological Trauma: Theory, Research, Practice, and Policy. DOI 10.1037/tra0000704.

[22] Ilesanmi, O., Afolabi, A., 2020, Perception and practices during the COVID-19 pandemic in an urban community in Nigeria: A cross-sectional study. PeerJ 8:e10038 DOI 10.7717/peerj.10038.

[23] Mishra, S.K., Togneri, E., Tripathi, B., and Trikamji, B., 2015, Spirituality and religiosity and its role in health and diseases. Journal of Religion and Health. Springer. DOI: 10.1007/s10943-0150100-z.

[24] Al-Hanawi, M.K., Angawi, K., Alshareef, N., Qattan, A.M.N., Helmy, H.Z., Abudawood, Y., Alqurashi, M., Kattan, W.M., Kadasah, N.A., Chirwa, G.C., Alsharqi, O., 2020, Knowledge, attitude and practice toward COVID-19 among the public in the Kingdom of Saudi Arabia: A cross- sectional study. Frontiers in Public Health 8, 1-9 DOI 10.3389/fpubh.2020.00217.

[25] Witte, K., 1998, Fear as motivator, fear as inhibitor: Using the extended parallel process model [26] to explain fear appeal successes and failures. In: The Handbook of Communication and Emotion: Research, Theory, Applications, and Contexts edited by Andersen, P.A., Guerrero, L.K., (San Diego: Academic), 423-450.

[27] Ufuwa, I.S., Akpa, C.O., Umeokonkwo, C.D., Umoke, M., Oguanuo, C.S., Olorukooba, A.A., Bamgboye, E., Balogun, M.S., 2020, Knowledge and risk perception towards Lassa fever infection among residents of affected communities in Ebonyi State, Nigeria: Implications for risk communication. BMC Public Health, 20(1),1-10 DOI 10.1186/s12889-020-8299-3.

[28] Tobin, E.A., Asogun, D.A., Isah, E.C., Ugege, O.G., Ebhodaghe, P., 2013, Knowledge and practice of infection control among primary care providers in an endemic suburban community of Edo State: Implications for control. Journal of Medicine and Medical Sciences, 4:311-318. 


\title{
Mitigating Strategies and its Challenges of COVID-19 Pandemic in Ogun State, Nigeria
}

\author{
Oni, Olawale Bashir-Ud-Deen \\ Department of Public Health, Texila American University, Guyana, USA
}

\begin{abstract}
Globally, coronavirus disease (COVID-19) is a major public health problem due to its high virulence associated with communities spreading with no definitive treatment and untimely death. Various perceptions have been associated with the COVID-19 pandemic. This study assessed the perception of mitigating strategies and its challenges regarding COVID-19 among residents in Ogun State, Nigeria. A descriptive cross-sectional study design using a multi-stage sampling technique was used to solicit information from 2400 respondents in Ogun State, Nigeria. Data were collected using an interviewer-administered questionnaire from 4th to 15th October 2020. Descriptive statistics were employed for data analysis. Findings of this study revealed that avoidance of social gathering (23.5\%), the use of face masks (23.3\%), and cleaning of hands with sanitizer (22.7) were the most common mitigation strategies adopted by the respondents in the study area, although full adherence was low. The most strategies to prevent the transmission of COVID-19 were suggested by the respondents. These strategies included regular quarantining affected person(s), practicing basic measures, and going to the hospital with 21.5\%, 20.6\%, and $19.7 \%$ respectively. The results also showed that going to Churches and Mosques, inconvenient time of using face masks and restriction from social gathering and clubbing during COVID-19 pandemic were the most challenges faced in the study area. This study concludes that there should be more provision of medical supplies and palliatives for individuals, health education, the enforcement of preventive measures, and free testing and treatment should receive much recognition.
\end{abstract}

Keywords: Challenges, COVID-19, mitigating strategies, Nigeria, Ogun State.

\section{Introduction}

The "coronavirus disease 2019" (COVID$19)$ is an emerging infectious illness which broke out during the winter of 2019 [1,2]. Due to its effects and presentation, it was declared and recognized as a global health emergence by World Health Organization (WHO) on February 11, 2020 [2]. The concept of "Coronaviruses" is described as zoonotic, as they are transmitted between animals and man $[3,4]$. These viruses are closely associated with infections such as pneumonia, the common cold and conditions like severe acute respiratory syndrome (SARS) and Middle East Respiratory Syndrome (MERS) [5].

Awareness of this infection is not a recent phenomenon. The first experience of man with diseases and infections which were naturally transmitted between animals and man probably extends back before written history [6]. The descriptions of clinical signs of disease and advice on preventive behaviours have historically been passed from one generation to another, helping to shape many religious and socio-cultural conventions [7]. An alarming response was introduced across the globe due to its high infectiousness and case fatality rate [8]. The identification of the risks and the prevention of infectivity regarding COVID-19 have been stated to depend on human perception [8]. Especially in the submergence of an infectious disease such as COVID-19, different thoughts have shaped individuals' views on the illness.

Though coronaviruses were first identified in 1937 as an infectious bronchitis virus with which birds suffered that could devastate poultry stocks [5]. In the past 70 years, researchers have found camels, cattle, cats, dogs, horses, mice, pigs, rats, and turkeys that were infected with coronaviruses [5]. At the place of COVID-19 emergence in Wuhan China, it was stated that most people who have 
been sickened and killed by the 2019-nCoV virus have been linked to a seafood and animal market [5]. Coronavirus disease spread over 213 countries and produced vast health, economic and social impacts. For example, it was reported that nearly 24 million confirmed cases and close to 820,000 recorded deaths [9, $10]$.

Publicly available reports from the Africa Centre for Disease Control (ACDC) states that confirmed cases of COVID-19 had risen to $1,203,769$ and 28,289 deaths as of 25 August 2020 [11]. As of 25th August 2020, the West African subregion accounted for a significant proportion of cumulative COVID-19 records in Africa. In Nigeria, there are 52,800 confirmed cases of COVID-19 with a total of 1,007 deaths as of 25 August $2020[4,9]$. In spite of the fact that Nigeria is the most populous country in Africa and 7th in the world, the country (Nigeria) had about $2.7 \%$ confirmed cases and $1.8 \%$ death of COVID-19 in the region as at the second quarter of 2020. Ogun State holds the third spot on the Nigeria Centre for Disease Control (NCDC) daily COVID-19 updates. Ogun State presents confirmed cases of COVID-19.

As a part of the emergency response activities across all States in Nigeria, health education campaigns have been directed at members of the public [4]. These campaigns have been aimed at knowledge improvement and the correction of certain misconceptions that have been widely circulated among community members [4]. Education on precautionary measures such as wearing of face masks, regular handwashing with soap and water or with alcohol-based hand sanitizers, and social distancing have been done [4, 12]. Mitigation policies and/or strategic measures were put in place to curb the spread of COVID19 in Nigeria and other parts of the world. Mitigation policy focuses on slowing but not necessarily stopping epidemic spread. Mitigation measures may involve a physical separation between workers, banning large gatherings, isolating the vulnerable, and identifying and quarantining contagious individuals and their recent contacts [13]. Few studies have recently been conducted on COVID-19 pandemic, but little or no studies have been conducted on the challenges facing the mitigating strategies of COVID-19 in Nigeria. This study thus aimed at assessing the perception on the challenges of mitigating strategies regarding COVID-19 in Ogun State, Nigeria.

\section{Materials and Methods}

The study area was confined to Ogun State, Nigeria. Ogun State is one of the fastest developing States in the country. It lies in the south-western part of the country between latitudes $6.20 \mathrm{~N}$ and $7.80 \mathrm{~N}$ of the equator, and longitudes 3.00E and 5.00 East of the Greenwich Meridian south (Figure. 1). Ogun State occupies an area of $16,980.55 \mathrm{~km} 2$ and a population of $3,751,140$, with a density of $220 / \mathrm{km} 2$ [14]. The State is bounded on the west by the Republic of Benin and on the east by Ondo State. To the north is Oyo State, while Lagos State and the Atlantic Ocean are to the south. The geographical location of the State makes it accessible to the economically developed regions in Nigeria. Ogun State is made up of 20 Local Government Areas (Figure. 1).

Data used in this study was collected through the use of survey questionnaire. The questionnaire was targeted the residents of the study who were 15 years and above. The 2020 projected population of the study area which would be estimated as 5, 954, 097 [15] was used to determine the sample size. The determination of the sample size involves disregarding sampling error. Using an online sample size calculator [16] on the 2020 projected population of the study area with $2 \%$ margin of error, $95 \%$ confidence level, and 50\% response distribution, the sample size was 2400 . A total of 2400 copies of well-structured questionnaire were administered design using a multi-stage sampling technique from all the 20 Local Government Areas of the State. 2363 copies of questionnaire were retrieved for the analysis using descriptive statistics, while the results were presented in frequencies tables, graphs, and pie charts. 


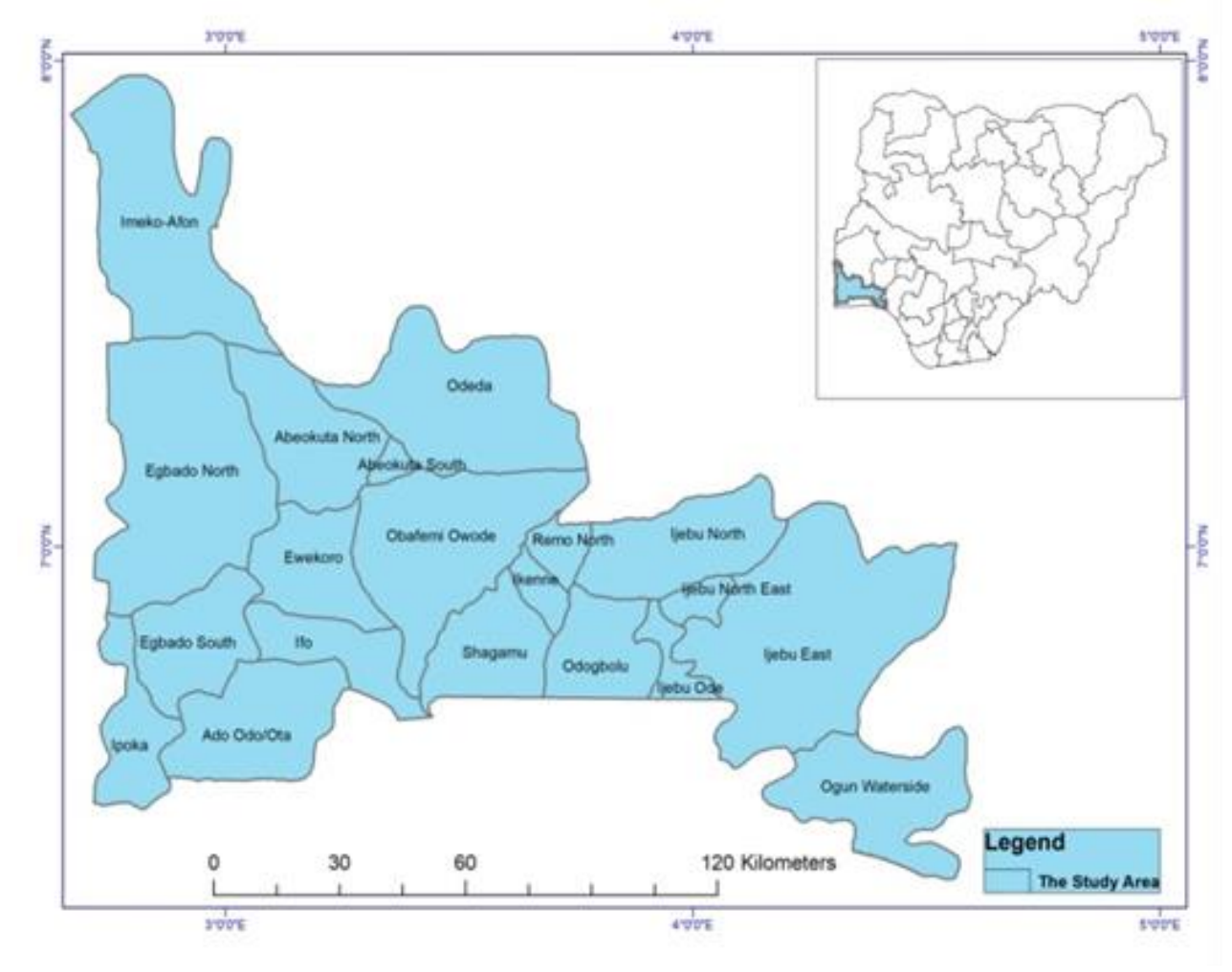

Figure 1. Ogun State, the Study Area

\section{Results}

\section{Demographic Characteristics of the Respondents in the Study Area}

The demographic characteristics of the respondents in the study area are presented in Table 1 while the local government areas and the profession of the respondents were presented in Figure. 2 and 3. Most of the respondents were Nigerians with $97.3 \%$ responses while $53.8 \%$ and $46.2 \%$ were male and female, respectively. The percentages of the respondents between the ages of $15-24$ and $25-34$ consisted of the larger population in the study area with $30.9 \%$ and $27.4 \%$ responses. The least age group was $1.3 \%$ representing only 30 respondents between the ages of 75 and above in the study area. Majority of the respondents were representing $46.1 \%$ and $45.9 \%$ were married and single, respectively.
The least percentage of the respondents which represents only $2.5 \%$ did not have formal education, while the number of respondents with secondary and university education constituted larger percentages with $30.9 \%$ and $20.8 \%$ respectively. As Islam and Christianity are the most common religious in the study area, a very small number of the respondents which represents $0.3 \%$ belonged to none of the three major religions. A total of 1603 which represents $67.8 \%$ worshiped God since they were born. The results also showed that $92.8 \%$ of the respondents were Yoruba, 4.4\% were Igbo, while Hausa constitutes 50 (2.1\%) of ethnic groups. Figure, 2 indicated that teachers and other professions constituted larger percentages of the respondents in the study area. The percentages of respondents from different Local Government Areas in the study area were presented in Figure. 3.

Table 1. Demographic Characteristics of the Respondents

\begin{tabular}{|l|l|l|l|}
\hline Demographic Characteristics & Frequency & Percent (\%) \\
\hline \multirow{2}{*}{ Nationality } & Nigerian & 2299 & 97.3 \\
\cline { 2 - 4 } & Others & 64 & 2.7 \\
\hline \multirow{2}{*}{ Sex } & Male & 1271 & 53.8 \\
\cline { 2 - 4 } & Female & 1092 & 46.2 \\
\hline Age Bracket & $15-24$ & 648 & 27.4 \\
\hline
\end{tabular}




\begin{tabular}{|c|c|c|c|}
\hline & $25-34$ & 729 & 30.9 \\
\hline & $35-44$ & 471 & 19.9 \\
\hline & $45-54$ & 287 & 12.1 \\
\hline & $55-64$ & 156 & 6.6 \\
\hline & $65-74$ & 42 & 1.8 \\
\hline & 75 and above & 30 & 1.3 \\
\hline \multirow[t]{6}{*}{ Marital Status } & Single & 1084 & 45.9 \\
\hline & Married & 1090 & 46.1 \\
\hline & Divorced & 62 & 2.6 \\
\hline & Separated & 47 & 2.0 \\
\hline & Widow & 38 & 1.6 \\
\hline & Widower & 42 & 1.8 \\
\hline \multirow[t]{7}{*}{ Level of Education } & No Formal Education & 60 & 2.5 \\
\hline & Primary & 108 & 4.6 \\
\hline & Secondary & 731 & 30.9 \\
\hline & Col. of Education & 262 & 11.1 \\
\hline & Polytechnic & 317 & 13.4 \\
\hline & University & 492 & 20.8 \\
\hline & Post Graduate & 393 & 16.6 \\
\hline \multirow[t]{4}{*}{ Religion } & Islam & 1388 & 58.7 \\
\hline & Christianity & 899 & 38.0 \\
\hline & Traditional & 69 & 2.9 \\
\hline & Others & 7 & .3 \\
\hline \multirow{5}{*}{$\begin{array}{l}\text { Years of } \\
\text { worshiping God }\end{array}$} & $<5$ years & 24 & 1.0 \\
\hline & $5-10$ years & 154 & 6.5 \\
\hline & $11-20$ years & 154 & 6.5 \\
\hline & $>20$ years & 428 & 18.1 \\
\hline & since birth & 1603 & 67.8 \\
\hline \multirow[t]{4}{*}{ Ethnicity } & Yoruba & 2193 & 92.8 \\
\hline & Igbo & 103 & 4.4 \\
\hline & Hausa & 50 & 2.1 \\
\hline & Others & 17 & 0.7 \\
\hline
\end{tabular}

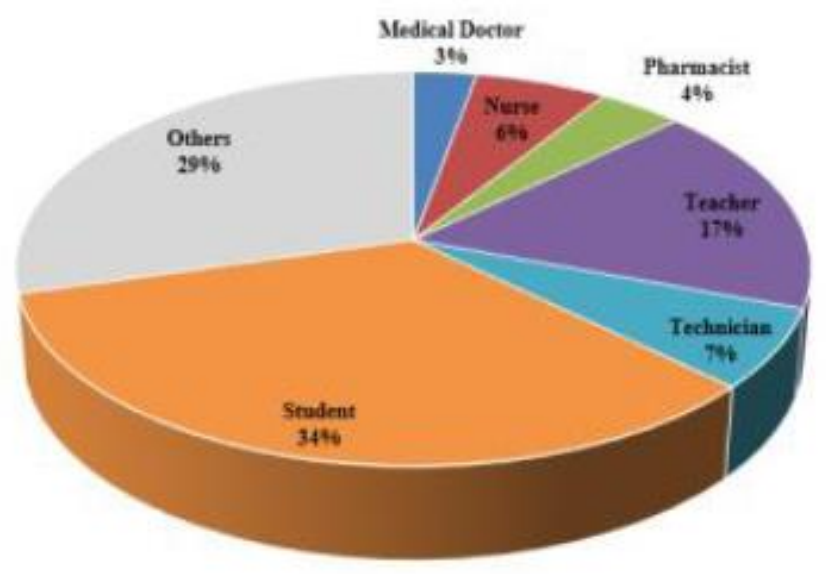

Figure 2. Profession of Respondents in the Study 


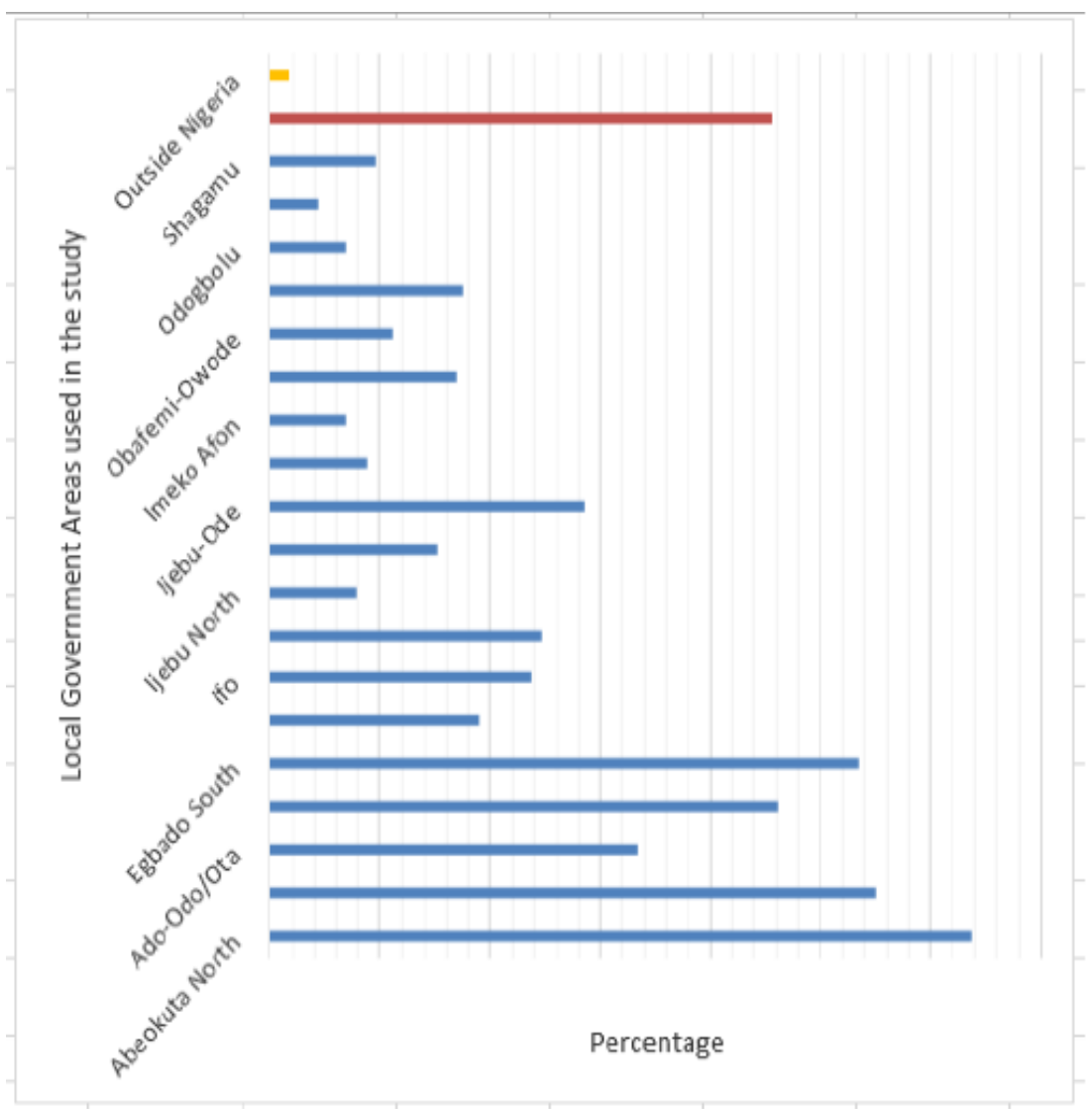

Figure 3. Local Government Area

\section{Mitigation Strategies against COVID-19}

Table 3 presents the mitigation strategies against COVID-19 in the study area. The most frequently reported practice for prevention of COVID-19 among respondents was the avoidance of social gathering by $(23.5 \%)$, the use of face masks by $224(23.3 \%)$ and cleaning of hands with sanitizer by $22.7 \%$. Others included: Praying and fasting (18.5\%), and washing of hands with soap (9.4\%). Only $2.6 \%$ did nothing to curb the spread of COVID-19 as shown in Figure.2.

\section{Best Strategies against COVID-19}

Table 4 illustrates the results of the best mitigation strategies against COVID-19 in the study area. The results ranked the best strategies from $21.5 \%$ to $0.7 \%$. Quarantining affected persons was ranked first, followed by practicing basic measures, and going to the hospital regularly with $21.5 \%, 20.6 \%$, and $19.7 \%$ respectively. Using incantation, juju and magic; taking anointed water from pastors/imams/Alfas; drinking of and bathing with salt water; by taking traditional medicine/herbs were ranked low as the best strategies against COVID-19 in the study area.

Table 2. Mitigation Strategies against COVID-19

\begin{tabular}{|c|c|c|c|}
\hline & \multicolumn{2}{|c|}{ Responses } \\
\hline & & $\mathbf{N}$ & Percent \\
\hline \multirow{6}{*}{$\begin{array}{l}\text { Mitigation Strategies } \\
\text { against COVID-19 }\end{array}$} & Nothing & 238 & $2.6 \%$ \\
\hline & Washing of hands with soap & 856 & $9.4 \%$ \\
\hline & Cleaning of hands with sanitizer & 2071 & $22.7 \%$ \\
\hline & Using of face mask or shield & 2121 & $23.3 \%$ \\
\hline & Avoiding social gathering & 2137 & $23.5 \%$ \\
\hline & Praying and fasting & 1683 & $18.5 \%$ \\
\hline \multicolumn{2}{|l|}{ Total } & 9106 & $100.0 \%$ \\
\hline
\end{tabular}

a. Dichotomy group tabulated at value 1 . 
Table 3. Best Strategies against COVID-19

\begin{tabular}{|l|l|c|c|}
\hline \multicolumn{2}{|c|}{} & \multicolumn{2}{|c|}{ Responses } \\
\cline { 3 - 4 } \multicolumn{1}{|c|}{} & $\mathbf{N}$ & Percent \\
\hline \multirow{5}{*}{$\begin{array}{l}\text { Best Strategies against } \\
\text { COVID-19 }\end{array}$} & By taking traditional medicine/herbs & 440 & $5.3 \%$ \\
\cline { 2 - 4 } & $\begin{array}{l}\text { By taking anointed water from } \\
\text { pastors/imams/Alfas }\end{array}$ & 214 & $2.6 \%$ \\
\cline { 2 - 4 } & Drinking of and bathing with salt water & 460 & $5.6 \%$ \\
\cline { 2 - 4 } & By using incantation, juju and magic & 58 & $0.7 \%$ \\
\cline { 2 - 4 } & Frequent prayer and fasting & 990 & $12.0 \%$ \\
\cline { 2 - 4 } & Taking of drugs like chloroquine & 990 & $12.0 \%$ \\
\cline { 2 - 4 } & By going to the hospital regularly & 1628 & $19.7 \%$ \\
\cline { 2 - 4 } & Affected persons should be quarantined & 1773 & $21.5 \%$ \\
\cline { 2 - 4 } & By practising basic measures & 1697 & $20.6 \%$ \\
\hline Total & & 8250 & $100.0 \%$ \\
\hline
\end{tabular}

a. Dichotomy group tabulated at value1.

\section{Constraints to Mitigation Strategies against COVID-19}

In Figure. 4, 64\% of the respondents preferred going to Churches and/or Mosques to use the face masks while 993 (42\%) did not have time to use face mask during COVID-19 (Figure. 5). The majority 1710 (72.4\%) of respondents were not convenient with the use of face mask (Figure. 6). A small percentage
$(16.9 \%)$ of the respondents felt good for not attending social gathering, while the majority $1165(49.3 \%)$ of the respondents felt badly for not attending social gathering during COVID19 (Table 4). The results in Figure. 7 shows that $79.3 \%$ of the respondents were not satisfied for not going for clubbing whenever they felt stressed out or bored during COVID-19.

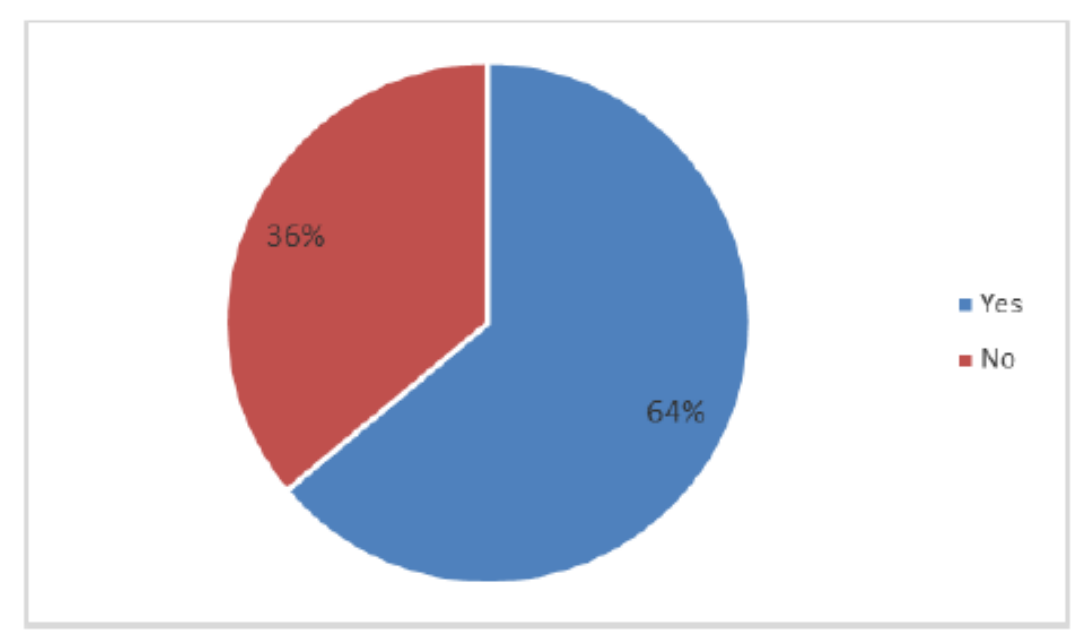

Figure 4. Preference to go to Churches and Mosque Instead of Using Face Masks 


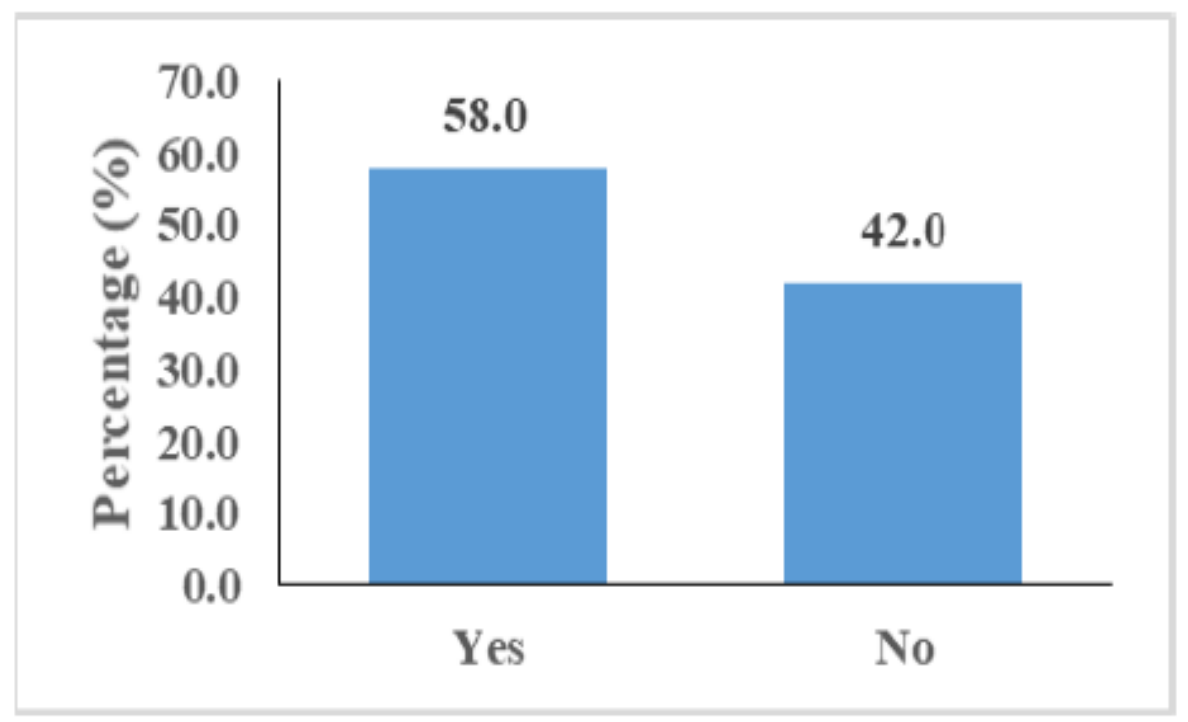

Figure 5. Having Time to use Face Mask

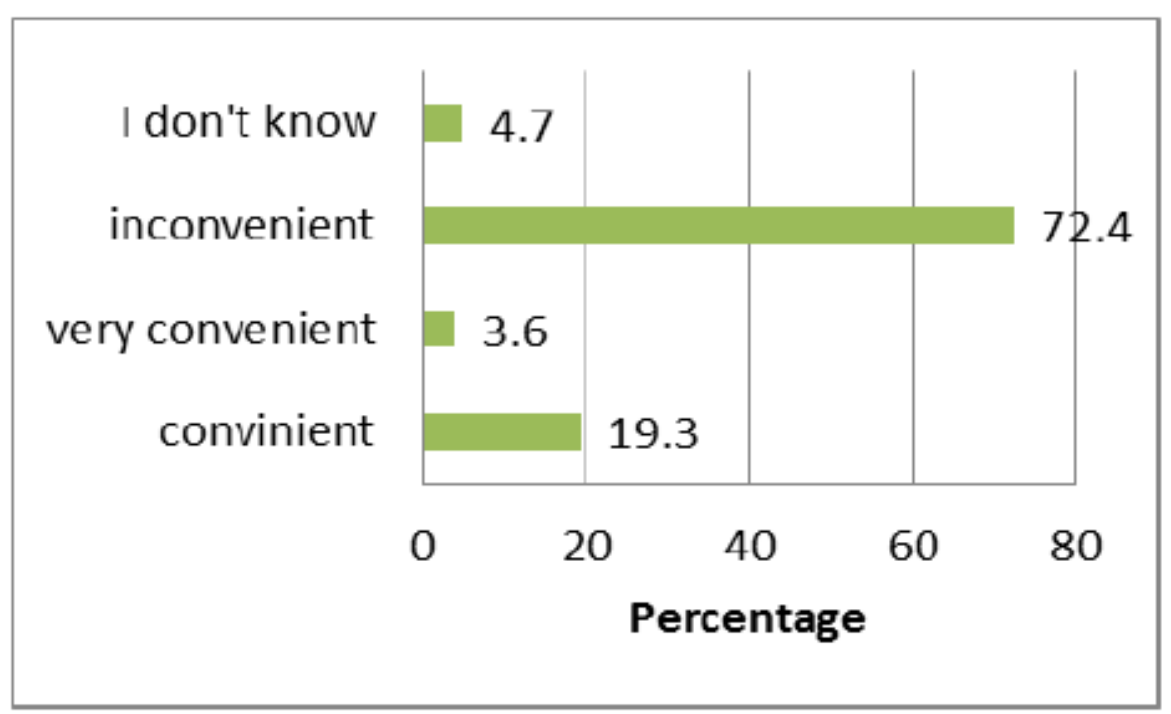

Figure 6. The use of Face Masks to Daily Activities

Table 4. Social Gathering

\begin{tabular}{|l|l|l|}
\hline Variables & Yes & No \\
\hline Good & 399 & $16.9 \%$ \\
\hline Bad & 1165 & $49.3 \%$ \\
\hline Sick & 141 & $6 \%$ \\
\hline Nothing & 2363 & 27.8 \\
\hline
\end{tabular}




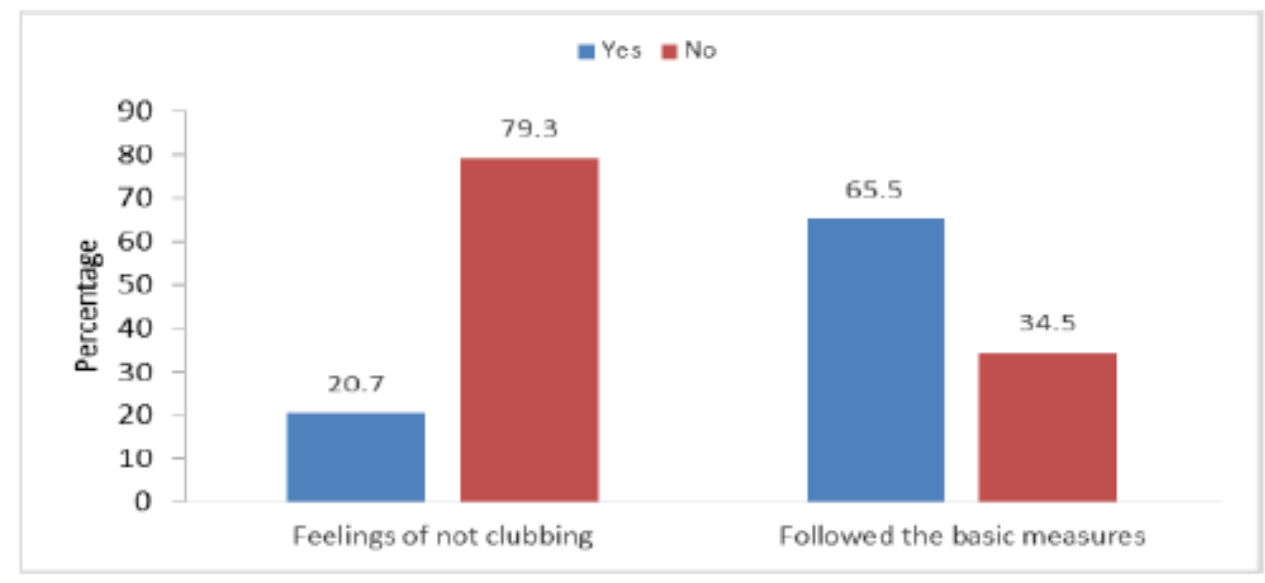

Figure 7. Death as an End Result of COVID-19

\section{Discussion}

From the present study, Nigerians were largely sampled with the ratio of male and female of 0.54 to 0.46 . This is because the study was conducted in Nigeria and the population of male was little more than female in the study area. Being a Gateway State and one of the foremost educated states in Nigeria, the results of this study showed that majority of the people in the study are educated with a very small number of people without formal education. Findings obtained from this study revealed that the perception on the mitigation strategies of COVID-19 were most adopted and practiced. This indicates that the precautionary measures put in place to curb the spread of COVID-19 were practiced as the majority of the respondents were educated. Many of the respondents had the knowledge of COVID-19. This might be the rationale of adopting the basic measures as mitigation strategies of COVID-19 in the study area. Although distrust in government capacity regarding COVID-19 is currently obtained, individuals are willing to take proactive measures following the suspected development of COVID-19 symptoms [17]. An Indian study similarly reported that hospital visitation was frequently opted for as a step to be taken following the development of COVID-19 in individuals in a close relationship [18].

This study found that avoidance of social gathering, the use of face masks and cleaning of hands with sanitizer were more frequently embraced among respondents compared with other COVID-19 mitigation measures, although full adherence was low. A web-based study conducted in Nigeria mostly stated mouth- covering while sneezing, wearing of face masks and avoidance of crowded spaces as selfreported practices among respondents [19]. In a similar study, the use of face masks and practice of social distancing measures were more adopted among respondents compared to other COVID-19 mitigation measures [20]. Findings of this study also revealed that multitudes of perceptions were associated with COVID-19, which include but not limited to an exaggerated illness with intentions for corruption, its highly infectious and deadly nature, and a reason for panic disorders.

Furthermore, the chance of positive mitigation strategies and/or practices regarding COVID-19 was associated with a positive perception of the risk involved [8]. In Nigeria, previous studies also substantiate the pivotal role of positive risk perception on imbibing COVID-19 mitigating strategies and/or protective measures and attitudes [19]. The results obtained in this study are like the knowledge concerning the practice of face masks in Saudi Arabia [1]. Due to deadly nature of COVID-19, it has presented anxiety and/or fear in every individual with similar symptoms of illness [8]. Studies have shown that fear could prompt healthy behaviour among individuals, most especially during epidemics, but such behaviour may not be viable $[21,22,23]$.

This study found that quarantining affected person with COVID-19; practicing basic measures such as regularly handwashing, use of face masks and others; and going to the hospital were indicated by the respondents as the best strategies for preventing COVID-19 in the study area. Though, other protective measures 
were also adopted by the respondents in the study area such as taking of chloroquine, prayers and fasting, use of salt water for drinking and bathing, and the use of medicinal herbs. Adoption of all these aforementioned strategies was because these individuals perceive themselves as vulnerable to COVID19 infection. Use of face masks and regular handwashing practices have been identified as the mitigation strategies for breaking the chain of COVID-19 transmission in the study area. An online survey conducted in Nigeria revealed a higher practice of handwashing compared to other COVID-19 preventive measures [19].

A study conducted in Ilaro on preventive practice of Ebola virus disease outbreak revealed regular handwashing and use of sanitizers as the most useful protective measures against EVD [24]. Like this finding, a study conducted in Ibadan on hand hygiene practices post the Ebola virus disease outbreak revealed a high proportion of inadequate selfreported hand hygiene practice [25]. Other studies conducted in Edo State on Lassa fever reported inadequate handwashing practices, while a similar study in Kaduna State, Nigeria, reported good handwashing practices among respondents [26]. Acceptance of the practice of regular handwashing in the management of infectious diseases is the most similar findings in the studies.

There are constraints to mitigation strategies of COVID-19 in the study area. During COVID-19, respondents preferred going to Churches and Mosques to the use of face masks. They also indicated that no time to use the face masks, and they were not convenient to use it. This justifies an assertion that the use of face masks was the most determinant factor to the mitigation strategies for COVID-19. Other challenges included restriction of individuals to attend social gathering and for clubbing.

In general, this study found that COVID-19 poses significant threat to local economy, resulting in low income and resultant hunger.
This is likely due to the increased cost of purchasing goods or a result of the lockdown, which has denied many individuals the opportunity to earn their income. The provision of medical supplies and palliatives should receive highest recommendation among respondents. Further, health education, the enforcement of preventive measures, and free testing and treatment should receive much recognition. Similar suggestions have been made in previous studies [27].

\section{Conclusion}

Mitigation strategies and challenges faced during COVID-19 pandemic in Ogun State, Nigeria has been assessed. The acceptance of precautionary actions is precarious to envision headlong spread of COVID-19. Ample and accurate risk insight for COVID-19 is a prerequisite to facilitate the espousal of COVID-19 safety procedures. This study hereby recommends heightened sensitization and health education sessions for all community adherents about COVID-19 in Ogun State, Nigeria, regardless of their sociodemographic characteristics. Further, there should be health campaigns more focusing on practices such as regular handwashing with soap and water and social distancing, which protects against transmission of COVID-19 among community members nonetheless of their sex. In addition, laws should be made on the mandatory use of face masks, and provision of accessible portable sources of water, soaps and sanitizers for regular handwashing and cleaning. Finally, free testing and treatment must receive much recognition, and the government should also install more infrastructures for water supply where dearth of water exists.

\section{Acknowledgements}

The author expresses his gratitude to all community members for their willingness and cooperation to participate in this study. 


\section{References}

[1] Al-Hanawi, M. K., Angawi, K., Alshareef, N., Qattan, A.M.N., Helmy, H.Z., Abudawood, Y., Alqurashi, M., Kattan, WM., Kadasah, N.A., Chirwa, G.C., and Alsharqi, O., 2020, Knowledge, attitude and practice toward COVID-19 among the public in the Kingdom of Saudi Arabia: A crosssectional study. Frontiers in Public Health, 8, 1-9 DOI 10.3389/fpubh.2020.00217.

[2] WHO 2020a, Coronavirus disease 2019 (COVID-19) situation report-51 Geneva: World Health Organization Accessed: 26 August 2020 https://covid19.who.int/.

[3] Weiner, L.P., 1987, Coronaviruses: A historical perspective. In: Corona Viruses: Advances in Experimental Medicine and Biology edited by Michael, M.C.L., and Stephen, A.S. (Plenum Press: New York and London), pp. 1-4.

[4] NCDC, 2020a, COVID-19 Nigeria-Nigeria centre for disease control. Accessed: 11 August 2020. https://covid19.ncdc.gov.ng/.

[5] International Medical Aids-IMA, 2020, Coronavirus: What you need to know. Accessed: 21 April 2020. https://medicalaid.org/.

[6] Reaser, J.K., Clark, E.E. Jr., and Meyers, N.M., 2008, All creatures great and minute: A public policy primer for companion animal zoonoses. Zoonoses and Public Health, 55,385-401.

[7] Shakespeare, M., 2002, Zoonoses. (London, U.K.: Pharmaceutical Press, Division of the Royal Pharmaceutical Society).

[8] Zhong, B-L, Luo, W., Li, H-M., Zhang, Q-Q., Liu, X-G., Li, W-T., Li, Y., 2020, Knowledge, attitudes and practices towards COVID19 among Chinese residents during the rapid rise period of the COVID-19 outbreak: A quick online cross-sectional survey. International Journal of Biological Sciences, 16(10), 1745-1752 DOI 10.7150/ijbs.45221.

[9] WHO, 2020b, Coronavirus disease (COVID-19) situation report-149 Geneva: World Health Organization Accessed: 26 August 2020 https:/www.who.int/docs/default-

source/coronaviruse/situationreports/20200623covid-19-sitrep-155.pdf?sfvrsn=ca01ebe_ 2 .

[10] WHO, 2020c, Coronavirus disease (COVID-19) advice for the public: World Health Organization Accessed: $\quad 25$ June 2020 https:/www.who.int/emergencies/diseases/novelcoronavirus-2019/advice-for-public.

[11]ACDC, 2020, Coronavirus disease 2019 (COVID-19): Africa centre for disease control. Accessed: $\quad 25 \quad$ August 2020. https://africacdc.org/\%20covid-19/.
[12] Gbadamosi, B., 2020, War on COVID-19: Oyo threatens to shut markets for flouting precautionary measures-Oyo state. The Pace Setter State. Accessed: $\quad 26 \quad$ June 2020. https://oyostate.gov.ng/war-on-covid-19oyothreatens-to-shut-markets-for-floutingprecautionary-measures/.

[13] Scherbina, B., 2020, Determining the optimal duration of the COVID-19 suppression policy: A cost-benefit analysis. AEI Economics Working Paper 2020-03. American Enterprise Institute, 1-28. [14] National Population Commission, 2006, Federal Republic of Nigeria 2006 Population and Housing Census, Priority Tables, Vol. VII Abuja, Nigeria.

[15] Ogun State Population, 2020, Population of Ogun State. Accessed: 16 April 2020. http://population.city/nigeria/adm/ogun/

[16] Sample Size 2020, Online Sample Size Calculator. Accessed: 15 May 2020. http://www.raosoft.com/samplesize.html.

[17] Chukwuorji, J.C., Iorfa, S.K., 2020, Commentary on the coronavirus pandemic: Nigeria. Psychological Trauma: Theory, Research, Practice, and Policy, 12(S1): S188-S190 DOI $10.1037 / \operatorname{tra} 0000786$.

[18]Dkhar, S.A., Quansar, R., Saleem, S.M., Khan, S.M., 2020, Knowledge, attitude, and practices related to COVID-19 pandemic among social media users in J\&K, India. Indian Journal of Public Health, 64(6), 205-210 DOI 10.4103/ijph.IJPH_469_20.

[19]Iorfa, S.K., Ottu, I.F.A., Oguntayo, R., Ayandele, O., Kolawole, S.O., Gandi, G.C., Dangiwa, A.L., Olapegba, P.O., 2020, COVID-19 knowledge, risk perception and precautionary behavior among Nigerians: A moderated mediation approach. medRxiv DOI 10.1101/2020.05.20.20104786.

[20]Ilesanmi, O., and Afolabi, A., 2020, Perception and practices during the COVID-19 pandemic in an urban community in Nigeria: A cross-sectional study. PeerJ, 8: e10038 DOI 10.7717/peerj.10038.

[21] Witte, K., 1998, Fear as motivator, fear as inhibitor: using the extended parallel process model to explain fear appeal successes and failures. In: The Handbook of Communication and Emotion: Research, Theory, Applications, and Contexts edited by Andersen PA, Guerrero L.K., (San Diego: Academic), pp. 423-450.

[22] Nabi, R.L., 1999, A cognitive-functional model for the effects of discrete negative emotions on information processing, attitude change, and recall. 
Communication Theory, 9(3), 292-320. DOI 10.1111/j.1468-2885. 1999.tb00172. x.

[23] Ufuwa, I.S., Akpa, C.O., Umeokonkwo, C.D., Umoke, M., Oguanuo, C.S., Olorukooba, A.A., Bamgboye, E., Balogun, M.S., 2020, Knowledge and risk perception towards Lassa fever infection among residents of affected communities in Ebonyi State, Nigeria: Implications for risk communication. BMC Public Health, 20(1):1-10 DOI 10.1186/s12889-020-8299-3.

[24] Oni, B.O., 2019, Knowledge, attitude and preventive practice of senior secondary school students on Ebola Virus Disease in Ilaro, Ogun State, Nigeria. Texila International Journal of Public Health, 7(4), 163-172.

[25] Martins, S.O., Osiyemi, A.A., 2017, Hand hygiene practices post Ebola virus disease outbreak in a Nigerian teaching hospital. Annals of Ibadan Postgraduate Medicine, 15, 16-22.

[26] Tobin, E.A., Asogun, D.A., Isah, E.C., Ugege, O.G., Ebhodaghe, P., 2013, Knowledge and practice of infection control among primary care providers in an endemic suburban community of Edo State: implications for control. Journal of Medicine and Medical Sciences, 4,311-318.

[27] Kebede, Y., Yitayih, Y., Birhanu, Z., Mekonen, S., Ambelu, A., 2020, Knowledge, perceptions and preventive practices towards COVID-19 early in the outbreak among Jimma university medical center visitors, Southwest Ethiopia. PLOS ONE, 15(5), e0233744 DOI 10.1371/journal.pone.0233744. 


\title{
Responding to Cholera Outbreaks in Zimbabwe: Building Resilience over Time - A Critical Review of Article
}

\author{
N.P. Sithole-Sibanda ${ }^{1 *}$, L. Nare ${ }^{2}$, D. Chirundu ${ }^{3}$, N.T. Gombe ${ }^{4}$, E. Sibanda ${ }^{1}$ \\ ${ }^{1}$ City of Bulawayo, Health Services Department, Bulawayo, Zimbabwe \\ ${ }^{2}$ Institute of Development Studies, National University of Science and Technology, Bulawayo, \\ Zimbabwe \\ ${ }^{3}$ Kadoma City Health Department, Zimbabwe \\ ${ }^{4}$ African Field Epidemiology Network, Uganda
}

\begin{abstract}
This is a critical review of an article based on the experiences of Epidemic Preparedness and Response pillars as they built resilient health systems while responding to various emerging and reemerging adverse events. The premise of the article is to explore the need and outline advantages of resilient health systems to those responsible for health outcomes at all levels, for effective public health action amidst adverse contexts. The article may be considered as objective and unbiased due to the peer review process. The article was published in a journal that provides a forum for a broad discussion of global health issues that range from systemic violence to infectious disease outbreaks. The article has contributed to literature and provides a basis for achieving resilience, improving public health action and indicates areas for further development of the knowledge base of health systems research. However, it is suggested that the concept of responsiveness be reemphasized and paired with resilience to improve the performance of health systems.
\end{abstract}

Keywords: Emergency, Outbreaks, Response, Resilience, Zimbabwe.

\section{Introduction}

This is a critical review of an article entitled 'Responding to Cholera Outbreaks in Zimbabwe: Building Resilience over Time' published in the 2018 issue of the Current Issues in Global Health Journal. The corresponding author is Chimusoro Anderson. This review will firstly give an overview of the article. Secondly, the article structure will be reviewed on the presentation of the content, the alignment and format of the article. Thirdly, the article will be critiqued looking at the authority, accuracy, currency, relevance, objectivity and coverage. Tables will also be looked at before judging the article's accessibility and credibility.

The central theme of the article is on the importance of building resilient health systems from experiences by Epidemic Preparedness and Response (EPR) pillars as they respond to various disease outbreaks (cholera, Corona Virus Disease of 2019) and disasters. The role of a resilient health system in emergencies response is to ensure that EPR pillars have the capacity to prepare for and effectively respond to crises; maintain core functions when a crisis hits; and, informed by lessons learned during the crisis, reorganise if conditions require it [1]. This occurs amidst economic and persistent system-wide challenges faced by countries in the WHO African region such as Zimbabwe.

\section{Article Summary}

The purpose of the article is to explore the need and outline advantages of resilient health systems. Critical elements that have built resilience include skilled and equipped rapid response teams, strengthened surveillance and maintaining high alert, effective multisectoral collaboration and high-level political engagement [2].

The authors refer to elements of health care systems in Zimbabwe that have become functional through the years, despite the adverse context that includes economic meltdown. The authoritative knowledge that the health workers can provide about the ability to continue operating in challenging environments has contributed to strengthening of the capacity 
of health systems to react to acute external shocks. This could form the basis of collaboration between researchers and health workers, leading to the development and implementation of successful strategies through operational research, to improve health outcomes even within adverse contexts and events such as infectious disease outbreaks.

The article outlines the trend of cholera in Zimbabwe and countries in the WHO African region that were affected by the cholera outbreak. A total of 21 countries in the WHO African region reported cholera outbreaks within the same period of time, reporting a total of 118769 cases and 2531deaths. The overall case fatality rate (CFR) is $2.1 \%$.

The article sets a benchmark for countries with weak health systems, especially lowincome countries, who are seeking to put in place effective measures to control cholera and other disease outbreaks and successfully build resilience to strengthen the capacity of their health systems to respond to outbreaks and crises before, during and after their occur.

\section{Article Structure}

The article was introduced with an abstract which provided the stance or thesis developed by the article as well as a brief overview of main points. The rationales for the article and for the research it describes was also included. The paragraphs in the body were short and therefore the information in each paragraph was easy to access. There were six (6) body headings with detailed information contained under each heading that allows the readers to easily articulate pertinent issues.

The structure of the article is coherent as the article contained the conventional information normally provided in such a study. For example, there are sections related to the background and significance of the research, a review of the literature and methodology used. The dependent and independent variables have been clearly defined. The findings and conclusions were developed towards the end of the article.

The conclusion comprehensively summarized the main points covered by the article and contributed to the development of future policies and research directions regarding resilience of health systems. References were cited in-text and set out clearly in the literature cited section. The article's structure was logically developed overall, with the use of short paragraphs helping the reader access the main points more easily.

The article was HMLT rather than a scanned PDF document and included many links, which helped to make the information accessible. There were links to author, journal, subjects, citations and references which allow the reader to evaluate the articles' worth more effectively. The linked headings and subheadings also allowed the reader to move through the paper more quickly.

\section{Article Critique}

\section{Authority}

The journal, Current Issues in Global Health, is a peer-reviewed scientific journal, which provides a forum for unbiased broad discussions of health issues that range from systemic violence to infectious diseases. The authors come from a variety of environments and strive to promote the maintenance of public health even across international borders, thereby qualifying as issues of global importance. The authors' credibility was established by the fact that the article was peer reviewed. Furthermore, the authors are experienced health practitioners and academics working for the World Health Organization (WHO) in collaboration with the Department of Epidemiology and Disease Control, Ministry of Health and Child Care, Zimbabwe.

\section{Currency}

The article was submitted for publishing on 6 March 2018, reviewed on 27 June 2018 and was accepted for publication on 21 November 2018. The research it describes was current, and the article cites up-to-date references in the body of the text (ranging from 1998 to 2018). Therefore, the article is current.

\section{Relevance}

This was an academic journal on an academic database, which has high credibility in an academic context. The article aimed to encourage countries with weak health systems, especially low-income countries, who are seeking to put in place effective measures to control emerging, re-emerging and rapidly evolving situations such as cholera and the Corona Virus of 2019 (COVID-19) disease 
outbreaks. However, resilience has not been paired with the concept of responsiveness to current and future needs. It is important for resilience (a supply side concept) to be matched by responsiveness if health systems are to effectively serve communities [3].

The article also aimed to commend lowincome countries such as Zimbabwe, that have successfully built resilience through the years as they learnt to positively adapt to adverse contexts and strengthen the capacity of their health systems to respond to outbreaks and crises before, during and after their occur. It helps to inform those responsible for health outcomes at local, provincial, national, regional and international levels on effective public health action rather than to entertain or advertise. It would be relevant to all these groups in their efforts to build resilience as they develop and strengthen the capacity of their health systems to respond to outbreaks or crises and maintain core functions before, during and after an outbreak or crises [4].

\section{Objectivity}

The information was objectively developed, well supported with a current research base and with all evidence acknowledged and referenced. There was no evidence of bias, a fact that was reinforced by the recognition that the article documents research, which followed the rigorous research processes, and the necessary ethical considerations demanded of such community-based research. The authors acknowledged the complexity of issues discussed in a number of ways. For example, the literature review provided explanations of the key terms discussed (for example, 'Resilience') and abbreviations used. The authors supported their research decisions with references from appropriate and relevant literature. The findings are relevant and can be generalized to other countries, especially those with weak health systems and adverse contexts.

\section{Stability}

The article is stable as a resource since it was published in a peer reviewed academic journal on an academic database. It can be depended on for guidance by other researchers and program managers.

\section{Analysis of tables}

There were no graphs in the article. However, one (1) detailed, clear and adequately labeled table was used to compare and describe countries in the WHO African Region that reported cholera outbreaks from January 2017 to March 2018.

\section{Recent advances to the topic}

The concept of 'resilience' is a recent addition to health systems policy and research [5]. It is an achievement in the field of health policy and systems research [4]. A resilient health system is one which is able to effectively prepare for, withstand the stress of, and respond to the public health consequences of disasters [6]. It can also be described as the capacity of health actors, institutions, and populations to prepare for and effectively respond to crisis, maintain core functions when a crisis hits; and, informed by lessons learnt during the crisis, reorganize if conditions require it [1]. Terms that are often used to further describe resilience include adaptation, maintenance, absorption, learning, transformation, withstanding and responding to shocks [7].

Health system resilience underwent a conceptual shift during the Ebola crisis; from a mere 'system' capacity to recognizing the contribution of individuals and their agency within that system and acknowledging the wider social, economic and political context in which responses occur [8]. Resilience and responsiveness are important attributes of an effective health system.

Health systems responsiveness is the ability of the health system to meet the population's legitimate expectations regarding their interaction with the health system, apart from expectations for improvements in health or wealth [9]. Responsive health systems anticipate and adapt to existing and future health needs [10]. Poor responsiveness can also negatively affect utilization of services and the effectiveness of interventions [11].

In recent years, health systems in many lowand middle-income countries have faced severe shocks that range from Ebola epidemics to political and financial crises [4]. Fragile health systems can become overwhelmed during public health crises, further exacerbating the 
human, economic, and political toll [12]. Weak health systems are considered a critical obstacle to improving health [4]. It is therefore important for countries to develop and maintain resilient, responsive health systems that can withstand adverse contexts and events.

Health systems resilience can be achieved, given the competing demands on countries to scale cost-effective health services with scant resources while continuing to be accountable to meet immediate public health needs, both routine and unexpected [13].

Research on resilience of health systems especially in low-income countries is scanty or lacking even as they struggle to function within the context of adverse conditions [2]. Examples of adverse contexts include some of the following: economic meltdown, evidence of instability and daily disruptions, El Niñoinduced drought, lack of access to potable or safe drinking water, climate change, floods and scarce resources [14]. Adverse events include high-consequence infectious diseases such as cholera, Corona Virus Disease of 19 (COVID19), typhoid fever, etc.

Recent global crises have brought into sharp relief the absolute necessity of resilient health systems that can recognize and react to societal crises [15]. This has resulted in resilience

\section{References}

[1]. Kruk, M.E., Myers, M., Varpilah, S.T. \& Dahn, B.T., 2015, What is a Resilient Health System? Lessons from Ebola. The Lancet, 385: 1910-12.

[2]. Chimusoro, A., Maphosa, S., Manangazira, P., Phiri, I., Nhende, T., Danda, S., Tapfumanei, O., Midzi, S.M. \& Nabyonga-Orem, J., 2018. Responding to Cholera Outbreaks in Zimbabwe: Building Resilience over time. Current Issues in Global Health.

[3]. Mills, A., 2017, Resilient and responsive health systems in a changing world, Health Policy and Planning, Volume 32, Issue suppl_3, November 2017, Pages iii1-iii2, https://doi.org/10.1093/heapol/czx117.

[4]. World Health Organization, 2016, Investing in Knowledge for Resilient Health Systems: Strategic Plan 2016-2020.

https://apps.who.int/iris/bitstream/handle/10665/204 806/WHO_HIS_HSR_16.1_eng.pdf?s.

[5]. Witter, S and Hunter, B., 2017, Resilience of health systems during and after crises - what does it becoming the new buzz word in international health policy debates as a way of thinking about how health systems cope with significant external shocks, like the Ebola crisis of 20142015, which is still ongoing. Further research can build on these insights to deepen understanding.

\section{Conclusion}

This was a critical review of Chimusoro et al's article 'Responding to Cholera Outbreaks in Zimbabwe: Building Resilience over Time'. The content, structure, strengths and limitations of the article were analyzed and critiqued. The article has contributed to literature and provides a basis for achieving resilience, improving public health action and indicates areas for further development of the knowledge base of health systems research. It sets a benchmark to other countries seeking to build resilience, develop and strengthen their health systems amidst the context of adversity such as economic meltdown and disease outbreaks such as cholera and the COVID-19 pandemic. However, it is suggested that the concept of responsiveness be re-emphasized and paired with resilience to improve the performance of health systems.

mean and how can it be enhanced? Health systems during and after crisis: evidence for better policy and practice: Brief 1: Rebuild Consortium. https://rebuildconsortium.com/media/1535/rebuild_b riefing_1_june_17_resilience.

[6]. Olu O., 2017, Resilient Health System as Conceptual Framework for Strengthening Public Health Disaster Risk Management: An African Viewpoint. Frontiers in public health, 5, 263. doi:10.3389/fpubh.2017.00263.

[7]. Fridell, M., Edwin, S., von Schreeb, J., \& Saulnier, D. D, 2020, Health System Resilience: What Are We Talking About? A Scoping Review Mapping Characteristics and Keywords. International journal of health policy and management, 9(1), 6-16 https://doi.org/10.15171/ijhpm.2019.71.

[8]. Biddle, L, Wahedi, K, Bozorgmehr, K., 2020, Health system resilience: a literature review of empirical research, Health Policy and Planning, Volume 35, Issue 8, pages 1084-1109, https://doi.org/10.1093/heapol/czaa03. 
[9]. Darby, C, Valentine, N, Murray, C.J.L. \& De Silva, A., 2000, World Health Organization: Strategy on Measuring Responsiveness. GPE Discussion Paper Series No. 23. EIP/GPE/FAR W.H.O.

https://www.researchgate.net/publication/268295796 _World_Health_Organization_WHO_Strategy_on_ Measuring_Responsiveness.

[10]. Mirzoev T, Kane S, 2017, What is health systems responsiveness? Review of existing knowledge and proposed conceptual framework. BMJ Glob Health. 2017;2: e000486. doi:10.1136/ bmjgh-2017-000486.

[11]. Kruk ME, Ling EJ, Bitton A, Cammett M, Cavanaugh K, Chopra M, et al., 2017, Building resilient health systems: a proposal for a resilience index. Biomedical Journal BMJ; 23:357-j2323.

[12]. Nuzzo, J.B., Meyer, D., Snyder, M. et al., 2019, What makes health systems resilient against infectious disease outbreaks and natural hazards? Results from a scoping review. BMC Public Health 19, 1310 (2019). https://doi.org/10.1186/s12889019-7707-z.

[13]. USAID, 2019, From Fragile to Resilient Health Systems: A Journey to Self-Reliance. https://www.usaid.gov/documents/1864/fragileresilient-health-systems-journey-self-reliance.

[14]. Food and Agriculture Organization of the United Nations, 2015, Climate Change and Food Security: Risks and Responses. http://www.fao.org/3/a-i5188e.pdf.

[15]. Gilson L, Barasa E, Nxumalo N, et al., 2017, Everyday resilience in district health systems: emerging insights from the front lines in Kenya and South Africa. BMJ Global Health; 2: e000224. 


\title{
Point of Care (POC) for Early Infant Diagnosis (EID) in Nigeria? Healthcare Workers Opinion
}

\author{
Busari Olusegun \\ ${ }^{1}$ Department of Public Health, Texila American University, Guyana
}

\begin{abstract}
Without access to life-saving drugs, including antiretroviral, about one-third of HIV exposed infants (HEI) will die by age 1 year and 50\% by age 2 years. A $75 \%$ reduction in disease progression and $76 \%$ reduction in HIV mortality in infants has been attributed to early diagnosis of HIV and early commencement on ART. Early Infant Diagnosis (EID) of HIV aids timely commencement on antiretroviral therapy $(A R T)$. Several challenges have been identified with the current process. Point of care (POC) technologies are recommended as a veritable means of addressing these challenges and improving EID uptake. With the aim of assessing the standard of care and the acceptability of POC for the provision of EID. A descriptive cross-sectional survey was conducted across eight healthcare facilities in Nigeria. The survey was conducted among 72 healthcare workers using self-administered questionnaire; with a recovery rate of $61(84.7 \%)$. Analysis of participants' responses indicate that $100 \%$ of the respondents believes there is a need for EID. Most respondent reported an average turnaround time (TAT) of 3-4 weeks (35.8\%) and >6 weeks (34.0\%). Most respondents identified distance to the PCR laboratories (45.7\%) and long TAT (34.8\%) as key issues affecting the conduct of EID. On the benefit of POC for EID; $90.2 \%$ of respondent believe it is beneficial; while $81.5 \%$ of respondent believe that with the introduction and use of POC for EID there will be an increase in EID uptake. The POC is a viable and acceptable alternative for EID to increase uptake.
\end{abstract}

Keywords: Early Infant Diagnosis, HIV/AIDS, Point of Care.

\section{Introduction}

Despite four (4) decades of the fight against the HIV/AIDS epidemic, the scourge, its impact, and its effects are still with us. Infants and children are one of the population groups that are highly affected by the HIV epidemic due to the aggressive course of the infection in them. About one-third of infants will die by age 1 year and $50 \%$ by age 2 years; without access to life-saving drugs; including antiretroviral [1]. As of 2018, 1.7 million children are estimated to be living with the HIV disease globally; $91 \%$ of them are in the sub-Saharan Africa region. Also, the region accounted for $88.8 \%(146,000)$ of the total global new infection, and $87 \%$ of the global AIDS-related death; among children $0-14$ years [2].

Globally, new infection in children has been attributed largely to mother to child transmission. Prevention of Mother to Child Transmission (PMTCT) programs provides a range of services to women and infants to prevent HIV infection, reduce perinatal, intrapartum, and postnatal HIV transmission and curb AIDS-related death. A critical part of this is the Early Infant Diagnosis (EID) of HIV. Early Infant Diagnosis of HIV is very critical as it aids the prompt identification of infants infected with the virus for the timely commencement of the lifesaving antiretroviral (ART) drugs. This is further emphasized with the evidence of a $75 \%$ reduction in disease progression and a $76 \%$ reduction in HIV mortality in infants attributed to early diagnosis of HIV and early commencement on ART [3].

EID involves the detection of HIV infection in children less than 18 months using the nucleic acid based virological assay. This is specific, reliable, and recommended by the World Health Organization (WHO). Traditionally, the virological assay is provided by centralized PCR laboratories, however, bedeviled by several challenges. With only $58.7 \%$ of HIV Exposed Infants having access to virological test within the first 2 months of life globally in 2018, [2] the challenges with access to EID is obvious. These challenges have been documented in many 
studies to include loss of samples, long turnaround time (TAT), backlogs in sample processing, inefficient sample transport, long equipment downtime, and stock out of reagents among others [4]. This continues to contribute to high loss to follow-up (LTFU) and consequently infected infants are not identified and do not receive the treatment they need. Even though these challenges are similar, however, the impacts are to varying degrees across the different regions and countries.

In 2018, Nigeria has the highest new infection and AIDS-related death in children (0-14 years), globally. However, only $23.8 \%$ of HIV-exposed infants received an EID test and $35 \%$ of children living with HIV received treatment (UNAIDS, 2019). Virological testing for Early Infant Diagnosis is provided through centralized PCR laboratories and relying on the sample referral network for the transportation of samples and return of results. The earliest return of results from the centralized laboratory has been documented as 3 months and 5.6 months, even with $81.7 \%$ and $62.3 \%$ collection of DBS samples within the stipulated 2 months respectively [5,6]. Documented challenges with EID are similar to other sub-Saharan countries [7].

Point of care (POC) technologies provide a platform for the provision of virological based testing outside the traditional centralized laboratories hence, a means to improve access to Early Infant Diagnosis (EID). This has been recommended as a key game-changer in achieving a prompt diagnosis of HIV in infants and timely initiation on treatment [8]. Point of Care tools are tests which can be carried out near the patient or at the treatment facility, thereby allowing for prompt diagnosis and/or client management [9]. It is usually rapid in providing test results with resultant positive impact on diagnosis, patient management and disease surveillance. In resource-limited settings, studies have identified the restricted availability of laboratory -based clinical management as part of major factors causing the lack of qualified health care and poor disease outcomes [10]. To bridge this gap in many disease epidemic, POC test has been employed to mitigate unmet diagnostic capabilities. The use of the POC test for high-burden infectious disease in endemic region has been estimated to save over one million lives annually due to improved clinical management [11].

For Early Infant Diagnosis of HIV infection, several benefits have been alluded to the POC technologies. These include-shorter test Turnaround Time (TAT) which allow results to be returned during the same visit, thereby significantly reducing Loss to Follow Up (LFTU) and allows for immediate clinical management decisions to impact patient care and improve patient retention; reduction in the burden of managing an extensive sample transportation network, particularly in hard-toreach places; and ease of use as it can be operated by health workers lacking specialized laboratory skills. In Mozambique, the introduction of the point of care (POC) EID testing was found to have a significant impact on TAT-0 days TAT with POC compared with 127 days with the standard of care (POC) using the centralized laboratories. Result return was $95 \%$ and $65 \%$ with the POC and the SOC, respectively. While $89.7 \%$ of children were initiated in the POC EID arm, an abysmal $12.8 \%$ were initiated on the SOC arm [12]. Another retrospective study across eight (8) African countries indicates, $92.3 \%$ prompt ART initiation in HIV positive infants in the POC arm and $43.3 \%$ in the SOC arm. Result return to guardians/parent of infants was $98.3 \%$ and $18.7 \%$ in the POC and SOC arms respectively [13].

Despite the gaps in Early Infant Diagnosis of HIV infections and the high AIDS related death rate among infants and children, Nigeria is yet to introduce the Point of Care EID; notwithstanding its attendant benefit to address these challenges as seen in other sub-Saharan Africa countries. Also, no study has been conducted on the view of healthcare workers on the introduction and acceptability of a POC for EID in Nigeria. With the aim of assessing the standard of care and the acceptability of POC for the provision of EID in Nigeria, a descriptive cross-sectional survey was conducted across selected healthcare facilities. The opinion of healthcare workers was sought on the need and possible introduction of Point of Care (POC) Early Infant Diagnosis (EID) in Nigeria. It is hoped that this insight will provide perspectives on the current situation and challenges with the standard of care; the need for the Point of Care EID, its acceptability to healthcare worker 
hence; necessary information to guide its introduction and implementation in Nigeria.

\section{Materials and Methods}

\section{Study Setting}

The study was conducted across eight (8) healthcare facilities in three (3) states-Kaduna, Kogi, and Benue-located within the north-west and north-central geopolitical zone of Nigeria states. The healthcare facilities provide Early Infant Diagnosis through sample referral to the Centralized PCR laboratories. Also, the location of the healthcare facilities cuts across urban, peri-urban, and rural areas; as well as the three (3) levels of the health systems in NigeriaPrimary, Secondary, and Tertiary healthcare levels.

\section{Study Population}

The study population were healthcare workers with direct or indirect responsibilities linking to the provision or use of EID. All healthcare workers were located within the north-east and north-west region of Nigeria.

\section{Sampling}

Health facilities were selected across the 3 states based on 1-year historical volume of HIV Exposed Infants accessing virological testing. Purposive sampling method was employed in recruiting participants. Only health care workers with direct or indirect responsibilities linking with the provision or use of EID within the selected health facilities were recruited for the study.

\section{Study Design}

This was a descriptive cross-sectional survey of the opinion of frontline healthcare workers across 8 healthcare facilities in the north-west and north-central Nigeria; on Early Infant Diagnosis (EID). Healthcare worker's opinion was abstracted through the administration of a structured questionnaire. Healthcare facilities were selected to cut across the urban, peri-urban, and rural areas as well as the 3 levels of healthcare systems in Nigeria - Primary, Secondary, and Tertiary.

\section{Study Instruments}

The study instrument was a structured selfadministered questionnaire which was used to abstract healthcare workers opinion to provide data as it relates to the Standard of Care for EID, current challenges as well as need and acceptability of a Point of Care for EID. Information including designation, location of practice, gender, and qualification was documented. Informed Consent was secured before the administration of the questionnaire and confidentiality ensured.

\section{Data Management and Analysis}

Qualitative data were extracted from the completed structured self-administered questionnaires. Descriptive analysis was carried out to summarize the outcome measures and the background characteristics of all study participants using percentages for categorical variables and mean, median and standard deviations for quantitative variables. The results were presented as frequency tables, graphs, and percentages as appropriate. The analysis was both descriptive and inferential with values set at 95\% confidence level, a p-value of 0.05 was considered significant. All Analyses will be carried out using Stata version 14 (StataCorp, College Station, Texas, USA); and statistical level of significance set at $\mathrm{P}$-value $\leq 0.05$.

\section{Ethical Considerations}

Ethical approvals were obtained from the Kaduna, Benue, and Kogi States Ministry of Health Research and Ethics Review Committee. Written informed consent was obtained from all participants before the administration of the questionnaire.

\section{Results}

\section{Socio-demographic Characteristics of Participants}

This study was conducted among 72 healthcare workers across 8 healthcare facilities in the 3 states of Kaduna, Kogi and Benue; located within north-west and north-east Nigeria. The questionnaire was selfadministered and only 61 participants completed and returned the questionnaire; giving a recovery rate of $84.7 \%$. Analysis of the reported designation by participants indicate the highest as Laboratory personnel and Nurses; 40.98\% and $26.3 \%$ respectively (See Table 2). As regards gender, $56 \%$ of the respondents were male and $44 \%$ were female (See Table 1). The years of experience of respondents (healthcare workers) ranges between 3-35 years; however, 
most respondents $(82.0 \%)$ have professional experience within 3-10 years (See Table 3). The educational qualification of respondents is largely tertiary level (98.3\%).

Table 1. Distribution of Respondents (Health Care Providers) Based on Gender

\begin{tabular}{|l|l|l|}
\hline Sex & Frequency $(\mathbf{n})$ & Percentage (\%) \\
\hline Male & 27 & 44.26 \\
\hline Female & 34 & 55.74 \\
\hline Total & 61 & 100.00 \\
\hline
\end{tabular}

$\bar{x}=30.5, \tilde{x}=30.5$

Table 2. Distribution of Respondents (Health Care Providers) Based on Designation

\begin{tabular}{|l|l|c|}
\hline Designation & Frequency (n) & Percentage (\%) \\
\hline Doctor & 1 & 0.02 \\
\hline Nurse & 16 & 26.23 \\
\hline Pharmacist & 6 & 9.84 \\
\hline Laboratory Scientist & 25 & 40.98 \\
\hline Community Health Extension Workers (CHEW) & 4 & 6.56 \\
\hline Others & 9 & 14.75 \\
\hline Total & $\mathbf{6 1}$ & $\mathbf{1 0 0 . 0 0}$ \\
\hline
\end{tabular}

Table 3. Distribution of Respondents (Health Care Providers) Based on Gender

\begin{tabular}{|l|l|l|}
\hline Year(s) of Experience & Frequency $(\mathbf{n})$ & Percentage (\%) \\
\hline $1-5$ & 37 & 60.66 \\
\hline $6-10$ & 13 & 21.31 \\
\hline $11-15$ & 3 & 4.92 \\
\hline $16-20$ & 3 & 4.92 \\
\hline $21-25$ & 1 & 1.64 \\
\hline $26-30$ & 2 & 3.28 \\
\hline$>30$ & 2 & 3.28 \\
\hline Total & $\mathbf{6 1}$ & $\mathbf{1 0 0 . 0 0}$ \\
\hline
\end{tabular}

$$
\bar{x}=30.5, \tilde{x}=30.5
$$

Table 4. Health Care Providers Opinion on Current EID Processes and the Need for POC EID

\begin{tabular}{|l|l|l|l|}
\hline Questions & Options & Responses (n) & Percentage (\%) \\
\hline \multirow{2}{*}{$\begin{array}{l}\text { Does your job involve working on the Early } \\
\text { Infant Diagnosis of HIV exposed Infant }\end{array}$} & Yes & 43 & 79.6 \\
\cline { 2 - 4 } & No & 11 & 20.4 \\
\cline { 2 - 4 } & No Response & 7 & 11.5 \\
\hline \multirow{2}{*}{$\begin{array}{l}\text { In your opinion, is there a need for Early } \\
\text { Infant Diagnosis? }\end{array}$} & Yes & 57 & 93.4 \\
\cline { 2 - 4 } & No & 0 & 0.0 \\
\cline { 2 - 4 } & No Response & 4 & 6.6 \\
\hline \multirow{2}{*}{$\begin{array}{l}\text { Is the PCR test for Early Infant Diagnosis } \\
\text { carried out in your facility? }\end{array}$} & Yes & 0 & 0.0 \\
\cline { 2 - 4 } & No & 52 & 85.3 \\
\cline { 2 - 4 } & No Response & 9 & 14.7 \\
\hline \multirow{2}{*}{$\begin{array}{l}\text { How often do you send Dried Blood } \\
\text { laboratory? }\end{array}$} & Weekly & 31 & 50.8 \\
\cline { 2 - 4 } & Every 2 weeks & 18 & 29.5 \\
\cline { 2 - 4 } & $>2$ weeks & 4 & 6.6 \\
\cline { 2 - 4 } & No Response & 8 & 13.1 \\
\hline & $1-2$ weeks & 6 & 9.8 \\
\hline
\end{tabular}




\begin{tabular}{|c|c|c|c|}
\hline \multirow{4}{*}{$\begin{array}{l}\text { How long does it typically take to get results } \\
\text { for EID? }\end{array}$} & $3-4$ weeks & 19 & 31.2 \\
\hline & $5-6$ weeks & 10 & 16.4 \\
\hline & $>6$ weeks & 18 & 29.5 \\
\hline & No Response & 8 & 13.1 \\
\hline \multirow{5}{*}{$\begin{array}{l}\text { What is the average distance (in Kilometers) } \\
\text { from your facility to the PCR laboratory? }\end{array}$} & $<100 \mathrm{~km}$ & 14 & 22.9 \\
\hline & $101-102 \mathrm{~km}$ & 12 & 19.7 \\
\hline & $201-400 \mathrm{~km}$ & 7 & 11.5 \\
\hline & $>400 \mathrm{~km}$ & 19 & 31.1 \\
\hline & No Response & 9 & 14.8 \\
\hline \multirow{5}{*}{$\begin{array}{l}\text { What is the average number of Dried Blood } \\
\text { Specimen you collect within a week? }\end{array}$} & $<10$ & 39 & 63.9 \\
\hline & $10-49$ & 10 & 16.4 \\
\hline & $50-100$ & 4 & 6.6 \\
\hline & $>100$ & 0 & 0.0 \\
\hline & No Response & 8 & 13.1 \\
\hline \multirow{5}{*}{$\begin{array}{l}\text { What issue have you identified with the } \\
\text { conduct of EID in your facility }\end{array}$} & Stock out & 9 & 14.8 \\
\hline & Long TAT & 16 & 26.2 \\
\hline & Distance to the PCR Lab & 21 & 34.4 \\
\hline & Others & 0 & 0.0 \\
\hline & No Response & 15 & 24.6 \\
\hline \multirow{3}{*}{$\begin{array}{l}\text { Are you aware of a Point of Care (POC) test } \\
\text { for Early Infant Diagnosis? }\end{array}$} & Yes & 42 & 68.9 \\
\hline & No & 12 & 19.7 \\
\hline & No Response & 7 & 11.4 \\
\hline \multirow{4}{*}{$\begin{array}{l}\text { Would the introduction of a Point of Care } \\
\text { (POC) Early Infant Diagnosis (EID) be } \\
\text { beneficial? }\end{array}$} & Yes & 46 & 75.4 \\
\hline & No & 0 & 0.0 \\
\hline & Not Sure & 5 & 8.2 \\
\hline & No Response & 10 & 16.4 \\
\hline \multirow{6}{*}{$\begin{array}{l}\text { On a scale of } 1-5,(5 \text { being the highest and } \\
1 \text { the lowest), how would you rate the need } \\
\text { for a Point of Care (POC) equipment on } \\
\text { Early Infant Diagnosis (EID) in your facility }\end{array}$} & 5 & 15 & 24.6 \\
\hline & 4 & 13 & 21.3 \\
\hline & 3 & 13 & 21.3 \\
\hline & 2 & 7 & 11.5 \\
\hline & 1 & 2 & 3.3 \\
\hline & No Response & 11 & 18.0 \\
\hline \multirow{4}{*}{$\begin{array}{l}\text { Would the use of the Point of Care increase } \\
\text { patient uptake of EID? }\end{array}$} & Yes & 44 & 72.1 \\
\hline & No & 2 & 3.3 \\
\hline & Not Sure & 8 & 13.1 \\
\hline & No Response & 7 & 11.5 \\
\hline \multirow{4}{*}{$\begin{array}{l}\text { Which would be your preferred method for } \\
\text { EID testing within your facility? }\end{array}$} & Point of Care & 7 & 75.4 \\
\hline & PCR Laboratory & 21 & 0.0 \\
\hline & Both & 21 & 8.2 \\
\hline & No Response & 12 & 16.4 \\
\hline
\end{tabular}




\section{Opinion on the Current Processes for the Standard of Care}

Analysis of participants' responses indicate that $100 \%$ of the respondents believes there is a need for Early Infant Diagnosis. Across the eight healthcare facilities; $87.3 \%$ submitted that the method for EID sample collection is Dried Blood Spot. (DBS) while $12.7 \%$ reported venous blood sample. $100 \%$ of respondents reported that the PCR laboratory is located outside the health facility hence they rely on sample transfer to the centralized PCR laboratory. On the frequency for sending samples to the PCR laboratory, $58.5 \%$ of respondents submitted that samples are sent weekly to the PCR laboratories, $34.0 \%$ biweekly and $7.5 \%$ greater than 2 weeks. The average turnaround time (TAT) for the receipt of EID results was reported as 3-4 weeks by $35.8 \%$ of respondent, $>6$ weeks by $34.0 \%$ of respondents, 5-6 weeks by $18.9 \%$ of respondents and 1-2 weeks by $11.3 \%$ of respondents. About $73.6 \%$ of the respondent reported an average of 10 DBS samples collected weekly. Greater number of respondent $(45.7 \%)$ identified distance to the PCR laboratories as a key issue affecting the conduct of EID. Other's issues identified by respondent include long TAT (34.8\%) and reagent stock out $(19.6 \%)$.

\section{Awareness and Need for Point of Care}

Based on the analysis of the responses; $77.8 \%$ of respondents are aware of the existence of a point of care platform for Early Infant Diagnosis; $23.2 \%$ of respondents are however not aware. In response to the question on the benefit of POC for EID; $90.2 \%$ of respondent believe it is beneficial, while $9.8 \%$ are not sure of the benefit of the POC for EID. No respondent has the opinion that the POC for EID is not beneficial. When asked to rate the need for a POC for EID on a scale of $1-5$, altogether $82 \%$ rated the need for POC for EID as $5(30 \%)$, $4(26 \%)$ and $3(26 \%)$. Opinion on the effect of POC use on EID uptake indicate that $81.5 \%$ of respondent believe that with the introduction and use of POC for EID there will be an increase in EID uptake.

\section{Discussion}

With the aim of assessing the current situation and attendant challenges with the standard of care for the provision of Early Infant Diagnosis as well as the need and acceptability of Point of Care testing; a descriptive cross-sectional survey was conducted across eight healthcare facilities. The survey was conducted among 72 healthcare workers using self-administered questionnaire with $84.7 \%$ (61) recovery rate.

Based on the respondents, the method for sample collection across the healthcare facility is mainly through the use of Dried Blood Spot (DBS). The use of the DBS is an innovation which is targeted at mitigating the challenges of strict sample transfer procedure required for venous blood. It is in line with the WHO recommendation and it is expected that with these challenges addressed there should be a significant reduction in the turnaround time. However, most respondents reported an average turnaround time of 3-4 weeks (34.0\%) and >6 weeks $(34.0 \%)$. In the Healthy Baby Initiative "Baby Shower "study conducted in south eastern Nigeria, [14] reported an average turnaround time of 5.6 months. In the same vein, [6] reported 3 months' average turnaround time in the MoMENt study conducted in north central Nigeria. This aligns with the opinion of the respondents and establishes the issue of long TAT with the standard of care in Nigeria.

According to the submission of the respondents, the major key issues identified were distance to the PCR laboratory (45.7\%) and long TAT (34.8\%). These aligns with the reported issues at the Moment study. One can easily relate to the challenge of distance to the centralized PCR laboratories in Nigeria. With a land mass of 923, $768 \mathrm{~km}$, several difficult terrains and long distances to the centralized PCR laboratories; accessibility is always a challenge. Out of the 52 participants that responded to the question on the average distance from the heath facility to the centralized PCR laboratories; $36.5 \%$ reported an average of $>400 \mathrm{~km}$, while $36.6 \%$ reported an average of 100-400km.

Despite the non-existence of the Point of Care platform for EID in Nigeria; it is of interest to note that $77.8 \%$ of respondents reported that they are aware of the existence of a POC for EID. On the possible benefit of POC for EID, 90.2\% of respondent reported that it would be beneficial, with $81.5 \%$ of respondents indicating that the introduction of the POC will increase the uptake of EID. With the attendant challenges of the SOC, alternatives to ensure the provision of 
timely EID and prompt commencement of treatment is a key concern of frontline healthcare workers. The analyzed responses above indicate the willingness and acceptability of the Point of care for Early Infant Diagnosis by healthcare workers.

One of the eluded benefits of the SOC is the ability to pool samples and analyze many samples at a time however, the POC can only analyze a minimal number of samples at a time. It therefore pertinent to note that the reported $<10$ Dried Blood Spot (DBS) collected per week by $73.5 \%$ participants who responded to the question affirm the applicability of the POC equipment in a lot of places.

\section{Conclusion}

With a focus on the opinion of frontline health care workers on the current situation and need/acceptability of Point of Care testing for the provision of Early Infant Diagnosis; this study concludes that there are attendant challenges with the SOC in Nigeria which has limited the uptake of EID, early diagnosis of HIV exposed infants and prompt commencement of antiretroviral therapy in infants. The Point of Care testing for EID is a viable and acceptable alternative to increase EID uptake and hence prompt commencement on treatment and saving of lives.

\section{References}

[1] WORLD HEALTH ORGANIZATION (WHO). Global Programme on AIDS, 1988. WHO Report Breastfeeding, breast milk and human immunodeficiency virus (HIV). Statement from the Consultation held in Geneva, 23-25 June, 1987. AIDS Action, (5), 1-2. Date of Access: 05/05/2020. https://pubmed.ncbi.nlm.nih.gov/12281628/.

[2] UNAIDS Data 2019. Date of Access: 06/05/2020 https://www.unaids.org/sites/default/files/media_ass et/2019-UNAIDS-data_en.pdf.

[3] WORLD HEALTH ORGASNIZATION, 2011. The interagency task team on the prevention and treatment of HIV infection in pregnant women, mothers and children (IATT) Annual meeting report (2-3 May 2011), Geneva, Switzerland). Date of Access: 01/03/2020.

https://apps.who.int/iris/bitstream/handle/10665/446 37/9789241501927_eng.pdf;jsessionid=92F8E333F D82CE0F5BE7461D59C7F1C7? sequence=1.

[4] Anisa Ghadrshenas, Yanis B. Amor, Joy Chang, Helen Dale. et. al. 2013. Improved access to early infant diagnosis is a critical part of a child-centric prevention of mother-to-child transmission agenda. AIDS 2013, 27 (Suppl. 2): S197-S205. Date of Access: 13/03/2020

https://journals.lww.com/aidsonline/Fulltext/2013/1 1002/Improved_access_to_early_infant_diagnosis_i s_a.8.aspx.

[5] Carlucci, J. G., Liu, Y., Friedman, H., Pelayo, B. E., Robelin, K., Sheldon, E. K., Clouse, K., \& Vermund, S. H. 2018. Attrition of HIV-exposed infants from early infant diagnosis services in lowand middle-income countries: a systematic review and meta-analysis. Journal of the International AIDS Society, 21(11), e25209. Date of Access: 15/5/2020 https://doi.org/10.1002/jia2.25209.

[6] Udochisom C. Anaba, Nadia A. Sam-Agudu, Habib O. Ramadhani, Nguavese Torbunde, Alash'le Abimiku, Patrick Dakum, Sani H. Aliyu, Manhattan Charurat, 2019. Missed opportunities for early infant diagnosis of HIV in rural North-Central Nigeria: A cascade analysis from the INSPIRE MoMent study. PLoS ONE. Date of Access: 15/5/2020. https://doi.org/10.1371/journal.pone.0220616.

[7] Isah HO, Ogum E, Cornelius LJ, Okundaye JN, Galadanci H, Charurat ME, et al. 2014. The MoMent Study: Client- and Community-Level Barriers to PMTCT Access and Uptake in Rural North-Central Nigeria. 8th INTEREST (International Workshop on HIV Treatment, Pathogenesis, and Prevention Research in Resource-Poor Settings) Workshop; Lusaka, Zambia. p. 45. Date of Access: 15/5/2020. http://regist2.virology-

education.com/abstractbook/2014_3.pdf.

[8] WORLD HEALTH ORGANIZATION (WHO) The treatment 2.0 framework for action: catalysing the next phase of treatment, care and support. (2011). The World Health Organization (WHO) publication 2011. Date of Access: 03/05/2020. https://apps.who.int/iris/bitstream/handle/10665/446 40/9789241501934_eng.pdf;jsessionid=01FAF23E0 5BA02AA84E195D24277E22D?sequence $=1$.

[9] Schito M, Peter TF, Cavanaugh S, Piatek AS, Young GJ, Alexander H, Coggin W, Domingo GJ, Ellenberger D, Ermantraut E, Jani IV, Katamba A, Palamountain KM, Essajee S, Dowdy DW. 2012. Opportunities and challenges for cost-efficient implementation of new point-of-care diagnostics for HIV and tuberculosis. J Infect Dis. 2012 May 15; 205 Suppl 2(): S169-80. Date of Access: 29/06/2020. https://academic.oup.com/jid/article/205/suppl_2/S1 69/805866.

[10] Urdea M, Penny LA, Olmsted SS, Giovanni MY, Kaspar P, Shepherd A, Wilson P, Dahl CA, 
Buchsbaum S, Moeller G, Hay Burgess DC, 2006. Requirements for high impact diagnostics in the developing world. Nature. 2006 Nov 23; 444 Suppl 1():73-9. Date of Access: 29/06/2020. https://www.nature.com/articles/nature05448.

[11] Burgess DCH, Wasserman J, Dahl CA, Girosi F, Olmsted SS, Keeler EB, et al. 2007. Estimating the Global Health Impact of Improved Diagnostic Tools for the Developing World. Santa Monica, CA: RAND Corporation; 2007. Date of Access: 29/06/2020. http://www.rand.org/pubs/research_briefs/RB9293.h tml.

[12] Jani IV, Meggi B, Loquiha O, et al. Effect of point-of-care early infant diagnosis on antiretroviral therapy initiation and retention of patients. AIDS. 2018;32(11):1453-1463. doi:10.1097/QAD.0000000000001846.

[13]Flavia Bianchi, Jennifer Cohn, Emma Sacks, Rebecca Bailey, Jean-Francois Lemaire and Rhoderick Machekano. 2019. Evaluation of a routine point-of-care intervention for early infant diagnosis of HIV: an observational study in eight African countries. The Lancet HIV Volume 6, Issue 6, June 2019, Pages e373-e38. Date Accessed: 15/5/2020. https://doi.org/10.1016/S2352-3018(19)30033-5.

[14]Pharr, Jennifer R., Obiefune, Michael C.; Ezeanolue, Chinenye O.; Osuji, Alice; Ogidi, Amaka G.; Gbadamosi, Semiu, Patel, Dina, Iwelunmor, Juliet; Yang, Wei; Ogedegbe, Gbenga; Ehiri, John E.; Sam-Agudu, Nadia A.; Ezeanolue, Echezona E. 2016. Linkage to Care, Early Infant Diagnosis, and Perinatal Transmission Among Infants Born to HIVInfected Nigerian Mothers: Evidence from the Healthy Beginning Initiative, JAIDS Journal of Acquired Immune Deficiency Syndromes: August 1, 2016 - Volume 72 - Issue - p S154-S160. Date of Access:

5/04/2020.https://doi.org/10.1097/QAI.0000000000 001051. 


\title{
Accuracy and Feasibility of Point of Care (POC) Early Infant Diagnosis (EID) in Nigeria: A Field Evaluation
}

\author{
Busari Olusegun \\ Department of Public Health, Texila American University, Guyana
}

\begin{abstract}
The timely commencement of treatment within the first 12 weeks of life in children reduces the HIV disease progression by $75 \%$ and mortality by $76 \%$. For all children infected with HIV to receive essential treatment and care, few things are more important than early and accurate HIV diagnosis. Traditional methods of providing Early Infant Diagnosis (EID) have been bedeviled with several challenges. Point of Care (POC) testing for EID has been recommended as a game-changer. A field evaluation was conducted across 6 healthcare facilities between February 2017 and August 2018 to determine the accuracy and operational feasibility of POC testing for EID in Nigeria. The conceptual framework rides on the WHO SDI ASSURED criteria. Participants were infants aged between 4 weeks and 18 months born to HIV-positive mothers and visiting the clinic for the first time for EID. Results obtained from the POC was compared with the Standard of Care (SOC) to determine accuracy and feasibility. A total of 245 participants took part in the study, with $76 \%$ visiting the clinic for EID within 2 months of life. The average turnaround time for EID test using the SOC was 67 days. Analysis of the $10.4 \%$ error rate indicate significant correlation by personnel $(r=0.01122, P=0.841706)$. An average concordance percentage of $99.6 \%$, sensitivity of $91.7 \%$ and specificity of $100.0 \%$ was observed. Operator's assessment indicates that the equipment is very good and acceptable. The POC testing for EID is acceptable, rapid, and robust; hence, viable for use in Nigeria.
\end{abstract}

Keywords: Early Infant Diagnosis, HIV/AIDS, Point of Care.

\section{Introduction}

Early diagnosis of HIV and the commencement of HIV-infected infants on ART within the first 12 weeks of life can save a significant number of lives [1]. Without access to treatment, which is determined by early diagnosis, about one-third of HIV-infected infants will die by age 1 year, and $50 \%$ by age 2 years [2]. Evidence has shown that the timely commencement of treatment in children reduces the disease progression by $75 \%$ and mortality from the infection by $76 \%$. However, only $54 \%$ of children living with HIV globally are on lifesaving antiretroviral therapy. In the sub-Saharan Africa region, which accounts for $91 \%$ of the 1.7 million children living with HIV/AIDS globally, ART coverage in children is 52\%: with the West and Central Africa region having the lowest regional ART coverage globally-28.4\% [3].

For all children infected with HIV to receive essential treatment and care, few things are more important than early and accurate HIV diagnosis. Early Infant Diagnosis (EID) aids the early detection of HIV infection in children, detection of prenatal, intrapartum, and postnatal transmission of HIV infection, timely initiation and commencement of life-saving antiretroviral therapy for HIV positive infants; as well as identifying successful prevention of mother to child transmission of HIV in HIV negative children [4].

Despite the many benefits of Early Infant Diagnosis, its uptake has been bedeviled with several challenges; resulting in high attrition and loss to follow up among the mother-baby pair among others [5]. Notwithstanding the many innovative solutions to address these challenges; the proportion of HIV exposed infants (HEI) who had virological testing to assess HIV status remains low. As of 2018, globally only $58.7 \%$ of infants born to pregnant women living with HIV had a virological test for HIV within 2 months of birth; with the West and Central Africa regions having an abysmal coverage of $29.3 \%$ [3].

According to the UNAIDS 2019 report, $46.4 \%$ of new infections (Adults and Children) in the West and Central Africa region occurred 
in Nigeria. In children (0-14years), a total of 24,000 new infections and 14,000 AIDS-related deaths were recorded in Nigeria. This is the highest number of new infection and AIDSrelated death in children globally. However, only $23.8 \%$ of HIV-exposed infants received an EID test and $35 \%$ of children living with HIV received treatment in 20183. In Nigeria, virological testing for Early Infant Diagnosis is provided through centralized PCR laboratories and relying on the sample referral network for the transportation of samples and return of results. Studies have shown the earliest return of results from the centralized laboratory to be at 3 months and 5.6 months, even with $81.7 \%$ and $62.3 \%$ collection of DBS samples within the stipulated 2 months by Nigeria National guideline [5,6]. Documented challenges with EID are similar to other sub-Saharan countries including stock-out of DBS commodities, collection of DBS samples only on a few designated days long TAT, delayed result return leading to loss to follow up (LTFU) and suboptimal sample referral network efficiency among others $[7,8]$.

Three (3) innovative approaches an early infant testing, expanded postnatal prophylaxis (ePNP); and Point of Care nucleic acid testinghas been recommended by the World Health Organization (WHO) as game changers in achieving prompt diagnosis of HIV in infants and initiation on treatment. The use of Point of Care (POC) nucleic acid testing has been shown to significantly increase access and uptake of EID by providing the platform for HIV nucleic acid testing at the point of service delivery, outside of the centralized laboratories. Also, notable advantages which impact patient outcomes have been alluded to POC technologies $[9,10]$. Currently, while expanded, postnatal prophylaxis (ePNP) are provided for HIV exposed infants; the use of point of care (POC) technologies for providing early infant diagnosis is yet to be introduced in Nigeria; despite several POC EID equipment evaluated and in use across some countries in sub-Saharan Africa. The Alere ${ }^{\mathrm{TM}} \mathrm{q}$ platform employs the Alere $^{\mathrm{TM}}$ q HIV1/2 - Detect, which is a qualitative method using the nucleic acid-based test for Early Infant Diagnosis. This has been prequalified by the WHO in 2016 as a POC for
Early Infant Diagnosis of HIV and is in use across some sub-Saharan Africa countries [11]. With the main goal of addressing gaps in ensuring early and reliable diagnosis of HIV in infants and expand access to treatment, which is a critical consideration for HIV epidemic control in Nigeria; this study assessed the accuracy and operational feasibility of using a point of care testing for Early Infant Diagnosis in Nigeria.

\section{Materials and Methods}

\section{Study Setting}

The study was conducted across six (6) healthcare facilities in three (3) states-Kaduna, Kogi, and Benue-located within the north-west and north-central geopolitical zone of Nigeria states. The healthcare facilities cut across urban, peri-urban, and rural areas; as well as the three (3) levels of the health systems in Nigeria Primary, Secondary, and Tertiary healthcare levels. Nigeria has a high burden of HIV/AIDS, second only to South Africa by global ranking; with an HIV prevalence of $1.4 \%$ and an estimated 1,900,000 persons living with HIV.

\section{Study Population}

The study population was infants born to HIV-positive mothers aged between 4 weeks and 18 months and visiting the clinic for the first time for the virological Early Infant Diagnosis test between February 2017 and August 2018.

\section{Conceptual Framework}

Employing a mixed-method approach, the conceptual framework (see Figure 1) rides on the World Health Organization (WHO) Sexually Transmitted Diseases Diagnostics Initiative (SDI) ASSURED (Affordable, Sensitive, Specific, User-friendly, Rapid and robust, Equipment-free and Deliverable to end-users) criteria as a benchmark for point-of-care (POC) tests which are recommended for resource limited settings [12]. Of the 7 WHO SDI ASSURED criteria, 5 were assessed through a quantitative comparative analysis of the POC with the gold standard/ local SOC. The assessment of the other 2 criteria involved the use of a qualitative analysis leveraging standardized questionnaires to abstract users' perspectives. 


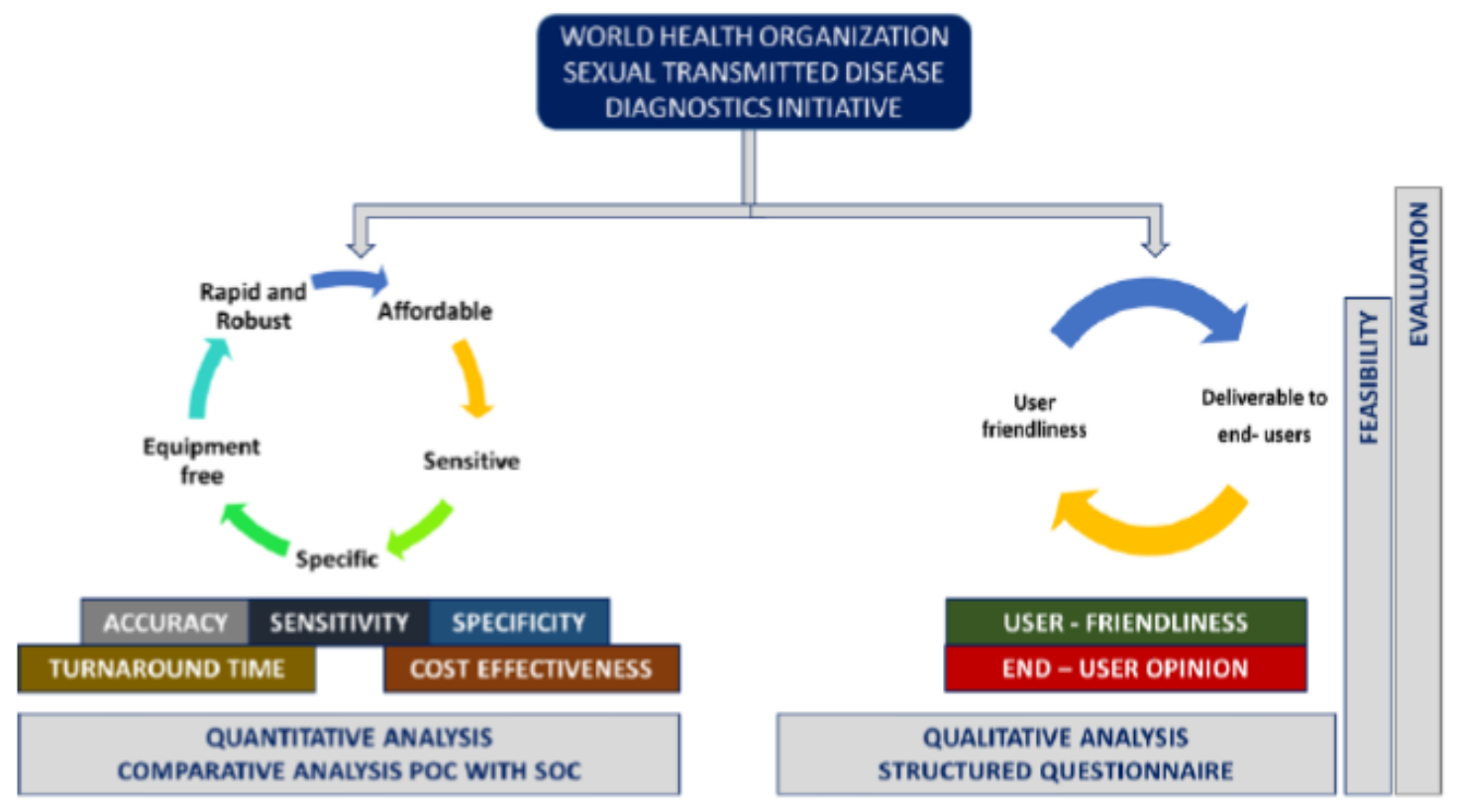

Figure 1. Conceptual Framework Based on WHO SDI Assured Criteria

\section{Study Design}

The study adopted a cross-sectional study design to evaluate the accuracy and feasibility of using the Point of Care (POC) N - Alere ${ }^{\mathrm{TM}} \mathrm{q}$ HIV-1/2 Detect - for Early Infant Diagnosis among HIV Exposed Infants across 2 tertiary, 3 secondary and 1 primary level healthcare facilities in Nigeria. All eligible and consenting participants were recruited consecutively across the states between February 2017 and August 2018. The selection of healthcare facilities was based on 1-year retrospective data on infant attendance. Written or thumb printed parental/guardian consent was requested for all infants to be enrolled. No infant was excluded based on gender, socioeconomic, racial, or ethnic grounds. Demographic information including gender and birth date for study participants were documented.

\section{Sample Size}

Sample size was calculated using the formula:

Where in,

$$
\text { Sample size, } \mathrm{n}=\mathrm{N} * \frac{\frac{Z^{2} * p *(1-p)}{e^{2}}}{\left[N-1+\frac{Z^{2} * p *(1-p)}{e^{2}}\right]}
$$

N, Population Size - 98,413.

(Total number of Infants (0-18 months born to HIV positive mothers in 2016).

$\mathrm{P}$, Population proportion $-18.9 \%$.
(Proportion of infants ( $0-18$ months) who had access to virological testing in 2016).

$\mathrm{Z}$, Critical Value at 95\% Confidence level 1.96.

e, Margin of error - $5 \%$.

The calculated Sample size is 235 .

\section{Sampling Technique}

Health facilities were selected across the 3 states based on 1-year historical volume of HIV Exposed Infants accessing virological testing. Consecutive sampling method was used in recruiting clients meeting the inclusion criteria for the evaluation study across 6 selected healthcare facilities. Written or thumb printed parental/guardian consent were requested for all infants to be enrolled. No infant was excluded on the basis of gender, socioeconomic, racial, or ethnic grounds. Demographic information including gender and birth date for study participants were documented.

\section{Procedure}

Group consent sessions were held for all clients visiting the clinic. This was followed by individual consent sessions where the criteria of participants to be part of the study are confirmed and individual consents documented. From each study participant, Dried Blood Spot (DBS) was collected for Early Infant Diagnosis (EID) using the Standard of Care (SOC). Six (6) blood spots were taken per each study participant and 
Quality Control verification carried out to ensure proper collection. During sample collection, $25 \mu \mathrm{l}$ of blood was collected and analyzed for Early Infant Diagnosis using the Alere ${ }^{\mathrm{TM}} \mathrm{q}$ HIV 1/2 Detect at the Point of Care (POC). Across each of the selected facilities, qualified healthcare workers who routinely collect Dried Blood Spot (DBS) were responsible for DBS sample collection and Alere ${ }^{\mathrm{TM}} \mathrm{q}$ HIV-1/2 Detect test. All healthcare workers responsible for DBS sample collection and assigned for the POC test were trained on the conduct of the Alere ${ }^{\mathrm{TM}} \mathrm{q}$ HIV-1/2 Detect test for EID. Error codes and other instrument error logs were documented by operators to establish the overall error rate. Results from the Alere ${ }^{\mathrm{TM}} \mathrm{q}$ HIV-1/2 Detect were documented. In line with the SOC, DBS was transported to the centralized PCR laboratories for analysis. At the centralized PCR laboratories, all DBS were assayed using the COBAS ${ }^{\circledR}$ AmpliPrep/COBAS ${ }^{\circledR} \quad$ TaqMan ${ }^{\circledR} \quad$ HIV-1 Qualitative Test, version 2.0; and results returned to the healthcare facility. Critical information to measure the turnaround time (TAT) and document test records aligned to the unique study identification number were captured and kept separately for each of POC and SOC to ensure participants' confidentiality and anonymity and avoid bias. Additionally, structured questionnaires were administered to healthcare workers including operators of the POC; across healthcare facilities to assess their views and opinion on the POC for EID. The operators assessed the equipment based on Turnaround Time (TAT), Quality of results, Reliability, Accuracy, Operation, Safety, and User-friendliness. Each of the criteria was graded by the operators and assessment points were weighted to determine final graded performance.

\section{Data Management and Analysis}

For the quantitative methods, participant's demographic data were abstracted using the participant enrollment forms. Study tools were developed and used to capture the study of technical data, including all process data as well as the outcome. Also, results from the Point of Care equipment were transmitted electronically through the Alere data point. This was accessed remotely electronically and monitored to ensure adherence to study protocol. Information captured on the Alere data point and all study tools were triangulated to validate the correctness and assure data integrity before analysis. Descriptive analysis was carried out to summarize the outcome measures and the background characteristics of all study participants using percentages for categorical variables and mean, median and standard deviations for quantitative variables. The accuracy (bias and limits of agreement) of the Alere $^{\mathrm{TM}}$ q HIV 1/2 - Detect in comparison with the COBAS ${ }^{\circledR}$ AmpliPrep/COBAS $®$ TaqMan ${ }^{\circledR}$ HIV-1 Qualitative Test, version 2.0 was determined. These include sensitivity, specificity, positive and negative predictive values. All Analyses will be carried out using Stata Version 14 (StataCorp, College Station, Texas, USA); and statistical level of significance set at $\mathrm{P}$-value $\leq 0.05$

\section{Ethical Considerations}

Ethical approvals were obtained from the Kaduna, Benue, and Kogi States Ministry of Health Research and Ethics Review Committee. Written informed consent was obtained for entry into the evaluation study from their guardian/parent of the infants. The evaluation study was described, and consent requested in the local language or English. Study participants unable to sign due to illiteracy use their thumbprint as a signature.

In carrying out the study, three (3) measure were put in place to assure privacy and confidentiality of participants. These are the use of assigned unique study identification number per participants, restricted access to study data with administrative permission level for all electronic and cloud-based data; and separation of study documentation from clinical data; triangulation of data only took place during analysis.

\section{Results}

The goal of this study is to assess the accuracy and feasibility of Alere ${ }^{\mathrm{TM}} \mathrm{q}$ point-of-care (POC) nucleic acid-based test (NAT) for early infant diagnosis in Nigeria. 


\section{Distribution of Healthcare Facilities and Socio-demographic Characteristics of Participants}

This study was conducted across six (6) healthcare facilities in 3 states located within the north-west and north-central region of Nigeria for infants aged 4 weeks-18 months with consenting parent/guardian. The healthcare facilities-2 Tertiary healthcare facilities, 3 Secondary healthcare facility and 1 primary healthcare facility; are located in the urban and peri-urban area of the states. The average distance from the healthcare facilities to the nearest centralized PCR laboratory is $204.8 \mathrm{~km}$ ranging from $81.7 \mathrm{~km}-371.3 \mathrm{~km}$ (see Table 1). A total of 249 participants took part in the study within the 19 months, 278 tests were conducted using the POC including 29 repeat tests. Four (4) participant's SOC results were yet to be returned at the end of the study, hence, were not included in the analysis. Out of all the study participants, $135(55 \%)$ were male and $110(45 \%)$ were female. Based on the age-group, $76.3 \%$ of the participants are $\leq 8$ weeks old, $17.1 \%$ participants are within the age group 9 weeks-12 months, while $6.5 \%$ are within the age-group $>12$ - 18 months (see Table 2).

Table 1. Distribution of Healthcare Facilities, Type, Location and Distance form PCR Laboratory

\begin{tabular}{|l|l|l|l|l|}
\hline \multirow{2}{*}{ State } & Facility & Type & Location & $\begin{array}{l}\text { Distance from the } \\
\text { assigned PCR } \\
\text { Laboratory }\end{array}$ \\
\hline \multirow{2}{*}{ Benue } & General Hospital Sankera & Secondary HF & Peri-urban & $201 \mathrm{~km}$ \\
\cline { 2 - 5 } & CHC, Gboko & Primary HF & Urban & $92.3 \mathrm{~km}$ \\
\hline Kaduna & $\begin{array}{l}\text { Barau Dikko Teaching } \\
\text { Hospital }\end{array}$ & Tertiary HF & Urban & $81.7 \mathrm{~km}$ \\
\cline { 2 - 5 } & General Hospital, Kafanchan & Secondary HF & Urban & $281.5 \mathrm{~km}$ \\
\hline \multirow{2}{*}{ Kogi } & $\begin{array}{l}\text { Federal Medical Centre, } \\
\text { Lokoja }\end{array}$ & Tertiary HF & Urban & $201 \mathrm{~km}$ \\
\cline { 2 - 5 } & General hospital Ankpa & Secondary HF & Peri-urban & $371.3 \mathrm{~km}$ \\
\hline
\end{tabular}

Table 2. Distribution of Study Participants Based on Age and Gender

\begin{tabular}{|c|c|c|c|}
\hline \multirow{3}{*}{ Age - group } & \multirow{3}{*}{ Total no. of Infants (N \%) } & \multicolumn{2}{|l|}{ Sex } \\
\hline & & $\mathbf{M}$ & $\mathbf{F}$ \\
\hline & & $(\mathrm{N} \%)$ & $(\mathbf{N} \%)$ \\
\hline$\leq 8$ weeks & $187(76.3 \%)$ & $99(53 \%)$ & $88(47 \%)$ \\
\hline 9 weeks - 12 months & $42(17.1 \%)$ & $26(62 \%)$ & $16(38 \%)$ \\
\hline$>12-18$ months & $16(6.5 \%)$ & $10(63 \%)$ & $6(37 \%)$ \\
\hline All & $245(100.0 \%)$ & $135(55 \%)$ & $110(45 \%)$ \\
\hline
\end{tabular}

\section{Facility Level Turnaround Time (TAT) for Early Infant Diagnosis (EID) Using the Standard of Care}

As part of the comparison and assessing the impact and need for the POC, the turnaround time for the return of results was captured. Turnaround time (TAT) was defined from the time of collection of the DBS samples for EID till the time the result was received from the centralized laboratory (SOC) at the health facility. The facility level turnaround time for EID test using the SOC ranges between 51 to 99 days (see Figure 2). As per age-group, the TAT ranges between 67 days for infants $\leq 8$ weeks, 50 days for infants 9 weeks -12 months and 62 days for infants within the age range $>12-18$ months. The average turnaround time for EID test using the SOC (Centralized PCR laboratories) is 67 days for infants visiting the clinic within 2 months after birth, as well as for all infants participating in the study (see Table 3). The TAT for the POC is 0 day as all results were obtained within 1-2 hours. 


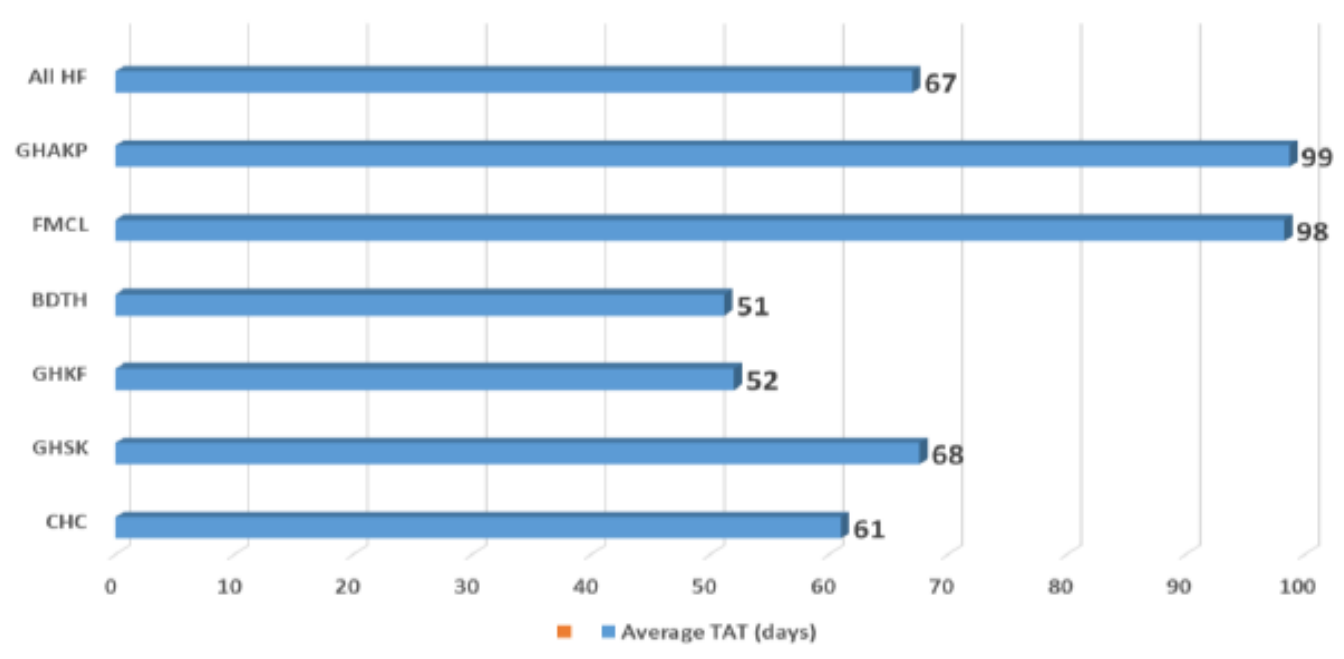

Figure 2. Facility Level Turnaround Time (TAT) on the Standard of Care (SOC)

Table 3. Turnaround Time (TAT) Per Age-Group Based on the Standard of Care (SOC)

\begin{tabular}{|l|l|l|l|l|}
\hline \multirow{2}{*}{ Age - group } & \multirow{2}{*}{ Total no. of Infants } & \multicolumn{3}{l|}{ Turnaround Time (TAT) } \\
\cline { 3 - 5 } & & Avg. TAT (days) & Range (days) & $\begin{array}{l}\text { Avg. TAT @ } \\
\text { HF (days) }\end{array}$ \\
\hline$\leq 8$ weeks & 187 & 67 & $17-138$ & 5 \\
\hline 9 weeks -12 months & 42 & 50 & $17-135$ & 5 \\
\hline$>12-18$ months & 16 & 80 & $39-121$ & 5 \\
\hline All & 245 & 67 & $14-144$ & 5 \\
\hline
\end{tabular}

\section{Analysis of Error Rate on the Point of Care (POC) - AlereTM q Platform}

In this study, a total of 278 Alere $^{\mathrm{TM}} \mathrm{q}$ HIV $1 / 2$ - Detect nucleic acid-based tests were conducted throughout the 19 months' period; including 29 repeat tests due to errors. Hence, $10.4 \%$ error rate. The error rate per facility ranges from $2.3 \%$ to $18.2 \%$ (see Table 4). All repeated tests came out with valid results. All errors recorded were analyzed based on the error code. Analysis indicates human error mostly due to low sample volume and partial entry of the cartridge into the equipment. In this study, 2 types of healthcare workers-Nurses and Laboratory personnel were responsible for carrying out the tests on the Alere $^{\mathrm{TM}} \mathrm{q}$ platforms. A regression analysis of the error rate based on the type of personnel handling the equipment indicate a significant adjusted regression of $0.01122(\mathrm{P}=0.841706)$.

Table 4. Analysis of Error Rate on Point of Care - AlereTM q Platform

\begin{tabular}{|l|l|l|l|l|l|}
\hline Facility & Personnel & Location & $\begin{array}{l}\text { Number of } \\
\text { Sample Run }\end{array}$ & $\begin{array}{l}\text { No of error } \\
\text { recorded }\end{array}$ & Error Rate \\
\hline CHC Gboko & Nurse & Urban & 84 & 12 & $14.3 \%$ \\
\hline GH Sankera & Nurse & Peri-urban & 55 & 10 & $18.2 \%$ \\
\hline BDTH & Nurse & Urban & 41 & 3 & $7.3 \%$ \\
\hline $\begin{array}{l}\text { GH } \\
\text { Kafanchan }\end{array}$ & Laboratory & Urban & 40 & 2 & $5.0 \%$ \\
\hline FMC Lokoja & Laboratory & Urban & 15 & 1 & $6.7 \%$ \\
\hline ZH Ankpa & Laboratory & Peri-urban & 43 & 1 & $2.3 \%$ \\
\hline TOTAL & 278 & 29 & $10.4 \%$ \\
\hline
\end{tabular}


Adjusted $\mathrm{R}^{2}-0.618513, \mathrm{P}=0.063533$ (-0.18469, 0.007974)

\section{Accuracy, Positive Predictive Value, and Negative Predictive Value of the Point of Care (POC) in Comparison with Standard of Care (SOC) for Early Infant Diagnosis}

A comparison of results recorded from the POC, Alere ${ }^{\mathrm{TM}} \mathrm{q}$; and the SOC, Roche Cobas CAP/CTM 48/96 indicate a non-concordance in only 1 of the entire 245 study participant's valid test conducted. An average concordance percentage of $99.6 \%$ with ranges between $98.6 \%$ and $100 \%$ across the 6 healthcare facilities was observed in this study (see Table 5). Outcome reveals sensitivity and specificity of $91.7 \%$ and
Adjusted $\mathrm{R}^{2}-0.01122, \mathrm{P}=0.841706(-0.135$, $0.157441)$

$100 \%$ respectively. A repeat of the discordant test by both platforms-SOC and POC-increased the sensitivity to $100 \%$. The POC was found to be consistent while the initial result provided by the SOC was found to be false positive. The sensitivity increased to $100 \%$ after the repeat testing of both SOC and POC. In this study, a Positive Predictive Value (PPV) of 100.0 and Negative predictive value of 99.6 was recorded. Accuracy of the POC nucleic acid-based test (NAT) in comparison with the Standard of Care in detecting HIV infection among infants aged 4 weeks to 18 months is $99.6 \%$.

Table 5. Sensitivity, Specificity and Accuracy of the POC in Relation with the SOC

\begin{tabular}{|c|c|c|c|c|c|c|}
\hline \multirow[b]{2}{*}{ Facility } & \multirow{2}{*}{$\begin{array}{l}\text { Number of } \\
\text { Sample Run }\end{array}$} & \multicolumn{2}{|c|}{ POC (Alere ${ }^{\mathrm{TM}} q$ ) } & \multicolumn{2}{|c|}{ SOC (Cobas CAP/CTM) } & \multirow[b]{2}{*}{$\begin{array}{l}\text { Concordance } \\
(\%)\end{array}$} \\
\hline & & $\begin{array}{l}\text { Total } \\
\text { Positive }\end{array}$ & $\begin{array}{l}\text { Total } \\
\text { Negative }\end{array}$ & $\begin{array}{l}\text { Total } \\
\text { Positive }\end{array}$ & $\begin{array}{l}\text { Total } \\
\text { Negative }\end{array}$ & \\
\hline CHC Gboko & 72 & 0 & 72 & 1 & 71 & 98.6 \\
\hline GH Sankera & 45 & 0 & 45 & 0 & 45 & 100.0 \\
\hline BDTH & 38 & 1 & 37 & 1 & 37 & 100.0 \\
\hline GH Kafanchan & 38 & 4 & 34 & 4 & 34 & 100.0 \\
\hline FMC Lokoja & 11 & 2 & 9 & 2 & 9 & 100.0 \\
\hline ZH Ankpa & 41 & 4 & 37 & 4 & 37 & 100.0 \\
\hline Total & 245 & 11 & 234 & 12 & 233 & 99.6 \\
\hline
\end{tabular}

Sensitivity $-91.7 \%, 95 \mathrm{CI}(0.9116,92167)$, Specificity $-100.0 \%, 95 \mathrm{CI}(1.0000,1.0000)$.

PPV - 100.0, 95CI (1.0000, 1.0000), NPV - 99.6, 95CI (0.99546, 0.99599).

Accuracy $-99.6 \%$.

\section{Operator's Appraisal of the Performance of Point of Care (POC) in Early Infant Diagnosis (EID) Testing}

Assessment of the POC by the healthcare workers responsible for the operation of the equipment' during the study covers defined performance criteria of Turnaround Time
(TAT), Quality of results, Reliability, Accuracy, Operation, Safety, and User-friendliness. The assessment of the POC equipment and test across the different criteria shows a weighted average ranging from $63 \%$ to $83 \%$ (see Table 6). Based on the graded weighted average, operators found the equipment very good across all the key criteria assessed.

Table 6. Operator's Assessment of POC Based on Defined Performance Criteria

\begin{tabular}{|c|c|c|c|c|c|c|c|}
\hline \multirow[b]{2}{*}{$\begin{array}{l}\text { Performance } \\
\text { Criteria }\end{array}$} & \multicolumn{5}{|c|}{ Grading } & \multirow{2}{*}{$\begin{array}{l}\text { Weighted } \\
\text { Average } \\
(\%)\end{array}$} & \multirow[b]{2}{*}{$\begin{array}{l}\text { Graded } \\
\text { Performance }\end{array}$} \\
\hline & $\begin{array}{l}\text { Poor } \\
\text { (0) }(\%)\end{array}$ & $\begin{array}{l}\text { Fair } \\
\text { (1) }(\%)\end{array}$ & $\begin{array}{l}\text { Satisfactory } \\
\text { (2) }(\%)\end{array}$ & $\begin{array}{l}\text { Very Good } \\
\text { (3) }(\%)\end{array}$ & $\begin{array}{l}\text { Excellent } \\
\text { (4) }(\%)\end{array}$ & & \\
\hline Turnaround Time & 0.0 & 16.7 & 0.0 & 50.0 & 33.3 & 75 & (3) \\
\hline Quality of Result & 16.7 & 0.0 & 0.0 & 0.0 & 83.3 & 83 & (3) \\
\hline Reliability & 16.7 & 0.0 & 0.0 & 66.7 & 33.3 & 67 & (3) \\
\hline Accuracy & 16.7 & 0.0 & 0.0 & 0.0 & 83.3 & 83 & (3) \\
\hline Operation & 0.0 & 16.7 & 33.3 & 33.3 & 16.7 & 63 & (3) \\
\hline Safety & 16.7 & 0.0 & 16.7 & 50.0 & 16.7 & 63 & (3) \\
\hline User-friendliness & 0.0 & 0.0 & 50.0 & 50.0 & 0.0 & 63 & (3) \\
\hline
\end{tabular}




\section{Discussion}

The study was conducted with the aim of assessing the accuracy and operational feasibility of using a point of care testing for Early Infant Diagnosis in Nigeria. Insight into this was expected to aid in addressing gaps in ensuring early and reliable diagnosis of HIV in infants and expand access to treatment, which is a critical consideration for HIV epidemic control in Nigeria. This study was conducted among infants aged 4 weeks -18 months with consenting parent/guardian across six (6) healthcare facilities in 3 states of Kaduna, Kogi and Benue states. A critical issue that has being identified with the provision of Early Infant Diagnosis (EID) service in Nigeria is distance from the centralized PCR laboratory. In this study, the distance of the healthcare facilities from the centralized PCR laboratories ranges between $81.7 \mathrm{~km}-371.3 \mathrm{~km}$; with an average distance of $204.8 \mathrm{~km}$

According to the recent WHO guideline, Early Infant Diagnosis is recommended to be conducted within 4-6 weeks of life however, the Nigeria National guideline for HIV/AIDS Prevention, Treatment and Care recommends 2 months (8 weeks) of life. According to the findings from this study, $41 \%$ of the infants visited the clinic for early infant diagnosis for the first time at age 4-6 weeks, while $76 \%$ of the study participants visited the clinic for Early Infant Diagnosis within 2 months after birth. This suggests that majority of children still visit the clinic for early infant diagnosis within the time period that ART commencement will aid optimal survival rate. The $72 \%$ DBS collection within 2 months of life is higher than the $62.3 \%$ finding of [13] in South-Eastern Nigeria and $50.1 \%$ of [14] in North central Nigeria; however, this correlates with the $81.1 \%$ observed in the Moment study in Nigeria as reported by [6] Also, $17 \%$ of the study participants visited the clinic between 9 weeks-12 months after birth and $7 \%$ of the infants visited after 12 months to 18 months after birth. Notwithstanding the percentage of infants having access to EID within the recommended period; this study indicates a gap of $24 \%$.

One of the issues that has been identified with the optimal uptake of EID, especially in resource limited countries is the long TAT. This has been shown to delay the commencement of HIVinfected Infants on treatment and Hence, adversely affects the survival of these infants. The Moment study in north central Nigeria and the Healthy Beginning Initiative in south eastern Nigeria, has indicated a TAT of 3 months and 5.6 months respectively. In this study, the average turnaround time for EID test using the SOC (Centralized PCR laboratories) is 67 days for infants visiting the clinic within 2 months after birth, as well as for all infants participating in the study. The TAT for the POC is 0 day as all results were obtained within 1-2 hours. Average time the EID samples spent at each of the healthcare facility is 5 days. Although lesser than other studies, however, this establishes the continuous challenge with long TAT for the receipt of results from the centralized PCR laboratories; and hence, delayed commencement of ART in infants.

An analysis of sample analysis with the Point of Care-Alere ${ }^{\mathrm{TM}} \mathrm{q}$ HIV-1/2 Detect, indicate an error rate of $10.4 \%$. This is comparable to the 9.0\% recorded in the study assessing Alere ${ }^{\mathrm{TM}} \mathrm{q}$ POC for EID in South Africa by [10] as well as the $11.2 \%$ error rate observed in Zimbabwe by [15]. However, in the study in Zimbabwe, the error rate decreases with time due to familiarity with the use of equipment and increased competency. This underscores the need for continuous training to assure competency and reduce error rat. In this study, all error tests were repeated with valid results. The error rate observed in this study is far lesser than the error rate reported in the CE-IVD and WHO prequalification. This may be attributed to the fact that prequalification and certification were laboratory based. An analysis of the error rate based on the type of personnel handling the equipment indicate a significant adjusted regression of $0.01122 \quad(\mathrm{P}=0.841706)$. This suggests that the type of personnel handling the equipment has an impact on the frequency of error rate recorded. However, [15] in the study carried out in Zimbabwe did not find any a significant error rate between laboratory and non-laboratory personnel. Error rate based on location which is either urban or peri-urban was found not significant.

With an average concordance of $99.6 \%$ between the Point of Care (POC) and the Standard of Care (SOC), the results obtained with the two platforms shows a comparable accuracy. The key focus of this study is to assess the accuracy and feasibility of the Point of care 
for Early Infant Diagnosis in Nigeria. In comparison with the SOC, the sensitivity and specificity obtained in this study was $91.7 \%$ and $100.0 \%$ respectively; with a positive predictive value of 100.0 and negative predictive value of 99.6. In the evaluation carried out in Cape Town South Africa, [10] observed $95.5 \%$ sensitivity and $99.8 \%$ specificity. While the sensitivity is higher than the one observed in this study, the specificity is well comparable. Also, a repeat of the only discordant test in this study by both platforms-SOC and POC-increased the sensitivity to $100 \%$. The POC was found to be consistent while the initial result provided by the SOC was found to be false positive. Results obtained shows that the Point of Care platformAlere $^{\mathrm{TM}} \mathrm{q}$ platform is reliable and has comparative ability with the standard of care for early infant diagnosis. Also, operator's assessment of performance criteria found the equipment very good and acceptable, with

\section{References}

[1] AVERT: Global HIV and AIDS Statistics. (February, 2020). Date of Access: 5/04/2020 https://www.avert.org/global-hiv-and-aidsstatisticsUpdated.

[2] WORLD HEALTH ORGANIZATION (WHO). Global Programme on AIDS, 1988. WHO report Breastfeeding, breast milk and human immunodeficiency virus (HIV) Statement from the Consultation held in Geneva, 23-25 June, 1987: AIDS Action, (5), 1-2: Date of Access: 05/05/2020. https://pubmed.ncbi.nlm.nih.gov/12281628/.

[3] UNAIDS Data 2019. Date of Access: 06/05/2020 https://www.unaids.org/sites/default/files/media_ass et/2019-UNAIDS-data_en.pdf.

[4] Anisa Ghadrshenas, Yanis B. Amor, Joy Chang, Helen Dale. et al. (2013). Improved access to early infant diagnosis is a critical part of a child-centric prevention of mother-to-child transmission agenda. AIDS 2013, 27 (Suppl. 2): S197-S205. Date of Access: $15 / 5 / 2020$

https://journals.lww.com/aidsonline/Fulltext/2013/1 1002/Improved_access_to_early_infant_diagnosis_i s_a.8.aspx.

[5] Carlucci, J. G., Liu, Y., Friedman, H., Pelayo, B. E., Robelin, K., Sheldon, E. K., Clouse, K., \& Vermund, S. H. 2018. Attrition of HIV-exposed infants from early infant diagnosis services in lowand middle-income countries: a systematic review and meta-analysis. Journal of the International AIDS weighted rating average ranging from $63 \%$ to $83 \%$.

\section{Conclusion}

Based on findings, this study concludes that the Point of Care, Alere ${ }^{\mathrm{TM}}$ q HIV-1/2-Detect using the AlereTM q platform; has comparative accuracy, sensitivity and specificity with the Standard of Care; COBAS ${ }^{\circledR}$ AmpliPrep/COBAS ${ }^{\circledR} \quad$ TaqMan ${ }^{\circledR} \quad$ HIV-1 Qualitative Test, version 2.0 on the Roche Cobas CAP/CTM 48 or 96 platforms; in the detection of HIV infection in infants. Also, the Point of Care testing for Early Infant Diagnosis has same day result return, is acceptable, rapid and robust; hence, viable and feasible for use in the early infant diagnosis of HIV in Nigeria. However, it is critical to note that there is the need for indepth training and close monitoring when the equipment will be handled by non-laboratorybased personnel.

Society, 21(11), e25209. Date of Access: 15/5/2020 https://doi.org/10.1002/jia2.25209.

[6] Udochisom C. Anaba, Nadia A. Sam-Agudu, Habib O. Ramadhani, Nguavese Torbunde, Alash'le Abimiku, Patrick Dakum, Sani H. Aliyu, Manhattan Charurat, 2019. Missed opportunities for early infant diagnosis of HIV in rural North-Central Nigeria: A cascade analysis from the INSPIRE MoMent study. PLoS ONE. Date of Access: 15/5/2020. https://doi.org/10.1371/journal.pone.0220616.

[7] Isah HO, Ogum E, Cornelius LJ, Okundaye JN, Galadanci H, Charurat ME, et al. 2014. The MoMent Study: Client- and Community-Level Barriers to PMTCT Access and Uptake in Rural North-Central Nigeria. 8th INTEREST (International Workshop on HIV Treatment, Pathogenesis, and Prevention Research in Resource-Poor Settings) Workshop; Lusaka, Zambia. p. 45. Date of Access: 15/5/2020. http://regist2.virology-

education.com/abstractbook/2014_3.pdf.

[8] Leroy, V., Malateste, K., Rabie, H., Lumbiganon, P., Ayaya, S., Dicko, F., Davies, M. A., Kariminia, A., Wools-Kaloustian, K., Aka, E., Phiri, S., Aurpibul, L., Yiannoutsos, C., Signaté-Sy, H., Mofenson, L., Dabis, F., \& International IeDEA Pediatric Working Group1 (2013). Outcomes of antiretroviral therapy in children in Asia and Africa: a comparative analysis of the IeDEA pediatric multiregional collaboration. Journal of acquired immune deficiency syndromes (1999), 62(2), 208- 
219. Date of Access: 14/04/2020 https://doi.org/10.1097/QAI.0b013e31827b70bf.

[9] Hsiao N-y, Dunning L, Kroon M, Myer L. 2016. Laboratory Evaluation of the Alere q Point-of-Care System for Early Infant HIV Diagnosis. PLOS ONE 11(3): e0152672. Date of Access: 5/04/2020 https://doi.org/10.1371/journal.pone.0152672.

[10]Dunning, L., Kroon, M., Hsiao, N. Y., \& Myer, L. 2017. Field evaluation of HIV point-of-care testing for early infant diagnosis in Cape Town, South Africa. PLoS ONE, 12(12), e0189226. Date of Access: 5/04/2020. https://doi.org/10.1371/journal.pone.0189226.

[11] WORLD HEALTH ORGANIZATION (WHO). (WHO). July 2017. Novel Point-of-Care Tools for Early Infant Diagnosis of HIV. Date of Access: 5/04/2020.

https://apps.who.int/iris/bitstream/handle/10665/255 857/WHO-HIV-2017.16-eng.pdf? sequence $=1$.

[12] Peeling R W, Holmes K K, Mabey D, et al. 2006. Rapid tests for sexually transmitted infections (STIs): the way forward Sex Transm Infect 2006 82: v1-v6. doi: 10.1136/sti.2006.024265. Date Accessed $6 / 05 / 2014$.

https://www.who.int/tdr/publications/journalsupplements/sti-way-forward/en/.

[13]Pharr, Jennifer R., Obiefune, Michael C.; Ezeanolue, Chinenye O.; Osuji, Alice; Ogidi, Amaka
G.; Gbadamosi, Semiu, Patel, Dina, Iwelunmor, Juliet; Yang, Wei; Ogedegbe, Gbenga; Ehiri, John E; Sam-Agudu, Nadia A.; Ezeanolue, Echezona E. 2016. Linkage to Care, Early Infant Diagnosis, and Perinatal Transmission Among Infants Born to HIVInfected Nigerian Mothers: Evidence from the Healthy Beginning Initiative, JAIDS Journal of Acquired Immune Deficiency Syndromes: August 1, 2016 - Volume 72 - Issue - p S154-S160. Date of Access: 5/04/2020. https://doi.org/10.1097/QAI.0000000000001051. [14] Aliyu, M. H., Blevins, M., Megazzini, K. M., Audet, C. M., Dunlap, J., Sodangi, I. S., Gebi, U. I., Shepherd, B. E., Wester, C. W., \& Vermund, S. H. 2014. Correlates of suboptimal entry into early infant diagnosis in rural north central Nigeria. Journal of acquired immune deficiency syndromes (1999), 67(1), e19-e26. Date of Access: 5/04/2020. https://doi.org/10.1097/QAI.0000000000000215.

[15] Simmonds, F.M., Cohn, J.E., Mafaune, H.W. et al. Task shifting for point-of-care early infant diagnosis: a comparison of the quality of testing between nurses and laboratory personnel in Zimbabwe. Hum Resour Health 18, 4 (2020). Date of Access: 05/05/2020 https://doi.org/10.1186/s12960020-0449-2. 


\title{
Breast Self-Examination: Knowledge and Practice Among Female Secondary School Students in Delta State, Nigeria
}

\author{
Morenike O. Akpo ${ }^{1 *}$, Ademola M. Amosu ${ }^{2}$, Dora O. Akinboye ${ }^{3}$ \\ ${ }^{1,2,3}$ Department of Public Health, Babcock University, Ogun State, Nigeria
}

\begin{abstract}
Breast self-examination (BSE) is a preventive tool for early identification of breast changes and abnormalities. This study was aimed at assessing breast self-examination knowledge and practice among female secondary students in Delta State, Nigeria. This descriptive cross-sectional study was carried out among female senior secondary school students from selected public schools in Delta State, Nigeria. This study utilized a self-administered 59-item validated questionnaire for data collection from 216 consenting female students who volunteered to take part in the study. The knowledge and practice of breast self-examination were measured on 33 and 18 points reference scales, respectively. Data were analyzed using SPSS version 23.0. Frequency, mean, standard deviation and correlation analysis were reported. All statistical tests were at $5 \%$ level of significance.

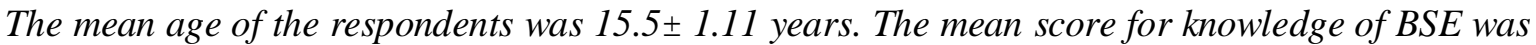
$5.8 \pm 3.8$ while the mean score for BSE practice was 7.3+2.1. Correlation analysis showed no significant relationship between knowledge and practice of BSE $(p=0.095, R=0.114)$. The overall knowledge and practice of BSE was very poor. This calls for the need to improve breast selfexamination advocacy among the adolescents; training and intervention programs to improve their knowledge as well as the regular practice of BSE.
\end{abstract}

Keywords: adolescents, Breast self-examination knowledge, Breast self-examination practice, Delta State, female secondary school students, Nigeria.

\section{Introduction}

Breast Self-Examination (BSE) involves both visual inspection and manual palpation of the breast. The aim is to detect breast abnormalities and changes early to enhance prompt medical attention and treatment. These breast changes and lumps may be benign or malignant. The methods and tools for generally assessing the breast include breast selfexamination (BSE), clinical breast examination (CBE) and mammography [1, 2, 3, 4, 5]. Other tools include magnetic resonance imaging (MRI) and digital breast tomosynthesis [6]. John Hopkins breast center Stated that [7], 40\% of diagnosed breast cancers are detected by women who feel a lump in their breast. This may mean that BSE is an important tool that makes a woman to be 'breast aware' $[3,6]$.

Breast self-examination is simple, easy to perform private, convenient, cost-effective and does not require the use of special equipment $[4,8,9]$. It is recommended that BSE should begin from 20 years of age $[10,11]$. However, it has also been advocated that BSE should commence earlier, starting from puberty and to continue throughout lifetime [12].

In developing countries where mammography is not readily available and clinical breast examination is not routinely done, breast self-examination remains the best option for women of all ages. Additionally, the adolescent breast has dense tissues which limit its sensitivity to mammography $[4,13,14]$.

The practice of BSE varies from country to country, from region to region, and among women of different levels of educational status. The practice of breast-self-examination has been reported to range from $19 \%$ to $43.2 \%$ in Nigeria $[15,16]$.

The World Health Organization defines individuals in 10-19 years age group as adolescents and the majority of secondary school students fall within this age group. The adolescent age is a transitory period from childhood to adulthood. It is associated with bodily changes, development of secondary sexual characteristics, including the breast. 
Promotion of positive preventive health behavior like BSE during this period may yield results that are carried on to adulthood. This is pertinent since the trend of development of breast abnormalities including breast cancer is increasing in females below 30 years of age $[17,18,19,20]$.

There are documented reports on BSE among women in the general population, but there are no previous reported studies on BSE among the female secondary school students in Delta state, more so that a previous study reported that benign breast tumor is common among the adolescent age group in this environment [18]. Hence the need to assess breast self-examination knowledge and practice among the female secondary school students in Delta State.

Establishing baseline knowledge and practice of BSE among this group of students will provide information for designing intervention programs to improve breast health and BSE skills among them and enhance policy making regarding the adolescent's health.

\section{General Objectives}

To assess the level of knowledge and practice of breast self-examination among female secondary school students in Delta State, Nigeria.

\section{Specific Objectives}

1. To determine the level of knowledge of the students on breast self-examination.

2. To determine the level of practice of breast self-examination among the students.

3. To determine if a relationship exists between the student's knowledge and Practice of BSE.

\section{Materials and Methods}

\section{Study Design}

This was a descriptive cross-sectional study carried out among female Senior Secondary School Two (SS2) students in public schools in Delta State, Nigeria.

\section{Study Area}

Two secondary schools were randomly selected from two local government areas in Delta State located in the South-South geopolitical zone of Nigeria. Ekpan secondary school was selected from Uvwie local government area and the other, Hussey College from Warri-South local government area. Uvwie is a gateway town in and out of the city of Warri. Warri-South local government area is predominantly riverine, and it is the commercial nerve center of the state. Both local government areas have several private and public secondary schools. Hussey College is one of the oldest and most prestigious colleges in the local government.

\section{Study Population}

The study population included female Senior Secondary Schools two (SS2) students of the selected schools. Other senior classes, SS1 and SS3 were excluded from participating. SS3 students were not allowed to participate because they were preparing for their school leaving examinations. The schools were randomly selected from the list of public schools in the two local government areas. Participation in this study was voluntary. Volunteers were obtained from all the arms of SS2 in the selected schools and only female SS2 students who were present in the school at the time of the study were allowed to participate in the study.

\section{Sample size Determination and Sampling Procedures}

The sample size calculation was adapted from Leslie-Kish formula.

$$
\mathrm{n}=\frac{(Z \alpha+Z \beta)^{2} \times(\mathrm{p} \times \mathrm{q})}{\mathrm{d}^{2}}
$$

The sample size (n) was calculated based on the following assumptions: $Z \alpha=$ Normal standard deviant at $95 \%$ confidence interval (1.96), $\mathrm{Z} \beta=$ Power at $80 \%$ (0.84), $\mathrm{q}=(1-\mathrm{P})$ where $\mathrm{P}=$ proportion of breast self-examination $=50 \%, \mathrm{~d}=$ level of Precision (0.1). The Calculated sample size was 196. After applying the $10 \%$ attrition rate, the final sample size was 216.

\section{Instrumentation}

The instrument for data collection for this study was a semi-structured self-administered questionnaire. The questionnaire was divided into three sections with 59 items. The 59 items were a mixture of multiple-choice questions and questions with categorical variables (yes/no/I don't know). Section A consisted of 
questions on the social demographic characteristics of the participants; Section B consisted of questions on knowledge of BSE (39 items) and Section C consist of questions on breast self- examination practice (15 items). Face and content validity was achieved by seeking opinions of experts in the field of Public health and Health promotion. The instrument was pilot-tested for its comprehensibly and clarity among a convenience sample of SS2 students from a non-participating school, who represent $10 \%$ of the of the calculated sample size. Modification of the questionnaire was however carried out based on the outcome of the pilot-testing before using it for final data collection. The overall reliability score (Cronbach alpha) was 0.74 .

\section{Measurement}

The respondents' knowledge score is measured on point rating scale with one point assigned to a correct answer and zero assigned to an incorrect answer. Participants who scored less than $50 \%$ of the knowledge questions were considered as having poor knowledge. Participants who scored between $50 \%$ and $75 \%$ were considered as average knowledge, and those who scored greater than $75 \%$ were classified as having good knowledge. The same was applied to the practice of breast selfexamination. The scores were grouped into poor practice, and good practice. Scores below $50 \%$ was grouped as poor practice while scores above $50 \%$ was grouped as good practice.

\section{Ethical Consideration}

Approval for the study was obtained from Babcock University Research and Ethics committee (reference number BUHREC036/20), the Chief Inspector of Education for Uvwie and Warri South local government area, as well as the principals of the participating schools. Informed consent was also obtained from the students.

\section{Data collection procedure}

Data was collected using self-administered questionnaire. This was achieved after the aim of the study was explained to the respondents and informed consent obtained from them, Confidentiality of information and anonymity was maintained.

\section{Data Analysis}

The data collected were entered into a personal computer and analyzed using the Statistical Package for the Social Sciences (SPSS) for Windows, version 23.0. Descriptive statistics (frequency distributions) for demographic characteristics; responses of the respondents, means and standard deviations were transformed into weighed aggregate scores. Correlational analysis between knowledge level of breast self-examination and breast self-examination practice were measured using Pearson Correlation. Significant level was set at $\mathrm{p}<0.05$ for all statistical analysis.

\section{Results}

A total of 216 students participated in this study, and the response rate was $100 \%$.

\section{Socio-demographic Characteristics of the Participants}

The socio-demographic characteristics of the students include their age, class, tribe, marital status and religion. The mean age for the respondents in the study was $15.5 \pm 1.11$ years. Most of the respondents were between 15 years and 16 years old (Table 1). Majority, 72 $(33.3 \%)$, were 16 years and $68(31.5 \%)$ were 15 years old. All the respondents $216(100 \%)$ were females in SS2 class. Majority 69 (31.9\%) were Urhobo by tribe followed by Ibo $28(13 \%)$, Itsekiri 25(11.6\%), Isoko 21(9.7\%), Ijaw $19(8.8 \%$ and Okpe 14(6.5\%). Other tribes accounted for $40(18.5 \%)$ of the respondents. All the respondents $216(100 \%)$ were single and $212(98.1 \%)$ of them were Christians.

\section{Knowledge of Breast Self-Examination}

Knowledge of breast self-examination was measured on a 33-point reference scale and the mean score was $5.8 \pm 3.8$ (Table 2). Ninety-three $(43.1 \%)$ of the respondents have heard of breast self-examination. Thirty-four $(15.7 \%)$ heard of it from the internet, $32(14.8 \%)$ from mother, and $30(13.9 \%)$ from school. Just a few of the respondents $83(38.4 \%)$ knew the meaning of breast self-examination. Forty-seven $(21.8 \%)$ respondents indicated that they have had previous training on BSE. Ninety-two (42.6\%) respondents asserted that they do not know the age BSE should commence and more than half 
of the respondents, $182(84.2 \%)$, did not know that BSE is done monthly. Regarding the positions taken during BSE, only 35 (16.4\%) respondents knew that it can be performed in a lying down position while only 4 (17.1\%) knew it can be done standing in front of a mirror.
Many of the respondents, 179 (82.8\%), do not know that the pads of the three middle fingers are used when examining the breast. Overall, $168(77.7 \%)$ respondents do not know the positions taken while performing BSE.

Table 1. Socio-Demographic Characteristics of the Respondents

\begin{tabular}{|c|c|c|}
\hline \multirow[t]{2}{*}{ Variables } & \multicolumn{2}{|c|}{ Respondents in the study $(\mathrm{N}=216)$} \\
\hline & Frequency $(\mathrm{N}=216)$ & Percentage $(\%)$ \\
\hline \multicolumn{3}{|c|}{ - 1 a } \\
\hline 13 years & 1 & 0.5 \\
\hline 14 years & 31 & 14.4 \\
\hline 15 years & 68 & 31.5 \\
\hline 16 years & 72 & 33.3 \\
\hline 17 years & 32 & 14.8 \\
\hline 18years & 10 & 4.6 \\
\hline 19years & 2 & 0.9 \\
\hline \multicolumn{3}{|l|}{ Gender } \\
\hline Male & 00 & 0.00 \\
\hline Female & 216 & 100 \\
\hline \multicolumn{3}{|l|}{ Tribe } \\
\hline Ibo & 28 & 13.0 \\
\hline Ijaw & 19 & 8.8 \\
\hline Itsekiri & 25 & 11.6 \\
\hline Urhobo & 69 & 31.9 \\
\hline Isoko & 21 & 9.7 \\
\hline Okpe & 14 & 6.5 \\
\hline Others & 40 & 18.5 \\
\hline \multicolumn{3}{|c|}{ Marital Status } \\
\hline Single & 216 & 100 \\
\hline Married & 00 & 0.00 \\
\hline \multicolumn{3}{|l|}{ Religion } \\
\hline Christian & 212 & 98.1 \\
\hline Muslim & 4 & 1.9 \\
\hline \multicolumn{3}{|c|}{ Academic level } \\
\hline SS2 & 216 & 100 \\
\hline Others & 00 & 0.00 \\
\hline
\end{tabular}

Table 2. Summary of Mean Scores

\begin{tabular}{|l|l|l|l|}
\hline \multirow{2}{*}{ Variables } & \multicolumn{3}{|c|}{ Respondents in the study (N= 216) } \\
\cline { 2 - 4 } & Rating Scale & Mean & SD \\
\hline Level of knowledge of BSE & 33 & 5.8 & 3.8 \\
\hline Level of BSE Practice & 18 & 7.3 & 2.1 \\
\hline
\end{tabular}




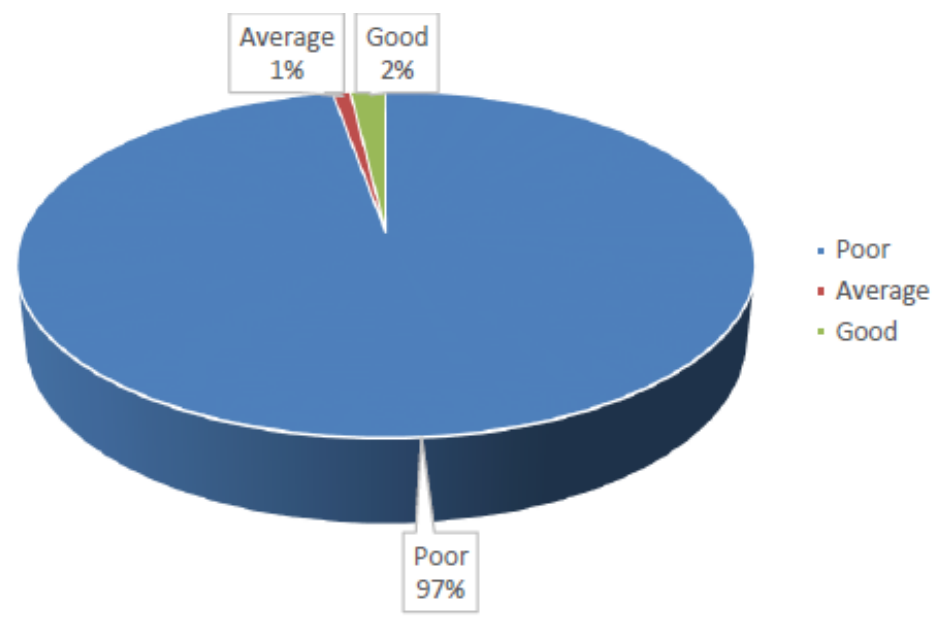

Figure 1. Knowledge of Breast Self-Examination $(n=216)$

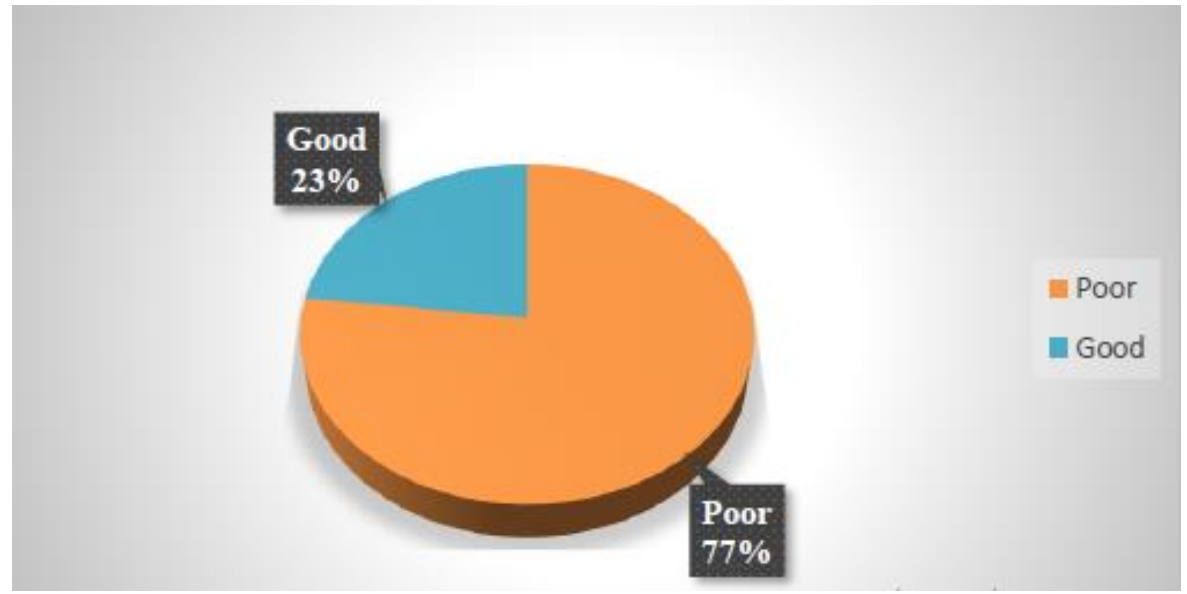

Figure 2. Practice of Breast Self-Examination $(\mathrm{n}=216)$

\section{Practice of Breast Self-Examination}

The practice of breast self-examination was measured on 18 points reference scale. The mean score was $7.3 \pm 2.1$ (Table 2) with $77 \%$ of the participants having poor practice of BSE (Fig 2). One hundred and eighty-nine (87.5\%) respondents have never performed a BSE while only $27(12.5 \%)$ of the respondents have ever performed BSE. Seven (3.2\%) respondents perform BSE monthly, while $12(5.6 \%)$ perform BSE anytime. Furthermore, only 8 $(2.8 \%)$ perform after their mensuration.

Though the practice was poor, the respondents gave reasons for engaging in BSE practice. Eighteen $(8.3 \%)$ said they are aware of the benefits, $22(10.2 \%)$ 'to avoid being diagnosed with breast cancer', 19 (8.8\%) 'Knew someone with breast cancer', 19 (8.8\%) 'to avoid the breast being cut off' and 20 $(9.25 \%)$ have of a family history of breast cancer. The most common reasons given by the respondents $(186 ; 86.1 \%)$ for not engaging in BSE was 'I do not know how to do it', fourteen $(6.6 \%)$ said they never knew about BSE, 32 (14.8\%) forgetfulness and $21(9.7 \%)$ do not want to be diagnosed as having breast cancer. Additional reasons given for not engaging in BSE practice include: 'I am not at risk of breast cancer or breast problems, I am not up to the age of doing BSE, I do not feel comfortable touching my breast and it is time-consuming'.

Correlation analysis was done to determine if there was any relationship between the level of knowledge of breast self-examination and the practice of breast self-examination. From the analysis, there was a positive relationship, but there was insufficient statistical evidence to conclude that there was significant relationship between the variables $(\mathrm{p}=0.095, \mathrm{R}=0.114)$.

\section{Discussion}

Breast self-examination is the simplest and safest way of identifying breast abnormalities 
early, and quickest way of getting familiar with one's own with regular practice. This is of great importance to the adolescent female who has limited options of breast screening tools.

The results obtained from the study showed that the level of knowledge of breast selfexamination and practice of breast selfexamination were poor. This indeed did not come as a surprise, though not welcoming because many females in this age group do not pay particular attention to their breast health and this is not included in their school curriculum.

More than $80 \%$ of the respondents scored below the mean score for the level of knowledge of BSE, and the practice of breast self-examination followed same with $76.9 \%$ of them having poor practice. Only $3.2 \%$ of respondent practice BSE monthly. The result is not totally different from that reported from similar studies across Nigeria, from different states using a similar group of senior secondary school students. They reported both poor knowledge and practice of BSE as it is the case with the present study [17, 21, 22, 23, 24, 25].

Similar findings have been reported among high school students outside Nigeria [26]. This problem is, therefore, not peculiar to Nigerian adolescents. This is because less emphasis is placed on breast health among the secondary school students, but more efforts seem to be directed towards older women. It should be remembered that both groups of women (the older women and the younger female secondary school students) are vulnerable to developing diseases of the breast including breast cancer though too common in the younger age group. Efforts should therefore be made to target this group of adolescents early with adequate knowledge and require skills in performing breast examination.

Lack of knowledge as to when and how BSE should be done were the most popular reasons cited by $86.1 \%$ of the respondents, as reasons for not practicing BSE. This can be said to be responsible for the poor practice of BSE among the respondents. This corroborates other similar studies [17, 22, 27].

Knowledge is antecedent to practice. It is the steppingstone to good practice and adoption of healthy behavior. Other reasons highlighted by the respondents that may also have accounted for the poor practice include perception of "not being at risk" and "not up to the age" of commencing BSE. This is the more reason why enlightenment and training about BSE should commence early in order to guide them and erase misconceptions they may have about BSE.

Students will benefit from inclusion of topics on breast health into their regular school curricula just as it with reproductive health. They need to know that being a woman is a risk factor for breast diseases, including breast cancer. There are previous reports of young females diagnosed with breast cancer between the ages of 14-16 years (Banjo, 2004). From the present study, just a few (8.3\%) respondents examine their breasts because they are aware of the benefits of doing so. This makes it essential for young females to be told about the benefits and limitations of BSE early so they can make an informed decision as to whether they want to adopt this practice.

Hearing about BSE does not translate into knowledge and practice as observed in this study where less than $50 \%$ of the respondents (43.1\%) have heard about BSE and yet the majority of those who have heard of BSE do not practice BSE. This outcome was found not to be too different from studies reported from Osun $(58.8 \%$ ) and $55.2 \%$ in Anambra State in Nigeria $[17,20]$. Among the Turkish students, a small percentage of them $(37.9 \%)$ were reported to have heard of BSE. The level of knowledge of BSE and practice of BSE among them were also reported as being poor. This invariably suggests that hearing or passing information is not enough. There is the need to engage the students, during the adolescent age, through continuous learning and practice in order to ensure adherence to BSE. This habit is expected to be carried on to adulthood. Educating young females early from the secondary school on breast self-examination and ensuring monthly and regular practice of BSE will have a greater and positive impact on the society, the family (sisters and mothers), friends and colleagues, in identifying breast abnormalities and preventing delay and late presentation in the hospital.

\section{Conclusion}

Considering the outcome of this study, there is the need to step up intervention programs to improve the knowledge of females in secondary 
school on breast health and preventive health practices regarding the breast. They seem to be the "neglected group" when it comes to issues of breast health. Though they are not likely to develop breast cancer at this age, they are at risk and are vulnerable to developing several breast abnormalities, including breast cancer. Therefore, empowering them with adequate knowledge and necessary skills to perform BSE will go a long way in securing their life and reducing morbidity and mortalities associated with breast diseases.

\section{Recommendations}

Breast health should be included in the secondary school curriculum covering different topics on the female breast. Teaching of BSE should be intensified beginning at this level, emphasizing the benefits and limitations of BSE.

Intervention programs, health talk, workshops and seminars should be organized from time to time for these students, for a continuous update of knowledge on issues related to female breast health.

The different platforms of social media can be used to disseminate information on BSE to the public.

\section{References}

[1] World Health Organization. (2020). Breast Cancer. Retrieved from https://www.who.int/cancer/prevention/diagnosisscreening/breast-cancer/en/.

[2] World Health Organization. (2020). Adolescent Health. Retrieved from https://www.who.int/southeastasia/healthtopics/adolescent-health.

[3] Centers for Diseases Control and Prevention. (2018). what is Breast Cancer Screening Retrieved from

https://www.cdc.gov/cancer/breast/basic_info/screen ing.html.

[4] Sani, A .M, \& Yau, S.L. (2018). Relationship between knowledge and practice of breast selfexamination among female workers in Sokoto, Nigeria. Obstetric and Gynecological International Journal. 9(3), 157-162. https//doi.org/ 10.15406/ogij.2018.09.00323.

[5] Takkar, N., Kochhar, S., Garg P, Pandey, A. K., Dalal, U.R, \& Handa, U. (2017). Screening methods (clinical breast examination and mammography) to
In addition, training of peer educators in schools should be encouraged to involve the female teachers and students. This will help to ensure sustainability and continuous practice.

\section{Strength of the study}

The questionnaire was worded in simple language, easy to understand by the respondents.

\section{Limitation}

The study respondents were all from public schools and in senior secondary school two. This may affect the generalization of this study to the entire female secondary school students in the state.

\section{Conflict of Interests}

The author declares that there is no conflict of interest.

\section{Acknowledgement}

The authors acknowledge the Chief Inspector of Education of the local government areas where the study took place, the principals, coordinating teachers of SS2 and all the students who took part in the study.

detect breast cancer in women aged 40-49 years. Journal of Mid-life Health, 8 (1), 2-10. Retrieved from

http://www.jmidlifehealth.org/text.asp?2017/8/1/2/2 01966.

[6] American Cancer Society. (2020). Recommendations for the Early Detection of Breast Cancer. Retrieved from https://www.cancer.org/cancer/breastcancer/screening-tests-and-early-detection/americancancer-society-recommenda.

[7] Johns Hopkins Breast Center. Breast Self-Exams. Retrieved from https://www.hopkinsmedicine.org/breast_center/trea tments_services/breast_cancer_screening/breast_self _exam.html.

[8] Kalliguddi, S., Sharma, S., \& Gore, C. A. (2019). Knowledge, attitude, and practice of breast selfexamination amongst female IT professionals in Silicon Valley of India. Journal of family medicine and primary care, 8(2), 568-572. https://doi.org/10.4103/jfmpc.jfmpc_315_18. 
[9] Shallso, S.A., Boru, J.D. Breast self-examination practice and associated factors among female healthcare workers in West Shoa Zone, Western Ethiopia: a cross-sectional study. (2019). BMC Research Notes 12, 637. https://doi.org/10.1186/s13104-019-4676-3.

[10] Sama, C. B., Dzekem, B., Kehbila, J., Ekabe, C. J., Vofo, B., Abua, N. L. ... Angwafo, F. (2017). Awareness of breast cancer and breast selfexamination among female undergraduate students in a higher teacher training college in Cameroon. The Pan African Medical Journal, 28, 91. https://doi.org/10.11604/pamj.2017.28.91.10986.

[11] Obaji, N., Elom, H., Agwu, U., Nwigwe, C., Ezeonu, P., \& Umeora, O. (2013). Awareness and Practice of Breast Self-Examination among Market Women in Abakaliki, South East Nigeria. Annals of medical and health sciences research, 3(1), 7-12. https://doi.org/10.4103/2141-9248.109457.

[12] American Society of Breast Surgeons. (2019). Breast Self-Examination. Retrieved from https://breast360.org/topic/2015/02/03/breast-selfexamination-bse/.

[13] Sani, M.A, \& Naab, F. (2014). Relationship between Age and Breast Self-Examination among Women in Nigeria. International Organization of Scientific Research- Journal of Nursing and health Science, 3(6), 34-39.

[14] Jones, K. N. (2013). Imaging of the adolescent breast. Seminars in plastic surgery, 27(1), 29-35. https://doi.org/10.1055/s-0033-1343994.

[15] Ahmed, A., Zahid, I., Ladiwala, Z., Sheikh, R., \& Memon, A. S. (2018). Breast self-examination awareness and practices in young women in developing countries: A survey of female students in Karachi, Pakistan. Journal of education and health promotion, 7 ,

90 . https://doi.org/10.4103/jehp.jehp_147_17.

[16] Gwarzo, U.M.D, Sabitu, H. \& Idris, S.H. (2009). Knowledge and practice of breast selfexamination among female undergraduate students of Ahmadu Bello University Zaria, northwestern Nigeria. Annals of African Medicine, 8(1), 55-58.

[17] Ifediora, C. O., \& Azuike, E. (2018). Tackling breast cancer in developing countries: Insights from the knowledge, attitudes and practices on breast cancer and its prevention among Nigerian teenagers in secondary schools. Journal of Preventive Medicine and Hygiene. 59(4), 282-300. https://doi.org/10.15167/2421-

4248/jpmh2018.59.4.964.

[18] Nwachokor, F., Igbe, A. P., \& Forae, G. D. (2013). Histopathological review of breast tumour in children and adolescents in Delta State Nigeria. African journal of Paediatric Surgery, 10 (2), 65-7.

[19]Banjo, A. (2004). Overview of breast and cervical cancers in Nigeria are there regional variations. In Paper presentation at the International workshop on new trends in Management of breast and cervical cancers, Lagos, Nigeria.

[20] Ihekwaba, F. (1992). Breast cancer in Nigerian women. British Journal of Surgery, 79 (8):771-5.

[21] Usman, I.N., Olarenwaju, S.O., Usman, S. (2020). Breast Self-Examination Practice among Female Secondary School Students in Oshogbo, Western Nigeria. European Journal of Medical and Health Sciences, 2 (2) 173-180. https://doi.org//10.24018/ejmed.2020.2.2.173.

[22] Ohaeri, B.M., \& Achilonu, B.O. (2019). Nigerian students' awareness of breast selfexamination. African Journal of Midwifery and Women's Health, 13(1). https://doi.org/10.12968/ajmw.2019.13.1.34.

[23] Adetule, Y. C. (2016). Breast Self-Examination (BSE): A strategy for early detection of breast cancer in Nigeria. Annals of Oncology, 27(9). https://doi.org/10.1093/annonc/mdw575.020.

[24] Irurhe, N.K., Raji, J.B., Olowoyeye, A.O., Ademoye, R.A., Arogundade, R.O., Soyebi, K.O., et al. (2012). Knowledge and Awareness of breast cancer among female secondary school students in Nigeria. Academic journal of cancer research, 5 (1). $1-5$.

[25] Isara, A.R., \& Ojedokun, C.I. (2011). Knowledge of breast cancer and practice of breast self-examination among female secondary school student. Journal of Preventive medicine and hygiene, 52 (4), 186-190.

[26] Al-Haji, K.M \& Moawed, S.A. (2015). Breast Self-Examination Knowledge among Female High School Students in Riyadh City. Middle East. Journal of Nursing, 9(1), 25-27.

[27] Ranasinghe, H.M., Ranasinghe, N., Rodrigo, C., De A Seneviratne, R. \& Rajapaksa, S. (2013). Awareness of breast cancer among adolescent girls in Colombo, Sri Lanka: a school-based study. BMC Public Health. 13, 1209.

[28] Azubuike, S. O., Muirhead, C., Hayes, L., \& McNally, R. (2018). Rising global burden of breast cancer: the case of sub-Saharan Africa (with emphasis on Nigeria) and implications for regional development: a review. World journal of surgical oncology, 16(1), 63. https://doi.org/10.1186/s12957018-1345-2. 


\title{
Determinants of EC Utilization among the Youth in the Tamale Municipality - A Cross-Sectional Study
}

\author{
Abdul-Malik, Abdulai ${ }^{*}$, Paul Armah Aryee ${ }^{2}$ \\ ${ }^{I}$ Nurses and Midwives Training College, Tamale, Ghana \\ ${ }^{2}$ Lecturer, University for Development Studies, Tamale, Ghana
}

\begin{abstract}
Unintended pregnancy among the adolescent globally is very high. It poses serious health risk to them and must be addressed to save the young girls. The adolescent females are mostly in unstable relations and are most unlikely to be on regular contraceptives. Sex among them is sporadic and impromptu, hence they are unable to negotiate for safer sex, which sometimes results in unintended pregnancy. Emergency contraceptives remain the only option to prevent unintended pregnancies after unprotected sex. This study, therefore, sought to determine the factors that promote EC utilization among the Muslim youth in the Tamale metropolis of the Northern region of Ghana. A communitybased cross-sectional design was adopted with a mixed method approach to collect both quantitative and qualitative data using a semi-structured questionnaire and FGD guide. A multi-staged sampling technique was used to select young Muslims, both males and females aged 15-24 years. Associated factors influencing EC use were determined using Chi-square $\left(\mathrm{Chi}^{2}\right)$ and logistic regression at $95 \%$ CI and significant level set at $p<0.05$. Socio-demographics and socio-cultural factors influencing knowledge and utilization of EC among young Muslims were; age $(O R=22.28$; $95 \%$ CI 2.97-171.85; $p=0.001)$, marital status $(O R=0.56 ; 95 \%$ CI 0.34-0.93; $p=0.030)$, education $(O R=0.19 ; 95 \% C I$ 0.05-0.66; $p<0.001)$, and partner approval $(O R=0.23 ; 95 \%$ CI 0.06-0.83; $p=0.020)$. Significant factors that determined EC utilization were age, educational level, marital status, and partner approval.
\end{abstract}

Keywords: Adolescent, Emergency contraceptive, Muslim, Unintended pregnancy.

\section{Introduction}

Unintended pregnancy is a serious health and social issue that needs to be addressed to save the future of young girls. Prevalence of unplanned pregnancy in adolescents worldwide ranges from $33 \%$ to $82 \%$ [1]. According to the WHO, approximately 16 million girls within 15 to 19 years' age bracket give birth each year in developing regions and every year, some 3.9 million adolescents aged 15 to 19 years undergo unsafe abortions as a result of unintended pregnancy. The situation is worse in Africa as close to one-fifth of adolescents become pregnant yearly [2]. Poor literacy, lack of knowledge and access to contraceptives has been cited as contributory factors and that is so because in Africa, and especially Ghana, cultural, social and religious norms restrict sexual intercourse to only the married people [3] thus excluding the young unmarried people, who are very sexually active and mostly vulnerable and subject to sexual abuse or exploitations from conversation involving sex and pregnancy prevention.

Because sexual intercourse in most adolescents is unplanned, there is an increased likelihood it will result in unintended pregnancy with its attending consequences. Emergency contraceptive will play a vital role in pregnancy prevention, unsafe abortion and unintended childbirth, which are the major problems of maternal health [4]. Previous studies elsewhere identified age, educational level, knowledge of ECs, culture, religion, sexual activity, previous use of regular contraceptives and marital status as strong predictors of EC utilization [5]. The northern region has seen an increasing trend, albeit slowly in the number of adolescents (1019 years) attending antenatal care in three successive years (2014-26) [6], an indication that teenage pregnancy is not under control in the region yet. For the females to benefit from EC and avoid unintended pregnancies, we must understand factors that predict its uptake. This study, therefore, intends to determine the factors 
that promote EC utilization among the Muslim youth in the Tamale metropolis of the Northern region of Ghana.

\section{Methods}

Tamale is the capital town of the Northern Region, one of the sixteen regional capitals in the country. It is located within the Guinea Savannah belt. The population of Tamale Metropolis, according to the 2010 Population and Housing Census, is 233,252 representing 9.4 percent of the region's population. Males constitute $49.7 \%$ and females represent $50.3 \%$. The proportion of the population living in urban localities $(80.8 \%)$ is higher than that living in rural localities $(19.1 \%)$ of the metropolis. The population of the metropolis is youthful (almost $36.4 \%$ of the population is below 15 years) depicting a broad-based population pyramid which tapers off with a small number of elderly persons (60 years and older) representing 5.1 percent.

A semi-structured questionnaire was used to collect data on the knowledge, socio-cultural acceptability and use of EC. Knowledge of Muslim youth on emergency contraceptive was assessed by evaluating their responses to ten (10) questions on ever heard of EC, EC information sources, type of EC, appropriate EC use time, when EC can cause abortions and conditions under which anyone can use EC such as forced sex/raped, condoms slipped off or burst, forgotten to take pill, when one has sex without using any FP method and when one want to terminate pregnancy (abortions). Each correct response to any of the knowledge questions attracted a score of " +1 " while each "wrong" or "don't know" response was assigned a score of " 0 ". The scores for each Muslim youth were summed and graded as follows; scores 0-4 scored point $=$ inadequate knowledge level, 5-10 scored point $=$ adequate knowledge level. The expanded programme of immunisation (EPI) method of selecting households was used in the data collection. In each of the communities, field teams first identified the centre of the community and spun a bottle to determine the direction to start with. All the eligible Muslim youths in the households were selected in the direction of the bottle using simple random sampling method. A sampling frame of all the houses was created using house numbers and a sampling interval of three (3) was used in the sample frame in the selection of house to select eligible households and Muslim youths. The selected households were entered by the field enumerators and study protocol was administered to eligible participants. In a house where there was more than one household, a simple random sampling method through balloting was used to select one eligible household. Also, within the household where there are more than one Muslim youth, one male and one female were equally selected through simple random method. The essence was to ensure heterogeneity in the sample, as people in the same household may have similar characteristics. This also helps to ensure that each house and household had an equal chance of participation in the study. The qualitative method was executed using focused group discussion and in-depth interview. Each focus group comprised of eight (8) participants. These meetings took place at their choice of venue and time; that is data was taken in the natural settings of the respondents. A discussion guide with open-ended questions was used to probes further in seeking information that would facilitate improvement in the discussions and findings of the study. The rules for the discussion were explained to the participants, and each of them was allowed with adequate time by the facilitator to express their views and contribute to the discussion. Discussions were recorded with a tape and field notes taken alongside to help capture the total views and contributions of each participant. The in-depth interview was also conducted with the participants in a similar manner using the interview guide.

\section{Results}

\section{Determinants of Emergency Contraceptives Utilization among Young Muslims}

Table 1 below summaries the determinants of EC utilization among young Muslims in the Tamale metropolis based on the logistic regression of significant socio-demographic, knowledge level, cultural and religious factors. Age of respondents in the bivariate analysis was found to significantly influence emergency contraceptives utilization among young Muslims, as those who were aged above 18 years were more likely to have used emergency contraception than those below 18 years $(\mathrm{OR}=$ 22.28; 95\% CI 2.97-171.85; $\mathrm{p}=0.001)$. However, 
in the multivariate regression analysis, it was found to have a 6.21 times likelihood of EC utilization, but the relationship was not significant (AOR $=6.21 ; 95 \%$ CI $0.82-47.16 ; \mathrm{p}$ $=0.192$ ). Also, marital status of young Muslims was significantly associated with emergency contraception use, as those who were not married had a decrease chance of $44 \%$ of using emergency contraception as compared to those who were married $(\mathrm{OR}=0.56$; $95 \%$ CI 0.34 $0.93 ; \mathrm{p}=0.041$ ). Marital status of young Muslims in the multivariate analysis was equally found to have had significant influence on the utilization of emergency contraception (AOR $=0.52 ; 95 \%$ CI 0.28-0.94; $\mathrm{p}=0.001$ ) as well as partner approval of emergency contraception was found to have positively influenced emergency contraception use among young Muslims as those who were married and had disapproval from the partner had a decreased chance of contraceptives use as compared to those who had approval from their partner $(\mathrm{AOR}=0.23 ; 95 \%$ CI $0.06-0.83 ; \mathrm{p}=0.021$ ).
Educational status equally had increased chance on emergency contraceptives, as emergency contraceptives use decreased with educational attainment $(\mathrm{OR}=0.09$; $95 \%$ CI 0.03 $0.31 ; \mathrm{p}<0.001)$. Again, the final multivariate regression model, educational attainment was still found to significantly influenced emergency contraception utilization among young Muslims as those with primary education had decreased chance of EC utilization as compared to those with Tertiary education $(\mathrm{AOR}=0.19 ; 95 \% \mathrm{CI}$ 0.05-0.66; $\mathrm{p}<0.001$ ).

Knowledge of Muslim youth on source of emergency contraceptives in both bivariate and multivariate analysis was associated with emergency contraceptives utilization as those who sourced emergency contraceptives information from health workers were found to have 1.94 times chance of emergency contraceptives utilization $(\mathrm{OR}=1.94 ; 95 \% \mathrm{CI}$ 1.02-3.72; $\mathrm{p}=0.044)$.

Table 1. Determinants of emergency contraceptives use among young Muslims

\begin{tabular}{|c|c|c|c|c|c|}
\hline Variable & \begin{tabular}{|l|} 
Ever use EC \\
Yes n $(\%)$ \\
\end{tabular} & $\begin{array}{l}\text { Unadjusted Odd } \\
\text { Ratio (OR) (95\% CI) }\end{array}$ & P-value & $\begin{array}{l}\text { Adjusted Odd Ratio } \\
\text { (AOR) (95\% CI) }\end{array}$ & P-value \\
\hline \multicolumn{6}{|l|}{ Age category } \\
\hline $15-17$ years & $1(0.7)$ & 1 (ref) & \multirow[t]{3}{*}{0.001} & 1 & \multirow[t]{3}{*}{0.192} \\
\hline $18-20$ years & $40(13.2)$ & $20.15(2.62-154.53)$ & & $6.52(0.85-49.73)$ & \\
\hline $21-24$ years & $54(14.5)$ & $22.58(2.96-171-85)$ & & $6.21(0.82-47.16)$ & \\
\hline \multicolumn{6}{|l|}{ Marital status } \\
\hline Married & $72(10.8)$ & 1 (ref) & \multirow[t]{2}{*}{0.041} & 1 & \multirow[t]{2}{*}{$0.011^{*}$} \\
\hline Unmarried & $23(17.7)$ & $0.56(0.33-0.93)$ & & $0.52(0.28-0.94$ & \\
\hline \multicolumn{6}{|c|}{ Educational status } \\
\hline Tertiary & $53(25.6)$ & 1 (ref) & \multirow[t]{4}{*}{$<0.001$} & 1 & \multirow[t]{4}{*}{$<0.001^{*}$} \\
\hline JHS/JSS/Middle & $9(3.9)$ & $0.12(0.05-0.25)$ & & $0.19(0.09-0.42)$ & \\
\hline SHS & $30(10.9)$ & $0.35(0.21-0.58)$ & & $0.42(0.25-0.69)$ & \\
\hline Primary & $3(3.1)$ & $0.09(0.02-0.32)$ & & $0.19(0.05-0.66)$ & \\
\hline \multicolumn{6}{|c|}{ Ever heard of EC } \\
\hline Yes & $88(92.6)$ & 1 (ref) & \multirow[b]{2}{*}{$<0.001$} & 1 & \multirow[b]{2}{*}{0.092} \\
\hline No & $7(7.4)$ & $0.10(0.05-0.23)$ & & $0.12(0.47-0.22)$ & \\
\hline \multicolumn{6}{|c|}{ Sources of EC information } \\
\hline Mass media & $22(25.0)$ & 1 (ref) & 0.032 & 1 & $0.044 *$ \\
\hline Health workers & $27(30.7)$ & $2.14(1.12-4.09)$ & & $1.94(1.02-3.72)$ & \\
\hline Friend & $32(36.4)$ & $0.92(0.51-1.66)$ & & $0.84(0.46-1.53)$ & \\
\hline Family members & $7(7.9)$ & $1.13(0.44-2.87)$ & & $1.04(0.41-2.66)$ & \\
\hline \multicolumn{6}{|c|}{ Can EC use cause abortion } \\
\hline Yes & $51(53.7)$ & 1 (ref) & \multirow[b]{2}{*}{$<0.001$} & 1 & \multirow[b]{2}{*}{0.052} \\
\hline No & $44(46.3)$ & $0.31(0.19-0.48)$ & & $0.62(0.38-1.03)$ & \\
\hline \multicolumn{6}{|c|}{ Society lived disapproved EC use } \\
\hline Yes & $43(12.9)$ & 1 (ref) & 0.021 & 1 (ref) & 0.219 \\
\hline
\end{tabular}




\begin{tabular}{|c|c|c|c|c|c|}
\hline No & $41(15.3)$ & $1.21(0.76-1.92)$ & & $1.29(0.78-2.14)$ & \\
\hline Don't know & $11(5.2)$ & $0.37(0.18-0.74)$ & & $0.67(0.31-1.49)$ & \\
\hline \multicolumn{6}{|c|}{ Religious sect disapproves EC use } \\
\hline Yes & $80(14.8)$ & 1 (ref) & \multirow[t]{3}{*}{0.044} & 1 (ref) & \multirow[t]{3}{*}{0.364} \\
\hline No & $3(3.0)$ & $0.17(0.05-0.58)$ & & $0.40(0.12-1.45)$ & \\
\hline Don't know & $12(7.1)$ & $0.44(0.23-0.84)$ & & $0.76(0.33-1.75)$ & \\
\hline \multicolumn{6}{|c|}{ Would you still recommend $\mathrm{EC}$ if the need arises } \\
\hline Yes & $58(14.0)$ & 1 (ref) & \multirow[t]{3}{*}{0.044} & 1 (ref) & \multirow[t]{3}{*}{0.364} \\
\hline No & $34(8.9)$ & $0.59(0.38-0.93)$ & & $0.86(0.47-1.59)$ & \\
\hline Don't know & $3(21.4)$ & $1.67(0.45-6.17)$ & & $1.69(0.43-6.59)$ & \\
\hline \multicolumn{6}{|c|}{ Partner approves the use of EC } \\
\hline Yes & $90(16.5)$ & 1 (ref) & \multirow[t]{2}{*}{$<0.001$} & 1 (ref) & \multirow[t]{2}{*}{$0.021 *$} \\
\hline No & $5(1.9)$ & $0.09(0.03-0.24)$ & & $0.23(0.06-0.83)$ & \\
\hline \multicolumn{6}{|c|}{ Advice on emergency contraception } \\
\hline Yes & $132(94.3)$ & 1 (ref) & \multirow[t]{2}{*}{$<0.001$} & 1 (ref) & \multirow[t]{2}{*}{0.112} \\
\hline No & $358(53.4)$ & $0.06(0.03-0.15)$ & & $0.30(0.12-0.74)$ & \\
\hline \multicolumn{6}{|c|}{ Bought emergency contraception } \\
\hline Yes & $114(95.8)$ & 1 (ref) & \multirow[t]{2}{*}{$<0.001$} & 1 (ref) & \multirow[t]{2}{*}{0.061} \\
\hline No & $376(54.4)$ & $0.05(0.02-0.14)$ & & $0.22(0.07-0.64)$ & \\
\hline \multicolumn{6}{|c|}{ Encourage EC purchase } \\
\hline Yes & $129(93.5)$ & 1 (ref) & \multirow[b]{2}{*}{$<0.0001$} & 1 (ref) & \multirow[t]{2}{*}{0.052} \\
\hline No & $361(46.3)$ & $0.08(0.04-0.16)$ & & $0.43(0.18-1.02)$ & \\
\hline
\end{tabular}

Source: Field Work, 2019

\section{Discussion}

Uptake and utilization of modern contraceptives among young people is influenced by many factors. In this study, sociodemographic, economic and cultural factors significantly influenced the participants' family planning and emergency contraceptives use. Factors such as cultural beliefs, religion, and sexual practices have been cited by many researchers to significantly influence young peoples' uptake and utilization of emergency contraceptives [7, 8, 9]. Strong predictors of young Muslim's utilization of EC in this study were found to be Age, Marital status, Educational status, and Partner approval. It was noted that the older young Muslims, those with higher educational qualification/attainment and the unmarried were more likely to use this form of contraceptive. These findings are consistent with a number of studies that found significant influence of socio-demographic variables such as age, educational level, and marital status on young people's utilization of emergency contraception $[9,10,11]$. Studies have found that persons who had approval of emergency contraception where more likely to use ECs and those who had no approval from their sexual partners had a decreased chance of utilization $[12,13,14,15]$. The link between educational attainment and increased EC use could be related to topics on family planning been discussed in schools at higher levels and access to more formal sources of information on contraception and $\mathrm{EC}$ for that matter, which will prevent misinformation and thus increase uptake and utilization.

Also, from this study, the unemployed group was associated with increased utilization of EC $(49.2 \%)$ and this may be due to the fact that they may be unable to cater adequately for the children they may give birth to in their current situation, hence, the need to enquire more about pregnancy prevention whilst they satisfy their sexual desires and this might have contributed to the increased level of knowledge.

\section{Conclusion}

Age, educational level, marital status, and partner approval were the factors that significantly influenced the utilization of EC among respondents in this study. Also, the unemployed group was associated with increased utilization of EC. This was probably due to the fact that they are not ready to have 
families they cannot take care of. This explanation fits well into the whole concept of family planning, where a couple gives birth when they are ready. Despite societal and

\section{References}

[1] Vázquez-Nava, F. et al. (2014) 'Unplanned pregnancy in adolescents: Association with family structure, employed mother, and female friends with health-risk habits and behaviors', Journal of Urban Health, 91(1), pp. 176-185. doi: 10.1007/s11524013-9819.

[2] Kassa, G.M., Arowojolu, A.O., Odukogbe, A.A. et al. Prevalence and determinants of adolescent pregnancy in Africa: a systematic review and Metaanalysis. Reprod Health 15, 195 (2018). https://doi.org/10.1186/s12978-018-0640-2.

[3] Awusabo-Asare K, Biddlecom A, Kumi-Kyereme A, Patterson K. (2006). Adolescent Sexual and Reproductive Health in Ghana: Results from the 2004 National Survey of Adolescents. Occasional Report No 22. New York, NY: Guttmacher Institute.

[4] Ethiopian Society of Obstetricians and Gynecologists (ESOG), MoHF, and ECafrique, "A training curriculum for mid-level health workers in Ethiopia. Addis Ababa, Ethiopia" vol. 1, no.2, 2005. [5] Habitu YA, Yeshita HY, Dadi AF and Galcha D. Prevalence of and factors associated with Emergency contraceptive use among female undergraduates in Arba Minch University, Southern Ethiopia, 2015: A Cross-Sectional Study. International Journal of Population Research, volume 2018, Article ID 2924308, $8 \quad$ pages. https://doi.org/10.1155/2018/2924308.

[6] GHS, 2016: Family Health Division Annual Report, Ghana Health Service. www.ghanahealthservice.org.

[7] Subedi, S. (2012). Knowledge, attitude and practice of emergency contraceptive among the youth of Parbat District. Journal of Health and Allied Sciences, 2(1)50-53.

[8] Hoque. E.M. \& Ghuman, S. (2012). Knowledge, practices, and attitudes of emergency contraception among female university students in KwaZulu-Natal, South Africa. PLoS ONE, vol. 7(9).

[9] Tilahun. D. F., Assefa. T., \& Belachew. T., (2010). Predictors of emergency contraceptive use among regular female students at Adam3a University, Central Ethiopia Pan Africa Medical Journal - ISSN: 1937- 8688.

[10] Amalba, A., Mogre, V., Appiah, M.N.A., and Mumuni, W.A., (2014) "Awareness, use and religious disapproval, the young people said they will still use EC and recommend it to their colleagues.

associated factors of emergency contraceptive pills among women of reproductive age (15-49 years) in Tamale, Ghana," BMCWomen'sHealth, vol.14(114). [11]Ezebialu I., \& Eke A., (2013). "Knowledge and practice of emergency contraception among female undergraduates in South Eastern Nigeria," Annals of Medical and Health Sciences Research, vol.3, no.4, pp.541-545,2013.

[12] Ejembi, C., L, Dahiru., T., ALIYU., A. A (2015) Contextual Factors Influencing Modern Contraceptive Use in Nigeria. ICF International, Rockville, Maryland, USA.

[13] Colleran, H., and R. Mace, (2015). "Social network and community-level influences on Contraceptive use: Evidence from rural Poland "Proceedings from Royal Society of London.

[14] Okezie, C. A., Ogbe, A. O. \& Okezie, C. R. (2010), Socio-economic Determinants of Contraceptive Use among Rural Women in Ikwuano Local Government Area of Abia State, Nigeria, International NGO Journal, Vol. 5(4), 74-77.

[15] Alkema, L., V. Kantorova, C. Menazzi, and A. Biddlecom. 2013. "National, regional and global rates and trends in contraceptive prevalence and unmet need for family planning between 1990 and 2015: A systematic and comprehensive analysis." The Lancet 381:1642-1652.

[16] Coughlin J (2016): Teenage pregnancy in Ghana: Assessing situation and moving forward. www.graphic.com.gh/news/general-

news/teenage/pregnancy-in-ghana-assessing-

situation-and-moving-forward.html.

[17] GoG (2014): Child Protection baseline research, Northern regional profile, GOG, Department of children (Ministry of Gender and Social Protection, 2014] www.unicef.org.

[18] Mohammed, F., Musa, A. and Amano, A. (2016) 'Prevalence and determinants of unintended pregnancy among pregnant woman attending ANC at Gelemso General Hospital, Oromiya Region, East Ethiopia: BMC Women's Health. 16(1), pp. 10-16. 


\title{
Health Budgeting at Woreda level and Effect on Access and Quality of Health Services in Somali Region of Ethiopia
}

\author{
Oladeji Olusola $^{1 *}$, Pieterse Pieternella ${ }^{2}$, Robins Ann ${ }^{3}$, Oladeji Bibilola ${ }^{4}$ \\ ${ }^{1}$ UNICEF Somali Field Office, Ethiopia \\ ${ }^{2}$ Dublin City University, Ireland \\ ${ }^{3}$ UNICEF Country Office, Ethiopia \\ ${ }^{4}$ College of Medicine, University of Ibadan, Nigeria
}

\begin{abstract}
Ethiopia has made a great effort in recent years to improve maternal, newborn, child health outcomes, however, the uptake of services in Somali Region of the country is still very low. The study was a cross-sectional descriptive survey using qualitative methods, and the participants were key individuals involved in the management of health systems and knowledgeable about on health service delivery in the study sites. The study aimed to explore the budgeting process at the woreda (district) level and its effect on the utilization of equitable quality health services in the region. The woreda health officers determined what is included in the budget of the health facilities without active participation of stakeholders such as health care providers or the community members. Their knowledge and understanding of the planning and budgeting processes varied and little or no support available to them. This suboptimal budgeting process impacts negatively on the quality of health care services being provided, with shortages of essential drugs identified as a major barrier affecting utilization. The need for better budgeting process at the woreda level which could perhaps involve a range of regional level, woreda level and citizen level measures and active participation. This include the implementation of clearer guidelines from regional level, maybe the introduction of standard formulae that ensures that each health centre receives certain percent of overall health budget and specific percentage to be allocated for drugs and supplies and other essential services instead of each woreda official deciding on how much is to allocated arbitrarily.
\end{abstract}

Keywords: accountability, budget, health, participation, woreda.

\section{Introduction}

Ethiopia has made great efforts in recent years to improve maternal, newborn, and child health $(\mathrm{MNCH})$ outcomes with the implementation of the country's health-sector transformation plan and other strategic initiatives that have driven a steady decline in maternal, newborn, infant, child and under five mortality [1].

Improvements in health outcomes have been positively influenced by the government's policy support for the Health Extension Program (HEP) especially the engagement of Health Extension Workers (HEWs), which has contributed to health promotion, disease prevention and community-based disease case management, leading to the reduction of morbidity and mortality [2]. Ethiopia was one of the low-income countries to have achieved the Millennium Development Goal four (MDG 4) target of reducing child mortality by twothirds (from 204 per 100,000 in 1990, to 68 per 100,000 in 2012) [1]. The maternal mortality has also significantly reduced to about 412 per 100,000 live births in 2016 from 676 per 100,000 livebirths in 2011 [3] and this has been attributed to the successful implementation of the country flagship health extension program [4].

However, Somali Region, which is one of Ethiopia's four Developing Regional States (DRS) and predominantly inhabited by pastoralists (85\%), faces developmental inequities and has shown less improvement in key health outcomes compared to the national average [5].

The 2019 Mini DHS records that Somali Region has the lowest percentage of fully vaccinated children, with only $18.2 \%$ having 
received all basic vaccinations, and $48.8 \%$ had received no vaccinations at all compared to the national average of $43.1 \%$ and $19.2 \%$ respectively [6]. Ethiopia has a decentralized health system and has introduced a series of institutional and policy reforms in the public sector aimed at capacity building, enhancing government responsiveness to citizens and implementation of the principles of good governance in the health sector include rule of law, transparency, inclusiveness and equity, responsiveness, efficiency and effectiveness and participatory engagement of citizens [5].

This study aims to explore the budgeting process at the woreda level in Somali Region and its effect on the quality and utilization of equitable health services in the region and identify innovative approaches for improving budgeting processes in the region.

\section{Materials and Methods}

The study was a cross-sectional descriptive survey using qualitative methods.

The study was conducted in 3 woredas (Gursum, Awbare and Kebribayah) and 2 municipal areas (Jijiga and Wachale) in Farfan zone in the region where social accountability mechanism in the health sector was being introduced by government. The study area has a total estimate population of 746,046 and 86 health facilities.

The study population included the key persons at the community, health facility, woreda/municipal offices, and the regional office with an active role in health care delivery, planning and budgeting in the study sites. The different respondent groups were identified, guided by the World Bank's framework on accountability: policy advisors, healthcare officials, healthcare providers, and citizens [7].

The study focused on assessing the budgeting process in a decentralised health system by reviewing the linkages and relationship between the region, woreda and the community and the perception of the community members on the effect of budgeting on health service delivery, especially on availability of essential drugs, supplies and vaccines.

The participants were purposefully identified and recruited based on their positions and roles in the management of health systems and knowledge of health service delivery in the study sites.

Data was collected through in-depth interviews and focus group discussions (FGDs). The in-depth interviews aimed at identifying the budgeting process at the woreda level. Decision makers involved in the budgeting process were asked about budget planning and budget execution, and how it affects health service delivery in the study sites. The FGDs aimed at identifying the perception of the beneficiaries on the utilization and quality of care provided in the health facilities. The FGDs with women groups were audio-taped and notes were also taken with prior consent from the participants. The study was conducted between December 2019 and January 2020.

The FGD data was collected from different categories of respondents and responses to the same questions were triangulated and transcribed verbatim to produce transcripts of narrative text for thematic analysis. The data were coded according to the types of themes and issues, and thematic analysis was used and comprised a mix of inductive and deductive coding. The outcome of the study was the woreda-based budgeting process and management and effect on quality of health service delivery were transcribed and initially presented as a series of case studies.

\section{Results}

The results are organized in two major themes: Budget planning process and implementation and the perception of beneficiaries about the quality of health services delivery.

Overview of the respondents: Table 1 shows the categories of the respondent interviewed durimg the study. These were the head of the planning, budgeting and $\mathrm{M} \& \mathrm{E}$ at the region, the heads of the woredas/municipal health offices, head of finance in one of the woredas, the heads of health centres and health posts in the five study sites and the representative of the women groups and selected women /care givers in three of the study sites. 


\section{The Health Budget Planning Process in Somali Region}

\section{The Funding Chain for the Health Sector in Ethiopia}

Figure 1 shows the funding chain for primary healthcare funding from the treasury in Ethiopia flows from national to regional, then to woreda/municipal and finally to health centers, which support the health posts as explained by the planning and budgeting officer at the regional level. There are only two types of primary healthcare facilities in Somali Region, health centers and health posts with each health centre responsible for a range of between $4-8$ health posts.

\section{Budget Planning Process and Implementation}

The budget cycle as described by the regional planning and budgeting officer is initiated at the regional level as follows; the Regional Bureau of Finance and Economic Development (BOFED) provides each woreda BOFED with indicative budget estimate; the Woreda BOFED asks for the budget estimates from all woreda sector offices, and the Woreda BOFED will then create budget suggestions after all of the sector heads have defended their budget. The proposed budget then goes to the woreda cabinet, which is entirely made up of the same sector heads who proposed the budget, which leads to an almost certain guarantee that the budget will be approved. Once the budget allocation to each sector within each woreda has been agreed, it is then sent to the regional bureaus and parliament for approval.

Once the woreda health office receives the indicative annual budget, it is at their discretion to allocate a running cost to each health centre, or not, and to divide the non-recurrent budget. The regional health bureau team focuses more on the technical performance of the woreda health facilities, measured through monthly statistics reported by the health facilities, rather than paying close attention to the financial performance of each woreda's administration of each of the 99 woredas in Somali region. However, extreme budgeting issues are questioned; a member of the regional health bureau explained:

'Sometimes the woreda budgets are so badly structured that the regional health bureau intervenes, overall, this is rare. For example, at some time in the past a woreda health officer had planned to spend the entire annual capital budget for his woreda on new office furniture, which was blocked by the regional health bureau. Unfortunately, there are few checks on how budgets are divided there are few checks regarding the financial performance of woredas'.

\section{Woreda/Municipal office}

The five woreda/municipal officials interviewed explained how the budget cycle works in their respective woreda/municipal areas. The finance office (at the woreda level) has the mandate to allocate budget according to the needs of the people. The cabinet delegates these decisions to the finance office, and the head of the finance office are a member of the cabinet. The finance office forwards the suggestions about the division of the budget at woreda level to the cabinet for approval. There is no participation of most of the key stakeholders like the community members, the board members overseeing the health centers, and the officers in charge of the health post during the budget discussion and planning process.

Each woreda health office leadership team decides on a budget for the essential drugs and supplies and there is no uniformity or any clear criteria that guides how much is allocated to each key subsection of health such as maternal and child health, disease prevention, immunization, etc. Within the five study sites, one woreda health office budgeted 500,000 ETB per annum for the revolving fund to purchase medications for the single health centre in that woreda, while another woreda health office budgeted 800,000 ETB per annum for the health centers in the woreda to share.

One of the officers explained further on how the budgeting process is done:

'The regional finance bureau allocates the amount to the municipality that they deem necessary, often based on previous years' budgets, and the total figure goes back to the municipal council. They decide on how the total sum that they have been allocated gets subdivided among all the sectors. The subdivision does not work according to any formula, it is more a case of "you got some money for construction last year, so we will 
provide more to the other sectors this year. It is then up to the sector heads to decide to further divide the funds that have been allocated' [Municipal Key Informant 1].

Most of the woreda officials mentioned that frequently not all of the approved budget is released to the woreda and the health centres in time and that there is always a delay in the release of approved budget from the region to the woredas.

\section{Health Centres}

During interviews with the head of the health centres, two concerns were highlighted; insufficient funds were being allocation for drugs and supplies, and low or no running cost are allocated or received for the health centres, which is to be shared with the health posts under each health centre. The experiences about budget releases varied from one health centre to the other. The five locations sampled included a health centre in one of the municipal areas which received running cost as per the budget, while other health centres received much less than the budgeted amount, and all reported delays in receiving funds. The running cost per health centres varied from 10,000- 20,000 ETB per month without no clear criteria on how this is determined.

However, shortages of drugs and other essential supplies were a major problem common to all the health centres. Health centre senior staff admitted:

'The medicines are always a problem, the amount of money spent on budget drugs is small, still based on the old population figures, and with patients from Somaliland crossing over the border to access our health centre, the medicines run out quickly' [Health Centre Key Informant 1].

'Our health centre also needs to provide free drugs to the health posts it supervises and supports, but this can be difficult when stocks are already low, so sometimes we can only provide about $40 \%$ of what a health posts ask for' [Health Centre Key Informant 2].

'Our biggest problem in the Health Centre is struggling with is the small running cost transfer to us which we are also expected to use for the health posts under us by which is even not enough for us. We always receive less than what we requested and budget and always coming late' [Health Centre Key Informant 3].
'My health centre sometimes solicits feedback from its patients, and in general the responses are positive. The usual and most common complaints from the patients is shortage of drugs, which is due to the insufficient amount allocated to drugs in our budget by the woreda without telling us why' [Health Centre Key Informant 4].

\section{The Health Posts}

Ethiopia's Health Extension Program (HEP), which has been lauded for bringing basic primary healthcare delivery closer to the communities, depends on the services of Health Extension Workers (HEWs), who are based at Health Posts in kebeles (communities) throughout Ethiopia. As noted, health posts are dependent on their nearest health centre for their drug supplies and running costs. As these were found to be in short supply in the health centres, it was not surprising that the issues were even more severe in the health posts that were visited. HEWs locations complained about not having a running cost budget and being dependent on the irregular supply of the health centre for even basics such as cleaning products and stationery, as well as medicine.

The lack of running costs at the health post level appears to affect the provision of services especially for transportation to pick up medicines or vaccines from the woreda health office or to go on outreach to immunise children in the communities close to the health post.

\section{Perception of Beneficiaries about Quality of Health Service Delivery}

The views of the women in the community on the quality of health services being provided was assessed through one of the women's group leaders and selected group of mothers/care givers. The leader of the one of the women's groups reported a good working relationship with the staffs in the health facilities, the women are happy with the services provided to them, but most of the complaints by the women when they visit the health facilities is about drugs supply.

'We have a good relationship with the health workers and anytime we go to them to raise complaint like when we bring a labouring mother to a health centre and she does not receive immediate attention or lack of drugs or 
vaccines in the clinic. We understand the problem of drugs or vaccines is from the woreda or health centre who bring little drug or vaccines to the clinics [Women's Group Key Informant].

The women in the focus group discussion revealed that, after facing the challenges of getting to the health facilities by all means because many of them live far away from the health facilities, they are disappointed to see the clinics not opened or not provided with all the needed services and drugs or vaccines. One of the women group members expressed her concern:

'In the clinic in our kebele the number of drugs is small and gets used up quickly and so we usually don't get treatment when we or children feel sick and because of that some women don't come to the clinic again' [Women group member during FGD].

\section{Discussion}

Universal health coverage requires an efficient health system that provides the entire population with access to good quality services, provided by sufficient health workers, who have accessed the requisite medicines and technologies.

This study shows that during our examination of the funding chain that runs from the national level, via region, woreda/municipality, to health centre and health posts, it appears that there are serious constraints with regards to the budget process at woreda and municipal level. At this level, a relatively small group of individuals determine what should be included in the budget without participation of other stakeholders like the community members and health care providers. This appears to be a suboptimal way of budget making, which undermines the quality of health service delivery in Somali Region and disadvantages the most vulnerable in society who need access to basic primary healthcare most.

In addition to the budget process lacking active engagement from the healthcare professionals who are charged with delivering health services in Somali Region, the process also lacks input from those community members who use the health services. This is against the principles of primary health care which recommended community participation in all the processing leading to the planning and budgeting of health care delivery for the communities. Community participation has been recognized as an important public health policy since the declaration of Alma-Ata presented it as one of the pillars of primary health care in 1978 [8] and reaffirmed 40 years after during the primary health care conference in Astana [9]. The Ottawa Charter for Health Promotion [10] and Jakarta Declaration [11], and most importantly the Ethiopian Government's own 5th Health Sector Transformation Plan, Strategic Objective P3 is 'Enhance Good Governance' [5] which all emphasize the importance of community participation as a key principle for effective health system strengthening.

Our study found that the woreda health officers' knowledge and understanding of the planning and budgeting process varied, and their understanding of the health sector needs seemed to be related to how much funding was allocated for key interventions like drugs supplies and running cost, compared to spending on the woreda health office's own needs. There is an obvious lack of guidance regarding the management of woreda health budgets, providing woreda health office heads with significant discretion to allocate funding, which has a direct, and sometimes negative, impact on the functioning of the health facilities within its jurisdiction.

This is like findings in other countries in the region which have reported limited knowledge and skills in planning among local government authority staff and councillors as among the challenges facing the implementation of decentralization in the health sector [12]. There is a need to build the capacity of woreda officers and provide institutional support to them for effective planning and budget management.

Introducing greater citizen engagement in the health sector needs to be done in a gradual and structured way that takes account of Somali Region's contextual challenges when it comes to inviting women to participate in public fora. In places where active women's groups can be found, these can be entry points for further engagement. Evidence suggests that when community members are invited to fully participate in the planning and budgeting processes, a number of benefits emerge; 
including better identification of community needs and priorities, increased knowledge of the community representatives about priority setting, increased transparency and accountability, promoted trust among health systems and communities, and perceived improved quality and accessibility of health $[13,14]$. Such interventions need to be introduced with significant support to expose the community to planning skills, knowledge, and confidence to enable them to engage meaningfully during planning and budgeting process in their respective woredas so as to achieve the purpose of their participation. Selecting suitable tools for citizen participation, such as gender-responsive budgeting [15] or citizen-led audits [16] can play a positive role.

Another major concern raised in this study was the late transfer of funds from the regional level to the woreda and to health facilities, which was reported to have had a negative impact on health service delivery. Most of the woredas are unable to generate their own funds to supplement what is provided to them from them from the region. The woredas in Somali region are not the only part of Ethiopia, or indeed the continent where such challenges exist. Studies from Tanzania, Uganda, Zambia and Ghana have similarly reported such issues $[12,17,18]$, whereby the allocations to the local, often rural, health authorities and facilities are not only inadequate to support local health needs, the central government disburses grants late, causing difficulties in the implementation of health activities. With many woredas in the region enjoying the financial and technical support being provided by NGOs and $\mathrm{UN}$ agencies, there is a need for the mapping and harmonization of such resources at the regional level to ensure that these are targeted to the woredas with the greatest need and least support, for efficient, effective and equitable service delivery.

In assessing the quality of health care services being provided, the study identified budget shortages leading to a lack funding to procure enough essential drugs and supplies and to cover transportation of vaccines from the woreda or health centres to the health post or to conduct outreach visits for immunisation. All of these shortcomings present major barriers affecting the utilization and access to health services in Somali Region. The study shows that continuous availability of essential medicines in the health facilities plays an important role in promoting access to and utilization of health services as articulated by the women interviewed and this finding is similar to other studies $[9,20,21]$, which reported that frequent stock-outs of medicines influence healthcare utilization and individual decisions to consult health service providers, leading to a distrust in healthcare providers and contributes to low utilization of the formal health care system. However, the study did not assess in detail other possible causes of the shortage of drugs supply apart from what was articulated by the health workers and the beneficiaries interviewed.

The availability of quality medicines in the provision of healthcare service is an integral part of universal health coverage for efficient, quality and equitable healthcare service delivery $[22,23]$.

\section{Conclusion}

It is clear that the processes of decision making and budgeting for health at the woreda level have a direct impact on the functioning of the health facilities and utilization of services. Understanding the budgeting system from the perspective of those who are directly involved with the process is extremely important in understanding and improving health care delivery.

Such a process would greatly benefit from being more participatory and inclusive of all stakeholders, especially female community members, to ensure greater accountability.

There is a need for better budgeting process at the woreda level which could perhaps involve a range of regional level, woreda level and citizen level measures and active participation. This include, for example, the implementation of clearer guidelines from regional level, maybe the introduction of standard formulae that ensures that each health centre receives a certain percent of overall health budget and specific percentage to be allocated for drugs and supplies and other essential services instead of each woreda official deciding on how much is to allocate arbitrarily. 


\section{Figures and Tables}

Table 1: Overview of the Respondents

\begin{tabular}{|l|l|}
\hline Respondents Categories & Number \\
\hline Health adminstrators/officials & \multicolumn{2}{|l|}{} \\
\hline Planning and budgeting officer at the regional level & 1 \\
\hline Head of woreda/municipal health offices & 5 \\
\hline Head of finance at the woreda level & 1 \\
\hline Head of health centres & 5 \\
\hline Officers in charges of health post & 3 \\
\hline Community members & 1 \\
\hline Representative of the womens' group & 32 \\
\hline Care givers/mothers during FGDs \\
\hline
\end{tabular}

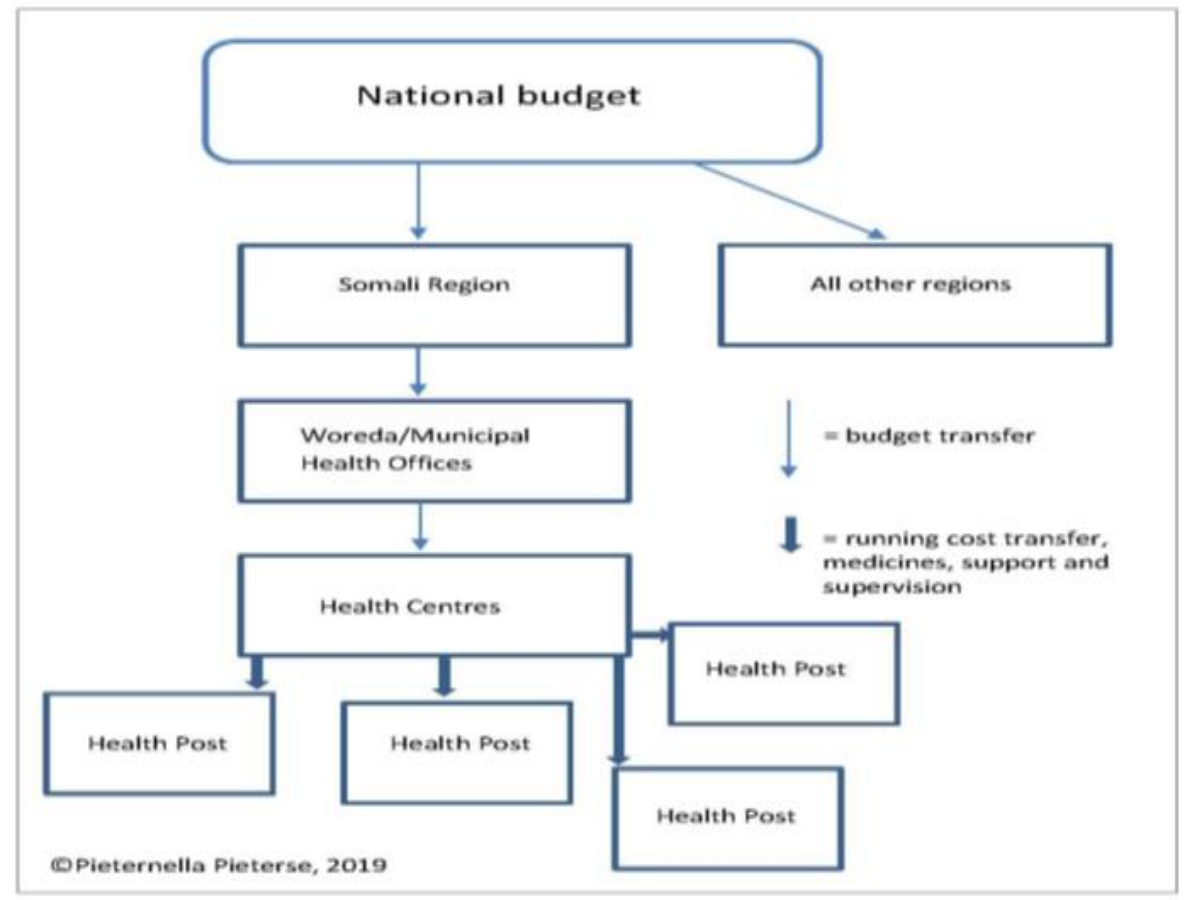

Figure 1: The funding Chain for the Health Sector in Ethiopia

\section{Acknowledgements}

The authors wish to thank all the individuals interviewed during the field work at the Regional and woreda level, including the women during the focused group discussion. We also Mohamed Ayanle Hassan, the Directorate Director of Planning, $\mathrm{M} \& \mathrm{E}$ and
NGOs Somali Regional Health Bureau who provided very useful information about the budgeting and planning process in the region and Asli Hassan, UNICEF C4D consultants who helped with interpretation during the field work. 


\section{References}

[1] United Nations. 2015, The Millennium Development Goals Report 2014, Ethiopia. Assessment of Ethiopia's progress towards the MDGs: National Planning Commission and the United Nations in Ethiopia. http://et.one.un.org/content/unct/ethiopia/en/home/as sistance-framework/millennium development goals. $\mathrm{html} /$.

[2] Assefa, Y., Gelaw, Y.A., Hill, P.S., Taye, B.W., and Van Damme, W., 2019, Community health extension program of Ethiopia, 2003-2018: successes and challenges toward universal coverage for primary healthcare services. Globalization and health; 15(1): 24. accessed 14th July 2020.

[3] Central Statistical Agency (CSA) [Ethiopia], ICF., 2016, Ethiopia Demographic and Health Survey 2016: Key Indicators Report. Addis Ababa, Ethiopia, and Rockville, Maryland, USA. CSA and ICF.

[4] Federal Ministry of Health of Ethiopia., 2010, Health Sector Development Plan (HSDP) IV, 2010/11-2014/15. Addis Ababa, Ethiopia: Ministry of Health.

http://www.nationalplanningcycles.org/sites/default/ files/country_docs/Ethiopia/ethiopia_hsdp_iv_final draft_2010_-2015.pdf.

[5] Federal Ministry of Health of Ethiopia., 2015, Ethiopia's Health Sector Transformation Plan (HSTP) (2016 -2020). https://www.globalfinancingfacility.org/ethiopiahealth sector transformation plan 201516-201920/ accessed 14th July 2020.

[6] Ethiopia Central Statistical Agency., ICF., 2019, mini-Ethiopia Demographic and Health Survey 2019. Addis Ababa, Ethiopia, and Rockville, Maryland, USA. accessed 2nd August 2020.

[7] World Bank.,2004, Making Services Work for Poor People. World Development Report 2004. Washington, DC: World Bank. https://openknowledge.worldbank.org/handle/10986/ 5986. accessed 23th September 2020.

[8] WHO., UNICEF., 1978, International conference on primary healthcare Alma-Ata, USSR, 6_12 September.https://www.who.int/publications/almaat a_declaration_en.pdf. accessed 23th September 2020.

[9] World Health Organization, United Nations Children's Fund. Declaration of Astana. Global Conference on primary health care. Astana Kazakhstan 25-26th October; 2018. https://www.who.int/docs/default-source/primary- health/declaration/gcphc-declaration.pdf accessed 23rd September 2020.

[10] World Health Organization.,1986, Ottawa charter for health promotion. Geneva: https://www.who.int/teams/healthpromotion/enhanced-wellbeing/first-globalconference. accessed 14th July 2020.

[11] World Health Organization.,1997, The Jakarta declaration: on leading health promotion into the 21st century. Geneva. https://www.who.int/healthpromotion/conferences/p revious/jakarta/declaration/en/ accessed 14th July 2020.

[12] Gasto, F., Tumaini, N., Mughwira, M., and Anna-Karin, H., 2013, Challenges to the implementation of health sector decentralization in Tanzania: experiences from Kongwa district council, Global Health Action; 6:1, DOI: 10.3402/gha. v6i0.20983. accessed 14th July 2020.

[13] Kamuzora, P., Maluka, S., Ndawi, B., Byskov, J., and Anna-Karin, H., 2013, Promoting community participation in priority setting in district health systems: experiences from Mbarali district, Tanzania, Global Health Action; 6:22669- DOI: 10.3402/gha. v6i0.22669 accessed 14th July 2020.

[14] McCoy, D., Hall, J., Ridge, M., 2012, A systematic review of the literature for evidence on health facility committees in low-and middleincome countries. Health Pol Plann; 27: 449-466.

[15]Nass, L., and Pieterse, P., 2018 Gender Responsive Budgeting in Ethiopia's Country-wide Social Accountability Program. Research Gate. https://www.researchgate.net/publication/327261578 accessed 14th July 2020.

[16] Mugizi, G. Interrogating Social Accountability in Tanzania, a Case Study. The PSAM and Policy Forum Learning Partnership August 2009 - April 2013. Public Service Accountability Monitor, Grahamstown, South Africa: Rhodes University;2013.

[17] Jeppsson, A., Okuonzi, SA.,2000, Vertical or holistic decentralization of the health sector? Experiences from Zambia and Uganda. Int $J$ Health Plann Manage; 15(4): 273-89. https://pubmed.ncbi.nlm.nih.gov/11246898/ accessed 14th July 2020.

[18] Kojo, E., Sakya, J., Awoonor-Williams, K., Adzei, FA., 2011, Barriers to implementing health sector administrative decentralization in Ghana: a study of the Nkwanta district health management team. J Health Organ Manag; 25: 400.

[19] Shan, L., Li, Y., Ding, D., Wu, Q., Liu, C., Jiao M, et al.,2016, Patient Satisfaction with Hospital 
Inpatient Care: Effects of Trust, Medical Insurance and Perceived Quality of Care. PLoS ONE 11(10): e0164366.

https://doi.org/10.1371/journal.pone0164366.

[20] Anselmi, L., Lagarde, M., and Hanson, K. Health service availability and health seeking behaviour in resource poor settings: evidence from Mozambique. Health Economics Review; 5:26. https://www.ncbi.nlm.nih.gov/pmc/articles/PMC455 $6719 /$.

[21] Musoke, D., Boynton, P., Butler, C., and Musoke, MB., 2014, Health seeking behaviour and challenges in utilising health facilities in Wakiso district, Uganda. Afr Health Sci ;14(4): 1046-55.doi: 10.4314/ahs. v14i4.36.
[22] Bigdeli, M., Laing, R., Tomson, G., and Babar, ZU., 2015, Medicines and universal health coverage: challenges and opportunities. Journal of Pharmaceutical Policy and Practices; 8: 8. https://joppp.biomedcentral.com/articles/10.1186/s4 [23] 0545-015-0028-4.accessed 26th August 2020. [24] Obare, V., Brolan, CE, Hill, PS., 2014, Indicators for universal health coverage: can Kenya comply with the proposed post-2015 monitoring recommendations? Int J Equity Health 13, 123. https://doi.org/10.1186/s12939-014-0123-1. accessed 26th August 2020\. 


\title{
Health Risk Associated with Near-Road Ambient Air Concentration of Particulate Matter in Mukono Municipal Council, Uganda
}

\author{
Edward Kibikyo Mukooza ${ }^{1 *}$, Sarah Kizza-Nkambwe ${ }^{2}$ \\ ${ }^{1}$ Uganda Christian University, Faculty of Health Sciences, Department of Public Health \\ ${ }^{2}$ Uganda Christian University, Faculty of Engineering and Environment
}

\begin{abstract}
More than $98 \%$ of urban centres exceeding 100,000 people in Low and Middle-Income Countries (LMICs), do not meet the WHO air quality limits. Data on air pollution from LMICs is scarce. We measured the mean concentrations of near-road PM2.5 in the period of Aug.-Dec. 2020, described the Mukono Municipality's near-road populations' exposure to PM2.5, and assessed the associated health risk. PurpleAir PA-II laser particle counters, measured near-road ambient air PM2.5 concentration in Mukono Municipality during the period of 09/1/20 to 12/04/20. Excel Toolpak was used for data analysis and the health risk assessed with the WHO AirQ+ tool. The mean ambient near-road PM2.5 in Mukono Municipality were 30.97, 33.84 and 47.74 ug/m3for background, nearunpaved and near-paved roads, respectively. Mukono Municipality's population was exposed to ambient PM2.5 concentrations higher than the WHO annual limit of $10 \mathrm{ug} / \mathrm{m} 3$. This level of air pollution is associated with preventable annual premature deaths of up to 133.11 per 100,000 population. Vehicles were assumed to be the predominant source of near-road ambient air PM2.5 pollution. The Municipality's population was exposed to near-road ambient air PM2.5 exceeding the WHO annual limit by as much as *4.7 for the paved roads, *3.3 for the unpaved roads and *3 for the background. This leads to increased risk of preventable premature deaths in the Municipality.Mukono Municipality could monitor PM2.5; guide developers to placebuildings more than 100 meters away from roadsides and should promotepolicies for newer vehicles on Ugandan roads.
\end{abstract}

Keywords: Ambient Air quality, Health risk, Mukono Municipality, Near-Road, PM 2.5.

\section{Introduction}

The United Nations categorizes clean air as a human right $[1,2]$. Air pollution is defined by the World Health Organisation [3] as "contamination of the indoor or outdoor environment by any chemical, physical or biological agent that modifies the natural characteristics of the atmosphere". Air Pollution can be ambient (outdoor) or household (indoor) but one can contribute to the other. According to the World Health Organisation, air pollution is the number one environmental health challenge with 7 million premature deaths associated with it and over $90 \%$ of the global population living in areas with air pollutants exceeding the WHO limits [4]. To guide member countries on air quality improvement, the United Nations set targets for air quality in SDGs 3.9, SDG 7 and SDG 11.6 and WHO set air pollution limits $[5,6]$. According to WHO [7], pollutants with strongest evidence of negative health effects are particulate matter (PM), Ozone $\left(\mathrm{O}_{3}\right)$, Nitrogen dioxide $\left(\mathrm{NO}_{2}\right)$ and Sulphur dioxide $\left(\mathrm{SO}_{2}\right)$. Particulate matter PM 2.5 is independently and consistently associated with the most serious health risks, even when the ambient concentration is below the WHO limits $[8,9]$. The World Health Organisation [10] asserts that air pollution is associated with excess Ischemic Heart Disease, Stroke, Chronic Obstructive Pulmonary Disease, Lung Cancer and Acute Respiratory Infections in children. The World Health Organisation estimates that outdoor air pollution leads to 4.2 million pre-mature deaths annually, and of these, 91\% occur in Middle and Low-Income Countries (LMIC) like Uganda. A recent study by Lelieveld and others [11] found that air pollution leads to more premature deaths than previously known, by a factor of two. Air pollution tends to be worse in urban areas and according to WHO, more than $98 \%$ of urban arreas with populations 
exceeding 100,000 population in LMIC, do not meet the WHO limits $[12,13]$. Data on air pollution, especially from LMIC, is limited [12, 14]. Particulate matter, which has no known threshold below which there is no health risk, is used as a proxy indicator for air quality since it is the most health damaging air pollutant $[15$, 16]. Literature shows that at population level, a $6 \%$ increase in all-cause mortality is associated with each $10 \mu \mathrm{g} / \mathrm{m}^{3}$ rise in ambient air particulate matter of size $2.5 \mu \mathrm{m}$ [PM2.5] [5, 15, 16]. The few publications from Uganda show that air in Kampala City and in the surrounding urban centers is polluted with particulate matter concentrations exceeding the WHO guidelines [17, 18, 19, 20]. Roadsides of busy highways are some of the most polluted sites in urban areas due to the presence of dense human and motor traffic [21, 21, 22, 23]. According to the World Health Organisation, PM2.5 originates primarily from combustion sources such as fossil fuel driven automobiles and biomass burning [5]. Limits of $10 \mu \mathrm{g} / \mathrm{m}^{3}$ for annual mean and $25 \mu \mathrm{g} / \mathrm{m}^{3}$ for 24-hour mean of PM2.5 were set by WHO [5] to guide efforts to improve air quality in the varying contexts. There is scarce data on Ugandan urban near-road air qualityand the health risks associated with it is unknown. Using low cost real time laser sensors of the type PurpleAir PA-II, this study measured the mean ambient air concentrations of near-road PM2.5 in Mukono Municipality during the period August $12^{\text {th }}$ to December $4^{\text {th }} 2020$, described the Municipality's near-road populations' exposure to PM2.5 and assessed the associated health risk.

\section{Methodology}

\section{The Setting}

Mukono Municipality with coordinates of $0.3549^{\circ} \mathrm{N}, 32.7520^{\circ} \mathrm{E}$ and an area of approximately $210 \mathrm{sq} \mathrm{km}$, is 21 kilometers from Kampala along the Kampala-Jinja highway which serves the countries of Kenya, Uganda, Rwanda, Burundi, South Sudan and Eastern Democratic Republic of Congo.Mukono district has a mean temperature of about 25 degrees celcius; humidity of about $75 \%$ and wind speed ranging between 4 and 12 kilometers per hour. The area has 5 to $>200$ mmof rain every month with peak rains in April/May and October/November [24]. The Kampala-Jinja
Highway is paved with bitumen, but most roads are gravel. Topography of the Municipality is generally homogeneous with single storey or low-rise buildings located close to either side of the roads (Figure 2). There is limited vegetation along the roads in the Municipality.Most buildings serve a dual purpose of business and accommodation and therefore, there is a high density of people working and residing alongside the roads in Mukono municipality.

\section{Materials}

Seven laser particle counters of the type PurpleAir (PA-II), were used to collect data for the period Aug-Dec 2020. The PA-II sensors' data correlate highly $(r>0.9)$ with the Standard United States Environmental Protection Agency (EPA) methods [25]. The sensors' range of 20 +60 ${ }^{\circ} \mathrm{C}$ and 0 99\% fits with the Mukono environment with high humidity most of the year and temperature of $24-33^{\circ} \mathrm{C}$ [26]. The PAII effective range of $0 \sim 500 \mu \mathrm{g} / \mathrm{m}^{3}$ and maximum range of $\geq 1000 \mu \mathrm{g} / \mathrm{m}^{3}$ is appropriate in environments where previous studies in nearby towns found concentrations of particulate matter above $100 \mu \mathrm{g} / \mathrm{m}^{3}[17,18,27]$. In consideration of the Mukono Municipality land area and population, the EPA urban scale of representativeness and the European Joint Research (JRC) centre recommendations, seven sensors were considered adequate to collect representative data [28, 29]. Each sensor was fixed at a purposefully selected near-the-road location in Mukono Municipality at a height of about 3 to 5 meters above the ground, connected to stable power and $\mathrm{Wi}-\mathrm{Fi}$, away from any obstructions and between 10 and 80 meters from the edge of the road [28].

\section{Data Collection and Analysis}

The PA-II laser particle counters report PM2.5 mass concentration to the purple air map in $\mu \mathrm{g} / \mathrm{m} 3$ on a downloadable excel sheet. The data was downloaded and analysed with Excel data analysis toolpak. The health risk was calculated using the World Health Organisation's AirQ+ - v.2.0 tool for health risk assessment of air pollution [15]. The 24 hour PM2.5 means were compared with the WHO guidelines since Uganda does not have published national ambient air quality standards [30]. The WHO tool calculates health risk for a defined population like that of Mukono 
Municipality [5, 15]. The adverse health outcome of interest in this study was preventable premature deaths due to long-term exposure to air pollution. The World Health Organisation [5] annual mean air quality limits for PM2.5, the ambient air PM2.5 mean measured by PA-II sensor during the data collection period of Aug-Dec. 2020, the Uganda crude death rate of 655.4/100,000 and an estimated population of 162,744 were used in the health risk assessment [5, 31]. The Environmental Health Risk Assessment Model (enHEALTH) [32] informed the methodology. The main issue being the potential gain in terms of premature deaths prevented if the quality of air in Mukono Municipality was maintained within the WHO [5] limits. The main hazard considered in this study was the near-road ambient air PM2.5 concentration. The main exposure pathways were considered being inhalation and contact with eyes and the skin.

\section{Ethical Considerations}

The protocol was submitted to the Uganda Christian University Research Ethics Committee for review and thereafter to the Uganda National Council for Science Technology, which granted permission number HS651ES to conduct this study. At each of the selected sampling sites, permission was obtained from the buildings' owners to permit mounting of the sensors.

\section{Definitions}

\section{Particulate Matter}

Particulate matter is a mixture of solid and/or liquid particles which may be organic or inorganic in nature. Particulate mattercan be $\leq$ PM10, which is equal to or less than ten microns; equal to or less than 2.5 microns (PM2.5) and the ultrafine PM1, which is equal to or less than one micron. Particulate matter size of focus in this study was PM2.5 because, according to the World Health Organisation, long-term exposure to PM2.5 is consistently associated with adverse health issues $[8,9]$.

\section{Near Road}

Distances ranging between 0 and 100 meters from the edge of a selected road. Within this distance, there is a little decay of particulate matter (PM) concentrations related to road activity [36].

\section{Background Air Quality Data}

This is a concentration of PM2.5 due to natural or unidentified sources.

In this study, population in areas more than 100 meters from the roadsides were assumed to be exposed to background air quality measured by the UCU Hamu Sensor.

\section{Health Risk}

The proportion of harmful consequences associated with exposure to PM2.5.

\section{Results}

\section{Mean Near-Road PM 2.5 Ambient Air Concentration in Mukono Municipal Council in the Period August 12th, 2020 to December 4th, 2020}

Figure 1 shows the trend of PM2.5 ambient near-road air concentrations recorded by seven laser sensors during the period $12^{\text {th }}$ August to $4^{\text {th }}$ December 2020 versus the annual WHO limit of ambient air PM2.5 concentration which is $10 \mathrm{ug} / \mathrm{m} 3$ [5]. The sensors' readings were all above the WHO [5] limit exept for UCU HamuMukasa Library and Namilyango Senior Secondary School (SSS) sensors on one day of 16th November 2020. Also, the trendlines for Namilyango SSS and for UCU Tech Park were generally lower than records from other sensors. The sensors with lower tred lines were on a busy but unpaved road used as an alternative route through Mukono Municipality during heavy traffic.

The 24-hour mean near-road ambient air PM2.5 concentrations for five sensors were found to be above the WHO (2005) limit of 10 $\mathrm{ug} / \mathrm{m}^{3}$ for the entire period of data collection. For the sensor at UCU Hamu which worked as the control and the sensor at Namilyango SSS which was alongside an unpaved road, the 24hour mean near-road ambient air PM2.5 concentrations were below the WHO [5] limit of $10 \mathrm{ug} / \mathrm{m} 3$ for one day during the whole period of data collection. When a hypothetical Mukono Municipality limit of $31 \mathrm{ug} / \mathrm{m}^{3}$ was assumed, the exceedences were still high, ranging from $35 \%$ at the background sensor to 99\% at Church of Uganda Hospital's sensor (Figure 2).

The sensors at the Church of Uganda Hospital, St. Paul Wantone and at Seeta Highway recorded the highest mean 
concentrations of ambient near the road PM2.5 concentrations and they also had higher standard deviations [Table 1].The mean nearroad ambient PM2.5 concentrations were lower for the unpaved roads compared to the paved roads. A t-test was performed to compare the 24-hour means for near-road ambient PM2.5 concentrations alongside the paved versus those of the unpaved roads and the difference was found to be statistically significant with a pvalue of 0.001 . The 24 hour mean near-road ambient PM2.5 concentration for the UCU Hamu sensor which provided background data was above the WHO limit of $10 \mathrm{ug} / \mathrm{m} 3$ for $99 \%$ of the days during data collection.

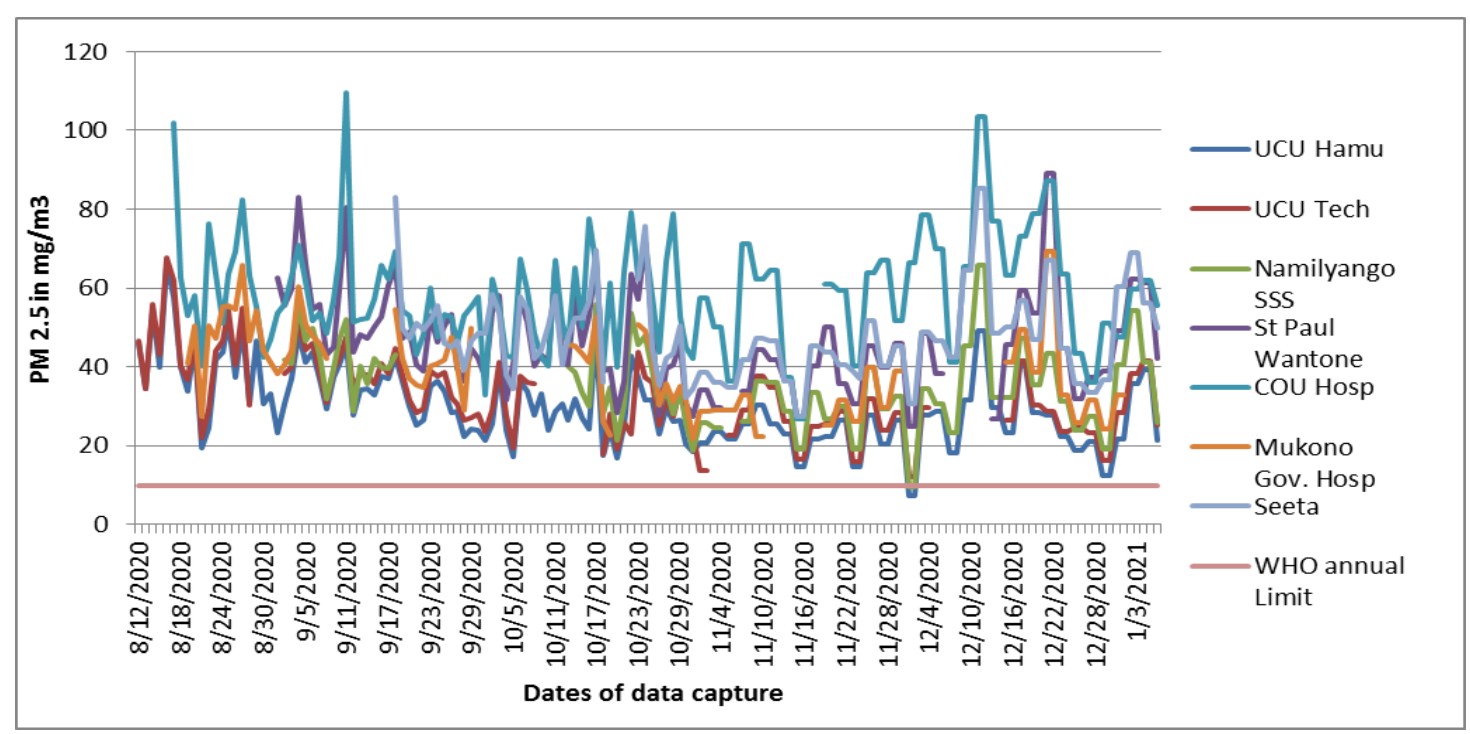

Figure 1. The Trends of Mean Concentration of PM 2.5 Recorded by Seven Sensors across the Period $12^{\text {th }}$ August to $4^{\text {rd }}$ December 2020 in Mukono Municipality, Uganda

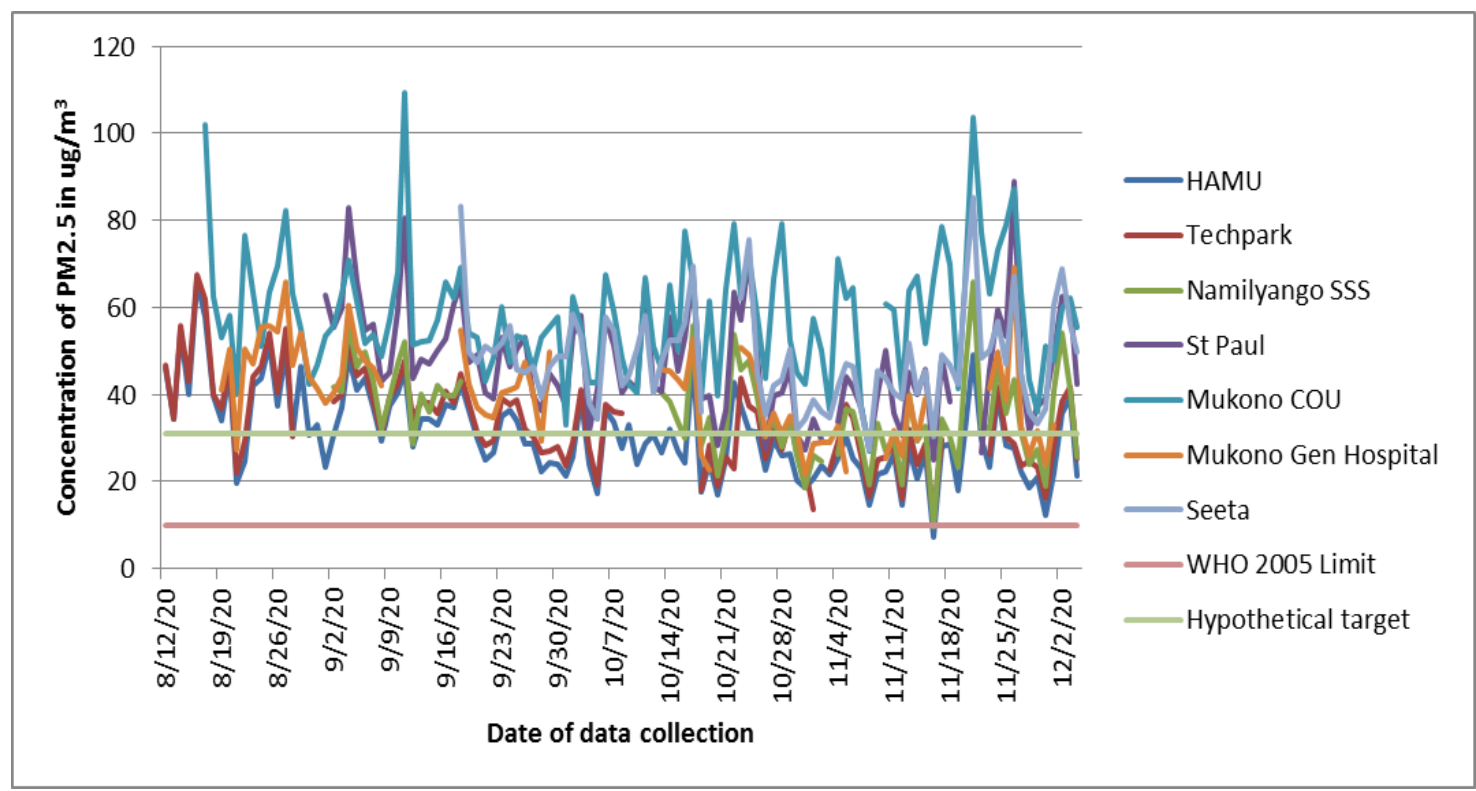

Figure 2. Means exceeding a hypothetical Mukono Municipality target of $31 \mathbf{u g} / \mathbf{m}^{3}$ 
Table 1. Descriptive Statistics of Mean, Minimum, Maximum, Standard Deviation, Percentage of days Exceeding WHO Limit of $10 \mathrm{ug} / \mathrm{m} 3$ and Percentage of Days Exceeding a Hypothetical Mukono Municipality limit of $31 \mathrm{ug} / \mathrm{m} 3$ for Seven Sensors

\begin{tabular}{|c|c|c|c|c|c|c|c|}
\hline & \multirow[t]{2}{*}{ Sensors } & \multicolumn{6}{|c|}{ Statistic } \\
\hline & & Mean & Minimum & Maximum & SD & $\begin{array}{l}\text { Percentage } \\
\text { of days } \\
\text { exceeding } \\
\text { WHO } \\
\text { limit of } 10 \\
\text { ug/m }\end{array}$ & $\begin{array}{l}\text { Percentage of } \\
\text { days exceeding } \\
\text { a hypothetical } \\
\text { Mukono } \\
\text { Municipality } \\
\text { limit of } 31 \mathrm{ug} / \mathbf{m}^{3}\end{array}$ \\
\hline & $\begin{array}{l}\text { UCU } \\
\text { Hamu(Background) }\end{array}$ & 30.97 & 7.25 & 66.25 & 10.12 & 99 & 35 \\
\hline \multirow[t]{3}{*}{ Unpaved } & UCU Tech & 32.17 & 12.13 & 67.62 & 10.21 & 100 & 55 \\
\hline & Namilyango SSS & 35.51 & 9.62 & 65.82 & 10.4 & 99 & 76 \\
\hline & $\begin{array}{l}\text { Mean PM } 2.5 \text { at } \\
\text { unpaved road }\end{array}$ & \multicolumn{4}{|l|}{33.84} & & \\
\hline \multirow[t]{5}{*}{ Paved road } & St Paul Wantone & 46.15 & 25.01 & 85.01 & 12.85 & 100 & 91 \\
\hline & COU Hospital & 58.31 & 26.83 & 109.45 & 14.24 & 100 & 99 \\
\hline & Mukono Gov. Hosp & 38.81 & 21.75 & 69.18 & 10.85 & 100 & 84 \\
\hline & Seeta Highway & 47.67 & 27.29 & 85.22 & 11.56 & 100 & 98 \\
\hline & $\begin{array}{l}\text { Mean PM } 2.5 \text { at } \\
\text { paved road }\end{array}$ & \multicolumn{4}{|l|}{47.74} & & \\
\hline
\end{tabular}

Mukono Municipality's Near-Road Populations' Exposure to PM2.5

A large proportion of the houses which serve as both commercial and residential spaces are located adjacent to the roads in Mukono Municipality as depicted in figure 3.This study focused on ambient air pollution but it was assumed that roadside air also infiltrated into working and residential spaces. The Mukono Municipality populations livingresiding more than 100 meters away from roadsides, which was assumed to be the background areas, were exposed to ambient mean PM 2.5 concentration of $30.97 \mathrm{ug} / \mathrm{m}^{3}$. The population residing within 100 meters of busy unpaved roads were exposed to ambient mean PM2.5 concentration of $33.84 \mathrm{ug} / \mathrm{m}^{3}$. The Mukono Municipality population, located within 100 meters of the paved Kampala-Jinja road highway, was exposed to ambient mean PM 2.5 concentration of $47.74 \mathrm{ug} / \mathrm{m}^{3}$. For the whole of Mukono Municipality population, regardless of location of the residences or workplaces, exceedences of the WHO (2005) limit for ambient air mean PM2.5 concentration in this study was $\geq 99 \%$.

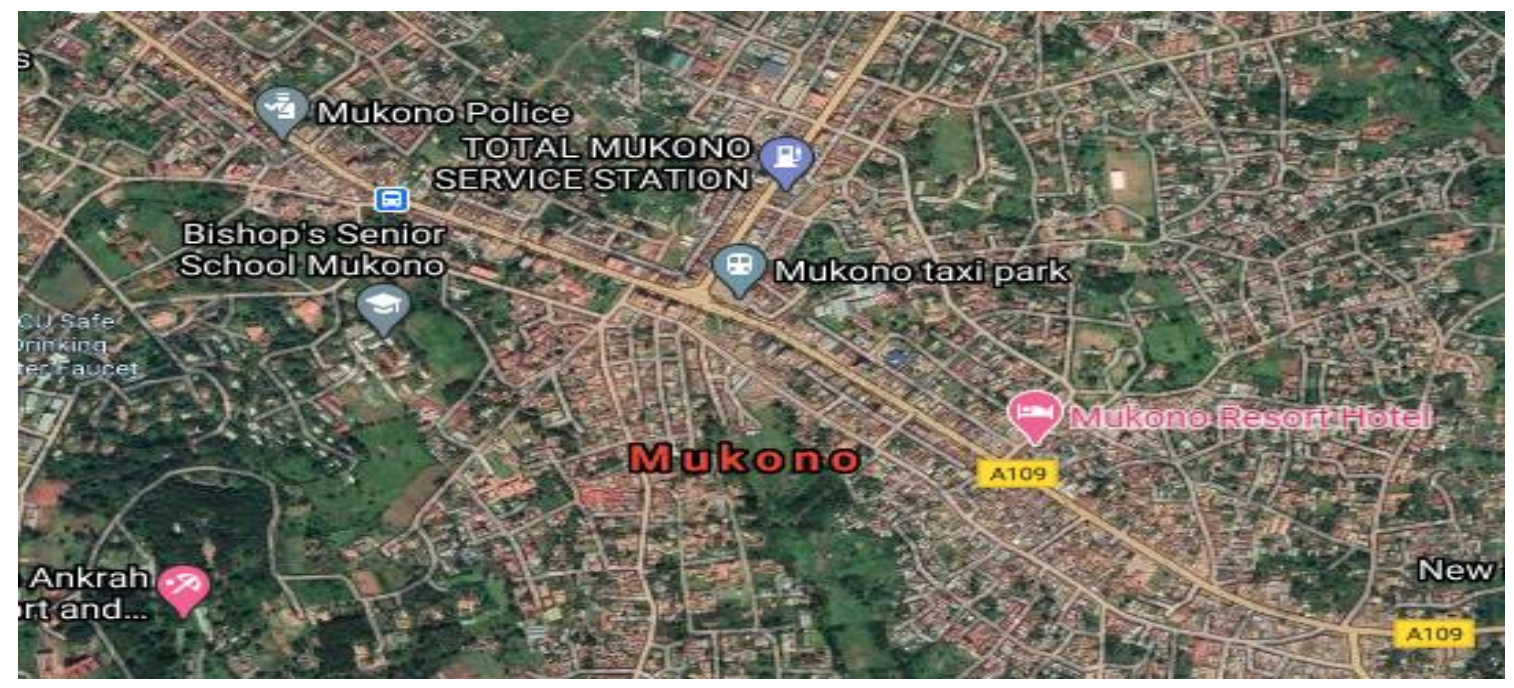

Figure 3. Showing Location of Buildings Adjacent to Roadsides in Mukono Municipality 
A hypothetical Mukono Municipality target of $31 \mathrm{ug} / \mathrm{m}^{3}$, which was measured by the UCU Hamu sensor, was assumed. The sensor collecting background data (UCU Hamu) exceeded the targed for about $50 \%$ of the days of data collection. The sensors on unpaved roads (UCU Techpark and Namilyango SSS), exceeded the hypothetical target for about $70 \%$ of the days of data collection. The sensors on the paved Kampala-Jinja Highway (Mukono COU, Mukono Govt Hospt, Seeta and St PaulWantone), exceeded the hypothetical target for approximately $94 \%$ of the days of data collection.

Table 2. Health Risk Associated with Background Ambient Air Concentration of PM 2.5 in Mukono Municipality

\begin{tabular}{|l|l|l|l|}
\hline & Central & Lower & Upper \\
\hline Estimated Attributable Proportion & $11.34 \%$ & $7.54 \%$ & $14.74 \%$ \\
\hline Astimated number of attributable cases & 121 & 80 & 157 \\
\hline $\begin{array}{l}\text { Estimated number of Attributable } \\
\text { Cases per 100,000 population at risk }\end{array}$ & 74.29 & 49.45 & 96.61 \\
\hline
\end{tabular}

Exposure of the Mukono Municipality population to the ambient background PM2.5 concentration of $30.97 \mathrm{ug} / \mathrm{m}^{3}$ in the long term would lead to more than 121 premature deaths caused by long-term exposure to PM2.5. These deathscould be avoided if concentration of PM2.5 would not exceed $10 \mu \mathrm{g} / \mathrm{m} 3$, which is the threshold recommendation by the WHO Air Quality Guidelines [5].

Table 3. Health Risk Associated with Near-Road Ambient Air Concentration of PM 2.5 along the Unpaved Roads

\begin{tabular}{|l|l|l|l|}
\hline & Central & Lower & Upper \\
\hline Estimated Attributable Proportion & $13.36 \%$ & $8.93 \%$ & $17.31 \%$ \\
\hline Astimated number of attributable cases & 142 & 95 & 185 \\
\hline $\begin{array}{l}\text { Estimated number of Attributable } \\
\text { Cases per 100,000 population at risk }\end{array}$ & 87.56 & 87.56 & 113.46 \\
\hline
\end{tabular}

Exposure of the Mukono Municipality population to the ambient near un-paved PM2.5 concentration of $33.84 \mathrm{ug} / \mathrm{m}^{3}$ in the long term would lead to more than 142 premature deaths caused by long-term exposure to PM2.5. These deaths could be avoided if concentration of PM2.5 would not exceed $10 \mu \mathrm{g} / \mathrm{m} 3$, which is the threshold recommendation by the WHO Air Quality Guidelines [5].

Table 4. Health Risk Associated with Near-Road Ambient Air Concentration of PM 2.5 along the Paved Kampala Jinja Highway

\begin{tabular}{|l|l|l|l|}
\hline & Central & Lower & Upper \\
\hline Estimated Attributable Proportion & $20.31 \%$ & $13.76 \%$ & $25.99 \%$ \\
\hline Astimated number of attributable cases & 217 & 147 & 277 \\
\hline $\begin{array}{l}\text { Estimated number of Attributable Cases } \\
\text { per 100,000 population at risk }\end{array}$ & 133.11 & 90.17 & 170.31 \\
\hline
\end{tabular}

Exposure of the Mukono Municipality population to the ambient near paved road PM2.5 concentration of $47.74 \mathrm{ug} / \mathrm{m}^{3}$ in the long term would lead to more than 217 premature deaths caused by long term exposure to PM2.5. These deaths could be avoided if concentration of PM2.5 would not exceed $10 \mu \mathrm{g} / \mathrm{m} 3$, which is the threshold recommendation by the WHO Air Quality Guidelines [5].

\section{Discussion}

\section{Mean Near-Road PM 2.5 Ambient Air Concentration in Mukono Municipal Council in the Period August 12th, 2020 to December 4th, 2020}

The trends of PM2.5 concentrations in ambient air along near unpaved and near paved roads in Mukono Municipality which was 
recorded by seven Purpleair sensors during the period August $12^{\text {th }} 2020$ to December $4^{\text {th }} 2020$ show air pollution level above the WHO [5] annual limit. This is true even for the sensor which measured ambient background PM2.5 concentration at UCU Hamu.The ambient air concentrations exceeded the WHO [5] annual limit by as much as $* 4.7$ for the paved roads, $* 3.3$ for the unpaved roads and *3 for the background. The PM2.5 ambient air concentration in Mukono Municipal Council was found to be much higher along the busy Kampala-Jinja paved road when compared to the unpaved road $(\mathrm{p}<0.001)$. This was different from the expected and also different from some documented literature [17]. However, the difference may be partly explained by the much heavier traffic on Kampala-Jinja highway when compared to the unpaved roads. The KampalaJinja highway is paved in most places, wider and is preferred by most motorists, especially those driving the large Cargo trucks. Additionally, the Kampala-Jinja highway has dust coming from the multiple potholes which are in the Mukono area. The PM2.5 in ambient air in urban areas is known to be related to fossil powered vehicles' trafficand indeed thebusier traffic locations including Seeta, St Paul Wantone and COU Mukono which recorded the highest PM2.5 concentrations [5, 34]. The heavier traffic which produces a lot of exhaust fumes and non-exhaust dust particles may explain the higher levels of pollution on the paved Kampala-Jinja road versus unpaved roads in the municipality [35]. The sensors at the COU and at the Mukono Government hospitals suggest that the patients and health workers, and especially the inpatients who sometimes stay for many days, may be exposed to high levels of air pollution which may worsen their health complications [36]. A positive correlation between outdoor and indoor PM2.5 has been documented by other researchers and therefore high levels of PM 2.5 does suggest high levels of the same indoors of hospitals, especially where there is no air conditioning as the case is in most Ugandan hospitals [37]. Although there was no accurate record of what proportion of the population in Mukono Municipality live or work within 100 meters of the roads, the google map in figure 3 shows that most houses are located close to the roads and especially close to Kampala-Jinja highway (A109). The 24 hour means of 33.84 $\mathrm{ug} / \mathrm{m} 3$ for the unpaved roads, $47.74 \mathrm{ug} / \mathrm{m} 3$ for the paved roads and $30.97 \mathrm{ug} / \mathrm{m}^{3}$ for the background are all above the WHO [5] 24-hour mean limit of $25 \mathrm{ug} / \mathrm{m}^{3}$ and much higher than the WHO [5] annual limit of $10 \mathrm{ug} / \mathrm{m} 3$ for PM2.5. The mean near-road ambient air concentrations found in this study were similar to the ambient air mean concetrations provided by Airqo station at Mukono Municipality, Ggulu station, which gave a mean of 49.32 (35.6-55.4) in the period of October-November 2020 [20]. The larger standard deviations readings along the paved Kampala-Jinja highway show more variation of ambient PM2.5 concentration probably related to variations in traffic volume, and it also implies that the concentrations frequently rise up to higher levels of health concern. The percentageof days exceeding WHO limit of 10 $\mathrm{ug} / \mathrm{m}^{3}$ for all sensers were high at $\geq 99 \%$ which means that exposure to concentrations of PM2.5 above the WHO [5] limit is long term and therefore, the Munkono Municipality nearthe-road population is vulnerable to the associated health risks of respiratory and heart disease as well as excessive premature mortality [36]. Even if Mukono Municipality targeted a limit of $31 \mathrm{ug} / \mathrm{m}^{3}$, there would still be many days exceeding this limit. This level of air pollution with PM2.5, according to the APA Air Quality Index, is graded as fair to poor and is associated with increased health risks particulay to the populations with pre-existing lung and heart problems. There is no known threshold below which ambient air particulate matter concentration is safe and so any concentrations above the WHO limitsis unhealthy $[5,15,16]$.

\section{Mukono Municipality's Near-Road Populations' Exposure to PM2.5}

Buildings in Mukono Municiplality are located very close to the edge of the road (Figure 2) and this exposes the occupants who work or reside there to high concentrations of PM 2.5 which infiltrates indoors as it disperses $[38,33]$. Some of the buildings are just a few meters off the edge of the road and threfore, close proximity to the road, combined with wind speeds of $4-12 \mathrm{~km} / \mathrm{hr}$ (up to 3 on the Beaufort scale) in Mukono Municipality, results into high concentrations of PM2.5 near the 
roads and thus exposing the population to the associated health risks for long periods of time $[38,24,39]$. The traffic along Kampala-Jinja road is usually very slow because of potholes and congestion, as well as frequent stop-and-go movements. There is a large number of heavyduty cargo trucks on the Kampala-Jinja highway. These trucks are rarely diverted to the smaller unpaved roads. Diesel powered heavyduty trucks are known to be more polluting with PM2.5 and other pollutants than smaller patrol powered cars [38]. These traffic and road characteristics, combined with low wind speed in Mukono, make exposure to PM2.5 air pollution worse [38].

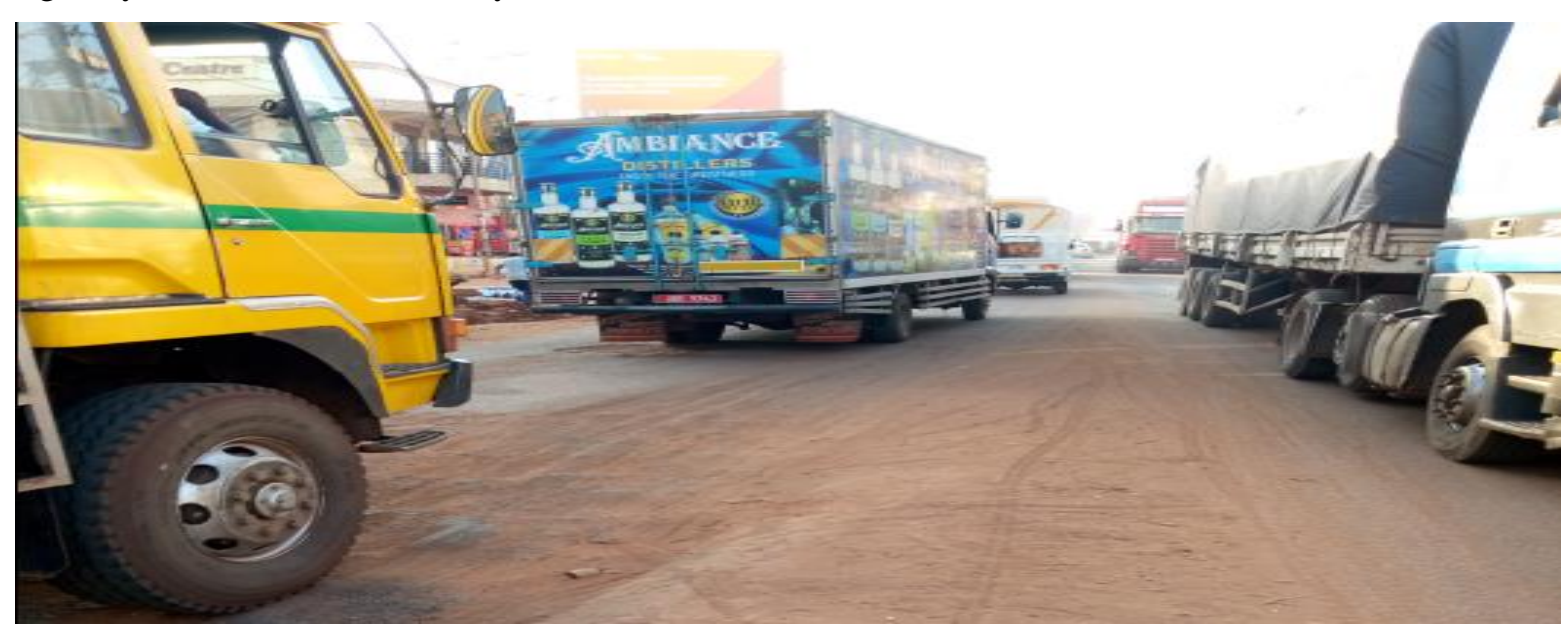

Figure 4. Traffic on Kampala-Jinja Highway near COU Hosp. Showing Lines of Vehicles, Potholes in the Road and a Haze due to Dust and Exhaust Fumes

The population located away from the roads, in the background areas, are also exposed to high levels of PM2.5 with $99 \%$ of the data collection days exceeding the WHO [5] limits. This implies that the whole population in Mukono Municipality, including that living away from the roadsides, is exposed to PM2.5 polution and the associated health risks. However, the risk to ambient PM2.5 exposure is higher for the population living in close proximity of $\leq 100$ meters from the edge of the paved Kampala-Jinja highway which registered the highest ambient mean PM2.5 concentration of $47.74 \mathrm{ug} / \mathrm{m}^{3}$ for the data collection period of August $12^{\text {th }}$ to December $4^{\text {th }} 2020$.

\section{Health Risk Associated with Ambient Near-Road PM2.5 in Mukono Municipality}

The outcome of interest for this near-road ambient air quality study in Mukono Municipality, was the preventable premature deaths if the quality of air met the WHO [5] annual limits or if management of the Municipality set and worked towards a PM2.5 target of $31 \mathrm{ug} / \mathrm{m} 3$ which was found in the background ambient air.The avoidable attributable cases were highest at
$133.11 / 100,000$ population at risk if the whole municipality was exposed to the ambient PM2.5 air quality along the paved roads (Table 4). Along the unpaved roads with ambient PM2.5 mean concentration of $33.84 \mathrm{ug} / \mathrm{m} 3$, the avoidable attributable cases were 87.56/100,000 population if the Municipality's population was exposed to this level of air quality (Table 3). On the other hand, if the Municipality's population was exposed to the background air quality, then the avoidable attributable cases would be 74.29/100,000 population (Table 2). A concentration-response relationship is known to exist between the ambient PM2.5 concentration and morbidity and mortality and the findings in this study are consistent with this literature [5, 40] If the Mukono Municipality leadership were to set a target of $31 \mathrm{ug} / \mathrm{m}^{3}$ for ambient air quality, the WHO AirQ+ (2019) tool shows that the avoidable attributable cases would be fewer at $62.78 / 100,000$ for the paved and $10.92 / 100,000$.for the unpaved roads. This implies that the preventable premature deaths are fewer if the target is set at a higher level, but quickly moving from high levels of air quality pollution to the WHO limit, may not always be possible given what it takes, 
especially considering resource and organizational capacity constraints [5].

\section{Conclusion}

The mean ambient near-road PM2.5 in Mukono Municipalityacross the period AugDec 2020 were $30.97 \mathrm{ug} / \mathrm{m}^{3}, 33.84 \mathrm{ug} / \mathrm{m}^{3}$ and, $47.74 \mathrm{ug} / \mathrm{m}^{3}$ for background, near-unpaved and near-paved roads respectively. These concentrations exceed the WHO [5] limit of $10 \mathrm{ug} / \mathrm{m}^{3}$ for annual ambient air mean. The nature of the roads, the type and charactristics of traffic and the proximity of the business and residential buildings as well as institutions like hospitals to the roads, are the factors which increase exposure of the Municipality's population to high levels of PM2.5. The whole Mukono municipality population is exposed to these high ambient PM2.5 concentrations since even the background mean of $30.97 \mathrm{ug} / \mathrm{m}^{3}$ is much higher than the WHO [5] annual limit of $10 \mathrm{ug} / \mathrm{m}^{3}$. This level of near-the-road, air pollution is associated with up to $133.11 / 100,000$ preventable deaths if the air quality was kept within the WHO [5] limit.

\section{Recommendations}

The Mukono Municipal Council's leadership should be aware of the high levels of air pollution in the municipality and the health risk associated with it. With the current availability of low-cost laser air quality sensors like Purpleair II, which correlate highly ( $r>0.9)$ with the Standard United States Environmental

\section{References}

[1] UN Climate Change. 2019. Clean Air is a Human Right - UN Special Rapporteur. From: https://unfccc.int/news/clean-air-is-a-human-right-

un-special-rapporteur (accessed on the 20th November, 2019).

[2] Boyd D. R. 2019. The Human Right to Breathe Clean Air.Annals of global health, 85(1), 146.https://doi.org/10.5334/aogh.2646.

[3] WHO.2020. Air Pollution. From: https://www.afro.who.int/health-topics/air-

pollution\#: :text=the $\% 20$ human $\% 20$ environment, $\mathrm{O}$ verview,common $\% 20$ sources\%20of\%20air\%20poll ution. (accessed on the $10^{\text {th }}$ of February, 2021).

[4] WHO. 2016a. Ambient air pollution: A global assessment of exposure and burden of disease.From: https://www.who.int/publications-detail/ambient-air-
Protection Agency (EPA) methods, the Municipality can monitor the PM2.5 in real time so that their decisions are evidence based. The Municipallity's planners should guide developers to put residential houses and institutions like hospitals and schools more than 100 meters away from busy roadways [41]. The Municipality's leadership can collaborate with National Environmental Management Authority (NEMA) and the Ministry of Works and Transport to develop policies which promote the use of newer vehicles whose exhaust gases are cleaner for common pollutants, including particulate matter [42].

\section{Limitations}

There were only seven sensors in an area of 210 square kilometers, and data was collected over a period of three months only. There were data collection gaps due to power and or internet disruptions. A longer period of data collection with more sensors would enable comparison of data across seasons.

\section{Suggestions for Further Research}

Indoor air pollution due to infiltration of ambient air PM 2.5 into buildings is likely to be a public health problem, particularly for buildings adjacent to busy motorways. A study to assess Mukono Municipality's indoor air quality would give policy makers more information about the magnitude of the problem.

pollution-a-global-assessment-of-exposure-andburden-of-disease (accessed on the 20th of Nov. 2019).

[5] WHO.2005.WHO Air quality guidelines for particulate matter, ozone, nitrogen dioxide and sulfur dioxide Global update 2005. From: https://apps.who.int/iris/bitstream/handle/10665/694 77/WHO_SDE_PHE_OEH_06.02_eng.pdf;jsessioni $\mathrm{d}=$ FFC62B0AC57ED51601FCB0B92DC728A9?seq uence $=1$.

[6] Institute for Global Environmental Strategies (IGES). 2016. Application of SDGs to Air Pollution. From: https://iges.or.jp/en/pub/application-sdgs-airpollution (accessed on the 5th Dec. 2019).

[7] WHO. 2019a. Ambient air pollution: Pollutants. From: 
https://www.who.int/airpollution/ambient/pollutants/ en/ (accessed on the $20^{\text {th }}$ of Nov. 2019).

[8] WHO. 2013. Health Effects f Particulate matter. From:

https://www.euro.who.int/_data/assets/pdf_file/000 6/189051/Health-effects-of-particulate-matter-finalEng.pdf (accessed on 10th November 2020).

[9] Yu W, Guo Y, Shi L and Li S. 2020. The association between long-term exposure to low-level PM2.5 and mortality in the state of Queensland, Australia: A modelling study with the difference-indifferences approach. Published: June 18, 2020 https://doi.org/10.1371/journal.pmed.1003141 From: https://journals.plos.org/plosmedicine/article/metrics ?id=10.1371/journal.pmed.1003141\#citedHeader.

[10]WHO. 2014. 7 million premature deaths annually linked to air pollution. From: https://www.who.int/mediacentre/news/releases/201

4/air-pollution/en/ (accessed on the $10^{\text {th }}$ December 2020).

[11]Lelieveld J, Pozzer A, Pöschl U, Fnais M, Haines A, Münzel T. 2020. Loss of life expectancy from air pollution compared to other risk factors: a worldwide perspective, Cardiovascular Research, https://doi.org/10.1093/cvr/cvaa025.

[12] WHO.2016c. Air pollution levels rising in many of the world's poorest cities. From: https://www.who.int/en/news-room/detail/12-052016-air-pollution-levels-rising-in-many-of-theworld-s-poorest-cities (accessed on the 23rd of November 2019).

[13] Strosnider H, Kennedy C, Monti M, Yip F. Rural and Urban Differences in Air Quality, 20082012, and Community Drinking Water Quality, 2010-2015 — United States. MMWR SurveillSumm 2017;66(No.SS-13):1-10.DOI: http://dx.doi.org/10.15585/mmwr.ss6613alexternalic on.

[14]WHO.2019b. Air Pollution. From: https://www.afro.who.int/health-topics/air-pollution (accessed on the 1st December, 2019).

[15]WHO. 2018. Ambient Air Pollution (out door).

Key Facts. From: https://www.who.int/newsroom/fact-sheets/detail/ambient-(outdoor)-airquality-and-health (accessed on $6^{\text {th }}$ Jan. 2020).

[16] Sanyal, S., Rochereau, T., Maesano, C. N., Com-Ruelle, L., \&Annesi-Maesano, I. 2018. LongTerm Effect of Outdoor Air Pollution on Mortality and Morbidity: A 12-Year Follow-Up Study for Metropolitan France. International journal of environmental research and public health, 15(11), 2487. https://doi.org/10.3390/ijerph15112487.
[17] Kirenga, B. J., Meng, Q., van Gemert, F., Aanyu-Tukamuhebwa, H., Chavannes, N., Katamba, A., Mohsenin, V. (2015). The State of Ambient Air Quality in Two Ugandan Cities: A Pilot CrossSectional Spatial Assessment. International Journal of Environmental Research and Public Health, 12(7), 8075-8091. https://doi.org/10.3390/ijerph120708075.

[18]Schwander, S., Okello, C., Freers, J., Chow, J.C., Watson, J.G., Corry, M., \&Meng, Q. (2014). Ambient Particulate Matter Air Pollution in Mpererwe District, Kampala, Uganda: A Pilot Study. Journal of environmental and public health.

[19] AirVisual. 2019. World most polluted cities 2018 (PM2.5). From: https://www.airvisual.com/world-most-pollutedcities?continent=59af92713e70001c1bd78e4e\&coun try $=\&$ state $=\&$ page $=1 \&$ perPage $=50 \&$ cities $=$ (accessed on the $8^{\text {th }}$ December 2019).

[20] Airqo. 2020. Know Your Air. From:https://www.airqo.net/ (accessed on the $13^{\text {th }}$ of Dec. 2020).

[21] Akumu, J. 2014. Improving Air Quality in African Cities. From:

https://wedocs.unep.org/bitstream/handle/20.500.11 822/16824/Overview_AirPollution_Africa.pdf?sequ ence $=1$ (accessed on the $29^{\text {th }}$ Nov. 2019).

[22] Alam M.J.B., Rahman M.H and Jaigirdar M.A. 1999. Ambient Air Quality At Roadside In Dhaka City. From:

http://www.envirobiotechjournals.com/article_abstra ct.php?aid $=3365 \&$ iid $=123 \&$ jid $=4$ (accessed on $20^{\text {th }}$ Jan 2021).

[23]Ai, Z.T, Mak, C.M and Lee.H,C. 2016. Roadside air quality and implications for control measures: A case study of Hong Kong. From: https://www.sciencedirect.com/science/article/abs/pi i/S1352231016303168.

[24] Worldweatheronline. 2020. Mukono weather. From:

https://www.worldweatheronline.com/mukonoweather-averages/mukono/ug.aspx (accessed on the 5th of March 2020).

[25] South Coast AQMD, 2019.Air Quality Sensor Performance Evaluation Centre.Summary Tables \& Reports. From: http://www.aqmd.gov/aqspec/evaluations/summary-pm (accessed on the 13th of Feb.2020).23rd of Nov. 2019).

[26]Elite Weather Systems NZ.2020. Purpleair Air Quality Sensor PA-II-SD. From 
https://www.elite-weather-systems-

nz.com/products/purpleair-air-quality-sensor-pa-ii (accessed on the $13^{\text {th }}$ Feb.2020).

[27] U.S. Embassy in Uganda.(2020). Air Quality Monitoring at U.S. Embassy Kampala. Form: https://ug.usembassy.gov/embassy/kampala/airquality-monitoring-at-u-s-embassy-kampala/ (accessed on the $8^{\text {th }}$ Dec. 2019).

[28]EPA. 2017. Quality Assurance Handbook for Air Pollution Measurement Systems Volume II Ambient AirQuality Monitoring Program From:https://www3.epa.gov/ttnamti1/files/ambient/p $\mathrm{m} 25 / \mathrm{qa} /$ Final\%20Handbook\%20Document\%201_17 .pdf(accessed on the 19th of Feb 2020).

[29]RC.n.d. Assessment on siting criteria, classification and representativeness of air quality monitoring stations. From: https://ec.europa.eu/environment/air/pdf/SCREAM \%20final.pdf (accessed 12 ${ }^{\text {th }}$ May 2019).

[30]UNEP. 2017. Uganda Air Quality Policies. From:

https://wedocs.unep.org/bitstream/handle/20.500.11 822/17133/Uganda.pdf?sequence=1\&isAllowed=y (accessed on the $5^{\text {th }}$ of Dec. 2019).

[31] The World Bank Data. 2020. Death rate, crude (per 1,000 people) - Uganda. From: https://data.worldbank.org/indicator/SP.DYN.CDRT .IN?locations=UG (accessed $30^{\text {th }}$ November, 2020). [32] enHealth. 2012. Environmental Health Risk Assessment. Guidelnes for assessing human health risks from environmental hazards. From: https://www1.health.gov.au/internet/main/publishing .nsf/content/A12B57E41EC9F326CA257BF0001F9 E7D/\$File/Environmental-health-Risk-

Assessment.pdf.

[33]Liu.S.V, Chen Fu-lin and Xue J. 2019. A metaanalysis of selected near-road air pollutants based on concentration decay rates. Heliyon, Vol. 5, Issue 8 DOI: https://doi.org/10.1016/j.heliyon.2019.e02236. [34]NEMA. 2019. WORLD ENVIRONMENT DAY. 5TH JUNE 2019 CELEBRATED. Theme: "Fight Air Pollution to Protect Human Health and Environment"

https://nema.go.ug/sites/all/themes/nema/docs/Jun e\%202019_NEMA\%20Newsletter\%20(1).pdf

(Accessed on the $4^{\text {th }}$ Dec 2019).
[35]Penkała M, OgrodnikP andRogula-Kozłowska W. 2018. Particulate Matter from the Road Surface Abrasion as a Problem of Non-Exhaust Emission Control. From file://C:/Users/ICMI\%20UCU/Downloads/enviro nments-05-00009.pdf.

[36] WHO. 2019c. Ambient air pollution: Health impacts. From: https://www.who.int/airpollution/ambient/healthimpacts/en/ (accessed on the $5^{\text {th }}$ Dec. 2019).

[37]Mohammadyan M, Keyvani S, Bahrami A, Yetilmezsoy K, Heibati B, Krystal J and Pollitt G. 2019. Assessment of indoor air pollution exposure in urban hospital microenvironments. From: https://core.ac.uk/download/pdf/199660135.pdf (accessed $17^{\text {th }}$ December, 2020).

[38]EPA. 2015.Near Roadway Air Pollution and Health: Frequently Asked Questions. From: https://www.epa.gov/sites/production/files/2015-

11/documents/420f14044_0.pdf.

[39] National Weather Service. 2020.Beaufort Scale. From: https://www.weather.gov/pqr/beaufort.

[40]Ren M, Fang X, Li M, SSun S, Pei L, Xu Q, Ye X, Cao Y, "Concentration-Response Relationship between PM2.5 and Daily Respiratory Deaths in China: A Systematic Review and Metaregression Analysis of Time-Series Studies", BioMed Research International, vol. 2017, Article ID 5806185, 15 pages, 2017. https://doi.org/10.1155/2017/5806185. [41]EPA. 2015b. Best Practices for Reducing NearRoad Pollution Exposure at Schools. From: https://www.epa.gov/sites/production/files/201510/documents/ochp_2015_near_road_pollution_boo klet_v16_508.pdf.

[42]EPA.2020. History of Reducing Air Pollution from Transportation in the United States. From: https://www.epa.gov/transportation-air-pollutionand-climate-change/accomplishments-and-successair-pollution-

transportation\#: :text=New\%20passenger\%20vehicl es $\% 20$ are $\% 2098$,pollutants $\% 20$ compared $\% 20$ to $\% 20$ the $\% 201960$ s.\&text $=$ U.S. $\% 20$ cities $\% 20$ have $\% 20 \mathrm{mu}$ ch\%20improved,sparked\%20technology\%20innovat ion $\% 20$ from $\% 20$ industry. 


\title{
Emergency Contraceptives for the Prevention of Unwanted Pregnancy among the Youth in Tamale - Perspective of the Clergy
}

\author{
Abdul-malik, abdulai ${ }^{*}$, Paul Armah Aryee ${ }^{2}$ \\ ${ }^{I}$ Nurses and Midwives Training College, Tamale, Ghana \\ ${ }^{2}$ Leturer, University for Development Studies, Tamale, Ghana
}

\begin{abstract}
Adolescent females are prone to unintended pregnancies due to the sporadic and impromptu sexual intercourse. Under such circumstances, they are unable to negotiate for safer sex. Emergency contraceptives is vital in the prevention of unintended pregnancies in such situations, but religious communities are perceived to resist modern contrasceptive. This study sought to assess the perspective of the Islamic clergy on the use EC for the prevention of pregnancy among young the people in the Tamale metropolis of the Northern Region of Ghana. A qualitative cross-sectional approach was used for this study. An in-depth interview was conducted involving a total of three clerics, one from each religious sect of the study area to assess their knowledge of EC and perspective on its use among the youth. 2 out of the 3 clerics demonstrated good knowledge of EC, including situations in which it is used and the correct time for use. They were unanimous in the use of family planning methods for birth control but indicated that it is the sole preserve of the married. They contended that the hormonal forms including EC are forbidden in Islam but in situations of forced sex; they had no objection to its use. Overall EC knowledge and awareness level among the clerics was high but strongly opposed the use of it for pregnancy prevention in general but raised no objection to its use in situations of forced sex or incest since they opined it is no fault of the victim under such circumstances.
\end{abstract}

Keywords: cleric, Emergency contraceptive, religion, unintended pregnancy.

\section{Introduction}

Unplanned or unintended pregnancy especially in adolescents constitute an important health problem worldwide and has been associated with a great number of negative health outcomes [1]. Adolescent females are more prone to unintended pregnancies because they have no stable sexual relations and therefore are unlikely to be on regular contraceptives. The unstable nature of their relationships makes sexual intercourse sporadic and impromptu, and under such circumstances they are unable to negotiate for safer sex, which may result in unintended pregnancy. The prevalence of unplanned pregnancy in adolescents worldwide ranges from $33 \%$ to 82 [2]. Approximately 16 million girls within 15 to 19 years' age bracket give birth each year in developing regions and every year, some 3.9 million adolescents aged 15 to 19 years undergo unsafe abortions as a result of unintended pregnancy [3]. In Africa, close to one-fifth of adolescents become pregnant yearly [4]. In Ghana the rate of unintended pregnancies among the age group 15-19 years stands at 69\% [5] and 30\% of all births registered in 2014 came from adolescents [6]. Socio-cultural and religious norms restrict sexual intercourse to only the married people [7] thus excluding the young unmarried people who are sexually active and also vulnerable and subject to sexual abuse or exploitations from conversation involving sex and pregnancy prevention. This practice limits their access to information on issues related to sexuality and contraception. Even if adolescents need information on sexuality and contraception, because of the cultural norms, they feel embarrassed going to parents, teachers and health facilities for information or services pertaining to sex and contraception [8]. Several studies have established a positive correlation between contraceptive knowledge and utilization and educational attainment $[9,10$, 11]. The northern region unfortunately has the 
lowest female literacy rate in Ghana and the teenage girls are usually sexually abused in schools and at home by their peers or older adults and the victims are blamed rather than the perpetrators. Majority of the teenage pregnancies arise from peer-to-peer relationships or abuse such as defilement by school teachers, and some of these girls die from complications in childbirth because their bodies are not developed enough to cope with the birthing process [12].

Because pregnancy is not the desired outcome in such instances, emergency contraception remains the only option to prevent pregnancy but its usage depends on the knowledge and the socio-cultural acceptability. Tamale is predominantly a Muslim community where the debate and criticism of FP among the religious scholars is ever going on. Many of the Islamic scholars are perceived to have an unfavorable attitude towards modern contraceptives, and this will serve as a major barrier to utilization since the cleric's views are sacrosanct.

For the young adolescent female to benefit from EC and avoid unplanned pregnancies, the product must be well known and accepted socio-culturally.

\section{Methods}

Tamale is the capital town of the Northern Region, one of the sixteen regional capitals in the country. It is located within the Guinea Savannah belt. The population of Tamale Metropolis, according to the 2010 Population and Housing Census, is 233,252 representing 9.4 percent of the region's population. Males constitute $49.7 \%$ and females represent $50.3 \%$. The proportion of the population living in urban localities $(80.8 \%)$ is higher than that living in rural localities $(19.1 \%)$ of the metropolis. The population of the metropolis is youthful (almost $36.4 \%$ of the population is below 15 years) depicting a broad-based population pyramid which tapers off with a small number of elderly persons (60 years and older) representing 5.1 percent.

A qualitative cross-sectional approach was used for this study. An in-depth interview was conducted involving a total of three clerics, to assess their knowledge on EC and perspective on its use among the youth.
A discussion guide with open-ended questions was used to probe further in seeking information that would facilitate improvement in the discussions and findings of the study. Discussions were recorded with a tape and field notes taken alongside to help capture the total views and contributions of each participant. They were asked specific questions about the position of their sect on the use of EC and other family planning products as per their religious faith, and follower's usage of contraceptives and family planning.

\section{Results}

The respondents were aged between 45 and 62 years and all were males. They were Imams or Sheiks; Arabic Instructors and others were Lecturers who were Islamic scholars at the university. 2 out of 3 clerics had good knowledge of EC including instances in which it is indicated and the right time for taking it.

All the clerics unanimously agreed that Sharia is not against family planning. They, however, indicated that Sharia does not permit the use of hormonal methods such as contraceptives pills/tablets, including EC and injectables. The reasons had been that these methods disturb the hormones in the woman and can cause some challenges in her menstrual cycle as well as health challenges. They also believe that at some point in the future the pills can stop the woman from giving birth again and so the use of such methods is not permissible.

The permission to use non-hormonal forms of contraceptive, was, however, restricted to only married adults and the cleric unanimously kicked against encouraging the Muslim youth to use FP including EC since they were of the view that Islam does not support the use of family planning among the unmarried. However, in instances of forced sex or incest, the clerics raised no objection to the use of EC since they contend it is no fault of the victim under such circumstances and also pregnancy is not the desired outcome.

\section{Discussion}

The influence of religion is pervasive in all aspects of an individual's life, including personal matters such as managing family size [13]. There are misconceptions about the permissibility of family planning in Islam and this has led to divided opinions on the part of 
the clerics on the use of modern family planning methods including EC. Religious leaders are held in high esteem in society and their views are usually sacrosanct. For this reason, their position on modern contraceptives heavily influences the uptake and utilization of these methods in the communities or societies they superintend. The Pakistan National Institute of Population Studies reported that women in communities where Ulema (Muslim religious leaders) approve the use of contraception methods were more likely to use them than women in communities where the Ulema disapproves of its use [14].

The Islamic Clerics in this study demonstrated good knowledge and understanding of FP, including EC, perhaps indicative of their sound education and experiences from elsewhere. This is similar to findings made by [15] in Asia, where Clerics reported a relatively more increased knowledge of EC.

The views of the clerics, who were the respondents on FP and EC use in this study, were clearly positive, and almost all of them agreed on how FP has been made possible by Allah. They, however, disagreed with the use of hormonal contraceptives because of the perceived interference with the female hormonal system. These views, however, contradicts those expressed by Muslim scholars in the study by [16]. According to them, with the exception of methods that leads to permanent deactivation of a reproductive organ (e.g., vasectomy and tubal ligation), which is inconsistent with Islamic teachings, any other form or method of contraception which doesn't alter the physical structure of the reproductive organ is permitted, and this includes hormonal forms. Muslim clerics in the study by [17], however, held a contrary view to the permissibility of family planning method in Islam. They opined that the prophet Muhammed entreated Muslims to multiply (that is to give birth to many children) in order to make him proud on the Day of Judgment and therefore reject FP because it will not serve the purpose of multiplication. Giving birth to many children, however, does not necessarily mean giving birth without limit, which is what FP is about. In Islam, FP is called "Tanzimulnasil" meaning "family arrangement". For those clerics who support family planning, they aver that 'family arrangement' means having a number that can be managed, which entails not just limiting births but also spacing the births as well, which brings to the fore family planning methods. They were unanimous in their view that FP was vital, and that was why Sharia permitted it, so that Muslims can plan their families, and use FP to space their children to avoid giving birth to many children which they cannot take care of on the forms of contraceptives, the Clerics did not agree to the use of the hormonal forms, which according to them, had side effects, such as interfering with the hormonal system of the woman with dire consequences. For this reason, Sharia forbids the use of these forms of contraceptives and this may influence negatively, the uptake and utilization of these forms of family planning methods including the use of EC. Similar reasons have been cited as barriers to the uptake and utilization of FP generally, among the Muslim communities in [18].

The right to FP, according to the secular laws of Ghana, means no one should be denied access and use of FP, including EC on religious grounds. The Muslim Clerics, however, were of the view that FP as a right is not universal or absolute. They restricted this right to only married couple despite the fact that unmarried young females are sexually active and would need modern family planning methods including EC. They were of the opinion that young unmarried Muslims would be encouraged to have sexual intercourse instead of abstaining if this right is extended to them.

When the question of pregnancy prevention in situations of rape or forced sex and incest using EC was posed to them, they all agreed to the use of EC since in their opinion, it will prevent having unwanted or bastard children. They averred that such situations arise not by deliberate or willful actions of the victim, and thus she cannot be made to suffer the consequences if she is not ready to do so.

Interestingly, the clerics unanimously agreed that society should be controlled by its religious beliefs which means that a predominantly Muslim society should live according to the tenets of the Islamic religion. They opined that sex education from parents is permissible and necessary in the socio-cultural context, to enable their wards take the right decisions to prevent unwanted and early pregnancy. 


\section{Conclusion and Recommendations}

According to the cleric, Sharia is not against FP; however, this right is solely the preserve of the married. They said "Sharia" permits the planning of families but were against the use of contraceptive forms that may affect the hormonal system of the woman including EC but will not object to the use of EC in pregnancy prevention in situations of rape/forced sex.

\section{References}

[1] Mohammed, F., Musa, A. and Amano, A. (2016) 'Prevalence and determinants of unintended pregnancy among pregnant woman attending ANC at Gelemso General Hospital, Oromiya Region, East Ethiopia: BMC Women's Health. 16(1), pp. 10-16.

[2] Vázquez-Nava, F. et al. (2014) 'Unplanned pregnancy in adolescents: Association with family structure, employed mother, and female friends with health-risk habits and behaviors', Journal of Urban Health, 91(1), pp. 176-185. doi: 10.1007/s11524013-9819.

[3] WHO (2018) Emergency contraception. Available at: http://www.who.int/en/newsroom/factsheets/detail/emergency-contraception

(Accessed: 19 May 2018).

[4] Kassa, G.M., Arowojolu, A.O., Odukogbe, A.A. et al. Prevalence and determinants of adolescent pregnancy in Africa: a systematic review and Metaanalysis. Reprod Health 15, 195 (2018). https://doi.org/10.1186/s12978-018-0640-2.

[5] Ameyaw, E.K. Prevalence and correlates of unintended pregnancy in Ghana: Analysis of 2014 Ghana Demographic and Health Survey. matern health, neonatol and perinatol 4, 17 (2018). https://doi.org/10.1186/s40748-018-0085-1.

[6] Coughlin J (2016): Teenage pregnancy in Ghana: Assessing situation and moving forward. www.graphic.com.gh/news/general-news/teenage pregnancy in ghana assessing situation and moving forward.html.

[7] Awusabo-Asare K, Biddlecom A, KumiKyereme A, Patterson K. (2006). Adolescent Sexual and Reproductive Health in Ghana: Results from the 2004 National Survey of Adolescents. Occasional Report No 22. New York, NY: Guttmacher Institute. [8] Rodriguez-Vignoli J. Adolescent fertility in Latin America and the Caribbean. nIUSSP [Internet]. 2017; May. Available from: http://www.niussp.org/article/adolescent fertility in
Since Ghana is a secular and not a religious state, it is recommended that health education should be extended to the Islamic scholars to help change some of their beliefs and perceptions regarding emergency contraception and other family planning methods in order for their followers to benefits greatly from family planning interventions.

latin America andthe-caribbeanla-feconditedesadolescentes-en-amerique-latine-et-dans-lesantilles.

[9] Amalba, A., Mogre, V., Appiah, M.N.A., and Mumuni, W.A., (2014) "Awareness, use and associated factors of emergency contraceptive pills among women of reproductive age (15-49 years) in Tamale, Ghana," BMC Women's Health, vol.14(114).

[10] Ezebialu I., \& Eke A., (2013). "Knowledge and practice of emergency contraception among female undergraduates in South Eastern Nigeria," Annals of Medical and Health Sciences Research, vol.3, no.4, pp.541-545,2013.

[11] Tilahun. D. F. Assefa. T., \& Belachew. T., (2010). Predictors of emergency contraceptive use among regular female students at Adama University, Central Ethiopia Pan Africa Medical Journal ISSN: 1937- 8688.

[12] GoG (2014): Child Protection baseline research, Northern regional profile, GOG, Department of children (Ministry of Gender and Social Protection, 2014] www.unicef.org.

[13] Mir A. M and Shaikha G. R (2013). Islam and family planning: changing perceptions of health care providers and medical faculty in Pakistan. Global Health: Science and Practice 1(2):228-236, DOI: 10.9745/GHSP-D-13-00019.

[14] Raza H, Sheraz A, Zafar R, Khan N, Ali H (2012). Effect of Islamic perception on family planning practices. OIDA Int J Sust Dev ;5(3):8596.

[15]Duze, M. and Mohammed, I. (2006). Male Knowledge, Attitudes, and Family Planning Practices in Northern Nigeria. African Journal of Reproductive Health, 10(3): 53-65.

[16] Yusuf B. J. (2014): Contraception and Sexual and Reproductive Awareness Among Ghanaian Muslim Youth: Issues, Challenges, and Prospects for Positive Development. 
[17] Al-Ghazali, A. H. M. (1939). Ihya' 'ulum-uddin [The revival of the religious sciences] (Vol. 2). Cairo, Egypt: Mustafa Al-Babi.
[18] Vanguard Newspaper. (2012). Jonathan's Birth

Control

Idea

Angers

Nigerians.

www.vanguardngr.com/health/contraception.

Acccessed on 14th July, 2013. 


\title{
Effectiveness of Mobile Positive Health Dignity and Prevention Messages on the Attitude of HIV Positive Young Adults receiving Antiretroviral Treatment in Yola, Nigeria
}

\author{
S O Adeyemi ${ }^{1 *}$, K U Suru ${ }^{2}$, J E Chiegil ${ }^{1}$, O F Martins ${ }^{2}$ \\ ${ }^{1}$ Texila American University, Guyan ${ }^{1}$ \\ ${ }^{2}$ Department of Public Health, Federal Medical Centre Yola, Adamawa State, Nigeria
}

\begin{abstract}
Positive Health, Dignity, and Prevention (PHDP) is a term for HIV prevention interventions with people living with HIV. Negative attitudes toward HIV medications may restrict utilization of antiretroviral therapy. Young adults with HIV are less likely to be adherent to ART. We investigated the effectiveness of mobile Positive Health Dignity and Prevention messages on the attitudes of HIV positive young adults (18-30 years) enrolled in care in the ART comprehensive sites in Yola, Nigeria. This was a randomized controlled trials study consisting of 371 young people living with HIV enrolled into antiretroviral treatment (ART) in 6 comprehensive sites in Yola. In addition to the routine care received during ART refill, the intervention group (186) received a total of 48 daily mobile PHDP text messages for the duration of 48 days while the control group (185) also received 48 daily mobile personal hygiene text messages for the duration of 48 days as placebo. A pre-validated structured questionnaire was used for data collected. Data was collected at baseline, two, four and six months respectively. Data was analyzed using SPSS version 24. Test of significance was at a level 0.05. Mean $\pm S D$ attitude scores at baseline and 6-month follow-up were $38.46 \pm 4.657$ and $40.04 \pm 4.943$ respectively in the intervention group. The control group had mean $\pm S D$ attitude score of $35.92 \pm 4.677$ at baseline and 35.88 \pm 4.704 at 6-month follow-up period. A repeated measures ANOVA with a GreenhouseGeisser correction showed a significant increase in the mean attitude scores from based line to 6 months follow up differed statistically significantly between the time points $\left(F_{(1.162,210.381)}=155.479 p<0.001\right)$ in intervention group. The repeated ANOVA measures for the control group from baseline to 6 months follow up did not show a statistical difference between the time points $\left(F_{(1.906,343.144)}=0.950 p=0.384\right)$, and indicate no statistically significance was seen. Mobile positive health dignity and prevention text messages were effective in improving the attitude of young PLWHA towards ART in Nigeria.
\end{abstract}

Keywords: Attitudes, ART, HIV positive young adults, Mobile Positive Health Dignity Preventive message, Nigeria.

\section{Introduction}

HIV is a major health challenge and one of the leading causes of death from infectious disease worldwide. It was estimated in 2016 that about 36.7 million people were living with HIV with about 1.8 million people became newly infected with HIV, an estimate of 1 million died from AIDS-related causes in 2016, and about 19.5 million people were accessing antiretroviral therapy in the same year [1]. An estimate of 4 million people living with HIV globally are young people between the age of 15-24 years [2]. Sub-Saharan Africa remained the most hit region with about 25.6 million people living with HIV, and two-thirds of new HIV infections globally occurred in this region. Young people make up a portion of the population that is specifically vulnerable to HIV [3]. Nigeria has the second highest HIV epidemic globally next to South Africa.

Adamawa state in the North-Eastern region of Nigeria has an estimated population of 4 million [4]. The state had witnessed fluctuations in the pattern of the ANC HIV sentinel prevalence between 1999 and 2010 showing prevalence of $4.5 \%$ in 2001 to $7.5 \%$ in 2003 , declining to $4.2 \%$ in 2005 and rising to $6.8 \%$ in 2008 but declined again to $3.8 \%$ in 2010 [4]. In 2015, prevalence of HIV in Adamawa State was $2.5 \%$ with an estimated 50,433 adult People Living with HIV (15 years +), adult ART achievement of 25,341 
(50.2\%). These PLWHA enrolled in care received Positive Health Dignity and Prevention intervention as part of the standard ART services.

Positive Health, Dignity, and Prevention (PHDP) is a term for HIV prevention interventions with people living with HIV. PHDP is alternatively known as positive prevention, prevention with positives, prevention by positives, and prevention for positives. It involves supporting $\mathrm{HIV}$-positive people to learn and practice how to live healthily and minimize the risks of their spreading the virus to others [5]. PHDP is a relatively new area of focus for HIV prevention programmes. Historically, HIV prevention efforts have tended to focus on reducing HIV risk among HIVnegative people or those with unknown serostatus, while overlooking the precise role that HIV-positive people can play in prevention. Substantial gains in the treatment and care of people living with HIV (PLHIV) and attention to and funding of ARV treatment have resulted in larger numbers of people living longer with HIV. There is thus a growing acknowledgment of the urgent need to find effective ways to engage this population in HIV prevention efforts that are suitable to their needs [6]. Adding a focus on HIV prevention interventions with PLHIV may improve overall HIV prevention strategies [7]. There is the need to strengthen PHDP intervention among PLWHA who are on ART.

Adherence to ART is one of the major identified elements to improve the quality of life of People Living with HIV/AIDS (PLWHA), avoid re-infection, and prevent further spread of resistant strains. ART has transformed HIV infection into a treatable, chronic condition like hypertension. Non-adherence has been tagged as one of the main contributing factors in HIV treatment failure, which can lead to clinical progression of the disease [8]. Negative attitudes toward HIV medications may further fuel nonadherence to ART [9]. Young adults with HIV are less likely to be adherent to ART $[10,11,12$, $13,14]$. There is the need to strengthen the delivery of interventions that encourages positive attitude towards ART among young people living with HIV/AIDS. This study evaluates the effectiveness of mobile PHDP messages on the attitudes of HIV positive young adults (18-30 years) enrolled in care in the ART comprehensive sites in Yola, Nigeria.
Young people are the highest users of mobile phones worldwide. The gains of mobile phone usage in improving health interventions across high and low-income countries cannot be overemphasised. Mobile phone technology has advanced so greatly in recent years that phones can no longer be seen as simple mobile communication devices. Medical community has over the last decade embraced this technology and is realizing its potential in healthcare information delivery, real-time patient monitoring, research data collection and mobile telemedicine for the provision of expertise to remote locations. Improved ART clinic attendance in Uganda was demonstrated when participants were sent SMS or voice reminders [15]. Two studies conducted in Nigeria demonstrated that adherence counselling and text message reminders improved adherence among HIV patients [16, 17].

A Cochrane database system review on SMS interventions in Kenya show that weekly SMS messaging improved adult ART adherence compared to standard care at 48-52 weeks [18]. A systematic review of PMTCT interventions found that SMS reminders is convenience, cost effective and improved retention of motherinfant pairs at 18 months [19]. Another study carried out in Malaysia indicated that mobile phone reminders (SMS and telephone call reminders) and peer counselling are effective in enhancing adherence and treatment outcomes among HIV-positive patients on ART in Malaysia [20]. Mobile phone text message, or SMS, reminders to promote ART adherence is recommended in PEPFAR [21] and WHO guidelines [22]. However, its utilization is low in many resource limited countries, Nigeria inclusive.

Although several studies have been conducted on the use of mobile phones to improve the outcomes of HIV/AIDS interventions, there is no documented literature on the use of mobile phone to improve Positive Health Dignity and Prevention amongst young PLWHA in Nigeria, hence the decision to conduct this study.

\section{Methods}

\section{Study Design}

The study was conducted in six selected comprehensive ART treatment sites located in Adamawa State, Nigeria (Yola Specialist 
Hospital, Federal Medical Centre Yola, St Francis Hospital Jimeta, Adamawa Hospital Yola, Peace Hospital Yola, and Boshang Clinic Jimeta. It utilized a two-arm single blind Randomized Controlled Trial (RCT) to evaluate the effectiveness of mobile Positive Health Dignity and Prevention (PHDP) messages on the attitudes of HIV positive young adults (18-30 years) enrolled in care in six selected comprehensive ART sites in Yola, Nigeria. The study was conducted from November 2017 to September 2018.

The study comprised of all young HIV patients (male and female) within the age of 1830 years who were enrolled in care and are currently receiving ART based on the national protocol during the period prior to the commencement of the study at the six selected study locations. The criteria for the inclusion of participants into this study involved all HIVpositive patients who were currently active on ART treatment at the selected study locations during the period before the commencement of this study, who were able to read, write and comprehend English and Hausa, had valid and active telephone number, and fell within the age range of 18-30 years. Clients who did not meet the inclusion criteria, and all confirmed pregnant clients were excluded from the study.

Sample size was calculated for all outcome variables. The largest sample size was obtained for the outcome variable of knowledge of HIV/AIDS. A total of $371(10 \%$ attrition inclusive) participants for both the intervention group and the control group was calculated using the formula below [23]. The sample frame consisted of all HIV positive young adults age 1830 years enrolled in care who attended ART clinic refill during the time of enrolment of participants into the study in the six study locations. The enrolment of participants was done during clinic ART refill days and it's lasted for 4 weeks across the six study locations.

$$
n=\frac{\left\{Z_{1-\alpha} / 2 \sqrt{2 \bar{P}(1-\bar{P})}+Z_{1-\beta} \sqrt{\left(P_{1}\left(1-P_{1}\right)+P_{2}\left(1-P_{2}\right)\right.}{ }^{2}\right.}{\left(P_{1}-P_{2}\right)^{2}}
$$

Where: $\mathrm{P}_{1}=0.90$ (Desired level of HIV/AIDS knowledge); $\mathrm{P}_{2}=0.77$ [24] Baseline; $\overline{\mathrm{P}}_{=} \mathrm{P}_{1}+\mathrm{P}_{2} / 2=$ $0.90+\frac{0.77}{2}=\frac{1.67}{2}=0.835 ;$ and $\mathrm{z} 1_{-\alpha / 2}=1.96$ at $95 \% \mathrm{C}$

\section{Sampling}

Eligible clients were sampled using systematic random sampling from the six study locations. One of the research assistants was asked to choose a lucky number from number 1 to 4 and she chose number 4 . Every fourth (4th) young PLWHA age 18-30 years who came to the clinic for Antiretroviral drug refill that day was sampled for eligibility to participate in the study across the 6 study locations. The sampling lasted for 4 weeks across the study locations. A total of 492 young PLWHA were sampled from the sample frame and were assessed out of which 98 did not meet the inclusion criteria and 23 declined participation. The clients (371) who met the inclusion criteria were randomised into the intervention group (186) and control group (185). Colour-coded sticky notes were used to allocate participants to intervention and control group. A total of 371 colour coded sticky notes were placed in separate sealed opaque brown envelopes (186 yellow notes represented intervention group; 185 blue notes represented control group). This was shuffled in the box and re-shuffled after each client picked. Clients picked a single envelope one by one under the supervision of the trained research assistants. The research assistant opened the sealed envelope and used the colour code to know which group the client belonged and so determined who received the intervention and who did not base on their chosen colour. A single blinded technique was used with clients do not know the group they belong to. A total of 17 PLHWA aged 18-30 years were sampled from study location one, 26 from study location two, 89 from study location three, 26 from study location four, 161 from study location five and 58 from study location six.

\section{Intervention}

A total of 48 mobile PHDP text messages were developed as the intervention. The messages included chronic HIV care with ART and prevention and Integrated Management of Adolescent and Adult Illness [25]. A total of 48 personal hygiene messages were adapted as 
mobile text messages from hygiene practices for patients with HIV/AIDS [26] as placebo.

The content validity of the all the messages developed were done in two phases. The first phase involved sharing the messages with 3 professionals including 1 Public Health Physician and 2 HIV/AIDS specialists for their feedback and recommendations which the researcher inputted. The interventions were field tested in Specialist hospital Yola, one of the study locations, in the second phase of validation. A total of 30 young PLWHA age 1830 (15 males and 15 females) were selected during ART clinic refill day based on their ability to read in both English and Hausa. The researcher assessed their understanding of each message and modified the messages based on the feedback received. The text messages were sent through bulk SMS services provided by LOFTYSMS [27], SMS service delivery provider. The mobile number of all the participants, collected at the time of enrolment, were stored based on the two research groups.

In addition to the routine PHDP care received during ART refill, the intervention group received a total of 48 daily mobile PHDP text messages for the duration of 48 days, one text message per day. The control group also received additional 48 daily mobile personal hygiene text messages for the duration of 48 days, one text message per day, as placebo. All the text messages, both the PHDP and the personal hygiene messages, were translated from English to Hausa and translated back into English by a certified translator.

\section{Data Collection Instrument}

The study instrument was a self-administered questionnaire consisting of closed-ended questions that were constructed of questions derived from previously validated questionnaires that were administered as part of relevant previous studies $[28,29,30,31,32,33$, $34]$. In order to assess the content validity of the questionnaire, it was assessed by 3 professionals in the field of infectious diseases, with a specialty in HIV/AIDs. The questionnaire was pretested in the ART clinic of St Francis hospital and Specialist Hospital Yola to assess the reliability. It involved 30 (15 males and 15 females) young PLWHA within the age of 18-30 years, who would not be considered part of the study group at the time the study would be conducted.

The attitudes portion of the questionnaire consisted of 13 items that were measured on a four-point Likert-type scale ranging from strongly agree to strongly disagree. Maximum possible score for the attitude section was $13 \times 4=52$ [35]. The 13 items regarding attitudes contains set of questions covering general stigma towards HIV/AIDS; medicine and stigma towards HIV/AIDS; emotions and fears regarding HIV/AIDS; and HIV/AIDS-related medical protocol. The internal validity (alpha Cronbach) of the attitude was 0.8252 .

\section{Data Collection}

Data was collected at baseline, two, four and six months respectively.

\section{Data Analysis}

Data was analysed using Statistical Package for Social Sciences (SPSS) version 24.0. Percentage distributions of attitude towards ART were performed and tabulated. A 4point Likert scale was used, ranging from strongly disagree to strongly agree. A mark of 1 was awarded for strongly disagree, 2 for disagree, 3 for agree and 4 for strongly agree. Negatively asked questions were reversed coded. All scores were added to get the aggregate score. The descriptive statistics for the mean of attitude scores were tabulated. Baseline comparison of mean attitude scores of the intervention and control groups were obtained by independent $t$ test, and repeated measures ANOVA was used to evaluate the effectiveness of the PHDP Messages on attitude scores at 2, 4 and 6 months. A p-value $<0.05$ was considered as statistically significant.

\section{Ethics}

Ethical clearance was obtained from the Adamawa State Ministry of Health, Department of Research and Statistics ethical committee. Informed consent was obtained from each participant through a written and signed informed consent form before they were enrolled into the study. 


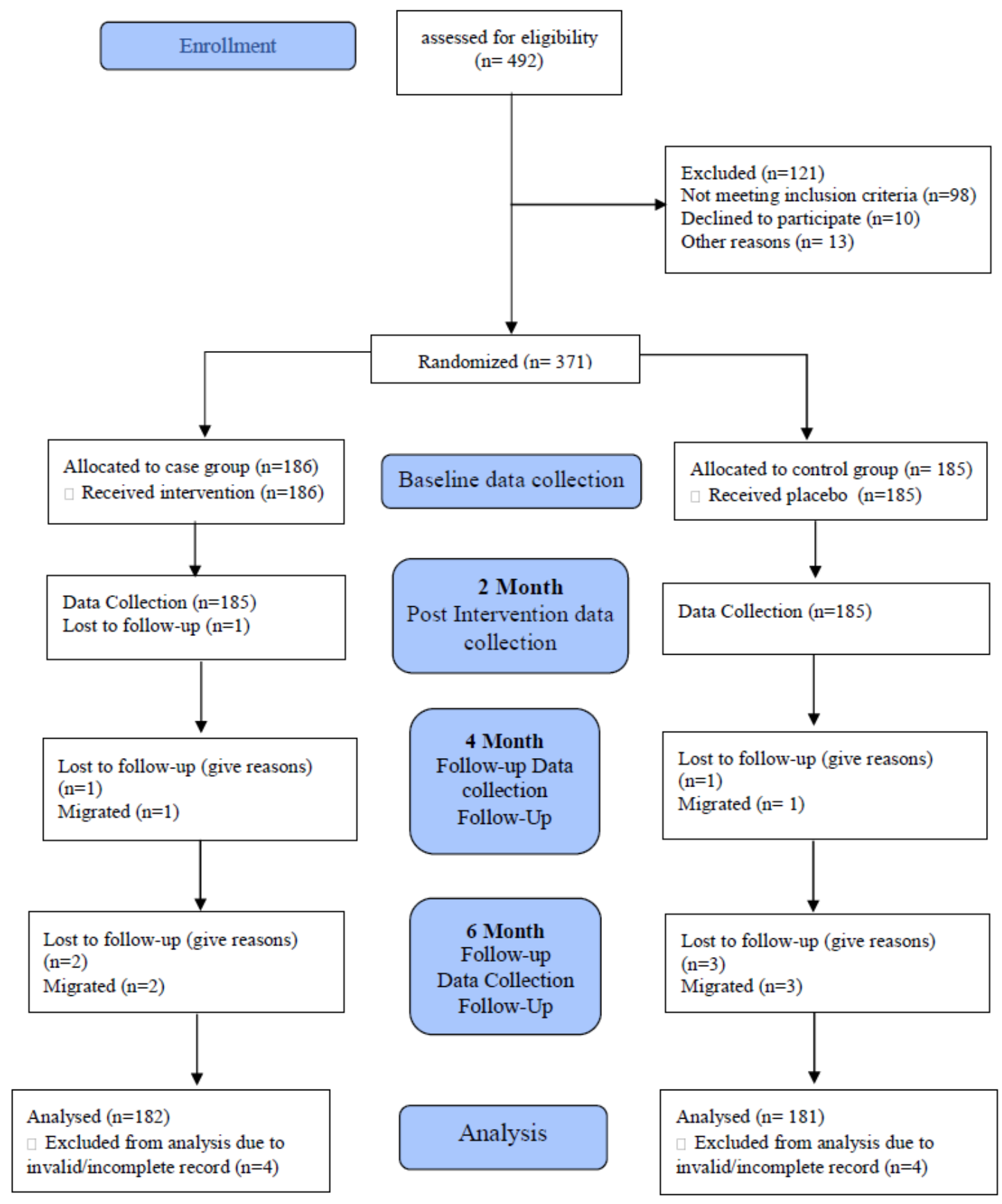

Figure 1. Activity Flow

\section{Results}

\section{Socio-demographic Characteristics of the Respondents}

Over half of the respondents $(57.5 \%$; 107) in the intervention group and about half of respondent $(50.3 \%)$ in the control group were between the ages 26 and 30 years. The mean \pm $\mathrm{SD}$ ages of the respondents in the intervention and control groups were $25.57 \pm 2.990$ years and $24.91 \pm 2.986$ years respectively. Majority of the HIV infected young adults in both intervention 
$(82.3 \%)$ and control (80.5\%) groups were females. The distribution of marital status showed that in the intervention group, over half of the young adults (55.9\%) were married and 19 participants had been divorced. In the control group, more participants were single $(55.1 \%)$ and $1.6 \%$ were widowed. About half of the participants $(49.5 \%$; 92) in the intervention group had a secondary level of education and $16.1 \%$ had no form of formal education. Only $25.9 \%$ had a higher/tertiary form of education in the control group, and $18.9 \%$ had no formal education. About a quarter of the young adults in the intervention group were housewives, $36.6 \%$ (68) were self-employed, while $16.1 \%$ were students. Almost half of the participants in the control group were self-employed and $14.6 \%$ (27) were students. No statistical differences were seen for age, sex, marital status, level of education and employment statuses between the intervention and control groups.

\section{Baseline Distribution of Respondents' Attitudinal Disposition towards Antiretroviral Medications}

The attitudinal disposition of the young people at baseline was measured with a 13-item scale. More of the young people in the intervention group $(60.2 \%)$ disagreed that they were worried about other people knowing their HIV status by noticing their medication intake; four people strongly agreed and 60 (32.2\%) agreed. In the control group, however, more people strongly agreed $(58 ; 31.4 \%)$ that they were worried and 24 people $(1.0 \%)$ strongly agreed. Almost two-thirds of the respondents in the intervention group $(64 \% ; 119)$ disagreed with the statement that inquired about their frustration of taking the medications because they had to plan their lives around it while $43.8 \%$ (81) of the young people in the control group felt same. Majority of the people in the intervention group (strongly agreed: $30.6 \%$; agreed; $59.1 \%$ ) agreed that their healthcare providers take their needs into account while about half had the same disposition in the control group (strongly agreed: 9.7\%; agreed; $43.8 \%$ ).

The proportion who agreed to have positive support from people who are aware of their status was high in the intervention group, but only a $40 \%$ agreed in the control group. About two-thirds $(67.2 \%)$ in the intervention group disagreed that they did not have the urge to have sex with strangers when they were drunk with alcohol, while only $36.8 \%$ had the same disposition in the control group.

\section{Comparison of Mean Baseline Attitude Scores between Intervention Group and Control Group}

The mean \pm SD baseline attitude score of the respondents in the intervention groups was $38.467 \pm 4.652$ and $35.929 \pm 4.677$ for the control group. The independent $t$ test result for equality of mean baseline HIV knowledge score between the intervention group and the control group was statistically significant $(\mathrm{p}=0.000)$. The result showed that both the intervention group and the control group had non-equal mean attitude scores at baseline. The intervention group has higher baseline mean attitude score than the control group. However, the Leven's test for equality of variance between the two groups was not statistically significant $(\mathrm{p}=0.267)$. This means that the variances are approximately equal. The result shows that the respondents in the two groups were drawn from the same sample population.

\section{Effectiveness of Mobile PHDP Intervention on the Attitudinal Disposition of Young People Living with HIV/AIDS}

A repeated measure ANOVA with a Greenhouse-Geisser correction determined that mean attitude score differed statistically significantly between the time points ( $\mathrm{F}_{(1.162}$, 210.381) $=155.479 \mathrm{p}<0.001)($ Table 1). Post hoc tests using the Bonferroni adjustment for multiple comparisons showed the mobile Positive Health Dignity and Preventive (PHDP) text messages elicited an increase in the level of attitude from baseline to 6 months follow-up period $\quad(38.46 \pm 4.657$ vs $40.04 \pm 4.943$ respectively) in the intervention group, which was statistically significant $(\mathrm{p}<0.01)$. The repeated ANOVA measures for the control group from baseline to 6 months follow up did not show a statistical difference between the time points $\left(\mathrm{F}_{(1.906,343.144)}=0.950 \mathrm{p}=0.384\right)$, and indicate no statistically significance was seen (Table 2). Therefore, we can conclude that a mobile PHDP text message was effective in improving the attitudes of young people PLWHA towards ART. 
Table 1. Test of within-Subject Effects for Attitude towards ART in Intervention Group

\begin{tabular}{|l|l|l|l|l|l|}
\hline \multicolumn{2}{|l|}{ Variable } & df & Mean Square & F & p-value $^{\mathbf{a}}$ \\
\hline Attitude towards ART & Greenhouse-Geisser & 1.162 & 356.498 & 155.479 & .000 \\
\hline $\begin{array}{l}\text { Error (Attitude towards } \\
\text { ART) }\end{array}$ & Greenhouse-Geisser & 210.381 & 2.293 & & \\
\hline
\end{tabular}

${ }^{\mathrm{a}} \mathrm{p}$-value obtained by repeated measures ANOVA

*Significant at $\mathrm{p}<0.05$

Table 2. Test of within-Subject Effects for Attitude towards ART in Control Group

\begin{tabular}{|l|l|l|l|l|l|}
\hline \multicolumn{2}{|l|}{ Variable } & df & Mean Square & F & p-value $^{\text {a }}$ \\
\hline Attitude towards ART & Greenhouse-Geisser & 1.906 & .330 & .950 & .384 \\
\hline $\begin{array}{l}\text { Error (Attitude towards } \\
\text { ART) }\end{array}$ & Greenhouse-Geisser & 343.144 & .348 & & \\
\hline
\end{tabular}

ap-value obtained by repeated measures ANOVA

*Significant at $\mathrm{p}<0.05$.

Post hoc tests using the Bonferroni for repeated measures analysis showed a significant increase in attitude scores in respondents

between baseline and 2 months, baseline and 4 months, and baseline and 6 months in intervention group (Table 3).

Table 3. A Repeated Measures ANOVA Analysis on the Effectiveness of the Mobile PHDP Text Messages on the Attitude towards ART of Young PLWHA in Intervention Group

\begin{tabular}{|l|l|l|l|l|}
\hline Time & Time & Attitude Mean Difference & Std. Error & p-value $^{\mathbf{a}}$ \\
\hline \multirow{3}{*}{ Baseline } & 2 months & $-.192^{*}$ & .047 & .000 \\
\cline { 2 - 5 } & 4 months & $-1.599^{*}$ & .122 & .000 \\
\cline { 2 - 5 } & 6 months & $-1.599^{*}$ & .122 & .000 \\
\hline \multirow{2}{*}{ 2 months } & 4 months & $-1.407^{*}$ & .116 & .000 \\
\cline { 2 - 5 } & 6 months & $-1.407^{*}$ & .116 & .000 \\
\hline \multirow{2}{*}{ 4 months } & 6 months & .000 & .000 &. \\
\hline
\end{tabular}

${ }^{a} \mathrm{p}$-value obtained by repeated measures ANOVA

Based on estimated marginal means

*. The mean difference is significant at the 0.05 level.

a. Adjustment for multiple comparisons: Bonferroni

Post hoc tests using the Bonferroni for repeated measures analysis did not show a significant increase in attitude scores in

respondents between baseline and 2 months, baseline and 4 months, and baseline and 6 months in the control group (Table 4).

Table 4. A Repeated Measures ANOVA Analysis on the Effectiveness of the mobile PHDP Text Messages on the Attitude towards ART of young PLWHA in Control Group

\begin{tabular}{|l|l|l|l|l|}
\hline Time & Time & Attitude Mean Difference & Std. Error & p-value $^{\mathbf{a}}$ \\
\hline \multirow{3}{*}{ Baseline } & 2 months & $-.050^{*}$ & .048 & 1.000 \\
\cline { 2 - 5 } & 4 months & $.033^{*}$ & .070 & 1.000 \\
\cline { 2 - 5 } & 6 months & $-.006^{*}$ & .050 & 1.000 \\
\hline \multirow{2}{*}{ 2 months } & 4 months & $.083^{*}$ & .044 & .376 \\
\cline { 2 - 5 } & 6 months & $.044^{*}$ & .020 & .193 \\
\hline \multirow{2}{*}{ 4 months } & 6 months & $-.039^{*}$ & .050 & 1.000 \\
\hline
\end{tabular}

${ }^{\mathrm{a}} \mathrm{p}$-value obtained by repeated measures ANOVA

Based on estimated marginal means

*. The mean difference is significant at the 0.05 level.

a. Adjustment for multiple comparisons: Bonferroni 


\section{Discussion}

The participants recruited for the study were young adults between the ages of 18 and 30 years. The mean age is like that reported in a study by [36]. The findings of this study show that majority of the participants were females. This indicates that there were more females than men in the ART clinics from which the young people were recruited. Similarly [37], in a study across 12 facilities in Nigeria, reported that were more females than men. There have been reports from around the world of the gender imbalance in the prevalence of HIV/AIDS. Females are reportedly disadvantaged compared to their male counterparts, and evidence from UNAIDS and World Health Organization shows that women are more vulnerable to the virus. In contrast to this [20] reported more men attendee in Malaysia. "The results could be due to the health seeking behaviour of women, and the cultural diversity in which women were mostly housewives and may unknowingly have to acquire the virus from their husbands without confirmation yet. [38] reported similar results to those in this present study". They confirmed that more HIV cases were seen in women and it could be attributed to heterosexual intercourse. In contrast, India records a higher prevalence among men compared to women [39].

\section{Attitude of PLWHA}

Majority of the participants in this study had a positive attitude towards HIV infection. Though they displayed positive disposition towards their condition, a close look at the items indicates that some of them still ranked poorly. Quite a few did not have confidence in their healthcare provider's recommendations about their medications. This lack of confidence could lead to loss of trust in the healthcare system and the antiretroviral therapy. As reported by [40], PLWHA usually seek assistance in making very complex decisions regarding their illness from their physicians. They may seek help occasionally and rather consult friends and family, instead of discussing with healthcare providers. Participants in this study who lack social support may find it difficult to adhere to medications or practice prevention because they may make decisions without guidance. Only about a two-thirds of the young adults reported to have positive support by people who are important to them. Studies have shown a positive association between overall improved health outcomes and social support for PLWHA [41, 42].

More than a quarter of the young adults stated that they were worried the medications they were given may hurt their health. This notion could have been developed due to inadequate knowledge of the effectiveness and role of ART for their conditions. The results show that the young adults were not quite knowledgeable about the importance of the therapy, hence the negative attitude. Few were worried about the development of side effects due to the medications they used. About half of the participants reported that they often found it difficult to take their medications and use a condom for sexual intercourse when they consume alcohol. Previous studies have established the relationship between unprotected sexual intercourse and consumption of alcohol among people who are infected with HIV [43, 44].

\section{Effectiveness of Mobile PHDP Text Messages on the Attitudinal Disposition of Young PLWHA}

Patients' beliefs regarding HIV/AIDS can facilitate or hinder their treatments. Patients' poor understanding of HIV and the effects of ART has been associated with a higher likelihood of non-adherence [45]. Patients may drop out of therapy and care and this will increase the risk behaviours and transmission potential of the virus. The mobile PHDP intervention effected a change in the attitudinal disposition of the HIV-infected young people in Yola, Adamawa. The observed mean difference between baseline and 6-month follows up period as measured by the repeated measure analysis was statistically significant.

In a study by [9], the results confirm the important potential of negative attitudes as barriers to the progression of HIV treatment among patients. Patients' loss of trust in care provider and the belief that they do not require to take their drugs when they are feeling healthy can severely compromise their immunity. Few of the participants reported concerns for the efficacy and side effects of the ART medications. The concerns the young adults have could be a product of inadequate knowledge of ART. This finding suggests that health provider engagement and counselling can be effective in 
reducing the negative attitudes towards ART and improve preventive behaviours [46, 47].

\section{Limitations}

With the questionnaire as a tool of data collection, responses are dependent on truthfulness of respondents.

\section{Conclusion}

The study shows that mobile positive health and dignity prevention text messages can improve the attitude of young PLWHA towards ART in Nigeria. The HIV-infected patients who received the intervention were more likely to practice prevention of HIV transmission than patients who received the standard care alone. The overall findings of this study suggest that a comprehensive integration of ART and prevention programs may help to improve attitude towards ART thus, reduce HIV transmission in Africa and support continued ART expansion. Although attention and resources have been focused on patients who are registered in ART clinics already, there is still a vast majority of people in need of ART in sub-

\section{References}

[1] UNAIDS. UNAIDS. [Online].; 2017 [cited 2017 November. Available from: http://www.unaids.org/en/resources/documents/2017 /UNAIDS_FactSheet.

[2] UNAIDS. UNAIDS. [Online].; 2017 [cited 2017 November. Available from: http://aidsinfo.unaids.org.

[3] Idele P, Gillespie A, Porth T, Suzuki C, Mahy M, Kasedde S, et al. Epidemiology of HIV and AIDS Among Adolescents: Current Status, Inequities, and Data Gaps. J Acquir Immune Defic Syndr. 2014; 66(2): p. 144-153.

[4] ADSACA. Adamawa State Agency for the Control of HIV/AIDS: 2015 Annual Report. Yola:; 2016.

[5] Bernard EJ. Positive Health, Dignity and Prevention. Technical Consultation Report, 27-28 April 2009, Hammamet, Tunisia. Amsterdam:; 2009. [6] UNAIDS. Consultation on concurrent sexual partnerships, Nairobi, Kenya: Recommendations. Geneva:; 2009.

[7] NACA. The mid-term review of the Botswana National Strategic Framework for HIV/AIDS 20032009: On the road to Vision 2016. Gaborone:; 2007.
Saharan Africa who have never tested for HIV or registered for ART.

Overall, the results of this study show that though the mobile phone PHDP intervention was effective, larger multi-centre studies are required in identifying the cost-effectiveness of the strategy in improving attitude towards treatment and preventive behaviours among the HIVinfected youth and ART population in Nigeria and Sub-Saharan Africa at large. Though the studies which have utilized the mobile technology in HIV control and transmission in Nigeria are few, there has been evidence of improved clinical outcomes and preventive behaviours. Findings suggest intervention studies that will counteract the negative attitudes exhibited by the young people.

\section{Acknowledgments}

We thank all the respondents who took part in this study and Adamawa State Ministry of Health. We would also like to acknowledge Dr. Arup Kumar Chakrabartty for the support and guidance during the period of this study.

[8] Uzochukwu B, Onwujekwe O, Onoka A, Okoli C, Uguru N, Chukwuogo O. Determinants of nonadherence to subsidized anti-retroviral treatment in southeast Nigeria. Health Policy Plan. 2009; 24(3): p. 189-96. doi: 10.1093/heapol/czp006.

[9] Culbert G, Bazazi A, Waluyo A, Murni A, Muchransyah A, Iriyanti M, et al. The Influence of Medication Attitudes on Utilization of Antiretroviral Therapy (ART) in Indonesian Prisons. AIDS and Behavior. 2015; 20(5): p. 1026-1038. doi:10.1007/s10461- 015-1198-4.

[10] Fetzer B, Mupenda B, Lusiama J, Kitetele F, Golin C, Behets F. Barriers to and facilitators of adherence to pediatric antiretroviral therapy in a subSaharan setting: insights from a qualitative study. AIDS patient care and STDs. 2011; 25(10): p. 61121.

[11] Rudy B, Murphy D, Harris D, Muenz L, Ellen J. Patient-related risks for nonadherence to antiretroviral therapy among HIV-infected youth in the United States: a study of prevalence and interactions. AIDS patient care and STDs. 2009; 23(3): p. 185-94.

[12] Barclay T, Hinkin C, Castellon S, al. e. Ageassociated predictors of medication adherence in HIV-positive adults: health beliefs, self-efficacy, and 
neurocognitive status. Health psychology : official journal of the Division of Health Psychology, American Psychological Association. 2007; 26(1): p. 40-9.

[13] Murphy D, Wilson C, Durako S, Muenz L, Belzer M. Antiretroviral medication adherence among the REACH HIV-infected adolescent cohort in the USA. AIDS care. 2001; 13(1): p. 27-40.

[14]Belzer M, Fuchs D, Luftman G, Tucker D. Antiretroviral adherence issues among HIVpositive adolescents and young adults. The Journal of adolescent health: official publication of the Society for Adolescent Medicine. 1999; 25(5): p. 316-9.

[15] Kunutsor S, Walley J, Katabira E, Muchuro S, Balidawa H, Namagala E, et al. Using mobile phones to improve clinic attendance amongst an antiretroviral treatment cohort in rural Uganda: a cross-sectional and prospective study. AIDS Behav. 2010; 14(6): p. 1347-52. doi: 10.1007/s10461-0109780-2.

[16] Maduka O, Tobin-West C. Adherence counseling and reminder text messages improve uptake of antiretroviral therapy in a tertiary hospital in Nigeria. Niger J Clin Pract. 2013; 16(3): p. 302-8. doi: 10.4103/1119-3077.113451.

[17] Alfa MA, Zezi AU, Gyang SS, Yusuf H, Aliyu IM. Effect of Counselling and Reminder Text Messages Follow-Up on Adherence to Antiretroviral Therapy in Hajiya Gambo Sawaba General Hospital, Zaria, Nigeria. Journal of Applied Pharmaceutical Science. 2016; 6(09): p. 174-178. DOI: 10.7324/JAPS.2016.60926.

[18] Horvath T, Azman H, Kennedy G, Rutherford G. Mobile phone text messaging for promoting adherence to antiretroviral therapy in patients with HIV infection. Cochrane Database Syst Rev. 2012; 3(Cd009756)

[19] Ambia J, Mandala J. A systematic review of interventions to improve prevention of mother-tochild HIV transmission service delivery and promote retention. J Int AIDS Soc. 2016; 19(1): p. 20309.

[20] Abdulrahman S, Rampal L, Ibrahim F, Radhakrishnan A, Kadir SH, Othman N. Mobile phone reminders and peer counseling improve adherence and treatment outcomes of patients on ART in Malasia: A randomise clinical trial. PLoS ONE. 2017; 12(5): p. e0177698.

[21] US President's Emergency Plan for AIDS Relief. US President's Emergency Plan for AIDS Relief. Monitoring, evaluation, and reporting indicator reference guide. Washington, DC:; 2018.

[22] World Health Organization. HIV strategic information for impact: cascade data use manual to identify gaps in HIV and health services for program improvement. Geneva, Switzerland:; 2019.

[23] Lemeshow S, David WH, Klar J, Lwanga SK. WHO. IRIS: 239. [Online]. IRIS: 239: WHO; 1990. Available from: http://www.who.int/irs/handle/10665/41607.accesse d.

[24] Olowookere SA, Fatiregun AA, Adewole IF. Knowledge and attitudes regarding HIV/AIDS and antiretroviral therapy among patients at a Nigerian treatment clinic. J Infect Dev Ctries. 2012; 6(11): p. 809-816.

[25] WHO/HTM. Chronic HIV care with ART and prevention : Integrated Management of Adolescent and Adult Illness, Integrated Management of Childhood Illness interim guidelines for health workers at health centre or district hospital outpatient clinic. Geneva:; 2007.

[26] da Cunha G, de Araujo T, Lima F, Cavalcante T, Galvão M. Hygiene practices for patients with HIV/AIDS. Rev Gaucha Enferm. 2014; 35(3): p. 137144. DOI: http://dx.doi.org/10.1590/19831447.2014.03.44928.

[27]LOFTYSMS. LOFTYSMS. [Online].; 2018 [cited 2018 February 14. Available from: https://www.loftysms.com/?gclid=CjwKCAiAtorUB RBnEiwAfcp_Ywz2r2xhnVAJ5WRNizUrLvH2ap3 G9Dhkq1CBCahhLQrk_aIkhJmihRoC2wwQAvD_ BwE.

[28] Strunin L, Culbert A, Crane S. First year medical students' attitudes and knowledge about AIDS. AIDS Care. 1989; 1(1): p. 105-10. DOI: 10.1080/09540128908260242.

[29] Li V, Cole B, Zhang S, Chen C. HIV-related knowledge and attitudes among medical students in China. AIDS Care. 1993; 5(3): p. 305-12. DOI: 10.1080/09540129308258613.

[30] Amalraj E, Chandrasekaran N, Solomon S, Sumbandam R. First-year medical students' AIDS knowledge and attitude. Indian J Community Med. 1995; 20: p. 36-40.

[31] Merakou K, Costopoulos C, Marcopoulou J, Kourea-Kremastinou J. Knowledge, attitudes and behaviour after 15 years of HIV/AIDS prevention in schools. Eur J Public Health. 2002; 12(2): p. 90-3.

[32] Stulhofer A, Graham C, Bozicević I, Kufrin K, Ajduković D. HIV/AIDS-Related Knowledge, Attitudes And Sexual Behaviors as Predictors of Condom Use Among Young Adults in Croatia. Int Fam Plan Perspect. 2007; 33(2): p. 58-65.

[33] Qu B, Guo H, Sun G, Zuo T, Zhang Y, Li B. HIV/AIDS Knowledge, Attitudes, and Behaviors of 
Construction Workers in China. Int $\mathbf{J}$ Biomed Sci. 2008; 4(3): p. 192-195.

[34] Ugarte W, Högberg U, Valladares E, Essén B. Assessing knowledge, attitudes, and behaviors related to HIV and AIDS in Nicaragua: A community-level perspective. Sex Reprod Healthc. 2013; 4(1): p. 37-44. doi: 10.1016/j.srhc.2012.11.001.

[35] Vaidya A, Aryal UR, Krettek A. Cardiovascular health knowledge, attitude and practice/behaviour in an urbanising community of Nepal: a populationbased cross-sectional study from Jhaukhel-Duwakot Health Demographic Surveillance Site. BMJ Open. 2013; doi: 10.1136/bmjopen-2013-002976: p. 3(10): 002976

[36] Beyrer C, Baral SD, Griensven F, Goodreau SM, Chariyalertsak S, Wirtz AL, et al. Global Epidemiology of HIV Infection in Men Who Have Sex with Men. The Lancet. 2012; 380(9839): p. 367377 doi: 10.1016/S0140-6736(12)60821-6.

[37] Anoje C, Agu KA, Oladele EA, Badru T, Adedokun O, Oqua D, et al. Adherence to On-Time ART Drug Pick-Up and Its Association with CD4 Changes and Clinical Outcomes Amongst HIV Infected Adults on First-Line Antiretroviral Therapy in Nigerian Hospitals. AIDS Behav. 2017; 21(2): p. 386-392. doi: 10.1007/s10461-016-1473-z.

[38] Saddki N, Sulaiman Z, Abdullah S, Zakaria N, Mohamad N, Ab Razak A, et al. HIV-related knowledge among people living with HIV/AIDS in Kelantan, Malaysia. Journal of HIV/AIDS \& Social Services. 2016; 15(2): p. 216-233 DOI: 10.1080/15381501.2013.816648.

[39] Ramchandani SR,MSH, Saple DG, Vaidya SB, Pandey VP, Vadrevu R, Gupta A. Knowledge, Attitudes, And Practices of Antiretroviral Therapy among HIV-Infected Adults Attending Private And Public Clinics in India. AIDS Patient Care STDS. 2007; 21(2): p. 129-42 doi:10.1089/apc.2006.0045. [40] Guenter D, Gillett J, Cain R, Pawluch D, Travers R. What Do People Living With HIV/AIDS Expect From Their Physicians? Professional Expertise and the Doctor- Patient Relationship. Journal of the International Association of Physicians in AIDS Care. 2010; 9(6): p. 341-345. doi: $10.1177 / 1545109710370486$.

[41] Shippy R, Karpiak S. The aging HIV/AIDS population: Fragile social networks. Aging \& Mental Health. 2005; 9(3): p. 246-254. DOI: $10.1080 / 13607860412331336850$.

[42] Kingori C, Haile Z, Ngatia P. Depression symptoms, social support and overall health among HIV-positive individuals in Kenya. International Journal of STD \& AIDS. 2015; 26(3): p. 65-72. doi: 10.1177/0956462414531933. Epub 2014 Apr 22.

[43] Ehrenstein V, Horton N, Samet J. Inconsistent condom use among HIVinfected patients with alcohol problems. Drug and Alcohol Dependence. 2004; 73(2): p. 159-166. DOI: 10.1016/j.drugalcdep.2003.10.011.

[44] Brown J, DiClemente R, Sales J, Rose E, Gause $\mathrm{N}$, Safonova $\mathrm{P}$, et al. Alcohol Use, Partner Characteristics, and Condom Use Among HIVInfected Russian Women: An Event-Level Study. Journal of Studies on Alcohol and Drugs. 2016; 77(6): p. 968-973. DOI: 10.15288/jsad.2016.77.968. [45] Langebeek N, Gisolf E, Reiss P, Vervoort S, Hafsteinsdóttir T, Richter C, et al. Predictors and correlates of adherence to combination antiretroviral therapy (ART) for chronic HIV infection: a metaanalysis. BMC Med. 2014; 12(142): p. doi: 10.1186/PREACCEPT-1453408941291432.

[46] Unge C, Johansson A, Zachariah R, Some D, Van Engelgem I, Ekstrom A. Reasons for unsatisfactory acceptance of antiretroviral treatment in the urban Kibera slum, Kenya. AIDS Care. 2008; 20(2): p. 146-9. doi: 10.1080/09540120701513677. [47] Wasti S, van Teijlingen E, Simkhada P, Randall J, Baxter S, Kirkpatrick P, et al. Factors influencing adherence to antiretroviral treatment in Asian developing countries: a systematic review. Trop Med Int Health. 2012; 17(1): p. 71-81. doi: 10.1111/j.1365-3156.2011.02888.x. 


\title{
Assessing Factors Contributing to Erratic Water Supply in Peri Urban Areas. A Case Study of Chazanga Compound in Lusaka
}

\author{
Reuben Lazarus Zulu ${ }^{1 *}$, Emmanuel Kooma ${ }^{2}$ \\ ${ }^{1}$ Department of Public Health, Texila American University, Lusaka, Zambia \\ ${ }^{2}$ Ministry of Health, National Malaria Elimination Centre, Lusaka, Zambia
}

\begin{abstract}
According to World Health Organisation, one person needs 20 litres of water per day for physiological and domestic purposes. However, in some places people received little or no water at all. This was the case of Chazanga compound where some households experienced erratic water supply daily. Erratic water supply resulted in people drawing water from shallow wells which were usually contaminated. Consumption of contaminated water led to diarrhoeal diseases. This prompted for research to be conducted in Chazanga compound. The main objective was to establish the factors contributing to erratic water supply in Chazanga compound. A questionnaire was administered to 397 households. The generated data was analyzed using the Statistical Package for the Social Sciences. The results revealed that the problem of erratic water supply was real in Chazanga Compound. The other factors were poor management by the water supplier, high demand due to population growth and high cost of water. Erratic water supply in Chazanga made residents resort to drawing water from shallow wells, resulting in the increase in diarrhoea cases. The study further revealed that to avert the erratic water supply, the supplier needed to repair all leaking water distribution pipes, sink more boreholes and erect a bigger water reservoir. The other recommendations were to fit bigger distribution pipes, construct more communal taps, and improve the management of water supply by the water suppliers. The purpose of this research was to have an improved supply of safe and adequate water in Chazanga compound.
\end{abstract}

Keywords: Chazanga, Contributing, Erratic, Factors, Peri-urban and Water Supply.

\section{Introduction}

The Millennium Development Goals Report indicated that 783 million people or 11 percent of the global population remained without access to an improved source of drinking water. Such sources included household connections, public standpipes, boreholes, protected dug wells, protected springs and rainwater collections. Furthermore, there were regions particularly affected such as the Sub-Saharan Africa where over $40 \%$ of all people without improved drinking water lived.

The United Nations had been addressing the global crisis caused by insufficient water supply to satisfy basic human needs and growing demands of the world's water resources to meet human, commercial, and agricultural needs. The United Nations Water Conference, the International Drinking Water Supply and Sanitation Decade, the International Conference on Water and the Environment and the Earth
Summit all focused on water supply [1]. This led to the establishment of the World Water Day which falls on $22^{\text {nd }}$ March. Every year on $22^{\text {nd }}$ March, the World commemorates the World Water Day, in order to emphasize on the importance of conserving and proper management of this vital resource. It also focuses on improving access to adequate, clean and safe drinking water.

Everyday millions of people in Africa, usually women and girls, walked long distances to have access to any water. The length of time it took to collect the little water they can get meant that they did not have time to do anything else during the day. In some countries, children did not get the chance to go to school simply because they were too busy collecting water. In some instances, water was rationed by the Water Utility Companies. Thus, limiting access to adequate and safe water to the people [2].

Zambia has had its share of the water supply challenges. In Zambia, more than one third of the 
population did not have access to clean water and more than half lacked access to proper sanitation facilities. Water and sanitation facilities in basic schools were generally poor. The Government's Educational Statistical Bulletin of 2004 indicated that more than 25 percent of basic schools did not have access to a safe water supply (borehole-piped, boreholepump, piped water, or protected well) and improved sanitation facilities. Not having access to clean and safe water led to diseases like diarrhea and cholera, among others [3].

Water, sanitation, and hygiene factors were responsible for over 24000 deaths in 2004, which accounted for 11.4 percent of all deaths in Zambia. In 1991, Zambia's water sector reforms prioritized the actions on improving domestic water supply and sanitation accessibility due to its impact on the population's health. The targets that were set to meet the MDG goals also influenced the investment [4]. UNICEF has been supporting the Government of the Republic of Zambia to achieve MDGs 7 and 10 to halve the proportion of people without sustainable access to safe drinking water and basic sanitation by 2015. The most affected by problems of water were peri urban and rural areas of Zambia. This led to the initiation of National Rural Water and Sanitation Programs in all rural and peri-urban districts in order to address the water and sanitation challenges [3]. One such area affected by water problems was Chazanga compound of Lusaka district in Zambia.

Chazanga compound had been experiencing erratic water supply for more than seven months. An average of 300 households either received as little as 20 litres per household or no water at all on a daily basis. This was against the World Health Organisation's recommendation of the minimum requirement of 20 litres of water per person in a day for physiological and domestic use [5]. The erratic water supply in Chazanga compound forced many households to draw water from the shallow wells which were located near the pit latrines. The erratic water supply contributed to a lot of diseases such as water washed and water-borne diseases.

The water borne diseases that arose from erratic water supply were cholera, typhoid, dysentery and other common diarrhoeas. The consumption of water from shallow wells as a result of erratic water supply contributed to the high incidence of diarrhoea cases in Chazanga [6].

The lack or inadequate water supply also contributed to poor hygiene practices where people were rationing of the little water resulted in not bathing, washing of clothes and not washing the hands after use of the toilet.

The other problems due to the erratic water supply in Chazanga compound were trachoma and pediculosis due to lice infestation. These diseases came as a result of an inadequate supply of water [7].

The Health Management Information System Outpatient registers at Chazanga Health Centre showed that among the top ten diseases were diarrhoea, digestive system and non-infectious skin cases [8] as shown in table 1 .

This prompted the researcher to look into the factors contributing to erratic water supply in Chazanga compound of Lusaka.

Chazanga Water Trust erected communal water points in the community for people to access clean and safe water. However, they were not adequate to cater for the growing population.

The solutions to erratic water supply were for the water supplier needed to repair all leaking water distribution pipes, sink more boreholes, erect a bigger water reservoir tanks, fit bigger distribution pipes, construct more communal taps and improve the management of water supply.

The purpose of the study was to establish the factors that contributed to the problem of erratic water supply and come up with interventions to address the causes of erratic water supply in order to improved supply of safe and adequate water in Chazanga compound and prevent the water-borne and water washed diseases.

The general objective of the research was to establish the factors contributing to erratic water supply in Chazanga compound.

The main limitations to this research were inadequate time and funds to carry out the research. 
Table 1. Top 10 Diseases at Chazanga Clinic (Source: Lusaka DHO HMIS)

\begin{tabular}{|l|l|l|}
\hline SN & Diseases & Number of Cases \\
\hline 1 & Respiratory Infection: non-pneumonia & 1158 \\
\hline 2 & Diarrhoea (non-bloody) & 585 \\
\hline 3 & Muscular skeletal and connective tissue (not trauma) & 258 \\
\hline 4 & Digestive system: (not infectious) & 250 \\
\hline 5 & Pyrexia of Unknown Origin (PUO) & 239 \\
\hline 6 & Clinical case of malaria & 197 \\
\hline 7 & Nervous System Disorders: Other & 190 \\
\hline 8 & Trauma: Other Injuries, wounds & 186 \\
\hline 9 & Throat Diseases & 161 \\
\hline 10 & Skin Diseases (not infectious) & 111 \\
\hline
\end{tabular}

\section{Materials and Methods}

The research was conducted in Chazanga compound. Chazanga compound was located approximately ten kilometres on the northern part of Lusaka City, bordering Chisamba district. On the southern side, it bordered Chipata compound with old Kabanana and Chipwalu village on the eastern side. On the western side was Lilanda village of Chisamba district.

Chazanga compound had a population of 38,601 people with 8,000 households. The majority of the population were youths. The compound was made up of two villages namely Lilanda and Chipwalu villages. The headmen were responsible for land allocation and arbitration over the traditional and cultural matters. The target population were the households, water providers or suppliers and organisations of Chazanga compound that drew water from the Chazanga Water Trust communal and individual taps for their domestic uses.

The economic activities of the residents were farming, trading in various commodities as well as government and private companies' employees. Sixty percent of the residents own small businesses such as shops, groceries, bars, clubs and market stalls while 35 percent were either employees in the government or private institutions. The remaining five percent were subsistence farmers.

The compound had one government health centre (Chazanga clinic) and one private health facility called Bwafwano Integrated Health Services. However, there were other unregistered private clinics which offer health services to the public in Chazanga compound.

The sample size for this research was two percent of the total households which was 397 households. 300 respondents came from Chazanga compound, while from Lilanda villages 97 respondents were selected. The sample was not very big because the population had similar characteristics and experienced the same water problem, hence no need for a bigger sample. The formula used to determine the sample size was:

$$
\mathrm{n}=\frac{\mathrm{N}}{1+\mathrm{N}(\overline{\mathrm{e}})^{2}}
$$

To ensure that each unit of the sample had an equal chance of being included in the study to avoid biases, systematic random sampling was used in sampling. This involved the selection of sample units at regular intervals. The systematic random sampling procedure was employed. The sampling interval was 25 , which meant samples were collected every after the 25th household. This was done as the research was going on using the research assistants. In order to ensure accuracy in data collected, a ninety-five percent confidence level was applied.

In this study, both qualitative and quantitative methods of data collection were employed. This helped to maximize information and quality of data collected to reduce the possibilities of any biases. The data collection tools used were field observations and structured interviews using the questionnaires. The main data collection tool was the questionnaire. This was done through structured interviews of the respondents.

After collection, the data was then analyzed using Microsoft Excel program for the generation of charts and Scientific Package for Social Sciences (SPSS) to come up with the frequency tables. 


\section{Results}

Chazanga compound had been experiencing erratic water supply for some time. An average of 300 households either received as little as 20 litres per household or no water at all on a daily basis. This was against the World Health Organisation's recommendation of the minimum requirement of 20 litres of water per person in a day for physiological and domestic use [5].

The inadequate water supply to majority of residents of Chazanga compound led to many health problems and concerns which included people being forced to draw water from shallow wells which were unsafe resulting in waterborne diseases such as cholera, typhoid, dysentery, amoebiasis, ascariasis, rotavirus diarrhoea, poliomyelitis and shigellosis.

The research was conducted to assess the factors that contributed to erratic water supply. The data was analysed the following results were obtained in relation to erratic water supply in Chazanga compound.

The demographic characteristics of the respondents showed that the majority of the respondents were in the age group 30-34 which represented of 16.4 percent and the minority were in the age group 80-84 with 0.3 percent. The results further indicate that from the total of 397 sampled respondents, the majority of them were females representing 79.3 percent, while the males were represented by the remaining 20.7 percent.

The marital status showed the married as the majority, which were represented 63.4 percent of the total 397 respondents. This was followed by 21.4 percent of the respondents that were single. Thirdly, 10.6 percent of the respondents indicated that they were widowed and amongst the respondent's 2.8 percent were separated. Lastly, the minority 1.8 percent were divorced. This is summarised in table 2 .

Many of the respondents in the sample had a male adult as the head of the household $(81.8$ percent) followed by the female-headed households with 17.9 percent and the least household being headed by a child at 0.3 percent.

The provision of an adequate amount of water to the people and where the water was drawn was essential to the wellbeing of humans. Water was supposed to be supplied in adequate amounts and also the place where it was being drawn or tapped should be safe for use. Table 3 shows the percent distribution of the various sources of water for domestic use in Chazanga compound. The results then indicate that most of the respondents drew water from communal taps with 83.9 percent followed by other sources of water other than those listed in the study with 13.9 percent. The least sources of water for domestic use were shallow wells, boreholes and rivers with $1.3,0.8$ and 0.3 percent respectively.

The average water use for drinking, cooking and personal hygiene in any household should be atleast 20 litres per person per day as recommended by World Health Organisation. The results in Table 4 show that most of the respondents used 60 litres of water per day, followed by households who used 100 litres of water per day with 42.3 percent. The rest of the households used 200 litres, 20 litres and above 200 litres represented by 5.8 percent, 4.3 percent and 3.5 percent respectively.

On the other hand, the results, as shown in table 5, revealed that many of the respondents representing 40.8 percent drew 100 litres of water from the source per day. This was followed by the respondents who drew 60 litres of water with 28 percent and thirdly respondents who drew 200 litres of water. The minority of the respondents said they drew above 200 litres of water from the source representing 6.3 percent.

The respondents were asked if there were times that they had experienced erratic water supply in the compound and the result are shown in figure 1 that of the sample of 397, 394 respondents representing 99 percent had experienced erratic water supply while the minority of 4 respondents representing 1 percent had not experienced erratic water supply. The results further showed that respondents drew water from other sources such as shallow wells, streams and boreholes when they experience erratic water supply as shown in table 6 .

Table 6 reveals that from the respondents who had experienced erratic water supply, the majority got water from a shallow well representing 76.8 percent followed by water drawn from boreholes with 17 percent. Thirdly, respondents asked their neighbours if they could draw water from their home, which was represented by 4.1 percent and water from other sources other than the ones mentioned in the research with 1.3 percent. The minority got water from a river/stream with 0.3 percent. 
Erratic water supply could lead to many health problems and concerns. Among the many diseases that could break out due to erratic water supply, Diarrhoea, Cholera, Cough, Eye problems, Typhoid fever and Malaria were the responses of the respondents. As indicated in table 7, the majority said that diarrhoea with 49.4 percent would likely come due to erratic water supply followed by cholera with 17.9 percent. Other respondents said a combination of cholera and diarrhoea would breakout which was represented by 15.4 percent. Fourthly, respondents said malaria would come due to inadequate water supply with 10.6 percent followed by typhoid fever represented by 4.8 percent, then eye problems and coughing both having 0.5 percent. However, one percent of the respondents said that they did not know what diseases came due to inadequate water supply.

The research revealed that there were varied reasons of why there was an inadequate supply of water in Chazanga compound. The respondents revealed the various factors contributing to the erratic supply of water in the compound which include few boreholes, high demand of water by a growing population, highland hence no water due to low pressure, poor planning of the compound and hence water shortages, leakages in the pipes, small water distribution pipes, high cost of water, few communal taps, load shading which affects supply of water, negligence by government, few tanks and poor management by water suppliers. The rest of the respondents did not know the cause of erratic water supply. The respondents said having a few tanks caused erratic water supply at 34.3 percent followed load shading at 17.8 percent and few boreholes at $10.1 \%$ then few communal taps with $8.6 \%$. The rest of the respondents said the high demand for water by a growing population at $8.3 \%$, poor water management from suppliers, leakages in water distribution pipes, and small water distribution pipes, at $8.3 \%, 7.6 \%, 7.5 \%$ and $2.7 \%$, respectively.

The minority of the respondents said the land was too high hence no water due to low pressure, water was costly and negligence by government at $1.3 \%, 0.5 \%$ and $0.3 \%$, respectively. On the other hand, $1 \%$ of the respondents did not have any knowledge of what causes the erratic water supply in the compound.
The lack of adequate boreholes in an area such as Chazanga could be useful in explaining what contributed to the inadequate supply of water to the area. The respondents represented by $35 \%$ strongly agreed that the number of boreholes affects the water supply to the compound, followed by the respondents who disagreed at $34 \%$ and $29.7 \%$ who agreed. The minority of the respondents strongly disagreed with $1.3 \%$.

The respondents were further asked if the daily yield from boreholes affects the amount of water supplied to the compound. The results to the question are shown in figure 3 indicating that the majority of the respondents strongly agreed that the daily yield from boreholes affects the amount of water supplied to Chazanga representing $36 \%$. This was followed by respondents who agreed at $31.7 \%$ and those that disagreed at $30.4 \%$; whereas $2 \%$ of the respondents strongly disagreed.

The respondents were also asked if the leakages in the water distribution pipes affected the amount of water supplied to the people. Overall, figure 4 shows that the majority of the respondents $(69.3 \%)$ strongly agreed that leakages in the water distribution pipes affected the water supplied to people. $26.2 \%$ of the respondents agreed to this while the minority disagreed and strongly disagreed both representing $2.3 \%$.

The size of water reservoirs and the amount of stored water should be able to meet the high demand for water during periods of erratic water supply. The respondents where then asked if the size of the water reservoirs affects the amount of water stored in order to meet the demand for water during the peak periods. Figure 5 graphically represented the results to the question that slightly over half of the respondents strongly agreed that the size of the water reservoirs affects the amount of water stored in order to meet the water demand during the peak periods. This was followed by $38 \%$ of the respondents who agreed to this and $9 \%$ who disagreed to this question while only $1 \%$ of the respondents strongly disagreed.

The erratic water supply that had been experienced in Chazanga compound for the past months called for immediate improvements to increase access to safe and adequate water supply to the population. When asked on what should be done to improve the supply of water to 
the compound, respondents gave various recommendations which include; Sink more boreholes, repair the leakages in the distribution pipes, erect more water tanks, fit bigger distribution pipes, construct more communal taps, find an alternative source of power for the submersible water pumps and improve the management of water supply by the water suppliers. Table 9 shows the \% distribution of the possible interventions to improve the supply of water in Chazanga compound.

Table 9 reveals that most of the respondents recommended that more water tanks should be erected $(47.1 \%)$. This was followed by the respondents who recommended the sinking of more boreholes $(21.2 \%)$ and construction of more communal taps at $16.6 \%$. Fitting bigger water distribution pipes and improving management of water by the distributors were also recommended, both representing $5.3 \%$. The minority suggested the repair of leakages in the water pipes and finding an alternative source of power for the water pumps at $2.8 \%$ and $1.7 \%$ respectively.

The factors contributing to erratic water supply played a part in the inadequate and safe supply of water. This section looked at the relationship between the people who experienced erratic water supply and the factors that contributing to inadequate water supply. Table 10 shows the relationship between respondents who experienced erratic water supply and the factors contributing to the problem.

It shows that the number of available boreholes was not statistically related to the erratic water supply in Chazanga compound. All the respondents who had experienced erratic water supply strongly disagreed that the number of boreholes did not contribute to the erratic water supply. The table also shows that there was no statistical relationship between the daily water yield from boreholes and the erratic supply of water.

Leakages from water distribution pipes was significantly related to the erratic supply of water at $\mathrm{P}<0.05$. Almost all the respondents strongly agreed (99.3\%) that leakages from water distribution pipes contributed to inadequate water supply to the compound.

Table 10 further shows that the size of the water reservoirs and the erratic water supply to the compound was not statistically significant.

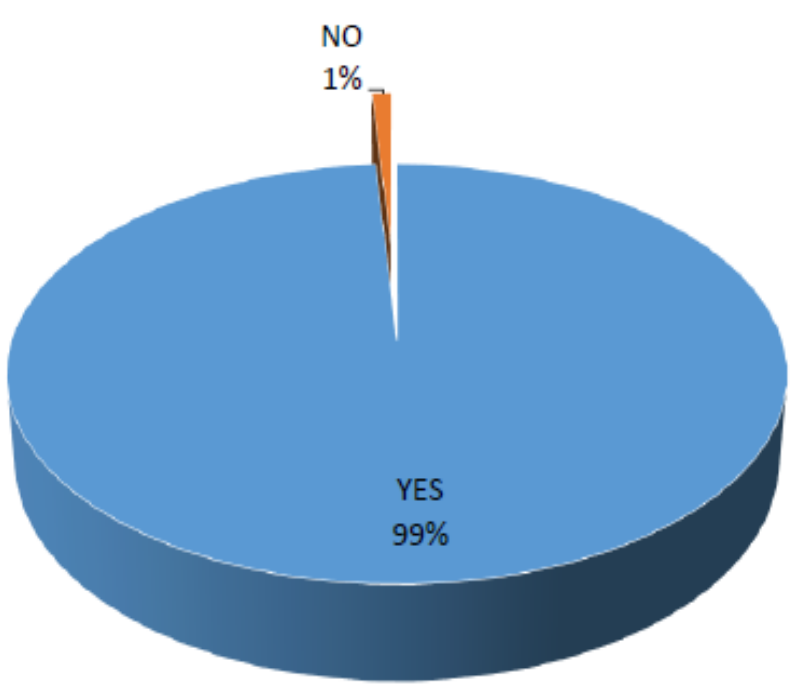

Figure 1. Percent Distribution of Whether Respondents had Experienced Erratic Water Supply 


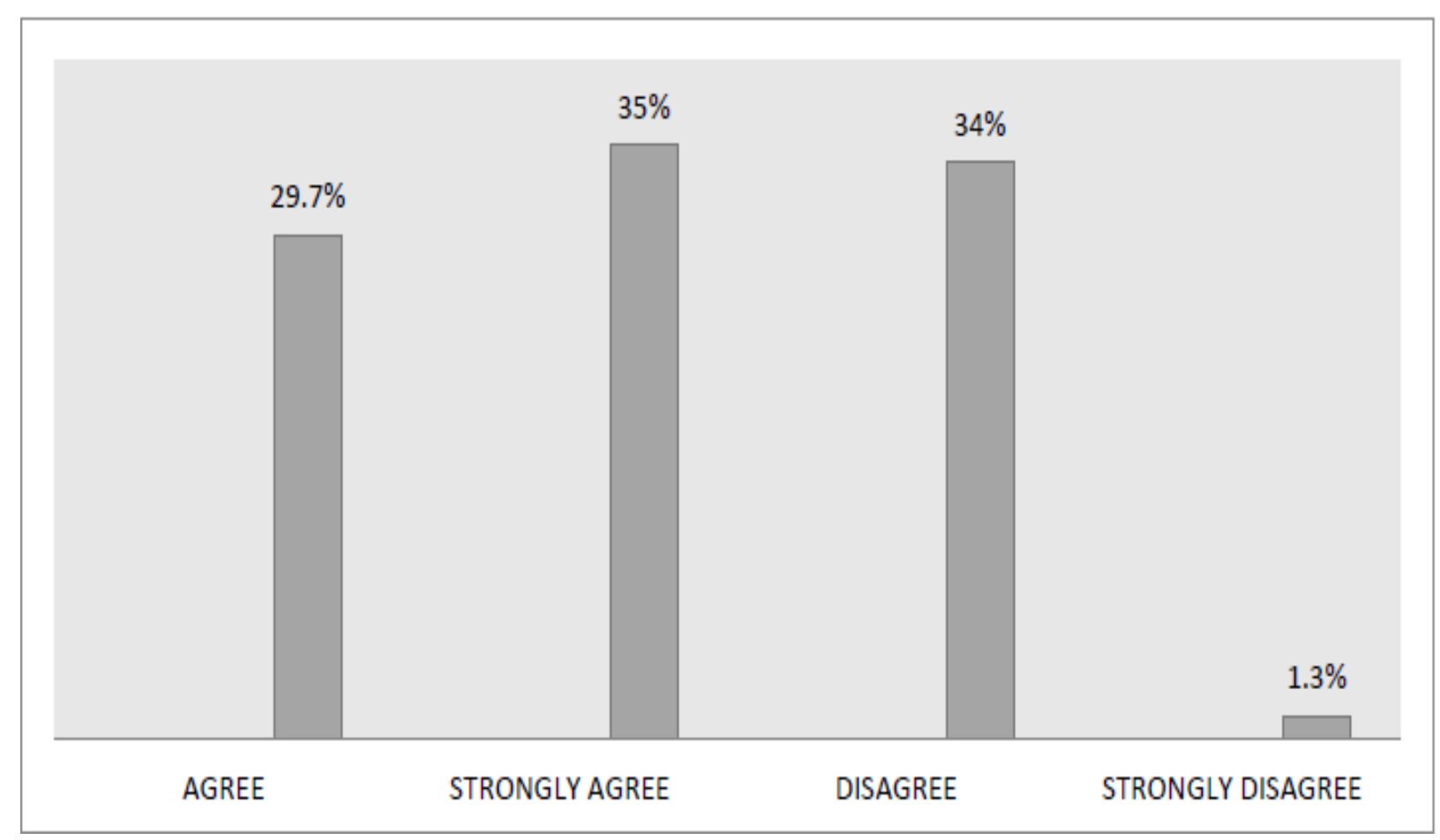

Figure2. Percent Distribution of Whether the Number of Boreholes Affected the Amount of Water Supply

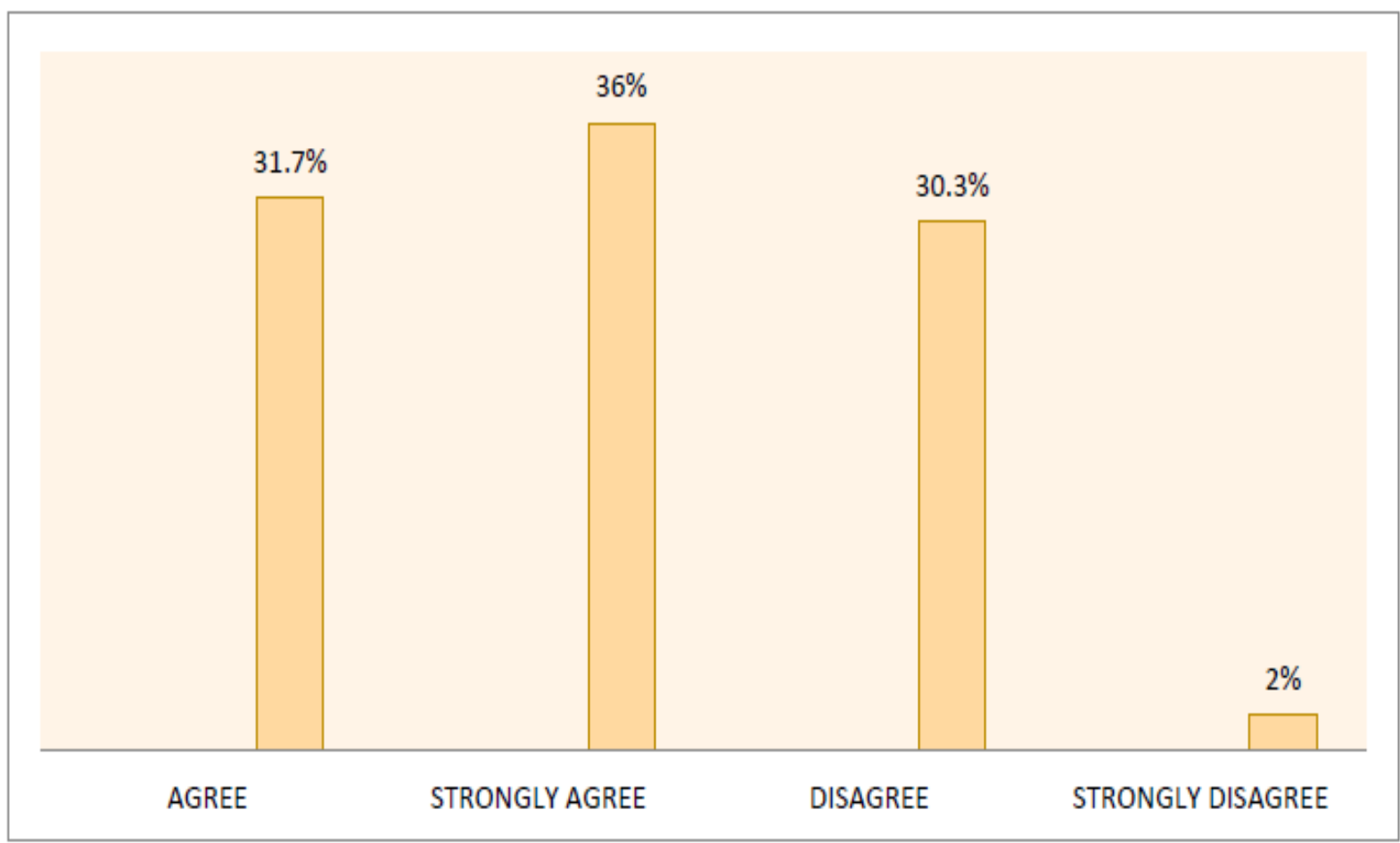

Figure 3. Percent Distribution of Whether the Daily Yield from Boreholes Affected the Amount of Water Supply 


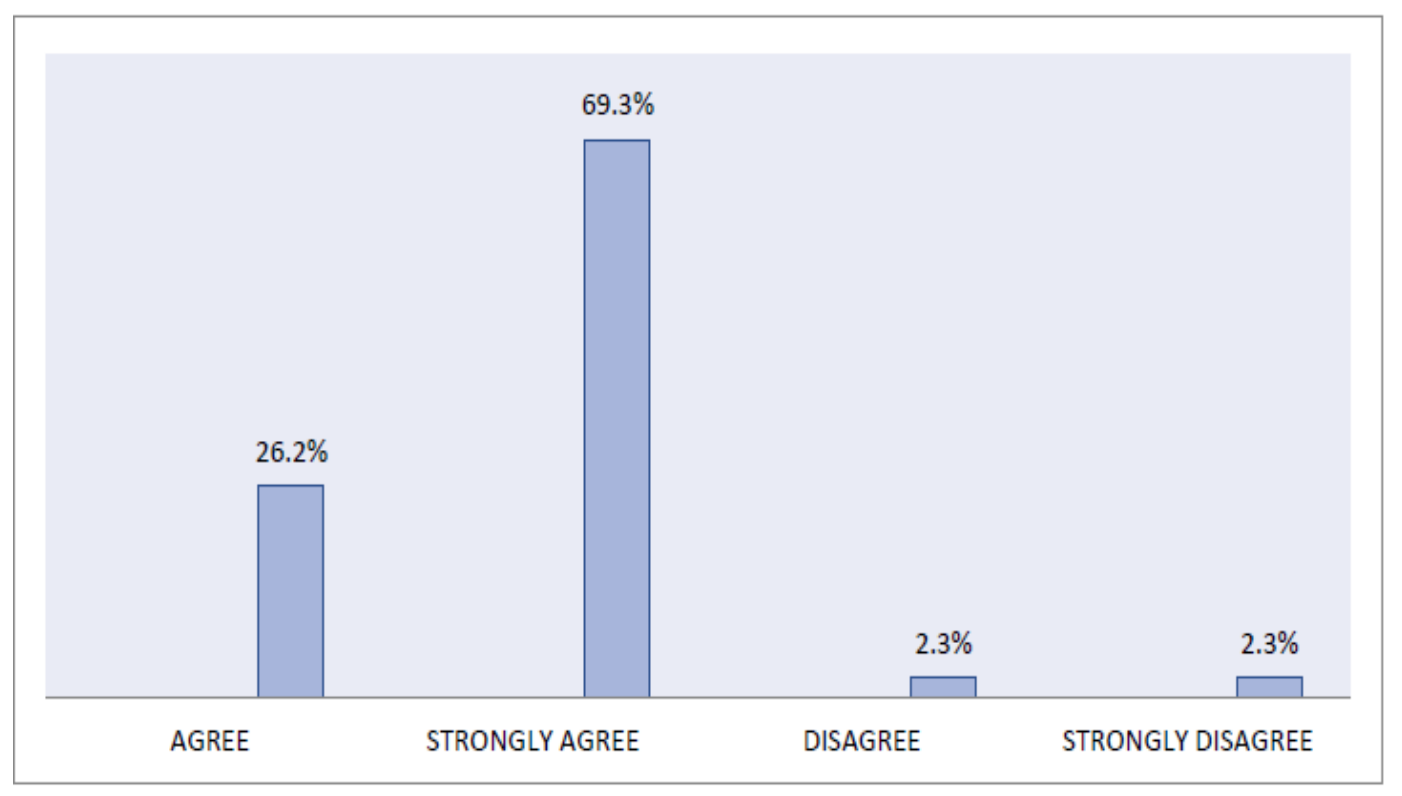

Figure 4. Percent Distribution of Whether the Leakages in the Distribution Pipes Affected the Water Supply

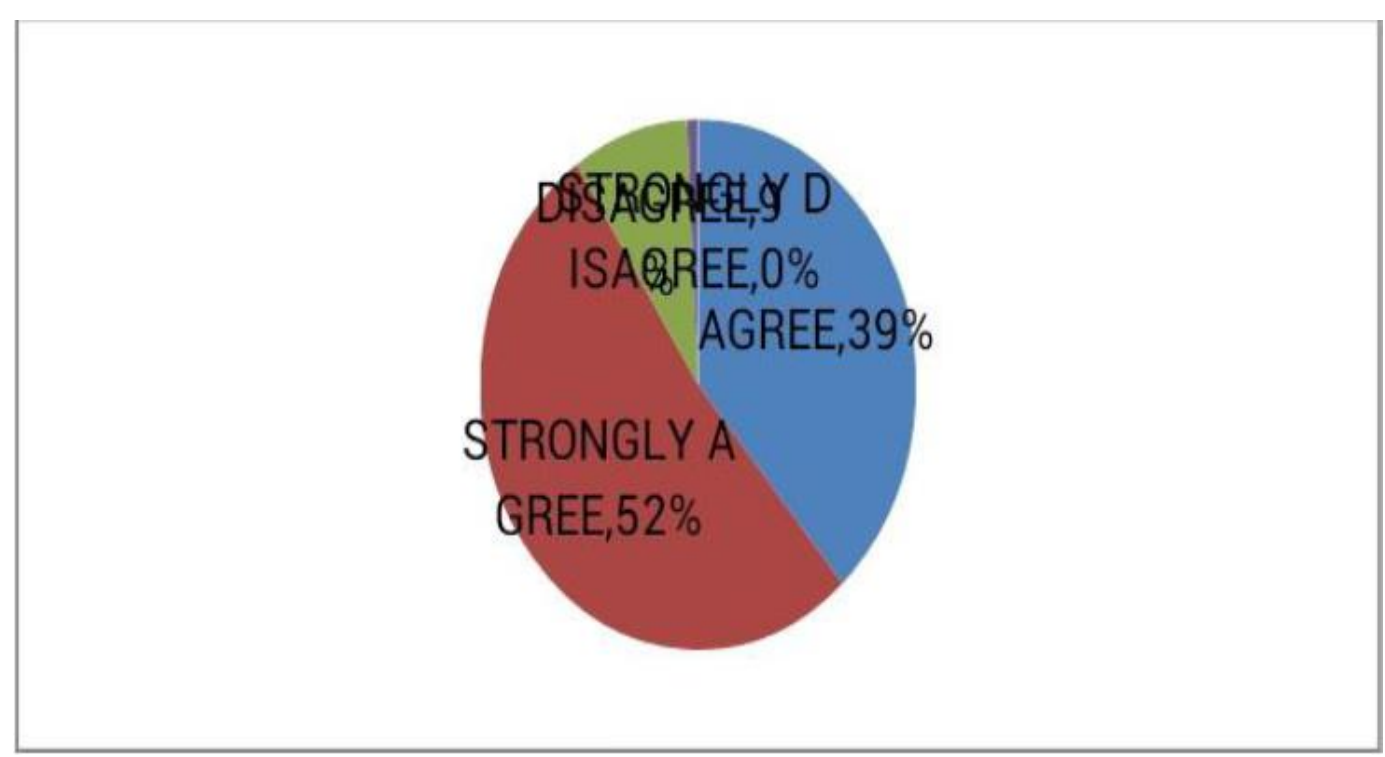

Figure 5. Percent Distribution of Whether Size of the Water Reservoirs Affected the Amount of Water Stored in Order to Meet the Demand During the Peak Periods

Table 2. Percent Distribution of Demographic Characteristics of Respondents

\begin{tabular}{|l|l|l|}
\hline Characteristics & Count & Percent \\
\hline Age Group & \multicolumn{2}{|l|}{} \\
\hline $15-19$ & 46 & 11.6 \\
\hline $20-24$ & 59 & 14.9 \\
\hline $25-29$ & 54 & 13.6 \\
\hline $30-34$ & 65 & 16.4 \\
\hline $35-39$ & 47 & 11.8 \\
\hline $40-44$ & 36 & 9.1 \\
\hline $45-49$ & 24 & 6 \\
\hline $50-54$ & 15 & 3.8 \\
\hline $55-59$ & 9 & 2.3 \\
\hline $60-64$ & 22 & 5.5 \\
\hline $65-69$ & 9 & 2.3 \\
\hline
\end{tabular}




\begin{tabular}{|l|l|l|}
\hline $70-74$ & 9 & 2.3 \\
\hline $75-79$ & 1 & 0.3 \\
\hline $80-84$ & 1 & 0.3 \\
\hline Sex & \multicolumn{3}{|l|}{} \\
\hline Male & 82 & 20.7 \\
\hline Female & 315 & 79.3 \\
\hline Marital Status \\
\hline Single & 85 & 21.4 \\
\hline Married & 252 & 63.4 \\
\hline Separated & 11 & 2.8 \\
\hline Divorced & 7 & 1.8 \\
\hline Widowed & 42 & 10.6 \\
\hline Head of Household \\
\hline Male Adult & 325 & 81.8 \\
\hline Female Adult & 71 & 17.9 \\
\hline Child headed & 1 & 0.3 \\
\hline Total & $\mathbf{3 9 7}$ & $\mathbf{1 0 0}$ \\
\hline
\end{tabular}

Table 3. Percent Distribution of Sources of Water for Domestic use in Chazanga

\begin{tabular}{|l|l|l|}
\hline Source & Count & Percent \\
\hline Communal tap & 333 & 83.9 \\
\hline River/stream & 1 & 0.3 \\
\hline Shallow well & 5 & 1.3 \\
\hline Borehole & 3 & 0.8 \\
\hline Other & 55 & 13.9 \\
\hline Total & $\mathbf{3 9 7}$ & $\mathbf{1 0 0}$ \\
\hline
\end{tabular}

Table 4. Percent Distribution of Litres of Water used in a Day by Households

\begin{tabular}{|l|l|l|}
\hline Litres & Count & Percent \\
\hline 20 & 17 & 4.3 \\
\hline 60 & 175 & 44.1 \\
\hline 100 & 168 & 42.3 \\
\hline 200 & 23 & 5.8 \\
\hline Above 200 & 14 & 3.5 \\
\hline Total & $\mathbf{3 9 7}$ & $\mathbf{1 0 0}$ \\
\hline
\end{tabular}

Table 5. Percent Distribution of Litres of Water Drawn from the Source per Day by Respondents

\begin{tabular}{|l|l|l|}
\hline Litres & Count & Percent \\
\hline 20 & 26 & 6.5 \\
\hline 60 & 111 & 28 \\
\hline 100 & 162 & 40.8 \\
\hline 200 & 73 & 18.4 \\
\hline Above 200 & 25 & 6.3 \\
\hline Total & $\mathbf{3 9 7}$ & $\mathbf{1 0 0}$ \\
\hline
\end{tabular}


Table 6. Percent Distribution of where the Respondents Drew Water from if they Experienced Erratic Water Supply

\begin{tabular}{|l|l|l|}
\hline Water Source & Count & Percent \\
\hline River/stream & 3 & 0.8 \\
\hline Shallow well & 302 & 76.8 \\
\hline Borehole & 67 & 17 \\
\hline Ask from neighbours & 16 & 4.1 \\
\hline Other & 5 & 1.3 \\
\hline Total & $\mathbf{3 9 4}$ & $\mathbf{1 0 0}$ \\
\hline
\end{tabular}

Table 7. Percent Distribution of Diseases that Could Come due to Erratic Water Supply

\begin{tabular}{|l|l|l|}
\hline Diseases & Count & Percent \\
\hline Diarrhoea & 196 & 49.4 \\
\hline Cholera & 71 & 17.9 \\
\hline Malaria & 42 & 10.6 \\
\hline Coughing & 2 & 0.5 \\
\hline Eye problems & 2 & 0.5 \\
\hline Typhoid & 19 & 4.8 \\
\hline Cholera and Diarrhoea & 61 & 15.4 \\
\hline Don't know & 4 & 1 \\
\hline Total & $\mathbf{3 9 7}$ & $\mathbf{1 0 0}$ \\
\hline
\end{tabular}

Table 8. Percent Distribution of the Likely Causes of Erratic Water Supply in Chazanga Compound

\begin{tabular}{|l|l|l|}
\hline Causes of Erratic Water Supply & Count & Percent \\
\hline Few boreholes & 40 & 10.1 \\
\hline High demand for water by a growing population & 33 & 8.3 \\
\hline The land is high hence no water due to low pressure & 5 & 1.3 \\
\hline Leakages in pipes & 30 & 7.5 \\
\hline Small water distribution pipes & 11 & 2.7 \\
\hline Water is costly & 2 & 0.5 \\
\hline Few communal taps & 34 & 8.6 \\
\hline Load shading affects water supply & 71 & 17.8 \\
\hline Negligence by government & 1 & 0.3 \\
\hline Few tanks & 136 & 34.3 \\
\hline Poor management by water suppliers & 30 & 7.6 \\
\hline Don't know & 4 & 1 \\
\hline Total & $\mathbf{3 9 7}$ & $\mathbf{1 0 0}$ \\
\hline
\end{tabular}

Table 9. Percent Distribution of What Should be Done to Improve the Water Supply in Chazanga.

\begin{tabular}{|l|l|l|}
\hline Possible Interventions & Count & Percent \\
\hline Sink more boreholes & 84 & 21.2 \\
\hline Repair the leakages in the water pipes & 11 & 2.8 \\
\hline Erect more water tanks & 187 & 47.1 \\
\hline Put bigger water distribution pipes & 21 & 5.3 \\
\hline Construct more communal taps & 66 & 16.6 \\
\hline $\begin{array}{l}\text { Find alternative source of power for } \\
\text { water pumps }\end{array}$ & 7 & 1.7 \\
\hline $\begin{array}{l}\text { Improve management by water } \\
\text { distributors }\end{array}$ & 21 & 5.3 \\
\hline Total & $\mathbf{3 9 7}$ & $\mathbf{1 0 0}$ \\
\hline
\end{tabular}


Table 10. Respondents who Experienced Erratic Water Supply and the Factors Contributing to Erratic Water Supply

\begin{tabular}{|l|l|l|l|l|l|}
\hline \multirow{2}{*}{ Factors } & \multicolumn{3}{l}{ Erratic Water Supply (N=397) } \\
\cline { 2 - 5 } & Yes & No & \multicolumn{2}{l|}{ sig (2 sided) } \\
\hline Number of Boreholes & $99.2 \%$ & $0.8 \%$ & & \\
\hline Agree & $99.3 \%$ & $0.7 \%$ & 0.919 & \\
\hline Strongly Agree & $98.5 \%$ & $1.5 \%$ & & \\
\hline Disagree & $100 \%$ & $0 \%$ & & \\
\hline Strongly Disagree & $98.4 \%$ & $1.6 \%$ & & \\
\hline Daily Yield from Boreholes & $99.3 \%$ & $0.7 \%$ & 0.878 & \\
\hline Agree & $99.2 \%$ & $0.8 \%$ & & \\
\hline Strongly Agree & $100 \%$ & $0 \%$ & & \\
\hline Disagree & $99.0 \%$ & $1 \%$ & & \\
\hline Strongly Disagree & $99.3 \%$ & $0.7 \%$ & 0.023 & $*$ \\
\hline Leakages from Pipes & $88.9 \%$ & $11.1 \%$ & & \\
\hline Agree & $99.0 \%$ & $1 \%$ & & \\
\hline Strongly Agree & & \multicolumn{2}{|l|}{} \\
\hline Disagree & $98.0 \%$ & $2 \%$ & & \\
\hline Strongly Disagree & $99.5 \%$ & $0.5 \%$ & 0.505 & \\
\hline Size of Water Reservoirs & $100 \%$ & $0 \%$ & & \\
\hline Agree & $100 \%$ & $0 \%$ & & \\
\hline Strongly Agree & &
\end{tabular}

$P$-value in parenthesis $* p<0.05$

\section{Discussion}

This research aimed to identify the factors contributing to the erratic water supply in Chazanga compound. The research identified factors affecting the supply of water to the compound. This section discusses the findings.

The Millennium Development Goals (MDG's) were agreed upon by the international community in 2000 with access to safe drinking water as one of the 18 objectives. By and large it had shown that water played a critical role in achieving all the MDG's and thus placing it at the centre. In Zambia, though significant progress was reported, achievement of the MDGs by 2015, particularly in Rural and PeriUrban areas was unlikely [9].

Environmental Council of Zambia, states that [10] increase in the population of Zambia especially in urban areas led to problems of accessing sufficient clean water supply. Lusaka province had an approximate population of over 3 million, which was mainly concentrated in the unplanned settlements or peri-urban areas (11). This increase in population in peri-urban areas like Chazanga compound led to increased demand for water supply, thereby introducing serious shortages which were further associated with adverse effects.

The research showed that there were varied reasons of why there was an inadequate supply of water in Chazanga compound. Overall, of all the sample of 397, 99 percent had experienced erratic water supply, while only 1 percent had not experienced erratic water supply over the past few months. The research also showed that most of the respondents drew water from communal taps, followed by other sources of water such their own taps, their neighbours' taps. The least sources of water for domestic use are shallow wells, boreholes, and rivers.

The research further reveals that most of the respondents used about 60 litres of water per day, followed by households who used about 100 litres of water. The minority of the households used about 200 litres, 20 litres and above 200 litres per day, respectively. This showed that the WHO recommended average water use for drinking, cooking and personal hygiene in any household of at least 20 litres per person per day was not being observed. Many of the respondents drew about 100 litres of water 
from the source per day, and the minority of the respondents said they drew above 200 litres of water from the source.

The respondents who had experienced erratic water supply were then further asked where they drew water. From the respondents who had experienced erratic water supply, the majority got water from a shallow well followed by water drawn from boreholes. Thirdly, respondents asked their neighbours if they could draw water from their home and water from other sources such as a nearby clinic. The minority got water from a river/stream.

Water quality and quantity was an important component to health. For instance, water-borne diseases like cholera spread very fast and affected many parts of the country [10]. The research showed that respondents said that diseases that would come due to lack of inadequate water in order of responses were diarrhoea, cholera, malaria, typhoid fever, eye problems and cough.

When asked about what caused the erratic water supply in Chazanga compound, the results from the research revealed that most of the respondents said having a few tanks caused erratic water supply followed by load shading and few boreholes then, few communal taps. The rest of the respondents said the high demand for water coupled with a growing population, poor water management from suppliers, leakages in water distribution pipes, and small water distribution pipes. The minority of the respondents said the land was too high, hence no water due to low pressure. Others said water was costly and there was negligence by government. On the other hand, only 1 percent of the respondents did not have any knowledge of what caused the erratic water supply in the compound.

The World Bank Report on upgrading of lowincome urban settlements in Lusaka put it clear that water supply from available boreholes was inadequate due to the high population growth that had exceeded the projected demand for water in the peri-urban compounds of Lusaka. However, the study revealed that the number of available boreholes was not statistically related to the erratic water supply in Chazanga compound. All the respondents who had experienced erratic water supply strongly disagreed that the number of boreholes contributed to the erratic water supply. Therefore, the hypothesis that the number of boreholes was not related to the amount of water supplied to the compound holds.

The respondents were further asked if the daily yield from boreholes affected the amount of water supplied to the compound. The study showed that there was no statistical relationship between the daily water yield from boreholes and the erratic supply of water. The hypothesis that the daily yield of water does not significantly affect the amount of water supplied to people also holds.

According to Nyambe and Feilberg [9] the challenges faced in provision of water were high levels of production cost, vandalism of infrastructure and run-down water distribution pipes. For most of the utility water companies in Zambia, there was a reliance on infrastructure that is 30 years old on average. Whereas water conservation was paramount when systems were new, over the years much of this infrastructure deteriorated due to untimely and lack of maintenance. The study showed that leakages from water distribution pipes were significantly related to the erratic supply of water. Based on the findings, the hypothesis that leakages from water distribution pipes do not affect the amount of water supplied was rejected.

Additionally, the study showed that the size of the water reservoirs and the erratic water supply to the compound were not statistically significant. Hence the hypothesis that size of the water reservoir does not significantly affect the erratic supply of water holds.

Finally, when asked on what should be done to improve the supply of water to the compound, respondents gave various recommendations which include; Sink more boreholes, repair the leakages in the distribution pipes, erect more water tanks, fit bigger distribution pipes, construct more communal taps, find an alternative source of power for the water tank and improve the management of water supply by the water suppliers.

In summary the water problems faced by the people in Chazanga compound were extensive and might have adverse effects on the wellbeing of the population in this area. There was, therefore, need for immediate improvements in the water supply to the compound.

The areas that require further research in future are the cost effectiveness of running communal taps against individual household taps; the quality of water in Chazanga compound 
in relation to the waterborne diseases reported at Chazanga clinic; people's attitude towards protecting the water infrastructure from vandalism; impact of effective management by water utility companies in customer satisfaction; and factor hindering full compliance in cost sharing by households in water supply service provision.

\section{Conclusion}

The study was conducted to establish factors contributing to erratic water supply in peri-urban areas, a case study of Chazanga compound of Lusaka district. The study looked at the aspects of available number of water sources, daily water yield, state of repair of water distribution pipes and the size of the water reservoir. The major problem was the erratic water supply in Chazanga compound.

To achieve this, a questionnaire was used to generate data. This was administered to 397 households who were randomly selected. The generated data was later analyzed using the Statistical Package for the Social Sciences (SPSS) for association of factors and the outcomes.

\section{References}

[1] United Nations (2012) Millennium Development Goals Report.

[2] Aster. N (2013) The Problems and Solutions to Safe Water in Africa: United Kingdom.

[3] United Nations (1992) International Conference on Water and the Environment. Dublin, Ireland.

[4] FAO (2013) Zambia UN-Water Country Brief. Zambia.

[5] Howard G and Bartram J (2003) Domestic Water Quantity, Service Level and Health: Geneva. WHO.

[6] MSF (2010) Lusaka's annual cholera disaster: Practical steps for a more effective response. Lusaka. [7] Rukunga G.K (2001) Environmental Health for East Africa. Nairobi: African Medical and Research Foundation.

[8] Lusaka DHMT (2012) Environmental Health Report on Typhoid outbreak in Mtendere east. Lusaka: HMIS.

[9] Nyambe. I and Feilberg. M. (2010). Zambia National Water Resources Report for WWDR3. Ministry of Energy and Water Development. Lusaka. [10]ECZ. (2008) Zambia Environmental Outlook Report 3. Environmental Council of Zambia. Lusaka.
The results of this study revealed interesting issues on the supply of water in Chazanga compound. The problem of erratic water supply was real, and the research revealed other factors other than those in the conceptual framework. Among the other factors were poor management by the water supplier, high demand due to population growth and high cost of water. This erratic water supply in the Chazanga made resident resort to drawing water from unsafe water sources such as shallow wells resulting increase in diarrhea cases reported at Chazanga clinic.

The study results also revealed that to avert the erratic water supply, Chazanga water trust will need to repair all leaking water distribution pipes, sink more boreholes, and erect a bigger water reservoir. The other recommendations were to fit bigger distribution pipes, construct more communal taps, find an alternative source of power for the water tank and improve the management of water supply by the water suppliers.

[11] Mulenga M and Gordon M (2011) Report on ground water self-supply in peri urban settlements of Zambia. Lusaka.

[12]Deming. D (2002) Introduction to Hydrogeology. New York: McGraw-Hill Companies Inc.

[13] Insel P.M and Roth W. T (2001) Core Concepts in Health $\left(9^{\text {th }} E d\right)$. USA: McGraw-Hill Companies Inc.

[14]NWASCO (2005) Urban and Peri-urban Water Supply and Sanitation Sector Report. Lusaka: NWASCO.

[15]Lusaka District Health Management Team (2004) Cholera control guidelines. Lusaka: JICA

[16] Schaefer W (1992) Public Health Engineering. Lusaka, Zambia: UNZA.

[17] World Bank (2002) Report on Upgrading of Low-Income Urban Settlements in Lusaka. Lusaka: World Bank.

[18] Davies M.L and Masten S.J (2004) Principles of Environmental Engineering and Science. New York: McGraw-Hill Companies Inc.

[19] Gleick P.H (1996) Basic water requirements for human activities: meeting basic needs. Vol 21, No. 2: 
Oakland. Pacific Institute for studies in Development, Environment and security.

[20] Kauffmann C (2007) Access to Drinking Water and Sanitation in Africa; policy insight No. 41: Paris.

[21] Muwanei F.W (2007) Research paper on Factors that contribute to inadequate and unsatisfactory storage, collection and disposal of solid waste in Mtendere squatter settlement peri urban in Lusaka. Lusaka. 


\title{
Appraisal of Nature of Capacity Building Programs of HIV/AIDS Supply Chain Workforce in Nigeria
}

\author{
Sunday O Aguora ${ }^{1 *}$, Azuka C Oparah ${ }^{2}$, Edith C Okechukwu ${ }^{1}$, Jeffrey S Soni ${ }^{2}$ \\ ${ }^{1}$ School of Public Health, Texila American University, Georgetown, Guyana, South America \\ ${ }^{2}$ Department of Pharmacy and Pharmacy Practice, Faculty of Pharmacy, University of \\ Benin, Benin City, Nigeria
}

\begin{abstract}
This study on appraisal of nature of capacity building programs of HIV/AIDS supply chain workforce in Nigeria involved cross-sectional observational design. A pre-tested self-completion structured questionnaire was administered to 422 participants drawn from HIV/AIDS supply chain workforce. The survey had a response rate of 396(93.8\%). The reliability statistics showed the questionnaire is reliable for nature of capacity building programs, Cronbach alpha $(\alpha=0.886)$. Onthe-job training was the most predominant capacity building approach, while task shifting and fellowship program were the least used. The study revealed nature of capacity building of HIVIAIDS supply chain workforce comprised of on-the-job training, short courses, residential training, fieldbased, work-based, in-service, pre-service and e-learning trainings as leading strategies and excellent in strengthening HIV/AIDS supply chain workforce capacity, mean \pm standard deviation score (3.774 \pm 0.9882) on a Likert scale of 1-5 (5-point scale). Others included collaboration, university-based model, mentorship, task shifting and fellowship program. Inferential statistics revealed that Managers and Directors with postgraduate qualification have more benefit from the capacity building programs $(p<0.05)$. Whilst age, sex and years of experience have no effect on the capacity building programs of HIV/AIDS supply chain workforce $(p>0.05)$. Chi-square statistic revealed that nature of capacity building program is a significant factor of HIV/AIDS supply chain workforce capacity $(p<0.05)$. Effective capacity building programs are central to the improvement of HIV/AIDS supply chain systems and responsiveness.
\end{abstract}

Keywords: Capacity building, HIV/AIDS, supply chain, workforce.

\section{Introduction}

The importance of building the capacity of workforce as part of strengthening health systems and ensuring sustainability cannot be overemphasized [1]. Workforce capacity can be developed through formal and informal programs to ensure availability of skills to provide quality health services [2]. Recognizable approaches for capacity development in supply chain management to ensure availability of skilled workforce include; pre-service, in-service, residential, onsite, fieldbased, work-based, on-the-job, distance learning, e-learning, mentorship, short courses, task shifting, face-to-face learning, blended learning, fellowship program, outsourcing, establishing logistics management units (LMUs), developing incentives, creating accreditation and strengthening policy $[3,4,5$, $6,7,8,9]$.

Some of the vital impacts of capacity building programs in Nigeria and other countries include; long-term availability of skills in-country crucial for success and sustainability of HIV/AIDS program in Nigeria [5]; improved access to safe, effective and quality-assured medicines for the treatment of HIV/AIDS, Tuberculosis and Malaria in the East African region [10]; enhanced workforce skills, health system performance and evidencebase for policies, programs and practice resulting in better control of communicable diseases in Australia [3]; boosted leadership and management capacity for HIV/AIDS program in Zimbabwe, Ethiopia, Iran, Egypt, Liberia and Uganda $[2,11,12,13,14,15,16$, 17]; better skills in pharmaceutical supply 
management in East Africa [18]; health facility management skills essential for long-term health systems strengthening in Liberia [17] and advanced institutional and workforce capacity to provide quality health services [2].

Nigeria's health sector has particularly experienced a number of other lingering crises in recent times [19, 20]. It has been reported that lack of adequate health workforce in Nigeria to potentially meet increased demand have also contributed to non-implementation of National Health Insurance Scheme (NHIS) at the state and local government levels [21]. Other actions that might be required to strengthen the supply chain workforce may be implemented as part of broader health workforce policies and include improving public sector pay and incentives [22]; creating rural pipelines to education and training to ease education and deployment in under-served areas [23]; improving education strategies to adapt content and modalities of training to current and emerging health system needs [24] and more delegation of tasks to cadres with shorter training [25].

While capacity building has been well developed in the private or for-profit business sector, it remains less well-defined in the public, non-profit and social sectors in low- and middle-income countries [1]. Often capacity building has resulted in disempowerment of local organizations rather than promoting local ownership and sustainability [1]. This study unlike others will strengthen existing literature on workforce capacity development and reduce the gap in knowledge applying to HIV/AIDS supply chain workforce. It will help the Federal and State Ministries of Health to determine a procedure for strengthening human resources in health supply chains.

In spite of the huge expenditure of millions of dollars, there have not been rigorous evaluations of capacity building efforts [1]. It is important that a firm evidence-base should be established concerning strategies that work and what doesn't work to build capacity before additional investments are made [1]. This will ensure that each country is better equipped to adopt and adapt the lessons learned from every other nation and shared learning would be greatly assisted by a global repository of evidence on health system performance [26]. This type of evidence is a global public good.
Therefore, it is important to first conduct health system assessments, analyze challenges to health system strengthening success, prioritize addressing challenges, and implement appropriate activities to build new capacity in overcoming challenges.

Therefore, the present study seeks to assess nature of capacity building programs of HIV/AIDS supply chain workforce in Nigeria.

\section{Methods}

\section{Selection of the Area}

This study was conducted in Abuja, the administrative centre of Nigeria. Abuja has six Area Councils and common boundary to the north with Kaduna State, to the west with Niger State, to east and south-east with Nassarawa State and to the south-west with Kogi State [27]. Abuja is a city ("Centre of Unity") and became the capital of Nigeria on December 12, 1991. Most of the HIV/AIDS organizations have their offices in Abuja from where they carry out their supply chain functions around the country.

\section{Sample Size Determination}

The representative sample size for the infinite population was calculated using Cochran's formula $\left(\mathrm{n}_{0}=\mathrm{z}^{2} \mathrm{pq} / \mathrm{e}^{2}\right)$ [28].

$\mathrm{n}_{0}=$ sample size

$\mathrm{z}=1.96$ (selected critical value of desired confidence level)

$\mathrm{p}=0.5$ (assuming the maximum variability, which is equal to $50 \%$ )

$$
q=1-\mathrm{p}
$$

$\mathrm{e}=0.05( \pm 5 \%$ desired level of precision at $95 \%$ confidence level)

$\mathrm{n}_{0}=(1.96)^{2}(0.5)(0.5) /(0.05)^{2}$

$\mathrm{n}_{0}=384.16$

To the calculated sample size, $10 \%$ overage was added to provide for drop out, nonresponse, incomplete response and late response. This ensured minimum response rate for the study.

\section{Sampling Technique}

HIV/AIDS supply chain workforce (422) from public sector, private sector, nongovernmental organization, faith-based organization and donor agency, minimum of bachelor's degree qualification and two (2) years in their organization, signed consent form and not a participant in the pilot without gender 
discrimination were selected using random sampling technique. The study excluded other supply chain workforce, HIV/AIDS supply chain workforce less than two (2) years in their organization, without at least bachelor's degree qualification, those that participated in pilot and declined to sign consent form.

\section{Data Collection}

Cross-sectional observational design was employed and comprised of two sources of data, namely primary and secondary sources of data. The primary sources of data were those collected from the field through a selfcompletion structured questionnaire. Secondary data were from published literature sources. The purpose of the study and questionnaire were explained to the participants. Participants read and signed the consent form before joining the study. Participants were informed they could withdraw at any point from the study without consequences. Identity of participants was kept anonymous and confidential by excluding all identifiers. The questionnaire had twenty (20) questions with which relevant information in the area of socio-demographic characteristics and nature of capacity building programs of HIV/AIDS supply chain workforce were obtained. The questionnaire was pretested with volunteers similar to expected participants to ascertain its effectiveness and suitability. Pre-testing of the questionnaire was done with 38 participants $(10 \%$ of the calculated sample size). After the pretest, amendments were made in the light of lessons learned.

The questionnaire required about fifteen (15) minutes to complete. Construct validity was ensured by fashioning the questionnaire based on relevant literatures and empirical studies. Content validity was ensured by modifying the questionnaire based on the results of the supervisor's review and pre-test. Social response bias was safeguarded as participants were allowed to complete and return the questionnaire on a later date, and not necessarily in the presence of the researcher. Ethical approval to carry out the study was granted by National Health Research Ethics Committee of Nigeria (NHREC).

\section{Data Analysis}

Data obtained were coded and analyzed using Statistical Package for Social Sciences (SPSS) version 22 (SPSS Inc., Chicago, Illinois, USA) for descriptive statistics. Items within each domain were summarized using descriptive statistics such as mean and standard deviation. Two-sided independent student's ttest and one-way analysis of variance (ANOVA) were used to compare means across groups with the aid of GraphPad Instant version 3 for inferential statistics, P-values set at $\mathrm{p}<0.05$. The negative response was $<2.5$ while positive response was $>2.5$. Chi-square statistic was used to determine the level of relationship at $5 \%$ level of significance ( $\mathrm{p} \leq 0.05)$.

\section{Results and Discussion}

The survey had a response rate of 396 (93.8\%). Table (1) socio-demographic characteristics, with most of the participants $328(82.9 \%)$ between the age 30 and 49 years. More of male participants 275 (69.4\%) and participant's years of experience in HIV/AIDS supply chain $345(87.1 \%)$ between 4 and 15 years. Majority $294(74.2 \%)$ in the rank of manager, supervisor, specialist, advisor and officer. More than half $221(55.8 \%)$ had a master's degree. Table (2) percentage frequency of nature of capacity building programs, Table (3) reliability analysis of nature of capacity building programs, Table (4) effect of socio-demographic characteristics on nature of capacity building programs and Table (5) Chi-square tests.

The participants have substantial experience with good understanding of capacity building strategies of HIV/AIDS supply chain workforce, and their opinion can be trusted for quality research outcomes. The respondents have an attained ample level of skill with over half of them with master's degree qualification and played key roles in strengthening capacity of HIV/AIDS supply chain workforce. They have practical knowledge of effective capacity building strategies and basic background required for supply chain functions.

The study revealed that on-the-job training is the predominant strategy in HIV/AIDS supply 
chain workforce capacity building programs. This is followed by short courses and jointly residential, field-based, work-based, in-service, pre-service and e-learning trainings. Collaboration among stakeholders, universitybased model and mentorship on real work situation and task shifting are in less use while fellowship training program seemed the least used strategy. The outcome of the present study suggests that the various capacity building strategies can be a useful model for strengthening human resources in HIV/AIDS supply chain for improved health service delivery and agrees with previously reported approaches for capacity development in supply chain management [4]. This is in addition to outsourcing, establishing logistics management units (LMUs), developing incentives, creating accreditation and strengthening policy [4]. Similar approaches have been used to strengthen health workforce capacity in other countries including The Gambia, Nicaragua and Liberia [2]. It is worth noting that some capacity building strategies have been implemented to ensure long-term availability of skills in different countries with positive results such as, on-site and off-site training in South Africa [29], collaboration among stakeholders in Uganda, Kenya, Tanzania and Rwanda [18], on-the-job training and short courses in Uganda, Kenya, Tanzania and Rwanda [10], mentorship on real work situation in Uganda [30], field-based training in Australia [3], skills transfer in Liberia [17], fellowship training program in Uganda [2], work-based/ hands-on training in Uganda [2], in-service, pre-service and e-learning training in Nigeria [5]. Furthermore, it has been reported that fellowship program does not yield quick returns but are critical in building longer-term capacities needed to address HIV/AIDS in coming generations [31].

The study further agreed with previous studies $[10,14]$ that skill building approaches/activities that do not take workers away from their places of work for long periods such as on-the-job training and short courses/incountry workshops with regular follow-up were effective and preferred modes of capacity building in Iran and East African countries, respectively. Effective capacity building program will guarantee improved capacity of workforces to ensure a reliable supply chain for HIV/AIDS program [32]. Workforces plays a vital role in supply chain management, thus improving their capacities would result in improved quality of HIV/AIDS services. It can be assumed that appropriate capacity building strategy equips workforce with skills that make them more efficient and productive. Welltrained supply chain workforce often has higher motivation and morale leading to lower turnover rates, more confident as well as aware of the expectations and work better than teams, more likely to accept change and take initiatives [33]. Skilled workforce is equipped to train other employees, thus reduces pressure on the management team. Similarly, it has been suggested that training is not a panacea and lack of frequent training is not necessarily the cause of under-performance, as the problem may not be the type solved by training [34].

The mean \pm standard deviation score $(3.774$ \pm 0.9882 ) for the nature of capacity building programs indicates that existing methods are excellent in strengthening workforce capacity. Factor loading (0.674-0.968) is good and entails all mean components are added to the summation. Cronbach's alpha, $\alpha=0.886$ showed the questionnaire is reliable.

Inferential statistics revealed that sociodemographic characteristics such as educational qualification and job title/rank have an effect on the nature of capacity building programs $(\mathrm{P}<0.05)$. Those in the rank of Managers and Directors with postgraduate qualification have more benefit from the capacity building programs. However, age, sex and years of experience have no effect on the capacity building programs of HIV/AIDS supply chain workforce.

Chi-square statistic was carried out to determine the level of relationship at 5\% level of significance $(\mathrm{P}<0.05)$ and there is a relationship between nature of capacity building programs and HIV/AIDS supply chain workforce capacity. It revealed that nature of capacity building programs is a significant factor of HIV/AIDS supply chain workforce capacity. 
Table 1. Socio-demographic Characteristics of HIV/AIDS Supply Chain Workforce (N=396)

\begin{tabular}{|c|c|c|}
\hline Socio-demographic Characteristics & Categorization & Number $(\%)$ \\
\hline \multirow{5}{*}{ Age (Years) } & $30-39$ & $121(30.6)$ \\
\hline & $40-49$ & $207(52.3)$ \\
\hline & $50-59$ & $52(13.1)$ \\
\hline & $\geq 60$ & $16(4.0)$ \\
\hline & Total & $396(100.0)$ \\
\hline \multirow[t]{3}{*}{ Gender } & Female & $121(30.6)$ \\
\hline & Male & $275(69.4)$ \\
\hline & Total & $396(100.0)$ \\
\hline \multirow[t]{6}{*}{ Years of Experience (years) } & $0-3$ & $34(8.6)$ \\
\hline & $4-7$ & $104(26.3)$ \\
\hline & $8-11$ & $138(34.8)$ \\
\hline & $12-15$ & $103(26.0)$ \\
\hline & $\geq 16$ & $17(4.3)$ \\
\hline & Total & $396(100.0)$ \\
\hline \multirow[t]{5}{*}{ Job Title } & Director & $68(17.2)$ \\
\hline & Associate/Assistant Director & $34(8.6)$ \\
\hline & Manager/Supervisor & $156(39.4)$ \\
\hline & Specialist/Advisor/Officer & $138(34.8)$ \\
\hline & Total & $396(100.0)$ \\
\hline \multirow[t]{6}{*}{ Highest Educational Qualification } & Bachelor's Degree & $119(30.1)$ \\
\hline & Postgraduate Diploma & $14(3.5)$ \\
\hline & Fellowship & $35(8.8)$ \\
\hline & Master's Degree & $221(55.8)$ \\
\hline & Doctorate & $7(1.8)$ \\
\hline & Total & $396(100.0)$ \\
\hline
\end{tabular}

Table 2. Percentage Frequency of Nature of Capacity Building Programs of HIV/AIDS Supply Chain Workforce $(\mathrm{N}=396)$

\begin{tabular}{|c|c|}
\hline \multirow[t]{2}{*}{ Items } & Positive Responses \\
\hline & Frequency N (\%) \\
\hline \multicolumn{2}{|c|}{$\begin{array}{l}\text { Capacity building strategies being used in Nigeria HIV/AIDS supply chain } \\
\text { to ensure availability of skilled workforce to provide quality health services }\end{array}$} \\
\hline Residential training & $327(82.6)$ \\
\hline Fellowship training & $190(48.0)$ \\
\hline Mentorship on real work situation & $276(69.7)$ \\
\hline Field-based training & $327(82.6)$ \\
\hline Work-based training & $327(82.6)$ \\
\hline On-the-job training & $396(100.0)$ \\
\hline Short courses & $362(91.4)$ \\
\hline University-based model & $293(74.0)$ \\
\hline In-service training & $327(82.6)$ \\
\hline Pre-service training & $327(82.6)$ \\
\hline E-learning training & $328(82.8)$ \\
\hline Task shifting & $258(65.2)$ \\
\hline Collaboration among stakeholders & $310(78.3)$ \\
\hline
\end{tabular}

Positive responses $=$ Agree/ Strongly Agree 
Table 3. Reliability Analysis of Nature of Capacity Building Programs of HIV/AIDS Supply Chain Workforce $(\mathrm{N}=396)$

\begin{tabular}{|l|l|l|l|l|l|}
\hline Items & Mean & SD & Factor Loading & Cronbach's Alpha \\
\hline $\begin{array}{l}\text { Capacity building strategies being } \\
\text { availability of skilled workforce to provide quality health services }\end{array}$ \\
\hline Residential training & 3.833 & 0.9613 & 0.674 & $\mathbf{0 . 8 8 6}$ \\
\hline Fellowship training & 3.104 & 1.2855 & 0.783 & \\
\hline Mentorship on real work situation & 3.793 & 1.2478 & 0.865 & \\
\hline Field-based training & 3.747 & 1.0296 & 0.922 & \\
\hline Work-based training & 3.747 & 1.0296 & 0.922 & \\
\hline On-the-job training & 4.306 & 0.4612 & 0.837 & \\
\hline Short courses & 4.003 & 0.7204 & 0.911 & \\
\hline University-based model & 3.576 & 1.0963 & 0.878 & \\
\hline In-service training & 3.833 & 0.9154 & 0.968 & \\
\hline Pre-service training & 3.879 & 0.9469 & 0.965 & \\
\hline E-learning training & 3.967 & 0.9995 & 0.933 & \\
\hline Task shifting & 3.487 & 1.1351 & 0.848 & \\
\hline Collaboration among stakeholders & 3.790 & 1.0183 & 0.888 & \\
\hline Mean of mean \pm SD & $\mathbf{3 . 7 7 4}$ & $\mathbf{0 . 9 8 8 2}$ & & \\
\hline
\end{tabular}

Table 4. Effect of Socio-demographic Characteristics on Nature of Capacity Building Programs of HIV/AIDS Supply Chain Workforce $(\mathrm{N}=396)$

\begin{tabular}{|l|l|l|}
\hline Variables & N & Nature of Capacity Building \\
\hline Age & 121 & $3.704 \pm 0.9816$ \\
\hline Below 40 & 275 & $3.778 \pm 0.9561$ \\
\hline Above 40 & 0.4861 \\
\hline P-value & \multicolumn{2}{|l|}{} \\
\hline Sex & 275 & $3.768 \pm 0.9560$ \\
\hline Male & 121 & $3.728 \pm 0.9865$ \\
\hline Female & \multicolumn{2}{|l|}{0.7043} \\
\hline P-value & 138 & $3.683 \pm 0.9846$ \\
\hline Years of experience & 258 & $3.795 \pm 0.9517$ \\
\hline Below 8 & \multicolumn{2}{|l|}{0.2709} \\
\hline Above 8 & 119 & $3.671 \pm 0.6700$ \\
\hline P-value & 277 & $3.792 \pm 0.6301$ \\
\hline Highest Education & \multicolumn{2}{|l|}{} \\
\hline Bachelor's Degree & \multicolumn{2}{|l|}{} \\
\hline Postgraduate & \multicolumn{2}{|l|}{} \\
\hline P-value & $3.774 \pm 0.9556$ \\
\hline Job Titles & 138 & $3.522 \pm 0.9829$ \\
\hline Managers/Directors & 258 & $\mathbf{0 . 0 1 7 9}$ \\
\hline Specialists/Advisors & 138 \\
\hline P-value & &
\end{tabular}

Table 5. Relationship between Nature of Capacity Building Programs and HIV/AIDS Supply Chain Workforce Capacity $(\mathrm{N}=396)$

\begin{tabular}{|l|l|l|l|l|l|}
\hline $\begin{array}{l}\text { Nature of Capacity } \\
\text { Building Programs }\end{array}$ & Factors of Supply Chain Workforce Capacity & Total & $\chi^{2}$ & p-value \\
\cline { 2 - 5 } $\begin{array}{l}\text { Good Capacity } \\
\text { Building }\end{array}$ & $199(92.1)$ & $17(7.9)$ & $216(100.0)$ & 206 & 0.001 \\
\cline { 1 - 4 } $\begin{array}{l}\text { Poor Capacity } \\
\text { Building }\end{array}$ & $38(21.1)$ & $142(78.9)$ & $180(100.0)$ & \\
\hline
\end{tabular}




\section{Null Hypothesis (Ho)}

Nature of capacity building programs is not a significant factor of HIV/AIDS supply chain workforce capacity.

\section{Alternative Hypothesis (Ha)}

Nature of capacity building programs is a significant factor of HIV/AIDS supply chain workforce capacity.

\section{Conclusion}

The study revealed that nature of capacity building programs to improve capacity of HIV/AIDS supply chain workforce include onthe-job training, short courses, residential training, field-based, work-based, in-service, pre-service and e-learning trainings as leading strategies. Other strategies include

\section{References}

[1] Goldberg, J. and Bryant, M. (2012). Country ownership and capacity building: the next buzzwords in health systems strengthening or a truly new approach to development? BMC Public Health, 12:531-539.

[2] Matovu, J. K. B., Rhoda, K., Wanyenze, Susan Mawemuko, Olico Okui, William Bazeyo and David Serwadda (2013). Strengthening health workforce capacity through work-based training; $B M C$ International Health and Human Rights, 13:8.

[3] Patel, M. S. and Phillips, C. (2009). Strengthening field-based training in low and middle-income countries to build to build public health capacity: Lessons from Australia's Master of Applied Epidemiology program. Aust New Zeal Health Pol, 6:5. doi: 10.1186/1743-8462-6-5.

[4] Brossette, V., Silve, B., Grall, A., Bardy, K., Pilz, K., Dicko, M., and Gerberg, L. (2011). Workforce Excellence in Health Supply Chain Management: Literature Review, 1-21.

[5] Adekola, A. and Adelanwa, A. (2014). Developing the SCM workforce in Nigeria through contextualized preservice education and continued professional development. Journal of Pharmaceutical Policy and Practice, 7(Suppl 1): O22.

[6] Brown, A. and Sankaranarayanan, A. (2014). Human Resource Development in Supply Chain Management of Health Commodities - A realist review of UN sources, ISBN: ISBN: 978-1-74088410-5. 10.13140/RG.2.1.2365.1046. collaboration, university-based model, mentorship, task shifting and fellowship program. The strategies are believed to be cost effective, with minimal disruption, and can lead to practice change.

\section{Recommendations}

Federal and State Ministries of Health should ensure implementation of effective capacity building programs as they are central to the improvement of HIV/AIDS supply chain systems and responsiveness. Capacity building should be integrated with strengthening organizational structures, policies and processes that guide and drive supply chain services and essential research including funding, national and international partnerships.

[7] Kattoua, T., Al-Lozi, M. and Alrowwad, A. (2016). A Review of Literature on E-Learning Systems in Higher Education. International Journal of Business Management and Economic Research (IJBMER), 7(5):754-762.

[8] Ahadi, S. and Jacobs, R. L. (2017). A Review of the Literature on Structured On-the-Job Training and Directions for Future Research. Human Resource Development Review, 16(4):323-349.

[9] Nortvig, A. M., Petersen, A. K., and Balle, S. H. (2018). A Literature Review of the Factors Influencing E-Learning and Blended Learning in Relation to Learning Outcome, Student Satisfaction and Engagement. The Electronic Journal of $e$ Learning, 16(1):46-55.

[10]Waako, P., Odoi, R.., Obua, C., Owino, E., Tumwikirize, W., Ogwal-Okeng, J., Anokbonggo, W., Matowe, L., and Aupont, O. (2009). Existing capacity to manage pharmaceuticals and related commodities in East Africa: An assessment with specific reference to antiretroviral therapy, Human Resources for Health 7(1):21 DOI: 10.1186/14784491-7-21.

[11]Feldman, M. D., Huang, L., Guglielmo, B. J., Jordan, R., Kahn, J., Creasman, J. M., WienerKronish, J. P., Lee, K. A., Tehrani, A., Yaffe, K., and Brown, J. S. (2009). Training the next generation of research mentors: The University of Calfornia, San Francisco, Clinical \& Translational Science Institute Mentor Development Program. Clin. Transl. Sci. 2(3):216-221.

[12] Jones, D. S., Tshimanga, M., Worlk, G., Nsubuga, P., Sunderland, N. L., Hader, S. L., and St 
Louis, M. E. (2009). Increasing leadership capacity for HIV/ AIDS programs by strengthening public health epidemiology and management training in Zimbabwe. Hum Res Health, 7:69. doi:10.1186/1478-4491-7-69.

[13] McNabb, M. E., Hiner, C. A., Pfitzer, A., Abduljewad, Y., Nadew, M., Faltamo, P. and Anderson, J. (2009). Tracking working status of HIV/AIDS trained service providers by means of a training information monitoring system in Ethiopia. Hum Res Health, 7:29. doi:10.1186/1478-4491-7-29. [14] Omar, M., Tarin, E., Ashjael, K., Mirzoev, T. and Sheikh, M. R. (2007). In-country capacity development of a training institute: an Iranian experience. Journal of Health Organization Management, 21(6):519-532.

[15] Mansour, M., Mansour, J. B. and El Swesy, A. H. (2010). Scaling up proven public health interventions through a locally owned and sustained leadership development program in rural Upper Egypt. Hum Res Health, 8:1-5.

[16] Mukanga, D., Namusisi, O., Gitta, S. N., Pariyo, G., Tshimanga, M., Weaver, A. and Trostle, M. (2010). Field epidemiology training programs in Africa - where are the graduates? Hum Res Health, 8:18. doi: 10.1186/1478-4491-8-18.

[17] Rowe, L. A., Brillant, S. B., Cleveland, E., Dahn, B. T., Ramanadhan, S., Podesta, M. and Bradley, E. H. (2010). Building capacity in health facility management: guiding principles for skills transfer in Liberia. Human Resources for Health, 8:5. doi: 10.1186/1478-4491-8-5.

[18] Matowe, L., Waako, P., Odoi-adome, R., Kibwage, I., Minzi, O. and Bienvenu, E. (2008). A strategy to improve skills in pharmaceutical supply management in East Africa: the regional technical resource collaboration for pharmaceutical management. Human Resources for Health, 6:30. doi:10.1186/1478-4491-6-30.

[19]WHO (2016): Nigeria. In: Global Health Workforce Alliance. Geneva, Switzerland.

[20] Adeloye, D., David, R. A., Olaogun, A. A., Auta, A., Adesokan, A., Gadanya, M., Opele, J. K., Owagbemi, O., and Iseolorunkanmi, A. (2017). Health workforce and governance: the crisis in Nigeria, Human Resources for Health, 15:32 DOI 10.1186/s12960-017-0205-4.

[21] Okebukola, P. O. and Brieger, W. R. (2016). Providing universal health insurance coverage in Nigeria. Int Q Community Health Educ., 36(4):241246.

[22] McCoy D, Bennett S, Witter S, Pond B, Baker B, Gow J, Chand S, Ensor T, McPake B. (2008).
Salaries and incomes of health workers in subSaharan Africa. Lancet, 371(9613):675-681.

[23] Dolea, C., Stormont, L. and Braichet, J. (2010). Evaluated strategies to increase attraction and retention of health workers in remote and rural areas. Bull World Health Organ, 88(5):379-385.

[24]Frenk, J., Bhutta, Z. A., Chen, L. C., Cohen, J., Crisp, N., Evans, T., Fineberg, H. V. Garcia, P., Ke, Y., Kelley, P., Kistnasamy, B., Meleis, A., Naylor, D., Pablos-Mendez, A., Reddy, S., Scrimshaw, S., Sepulveda, J., Serwadda, D., Zurayk, H. (2010). Health professionals for a new century: transforming education to strengthen health systems in an interdependent world. The Lancet Commissions, 376 (9756):1923-1958.

[25]Foster, N. and McIntyre D. (2012). Economic evaluation of task-shifting approaches to the dispensing of anti-retroviral therapy. Hum Resour Health, 10(1):32.

[26] Reich MR, Takemi K, Roberts MJ, Hsiao WC. (2008). Global action on health systems: A proposal for the Toyako G8 summit. Lancet 371:865-869.

[27]Ebele, F.U., Aregbosola, B.G., Hasstrup, D.T. and Adams, E. (2014). The Effect of Climate Change on Agricultural Production among Farmers in Kwali Area Council of Federal Capital Territory of Nigeria. Advances in Social Sciences Research Journal, 1(2):13-26.

[28] Cochran, W.G. (1977). Sampling Techniques. 3rd Edition, John Wiley \& Sons, New York.

[29] Bergh, A. M., Van Rooyen, E. and Pattinson, R. C. (2008). Scaling up kangaroo mother care in South Africa: 'on-site versus 'off-site' educational facilitation. Hum Resour Health, 6: 13.doi: 10.11186/1478-4491-6-13.

[30] Starcevich, M. M. (2009). Coach mentor: is there a difference? CEO Center for Coaching and Mentoring, Inc. Available from: http://www.coachingandmentoring.com/Articles/me ntoring.html (accessed 13 December 2019).

[31] IOM (Institute of Medicine) (2011). Preparing for the Future of HIV/ AIDS in Africa: A Shared Responsibility. Washington, DC: The National Academies Press.

[32] IOM (Institute of Medicine). (2013). Evaluation of PEPFAR. Washington, DC: The National Academies Press.

[33] Devins, D., Johnson, S. and Sutherland J. (2012). Employee training benefits to small businesses. Journal of Small Business and Enterprise Development, 11: 4.

[34]Daniels, S. (2010). Employee training: a strategic approach to better return on investment. Journal of Business Strategy, 24(5):39-42. 


\title{
Determinants of Immunization Coverage and Associated Factors among Children aged under Two-Year-Old in the National Immunization Program of Mewat district, Haryana (2019-2020)
}

\author{
Vishesh Kumar \\ Doctor of Medicine, Texila American University, India
}

\begin{abstract}
Background: Vaccination against childhood communicable diseases through Expanded Program on Immunization is one of the most cost-effective public health interventions. Additional 1.5 million child deaths can be prevented if global vaccination coverage is improved. Mewat district has one of India's lowest immunization rates despite a long-standing Universal Immunization Program and continues to sustain a high prevalence of vaccine-preventable diseases. This study investigates determinants of immunization status among children aged 0-23 months. Methods: A community-based cross-sectional study was conducted from December 2019 to June 2020, among 800 children aged 023 months, randomly selected in one rural and one urban ward each from all 4 blocks of Mewat. Socio-demographic conditions and vaccine-related data were collected using a semi-structured questionnaire. Immunization was assessed by vaccination card and by mother's recall where the card was unavailable. Results:Mewat has increased full immunization coverage from 13.1\% in 2015-16 to 59.4\%. Immunization card was available with 68.5\% (292/426) beneficiaries. Dropout rates for Pentavalent1 to Pentavalent 3 was $27.5 \%$ and $54 \%$ for Bacillus Calmette-Guerin to measles. After adjusting for the state of residence, religion, gender, paternal education, health professional presence during birth, place of vaccination and knowledge of mother on due dose were significantly associated with full immunization. Awareness gap and fear of side effects for vaccines were main reasons of vaccine hesitancy. Conclusion: Full immunization coverage in the district is sub optimal and behind the desired coverage goal, mainly due to vaccine hesitancy. Enhancing community knowledge about the benefits of vaccination is recommended.
\end{abstract}

Keywords: Below two years children, immunization, reasons for partial immunization, drop out, full immunization.

\section{Introduction}

Vaccination against childhood communicable diseases through the Expanded Programme on immunization (EPI) is one of the most cost-effective public health interventions. Vaccination contributes substantially to the achievement of Sustainable Development Goals (SDGs) by reducing mortality and morbidity among children. Globally around $29 \%$ of under-five deaths were due to vaccine-preventable diseases (VPD) in 2017 as estimated by the United Nations interagency group for child mortality estimation [1]. India accounted for the highest number of under-five deaths globally in 2015 [2]. Routine immunization is the nation's strategic investment and an essential strategy for saving lives and protecting health of population.
The Global Vaccine Action Plan 2011-2020 (GVAP) was unanimously endorsed in 2012 by the World Health Assembly (WHA). Globally, 19.7 million children and $70 \%$ of whom were zero-dose children still remain unvaccinated with basic childhood vaccines in 2018 [3]. GVAP had put a goal to reach immunization coverage of at least $90 \%$ children in each nation and $80 \%$ in every district by 2020 . GVAP goals could potentially avert 25 million vaccinepreventable deaths by the end of the 2020 [4, 5].

India launched the Expanded Program on Immunization in 1978 and converted to the Universal Immunization Program (UIP) in 1985. It is one of the world's largest programs and currently catering to an annual cohort of 26.7 million infants and 30 million pregnant women. An estimated $38 \%$ of children still 
failed to receive all essential vaccines in their first year of life in 2016 in the country [6]. The Ministry of Health and Family Welfare Government of India launched Mission Indradhanush in December 2014 and Intensified Mission Indradhanush (IMI) in October 2017 with an aim to vaccinate all children under 2 years of age [7, 8].

Various national immunization surveys conducted from time to time had shown suboptimal vaccination coverage in Mewat district. The coverage had always been historically low as compared to the other districts of Haryana State. District Level Household and Facility Surveys-3 (DLHS-3) conducted in 2007-08 had $11.0 \%$ full vaccination (rural 9.6\%) and DLHS4 in 2012-13 had 27.3\% full vaccination (rural 20.8\%) [9]. National Family Health Survey-4 (NFHS-4) in 2015-16 had shown $13.1 \%$ full vaccination in Mewat (rural 11\%) [10].

Mewat district had been targeted for immunization intensification activities since December 2014 through Mission Indradhanush and Intensified Mission Indradhanush by the federal government with the goal of improving full vaccination to $90 \%$ within 5 years. To measure the impact of these immunization intensification campaigns, the Coverage Evaluation Survey (CES) was conducted by a government of India in 2018. This survey had shown that $22.5 \%$ of children did not receive any vaccine and full immunization coverage was $40.8 \%$ in Mewat [11]. Government of India had prepared a road map for achieving $90 \%$ full immunization coverage across the country in 2019 [12]. It is well recognized that national, state and district level immunization averages mask inequities in coverage, knowledge of which is essential to devise corrective strategies at the sub-districts level.

Mewat is one of the most socioeconomically backward district and mainly inhabited by Meo Muslims. They constitute $79.2 \%$ of the total population as per 2011 census. A high birth rate characterizes the district; most families have more than three to four living children in the study population. The proportion of beneficiaries for vaccination services were relatively higher, with infants and children below six years constituting $22.78 \%$ of the total population [13]. The majority $(89 \%)$ of the population is living in rural areas. The lack of literacy, public transport, inadequate health facilities, and a chronic shortage of potable water add immense difficulty to the masses and in particularly to the lives of ordinary women in Mewat [14]. The district had reported multiple diphtheria and measles outbreaks in 2018-19 as per the WHO-National Public Health Surveillance (NPSP) data. Mewat's large incompletely immunized susceptible cohort translates into increased risk for vaccinepreventable diseases, which partially explains the continued high burden of morbidity and mortality from such infections in children of this district. We assessed the routine immunization coverage in children below two years to determine the reasons for incomplete immunization in to identify areas for improvement.

\section{Materials and Methods}

\section{Study Area}

The study was conducted in urban and rura area of district Mewat (Haryana). Study design: It was community based cross-sectional study.

\section{Study Period}

Study was conducted from December 2019 to May 2020. Study population: The study included children aged between 0-23 months whose parents resided in the area for the last two years.

\section{Inclusion criteria}

1. Children aged between 0-23 completed months at time of study.

2. Children in the age group of 0-23 months whose parents were residing in the study area for a period of not less than two years.

3. Mothers/ Caregivers/Guardians who gave the consent for participation.

\section{Exclusion criteria}

1. Children in the age group of 0-23 months whose parents were residing in the study area for less than two years.

2. Parents who were not willing to participate in the study.

A community-based cross-sectional study was conducted from December 2019 to May 2020 in Mewat district. The study was conducted in all four blocks (Nuh, Ferozepur Jhirka, Punhana, and Taoru). A mixed-method design was adopted for the assessment, which was conducted in two stages. A complete list of 
villages in rural areas and wards in the Mewat district's urban areas was procured from the census department. From this sampling frame, randomly one rural and one urban ward areas were selected from each block.

\section{Sample Size Calculation for Quantitative Data Collection}

The sample size was calculated based on the proportion of partial and unimmunized children in Mewat from the latest available information of Intensified Mission Indradhanush-Coverage Evaluation Survey, 2018. The sample size was calculated using the following formula [15]:

$$
\mathrm{N}=[\operatorname{De} \times \mathrm{Z} 2 \times \mathrm{p}(1-\mathrm{p})] / \mathrm{d} 2
$$

Where $\mathrm{N}$ is the sample size, De (2) is the design effect, the ratio between the variance from the cluster design to the variance that was obtained from a simple random sampling, $\mathrm{Z}$ (1.96) is the certainty wanted to be expressed in the percentage point of the normal distribution corresponding to the 2-sided level of significant, $P(\sim 41 \%)$ is the immunization coverage of Mewat and d (5\%) is the desired width of the confidence interval.

Therefore,

$$
\mathrm{N}=\left[2 \times(1.96)^{2} \times 0.41 \times 0.59\right] /(0.05) 2=742 \text {. }
$$

A non-response rate of $8 \%$ was added for a total sample size of 800 .

In the second stage, households were surveyed for quantitative data collection. A simple random sampling (using the revolving pen technique) was used to select the first household for the survey in each selected village or ward. Every household with a child below two years was selected until the desired number of children were met from each selected village and urban ward. Information regarding 0-23 months children was recorded from selected households using an ODK tool, an Android-based tool. Mother/caregiver having at least one child aged 0-23 months were included, while those children whose mothers/caregivers were found to be mentally/critically ill during the data collection period were excluded from the study.

\section{Data Processing and Analysis}

For quantitative data collection, a structured questionnaire was administered to the key respondents. The questionnaire was designed on an android based ODK tool. The questionnaire mainly included immunization histories of children, mothers' sociodemographic characteristics, and knowledge of mothers on immunization. Information on vaccination coverage was collected in two ways: from the maternal and child protection (MCP) card or from the mother's/caregiver's verbal report. Data from MCP card was extracted in cases where a child immunization card was available. When there was no vaccination card for the child or if a vaccine had not been recorded on the card as being given, the mothers were asked to recall the specific vaccines given to their children. The information obtained from the child's card was taken when both conditions have been met. Before starting the actual data collection, the questionnaire was pretested on 5\% of similar respondents in a similar locality of adjoining Gurugram district, which was not included in the final study. All field staff and the principal investigator have assessed the clarity and completeness, consistency, accuracy of the data. The data were cleaned and entered EpiInfo 7 for further analysis.

An excel-based and EPI -Info 7 calculations worksheet was prepared for the analysis. Bivariate and multivariate logistic regression analyses were conducted along with adjusted Odds Ratios. In the bivariable analysis, independent variables significantly associated with the dependent variable at $\mathrm{p}$-value $<0.20$ were included in the multivariable logistic regression analysis. The variables significantly associated at $\mathrm{p}$-value $<0.05$ were identified as predictors of immunization status. The degree of association was also assessed using crude and adjusted odds ratios.

\section{Determinants of Immunization Status}

Eight household determinants were taken into consideration, including the residence type (urban or rural), presence of a professional

attendant during childbirth (institutional delivery or home delivery), mother's 
employment status, parental education, number of living children or parity status, decisionmaker for immunization in the family, wealth status and household income. The residence type was categorized into rural and urban areas. The presence of a professional birth attendant during childbirth was defined as either the birth was attended by an auxiliary nurse-midwife or attended by a health professional (physician or trained nurse). Educational levels of parents were defined as no education, primary and higher than primary. Mothers' employment status was categorized as unemployed or employed. Parity status was considered low if the family had one to three children and high if the family had four or more than a four number of living children. Distance to a health facility or immunization session site was convenient if less than 30 minutes' walk to the session site.

\section{Ethical Considerations}

To maintain regular protocols of ethics, informed verbal consent was obtained from the respondents, and no attempt was made to capture the interviewees' identities.

\section{Definitions}

The immunization status of the children were categorized as follows:

\section{Fully Immunized}

Fully immunized child was defined as a child who had received one dose of Bacillus Calmette-Guerin (BCG), 3 doses of Diphtheria, Pertussis, Tetanus (DPT)/Pentavalent vaccine and 3 doses of Oral Polio Vaccine and one dose of Measles Containing Vaccine (MCV) within the age of one year as per national immunization schedule.

\section{Partial Immunization}

A child who has received at least one of the vaccines but has not completed the entire set of vaccines as per the national immunization schedule.

\section{Not Immunized}

When a child who has not received any vaccine as per the universal immunization programme schedule.

\section{Not fully Immunized}

A combination of both partially immunized and not immunized. Pentavalent vaccine: This is a combination of Diphtheria, Pertussis, Tetanus, Haemophilus Influenza type B and hepatitis B antigens.

\section{Delayed Vaccination}

Delayed vaccination for each vaccine was defined as administering the vaccine dose after 28 days of the minimum recommended age, as per India's national immunization schedule.

\section{Distance to Health Facility (in walk time)}

Distance to a health facility or immunization session site, if $<30$ minutes, was taken as session site convenient for vaccination.

A pre-designed survey questionnaire was used to assess the reasons for nonimmunization and partial immunization of the selected child aged below 2 years.

\section{Results}

Eight hundred children aged 0-23 months were included in the study. A mean and standard deviation $( \pm \mathrm{SD})$ of mothers' age was $24.1( \pm 3.3)$ years. The mean age of the child was $11.1( \pm 6.5)$ months, and $48.4 \%$ of them were females. Half 388 (48.5\%) of the mothers were not able to read and write, while only $7.3 \%$ of them attained a secondary or higher level of education. Nearly one-half 390 (48.8\%) of the father were also uneducated. About 427 (53.4\%) respondents were Muslims, while 373 (46.6\%) were Hindus. About two-thirds 595 (74.4\%) of the total children belonged to other backward classes (OBCs) and mainly were Muslim OBCs (53.3\%). About 123 (15.4\%) belonged to the scheduled caste (SC), $8(1 \%)$ to the scheduled tribe (ST), and $74(9.3 \%)$ to the non-SC/ST/OBC category.

Most children, 690 (86.3\%), were born in public or private institutions, while $110(13.8 \%)$ were home delivered. Around 203 (25.4\%) of the children included in the study were of birth order four and above, reflecting a bigger family size in the sample. A few more than a quarter, $224(28 \%)$ were of the first order. The children of second and third order were $216(27 \%)$ and 157 (19.6\%). More than one-fourth 206 (26.4\%) of the households had four or more living children. About 353 (44.2\%) of the households had an average monthly income below 10,000 rupees per month (Below Poverty Line limit). More than one-third $(36.4 \%)$ of caregivers were agricultural laborers and 
$353(44.1 \%)$ were of low economic status. (Table1 and Table 2).

Figure 1 and 2 shows immunization coverage in Haryana and Mewat in various national immunization surveys. Immunization status of the total included children $(\mathrm{N}=800)$, $426(53.25 \%)$ of them were fully immunized as per age, $345(43.13 \%)$ were partially vaccinated, and the rest $29(3.63 \%)$ had not received any antigen. Out of 426 fully vaccinated children, 292 (68.5\%) had evidence of immunization supported by the card, while the vaccination status of 134 (31.5\%) children was determined by mothers to recall. Similarly, 173 (50.1\%) were confirmed as partially immunized by card, while $172(49.9 \%)$ were based on mothers' recall. On the other hand, of the fully immunized children, 146 (18.25\%) had received timely vaccination, while 280 (35\%) received delayed vaccination. Table 3.

Turning to the individual types of immunization covered (Figure 3 and Figure 4) by the study, 769 (96.1\%) of children received BCG, $706(88.3 \%)$ of the children received both OPV1 and Pentavalent1, and 353 (44.1\%) received the measles-containing vaccine. Coverage rates declined for subsequent vaccine doses as $63.5 \%$ of children received OPV3, $63.9 \%$ Pentavalent 3 . The proportion of children who started certain vaccines but did not complete the next intended vaccine (dropout rate) was $28.4 \%$ for OPV1 to OPV3, 27.5\% was for Pentavalent1 to Pentavalent3, and 54\% for BCG to Measles containing vaccine.

Table 1. Socio-demographic and Economic Characteristics of Children aged 0-23 months in Mewat, Haryana 2019

\begin{tabular}{|c|c|c|c|c|}
\hline \multirow{2}{*}{ Characteristics } & \multicolumn{2}{|l|}{ Urban } & \multicolumn{2}{|l|}{ Rural } \\
\hline & Frequency $(\mathbf{N})$ & Percentage $(\%)$ & Frequency $(\mathbf{N})$ & Percentage (\%) \\
\hline \multicolumn{5}{|l|}{ Religion } \\
\hline Hindu & 234 & 58.5 & 139 & 34.8 \\
\hline Muslim & 166 & 41.5 & 261 & 65.3 \\
\hline \multicolumn{5}{|l|}{ Caste } \\
\hline Scheduled Caste & 92 & 23.0 & 31 & 7.8 \\
\hline Scheduled Tribe & 7 & 1.8 & 1 & 0.3 \\
\hline $\begin{array}{l}\text { Other Backward Caste } \\
\text { (OBC) }\end{array}$ & 269 & 67.3 & 326 & 81.5 \\
\hline General Caste & 32 & 8.0 & 42 & 10.5 \\
\hline \multicolumn{5}{|l|}{ MCP card } \\
\hline Yes & 260 & 65.0 & 208 & 52.0 \\
\hline No & 140 & 35.0 & 192 & 48.0 \\
\hline \multicolumn{5}{|l|}{ Gender } \\
\hline Male & 206 & 51.5 & 207 & 51.8 \\
\hline Female & 194 & 48.5 & 193 & 48.3 \\
\hline \multicolumn{5}{|l|}{ Place of delivery } \\
\hline Government & 205 & 51.3 & 208 & 52.0 \\
\hline Private & 155 & 38.8 & 122 & 30.5 \\
\hline Home & 40 & 10.0 & 70 & 17.5 \\
\hline \multicolumn{5}{|l|}{ Birth Order of the child } \\
\hline First & 113 & 28.3 & 111 & 27.8 \\
\hline Second & 120 & 30.0 & 96 & 24.0 \\
\hline Third & 83 & 20.8 & 74 & 18.5 \\
\hline Four and above & 84 & 21.0 & 119 & 29.8 \\
\hline \multicolumn{5}{|l|}{ Care provider } \\
\hline Mother & 359 & 89.8 & 364 & 91.0 \\
\hline Other Family members & 41 & 10.3 & 36 & 9.0 \\
\hline
\end{tabular}




\begin{tabular}{|c|c|c|c|c|}
\hline No schooling & 155 & 38.8 & 233 & 58.3 \\
\hline Primary & 84 & 21.0 & 63 & 15.8 \\
\hline Middle & 49 & 12.3 & 49 & 12.3 \\
\hline High/Secondary & 71 & 17.8 & 38 & 9.5 \\
\hline$\geq$ twelfth & 41 & 10.3 & 17 & 4.3 \\
\hline \multicolumn{5}{|l|}{ Father education } \\
\hline No schooling & 185 & 46.3 & 205 & 51.3 \\
\hline Primary & 33 & 8.3 & 30 & 7.5 \\
\hline Middle & 36 & 9.0 & 36 & 9.0 \\
\hline High/Secondary & 64 & 16.0 & 55 & 13.8 \\
\hline$\geq$ twelfth & 82 & 20.5 & 74 & 18.5 \\
\hline \multicolumn{5}{|c|}{ Employment of caregiver } \\
\hline Agriculture & 6 & 1.5 & 24 & 6.0 \\
\hline $\begin{array}{l}\text { Government/Private } \\
\text { job }\end{array}$ & 79 & 19.8 & 99 & 24.8 \\
\hline $\begin{array}{l}\text { Self-employed/Shop } \\
\text { keeper }\end{array}$ & 106 & 26.5 & 40 & 10.0 \\
\hline Daily wage laborer & 150 & 37.5 & 141 & 35.3 \\
\hline $\begin{array}{l}\text { Skilled labor } \\
\text { (mechanic/tailor/driver) }\end{array}$ & 59 & 14.8 & 96 & 24.0 \\
\hline \multicolumn{5}{|c|}{ Monthly income (Rupees) } \\
\hline BPL $(<10000)$ & 132 & 33.0 & 221 & 55.3 \\
\hline Middle (10000-25000 & 243 & 60.8 & 150 & 37.5 \\
\hline High $(>=25000$ & 25 & 6.3 & 29 & 7.3 \\
\hline \multicolumn{5}{|c|}{ Number of living children (Parity) } \\
\hline 1 & 113 & 28.3 & 113 & 28.3 \\
\hline 2 & 123 & 30.8 & 92 & 23.0 \\
\hline 3 & 79 & 19.8 & 71 & 17.8 \\
\hline$>4$ & 85 & 21.3 & 124 & 31.0 \\
\hline \multicolumn{5}{|l|}{ Type of Dwelling } \\
\hline Pucca & 388 & 97.0 & 332 & 83.0 \\
\hline Semi-Pucca & 12 & 3.0 & 36 & 9.0 \\
\hline Kutcha & 0 & 0.0 & 32 & 8.0 \\
\hline \multicolumn{5}{|c|}{ Source of fuel for cooking } \\
\hline Firewood / Dung cake & 14 & 3.5 & 305 & 76.0 \\
\hline LPG & 386 & 96.5 & 95 & 23.8 \\
\hline \multicolumn{5}{|l|}{ Place of vaccination } \\
\hline $\begin{array}{l}\text { Government Health } \\
\text { Facilities }\end{array}$ & 179 & 44.8 & 98 & 24.5 \\
\hline $\begin{array}{l}\text { Private Health } \\
\text { Facilities }\end{array}$ & 8 & 2.0 & 8 & 2.0 \\
\hline Outreach AWC & 213 & 53.3 & 294 & 73.5 \\
\hline \multicolumn{5}{|c|}{ Immunization site convenient } \\
\hline Yes & 388 & 97.0 & 391 & 97.8 \\
\hline No & 12 & 3.0 & 9 & 2.3 \\
\hline \multicolumn{5}{|c|}{ ASHA visited after side effects } \\
\hline Yes & 142 & 67.3 & 126 & 56.0 \\
\hline No & 69 & 32.7 & 99 & 44.0 \\
\hline \multicolumn{5}{|c|}{ Taken for next dose after adverse effect } \\
\hline Yes & 190 & 90.0 & 179 & 79.6 \\
\hline No & 21 & 10.0 & 46 & 20.4 \\
\hline
\end{tabular}




\begin{tabular}{|l|l|l|l|l|}
\hline \multicolumn{2}{|l|}{ Received four key messages } & 25.3 & 197 & 26.5 \\
\hline $\begin{array}{l}\text { Which vaccines and } \\
\text { they prevent which } \\
\text { diseases }\end{array}$ & 216 & 25.0 & 162 & 21.8 \\
\hline $\begin{array}{l}\text { Side-effects of vaccines } \\
\text { \& management } \\
\text { explained }\end{array}$ & 213 & 23.0 & 150 & 20.2 \\
\hline $\begin{array}{l}\text { When and where to } \\
\text { come for the next } \\
\text { immunization }\end{array}$ & 196 & 12.4 & 95 & 12.8 \\
\hline $\begin{array}{l}\text { Remember to bring a } \\
\text { card during the next } \\
\text { visit }\end{array}$ & 106 & 14.3 & 140 & 18.8 \\
\hline $\begin{array}{l}\text { Did not receive any } \\
\text { message/no time to } \\
\text { discuss }\end{array}$ & 122 & 11.3 & 71 & 17.8 \\
\hline Heard negative stories about immunization & 45 & 88.8 & 329 & 82.3 \\
\hline Yes & 355 & & \\
\hline No & & & \\
\hline
\end{tabular}

Table 2. Distribution of Individual and Socio-Demographic Factors in Mewat, Haryana 2019-20

\begin{tabular}{|c|c|c|c|c|c|c|c|}
\hline \multirow{3}{*}{ Variable } & \multirow{2}{*}{\multicolumn{2}{|c|}{$\begin{array}{l}\begin{array}{l}\text { Completely } \\
\text { immunized }\end{array} \\
(\mathrm{N}=426)\end{array}$}} & \multirow{2}{*}{\multicolumn{2}{|c|}{$\begin{array}{l}\text { Partially / } \\
\text { Unimmunized } \\
(\mathrm{N}=374 \\
\end{array}$}} & \multirow{3}{*}{$\begin{array}{l}\text { Odds Ratio } \\
\text { OR }(95 \% \mathrm{CI}) \\
\text { value }\end{array}$} & \multirow{3}{*}{$\begin{array}{l}\text { Adjusted Odds } \\
\text { Ratio } \\
\text { AOR (95\% CI) } \\
\end{array}$} & \multirow[t]{3}{*}{ P-value } \\
\hline & & & & & & & \\
\hline & No. & $\%$ & No. & $\%$ & & & \\
\hline \multicolumn{8}{|l|}{ Area of residence } \\
\hline Urban & 215 & 53.7 & 185 & 46.3 & & & \\
\hline Rural & 211 & 52.7 & 189 & 47.3 & $0.96(0.72-1.26)$ & $0.80(0.58-1.1$ & 0.19 \\
\hline \multicolumn{8}{|l|}{ Primary caregiver } \\
\hline Mother & 362 & 50 & 361 & 50 & & & \\
\hline Others & 64 & 83.1 & 13 & 16.9 & $0.20(0.11-0.37)$ & & 0.00 \\
\hline \multicolumn{8}{|l|}{ Religion } \\
\hline Hindu & 272 & 72.9 & 101 & 27.1 & & & \\
\hline Muslim & 154 & 36 & 273 & 64 & $4.77(3.52-6.45)$ & $4.94(3.64-6.71)$ & 0.00 \\
\hline \multicolumn{8}{|l|}{ Caste } \\
\hline Hindu OBC and others & 272 & 72.9 & 101 & 27.1 & & & \\
\hline Muslim backward class & 154 & 36 & 273 & 70 & $4.77(3.52-6.45)$ & & 0.00 \\
\hline \multicolumn{8}{|l|}{ Gender } \\
\hline Male & 229 & 55.4 & 184 & 44.6 & & & \\
\hline Female & 197 & 50.9 & 190 & 49.1 & $1.20(0.90-1.58)$ & $1.40(1.03-1.90)$ & 0.02 \\
\hline \multicolumn{8}{|l|}{ Religion wise gender } \\
\hline Others religion male & 336 & 59.4 & 229 & 40.6 & & & \\
\hline Muslim Male & 90 & 38.3 & 145 & 61.7 & $2.36(1.73-3.22)$ & & 0.00 \\
\hline \multicolumn{8}{|l|}{ Birth Oder } \\
\hline$\leq 2$ & 261 & 56.3 & 179 & 40.7 & & & \\
\hline$>2$ & 165 & 45.8 & 195 & 54.2 & $1.72(1.30-2.28)$ & & 0.00 \\
\hline \multicolumn{8}{|l|}{ MCP card } \\
\hline Available & 292 & 62.3 & 176 & 37.7 & & & \\
\hline Not available & 134 & 40.3 & 198 & 59.7 & $2.45(1.83-3.27)$ & & 0.00 \\
\hline \multicolumn{8}{|l|}{ Maternal education } \\
\hline Primary and above & 284 & 68.9 & 128 & 31.1 & & & \\
\hline
\end{tabular}




\begin{tabular}{|c|c|c|c|c|c|c|c|}
\hline No education & 142 & 36.6 & 246 & 63.4 & $3.84(2.86-5.15)$ & $2.72(1.85-3.99)$ & 0.00 \\
\hline \multicolumn{8}{|l|}{ Father education } \\
\hline Primary and above & 275 & 67 & 135 & 33 & & & \\
\hline No education & 151 & 38.7 & 239 & 61.3 & $3.22(2.41-4.30)$ & $1.63(1.08-2.49)$ & 0.02 \\
\hline \multicolumn{8}{|l|}{ Employment } \\
\hline $\begin{array}{l}\text { Employed/Self } \\
\text { employed }\end{array}$ & 285 & 59.5 & 194 & 40.5 & & & \\
\hline Unemployed & 141 & 43.9 & 180 & 56.1 & $1.87(1.40-2.49)$ & $1.16(0.81-1.66)$ & 0.39 \\
\hline \multicolumn{8}{|c|}{ Monthly income (in Rupees) } \\
\hline More than 5000 & 366 & 54.3 & 307 & 45.7 & & & \\
\hline Less than 5000 & 60 & 47.2 & 67 & 52.8 & $1.33(0.91-1.94)$ & $0.94(0.60-1.45)$ & 0.78 \\
\hline \multicolumn{8}{|c|}{ Parity status (number of living children) } \\
\hline$\leq 4$ Children & 385 & 56.7 & 293 & 43.3 & & & \\
\hline$>4$ Children & 41 & 33.6 & 81 & 66.4 & $2.59(1.73-3.89)$ & $1.47(0.94-2.28)$ & 0.08 \\
\hline \multicolumn{8}{|l|}{ Place of vaccination } \\
\hline Govt/Pvt & 207 & 70.6 & 86 & 29.4 & & & \\
\hline Outreach & 219 & 43.2 & 288 & 56.8 & $3.16(2.32-4.30)$ & $2.34(1.68-3.24)$ & 0.00 \\
\hline \multicolumn{8}{|c|}{ Received 4 Key messages } \\
\hline Received & 312 & 57.9 & 227 & 42.1 & & & \\
\hline Did not receive & 114 & 43.7 & 147 & 56.3 & $1.77(1.31-2.38)$ & & 0.00 \\
\hline \multicolumn{8}{|c|}{ Distance to health facility (in walk time) } \\
\hline$\leq 30$ minutes & 418 & 54 & 356 & 46 & & & \\
\hline$>30$ minutes & 8 & 30.7 & 18 & 69.3 & $2.64(1.13-6.14)$ & & \\
\hline \multicolumn{8}{|c|}{ Aware of next due dose of vaccine } \\
\hline Aware & 317 & 60.7 & 205 & 39.3 & & & \\
\hline Not Aware & 109 & 39.2 & 169 & 60.8 & $2.39(1.77-3.23)$ & $1.95(1.41-2.68)$ & 0.00 \\
\hline \multicolumn{8}{|c|}{ Received Anganwadi services } \\
\hline Yes & 215 & 59.3 & 147 & 40.7 & & & \\
\hline No & 211 & 48.1 & 227 & 51.9 & $1.57(1.18-2.08)$ & & \\
\hline \multicolumn{8}{|c|}{ Decision maker for immunization } \\
\hline Primary care giver & 205 & 58 & 148 & 42 & & & \\
\hline Mainly Husband & 221 & 49.4 & 226 & 50.6 & $1.41(1.06-1.87)$ & 0.0007 & \\
\hline \multicolumn{8}{|l|}{ Birth } \\
\hline $\begin{array}{l}\text { Attended by the health } \\
\text { worker }\end{array}$ & 378 & 54.7 & 312 & 45.3 & & & \\
\hline $\begin{array}{l}\text { Not attended by health } \\
\text { worker }\end{array}$ & 48 & 43.6 & 62 & 56.4 & $1.56(1.04-2.34)$ & $0.97(0.62-1.52)$ & 0.78 \\
\hline
\end{tabular}

Table 3. Full Immunization Status of Study Participants in Mewat (12-23 months children)

\begin{tabular}{|l|l|l|l|}
\hline Immunization status & Urban & Rural & Total \\
\hline Eligible for Full immunization & 157 & 166 & 323 \\
\hline Fully immunized & 92 & 100 & 192 \\
\hline \% Fully immunized & 59 & 60 & 59 \\
\hline
\end{tabular}




\section{Haryana: Immunization Coverage in Various Surveys}

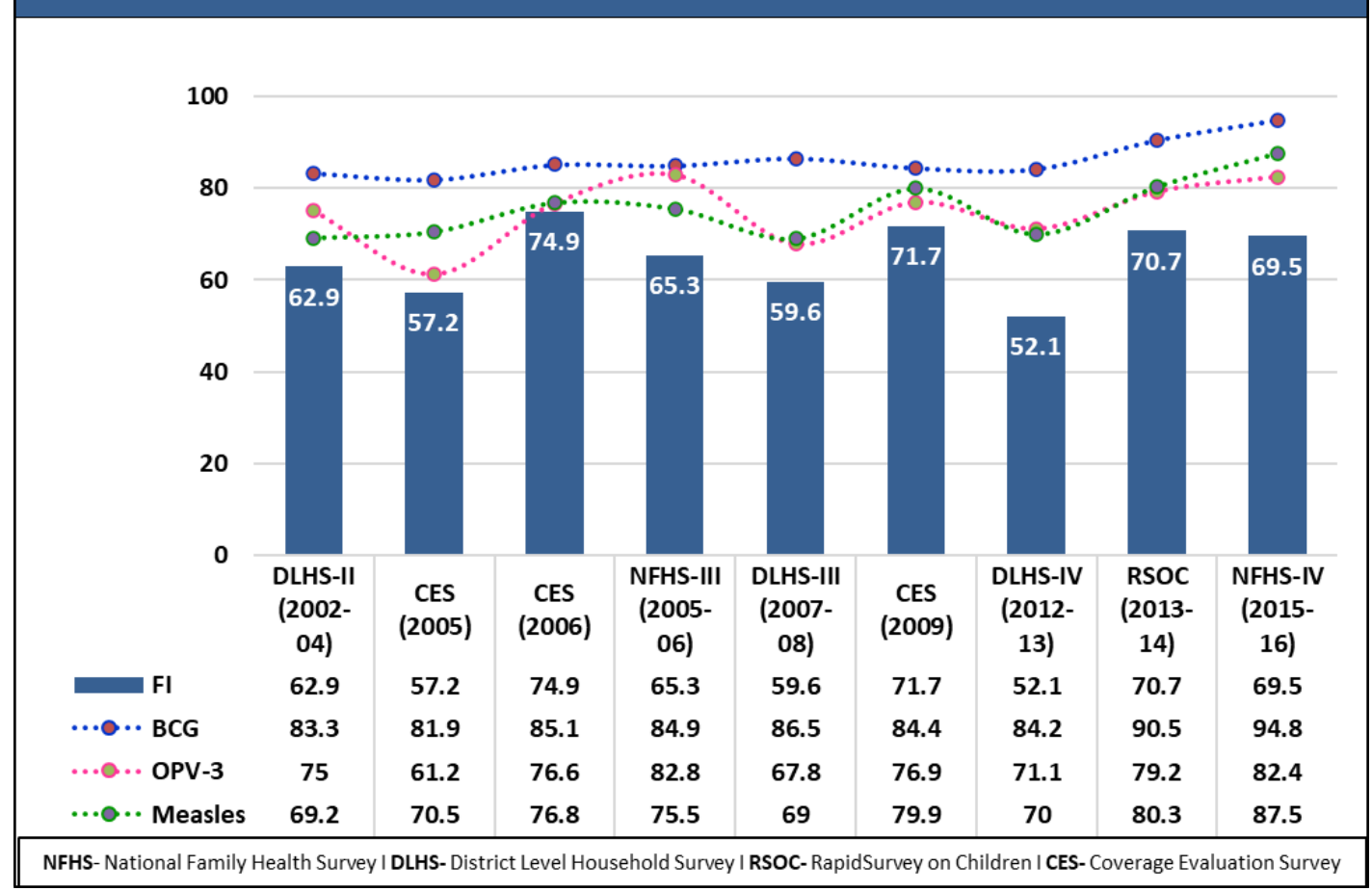

Figure 1. Haryana Full Immunization Coverage in Various Surveys 2002-2016

\section{Mewat: Immunization Coverage in Various Surveys}

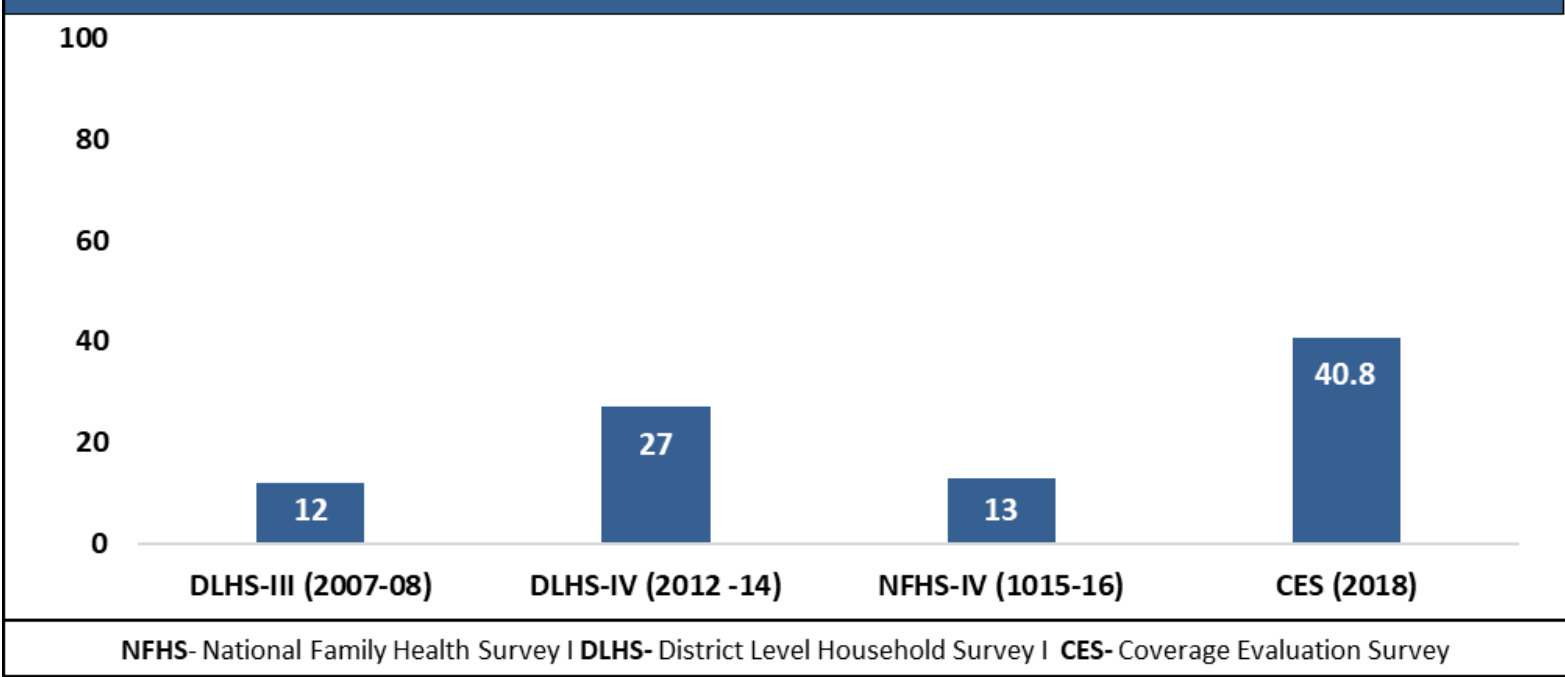

Figure 2. Mewat Full Immunization Coverage in Various Surveys 


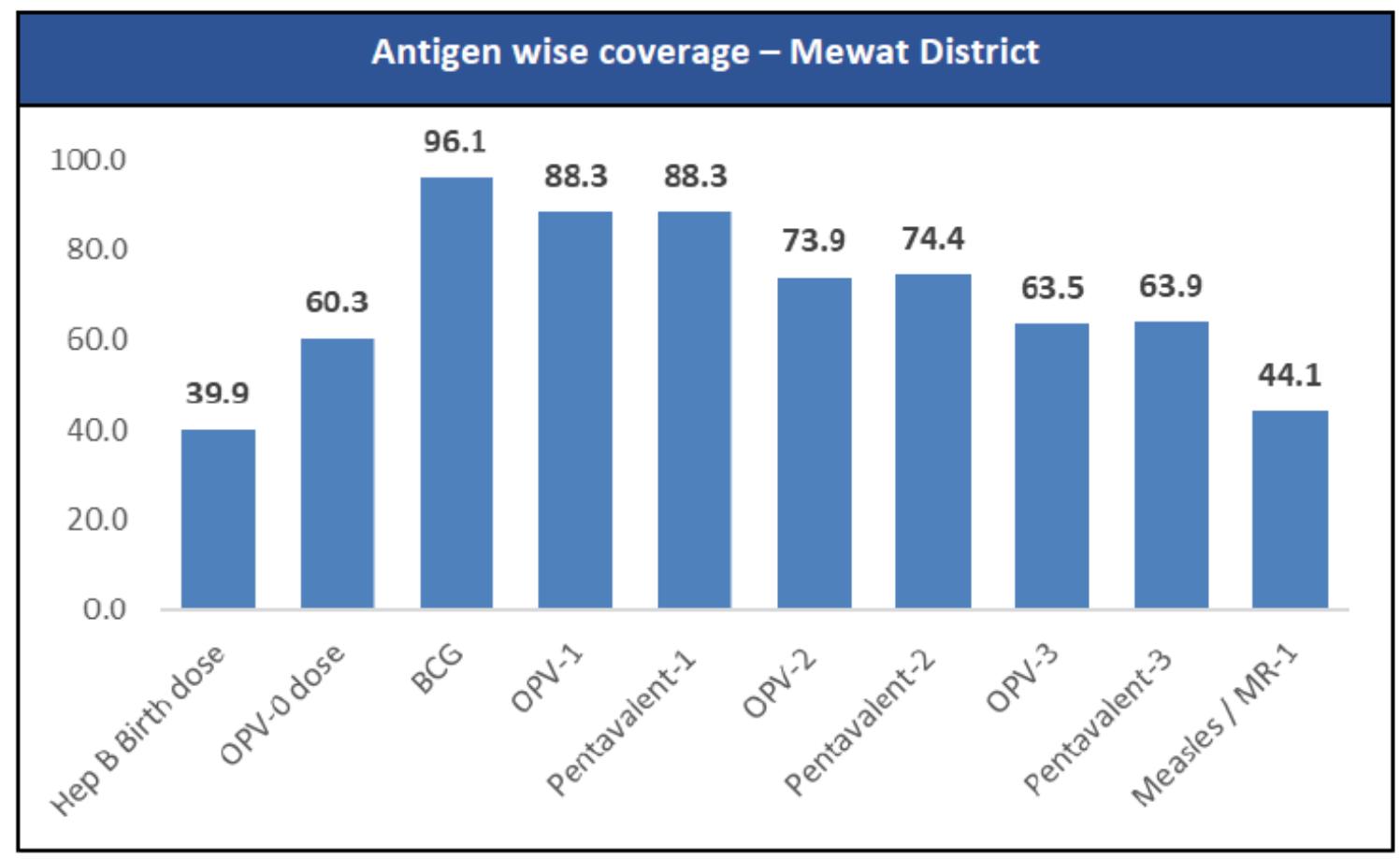

Figure 3. Antigen Wise Coverage in the Study Population -Mewat District 2019-2020

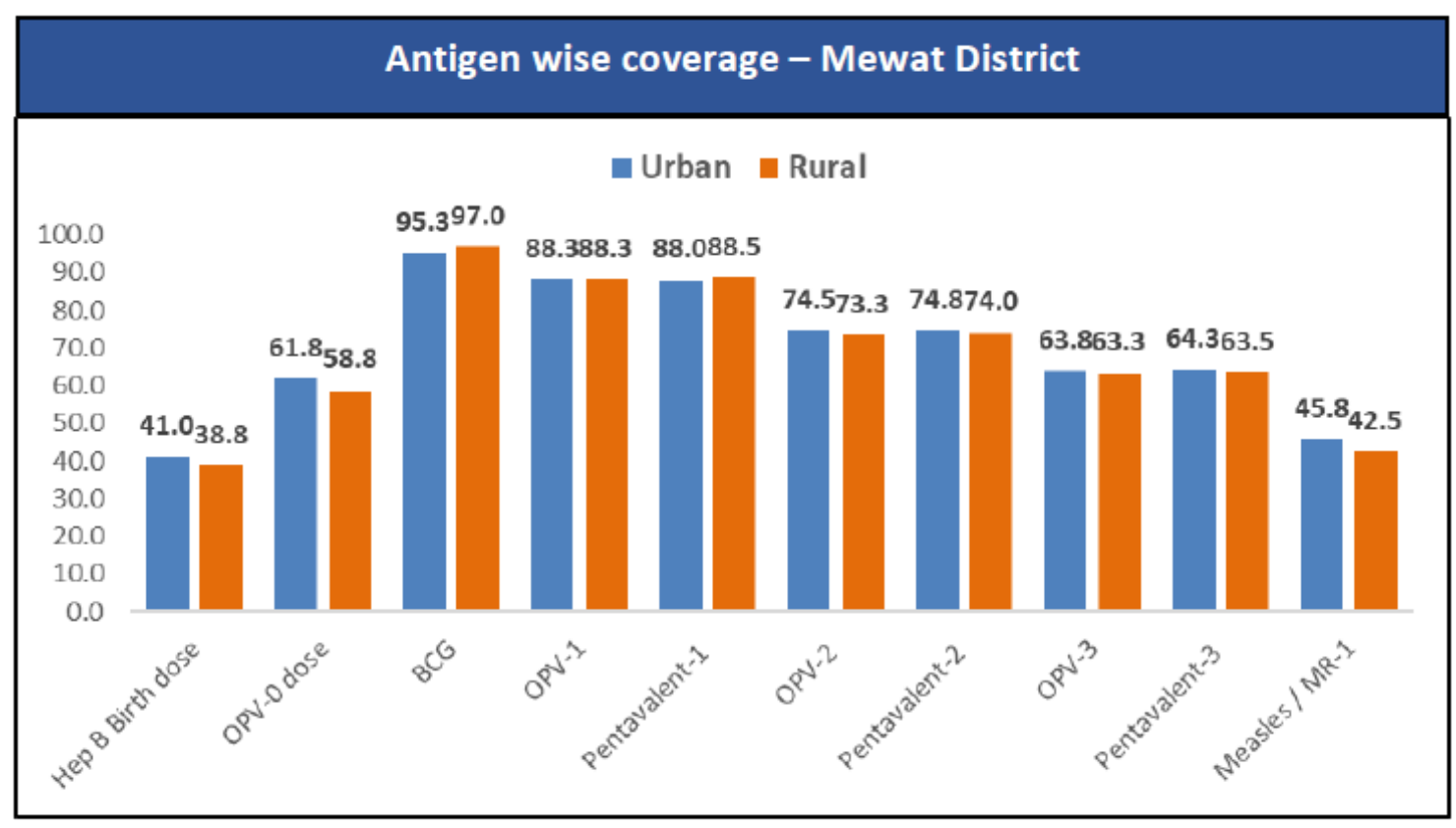

Figure 4. Urban -Rural Antigen Wise Coverage in Study Area of District Mewat 2019-20

\section{Factors Associated with Full Immunization Status of Children}

On the bi-variable analysis, birth order of the child, mothers age, parental educational status, number of living children in the family, employment, religion, caste, place of vaccination, awareness about next due dose of vaccine, the presence of a professional birth attendant in the delivery process, decisionmaker for immunization in the family, distance to a health facility were found to be significantly associated with children's full immunization status. However, in the multivariate analysis, religion, gender, parental education, place of vaccination, and next due 
dose of vaccine by mother were significantly associated (Table 2).

Table 2 shows that mothers who attained primary or higher education levels were 3.84 times more likely to have fully immunized children than illiterate mothers (Adjusted Odds Ratio (AOR) $=2.72 \quad 95 \% \quad \mathrm{CI}=1.85-3.99$ ). Mothers who had good knowledge and awareness about the next due dose about immunization were 1.9 times more likely to have a fully immunized child than those who had poor knowledge (AOR $=1.95, \quad 95 \%$ $\mathrm{CI}=1.41-2.68)$. Children of the Hindu religion were 4.9 times more likely to have fully immunized than Muslim religion ( $\mathrm{AOR}=4.94,95 \% \mathrm{CI}=3.64-6.71)$. Children born in health institutions had 2.34 times more chance of being fully vaccinated than children born at home $(\mathrm{AOR}=2.34,95 \% \mathrm{CI}=1.68-3.24)$. Children with male gender had 1.4 times more chance of being fully immunized than female gender $(\mathrm{AOR}=1.40,95 \% \mathrm{CI}=1.03-1.90)$.

Younger mothers ( $<20$ years of age) were less likely to vaccinate their children than older mothers $(\mathrm{AOR}=4.1,95 \% \mathrm{CI}=1.94-8.71)$.

Figure 3 shows antigen wise coverage among 0-23 months children; BCG had the highest coverage $(96.1 \%)$, followed by a first, second, and third dose of oral polio vaccine and Pentavalent vaccines. Overall, a decreasing trend was observed with OPV-1 (88.3\%), Pentavalent-1 $(88.3 \%)$ to OPV-3 (63.5\%), Pentavalent-3 $(63.9 \%)$ and further fall was observed for MCV-1 (44.1\%). The dropout rates from $\mathrm{BCG}$ to $\mathrm{MCV}-1$ was $15.6 \%$, while Pentavalent- 1 to Pentavalent-3, it was $7.2 \%$.

Figure 4 shows the overall vaccination coverage of each vaccine in urban and rural areas. Overall, Hep B vaccination coverage at birth was 319 (39.9\%), which was the lowest compared to other antigens. It was $38.8 \%$ for rural and $41 \%$ in urban areas. Overall OPV-0 dose vaccination coverage was $60.3 \%$, while, in urban and rural areas, it was $61.8 \%$ and $58.8 \%$, respectively. Overall, BCG vaccination coverage was $96.1 \%$, while, in urban and rural areas, it was $95.3 \%$ and $97 \%$, respectively. OPV1 vaccination coverage was $88.3 \%$ and $88.3 \%$ in urban and rural areas, respectively, while overall it was $88.3 \%$. Pentavalent1 vaccination coverage was $88 \%$ and $88.5 \%$ in urban and rural areas, respectively, while overall it was $88.3 \%$. OPV2 vaccination coverage was $74.5 \%$ and $73.3 \%$ in urban and rural areas, respectively, while overall it was $73.9 \%$. Pentavalent 2 vaccination coverage was $74.8 \%$ and $74 \%$ in urban and rural areas, respectively, while overall it was $74.4 \%$. OPV3 vaccination coverage was $63.8 \%$ and $63.3 \%$ in urban and rural areas, respectively, while overall it was $63.5 \%$. Pentavalent 3 vaccination coverage was $64.3 \%$ and $63.5 \%$ in urban and rural areas, respectively, while overall it was 63.9\%. Overall, measles-rubella vaccination coverage was $44.1 \%$, while, in urban and rural areas, it was $45.8 \%$ and $42.5 \%$, respectively. Overall, DPT booster 1 coverage was $15.5 \%$ and MR2 coverage was $15.6 \%$ at the district. The dropout rate for BCG to measles-rubella vaccine in the age group of (12-23 months) in urban was $12.5 \%$, while it was $18.4 \%$ in rural, whereas the overall dropout rate was $15.6 \%$. The dropout rate for pentavalent 1 to pentavalent3 in urban was $11.3 \%$, while it was $11.9 \%$ in rural areas, whereas the overall dropout rate was $11.7 \%$. The dropout rate for OPV1 to OPV3 in urban areas was $12 \%$, while it was $11.4 \%$ in rural areas; the overall dropout rate for OPV1 to OPV3 was $11.76 \%$. The dropout rate for MR1 to MR2 in urban areas was $57.14 \%$, while it was $52.6 \%$ in rural areas; the overall dropout rate at the district level was $54.8 \%$.

More than half $(51.6 \%)$ of the respondents chose government facilities for the delivery, one-third $(34.6 \%)$ chose private health facilities for a delivery while, $13.8 \%$ delivered at home. The majority (77\%) of the respondents chose government health facilities for delivery in Punhana block while only one-third in Taoru block. Overall availability of immunization card in the district was $58.5 \%$, maximum in Taoru block $75 \%$, and minimum in Nuh block $40 \%$. Decisions regarding vaccination of the children were dependent on either their husband or family members. The prime influence was the husband in $54.3 \%$ at the district level 62.3\% in rural areas and $46.3 \%$ in the urban areas.

Overall, $426(53.3 \%)$ children in the age group of 0-23 months were fully immunized, $345(43.1 \%)$ were partially immunized and 29 $(3.6 \%)$ completely unimmunized. Notably, $46.7 \%$ of the children did not receive ageappropriate immunization. Only $18.3 \%$ of the children were immunized on time as per age in 
0-23 months. The most common reason for no immunization/partial immunization was fear of side effects of vaccines $(28 \%)$, followed by the awareness gap (24\%), child traveling (21\%), and operational reasons (16\%), as shown in Figure 5.

Among children aged 12-23 months, timely immunization was seen in $3.1 \%$ and delayed in more than half $(56.3 \%)$ of the children. About $38.4 \%$ of children were partially immunized, and $2.2 \%$ did not receive any vaccines. The common reason for no or partial immunization was lack of awareness in (32\%) followed by fear of side effects of the vaccine (27\%) of the children, as shown in Figure 6.

Reasons for 426 fully vaccinated (age appropriate vaccination) children aged 0-23 months were analyzed. It was observed that 145 (34\%) caregivers accepted immunization after counseled by the health workers regarding benefits of immunization. zing their children, $221(51.9 \%)$ replied that vaccines prevent children from diseases.About 51(12\%) trusted health system and vaccines and only $9(2.1 \%)$ were self motivated to get their children vaccinated.

Reasons for 374 partially and unimmunized children were also analyzed in detail. The most common reason for partial or no immunization was fear of adverse events following vaccination in $119(27 \%), 93(21.5 \%)$ child away from home, 57 (13\%) no one contacted the family, $67(15.2 \%)$ immunization session not held, $24(5.5 \%)$ family not aware of the need of immunization and $18(4.1 \%)$ were unaware of the missed dose,12 $(2.7 \%)$ child was sick and caregiver did not opt for vaccination, $12(2.7 \%)$ family was resistant to immunization, $4(0.9 \%)$ had concern for loss of wages, $3(0.7 \%)$ caregiver not opted for multiple injections, $2(0.5 \%)$ vaccine was not available at session site and $24(5.5 \%)$ did not specify any reason for not getting immunized.

\section{Age appropriate immunization ( $0-23$ months) - Mewat District}

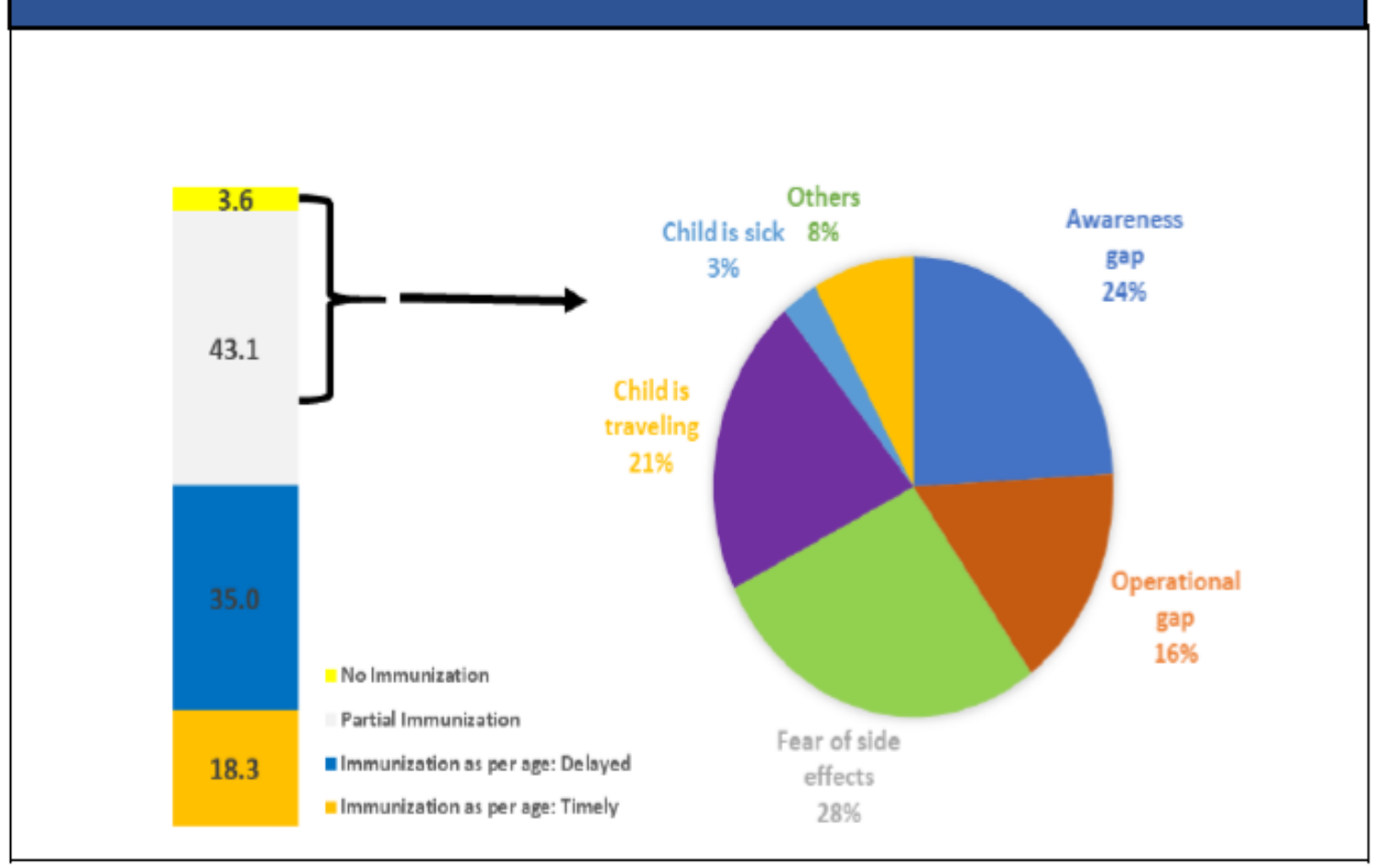

Figure 5. Age Appropriate Immunization in the Study Area in 0-23 Months Children in Mewat 2019-2020 


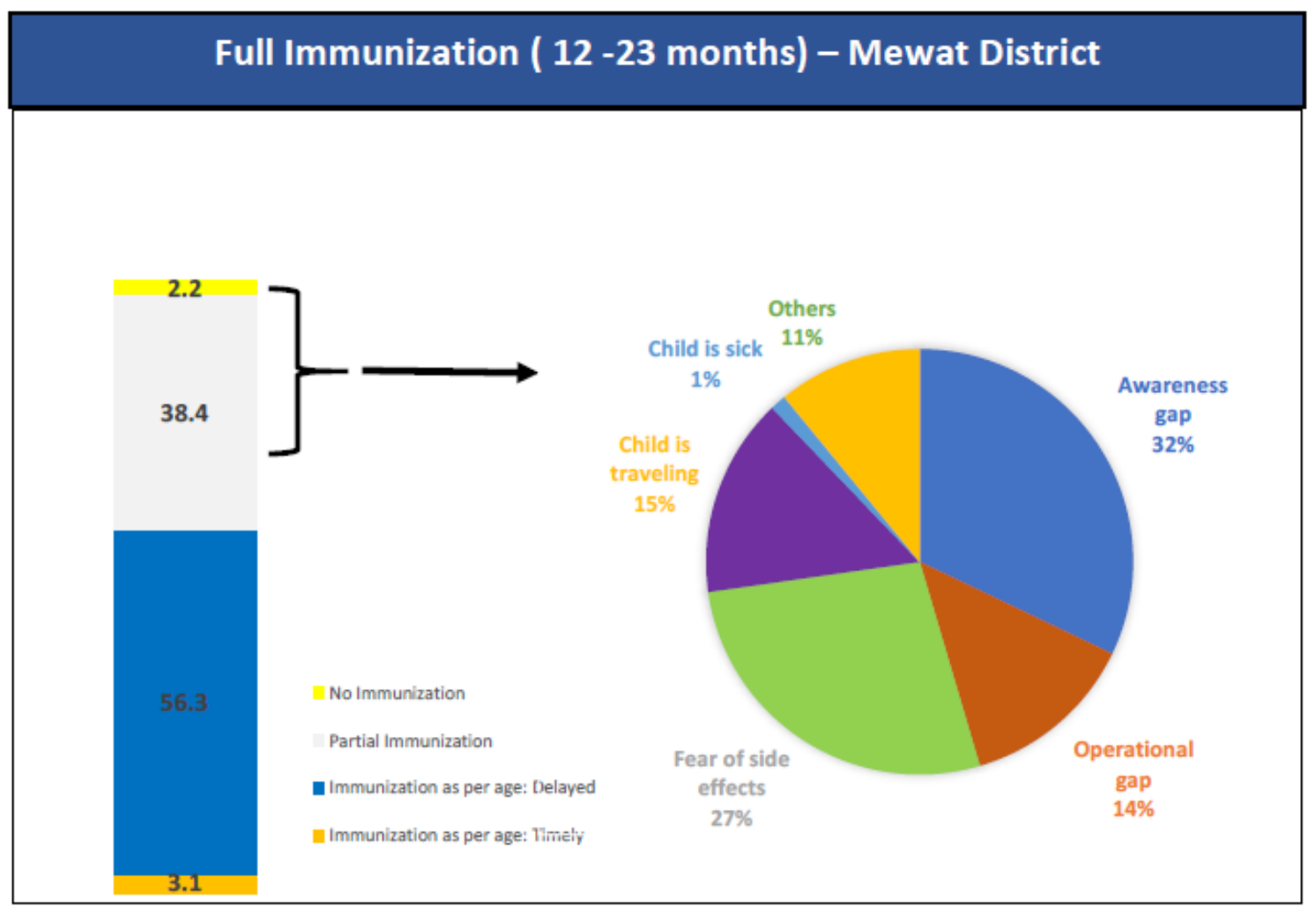

Figure 6. Full Immunization in the Study Area in 12-23 Months Children in Mewat 2019-2020

\section{Discussion}

A total of 800 children (400 from urban areas and 400 from rural areas) aged 0-23 months were residing in the rural and urban areas of district Mewat were included in the study. The coverage of fully immunized children in the study area was found to be $59 \%$ (59\% in urban area and 60\% in rural area) to be quite high as compared to National Family Health Survey (NFHS-4) (2015-16) district figures i.e., $13.1 \%$ (rural 11\%) indicating that there has been a significant improvement in overall immunization coverage of all vaccines in recent years, as a result of continuous efforts being put in to achieve universal immunization coverage by the government. Similarly, the coverage in this study was higher when compared to the District Level Household Survey (DLHS-4) (2012-13), where the percentage of fully immunized children was only $27.3 \%$ in the district (rural 20.8\%). Mewat district had the highest percentage (46\%) of "partially immunized" and 16\% "no immunized" children in 2018 [16]. All other Haryana districts had full immunization coverage (FIC) of more than $60 \%$. Coverage evaluation survey (CES) in 2018 had also shown that the percentage of children aged 12-
23 months who received full immunizations increased from $13.1 \%$ in $2015-16$ to $40.8 \%$ in Mewat.

Our findings revealed that more than onethird $(40.6 \%)$ of the children in $12-23$ months age group were "partially immunized" or had "no immunization." More than one-third (37.4\%) of the primary caregivers were not aware of the vaccine's next due date in the present study, which was similar to the study conducted in Bijapur, Karnataka [17]. Full immunization coverage in the district still falls short of the WHO and UNICEF's Global Immunization Vision and Strategy goal of $80 \%$ coverage [18].

Factors affecting the childhood vaccinations are more complex and multifactorial. Various factors included the locality (urban/rural/slums) of residence $[19,20]$ parental education $[21,22]$ socioeconomic status of the households [23, 24, 25] caste and religion [26, 27], parity and mother's age at birth [28, 29] and distance to health service centers [30, 31]. Gender discrimination disfavoring female child is also an essential determinant of childhood vaccination in India [28, 29]. Parental education, religion, employment, family size, and place of delivery were the main 
demographical factors that affected immunization in the district. Mothers were the primary caregiver in the majority of the cases in our study. Approximately half of the primary caregivers $(48.5 \%)$ in the study were not having any formal education. Overall low literacy rate of $54.08 \%$ (males $69.9 \%$; females $36.6 \%$ ) in the district probably contributed to the ignorance and blind beliefs or myths among the beneficiary's families and society. Illiterate parents were not aware of the benefits of immunization and its schedule and had shown a lack of interest in the child's vaccination. Decisions for vaccination of the children were dependent either on their husband or elderly male family members. Only $3.8 \%$ of primary caregivers independently decided to get their children vaccinated. About one-third of primary caregivers believed that immunization makes their children sterile.

The institutional births had improved from $37.6 \%$ in $2015-16$ to $86.3 \%$ during the study period. We found that improvement in the institutional delivery rates and availability of the professional birth attendant during the delivery process had a positive and significant association with children's immunization status. Higher immunization coverage were seen in the studies where professional birth attendant were present during the process [32, 33]. The auxiliary nursing midwives (ANMs) provide antenatal, perinatal, nutrition \& reproductive advices, and immunization services in villages. They are accepted by the local community and play important role in mobilizing them for vaccination.

During our study, it was revealed that maternal age was significantly associated with immunization coverage. There were 3.5 times more chances of children being fully vaccinated if the maternal age was more than 20 years $(\mathrm{AOR}=3.53,95 \%$ CI 1.75-7.10). Children of older mothers were more likely to be fully immunized. Our study results were similar to the study conducted by [34]. Women under 20 years of age in Mewat may be less likely to make their own decisions regarding vaccinating their children; mainly husbands and family members are the decision-makers. Older mothers are likely to have more experience raising children and more likely to be knowledgeable about children's health, which may be the possible explanation of improved coverage at this age.

In the present study, coverage for the BCG vaccine was remarkably high, indicating a certain healthcare services access by the community. BCG vaccine is provided at the time of birth in government institutions, and an increase in institutional deliveries in recent years may be a contributing factor. The gradual decrease in the vaccination coverage from the birth-administered BCG to DPT3/ Pentavalent3 given at age six months could be secondary to difficulty in accessing immunization services, lack of understanding for the need for further vaccination, loss in motivation or perceived need for child vaccination, or a combination of all these factors. Difficulty in accessing health services could be explained, at least in part, by institutional and societal discrimination directed at parents belonging to lower socioeconomic strata, castes and poorer households, and physical barriers such as unavailability of services due to long distances to health centers, and unavailability of health workers at the health centers.

Usually, children in urban areas had been reporting to have better vaccination outcomes than children residing in rural areas. The proportion of fully vaccinated children was slightly better in urban areas $(53.7 \%)$ than in rural areas $(52.7 \%)$; however, we did not find any significant difference in our study. An extensive network of community health workers (Anganwadi and ASHA workers) in rural areas of Mewat and their task is to mobilize children and pregnant women to receive immunization services; a comparable network may not exist in urban areas may the possible reason. This could partially account for our finding that urban children with the same level of poverty, education, religion, and caste as rural children still have lower chances of being fully vaccinated, with significant implications for targeted immunization intervention programs and related policies. The urban areas in Mewat have both middle-class neighborhoods and large concentrations of poor and uneducated families (of Muslim religion), who mostly lack of awareness about the benefits of immunization. It was found in the study that women do not get their children adequately immunized, saying that multiple injections hurt $(7.8 \%)$ their children and cause 
other kinds of side-effects (61.2\%). They were also of the view that their children were doing well without immunization; hence there was no need to give them pain by the injections. Findings revealed that overall awareness for the next vaccination due date was among $61 \%$ of primary caregivers. In the present study, most respondents cited the main reason for low immunization was the awareness gap followed by fear of side effects. Awareness about vaccination plays a critical role in vaccine acceptance. Information regarding the immunization schedule and the next due date of vaccination allows mothers and caregivers to plan well in advance, reducing the probability of missed vaccinations. Similar results have been shown in a study conducted $[35,36]$. in Lucknow district, and Nath B in urban slums of Lucknow [37] stated that low awareness was the most common reason for partial or no immunization from Kakinada, Andhra Pradesh [38] showed that the most common reasons for partial/no immunization were an ill child (27.5\%), lack of knowledge about vaccination (25.12\%), migration to other places with no understanding of place and time of vaccination (17.5\%). A study [39] from the rural area of district Tonk, Rajasthan showed the most common reason for partial/nonimmunized was sickness $22(36.06 \%)$ of an elder sibling because of the previous vaccination followed by $20(32.07 \%)$ of the illness of the beneficiary at the time of vaccination. A study [40] in tertiary care hospital of North India showed that the common reasons for partial immunization and non-immunization were lack of knowledge about vaccination $(30.3 \%)$, apprehension about side effects of vaccination (28.8\%), and lack of knowledge about subsequent doses (22.09\%). Another focal study from Surajgarha Block, [41] was 55.2\%. In rural Uttar Pradesh, it was $50 \%$ as per [42]. The full immunization coverage was much lower in the studies from Bihar and Uttar Pradesh. This may be attributed to the lower awareness level and fewer health services utilization in both the territories.

In the present study, $59.4 \%$ of children were fully immunized in the age group of 12-23 months in a rural area of Tripura [43] highlighted in their research that the main reasons for low immunization are the lack of knowledge $(26.7 \%)$, any illness of the child (26.7\%), followed by fear of possible adverse effects (20\%). The consolidated Intensified Mission Indradhanush report stated the reason for non-vaccination were awareness issues (45\%), AEFI apprehension (24\%), vaccine resistance $11 \%$ ), child traveling (8\%), and program-related gaps in $4 \%$ of the respondents. Our research found that most Mewat children who received partial immunizations missed the pentavalent vaccine (DPT, Hepatitis B and Haemophilus influenza $b$ ) and measles vaccine. The dropout rate for BCG to measles in the present study was $54 \%$ and pentavalent- 1 to pentavalent-3 was $27.5 \%$. Dropout rates were much higher in our study than the research conducted in Tamil Nadu [44], the dropout rate from BCG to measles was $15.9 \%$ and pentavalent-1 to pentavalent-3 was $4.1 \%$. Pentavalent vaccine consists of a series of three injections, and children with partial immunizations had received the first one or two injections. During our study, we found the most common reason for partial or no immunization was fear of side effects following vaccination. Also, we found a significant drop out of $54 \%$ in BCG to measles-rubella1. The possible explanation may be that mothers forget to have their children immunized once they reach a certain age, such as nine months, the period for measles vaccination.

Commonly, DPT vaccine coverage is accepted as the standard reflecting immunization program performance. The first DPT/ Pentavalent vaccine dose is an indicator of access to health care services. The third DPT/Pentavalent dose coverage demonstrates the family's ability to access and utilize immunization services in multiple visits. The high dropout (more than 10\%) of DPT/Pentavalent services in Mewat shows that information regarding the benefits of immunization and the need for multiple immunization visits have not reached all the mothers. Our study had revealed the highest coverage $(97.5 \%)$ with BCG vaccine. It is administered up to first 15 days as a birth dose and up to one year of the age. The increasing number of institutional delivered babies with the help of health workers played a significant role in increasing the coverage of $\mathrm{BCG}$ vaccination.

In the present study, we found the availability of immunization cards with $58.5 \%$ of the beneficiaries on the survey's date. The 
vaccination card availability was the highest (75\%) of the children in Taoru block and the lowest in Nuh block (40\%). Our study results were similar to a tribal block of Thane district [45]. In the study conducted in Surajgarha block of Bihar [41], and the availability was $65.7 \%$ and $88.4 \%$ in the study executed in urban slums of Ahmedabad city [46].

In our study $43.3 \%$ (36/83) Muslim male children were fully immunized as compared to 80.9\% (68/84) Hindu male children. Similarly, $34.2 \%$ Muslim female children were fully immunized as compared to $74.4 \%$ Hindu female children. Overall, gender disparity in full immunization was highest among Muslims compared to Hindus. Girls born in India have a $40 \%$ higher risk of ill-health as compared to boys and are less likely to access healthcare services, including immunization. Girls have lower immunization coverage than boys also reinforce the findings of previous studies of gender disparities in childhood immunization. Evidence outside India indicates more significant gender-based discrimination among Muslims than non-Muslim religions [47, 48]. A recent study has documented son preference among various religious groups in India and found that women from Muslim households have a slightly higher son preference. Women from other non-Hindu, non-Muslim religions, have slightly lower preference for sons than the Hindu and Muslim women. Among Muslims, lack of education, and relatively poor socioeconomic status (due to the patriarchal social setup and ideology) may produce circumstances leading to son being the most dependable socioeconomic insurance [49]. Such consideration may have resulted in gender discrimination healthcare utilization among Muslim children.

Mothers/caregivers having Muslim as their religion were less likely to be fully immunized. Most Muslims are often not formally educated and not in employment. Immunization activities are perceived to be deliberately designed by outsiders (enemies of Islam) to reduce the Muslim population through vaccines' fortification [50]. Misconceptions like this could have flown over to countries, including India. Children from Hindu religious affiliations had better vaccination coverage. The factors affecting childhood vaccination in the Indian states of Madhya Pradesh, Bihar,
Uttar Pradesh, and Rajasthan [51]. It showed that children are more likely to receive immunization if their parents are a couple, with the father literate and the mother with at least a middle-school-education level who received antenatal care or delivered in an institutional environment. The importance of maternal education in children's health is universally recognized. Children of more educated mothers are more likely to be fully immunized [52, 53]. A woman with a better educational background is more likely to be aware of immunization's importance. It is also possible that bettereducated mothers are more receptive to novelty and modern ideas, more confident in making decisions for their families' health, and more skilled at obtaining health information. Furthermore, preventive health services are more readily accepted by people with better educational backgrounds. Women with the most education are likely to be wealthier; they also have better access to health facilities and immunization services. Education is correlated with family welfare. Maternal education has also long been established as a significant predictor of childhood vaccination in India. Well-educated mothers have a positive relationship between immunization and maternal education [54]. Based on these findings, when there is a higher concentration of illiterate people in more deficient healthcare services settings, improving access to PHCs could help address inequities in vaccination coverage in areas characterized by lower maternal education levels. In our study, approximately half $(48.5 \%)$ of mothers were illiterate.

In our study, $204(49.3 \%)$ children born in government institutions, $174(62.8 \%)$ born in private institutions received all age-appropriate doses of immunization. Our finding that children born in government institutions were at greater risk of non-vaccination than those born in private institutions. Government institutions need to be further strengthened to deliver immunizations or increase immunization coverage. There is a need to provide financial or policy incentives for government facilities to ensure that children are appropriately immunized.

Another finding in the study was the poor knowledge of the caregivers regarding immunization. Though a clear majority of the 
respondents agreed that vaccination is essential to protect their children from deadly infectious diseases, most of them could not even name one condition that immunization protected against. This observation further cemented with the finding that the main reason for the failure of vaccination was a lack of knowledge about the universal immunization schedule. Previous studies had highlighted that India's existing health inequities are related to a lack of attention to social determinants of health, including education, employment, and the healthcare system's failure to deliver to those in need [55]. We have found significant disparities in vaccination coverage between the richest and poorest children and between the children of mothers with high education and low education, confirming findings in previous literature [56, 57, 58]. Inequities in vaccination coverage among social and religious groups in India were also clearly evident. Previous vaccination studies [59] that investigated the effects of religion on vaccination coverage dichotomized religion as Hindu and non-Hindu and found that non-Hindu religions have lower vaccination coverages. Similar findings were seen in the study [60], who concluded that though many parents were aware of the importance of vaccination in general, specific information on the importance of completing the schedule and knowledge on vaccine-preventable diseases other than poliomyelitis were limited.

The present study was conducted at the grassroots level in all the four blocks of Mewat district, which shows the factors like lack of awareness regarding benefits of immunization at the community level, fear of the side effects because of vaccines is some of the challenges which need to be addressed at primary care level to achieve full immunization coverage. Briefly, community preparedness can be assessed and compared between the blocks to identify high priority areas for different stakeholders.

Although, UIP vaccines have been offered free of cost to everyone by the government. The time and financial cost of reaching the health facilities can be an obstacle to the parents. Household income influences the likelihood that children receive full immunization. This result is like the results of many previous studies that show that children from wealthier families are more likely to be immunized than from poorer families [61, 62, 63].

Similar to previous research studies about the number of living children or parity status, our study also showed that mothers who had more than four children were less likely to immunize their children; many children in the family decreased the chance of children receiving full immunization. The mother might become busy fulfilling her children's need as the number of children in the family increase [64].

Children in rural areas had no significantly different probability of receiving full immunization than children in urban areas. The sources of information in the present study regarding immunization were mainly healthcare workers $703(87.9 \%)$. Similar results were found in a survey [37]. They concluded that Auxiliary Nurse Midwives (ANMs), paramedical workers, were the primary source of information regarding children's immunization. Similar findings were seen in a study [65] that the most used source of vaccine information was the health care provider, i.e. (91.7\%).

Decreasing in coverage rates was observed between the subsequent vaccine doses. The dropout rate observed in this study was exceeding the WHO acceptable dropout limits $(>10 \%)$.

The gender gap in immunization coverage has been shown to exist in all states of India. These studies showed that female children are significantly less likely to receive full immunization than their male counterparts. Similar results were observed $(\mathrm{AOR}=1.40,95 \%$ CI 1.03-1.90)) and p-value $<0.02$ in the present study. The reasons for under- and nonvaccination were multifactorial and complex. Educational status of parents, place of delivery of the child, lack of awareness of next vaccine due dose, and lack of knowledge about immunization schedule, long-distance to a health facility, big family size was identified as predictors of full immunization coverage in the study.

\section{Conclusion}

As mentioned earlier, despite the program being in operation for more than three decades, the immunization program has not only failed in achieving its target but lagging far behind the 
90\% coverage mark in the district. An unfortunate fact is that though a clear majority of the population recognized the importance of immunization, superficial knowledge of the immunization schedule and failure in motivating the target population for completing the immunization schedule has led to a large proportion of the children being partially immunized. Fear of AEFIs has also played a critical role in preventing children from getting vaccinated without proper communication to alleviate the concern by the health system.

The government should develop a comprehensive multi-pronged strategy to address vaccine hesitancy and bring out the observed changes in society's male members' attitudes and practices. These efforts should be directed in both directions. The demand side should raise the community awareness of the importance of timely completion of vaccination. From the supply side, the government should create effective communication strategies to address the fears regarding AEFIs among the community to participate in the vaccination program effectively.

Findings of our study call for a social mobilization programme which is required to prevent dropout from immunization, particularly by families of the girl children. The government and local administration must mobilize community and religious leaders to boost immunization rates and ensure equity in demand for immunization and access by children of both the genders. As a matter of policy, gender issues must be integrated into child immunization programme of the state, particularly in Mewat.

\section{Limitation}

The immunization history by mother's recall was a limitation. This is prone to systematic error (recall bias) caused by differences in accuracy of immunization information over a period up to 2 years, and most were uneducated. Since immunization status and predicting factors were assessed simultaneously, it is impossible to establish a cause-effect relationship. Despite this limitation, the results are useful for immunization program managers, the research community, and Haryana's government.

To improve immunization coverage, the Government of India has launched several programs. One of these is the Mission Indradhanush program, which provides immunization services closer to the community. Even though immunization coverage has been improving year by year in the country, it is still below the WHO standard of $80 \%$ in Mewat. This disparity might be elucidated by either household- or district-level determinants. Low maternal education levels, high poverty levels, and poor access to professional health attendants for maternal and child health services are among the district's characteristics with low immunization coverage. Mewat is having relatively few hospitals and health centers.

Our recommendations to the government could enhance the sub-health centers in the villages and ensure community empowerment. Improving health workers' communication skills can be key in imparting information about immunization to families and decision-makers. Improving mothers' and fathers' health knowledge by merely involving the community leaders would provide an approach to informing families about immunization, especially for fathers with lower formal education levels. Increasing the number of health workers (auxiliary nursing midwives) is essential for immunization coverage. The government should provide funding to increase the number of health workers at the village level. Improvement of health workers' quality has also proven an excellent policy to improve the quality of health. Finally, reducing economic inequality among all to ensure equitable coverage. 


\section{References}

[1] United Nations Inter-Agency Group for Child Mortality Estimation (UN IGME) United Nations Children's Fund; New York: 2017. Levels \& Trends in Child Mortality: Report 2017. Estimates Developed by the UN Inter-agency Group for Child Mortality Estimation.

[2] National, regional, and global levels and trends in neonatal mortality between 1990 and 2017, with scenario-based projections to 2030: a systematic analysis. Lucia Hug, Monica Alexander, Danzhen You, Leontine Alkema on behalf of the UN Interagency Group for Child Mortality Estimation. Published: June, 2019 DOI: https://doi.org/10.1016/S2214-109X(19)30163-9.

[3] https://www.who.int/immunization/monitoring_s urveillance/who-immuniz.pdf.

[4] https://www. who.int/teams/immunizationvaccines-and-biologicals/strategies/global-vaccineaction-plan.

[5] World Health Organization (WHO).2017.10 Facts on Immunization. retrieved from: http://www.who.int/features/factfiles/immunization/ en/.

[6] Gurnani V, Haldar P, Aggarwal MK, Das MK, Chauhan A, Murray J, et al. Improving vaccination coverage in India: Lessons from intensified mission Indra Dhanush, cross-sectoral systems strengthening strategy. BMJ. 2018;363: k4782.

[7] Ministry of Health and Family Welfare. Mission Indradhanush, operational guidelines. Delhi, India: MOHFW,

2014.

http://164.100.158.44/showfile.php?lid=4258.

[8] Ministry of Health and Family Welfare (MOHFW). Intensified Mission Indradhanush, operational guidelines. MOHFW, 2017.https://mohfw.gov.in/sites/default/files/Missio n\%20Indradhanush\%20Guidelines.pdf.

[9] International Institute for Population Sciences. District Level Household and Facility Survey-4: District Fact Sheet Mewat (2012-13). Mumbai: Ministry of Health and Family Welfare; 2012.

[10] International Institute for Population Sciences (IIPS) and ICF. National family health survey (NFHS-4), 2015-16: India. IIPS, 2017. https://dhsprogram.com/pubs/pdf/FR339/FR339.pdf. [11] https://nhm.gov.in/New_Updates_2018/NHM_ Components/Immunization/Guildelines_for_immuni zation/IMI_CES_Survey_Report.pdf.

[12] Immunization Division, Ministry of Health and Family Welfare, Government of India. (2019). Road Map for achieving $90 \%$ full immunization coverage in India, a guiding document for the states. MoHFW: New Delhi.

[13]Directorate of Census Operations Haryana. Census of India 2011 Haryana: Series-07: Part XIIB: District Census Handbook Mewat: Village and Town Wise Primary Census Abstract (PCA) [Internet]. Chandigarh: Ministry of Home Affairs, Government of India; 2011. http://censusindia.gov.in/2011census/dchb/0619_PA RT_B_DCHB_MEWAT.pdf.

[14]Philip, Rachel. 2017.Breaking Barriers: The Status of Adolescent Girls' Education in Mewat, Haryana. Doi. 10.13140/RG.2.2.30113.56160.

[15]Lwanga SK, Lamshhow S. Sample Determination in Health Studies; A Practical Manual. Geneva: World Health Organization; 1991. [16]Prinja S, Monga D, Rana SK, Sharma A, Dalpath S, Bahuguna P, Gupta R, Aggarwal AK. District-Level Analysis of Routine Immunization in Haryana State: Implications for Mission Indradhanush under Universal Immunization Programme. Indian J Community Med. 2018 JulSep;43(3):209-214. doi: 10.4103/ijcm.IJCM_306_17. PMID: 30294090; PMCID: PMC6166503.

[17] Angadi MM, Jose AP, Udgiri R, Masali KA, Sorganvi V. A Study of Knowledge, Attitude and Practices on Immunization of Children in Urban Slums of Bijapur City, Karnataka, India. Journal of Clinical and Diagnostic Research. 2013;7(12): 28036.

[18]WHO. Immunization Coverage [Internet]. World Heal. Organ. Fact Sheet Immun. Cover. 2016. [cited 2017 Mar 6]. Available from: http://www.who.int/mediacentre/factsheets/fs378/en. [19] Nair TN, Varughese E (1994) Immunization coverage of infants - the rural-urban difference in Kerala. Indian Pediatrics 31:139-143.

[20] Agarwal S, Bhanot A, Goindi G (2005) Understanding and addressing childhood immunization coverage in urban slums. Indian Pediatrics 42: 653-663.

[21]Desai S, Alva S (1998) Maternal education and child health: Is there a strong causal relationship? Demography 35 1: 71-81.

[22] UNICEF (2009) Coverage Evaluation Survey. Government of India, Ministry of Health and Family Welfare and UNIC EF. Available: www.unicef.org/india/health_5578.htm and www.unicef.org/india/National_Fact_Sheet_CES_2 009.pdf.

[23] Gaudin S, Yazbeck AS (2006) Immunization in India 1993-1999: Wealth, gender, and regional 
inequalities revisited. Social Science and Medicine 62: 694-706.

[24] Mohanty SK, Pathak PK (2009) Rich-poor gap in utilization of reproductive and child health care services in India, 1992-2005. Journal of Biosocial Sciences 41 3: 381-398.

[25] Arokiasamy P, Pradhan J (2011) Measuring wealth-based health inequality among Indian children: the importance of equity vs. efficiency. Health Policy and Planning 26: 429-440.

[26] Dalal A, Silveira MP (2005) Immunization status of children in Goa. Indian Paediatrics 42: 401-402.

[27] Kumar A, Mohanty SK (2011) Socioeconomic differentials in childhood immunization in India, 1992-2006. Journal of Population Research 28 4: 301-324.

[28] Pande R (2003) Selective Gender differences in childhood nutrition and immunization in rural India: The role of siblings. Demography 40: 395-418.

[29] Corsi DJ, Bassani DG, Kumar R, Awasthi S, Jotkar R, et al. (2009) Gender inequity and ageappropriate immunization coverage in India from 1992 to 2006. BMC International Health Human Rights 14 Suppl. 1: S3-9.

[30] Singh P, Yadav RJ (2000) Immunization status of children of India. Indian Pediatrics 37: 1194 1199.

[31]Phukan RK, Barman MP, Mahanta J (2009) Factors associated with immunization coverage of children in Assam, India: over the first year of life. Journal of Tropical Pediatrics 55: 249-252.

[32] Babirye JN, Engebretsen IMS, Makumbi F, Fadnes LT, Wamani H, Tylleskar T, et al. timeliness of childhood vaccinations in Kampala Uganda: a community-based cross-sectional study. PLoS One. 2012; 7:1-6. 24.

[33] Etana B, Deressa W, Angela G, Zulfiqar B, Lulu B, Aly G, et al. Factors associated with complete immunization coverage in children aged 12-23 months in ambo Woreda, Central Ethiopia. BMC Public Health. 2012; 12:566. 25.

[34]Reynolds HW, Wong EL, Tucker H. Adolescents' use of maternal and child health services in developing countries. Int Fam Plan Perspect. 2006; 32:6-16.

[35] Nath L, Kaur P, Tripathi S. Evaluation of the universal immunization program and challenges in coverage of migrant children in Haridwar, Uttarakhand, India. Indian $\mathrm{J}$ Community Med [Internet] [cited 2020 Nov 10]. Available from: http://www.ijcm.org.in/article.asp?issn=0970-
0218 ; year $=2015 ;$ volume $=40 ;$ issue $=4$; spage $=239$; epa ge $=245$; aulast $=$ Nath .

[36] Vohra. Immunization coverage and its determinants among 12-23 months old children of Lucknow [Internet] [cited 2020 Nov 10]. Available from: http://www.mjmsr.net/article.asp?issn=09759727; year $=2013$; volume $=4$;issue $=2$; spage $=90$; epage $=95$; aulast $=$ Vohra.

[37] Nath B, Singh JV, Awasthi S, Bhushan V, Kumar V, Singh SK. A study on determinants of immunization coverage among 12-23 months old children in urban slums of Lucknow district, India. Indian J Med Sci. 2007; 61:598-606.

[38] Madhavi N, Manikyamba D. Evaluation of immunization status and factors responsible for dropouts in primary immunization in children between 1-2 years - A hospital-based study. Pediatr Rev Int J Pediatr Res. 2016; 3:332. Available from: http://medresearch.in/index.php/IJPR/article/view/74 7.

[39] Singhal G, Mathur H, Dixit M, Khandelwal A. Factors affecting immunization among children of the rural population of block Malpura, district Tonk, Rajasthan, India. Int J Community Med Public Health. 2016; 3:641-6.

[40]Kumar D, Aggarwal A, Gomber S. Immunization status of children admitted to a tertiary-care hospital of North India: Reasons for partial immunization or non-immunization. J Health, Popul Nutr. 2010;28(3):300-4.

[41] Kumar A, George K, Bose A. Immunization coverage among children aged 12-23 months in Surajgarha Block, Lakhisarai District, Bihar: A cluster sampling survey. National J Community Med. 2018; 9:5.

[42] Ahmad J, Khan ME, Hazra A. Increasing complete immunization in rural Uttar Pradesh. J Fam Welf. 2010; 56:65-72.

[43] Datta A, Baidya S, Datta S, Mog C, Das S. A study to find out the full immunization coverage of 12- to 23-month-old children and areas of underperformance using LQAS technique in a Rural Area of Tripura. J Clin Diagn Res JCDR. 2017;11:LC014.

[44] Murhekar MV, Kamaraj P, Kanagasabai K, Elavarasu G, Rajasekar TD, Boopathi K, et al. Coverage of childhood vaccination among children aged 12-23 months, Tamil Nadu, 2015, India. Indian J Med Res. 2017; 145:377.

[45] Khargekar NC, Khargekar VC, Shingade PP. Immunization status of children under 5 years in a Tribal Area, Parol, Thane District. Natl J Community Med. 2015; 6:522-7. 
[46] Kadri AM, Singh A, Jain S, Mahajan RG, Trivedi A. Study on immunization coverage in urban slums of Ahmedabad City. Indian J Public Health Res Dev. 2010; 33:5.

[47]Prusty RK, Kumar A (2014) Socioeconomic Dynamics of Gender Disparity in Childhood Immunization in India, 1992-2006. PLoS ONE 9(8): e104598. doi: 10.1371/journal.pone.0104598.

[48] Parpiev Z, Yusupov K (2009) Intrahousehold gender-based discrimination among children in Uzbekistan. Working paper, No 09/10E. Economics Education and Research Consortium.

[49] Nasir R, Kalla AK (2006) Kinship system, fertility, and son preferences among the Muslims: A review. Anthropologist 8 4: 275-281.

[50] Pande R, Astone NM (2007) Explaining son preference in rural India: The independent role of structural versus individual factors. Population Research and Policy Review 26(1):1-29.

[51] Partha D, Bhattacharya BN. Determinants of child immunization in four less-developed states of north India. J Child Health Care. 2002 Mar;6(1):3450. doi: 10.1177/136749350200600105. PMID: 12036175 .

[52]Rammohan A, Awofeso N, Fernandez RC. Paternal education status significantly influences infants' measles vaccination uptake, independent of maternal education status. BMC Public Health. 2012;12(1):336. （http://dx.doi.org/10.1186/14712458-12-336).

[53] Mathew JL. Inequity in childhood immunization in India: a systematic review. Indian Pediatr. 2012;49(3):203-223. http://dx.doi.org/10.1007/s13312-012-0063-z. [54] Vikram K., Vanneman R., Desai S. Linkages between maternal education and childhood immunization in India. Soc. Sci. Med. 2012; 75:331-339. doi: 10.1016/j.socscimed.2012.02.043. [55]P.K. Singh, C. Kumar, R.K. Rai, L. Singh. Factors associated with maternal healthcare services utilization in nine high focus states in India: a multilevel analysis based on 14385 communities in 292 districts. Health Policy Plan, 29 (5) (2014), pp. 542-559. (http://dx.doi.org/10.1093/heapol/czt039). [56]Kumar A, Mohanty SK. Socioeconomic differentials in childhood immunization in India,
1992-2006. J Popul Res. 2011;28(4):301-324. (http://dx.doi.org/10.1007/s12546-011-9069-y).

[57] Joe W, Mishra US, Navaneetham K. Socioeconomic inequalities in child health: recent evidence from India. Glob Public Health. 2010;5 (5):493-508. (http://dx.doi.org/10.1080/17441690903213774). [58] Fernandez R, Rammohan A, Awofeso N. Correlates of the first dose of measles vaccination delivery and uptake in Indonesia. Asian Pac J Trop Med. 2011; 4:140-5. 14.

[59] Gatchell M, Thind A, Hagigi F. Informing statelevel health policy in India: the case of childhood immunizations in Maharashtra and Bihar. Acta Paediatr. 2008;97(1):124-126.

(http://dx.doi.org/10.1111/j.1651-

2227.2007.00569.x)

[60] Manjunath U, Pareek RP. Maternal knowledge and perceptions about the routine immunization program. A study in a semi-urban area in Rajasthan. India J Med Sci. 2003; 57:158-63.

[61] Mbengue MAS, Sarr M, Faye A, Badiane O, Camara FBN, Mboup S, et al. Determinants of complete immunization among Senegalese children aged 12-23 months: evidence from the demographic and health survey. BMC Public Health. 2017; 17:630. 39.

[62] Lakew Y, Bekele A, Biadgilign S. Factors influencing full immunization coverage among 1223 months of age children in Ethiopia: evidence from the national demographic and health survey in 2011. BMC Public Health. 2015; 15:728. 40.

[63] Adedokun ST, Uthman OA, Adekanmbi VT, Wiysonge CS. Incomplete childhood immunization in Nigeria: a multilevel analysis of individual and contextual factors. BMC Public Health. 2017; 17:236.

[64] Sia D, Fournier P, Kobiané J-F, Sondo BK. Rates of coverage and determinants of complete vaccination of children in rural areas of Burkina Faso (1998-2003). BMC Public Health. 2009; 9:416. [65] Abbey M. Jones, Saad B. Omer, Rober A. Bednarczyk, Neal A. Halsey, Lawrence H. Moulton, and Daniel A. Salmon. Advances in Preventive Medicine. Volume 2012, Article ID 932741. Doi:10.1155/2012/932741. 


\title{
Effectiveness of Mobile Phone Reminders in Improving Adherence and Treatment Outcomes of Patients on Art in Adamawa State, Nigeria: A Ramdomized Controlled Trail
}

\author{
Kabiru Usman Suru ${ }^{1 *}$, J E Chiegil ${ }^{1}$, S O Adeyemi ${ }^{2}$, O F Martins ${ }^{2}$ \\ ${ }^{1}$ Department of Public Health, Texila American University Guyana \\ ${ }^{2}$ Department of Public Health, Federal Medical Centre Yola, Adamawa State, Nigeria
}

\begin{abstract}
Adherence to antiretroviral therapy (ART) among people living with human immunodeficiency virus (PLHIV) is very imperative in achieving successful treatment outcome and decreased risk of HIV transmission to uninfected people. This is a randomized controlled trial study conducted in Adamawa State, Nigeria. 244 patients were randomized to intervention or control group. Data obtained from the study was analyzed using SPSS Version 21. Frequencies distributions, descriptive statistics were presented, Inferential statistics such as Pearson Chi square, McNemar's test, Paired T test, correlation and repeated measures ANOVA were used to measure the strength of associations and relationships between the various variables and probability of statistically significant level set $<0.05$ at $95 \%$ Confidence interval. The response rates in the intervention and control groups were $99 \%$ and $96.7 \%$ at 3 months; $97.5 \%$ and $92.6 \%$ at 6 months, respectively. Individual socio-demographic characteristics were not found to be associated with adherence levels in this study. At six months follow up the proportion of the respondents who had good adherence (>95\%) was higher (89.1\%) and statistically significant $(p=0.001)$ in the intervention group compared to control group $(63.1 \%)$ and $(p=0.617)$. A significantly higher frequency in missed clinic appointments (7.98 vs 1.68) $(p=0.024)$ was noticed in the control group, and a statistically significant increase in the proportion of participants who reported an increase in weight $(p=0.001), C D 4$ cells counts $(p=0.001)$ and decrease in the presence of tuberculosis and other opportunistic infections were observed among patients in the intervention group.
\end{abstract}

Keywords: Adherence, Antiretroviral Therapy (ART), CD4 cell count, Nigeria, People Living with HIV (PLWH).

\section{Introduction}

The HIV/AIDS pandemic remains a major public health problem worldwide, more especially in sub-Saharan Africa. About 36.9 million people are living with HIV/AIDS globally as at 2017 , of which $69.93 \%$ reside in African countries [1]. Nigeria has the second highest burden of people living with HIV (PLHIV) in the world after South Africa [2]. As of 2017 about 3.1 million people are currently estimated to be living with HIV in Nigeria, and about 880,668 PLHIV are receiving treatment, (34\% and $24 \%$ of Adult and children living with HIV are on ART) [1]. According to UNAID report in 2018, approximately 150,000 people died from AIDS-related illnesses in Nigeria in 2017 [1]. Adamawa state with Yola as capital is located in the northeastern region of Nigeria and has a prevalence of $2.5 \%$. This is comparatively lower than the neighboring states Taraba and Gombe which have a prevalence of $5.2 \%$ and $3.4 \%$ respectively [3] and higher than Borno State which is $1.1 \%$ [3].

The goal of HIV treatment is to reduce HIVassociated morbidity and mortality, restored and preserved immunologic function, sustain viral suppression, and prevent transmission of HIV infection and subsequently prolonged duration of survival. But unfortunately, maintaining adequate levels of adherence to antiretroviral medications has become a challenge to many people living with HIV, and even healthcare providers, because a failing regimen as a result of poor adherence leads to increased opportunistic infections, increased hospitalization, and outpatient visits, thereby increasing the workload to health care providers. Inadequate adherence to treatment is also associated with decrease CD4 counts, increase 
detectible viral loads, disease progression, frequent reoccurrence of opportunistic infections, and deteriorating health outcomes [4].

According to $\mathrm{WHO}, 95 \%$ minimum adherence is required to achieve treatment success [5]. Although the roll-out of antiretroviral therapy significantly reduced human immunodeficiency virus related morbidity and mortality, access and adequate adherence to treatment are needed to achieve good clinical outcomes [6]. However, in Nigeria this is still a major problem due to problem of poor adherence to ART. In one of the studies conducted in Nigeria, adherence level among the PLWHIV on ART was just $73.4 \%$ [7]. Forgetfulness, too busy to remember, wanting to avoid side effects, lack of social support, negative perceptions, poor communication with providers, stigma and discrimination, non-disclosure of status and pills burden are some of the major contributing factors to the non-adherence to ART.

Mobile phones present a promising means to improve patient adherence and health outcomes. Though, there is finite information on the effect of mobile phones for health programs on ART adherence or the behavior change processes through which such interventions may improve patient health outcome [8]. Poor adherence to antiretroviral therapy is a critical challenge in achieving good HIV treatment outcome in Nigeria. It results in suboptimal viral suppression, increase viral replication, emergence of drug resistance, treatment failure and loss of future treatment options [9]. Therefore, it is very imperative to ensure strict adherence to Antiretroviral (ARV) medications to achieve sustained HIV viral suppression, reduced risk of drug resistance, improved overall health, quality of life, and survival, as well as decreased risk of HIV transmission to uninfected people. This will also reduce the need for more frequent, complicated regimens which are relatively expensive and add more burden to both patients and government [9]. Monitoring people on antiretroviral therapy (ART) is important to ensure successful treatment, identify adherence problems, and determine whether to switched ART regimen or not in case of treatment failure.

With the rapid increase of PLWHIV commenced on ART due to rapid expansion of ART centers and the implementation of the 2016 National Guidelines for HIV prevention treatment and care in Nigeria, which recommended test and start, the possibility of poor retention to ART may likely be higher if nothing is done to strengthen adherence among PLWHIV. The use of mobile phones to remind the clients on their appointment schedule in country with more than 80 million people using mobile phone may possibly improve the retention of clients on Antiretroviral treatment. This research is also consistent with current PEPFAR and WHO guidelines recommendation on mobile phone text messages, or SMS, reminders to promote ART adherence among HIV-positive patients on ART [10, 11]. However, its utilization is low in many resource limited countries, including Nigeria. Although many studies have been carried out worldwide on the effectiveness of mobile phone reminders on adherence and patient retention, little is available in the literature concerning such works in northeastern Nigeria, hence the decision to carry out this study.

This study aimed to evaluate the effectiveness of mobile phone reminders and patient tracking in improving medication adherence, clinic attendance, retention to care and clinical outcomes of anti-retroviral therapy among PLWHIV enrolled in to care and treatment at selected hospital in Adamawa, Nigeria.

\section{Methods}

A randomized control clinical trial study was conducted in five selected comprehensive Antiretroviral Therapy (ART) sites located across the three geo-political zone in Adamawa state, Nigeria (Federal Medical Centre (FMC) Yola, State Specialist Hospital Yola, St Francis Hospital Jambutu in Yola, General hospital Mubi and General hospital Mayo Belwa), to assess the effectiveness of mobile phone reminders and patient tracking on adherence, retention and clinical outcomes among clients on anti-retroviral therapy. This study was conducted from November 2017 to May 2018. The study population were all adult HIVpositive patients who were enrolled in to care and initiated on ART three month before the study at the ART clinics in Federal medical centre Yola, Specialist hospital Yola, St Francis Hospital Yola, General Hospital Mubi and General hospital Mayo Belwa, based on the Nigeria 2016 National Guidelines for HIV prevention treatment and care. Clients from 18 years and above initiated on ART for at least 
three months before the study in ART clinic at five selected sites with valid telephone numbers, able to read text messages were included in the study. While clients less than 18 years, less than 3 months on ART, restarting ART due to previous history of defaulting, Pregnant patients and clients transferred inn from other facilities were excluded from the study.

Sample size estimation: The sample size was calculated using the formula below [12].

$$
n=\frac{\left\{Z_{1-\alpha} / 2 \sqrt{2 \bar{P}(1-\bar{P})}+Z_{1-\beta} \sqrt{\left(P_{1}\left(1-P_{1}\right)+P_{2}\left(1-P_{2}\right)\right.}\right\}}{2}
$$

The largest sample size was obtained for the outcome variable of adherence to Antiretroviral therapy. For an estimated improvement in adherence to antiretroviral therapy.

Where:

$\mathrm{P}_{1}=0.95$ (Desired level of adherence to ART)

$\mathrm{P}_{2}=0.81$ (Shittu RO, et al. 2013) Baseline

$$
\begin{gathered}
\overline{\mathrm{P}}=\mathrm{P}_{1}+\mathrm{P}_{2} / 2=0.95+\frac{0.81}{2}=\frac{1.76}{2}=0.88 \\
\mathrm{Z}_{1-\alpha / 2}=1.96 \text { at } 95 \% \mathrm{CI} \\
\mathrm{Z}_{1-\beta}=1.282 \text {, at } 90 \% \text { power }
\end{gathered}
$$

$$
\begin{gathered}
n=\frac{\{1.96 \sqrt{2 \times 0.88 \times(1-0.88}+1.282 \sqrt{0.95(1-0.95)+0.81(1-0.81)}\}^{2}}{(0.95-0.81)^{2}} \\
n=\frac{\{1.96 \sqrt{0.2112}+1.282 \sqrt{0.0475+0.1539}\}^{2}}{0.14^{2}} \\
=\frac{\{.9+0.575\}^{2}}{0.0196} \\
n=1166
\end{gathered}
$$

$n=111 \times 2=222,10 \%$ attrition $=22$.

Total $=222+22=244$.

The clinic ART patients' registers containing the list of all HIV-positive patients initiated on ART based on the 2016 Nigeria, national guideline for HIV prevention treatment and care from August 2017 to October 2017 at the five selected recruitment sites was used as the sampling frame.

A simple random sampling method was used to select the eligible clients for the study from the study population. Color-coded cards were used to allocate participants to intervention and control group. A total of 244 color coded cards put in separate sealed opaque envelopes (122 green cards represented intervention group; 122 white cards represented the control group). Client could pick a single envelope one by one under the supervision of the trained research assistants. The research assistant opened the sealed envelope and used the colour code to know which group the client belonged and so determined who received the intervention and who did not base on their chosen colour. A single blinded technique was used with clients not knowing which group they belonged to the respondents in both the control and intervention group received routine adherence counselling session, clinical symptoms, TB status screening, Opportunistic infections screening, weight measurement at baseline, 3 months and 6 months, CD4 count was measured at based line and 6 months. In addition to these standard cares the intervention group received a minimum of three (at based line, 3 and month 6) individual counselling sessions with the research assistants lasting an average of 10 minutes per encounter, weekly text message medication reminder, text message reminders 3 days before scheduled clinic appointments and phone call a day to appointment scheduled by the trained research assistants for the period of six months. The clients who did not show up for their medication refills were tracked by the trained research assistant. 


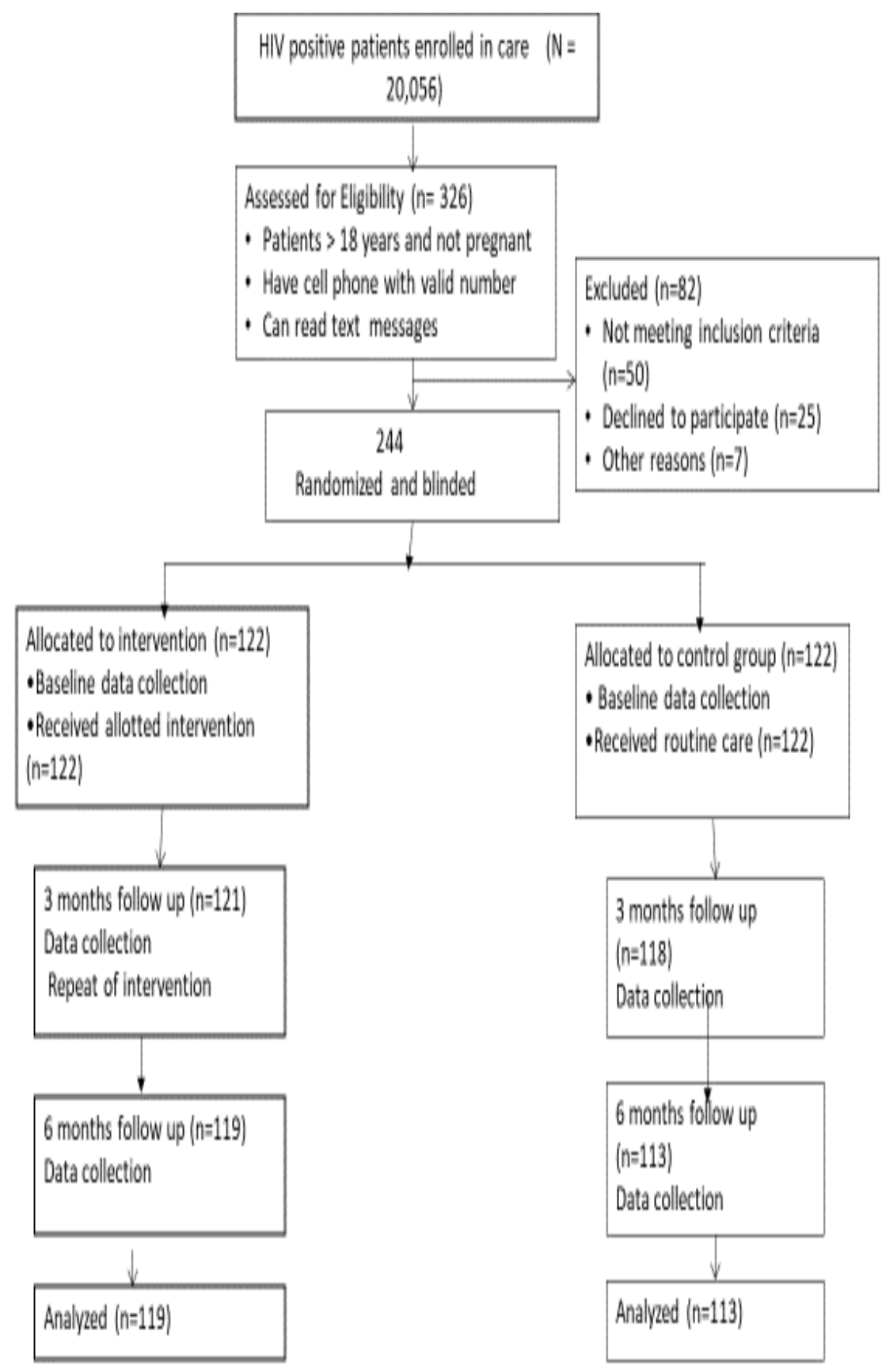

Figure 1. Flow Diagram of Patient Participants in a Randomized Clinical Trial Conducted among HIV Positive Patient in 5 Selected Comprehensive ART Sites in Adamawa State, Nigeria

The primary and secondary data for both the control and intervention groups were collected at baseline, 3 months and 6 months using a standard adherence questionnaire and approved hospital client's medical records tools. Data obtained from the study was coded and entered into Statistical Package for Social Sciences (SPSS) Version 21. The data was checked and cleared for double entry and outliers before analysis was done. The data analysis was conducted using frequencies distributions, descriptive statistics (means, standard deviation, standard error of mean). Inferential statistics such as Pearson Chi square, McNemar's test and correlation were used to determine associations and relationships. The confidence interval was set at $95 \%$ for mean estimations. The level of significance; alpha $(\alpha)$ was set at 0.05 . A decision rule to reject the null hypothesis when $p$ is less than 0.05 .

Ethical Consideration: Ethical clearance was obtained from the Adamawa State Ministry of 
Health, Department of Research and Statistics, Ethical Committee. A written and signed informed consent was obtained from each participant before he or she was enrolled into the study.

\section{Results}

A total of two hundred and forty-four (244) HIV-positive patients were recruited from five HIV/AIDS clinics providing comprehensive Antiretroviral Therapy (ART) in Adamawa State and participated in the study. At baseline, the intervention and control groups had an equal number of 122 participants each. The response rates in the intervention and control groups were 99\% and $96.7 \%$ at 3 months; $97.5 \%$ and $92.6 \%$ at 6 months, respectively. Out of the five patients lost in the two groups, only one was lost to follow up in the intervention group while in the control group, two were lost to follow up and two died. By the 6-month follow-up period, three participants had died, three transferred to other facilities while six were lost to follow up.

\section{Baseline Socio-demographic Characteristics of the Respondents}

Most of the respondents were middle aged with the highest proportion of $37.7 \%$ within the 36 - 45 years age grouping in the intervention group and $39.3 \%$ within the $26-35$ years age grouping in the control group. A higher proportion of the participants were females in both the intervention (64.8\%) and control (63.1\%) groups (Table 1). About a third of the participants had a tertiary educational degree in both groups and half were married and Christians (Table 1). More of the respondents were from the smaller ethnic groups (intervention $=60.7 \%$; control $=64.8 \%$ ) and were self-employed (intervention $=34.4 \%$ control $=41.8 \%)$ (Table 1). More people reported to have monthly income between $\mathrm{N} 5,000$ and $\mathrm{N} 20,000$ and residing in urban areas in both the intervention and control groups (Table 1).

Table 1. Baseline Distribution of Socio-demographic Characteristics of Respondents in Intervention and Control Groups

\begin{tabular}{|c|c|c|c|c|c|}
\hline \multirow[t]{2}{*}{ Variables } & \multirow{2}{*}{\multicolumn{2}{|c|}{ Intervention }} & \multicolumn{2}{|c|}{ Control } & \multirow[t]{2}{*}{ p-value } \\
\hline & & & $\mathbf{N o}^{0}$ & & \\
\hline \multicolumn{6}{|l|}{ Age } \\
\hline $18-25$ & 9 & 7.4 & 11 & 9.0 & \multirow[t]{4}{*}{$0.822^{\mathrm{a}}$} \\
\hline $26-35$ & 43 & 35.2 & 48 & 39.3 & \\
\hline $36-45$ & 46 & 37.7 & 40 & 32.8 & \\
\hline$>45$ & 24 & 19.7 & 23 & 18.9 & \\
\hline \multicolumn{6}{|l|}{ Gender } \\
\hline Male & 43 & 35.2 & 45 & 36.9 & \multirow[t]{2}{*}{$0.790^{\mathrm{b}}$} \\
\hline Female & 79 & 64.8 & 77 & 63.1 & \\
\hline \multicolumn{6}{|l|}{ Marital Status } \\
\hline Single & 28 & 23.0 & 29 & 23.8 & \multirow[t]{5}{*}{$0.984^{\mathrm{a}}$} \\
\hline Married & 63 & 51.6 & 66 & 54.1 & \\
\hline Separated & 11 & 9.0 & 10 & 8.2 & \\
\hline Divorced & 7 & 5.7 & 6 & 4.9 & \\
\hline Widow/Widower & 13 & 10.7 & 11 & 9.0 & \\
\hline \multicolumn{6}{|l|}{ Religion } \\
\hline Christianity & 66 & 54.1 & 64 & 52.5 & \multirow[t]{2}{*}{$0.797^{\mathrm{b}}$} \\
\hline Islam & 56 & 45.9 & 58 & 47.5 & \\
\hline \multicolumn{6}{|l|}{ Education } \\
\hline Non-formal & 24 & 19.7 & 24 & 19.7 & $0.992^{\mathrm{a}}$ \\
\hline Primary & 19 & 15.6 & 19 & 15.6 & \\
\hline Secondary & 36 & 29.5 & 38 & 31.1 & \\
\hline Tertiary & 43 & 35.2 & 41 & 33.6 & \\
\hline \multicolumn{6}{|l|}{ Ethnicity } \\
\hline Fulani & 31 & 25.4 & 29 & 23.8 & $0.774^{\mathrm{a}}$ \\
\hline
\end{tabular}




\begin{tabular}{|l|l|l|l|l|l|}
\hline Hausa & 17 & 13.9 & 14 & 11.5 & \\
\hline Others & 74 & 60.7 & 79 & 64.8 & \\
\hline Employment Status & 32 & 26.2 & 29 & 23.8 & $0.686^{\text {a }}$ \\
\hline Unemployed & 42 & 34.4 & 51 & 41.8 & \\
\hline Self-employed & 39 & 32.0 & 35 & 28.7 & \\
\hline Civil Servant & 9 & 7.4 & 7 & 5.7 & \\
\hline Others \\
\hline Residential Location \\
\hline Rural & 39 & 32.0 & 37 & 30.3 & $0.954^{\text {a }}$ \\
\hline Semi-Urban & 35 & 28.7 & 35 & 28.7 & \\
\hline Urban & 48 & 39.3 & 50 & 41.0 & \\
\hline Monthly Income (Naira) & 31 & 25.4 & 29 & 23.8 & $0.856^{\text {a }}$ \\
\hline$<5,000$ & 50 & 41.0 & 55 & 45.1 & \\
\hline $5000-20000$ & 21 & 17.2 & 22 & 18.0 & \\
\hline $20000-50000$ & 20 & 16.4 & 16 & 13.1 & \\
\hline$>50000$ &
\end{tabular}

${ }^{a}$ p-value obtained by Chi-Square Test

${ }^{b}$ p-value obtained by McNemar's

$*$ Sig at $\mathrm{p}<0.05$

\section{Analysis of Effectiveness of Intervention on Medication Adherence}

A repeated measures analysis was performed to determine the effect of the intervention on the groups and the interaction between the groups.

In the intervention group, a statistically significant increase in percentage was observed between the baseline and 6-month time periods (Table 2). There was an increase of $19.4 \%$ in the proportion of respondents who had a good level of adherence to medication between baseline and 6 months $(\mathrm{p}<0.001)$. Meanwhile, in the control group, the proportion of participants with good adherence level to medication decreased by $14.8 \%$ (Table 3). This change in the levels was not statistically significant $(\mathrm{p}=0.617)$.

Between the 3 months and 6-months periods in the intervention group, there was a $4.7 \%$ increase in the proportion of participants who had a good level of adherence to medications (Table 2). The change in the level of adherence between the two time periods was statistically significant $(\mathrm{p}<0.001)$. In the control group, there was a decrease in the percentage of people who adhered to their medications by $6.6 \%$.

Table 2. Change in the Level of Adherence Following Intervention in the Intervention Group

\begin{tabular}{|l|l|l|l|l|}
\hline Medication Adherence & \multicolumn{2}{|l|}{ Frequency n (\%) } & Change in \% & p-value \\
\hline & Baseline & 3-month follow up & & \\
\hline Poor (> 80\%) & $4(3.3)$ & $0(0.0)$ & & \\
\hline Fair $(80-95 \%)$ & $33(27.0)$ & $18(14.8)$ & & \\
\hline Good (> 95\%) & $85(69.7)$ & $103(84.4)$ & 14.7 & $0.001^{\text {a } *}$ \\
\hline Total & $122(100)$ & $121(99.2)$ & & \\
\hline & Baseline & 6-month follow up & & \\
\hline Poor (> 80\%) & $4(3.3)$ & $0(0.0)$ & & \\
\hline Fair $(80-95 \%)$ & $33(27.0)$ & $13(10.7)$ & & $0.001^{\text {a* }}$ \\
\hline Good (>95\%) & $85(69.7)$ & $106(89.1)$ & 19.4 & \\
\hline Total & $122(100)$ & $119(97.5)$ & & \\
\hline & 3-month follow up & 6-month follow up & & \\
\hline Poor $(>80 \%)$ & $0(0.0)$ & $0(0.0)$ & & $0.001^{\text {a* }}$ \\
\hline Fair $(80-95 \%)$ & $18(14.8)$ & $13(10.7)$ & & \\
\hline Good $(>95 \%)$ & $103(84.4)$ & $106(89.1)$ & 4.7 & \\
\hline Total & $121(99.2)$ & $119(97.5)$ & & \\
\hline
\end{tabular}

${ }^{a} p$ value was calculated using McNemar's Test

*significant at $<0.05$ 
Table 3: Change in the Level of Adherence Following Intervention in the Control Group

\begin{tabular}{|l|l|l|l|l|}
\hline \multirow{2}{*}{ Medication Adherence } & \multicolumn{2}{|l|}{ Frequency } & Change in \% & \multirow{2}{*}{ p-value } \\
\cline { 2 - 3 } & N $(\%)$ & & \\
\hline & Baseline & 3-month follow up & & \\
\hline Poor $(>80 \%)$ & $7(5.7)$ & $6(4.9)$ & & \\
\hline Fair $(80-95 \%)$ & $20(16.4)$ & $27(22.1)$ & & \\
\hline Good (> 95\%) & $95(77.9)$ & $85(69.7)$ & -8.2 & $0.774^{\text {a }}$ \\
\hline Total & $122(100)$ & $121(99.2)$ & & \\
\hline & Baseline & 6-month follow up & & \\
\hline Poor $(>80 \%)$ & $7(5.7)$ & $4(3.3)$ & & \\
\hline Fair $(80-95 \%)$ & $20(16.4)$ & $32(26.2)$ & & \\
\hline Good $(>95 \%)$ & $95(77.9)$ & $77(63.1)$ & -14.8 & \\
\hline Total & $122(100)$ & $113(92.6)$ & & \\
\hline & $\mathbf{3 - m o n t h}$ follow up & $\mathbf{6 - m o n t h}$ follow up & & \\
\hline Poor $(>80 \%)$ & $6(4.9)$ & $4(3.3)$ & & \\
\hline Fair $(80-95 \%)$ & $27(22.1)$ & $32(26.2)$ & & \\
\hline Good $(>95 \%)$ & $85(69.7)$ & $77(63.1)$ & -6.6 & \\
\hline Total & $121(99.2)$ & $113(92.6)$ & & \\
\hline
\end{tabular}

ap value was calculated using McNemar's Test

* significant at $<0.05$

\section{Analysis of Effectiveness of Intervention on Clinic Attendance}

At three months, out of the total participants in the intervention group (121), only 4(3.3) participants missed their clinic appointment while 9 participants (7.63) missed their clinic appointment in the control group. While at six months, out of the total participants in the intervention group (119), only 2 (1.68) participants missed their clinic appointment while 9 participants (7.9.8) missed their clinic appointment in the control group (Table 4).

The intervention had a positive change in the frequency of clinic appointments among the HIV patients in Adamawa State. The results that there was an equal proportion of participants (117) who did not miss their clinic appointments at 3 months in the intervention group. The proportion was maintained across the time periods (Table 5). After 3 months, one participant was lost to follow up in the intervention group and 3 after 6 months. In the control group, 4 and 9 participants were lost to follow up or died at 3 months and 6 months respectively. The proportion of participant who missed clinic appointment in the control group reduced from $109(89.3 \%)$ to 104 $(85.2 \%)$ in the control group (Table 6).

Table 4. Distribution of Participants' Missed Clinic Appointment in Intervention and Control Group

\begin{tabular}{|l|l|l|l|l|l|l|}
\hline Outcome: Missed Clinic Appointment & Intervention & Control & \multicolumn{2}{l|}{ p-value } \\
\cline { 2 - 6 } & $\mathbf{N} \%$ & N \% & \multicolumn{2}{l|}{} \\
\hline 3 Months & 117 & 96.69 & 109 & 92.37 & $0.141^{\text {a }}$ \\
\hline No & 4 & 3.3 & 9 & 7.63 & \\
\hline Yes & $\mathbf{1 2 1}$ & $\mathbf{1 0 0}$ & $\mathbf{1 1 8}$ & $\mathbf{1 0 0}$ & \\
\hline Total & 117 & 98.32 & 104 & 92.04 & \multirow{2}{*}{$0.024^{\text {a* }}$} \\
\hline 6 Months & 2 & 1.68 & 9 & 7.96 & \\
\hline No & $\mathbf{1 1 9}$ & $\mathbf{1 0 0}$ & $\mathbf{1 1 3}$ & $\mathbf{1 0 0}$ & \\
\hline Yes &
\end{tabular}

ap-value calculated by McNemar's test

*Significant at $\mathrm{p}<0.05$ 
Table 5. Change in Missed Clinic Attendance in the Intervention Group

\begin{tabular}{|l|l|l|l|l|}
\hline \multirow{2}{*}{ Items } & \multicolumn{2}{|l|}{ Frequency } & Change in \% & p-value \\
\cline { 2 - 5 } & N $(\%)$ & & \\
\hline Missed Clinic Appointment & 3-month follow up & 6-month follow up & & \\
\hline No & $117(95.9)$ & $117(95.9)$ & 0.00 & $1.000^{\mathrm{a}}$ \\
\hline Yes & $4(3.3)$ & $2(1.6)$ & 1.5 & \\
\hline Lost to follow up/death/transfer & $1(0.8)$ & $3(2.5)$ & 1.7 & \\
\hline Total & $\mathbf{1 2 2}(\mathbf{1 0 0})$ & $\mathbf{1 2 2}(\mathbf{1 0 0})$ & & \\
\hline
\end{tabular}

${ }^{a} \mathrm{p}$-value calculated by McNemar's test

*Significant at $\mathrm{p}<0.05$

Table 6. Change in Missed Clinic Attendance in the Control Group

\begin{tabular}{|l|l|l|l|l|}
\hline \multirow{2}{*}{ Items } & \multicolumn{2}{|l|}{ Frequency } & Change in \% & \multirow{2}{*}{ p-value } \\
\cline { 2 - 3 } & N (\%) & & \\
\hline Missed Clinic Appointment & 3-month follow up & 6-month follow up & & \\
\hline No & $109(89.3)$ & $104(85.2)$ & 4.1 & $1.000^{\text {a }}$ \\
\hline Yes & $9(7.4)$ & $9(7.4)$ & 0.0 & \\
\hline Lost to follow up/death/transfer & $4(3.3)$ & $9(7.4)$ & -4.1 & \\
\hline Total & $\mathbf{1 2 2}(\mathbf{1 0 0})$ & $\mathbf{1 2 2}(\mathbf{1 0 0})$ & & \\
\hline
\end{tabular}

a $\mathrm{p}$ value was calculated using McNemar's Test

*significant at $<0.05$

\section{Analysis of Effectiveness of Intervention on Clinical Outcome}

The change in clinical outcome of the HIV patients was measured by evaluating the following variables: weight, CD4 cell count, presence of tuberculosis and other opportunistic infections. A statistically significant increase in the proportion of participants who reported an increase in weight, CD4 cells counts and a decrease in the presence of tuberculosis and other opportunistic infections is an indication of the effectiveness of the intervention.

\section{Changes in Weight Following Intervention}

The change in the participants' weight between the baseline to 3-month follow-up; baseline to 6-month follow-up and 3-month and 6-month follow up periods were statistically significant $(\mathrm{p}<0.001)$ in the intervention group (Table 7). However, in the control group, the change observed between the baseline and 3month follow up was not statistically significant $(p=0.300)$ but the change observed among the two other times compared was statistically significant $(\mathrm{p}<0.001)$ (Table 8).

Table 7. Change in Weight Following Intervention Administration in the Intervention Group

\begin{tabular}{|l|l|l|l|l|}
\hline \multirow{2}{*}{ Weight } & \multicolumn{2}{|l|}{ Frequency } & Change in \% & p-value \\
\cline { 2 - 3 } & $\mathbf{N}(\%)$ & & \\
\hline & Baseline & 3-month follow up & & \\
\hline$>25 \mathrm{~kg}$ & $1(0.8)$ & $1(0.8)$ & & \\
\hline $26-50 \mathrm{~kg}$ & $40(32.8)$ & $38(31.1)$ & & \\
\hline $51-75 \mathrm{~kg}$ & $72(59.0)$ & $72(59.0)$ & & \\
\hline $75-100 \mathrm{~kg}$ & $9(9)$ & $7(5.7)$ & -3.3 & $0.001^{\text {a* }}$ \\
\hline Total & $\mathbf{1 2 2}$ & $\mathbf{1 1 8}$ & & \\
\hline & Baseline & $\mathbf{6 - m o n t h}$ follow up & & \\
\hline$>25 \mathrm{~kg}$ & $1(0.8)$ & $0(0.0)$ & & \\
\hline $26-50 \mathrm{~kg}$ & $40(32.8)$ & $32(26.2)$ & & \\
\hline $51-75 \mathrm{~kg}$ & $72(59.0)$ & $72(59.0)$ & & \\
\hline $75-100 \mathrm{~kg}$ & $9(9)$ & $9(7.4)$ & -1.6 & $0.001^{\text {a* }}$ \\
\hline Total & $\mathbf{1 2 2}$ & $\mathbf{1 1 3}$ & & \\
\hline & $\mathbf{3 - m o n t h ~ f o l l o w ~ u p ~}$ & $\mathbf{6 - m o n t h}$ follow up & & \\
\hline
\end{tabular}




\begin{tabular}{|l|l|l|l|l|}
\hline$>25 \mathrm{~kg}$ & $1(0.8)$ & $0(0.0)$ & & \\
\hline $26-50 \mathrm{~kg}$ & $38(31.1)$ & $32(26.2)$ & & \\
\hline $51-75 \mathrm{~kg}$ & $72(59.0)$ & $72(59.0)$ & & \\
\hline $75-100 \mathrm{~kg}$ & $7(5.7)$ & $9(7.4)$ & 1.7 & $0.007^{\text {a } *}$ \\
\hline Total & $\mathbf{1 1 8}$ & $\mathbf{1 1 3}$ & & \\
\hline
\end{tabular}

${ }^{a}$ p-value was calculated using McNemar's Test

*significant at $<0.05$

Table 8. Change in Weight Following Intervention Administration in the Control Group

\begin{tabular}{|c|c|c|c|c|}
\hline \multirow[t]{3}{*}{ Weight } & \multicolumn{2}{|l|}{ Frequency } & \multirow[t]{3}{*}{ Change in \% } & \multirow[t]{2}{*}{ p-value } \\
\hline & \multicolumn{2}{|l|}{$\mathbf{N}(\%)$} & & \\
\hline & Baseline & 3-month follow up & & \\
\hline$>25 \mathrm{~kg}$ & $1(0.8)$ & $1(0.8)$ & & \\
\hline $26-50 \mathrm{~kg}$ & $40(32.8)$ & $38(31.1)$ & & \\
\hline $51-75 \mathrm{~kg}$ & $72(59.0)$ & $72(59.0)$ & & \\
\hline $75-100 \mathrm{~kg}$ & $9(9)$ & $7(5.7)$ & -3.3 & $0.300^{\mathrm{a}}$ \\
\hline \multirow[t]{2}{*}{ Total } & 122 & 118 & & \\
\hline & Baseline & 6-month follow up & & \\
\hline$>25 \mathrm{~kg}$ & $1(0.8)$ & $0(0.0)$ & & \\
\hline $26-50 \mathrm{~kg}$ & $40(32.8)$ & $32(26.2)$ & & \\
\hline $51-75 \mathrm{~kg}$ & $72(59.0)$ & $72(59.0)$ & & \\
\hline $75-100 \mathrm{~kg}$ & $9(9)$ & $9(7.4)$ & -1.6 & $0.001^{\mathrm{a} *}$ \\
\hline \multirow{2}{*}{ Total } & 122 & 113 & & \\
\hline & 3-month follow up & 6-month follow up & & \\
\hline$>25 \mathrm{~kg}$ & $1(0.8)$ & $0(0.0)$ & & \\
\hline $26-50 \mathrm{~kg}$ & $38(31.1)$ & $32(26.2)$ & & \\
\hline $51-75 \mathrm{~kg}$ & $72(59.0)$ & $72(59.0)$ & & \\
\hline $75-100 \mathrm{~kg}$ & $7(5.7)$ & $9(7.4)$ & 1.7 & $0.001^{\mathrm{a}^{*}}$ \\
\hline Total & 118 & 113 & & \\
\hline
\end{tabular}

ap value was calculated using McNemar's Test

*significant at $<0.05$

\section{Change in CD4 Cell Count after Intervention}

The mean (SD) CD4 cell count at baseline for the intervention group and control group were $498.92 \quad(168.851)$ and 497.07 (217.561) respectively. After 3 months, the recorded mean (SD) was 498.92 (168.851 for the intervention group (Table 4.39) and 497.07 (217.561) for the control (Table 9). The mean (SD) of the CD4 cells had increased by the 6th months to 587.47 (146.675) in the intervention group and 541.26 (190.366) in the control group. The increase in the mean of CD4 cells from baseline to 6-month follow-up indicates that the intervention on SMS and call reminders helped in improving the CD4 cell count and general clinical outcome of the HIV-positive patients on antiretroviral therapy.

Table 9: Summary of Descriptive of CD4 Cell Count at Baseline, 3 Months Follow up and 6 Months for Control and Intervention Groups

\begin{tabular}{|l|l|l|l|l|}
\hline \multirow{2}{*}{ Time } & \multicolumn{2}{|l|}{ Control } & \multicolumn{2}{l|}{ Intervention } \\
\cline { 2 - 5 } & $\mathbf{N = 1 1 3}$ & $\mathbf{N}=\mathbf{1 1 9}$ & \\
\cline { 2 - 5 } & $\mathbf{X}(\mathbf{S E})$ & $\mathbf{\pm S D}$ & $\mathbf{X}(\mathbf{S E})$ & $\mathbf{\pm S D}$ \\
\hline Baseline & $497.07(20.466))$ & 217.561 & $498.92(15.479)$ & 168.851 \\
\hline 3 months follow up & $497.07(20.466)$ & 217.561 & $498.92(15.479)$ & 168.851 \\
\hline 6 months follow up & $541.26(17.908)$ & 190.366 & $587.47(13.446)$ & 146.675 \\
\hline
\end{tabular}

SD standard deviation

$\mathrm{X}$ Mean 
Using paired t-test for the analysis: Comparing baseline and 6-month follow-up results, there was a difference in mean of CD4 count between control and intervention group at 6 months follow up. The immunological response was better in the intervention group at 6-month follow-up (mean \pm SD = $88.555 \pm 73.289$ ) (Table 10). The change in the
CD4 count was statistically significant $(\mathrm{t}(231)=$ -13.181; $\mathrm{p}$ <0.01). There was a change in CD4 in the control group as well, but the level of change was not as much as the change observed in the intervention group. (Table 10) Overall, this suggests that phone reminders elicited a change in the level of CD4 count among HIV patients.

Table 10. Paired Sample T-Test of CD4 Count in the Intervention and Control Group

\begin{tabular}{|l|l|l|l|l|l|l|}
\hline Pair & Mean & SE & SD & df & t & P -value \\
\hline Intervention \\
\hline Baseline vs 6 months & -88.555 & 6.718 & 73.289 & 118 & -13.181 & 0.001 \\
\hline Control & & & \\
\hline Baseline vs 6 months & -44.186 & 6.810 & 72.394 & 112 & -6.488 & 0.001 \\
\hline
\end{tabular}

*significant at $<0.05$

\section{Change in Proportion of Tuberculosis and Other Opportunistic Infections}

The participants who had other opportunistic infections in the intervention group were 14 at baseline (Table 11) and by the 3-month and 6month follow-up period, there were only 8 and 5 HIV-positive patients with confirmed opportunistic infection respectively. This indicates that the intervention was effective in reducing the presence of opportunistic infections among HIV positive patients on antiretroviral therapy and subsequently improving clinical outcome in the respondents. At the 3-month follow-up assessment, the number of patients who had opportunistic infections had increased to 22 from 20 in the control group. The 6-month follow-up assessment shows (Table 12) that at 6month follow-up, there was a $6.5 \%$ decrease in the proportion of patients with opportunistic infections.

Table 11. Change in Proportion of Participants with Tuberculosis and other Opportunistic Infections in the Intervention Group

\begin{tabular}{|c|c|c|c|c|c|c|c|}
\hline Items & \multicolumn{2}{|c|}{ Baseline } & \multicolumn{2}{|c|}{ 3-month follow up } & \multicolumn{2}{|c|}{ 6-month follow up } & p-value \\
\hline \multicolumn{8}{|l|}{ Tuberculosis } \\
\hline No sign of symptom of TB & 68 & 55.7 & 76 & 62.3 & 74 & 60.7 & \multirow[t]{6}{*}{$0.735^{\mathrm{a}}$} \\
\hline Presumptive TB & 16 & 13.1 & 10 & 8.2 & 3 & 2.5 & \\
\hline Currently on Isoniazid & 32 & 26.2 & 29 & 23.8 & 34 & 27.9 & \\
\hline Confirmed TB case & 4 & 3.3 & 1 & 0.8 & 0 & 0 & \\
\hline TB treatment & 2 & 1.6 & 5 & 4.1 & 8 & 6.6 & \\
\hline Total & 122 & 100 & 121 & 99.2 & 119 & 97.5 & \\
\hline \multicolumn{8}{|c|}{ Presence of Opportunistic Infections } \\
\hline No & 108 & 88.5 & 113 & 92.6 & 114 & 93.4 & \multirow[t]{3}{*}{$0.064^{\mathrm{a}}$} \\
\hline Yes & 14 & 11.5 & 8 & 6.6 & 5 & 4.1 & \\
\hline Total & 122 & 100 & 121 & 992 & 119 & 975 & \\
\hline
\end{tabular}

${ }^{a} \mathrm{p}$ value was calculated using McNemar's Test

*significant at $<0.05$ 
Table 12: Change in Proportion of Participants with Tuberculosis and other Opportunistic Infections in the Control Group

\begin{tabular}{|c|c|c|c|c|c|c|c|}
\hline Items & \multicolumn{2}{|c|}{ Baseline } & \multicolumn{2}{|c|}{ 3-month follow up } & \multicolumn{2}{|c|}{ 6-month follow up } & p-value \\
\hline \multicolumn{8}{|l|}{ Tuberculosis } \\
\hline No sign of symptom of TB & 89 & 73.0 & 67 & 54.9 & 58 & 47.5 & \multirow[t]{6}{*}{$0.128^{\mathrm{a}}$} \\
\hline Presumptive TB & 11 & 9.0 & 9 & 7.4 & 7 & 5.7 & \\
\hline Currently on Isoniazid & 17 & 13.9 & 34 & 27.9 & 34 & 27.9 & \\
\hline Confirmed TB case & 4 & 3.3 & 5 & 4.1 & 4 & 3.3 & \\
\hline TB treatment & 1 & 0.8 & 3 & 2.5 & 10 & 8.2 & \\
\hline Total & 122 & 100 & 118 & 96.7 & 113 & 92.6 & \\
\hline \multicolumn{8}{|c|}{ Presence of Opportunistic Infections } \\
\hline No & 102 & 83.6 & 96 & 78.7 & 99 & 81.1 & \multirow[t]{3}{*}{$0.912^{\mathrm{a}}$} \\
\hline Yes & 20 & 16.4 & 22 & 18.0 & 14 & 11.5 & \\
\hline Total & 122 & 100 & 118 & 96.7 & 113 & 92.6 & \\
\hline
\end{tabular}

${ }^{a} \mathrm{p}$ value was calculated using McNemar's Test

*significant at $<0.05$

\section{Discussion}

\section{Socio-demographic Characteristics of the Respondents}

The findings of this study show that more participants were middle-aged with about twothirds between the ages $26-45$ years. This distribution was observed in both the control and intervention groups and similar findings were reported in a study carried out in the southwestern region of Nigeria [13]. Also, more patients attending antiretroviral clinics in Nigeria were reported to be between the ages 18-40 years [14]. There was no statistically significant relationship between gender and adherence in this study, these findings are similar in studies conducted and reported in many countries [6,15-23]. Marital status had an insignificant role on participants' medication adherence, and this is in line with the findings from study conducted in Brazil [24] and United State [26], however reported that marital status had an association with adherence.

\section{Effectiveness of Mobile Phone Reminder on Medication Adherence}

There was an increase in the level of adherence to medication among intervention group after the intervention was administered as compared to the control group where they had a drop in adherence. These corroborate the findings of some studies reported [26-28]. This explains that the intervention program on medication adherence has an effect on the participants.
This study utilized both phone calls and short messaging services to remind the patients of their appointments. The phone calls were placed 3 days before their scheduled clinic days and a SMS was sent out a day to appointment. Similar findings were reported in Kenya [29]. Another study reported significant improvements in adherence and viral suppression among an intervention group that received weekly interactive SMS (inquiring about health and well-being), with follow-up calls after 48 hours [30].

Further evidence to support on the importance of reminders are available from reports in literature. A study conducted in USA made recommendations for the use of programmable electronic medication reminders to increase quality of cues to reduce forgetfulness among patients and thereby improve adherence to medications [31]. RCT study conducted in Nairobi, Kenya, the use of digital reminders was not found to influence the adherence to ART among the patients. The study utilized an early adherence intensive counseling and compared the effects of the counseling to the effects from the use of digital reminders [32] Also, in Kenya, another study reported a larger proportion of adherent participants exposed to SMS reminders in comparison to controls [29].

\section{Effectiveness of Mobile Phone Reminders on Clinic Attendance}

The mobile phone reminder intervention had a change in the frequency of clinic attendance of the patients. After 3 months follow-up, there was a high frequency of attendance in the 
intervention group, but this frequency was not statistically significant. This implies that the recorded figures could have been as a result of factors other than the intervention. At 6-month follow-up, the observed frequency was increased, and this was statistically significant. This indicates that the intervention influenced the patients' clinic attendance. In a study conducted in Malaysia, the findings showed that the intervention produced a higher proportion of regular clinic attendees and a lower proportion of missed appointments [33]. Also, another study conducted in Uganda reported lower missed clinic attendance among the patients recruited for the study and this corresponded to improved adherence [34].

\section{Effectiveness of Mobile Phone Reminder on Treatment Outcomes}

The clinical outcomes measured among the patients were their weight, CD4 cell count, presence of tuberculosis and other opportunistic infections. The mobile phone reminder intervention proved to be effective in changing the levels of the desired variables.

Change in participant weight: The study findings showed that there was a change in the weight mean after the mobile phone reminder intervention. The changes in mean weight across the three time periods were statistically significant. The control group which had no intervention administered recorded some slight increase in weight also after the study, but there was no statistical basis for the change recorded. This finding indicates that the intervention was effective in improving the clinical outcome among the patients attending ART clinics in Adamawa State.

Few studies have established the relationship between medication adherence and weight of respondents. The findings of this study were similar to findings by researchers from SubSaharan Africa, Kenya and Rwanda specifically [35]. The study tested the short- and long-term effect of the Modified Directly Observed Antiretroviral Treatment among infected individuals. The result showed that there was an impact of the intervention on the weight of the PLWHAs. Also, study conducted in Rwanda reported weight increase [36]. Despite the same follow-up period of 6-months as reported by this present study and study conducted in Malaysia, the latter showed no positive effect of the intervention on the weight of participants and the differing results could be as a result of the influence of socio-demographic factors of the participants [33].

Change in CD4 cell count: The findings of this study showed that there was a significant rise in CD4 count in the intervention group after six months follow up. At three months, the rise was little, but by the sixth month postintervention, there was a highly significant rise in the mean (from 496.38 cells $/ \mathrm{mm}^{3}$ to 587.47 cells $/ \mathrm{mm}^{3}$ ). Similar results to those observed in this study were reported by Abdulrahman et al., 2017 in a study carried out in Malaysia. A report of the study conducted in Nigeria is also in agreement with the findings of this present study [14]. They recorded a mean rise in CD4 count among adherent patients at one-year follow-up compared to the non-adherent group. The lower counts of CD4 cell observed in this study could be due to the shorter follow-up period of 6 months compared to the 12 months [14]. Higher CD4 count was reported in among the participants in United State of America after a 12-month follow-up period [37]. Another related study in South Africa reported higher CD4 changes and greater viral load suppression in their patients [38].

Compelling evidence on the association between CD4 count and adherence levels have been established in several studies. Individual interventions or program-level interventions that are designed and targeted to improve ARV medication adherence among patients would invariably produce a positive impact on immunologic response (CD4 count) to treatment.

Change in Tuberculosis and other Opportunistic Infections: There was an increase in the proportion of patients who had no signs of tuberculosis at 3 months follow up. This is an indication that the use of the medications reduced some clinical outcomes by reminding the HIV-positive patients of their drug regimen and clinic appointments. In the control group also, there was a decrease in the proportion of participants who had no sign and symptom of tuberculosis from baseline to 6-month followup. The change in proportion observed in the two groups were however not statistically significant. This indicates that the change could have been due to some other factors which were not related to the mobile phone reminder. 
Finding of this study shows a decrease in the proportion of participants who had no sign and symptom of tuberculosis from baseline to 6month follow-up. The change in proportion observed in the two groups were however not statistically significant. Similar findings were reported in Brazil [39, 40]. In Malaysia, a significant decrease in the proportion of patients in the intervention group who were tuberculosis suspects was reported [33].

\section{Limitations}

The result of the improve patient's adherence was obtained through self-report and pill count, therefore, the quality of the data obtained from pill counting could be affected because some clients may discard tablets not taken prior to their routine clinic visit, that can lead to overestimated adherence.

Unannounced patients home visit pills count, which may be more accurate could not be conducted due to limited resources and issues of confidentiality and stigma in the community.

Self-report is subjected to recall bias, and that may affect the quality of the results of the study.

Due to budget constraints, viral loads could not be monitored even though it is considered to

\section{References}

[1] Joint United Nation Programme on HIV/AIDS (UNAIDS, 2018). Global HIV \& AIDS statistics. 2018 fact sheet. http://www.unaids.org/en/resources/fact-sheet).

[2] National Agency for Control of AIDS (NACA) (2017). 'National Strategic Framework on HIV and AIDS: $2017 \quad-2021 . \quad$ Page 6-16 https://www.childrenandaids.org/sites/default/files/2 01711/NATIONAL-HIV-AND AIDS-STRATEGIC FRAMEWORK.pdf.

[3] National HIV Sero-prevalence Sentinel Survey (NHSS 2014).

[4] Bekele Belayihun1 and Rahma Negus (2015). Antiretroviral Treatment Adherence Rate and Associated Factors among People Living with HIV in Dubti Hospital, Afar Regional State, East Ethiopia. Hindawi Publishing Corporation International Scholarly Research Notices Volume 2015, Article ID 187360, 5 pages. http://dx.doi.org/10.1155/2015/187360.

[5] World Health Organization. (WHO, 2005) Interim WHO clinical staging of HIV/AIDS and HIV/AIDS case definitions for surveillance: African region. be the gold standard for monitoring adherence and confirming treatment response.

Also, short duration of the study (6 months) follow-up may have resulted in adherence estimates and retention that represent the bestcase scenario evidence and not necessarily an accurate estimate.

\section{Conclusion}

The findings of this study have established that simple technologies such as a phone call or short messaging service (SMS) could be an important strategy to sustain or increase levels of medication adherence, improved clinic attendance and clinical outcomes among HIVinfected individuals on antiretroviral therapy.

\section{Acknowledgments}

The authors would like to acknowledge the hospital management and entire ART Unit staff of the FMC Yola, Specialist Hospital Yola, St Francis Jambutu, GH Mubi and GH Mayo Belwa. Also acknowledged the contributions of all the members of the research team toward the success of this study.

Switzerland:

https://www.who.int/hiv/pub/guidelines/clinicalstagi ng.pdf.

[6] Paterson DL, Swindells S, Mohr J, Brester M, Vergis EN, Squier C, et al. (2002) Adherence to protease inhibitor therapy and outcomes in patients with HIV infection. Annals of internal medicine. 2000;133(1):21-30. pmid:10877736.

[7] Suleiman IA, Momo A. Adherence to antiretroviral therapy and its determinants among persons living with HIV/AIDS in Bayelsa state, Nigeria. Pharmacy Practice 2016 Jan-Mar;14(1):631. doi: 10.18549/PharmPract.2016.01.631.

[8] Kelley LL' Engle, Kimberly Green MA, Stacey M Succop et al., (2015). Scaled-Up Mobile Phone Intervention for HIV Care and Treatment: Protocol for a Facility Randomized Controlled Trial. JMIR Res Protoc 2015;4(1): e11) doi:10.2196/resprot.3659 https://www.ncbi.nlm.nih.gov/pmc/articles/PMC431 9075/.

[9] National Guideline for HIV Prevention Treatment and Care (2016)- Nigeria. http://apps.who.int/medicinedocs/documents/s23252 en/s23252en.pdf. 
[10] President Emergency Plan for AIDS Relief (PEPFAR) (2016). Country/Regional Operational Plan (COP/ROP) 2016 guidance. Office of the U.S. Global AIDS Coordinator, Washington, D.C.: OGAC;2015.

[11] World Health Organization (WHO, 2015). Guideline on when to start antiretroviral therapy and on pre-exposure prophylaxis for HIV. Geneva: World Health Organization 2015 (http://www.who.int/hiv/pub/guidelines/earlyrelease -arv/en.

[12] Lemeshow S, David W. Ho, J Klar, S K. Lwanga and World Health Organization (1990). Adequacy of sample size in health studies. WHO IRIS: 239. http://www.who.int/irs/handle/10665/41607.accesse d.

[13] Olowookere, S.A., Fatiregun, A.A, Ladipo, M.M.A, Abioye-Kuteyi, E.A. \& Adewole, I.F. (2016). Effects of adherence to antiretroviral therapy on body mass index, immunological and virological status of Nigerians living with HIV/AIDS. Alexandria Journal of Medicine (2016) 52, 51-54.

[14] Anoje, C., Agu, K.A., Oladele, E.A., Badru, T., Adedokun, O., Oqua, D., Khamofu, H., Adebayo, O., Torpey, K., Chabikuli, O.N. (2017). Adherence to On-Time ART Drug Pick-Up and Its Association with CD4 Changes and Clinical Outcomes Amongst HIV Infected Adults on First-Line Antiretroviral Therapy in Nigerian Hospitals AIDS Behav. 2017 Feb;21(2):386-392. doi: 10.1007/s10461-016-1473$\mathrm{z}$.

[15] Applebaum AJ, Richardson MA, Brady SM, Brief DJ, keane TM (2009). Gender and Other psychosocial factors as predictors of adherence to HAART in adults with comorbid HIV/aids, psychiatric and substance related disorder. Aids Behav. ;13(1):60-5.

[16] Carrieri MP, Chesney MA, Spire B, et al. (1999). Failure to maintain adherence to HAART in a cohort of French HIV-positive injecting drug users. Int $\mathrm{J}$ Behav Med. 2003; 10:1-14.8. Holzemer WL, Corless IB, Nokes KM, et al (2000). Predictors of selfreported adherence in persons living with HIV disease. AIDS Patient Care STDS.13:185-97.9.

[17]Bouhnik AD, Chesney M, Carrieri $\mathrm{P}$, et al. (2002) Non adherence among HIV-infected injecting drug users: the impact of social instability. J Acquire Immune Defic Syndr. ;31(suppl 3): S149 -S153.10.

[18] Golin CE, Liu H, Hays RD, et al. (2002). A prospective study of predictors of adherence to combination antiretroviral medication. $\mathrm{J}$ Gen InternMed. 2002; 17:756 - 65.11.
[19] Gordillo V, del Amo J, Soriano V, GonzalezLahoz J. (1999) Socio demo-graphic and psychological variables influencing adherence to antiretroviral therapy. AIDS.13:1763-9.12.

[20]Chesney, M.A. (2000). Factors affecting adherence to antiretroviral therapy. Clinical Infectious Disease 2000; 30 S171-S76.

[21]Eldred LJ, Wu AW, Chaisson RE, Moore RD (1998) Adherence to antiretroviral and pneumocystis prophylaxis in HIV disease. J Acquired Immune Defic Syndr Hum Retrovirol.; 18:117-25.5.

[22] Moatti J.P, Carrieri M.P, Spire B, Gastaut J.A, Cassuto J.P, Moreau J. (2000) Adherence to HAART in French HIV-infected injecting drug users: the contribution of buprenorphine drug maintenance treatment. The Manif 2000 study group. AIDS. 2000; 14:151-5.6.

[23] Wagner, G.J. (2002). Predictors of antiretroviral adherence as measured by self-report, electronic monitoring, and medication diaries. AIDS Patient Care STDS. 16:599 - 608.

[24] Nduaguba, S.O., Soremekun, R.O., Olugbake, O.A., \& Barner, J.C (2017). The relationship between patient-related factors and medication adherence among Nigerian patients taking highly active antiretroviral therapy. Africa Health Science. 17(3): 738745.

[25]Bonolo, P.F., Ceccato, M.B., Rocha, G. M., Acúrcio, F.A., Campos, L. N., \& Guimarães, M. C. (2013). Gender differences in non-adherence among Brazilian patients initiating antiretroviral therapy. Clinics (Sao Paulo). 68, 612-620.

[26] Simoni, J.M., Pearson, C.R., Pantalone, D.W., et al. (2006) Efficacy of interventions in improving highly active antiretroviral therapy adherence and HIV-1 RNA viral load. A meta-analytic review of randomized controlled trials. Journal Acquired Immune Deficiency Syndrome 43(Suppl 1): S23S35.

[27] Wagner, G.J, Kanouse, D.E., Golinelli, D., et al (2006). Cognitive-behavioral intervention to enhance adherence to antiretroviral therapy: a randomized controlled trial (CCTG 578) AIDS 20:1295-1302.

[28] Carrico, A.W, Antoni, M.H., Duran, R.E., et al. (2006). Reductions in depressed mood and denial coping during cognitive behavioral stress management with HIV-positive gay men treated with HAART. Annual Behavior Medicine 31:155-164.

[29] Pop-Eleches C, Thirumurthy H, Habyarimana JP, Zivin JG, Goldstein MP, de Walque D, et al. (2011). Mobile phone technologies improve adherence to antiretroviral treatment in a resource- 
limited setting: a randomized controlled trial of text message reminders. AIDS. 2011;25(6):825-34. pmid:21252632.

[30]Lester RT, Ritvo P, Mills EJ, Kariri A, Karanja S, Chung MH, et al. (2010). Effects of a mobile phone short message service on antiretroviral treatment adherence in Kenya (WelTel Kenya1): a randomized trial. Lancet. 2010;376(9755):1838-45. pmid:21071074 [doi:10.1016/S01406736(10)61997-6].

[31] Woods SP, Moran LM, Carey CL, Dawson MS, Iudicello JE, et al. (2008) Prospective memory in HIV infection: is "remembering to remember" a unique predictor of self-reported medication management? Arch Clin Neuropsychology 23:257270.

[32]Chung MH, Richardson BA, Tapia K, BenkiNugent S, Kiarie JN, Simoni JM, et al. (2011). A randomized controlled trial comparing the effects of counseling and alarm device on HAART adherence and virologic outcomes. PLoS Medicine. 2011;8(3): e1000422. pmid:21390262.

[33] Abdulrahman SA, Rampal L, Ibrahim F, Radhakrishnan AP, Kadir Shahar H, Othman N (2017) Mobile phone reminders and peer counseling improve adherence and treatment outcomes of patients on ART in Malaysia: A randomized clinical trial. PLoS ONE 12(5): e0177698. https://doi.org/10.1371/journal.pone.0177698.

[34] Kunutsor S, Walley J, Katabira E, Muchuro S, Balidawa H, Namagala E, et al. Using mobile phones to improve clinic attendance amongst an antiretroviral treatment cohort in rural Uganda: A cross-sectional and prospective study. AIDS Behav. 2010; $\quad$ 14(6): $1347 \pm 1353$. https://doi.org/10.1007/s10461-010-9780-2 PMID: 20700644.
[35] Sarna A, Luchters S, Geibel S, Chersich MF, Munyao P, Kaai S, et al. Short-and long-term efficacy of modified directly observed antiretroviral treatment in Mombasa, Kenya: a randomized trial. J Acquir

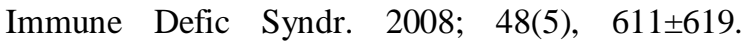
https://doi.org/10.1097/QAI.0b013e3181806bf1 PMID: 18645509.

[36] Rich ML, Miller AC, Niyigena P, Franke MF, Niyonzima JB, Socci A, et al. (2012). Excellent Clinical Outcomes and High Retention in Care among Adults in a Community-Based HIV Treatment Program in Rural Rwanda J Acquire Immune Defic

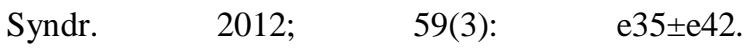
https://doi.org/10.1097/QAI.0b013e31824476c4 PMID: 22156912.

[37] Mannheimer S, Friedland G, Matts J, Child C, Chesney M. The consistency of adherence to antiretroviral therapy predicts biologic outcomes for human immunodeficiency virus infected persons in clinical trials. Clin Infect Dis. 2002; 34:1115-21.

[38] El-Khatib Z, Ekstrom AM, Coovadia A, Abrams EJ, Petzold M, et al. (2011) Adherence and virologic suppression during the first 24 weeks on antiretroviral therapy among women in Johannesburg, South Africa - a prospective cohort study. BMC Public Health 11: 88.

[39] Sampaio-Sa M, Page-Shafer K, Bangsberg DR, et al. 100\% adherence study: educational workshops vs video sessions to improve adherence among ARTnaive patients in Salvador, Brazil. AIDS Behaviour. 2008;12(4 Suppl): S54-S62.

[40] Garcia R, Ponde M, Lima M, Souza AR, Stolze SM, Badaro R. Lack of effect of motivation on the adherence of HIV-positive/AIDS patients to antiretroviral treatment. Braz J Infect Dis. 2005;9(6):494-499. 
